\title{
RELAP5-3D Input Model for the High Temperature Test Facility
}

Paul D. Bayless

June 2018

The INL is a

U.S. Department of Energy National Laboratory

operated by

Battelle Energy Alliance

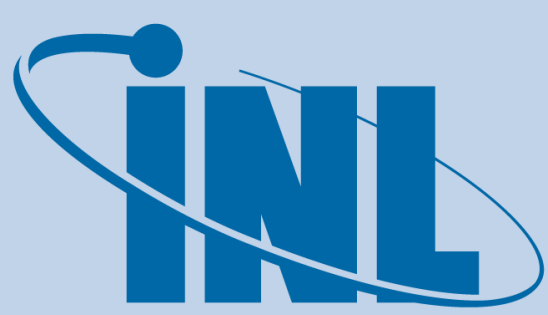

Idaho National Laboratory

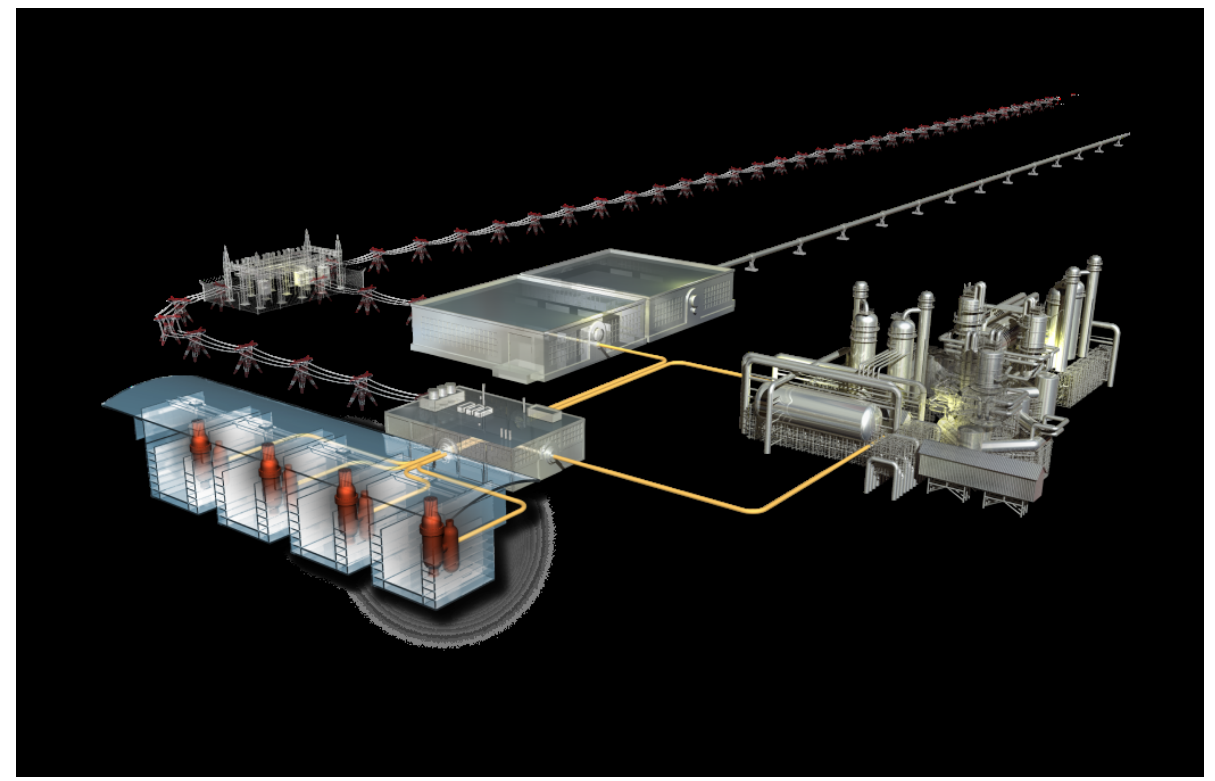




\section{DISCLAIMER}

This information was prepared as an account of work sponsored by an agency of the U.S. Government. Neither the U.S. Government nor any agency thereof, nor any of their employees, makes any warranty, expressed or implied, or assumes any legal liability or responsibility for the accuracy, completeness, or usefulness, of any information, apparatus, product, or process disclosed, or represents that its use would not infringe privately owned rights. References herein to any specific commercial product, process, or service by trade name, trade mark, manufacturer, or otherwise, does not necessarily constitute or imply its endorsement, recommendation, or favoring by the U.S. Government or any agency thereof. The views and opinions of authors expressed herein do not necessarily state or reflect those of the U.S. Government or any agency thereof. 


\title{
RELAP5-3D Input Model for the High Temperature Test Facility
}

\author{
Paul D. Bayless
}

June 2018

\begin{abstract}
Idaho National Laboratory
INL ART Program

Idaho Falls, Idaho 83415
\end{abstract}

http://www.inl.gov

Prepared for the

U.S. Department of Energy

Office of Nuclear Energy

Under DOE Idaho Operations Office

Contract DE-AC07-05ID14517 



\section{INL ART Program}

\section{RELAP5-3D Input Model for the High Temperature Test Facility}

INL/EXT-18-45579

June 2018

Author:

Pauld. Bayless

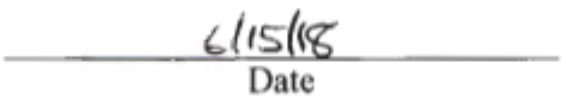

INL ART Nuclear Engineer

Technical Reviewer:
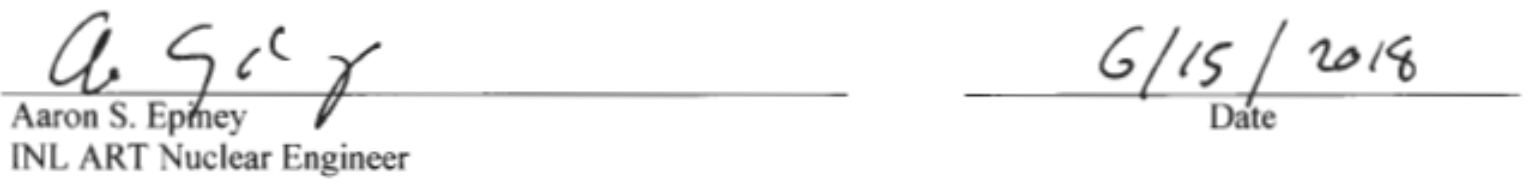

Approved by:
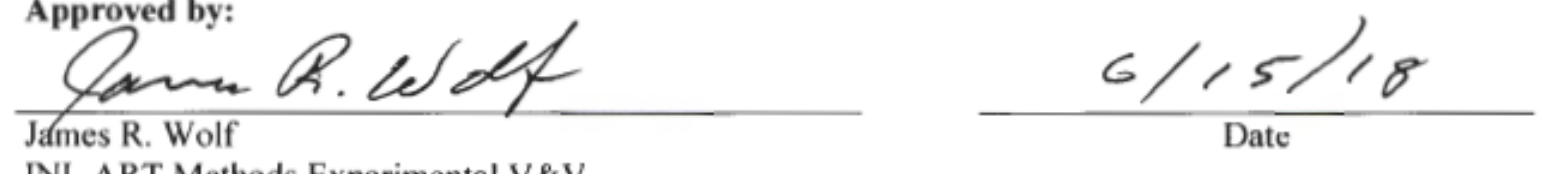

INL ART Methods Experimental V\&V

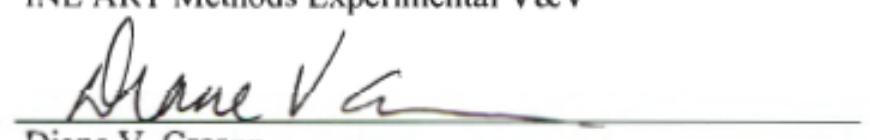

Diane V. Croson

INL ART Deputy Director
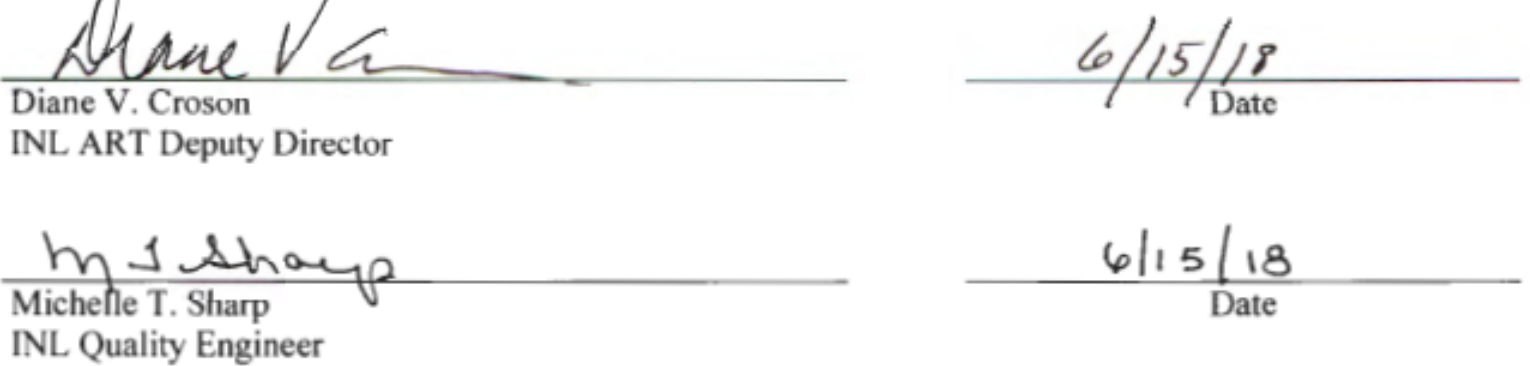

$\frac{6 / 15 / 18}{\text { Date }}$ 



\begin{abstract}
A RELAP5-3D model of the High Temperature Test Facility at Oregon State University has been developed. The model includes the systems, components, and controls needed to perform code assessment calculations using data from the facility. Details of the model are provided. The input was developed for RELAP5-3D version 4.4.2. An independent quality assurance review of the model was performed.
\end{abstract}




\section{CONTENTS}

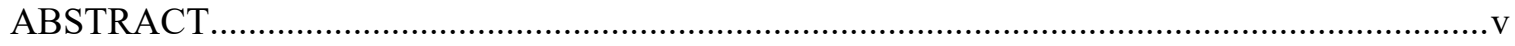

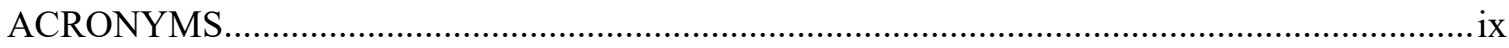

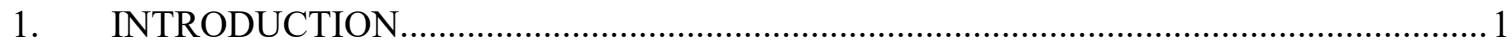

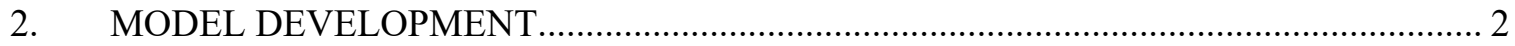

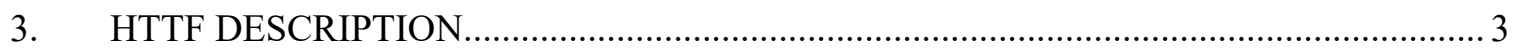

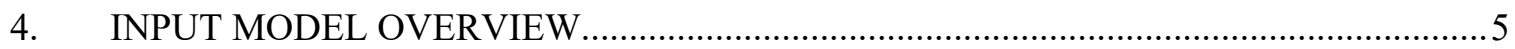

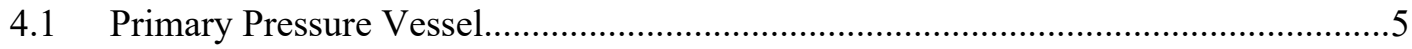

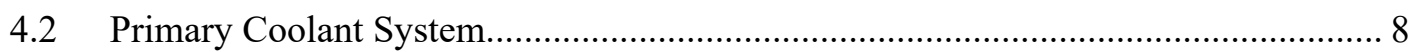

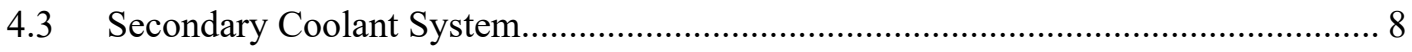

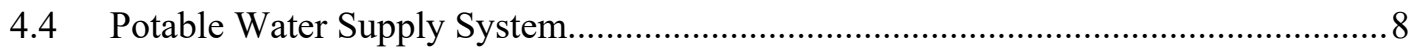

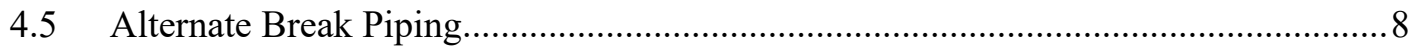

4.6 Reactor Cavity and Reactor Cavity Cooling System............................................. 9

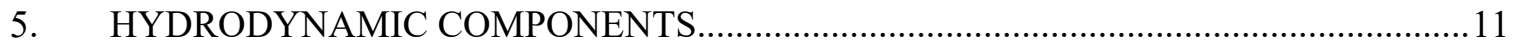

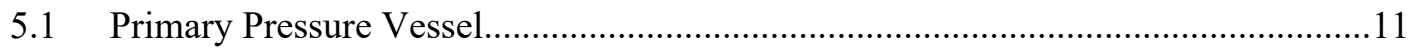

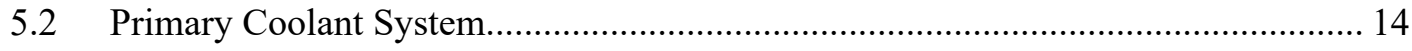

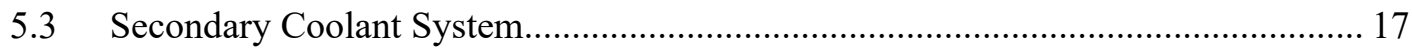

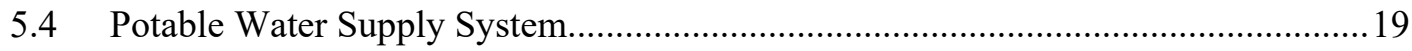

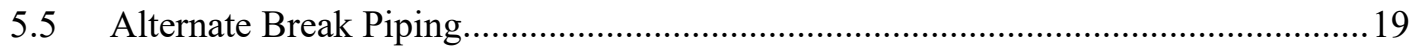

5.6 Reactor Cavity and Reactor Cavity Cooling System........................................... 21

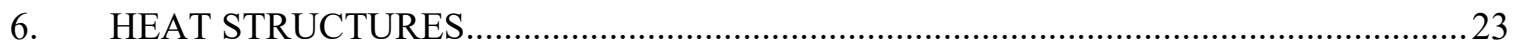

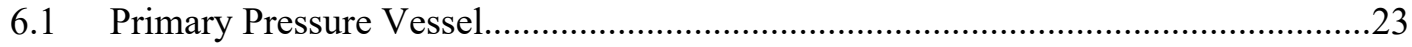

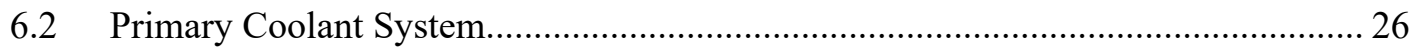

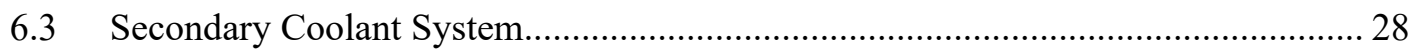

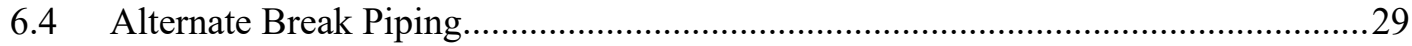

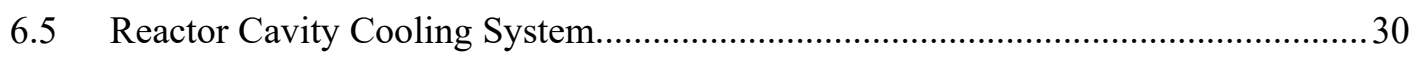

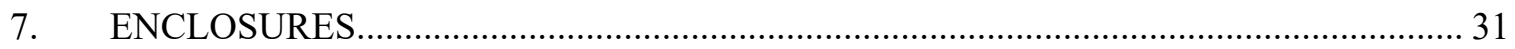

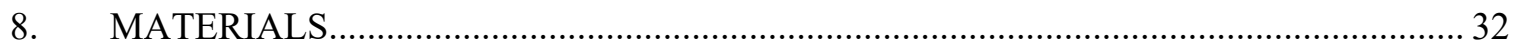

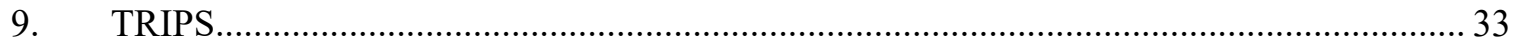

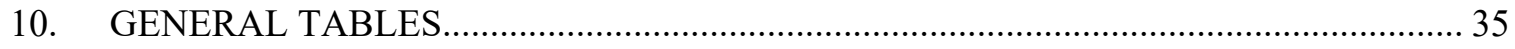

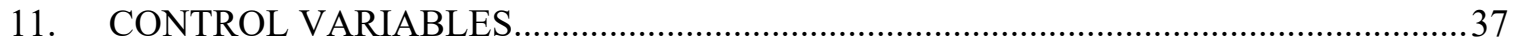

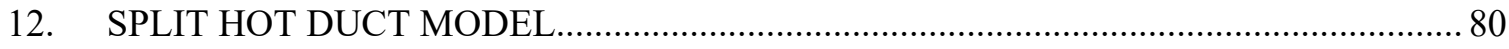

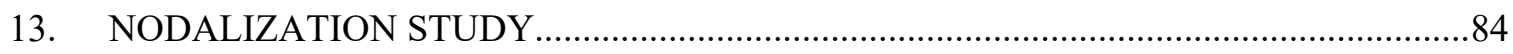

vii 


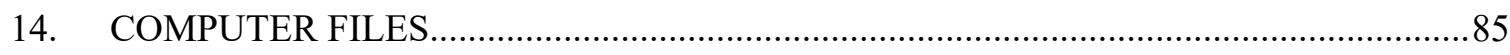

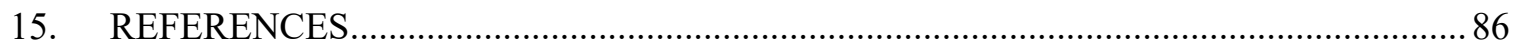

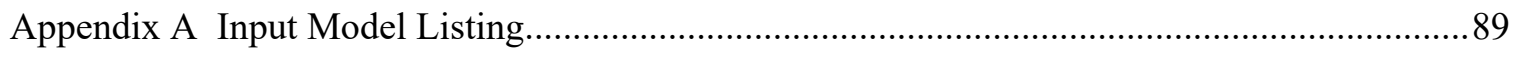

\section{FIGURES}

Figure 1. Diagram of the HTTF primary pressure vessel (right), RCST, and hot and cold ducts.

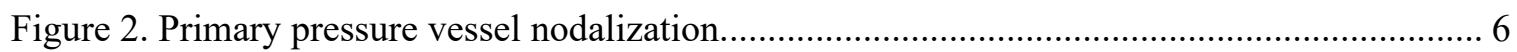

Figure 3. Primary pressure vessel radial nodalization................................................................. 7

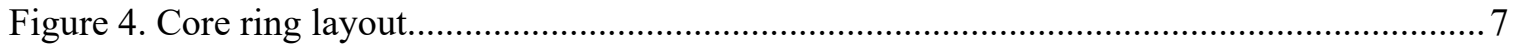

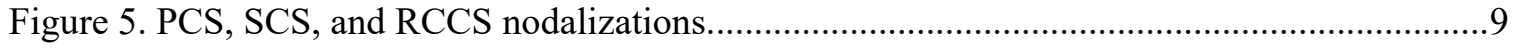

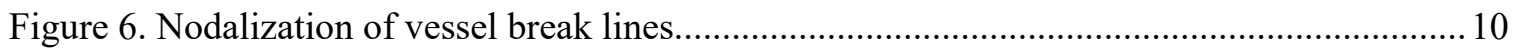

Figure 7. Revised nodalization for the split hot duct input model............................................. 80

\section{TABLES}

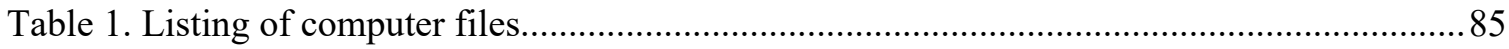

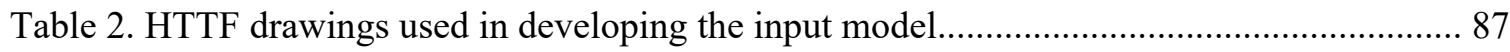




\section{ACRONYMS}

2-D two-dimensional

ASTM American Society for Testing and Materials

$\mathrm{CV} \quad$ control variable

DOE Department of Energy

HTTF High Temperature Test Facility

INL Idaho National Laboratory

PCS primary coolant system

RCCS reactor cavity cooling system

RCST reactor cavity simulation tank

SCS secondary coolant system 


\section{RELAP5-3D Input Model for the High Temperature Test Facility \\ 1. INTRODUCTION}

A quality-assured RELAP5-3D input model has been developed for the High Temperature Test Facility (HTTF) at Oregon State University. The model was developed to perform code assessment using experiment data from the HTTF, and is consistent with the input requirements for code Version 4.4.2 (INL 2018).

The model development and quality assurance process is described in Section 2. A brief description of the HTTF is given in Section 3. Section 4 provides an overview of the input model structure. Details on each of the hydrodynamic components are provided in Section 5, followed by the heat structures in Section 6, the radiation and conduction enclosures in Section 7, material properties in Section 8, trips in Section 9, general tables in Section 10, and control variables in Section 11. An alternate nodalization of the outlet plenum and hot duct is described in Section 12. Results of a steam generator nodalization study are presented in Section 13. A list of input files significant to the model development effort is provided in Section 14. References used in developing the input model are listed in Section 15. Appendix A contains a listing of the input model. 


\section{MODEL DEVELOPMENT}

The model was developed and documented in an Excel workbook. The principal advantage of this approach is that changes to reference information are automatically propagated throughout the workbook, altering all subsequent uses of those values, including updating the RELAP5-3D input model; this is particularly useful when the design is evolving as code calculations are being performed. One drawback is that the quality assurance effort to review the input model can become tedious.

There are two principal spreadsheets in the workbook, "geometry" and "RELAP5 input." The geometry spreadsheet identifies the sources of reference information, and then manipulates the reference data as required to provide the RELAP5-3D input parameters. As its name suggests, the "RELAP5 input" spreadsheet is simply the RELAP5-3D input file. The input parameters are linked to the other spreadsheets in the workbook in which any necessary calculations were performed.

Other spreadsheets provide specialized input or calculations. "Materials" contains the heat structure material property data. "Convars" manipulates the geometric information from the hydrodynamic components and heat structures to generate multipliers for the control variables in the input model. "Power mapping" maps the power from the 10 heater rod banks into the three heater rod heat structures in the model. "Test 140" and "test 150" mimic the inner and outer core rings, but with actual coolant channel sizes; they are used to determine the input model channel hydraulic diameter that preserves the pressure drop through the core. "Benchmarking" contains input parameters that supersede the values originally calculated, based on results from the system characterization and shakedown testing and from the "test 140" and "test 150" calculations.

A large number of control variables are included in the input model. While some of them provide controls for establishing steady-state conditions, most generate parameters to assist in analyzing the code output, such as computing energy balances or peak temperatures. Some of the control variables also calculate parameters that are of interest in scaling analyses.

The principal sources of geometric information were the facility drawings and the facility description report (Woods 2017a). Dimensions of the stainless steel piping were taken from Crane 1988, and of the copper piping from Marks' handbook (Baumeister, Avallone, and Baumeister 1978). Some specific component geometry was obtained from manufacturers' product data sheets (Mueller 2011a and 2011b). Initial loss coefficients were calculated from the system geometry using formulas from Crane 1988 or Idelchik 1994. Material properties were obtained from a variety of sources, including testing done specifically for the HTTF.

A detailed, independent quality assurance review of the model was performed at several stages during the model development effort. The review consisted of several steps. First, each reference value identified in the spreadsheets was checked against the reference document. Second, a cell-by-cell check was performed of the calculations manipulating the reference data into code input format. Finally, a cell-bycell check of the RELAP5-3D input spreadsheet was performed to ensure that each input value was linked to the proper calculated value in the supporting spreadsheets. 


\section{HTTF DESCRIPTION}

The HTTF is a helium-cooled, electrically-heated integral experiment facility. The reference design for the facility is General Atomics' modular high-temperature gas-cooled reactor (DOE 1986), which uses prismatic graphite blocks in the core and reflectors. The HTTF primary pressure vessel and core are onefourth scale in length and diameter. Most of the coolant channels in the core are full scale, with smaller diameter channels around the core periphery. The facility operates at low pressure, compared to the prototype reactor, and is designed primarily to investigate depressurized conduction cooldown transients.

The facility, described in detail in Woods 2017a, includes a number of systems. The primary coolant system (PCS) has a pressure vessel, a concentric hot and cold duct, a steam generator, a gas circulator, and connecting pipes. Break valves in both the hot and cold legs connect to a large reactor cavity simulation tank (RCST), whose gas composition can be initialized to a range of values to simulate the different conditions that may exist outside the reactor vessel following a loss-of-coolant accident. Figure 1 presents a rendering of the primary pressure vessel, RCST, and hot and cold ducts (Gutowska 2018).

Alumina ceramic blocks are used to simulate the core and top and bottom reflectors. Each block encompasses the radial region occupied by the central reflector, fuel, and side reflector in the reference reactor. Holes in the blocks provide channels for the heater rods, which consist of stacks of graphite rodlets. The rods are grouped into 10 heater banks, each of which contains 21 heater rods. Smaller coolant holes are arranged in a hexagonal pattern around the heater rods. Larger holes cast in the central and side reflector regions represent the core bypass flow in these regions. Permanent or outer reflector blocks, made of a different ceramic material, are located between the core blocks and the core barrel. A graphite plate in the upper plenum covers the gaps on either side of the permanent reflector blocks, so that the only flow through the core is in the holes cast in the core blocks.

The steam generator has 188 U-tubes. Feedwater is pumped from a supply tank into the downcomer on the secondary side, and any steam generated is vented to the atmosphere.

The principal feature of the reactor cavity cooling system (RCCS) is the cooling panels that surround the pressure vessel. Water flowing through the panels provides the heat sink for the PCS during most transients. Water is pumped from the same tank as the steam generator feedwater, but is recirculated back to the tank after exiting the top of the cooling panels. The inlet flow can be controlled to provide a desired panel outlet temperature, and isolation valves on the panels can be closed to simulate a degraded heat sink. There is a cover above the space between the pressure vessel and the RCCS panels, so that there is no direct natural circulation path between the building and the pressure vessel to provide unwanted cooling.

Two additional break lines are available, from the top of the primary pressure vessel to the top of the RCST, and from the bottom of the pressure vessel to the bottom of the RCST.

The facility has over 500 instruments, which are described in Woods 2018. Most of these are thermocouples in the core region to provide a temperature profile of the ceramic. There are also vertical thermocouple rakes in the upper and lower plenums, and in the hot and cold ducts, to try to capture temperature variations associated with recirculating or unmixed flow streams. The core and reflector instrumentation is generally arranged in one-sixth azimuthal sectors. The primary measurement sector is opposite the outlet plenum connection to the hot duct (on the east side of the plenum); the secondary sector is adjacent to the hot duct (west side), and the tertiary sector is next to (south of) the secondary sector. 


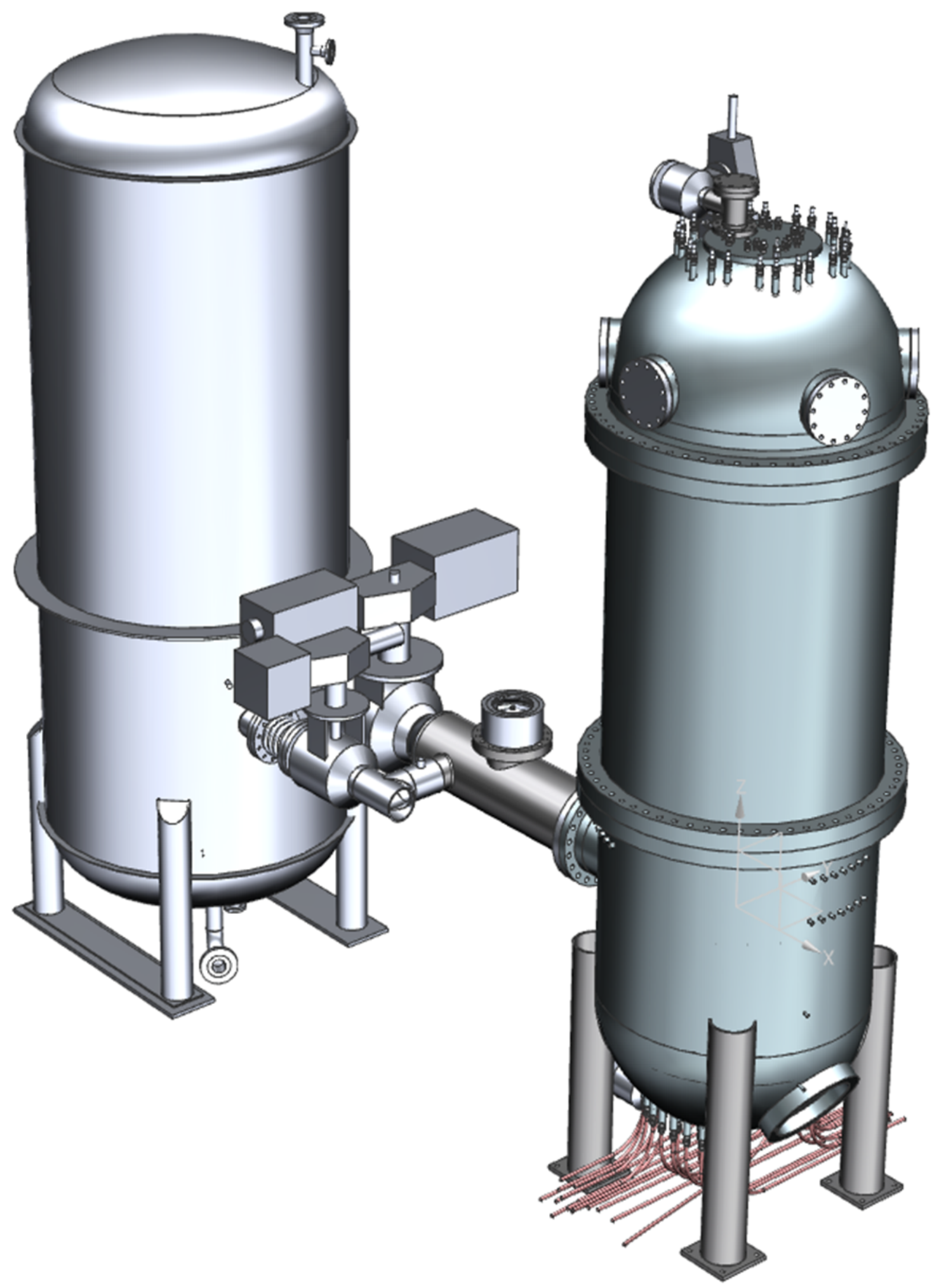

Figure 1. Diagram of the HTTF primary pressure vessel (right), RCST, and hot and cold ducts. 


\section{INPUT MODEL OVERVIEW}

The input model includes hydrodynamic components, heat structures, trips, and control systems. Systems modeled are the PCS, secondary coolant system (SCS), RCCS, potable water system that supplies both the SCS and the RCCS, and reactor cavity. The RCST is considered part of the PCS.

The general hydrodynamic component numbering scheme is:

1-99: alternate break piping

100-199: primary pressure vessel

200-299: PCS piping and components

300-399: secondary coolant system

400-499: potable water system

900-999: reactor cavity and RCCS

More details on all of the components are provided below.

\subsection{Primary Pressure Vessel}

The hydrodynamic component numbers in the primary pressure vessel are from 100 to 199 . Heat structures are generally numbered the same as the fluid volumes connected to them.

The primary pressure vessel nodalization is shown in Figure 2. Flow enters from the cold duct, passes through the core support structure under the outlet plenum bottom plate, then flows up between the primary pressure vessel and core barrel to the inlet plenum. Flow then passes down through various flow channels in the core and reflectors, recombines in the outlet plenum, then flows out into the hot duct.

The heated region of the core is divided into 10 equal-length axial segments, one for each block. The upper and lower reflectors each have two axial regions. This axial nodalization extends through each of the radial components in the vessel and in the RCCS.

The primary pressure vessel is divided into a number of different radial regions, as illustrated in Figure 3. The central reflector is divided into three regions: a central solid cylinder, a middle ring that contains the six 0.75 -in.-diameter gap simulation channels and the ceramic that is directly influenced by the holes, and a solid outer ring that is adjacent to the core. The core is also divided into three rings, as it is designed on the hexagonal block pattern of the modular high-temperature gas-cooled reactor, which has three fueled rings. Figure 4 shows which blocks are included in each of the rings in a 60-degree sector; the boundaries of the inner and outer rings were extended beyond the full hexagonal block geometry to include all of the coolant channels. The inner ring includes 23 hexagonal blocks with 56 heater rods and 138 coolant channels, the middle ring models 24 blocks with 72 heater rods and 144 coolant channels, and the outer ring includes 39 blocks with 82 heater rods and 234 coolant channels. The side reflector is divided into three regions: an inner solid ring next to the outer core ring, a middle ring that contains the thirty-six 0.625 -in.-diameter gap simulation channels and associated ceramic, and a solid outer ring. The next radial structure is the permanent or outer reflector (permanent side reflector in the reference plant), which has a coolant gap on either side (Components 164 and 166); these gaps do not have axial flow through them, as the top is covered by a plate (the upper plenum floor), leaving them open only to the outlet plenum. Continuing outward, the core barrel is next, followed by the coolant upcomer region between the core barrel and the pressure vessel wall, and finally the primary pressure vessel itself. 


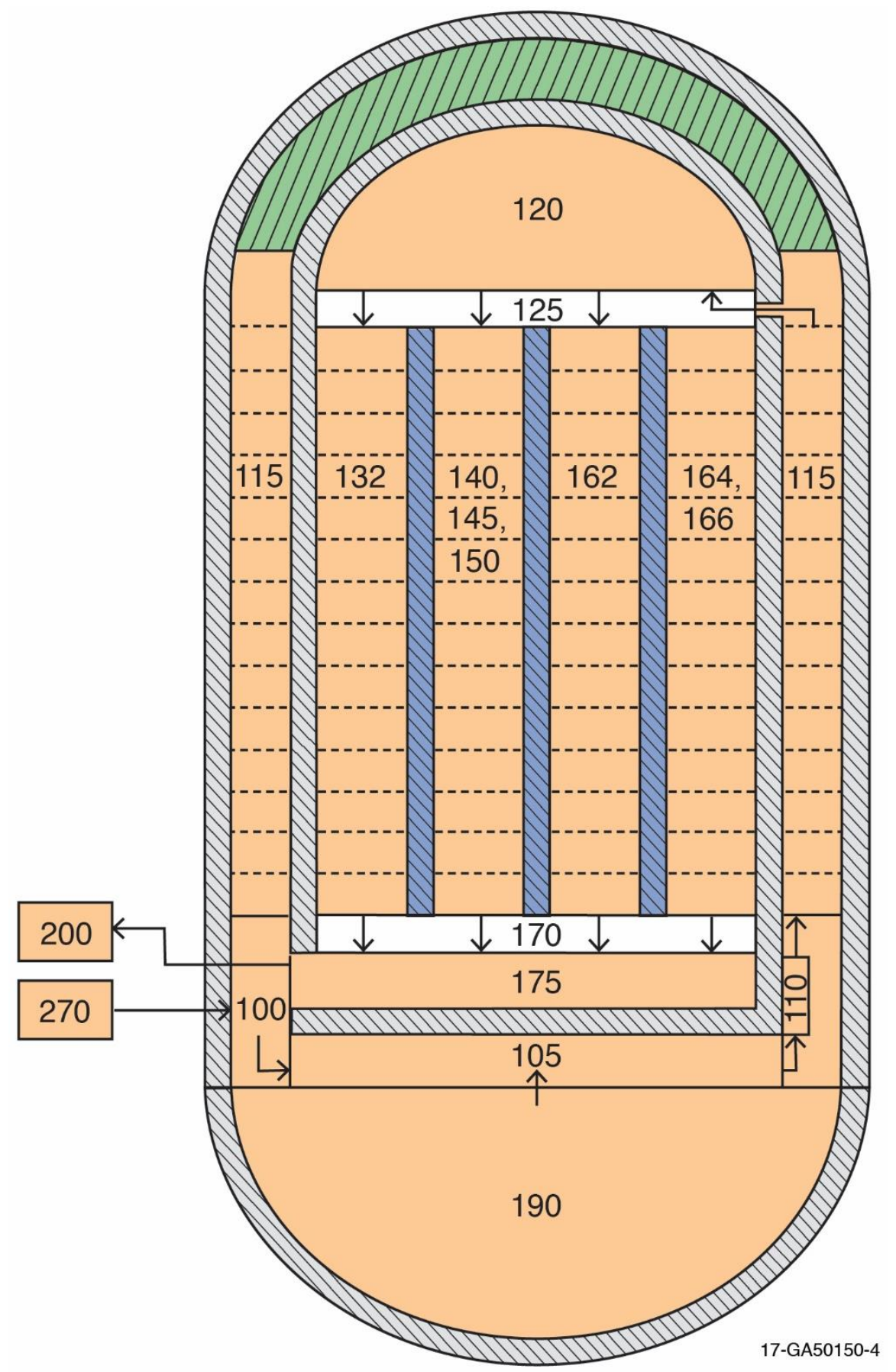

Figure 2. Primary pressure vessel nodalization. 


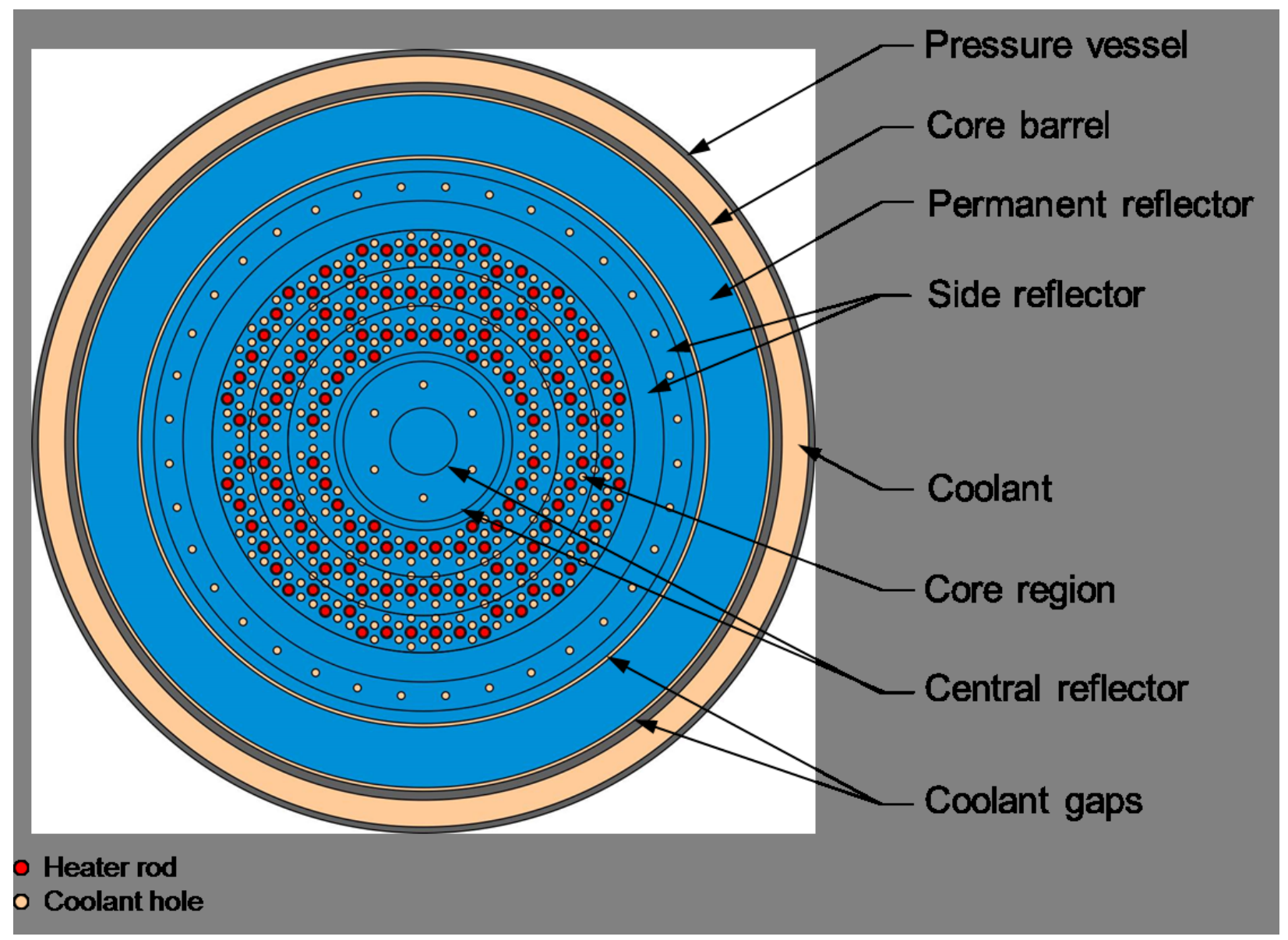

Figure 3. Primary pressure vessel radial nodalization.

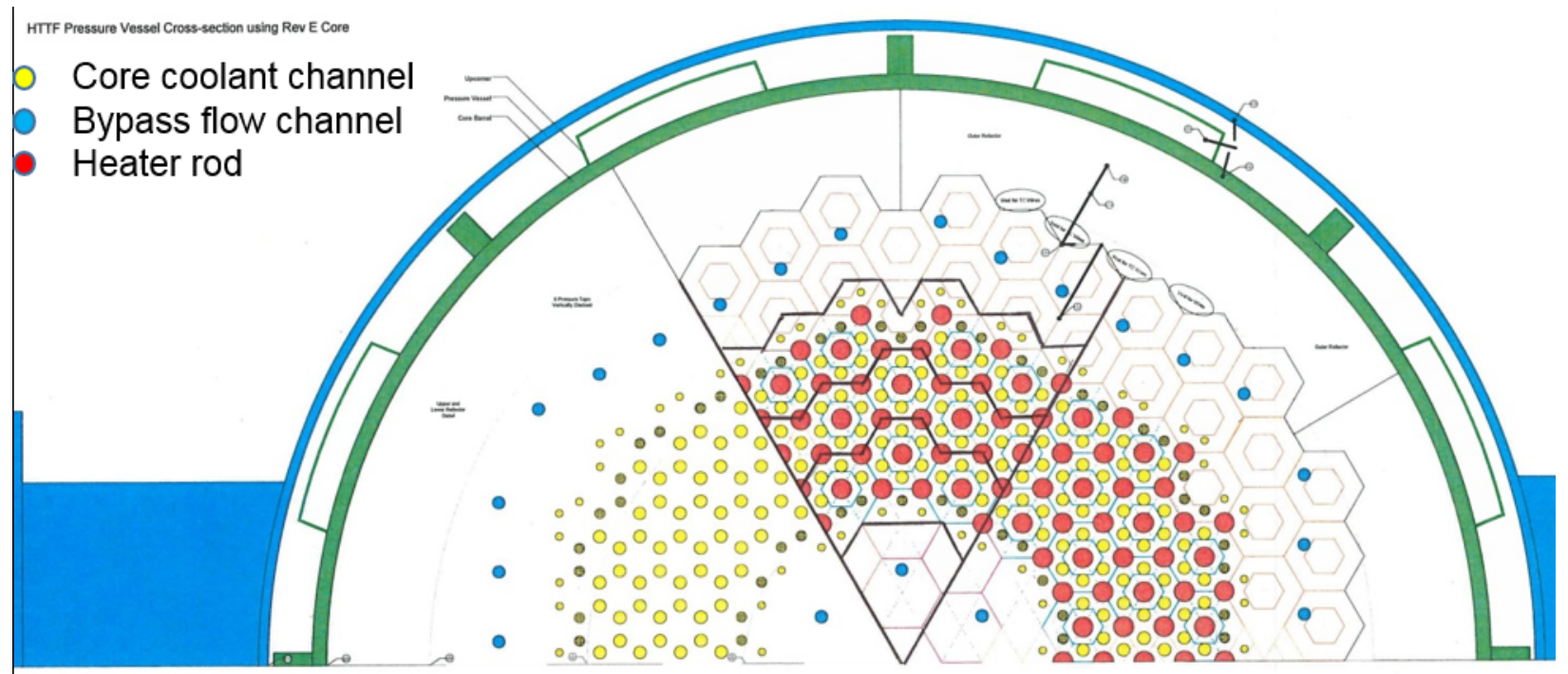

Figure 4. Core ring layout. 


\subsection{Primary Coolant System}

The hydrodynamic component numbers in the PCS are from 200 to 299. Heat structures are generally numbered the same as the fluid volumes connected to them.

The nodalization of the PCS is shown in Figure 5. Hot gas exits the primary pressure vessel into the hot duct, then flows up through a check valve and into the steam generator inlet plenum and tubes. The cooled gas flows out of the steam generator into piping that leads to the gas circulator. From the circulator, flow proceeds through an isolation valve, into a crossover pipe, into an annulus around the hot duct, and then back into the primary pressure vessel.

Break valves are located on the ends of the hot duct and the circulator discharge pipe, connecting them to the RCST. These valves are closed during steady state operation. Safety relief valves and a depressurization line are connected to the cold leg piping between the circulator and the loop isolation valve. These are modeled as a single line in the RELAP5-3D input model.

\subsection{Secondary Coolant System}

The hydrodynamic component numbers in the SCS are from 300 to 399. Heat structures are generally numbered the same as the fluid volumes connected to them.

The nodalization of the SCS is also provided in Figure 5. The feedwater pump draws suction from a water storage day tank and pumps it into the steam generator downcomer. The downcomer extends to near the top of the tube sheet. The water is then boiled on the outside of the tubes as it flows upward to the steam dome at the top of the steam generator. The steam then turns back downward before exiting out the side of the steam generator. The steam then flows through a pressure control valve in the steam line before flowing through more piping and being vented to the atmosphere. This downstream piping is not included in the RELAP5-3D input model. A safety relief valve is connected to a nozzle on the top of the steam generator. The piping downstream of the relief valve is not included in the input model.

\subsection{Potable Water Supply System}

Hydrodynamic components in the potable water supply system are numbered from 400 to 499 . There are no heat structures associated with this system.

The principal component in the system is the water storage day tank. This tank is the water source for both the SCS and the RCCS. The tank water level is maintained within a specified range. When the level gets too low, a valve opens in the supply line, allowing water from the public water system to flow into the tank. When the level rises to a certain level, the supply line valve is closed. The tank also has an interior drain/vent line that extends from the bottom of the tank to near the top; it is modeled as being open to the atmosphere below the tank. An outlet line is connected to the bottom of the tank; both the feedwater and RCCS pumps take suction from this outlet line.

\subsection{Alternate Break Piping}

Piping and valves associated with breaks located at the top and bottom of the pressure vessel are numbered from 1 to 99 . Heat structures are generally numbered the same as the fluid volumes connected to them.

Figure 6 presents the nodalization for these two break lines. These components are usually inactive in the input model because they would only be active during an appropriate break simulation and would otherwise slow the system calculations down without providing any beneficial information. The component numbering was selected so that the molecular diffusion model could be used for these breaks without including volumes outside the PCS. Because molecular diffusion is expected to be important when these breaks are active, a large number of control volumes are included in the piping, with a target cell length of about $2.0 \mathrm{~cm}$. 


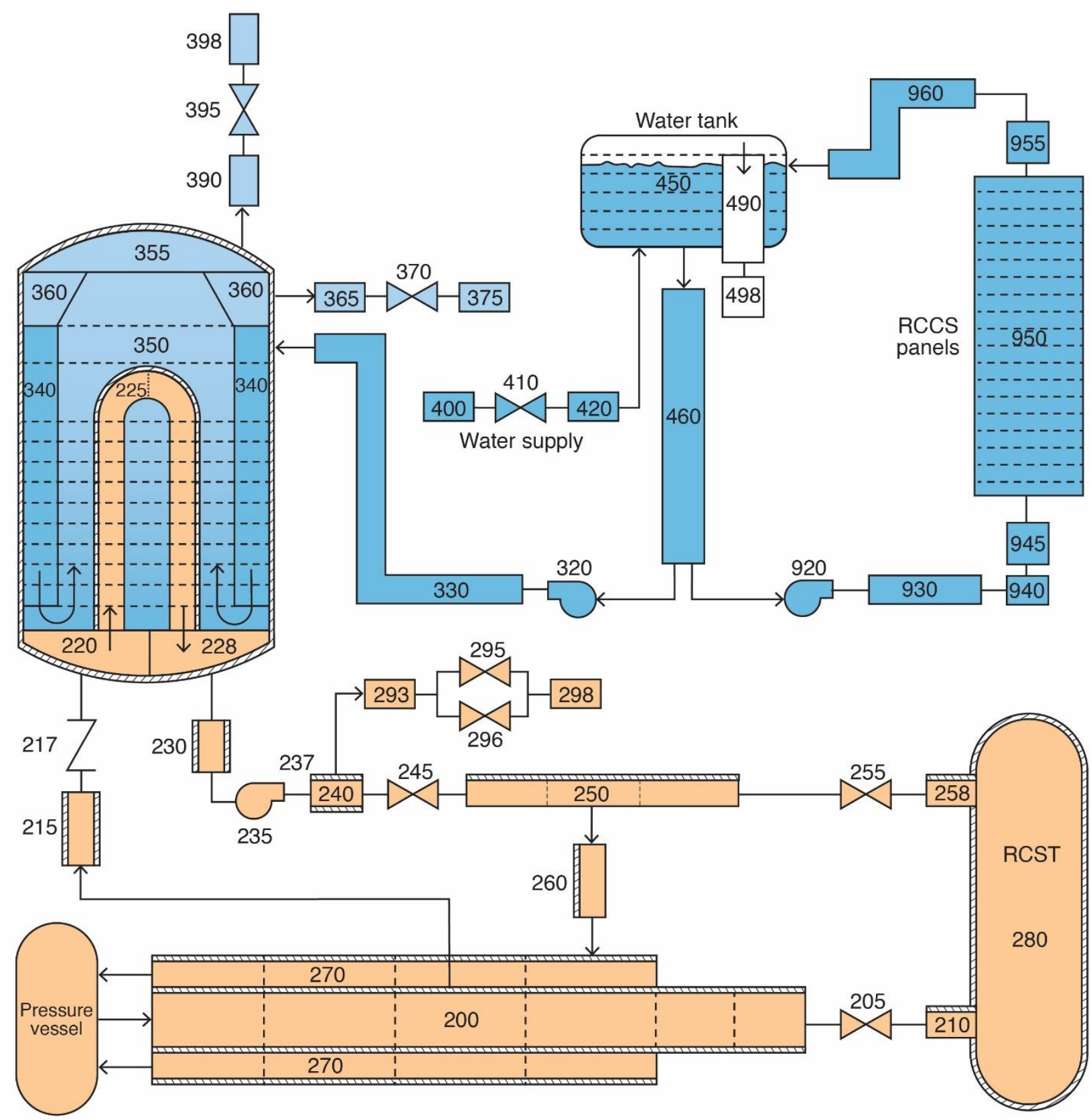

17-GA50150-2

Figure 5. PCS, SCS, and RCCS nodalizations.

\subsection{Reactor Cavity and Reactor Cavity Cooling System}

Hydrodynamic components in the reactor cavity and RCCS are numbered from 900 to 999 . Heat structures are generally numbered the same as the fluid volumes connected to them.

The reactor cavity is modeled as a large air-filled volume at atmospheric pressure, and is located between the primary pressure vessel and the RCCS panels. The roof covering this region is not included in the model. The RCCS draws flow from the water storage tank and pumps it through a series of pipes 


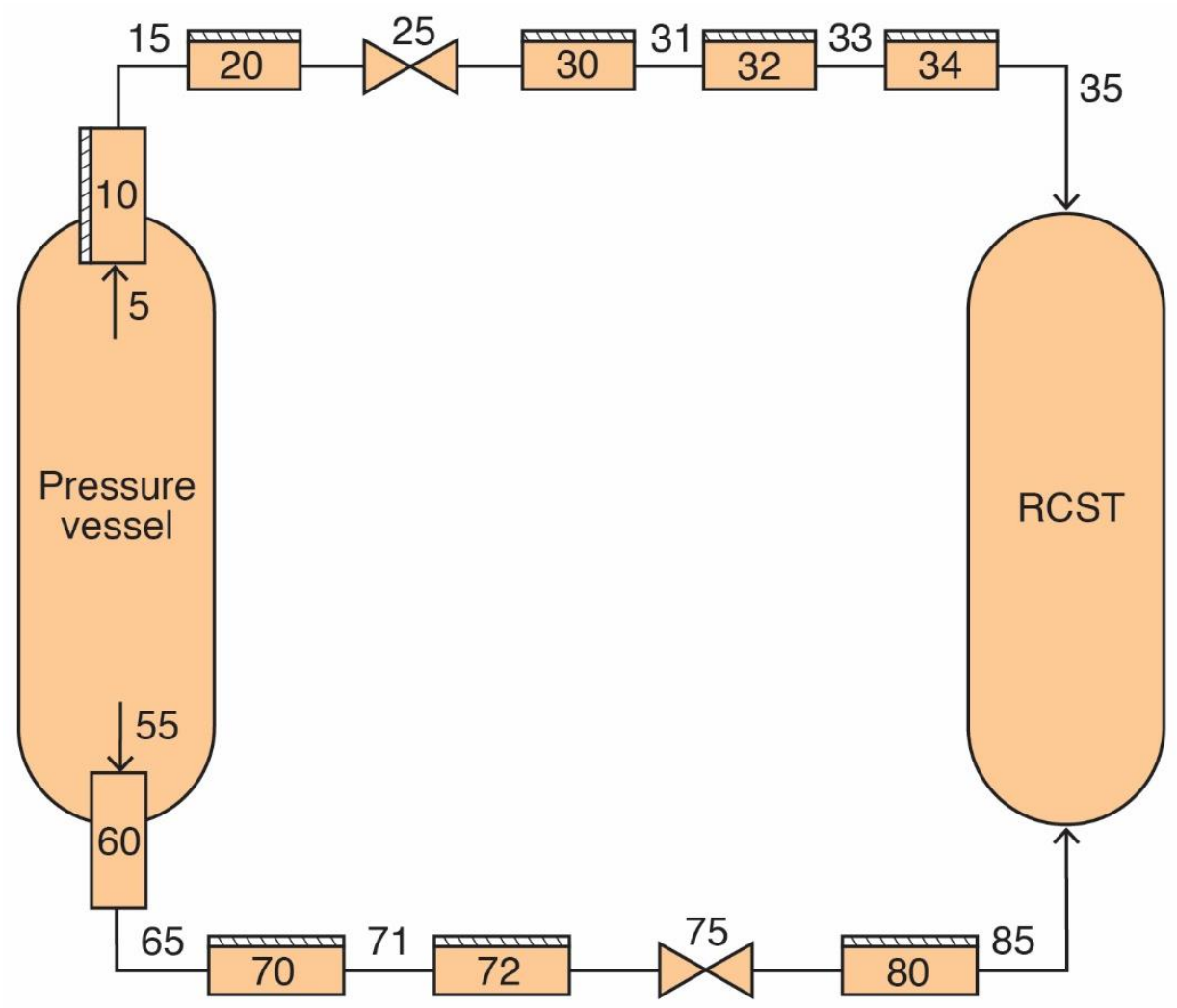

17-GA50150-5

Figure 6. Nodalization of vessel break lines.

into the cooling panels surrounding the primary pressure vessel. Water exiting the top of the panels is collected and returned to the water storage tank.

In some cases, it may make more sense to simplify the RCCS model so that it does not recirculate through the water storage tank; this will likely be true for post-test calculations because the temperature in the water storage tank can only be controlled manually. For this model, a time-dependent volume and junction supply the desired inlet flow rate and temperature, with the panel outlet flow being collected and discharged to a time-dependent volume.

Subsequent sections provide details on each of the components in the input model, grouped by component type. These are followed by a brief description of changes made to the model during initial steady-state testing, and then by references used in developing the input model. 


\section{HYDRODYNAMIC COMPONENTS}

Unless otherwise noted, default values for the volume and junction flags are used.

Approximate initial conditions are entered, as it is expected that a steady-state calculation will be run to establish the desired conditions prior to a transient calculation. The initial values entered are for normal steady-state operation at full power $(2200 \mathrm{~kW})$.

\subsection{Primary Pressure Vessel}

Component 100 is a two-junction branch representing the primary pressure vessel coolant inlet region. It is a vertical volume, with the top at the midpoint of the outlet plenum and the bottom at the midpoint of the coolant region between the lower support plate and the middle distributor plate. It represents the annulus between the pressure vessel and core barrel, from the top of the bottom support plate to the bottom of the liner shell ring. Junction 1 connects the outlet of the cold duct (Component 270) to the inlet of this component, with momentum flux turned off on the vessel side of the junction (flag $\mathrm{s}=1$ ); the loss coefficients are approximated based on the area change between the cold duct and the inlet annulus. Junction 2 connects the outlet of this component to the inlet of Component 105, using an abrupt area change (flag $\mathrm{a}=1$ ) with code-calculated loss coefficients and with momentum flux from this component turned off (flag $\mathrm{s}=2$ ). Three heat structures are attached to this component: Structure 1000 (pressure vessel wall), Structure 1100, (jacket shell), and Structure 1150 (core barrel).

Component 105 is a two-volume pipe representing the coolant region below the core support plate. The first volume includes the volume between the lower support plate and the middle distributor plate; the second volume includes the volume between the middle distributor plate and the upper bulkhead plate. It is assumed that there are thirty 1.75-in.-diameter cylinders extending through both flow regions, providing the power supply to the heater rods. The coolant volume in the gaps around the power supply cylinders where they pass through the middle distributor plate is neglected. The length of each volume is assumed to be equal to the radius of the middle plate, as the flow comes from the periphery to the center, then back out to the periphery. The elevation change between the two volumes is included in the first volume. Z-direction data are also input for the component, with the length equal to the distance between the plates. Since the flow changes direction between the lower and upper volumes, a loss coefficient for a 180-degree change in flow direction is included at the internal junction. Three heat structures are attached to this component: Structure 1050 (middle distributor plate), Structure 1150 (core barrel), and Structure 1750 (outlet plenum bottom plate).

Component 110 is a two-junction branch representing the coolant in the region between the core barrel and the upcomer shell (referred to as the "jacket shell" on Drawing OSU-HTTF-PRIM-DWG-002, sheet 6). Junction 1 connects the outlet of Component 105 to the inlet of this component, and Junction 2 connects the outlet of this component to the inlet of Component 115. Junction 1 is modeled as a smooth area change with no user-input loss coefficients. Junction 2 is modeled as an abrupt area change with code-calculated loss coefficients. Two heat structures are attached to this component: Structure 1100 (jacket shell) and Structure 1150 (core barrel).

Component 115 is a 15 -volume pipe representing the gap between the core barrel and the primary pressure vessel. It spans the elevation from the lower core support plate to above the flow slots in the upper plenum. The axial nodalization is the same as that inside the core barrel. The top volume is stagnant, as normal coolant flow exits the fourteenth volume. Three heat structures are attached to this component: Structure 1000 (pressure vessel wall), Structure 1150 (core barrel), and Structure 1200 (upper plenum cylinder).

Component 120 is a branch component representing the inlet (upper) plenum. It has one junction connecting to the coolant gap between the core barrel and the primary pressure vessel (Component 115). This volume extends from the top of the core barrel to the top of the upper plenum shroud. The junction is modeled as a smooth area change with loss coefficients representing the loss through the flow slots. Four heat structures are attached to this component: Structure 1001 (upper plenum shroud), Structure 1200 
(upper plenum cylinder), Structure 1201 (upper plenum floor), and Structure 1202 (upper plenum internals).

Component 125 is a multiple junction component that connects the inlet plenum to the inlets of each of the core and reflector cooling channels. It has five junctions. Junction 1 connects to the central reflector, Junction 2 to the inner core ring, Junction 3 to the middle core ring, Junction 4 to the outer core ring, and Junction 5 to the side reflector. All junctions are modeled as abrupt area changes with user-input loss coefficients (flag a $=2$ ) of 0.5 for forward flow and 1.0 for reverse flow, standard for sudden sharpedged contractions/expansions with a large area change.

Component 132 is a 14 -volume pipe component representing the six 0.75 -in.-diameter holes in the central reflector. It extends from the bottom of the inlet plenum to the top of the outlet plenum. Heat Structure 1320 (central reflector middle ring) is attached to this component.

Component 140 is a 14-volume pipe component that represents the coolant channels in the inner core ring, extending from the bottom of the inlet plenum to the top of the outlet plenum. This includes the area of eighty-four 0.625 -in.-diameter holes, thirty 0.5 -in.-diameter holes, and twenty-four 0.375 -in.-diameter holes. The hydraulic diameter of the channel was adjusted to provide the same pressure drop as if the holes were modeled individually; this diameter was determined by running a stand-alone model of this core ring with the three different holes sizes modeled individually and iterating on the combined channel hydraulic diameter. Three heat structures are attached to this component: Structure 1400 (inner core ring upper reflector), Structure 1401 (inner core ring ceramic), and Structure 1402 (inner core ring bottom reflector).

Component 141 is a 10-volume pipe component representing the helium gap around the inner core ring heater rods. It extends over the heated length. One heat structure is attached to this component: Structure 1401 (inner core ring ceramic).

Component 142 is a single junction component connecting Component 141 to Component 143.

Component 143 is a time-dependent volume that maintains a constant pressure in the helium gap around the inner core ring heater rods. Its temperature is set to the same value as in the adjacent volume in Component 141.

Component 145 is a 14 -volume pipe component that represents the one hundred forty-four 0.625 -in.diameter cooling holes in the middle core ring. It extends from the bottom of the inlet plenum to the top of the outlet plenum. Three heat structures are attached to this component: Structure 1450 (middle core ring upper reflector), Structure 1451 (middle core ring ceramic), and Structure 1452 (middle core ring bottom reflector).

Component 146 is a 10 -volume pipe component representing the helium gap around the middle core ring heater rods. It extends over the heated length. One heat structure is attached to this component: Structure 1451 (middle core ring ceramic).

Component 147 is a single junction component connecting Component 146 to Component 148.

Component 148 is a time-dependent volume that maintains a constant pressure in the helium gap around the middle core ring heater rods. Its temperature is set to the same value as in the adjacent volume in Component 146.

Component 150 is a 14 -volume pipe component representing the coolant channels in the outer core ring, extending from the bottom of the inlet plenum to the top of the outlet plenum. This includes the area of ninety-six 0.625-in.-diameter holes, sixty-six 0.5-in.-diameter holes, and seventy-two 0.375-in.diameter holes. As with Component 140, the channel hydraulic diameter was adjusted to provide the appropriate pressure drop. Three heat structures are attached to this component: Structure 1500 (outer core ring upper reflector), Structure 1501 (outer core ring ceramic), and Structure 1502 (outer core ring bottom reflector). 
Component 151 is a 10 -volume pipe component representing the helium gap around the outer core ring heater rods. It extends over the heated length. One heat structure is attached to this component: Structure 1501 (outer core ring ceramic).

Component 152 is a single junction component connecting Component 151 to Component 153.

Component 153 is a time-dependent volume that maintains a constant pressure in the helium gap around the outer core ring heater rods. Its temperature is set to the same value as in the adjacent volume in Component 151.

Component 162 is a 14-volume pipe component that represents the thirty-six 0.625 -in.-diameter holes in the side reflector. It extends from the bottom of the inlet plenum to the top of the outlet plenum. Heat Structure 1620 (side reflector middle ring) is attached to this component.

Component 164 is a 14-volume pipe component that represents the gap between the side reflector and the outer reflector. It extends from the top of the upper reflector to the top of the outlet plenum. It is connected to the outlet plenum, but not to the inlet plenum, as this gap is covered by the upper reflector top plate. Two heat structures are attached to this component: Structure 1640 (side reflector outer ring) and Structure 1660 (outer reflector).

Component 166 is a 15 -volume pipe component that represents the gap between the outer reflector and the core barrel. It extends from the top of the upper reflector to the bottom of the outlet plenum. It is connected to the outlet plenum, but not to the inlet plenum, as this gap is also covered by the upper reflector top plate. Two heat structures are attached to this component: Structure 1660 (outer reflector) and Structure 1150 (core barrel).

Component 168 is a single junction component connecting the middle of the last cell in Component 166 to the middle of Component 175, the outlet plenum. The connection is modeled as a crossflow junction with momentum flux turned off on both sides of the junction (flag $\mathrm{s}=3$ ). The junction area is modeled as the perimeter of the hot duct flow opening through the side reflector multiplied by the gap width between the outer reflector and the core barrel. Loss coefficients are calculated based on the ratio of the junction flow area to the hot duct flow area.

Component 170 is a multiple junction component connecting the core and reflector coolant channels and gaps to the outlet plenum. It has six junctions. Junction 1 connects to the central reflector, Junction 2 to the inner core ring, Junction 3 to the middle core ring, Junction 4 to the outer core ring, Junction 5 to the side reflector, and Junction 6 to the gap between the side and outer reflectors. These junctions are all modeled as abrupt area changes with user-input loss coefficients (flag a $=2$ ). The three core channels have forward and reverse loss coefficients of 2.5 to account for the channeling of the individual flow paths in the bottom reflector region. The reflector channels have forward loss coefficients of 1.0 and reverse loss coefficients of 0.5 , as they are straight flow paths with a sudden expansion into the outlet plenum.

Component 175 is a branch component representing the outlet plenum. It has one junction connecting the middle of this component to the inlet of the hot duct (Component 200); momentum flux is turned off on the plenum side of the junction (flag $\mathrm{s}=2$ ). Four heat structures are attached to this component: Structure 1150 (core barrel), Structure 1660 (outer reflector), Structure 1750 (outlet plenum bottom plate), and Structure 1751 (support posts).

Component 190 is a branch component representing the pressure vessel lower head. It has one junction connecting the outlet of this component to the middle of the first volume of Component 105 . The junction area is based on flow gaps in the lower support plate. An abrupt area change (flag a =1) with code-calculated loss coefficients is used, and momentum flux is turned off in the core support region volume (flag s = 1). Structure 1002 (pressure vessel lower head) is connected to this component. 


\subsection{Primary Coolant System}

Component 200 is the hot duct. It is modeled as a six-volume pipe. Cell lengths are selected such that the first instrument rake, the pipe to the steam generator, and the return pipe from the circulator to the cold duct are at cell centers. The segment from the end of the fourth cell to the modeled break valve (Component 205) includes the physical valve in the facility; this segment is divided into two cells to have comparable cell lengths through the hot leg. The loss coefficient for flow through the valve is located at internal Junction 5 in the pipe, rather than in the valve junction. It is assumed that the valve flow area is equal to that of the hot duct. The loss coefficient is based on the nominal hot leg Reynolds number and flow through an open ball valve. Losses associated with the very small area change between the concentric duct and the pipe leading to the RCST are neglected. Two heat structures are attached to this component: Structure 2000 (wall between hot and cold ducts) and Structure 2001 (pipe wall outside the concentric duct region).

Component 205 is a valve representing valve V-313, the hot duct break valve leading to the RCST. It connects the outlet of Component 200 to the inlet of Component 210, and is modeled as a motor valve with a stroke time of 5 seconds (assumed value pending receipt of actual data). The abrupt area change model is used with user-input loss coefficients of 0.0 (flag $\mathrm{a}=2)$, as the losses associated with the valve are included in Component 200. The valve area is modeled as changing linearly with the stem position. Trip 205 opens the valve, and Trip 206 closes it.

Component 210 is the pipe between valve V-313 and the RCST. It is modeled as a branch with one junction, connecting the outlet of this component to the bottom of the second volume in Component 280 , the RCST. The junction is modeled as an abrupt area change with user-input loss coefficients; the forward and reverse loss coefficients are for a sudden expansion/contraction with a large area ratio. If a hot duct break is being simulated, with the spool piece installed, the junction connects the outlet of Component 282 to the outlet of this component; in this case, the area change is modeled as abrupt with code-calculated loss coefficients. Heat Structure 2100 (pipe wall) is attached to this component.

Component 215 is the pipe between the hot duct and the steam generator inlet. It consists of the steam generator nozzle and the check valve body shown on Drawing OSU-HTTF-PRIM-DWG-005A. The pipe is modeled as a branch with one junction, connecting the top of the third volume in the hot duct to the inlet of this branch. Heat Structure 2150 (pipe wall) is attached to this component.

Component 217 is the check valve $(\mathrm{V}-101)$ in the pipe between the hot duct and the steam generator inlet. It is modeled at the steam generator inlet plenum, connecting the outlet of Component 215 to the inlet of Component 220. The differential pressure required to open the valve is $500 \mathrm{~Pa}$ (assumed value pending receipt of actual data). The loss coefficients include the loss from the 45-degree elbow in the steam generator inlet line and the area change between the pipe and inlet plenum; the latter loss is assumed to be an abrupt contraction from the pipe flow area to the average flow area in the plenum. An alternate model for this component is also available, representing a 4-in. (10-cm) diameter orifice that is installed in place of the check valve during system characterization testing.

Component 220 is the steam generator inlet plenum. It includes both the plenum and the 45 -degree elbow between the plenum and the flange. It is modeled as a branch with one junction, connecting the outlet of this component to the inlet of the steam generator tubes. This junction is modeled as an abrupt area change with user-input loss coefficients. The loss coefficients are based on a sudden contraction/expansion from the plenum flow area at the tube sheet to the tube flow area. The loss from the elbow and the entrance to the plenum are included in the Component 217 loss coefficient. Two heat structures are attached to this component: Structure 2200 (plenum and inlet pipe walls) and Structure 2201 (plenum pass partition).

Component 225 is the steam generator tubes. The 188 tubes are modeled as a 22-volume pipe. Cells 1-10 carry the gas flow up, Cells 11 and 12 are the U-bend, and Cells 13-22 are the downflow side. The tube bends are assumed to start at the top baffle plate. They are also assumed to be smooth 180-degree 
bends, so that the radius of the bend is equal to the distance from the center of the bundle (90-270 degree line on Drawing OSU-HTTF-SEC-DWG-003C) to the center of each tube. The loss from the bend is located at the junction at the top of the tubes, Junction 11. The first and last cells include the flow length through the tube sheet. Two heat structures are attached to this component: Structure 2250 (steam generator tubes) and Structure 2251 (tube sheet).

Component 228 is the steam generator outlet plenum. It includes both the plenum and the 45-degree elbow between the plenum and the flange. It is modeled as a branch with two junctions. The inlet junction is modeled as an abrupt area change at the tube sheet with user-input loss coefficients; the loss coefficients are based on a sudden expansion/contraction from the tube flow area to the plenum flow area at the tube sheet. The outlet junction is modeled as a smooth area change with a loss coefficient equal to that of a sudden expansion from the average plenum area to the pipe area plus a 45-degree elbow. Two heat structures are attached to this component: Structure 2280 (plenum and outlet pipe walls) and Structure 2201 (plenum pass partition).

Component 230 is the pipe between the steam generator outlet and the gas circulator inlet. It is modeled using a single volume component. There are two bends in this section of piping. The losses associated with these bends are included in the circulator inlet junction; the estimated friction loss in the bends is subtracted from the published loss coefficient values, as the code will calculate the friction loss. Heat Structure 2300 (pipe wall) is attached to this component.

Component 233 is a single junction connecting the outlet of Component 230 to the inlet of Component 234; it is used only during steady-state calculations and is deleted for transient calculations.

Component 234 is a time-dependent volume that provides pressure control during steady-state calculations; it is deleted for transient calculations. The volume is maintained at a constant temperature equal to the desired primary pressure vessel inlet temperature. The pressure is controlled by control variable $(\mathrm{CV}) 234$ to provide the desired pressure vessel inlet pressure.

Component 235 is the gas circulator volume. It is modeled as a branch with one junction, connecting the outlet of Component 230 to the inlet of this component. Loss coefficients represent the losses associated with the two bends in the inlet piping. Heat Structure 2350 (circulator body) is attached to this component.

Component 237 provides the circulator forced flow, connecting the outlet of Component 235 to the inlet of Component 240. It is modeled as a time-dependent junction, with the flow rate determined by CV 237 during steady state. The time-dependent junction component is expected to provide sufficient modeling of the circulator function, as transients should result in isolation of the portion of the loop piping containing the circulator.

Component 240 is the pipe between the gas circulator outlet and valve V-203 (Component 245). It is modeled as a single volume, and includes the volume of the pipe and half of the valve. The flow area of the valve is assumed to be the same as that of the pipe. Heat Structure 2400 (pipe wall) is attached to this component.

Component 245 is a valve representing valve V-203. It connects the outlet of Component 240 to the inlet of Component 250, and is modeled as a motor valve with a stroke time of 5 seconds (assumed value pending receipt of actual data). The valve area is modeled as changing linearly with the stem position. Trip 245 opens the valve, and Trip 246 closes it. The junction is modeled as an abrupt area change with user-input loss coefficients; the loss coefficients are based on flow through a ball valve and through one 90-degree bend (between the circulator and the valve).

Component 250 is the pipe between valve V-203 and valve V-311 (Component 255). It is modeled as a pipe with three volumes. The first volume extends from the middle of valve V-203 to the tee upstream of the break valve. The second volume is the straight passage of the tee. The third volume is the volume in valve V-313, which is assumed to have the same flow area as the upstream piping. The first junction includes the loss coefficient from the 90-degree elbow in the piping. Heat Structure 2500 (pipe wall) is 
attached to this component.

Component 255 is valve V-311, which is the cold leg break valve leading to the RCST. It connects the outlet of Component 250 to the inlet of Component 258, and is modeled as a motor valve with a stroke time of 5 seconds (assumed value pending receipt of actual data). The valve area is modeled as changing linearly with the stem position. Trip 255 opens the valve, and Trip 256 closes it. The loss coefficient is based on the nominal cold leg Reynolds number and flow through an open ball valve.

Component 258 is the pipe between valve V-311 and the RCST. It is modeled as a branch with one junction, connecting the outlet of this component to the inlet of the second volume in Component 280, the RCST. The junction is modeled as an abrupt area change with user-input loss coefficients; the forward and reverse loss coefficients are for a sudden expansion/contraction with a large area ratio. If a hot duct break is being simulated, with the spool piece installed, the junction connects the outlet of this component to the inlet of Component 282; in this case, the area change is modeled as smooth with loss coefficients of 0.0 . Heat Structure 2580 (pipe wall) is attached to this component.

Component 260 is the crossover pipe from the cold leg tee to the cold duct. It is modeled as a branch with two junctions. The first junction is the tee off of the cold leg pipe upstream of the break valve, connecting the side of the second volume of Component 250 to the inlet of this component. The forward loss coefficient is that of flow for a diverging wye, and the reverse loss coefficient is that for a converging wye; in both cases, all of the flow is through the branch. The second junction connects the outlet of this component to the side of the first volume in the cold duct. The forward loss coefficient at this junction is approximated as that of flow from the side branch of a converging wye. The reverse loss coefficient is for a diverging wye. The geometry of the connection does not match either of the formulas associated with Diagram 7-18 in Idelchik 1994; the second formula is used, and uncertainties in this loss coefficient should not be significant as reverse flow is only expected during some transient tests with natural circulation flow. Heat Structure 2600 (pipe wall) is attached to this component.

Component 270 is the cold duct. It is modeled as a four-volume pipe. The junctions are at the same locations as those in the common portion of the hot duct. Two heat structures are attached to this component: Structure 2000 (wall between hot and cold ducts) and Structure 2700 (outer pipe wall).

Component 280 is the RCST. It is normally modeled as a two-volume vertical pipe. The lower volume represents the region below the break nozzles, which is assumed to not participate in any gas mixing in the tank. The upper volume represents the portion of the tank that will participate in mixing with gas entering from the PCS. With this being modeled as a single cell, all of the fluid will be perfectly mixed. This will overestimate the temperature of gas re-entering the PCS from the tank, as no thermal stratification will occur in the tank; this is a limitation of the one-dimensional modeling of the tank. However, there is no basis for a two- or three-dimensional model, and unphysically large recirculating flows have been observed in the past when such a modeling approach was attempted. The lengths of the two volumes are distorted to maintain the top and bottom of the tank at the appropriate elevations; the total volume is preserved, and the hydraulic diameter used is that of the tank cylinder. A single-volume model is also available; this model is intended to be used when the hot duct break spool piece is installed in the tank (see Component 282). There are normally three heat structures attached to this component: Structure 2100 (hot duct nozzle), Structure 2580 (cold duct nozzle), and Structure 2800 (tank wall). Structure 2820 (spool piece wall) is also attached if the break spool piece (Component 282) is installed.

Component 282 is the spool piece that is installed for hot duct breaks, connecting the hot and cold leg break nozzles inside the RCST. It is modeled as a single volume. Without a full set of dimensional information, the pipe is assumed to be a 180-degree bend with a bend diameter equal to the distance between the hot and cold break nozzle centerlines. From Drawing OSU-HTTF-RCSS-DWG-008C, it appears that the pipe is the same size as the cold leg nozzle piping, and that is therefore assumed to be the case. Heat Structure 2820 (pipe wall) is attached to this component.

Component 293 is the piping leading to the inlet of valves PSV-100 (Component 295) and V-400 (Component 296). It is modeled as a branch with one junction connecting the side of Component 240 to 
the inlet of this component. The forward loss coefficient at the junction is that of flow into the side branch of a diverging wye. The reverse loss coefficient is for flow from the side branch of a converging wye; this loss coefficient should not matter, as reverse flow through the pressure relief line should not occur.

Component 295 is the pressure relief valve (PSV-100). It connects the outlet of Component 293 to the inlet of Component 298, and is modeled as a trip valve that is open when trip 1295 is true. The flow area of the valve is set to that of the pipe, and will be adjusted when performance data for the valve are available.

Component 296 is the depressurization valve (V-400). It connects the outlet of Component 293 to the inlet of Component 298, and is modeled as a trip valve that is open when trip 1296 is true. The flow area of the valve is assumed to be the same as that of the pipe. The junction is modeled as a smooth area changed with a user-input loss coefficient based on flow through an open ball valve.

Component 298 is the pressure boundary volume downstream of the pressure relief and depressurization valves. It is modeled as a helium-filled volume at atmospheric pressure. Helium is used (rather than air) to avoid some code failures when air flowed back into the PCS through an open valve; since both valves connected to this volume are used to depressurize the PCS, backflow should not occur in the facility.

\subsection{Secondary Coolant System}

Component 320 is the feedwater pump (P-010). It is modeled as a time-dependent junction. The flow through the pump is determined by CV 320. The pump suction is taken from the water storage tank outlet line, Component 460. The pump discharge is connected to the inlet of Component 330.

Component 330 is the piping between the feedwater pump and the steam generator. The valves in this piping, V-011, V-012, and LCV-013, are not modeled explicitly. The logic controlling LCV-013 will be included in the controls for Component 320. The piping is modeled using a branch component with one junction; the junction connects the outlet of this component to the inlet of Component 340, with momentum flux turned off in the "to" volume (flag $\mathrm{s}=1$ ). Details of the pipe configuration are not shown on drawing OSU-HTTF-GEN-DWG-009H, so the length is estimated to be $20 \%$ greater than the elevation change between the feedwater pump and the feedwater nozzle on the steam generator to accommodate the horizontal runs. This assumption should have no effect on the calculated plant response, as the feedwater flow rate and steam generator pressure are controlled, so the pressure loss in this piping will be immaterial. The loss coefficients at the junction were calculated assuming the connection is a tee with all of the flow going between the branch and one leg of the tee. The pipe walls are not modeled with heat structures, as heat transfer in the feedwater system is not expected to be important to the steam generator conditions.

Component 340 is the steam generator downcomer. It is modeled as an 11-volume pipe extending from the bottom of the inner shell lap ring to the bottom of the inner shell. The internal junctions are located at the same elevations as those in the boiler region. Two heat structures are attached to this component: Structure 3400 (steam generator outer shell) and Structure 3500 (steam generator inner shell).

Component 345 (not shown in Figure 5) is the junction between the steam generator downcomer and the boiler region. It is modeled using a single junction component connecting the outlet of Component 340 to the outlet of the first cell in Component 350. The junction area and hydraulic diameter are those of the downcomer. The abrupt area change flag is set to 2, and the loss coefficient is based on a sudden expansion (contraction in reverse flow) into the bottom boiler volume.

Component 350 is the steam generator boiler region. It is modeled as a 13 -volume pipe extending from the top of the tube sheet to the top of the inner cone. Node boundaries in the boiler region are placed at the centerlines of the baffle plates and halfway in between them, resulting in 10 cells spanning the straight portion of the tubes. The flow area at the baffle plates is modeled as just the flow around the end of the plate; it is assumed that thermal expansion of the tubes and tie rods will result in a negligible flow area between the tubes and the baffle plate. The volume occupied by the baffle plates is also neglected. 
Loss coefficients at the baffle plates are estimated as though the area change was through a sharp-edged orifice, and are based on the volume flow area. Cells 11 and 12 are equal-length cells extending from the top baffle plate to the bottom of the inner cone, while cell 13 is the volume inside the inner cone. The Ubends in the steam generator tubes are contained in cell 11 . The bundle interphase drag model $($ flag $b=1)$ is used in volumes 1-11. Three heat structures are attached to this component: Structure 3400 (steam generator outer shell), Structure 3500 (steam generator inner shell), and Structure 2250 (steam generator tubes).

Component 355 is the steam dome, the region above the top of the inner cone. It is modeled as a branch with two junctions. The dome includes only part of the rounded portion of the end cap; the rest, together with the cylindrical (straight) portion, is included in Component 360. The first junction is the inlet from Component 350 and is modeled as a smooth area change with no loss coefficients: it is assumed that the entering flow occupies the same area as the top of the inner cone, and that the flow going down into the upper annulus occupies the same area as the annulus. The second junction is the connection from the outlet of this component to the inlet of the relief valve inlet piping, Component 390 . It is modeled as an abrupt area change with user-input loss coefficients based on the flow area ratios of the pipe and steam dome. Heat Structure 3550 (upper head) is attached to this component.

Component 360 is the steam annulus, the region between the upper cone and the outer shell. It is modeled as a downward-oriented branch with two junctions. The volume includes the region between the inner cone and the upper shell, and a small cylindrical section below between the inner shell and the flange. The first junction is the inlet from Component 355, which is modeled as a smooth area change with no loss coefficients. The second junction is the connection to the steam line, which is modeled as being from the side of this volume to the inlet of Component 365; the steam line area and hydraulic diameter are used for the junction. Momentum flux is turned on, as there should be a radial component to the flow in the facility as it moves around the inner cone to the steam line. The abrupt area change flag is set to 2, with loss coefficients based on an abrupt area change from the crossflow area into the pipe. Heat Structure 3400 (steam generator shell) is attached to this component.

Component 365 is the 4-in. piping in the steam line. It includes valve PCV-602 (Component 370), which is located at the end of the pipe section in the model. It is modeled using a single volume component. The check valve in this line (V-601) is not modeled explicitly. The component length is estimated, and will not have any effect on the calculated behavior in the steam generator as the steam dome pressure is controlled during steady-state operation, and the steam generator is expected to be isolated during most transients.

Component 370 is the pressure control valve (PCV-602). It connects the outlet of Component 365 to the inlet of Component 375, and is modeled as a servo valve controlled by CV 370 . The flow area is the same as that of the upstream volume (Component 365). The abrupt area change model is used with codecalculated loss coefficients (flag $\mathrm{a}=1$ ). The valve area is modeled as changing linearly with the stem position. The valve is expected to be closed during transient calculations; even if it is not, the steam generator tubes will be isolated on the primary system side, so that any residual heat transfer in the steam generator will not affect the plant response of interest.

Component 375 is the pressure boundary volume downstream of the pressure control valve. It is modeled as a steam-filled volume at atmospheric pressure.

Component 390 is the pipe from the steam generator dome to valve PSV-600 (Component 395). It is modeled as a single volume component.

Component 395 is the pressure relief valve (PSV-600). It is modeled as a trip valve connecting the outlet of Component 390 to the inlet of Component 398. The valve is open when trip 1395 is true. The abrupt area change model is used with code-calculated loss coefficients. The flow area of the valve is set to that of the pipe, and will be adjusted when performance data for the valve are available.

Component 398 is the pressure boundary volume downstream of the pressure relief valve. It is modeled as a steam-filled volume at atmospheric pressure. 


\subsection{Potable Water Supply System}

Choking is turned off (flag $\mathrm{c}=1)$ at all junctions in this system.

Component 400 is the supply pressure boundary volume for the potable water system. It contains $290 \mathrm{~K}$ water at a pressure of $400 \mathrm{kPa}$ (assumed values pending receipt of actual data).

Component 410 is level control valve LCV-010. It connects the outlet of Component 400 to the inlet of Component 420, and is modeled as a servo valve controlled by CV 410. The valve area is modeled as changing linearly with the stem position. The abrupt area change model is used with code-calculated loss coefficients, and choking is turned off. A very small flow is maintained through the valve to avoid occasional code thermodynamic property failures in Component 420.

Component 420 is the piping between the level control valve and tank T-010 (Component 450). It is modeled as a branch with one junction, with an assumed length long enough to prevent this volume from controlling the Courant limit. The junction connects the outlet of this component to the inlet of Component 450. User-input loss coefficients are for an abrupt area change (flag a $=2$ ) between the small pipe and the large tank.

Component 450 is the RCCS/coolant day tank, tank T-010. It is modeled as a 6-volume pipe. The mixture level tracking model is turned on where permitted to try to prevent air from entering the feedwater or RCCS lines. The thermal stratification model is turned on where permitted to keep hot water returning from the RCCS panels segregated from the cooler water in the tank, and to segregate the colder supply water being added at the bottom of the tank. There are no heat structures modeling the tank wall, as heat transfer to the wall is not expected to be important to either the steam generator or RCCS behavior.

Component 460 is the tank T-010 outlet line, which provides feedwater to both the steam generator and the RCCS. It is modeled as a branch with one junction. The junction connects the bottom of the tank, the inlet of Component 450, to the inlet of this component. There are no details about the pipe configuration. Since the important part of this section of pipe is the elevation change, which provides the head at the pump suction, the pipe is modeled as a straight vertical run. There is no heat structure modeling the pipe wall, as heat transfer in this piping is not expected to be important to either the steam generator or RCCS behavior.

Component 490 is the vent/overflow line on tank T-010. It is modeled as a branch with two junctions. Its length is sufficient to allow the pipe to exit the bottom of the tank; piping beyond this is neglected. Junction 1 connects the outlet of cell 5 of Component 450 to the inlet of this component. Junction 2 connects the outlet of this component to the inlet of Component 498. Both junctions are modeled as abrupt area changes (flag $\mathrm{a}=2$ ) with user-input loss coefficients for a contraction or expansion with a large area change.

Component 498 is the pressure boundary volume at the end of the vent/overflow line on tank T-010, Component 490. It is filled with $295 \mathrm{~K}$ air at atmospheric pressure.

\subsection{Alternate Break Piping}

These components are not active in the base input model, but are activated as needed for the specific transient being modeled.

Component 5 is the junction between the upper plenum and the control rod drive break nozzle. It is modeled as a single junction connecting the outlet of Component 120 to the inlet of Component 10 . The abrupt area change model is used with user-defined loss coefficients (flag a $=2$ ). The loss coefficients are based on the area change between the top of the plenum and the nozzle interior.

Component 10 is the control rod drive break nozzle from the inlet to the center of the piping offtake. It is modeled as a pipe with 25 volumes; the large number of volumes reflects the expectation that molecular diffusion will be the principal phenomenon occurring when this break is included in the model. 
Heat Structure 0100 (pipe wall) is attached to this component.

Component 15 is the junction between the control rod drive break nozzle and the piping. It is modeled as a single junction connecting the outlet of Component 10 to the inlet of Component 20. It uses the abrupt area change model with user-input loss coefficients (flag a $=2$ ); the loss is approximated as that through the branch of a tee.

Component 20 is the piping between the control rod drive break nozzle and valve V-332 (Component 25). It is modeled as a pipe with 35 volumes; the large number of volumes reflects the expectation that molecular diffusion will be the principal phenomenon occurring when this break is included in the model. Heat Structure 0200 (pipe wall) is attached to this component.

Component 25 is the control rod drive break valve, $\mathrm{V}-332$. It is modeled as a trip valve, using trip 625. It connects the outlet of Component 20 to the inlet of Component 30 . The abrupt area change model is used (flag $\mathrm{a}=2$ ) with user-input loss coefficients. The loss coefficients are based on a large flow through the valve, but minimal flow is expected during transients when this valve is open.

Component 30 is the first third of the piping between valve V-332 and the RCST. It is modeled as a pipe with 92 volumes; the large number of volumes reflects the expectation that molecular diffusion will be the principal phenomenon occurring when this break is included in the model. Heat Structure 0300 (pipe wall) is attached to this component.

Component 31 is a single junction connecting the outlet of Component 30 to the inlet of Component 32. It uses the smooth area change model with no loss coefficients.

Component 32 is the middle third of the piping between valve V-332 and the RCST. It is modeled as a pipe with 92 volumes; the large number of volumes reflects the expectation that molecular diffusion will be the principal phenomenon occurring when this break is included in the model. Heat Structure 0320 (pipe wall) is attached to this component.

Component 33 is a single junction connecting the outlet of Component 32 to the inlet of Component 34. It uses the smooth area change model with no loss coefficients.

Component 34 is the final third of the piping between valve V-332 and the RCST. It is modeled as a pipe with 92 volumes; the large number of volumes reflects the expectation that molecular diffusion will be the principal phenomenon occurring when this break is included in the model. Heat Structure 0340 (pipe wall) is attached to this component.

Component 35 is a single junction connecting the outlet of Component 34 to the top of the RCST, Component 280. It uses the abrupt area change model (flag a $=2$ ) with user-input loss coefficients representing the large area change between the pipe and the tank.

Component 55 is the junction between the coolant region below the core support plate and the vessel bottom break line nozzle stub. It is modeled as a single junction connecting the bottom of the middle of the first volume in Component 105 to the inlet of Component 60. This connection places the nozzle somewhat higher in the model than in the facility, but the distortion is not expected to be significant for the transients in which the vessel bottom break line is active. The abrupt area change model is used with user-defined loss coefficients (flag a $=2$ ). The loss coefficients are based on the area ratio between the lower support plate and the nozzle stub. Momentum flux is turned off on the vessel side of the junction (flag $\mathrm{s}=2$ ).

Component 60 is the vessel bottom break line nozzle stub. It is modeled as a pipe with 43 volumes; the large number of volumes reflects the expectation that molecular diffusion will be the principal phenomenon occurring when this break is included in the model.

Component 65 is the junction between the bottom break line nozzle stub and the bottom break line piping. It is modeled as a single junction connecting the outlet of Component 60 to the inlet of Component 70. It used the abrupt area change model with user-input loss coefficients $($ flag a $=2$ ). 
Component 70 is the first half of the vessel bottom break line piping between the pressure vessel nozzle stub and valve V-331 (Component 75). It is modeled as a pipe with 73 volumes; the large number of volumes reflects the expectation that molecular diffusion will be the principal phenomenon occurring when this break is included in the model. Heat Structure 0700 (pipe wall) is attached to this component.

Component 71 is a single junction connecting the outlet of Component 70 to the inlet of Component 72. It uses the smooth area change model with no loss coefficients.

Component 72 is the second half of the vessel bottom break line piping between the pressure vessel nozzle stub and valve V-331. It is modeled as a pipe with 73 volumes; the large number of volumes reflects the expectation that molecular diffusion will be the principal phenomenon occurring when this break is included in the model. Heat Structure 0720 (pipe wall) is attached to this component.

Component 75 is the pressure vessel bottom break valve, V-331. It is modeled as a trip valve, using trip 675. It connects the outlet of Component 72 to the inlet of Component 80 . The abrupt area change model is used (flag $\mathrm{a}=2$ ) with user-input loss coefficients. The loss coefficients are based on a large flow through the valve, but minimal flow is expected during transients when this valve is open.

Component 80 is the piping between valve V-331 and the RCST. It is modeled as a pipe with 96 volumes; the large number of volumes reflects the expectation that molecular diffusion will be the principal phenomenon occurring when this break is included in the model. Heat Structure 0800 (pipe wall) is attached to this component.

Component 85 is a single junction connecting the outlet of Component 80 to the bottom of the RCST, Component 280. It uses the abrupt area change model (flag $\mathrm{a}=2$ ) with user-input loss coefficients representing the large area change between the pipe and the tank.

\subsection{Reactor Cavity and Reactor Cavity Cooling System}

Choking is turned off (flag c $=1$ ) at all junctions in the RCCS.

Component 900 is the reactor cavity between the primary pressure vessel and the RCCS panels, extending from the floor to the top of the RCCS panels. It is modeled as a single volume filled with air. An alternate model using a 20-volume pipe filled is included in the input deck for use with code versions in which the heat structure lengths cannot be input on the heat structure 500/600 series cards. The axial nodalization is consistent with the axial nodalization inside the primary pressure vessel. The only connection to the pipe is at the top, so an unphysical temperature profile will occur in the pipe if that nodalization is used. The single volume approach will overestimate the mixing in the cavity by making the air all the same temperature; this is expected to be closer to the actual conditions in the cavity than those that will be calculated using the pipe component. Three heat structures are attached to this component: Structure 1000 (pressure vessel wall), Structure 1001 (pressure vessel upper head), and Structure 9500 (RCCS panels).

Component 903 is a single junction connecting the top of the reactor cavity (outlet of Component 900) to the pressure boundary volume (inlet of Component 905).

Component 905 is the pressure boundary volume for the reactor cavity. It is a time-dependent volume containing $295 \mathrm{~K}$ air at a constant pressure of $100 \mathrm{kPa}$.

Component 915 is the alternate source volume for the RCCS pump. It is a time-dependent volume whose conditions need to be input by the user. The default conditions are $290 \mathrm{~K}$ water at a pressure of $100 \mathrm{kPa}$. This component is not active in the base input model.

Component 920 is the RCCS pump. It is modeled as a time-dependent junction, with the flow determined by CV 920. The suction is taken from the outlet of the water storage tank outlet line, Component 460, and the discharge is to the inlet of Component 930. Suction can also be taken from Component 915. 
Component 930 is the piping between the RCCS pump outlet and the RCCS panel inlet headers. It also includes the short section of piping upstream of the pump, as well as the volumes in the pump and valves. The valves in this line (V-805 and PCV-807) are not modeled explicitly. This piping is modeled with a single volume component and no heat structures for the pipe walls, as heat transfer in this piping is not expected to be important to the RCCS behavior.

Component 940 represents the RCCS panel inlet headers. It is modeled as a branch with one junction, connecting the outlet of Component 930 to the inlet of this component. The junction is modeled as an abrupt area change (flag $\mathrm{a}=2$ ) with momentum flux turned off on the header side (flag $\mathrm{s}=1$ ). The loss coefficients are based on branching at a tee. There is no heat structure modeling the pipe wall, as heat transfer in this piping is not expected to be important to the RCCS behavior.

Component 945 represents the RCCS panel inlet lines. The valves in the lines are not modeled explicitly. The inlet lines are modeled as a branch with two junctions. The first junction connects the outlet of Component 940 to the inlet of this component. The second junction connects the outlet of this component to the inlet of the RCCS panels, Component 950. Since the RCCS flow is being provided by a time-dependent junction, the pressure loss in the piping is not important (the flow rate does not depend on a balance between the pump head and the piping pressure loss), and loss coefficients of 0.0 are entered for the junctions for simplicity. There is no heat structure modeling the pipe wall, as heat transfer in this piping is not expected to be important to the RCCS behavior.

Component 950 represents the RCCS panels. They are modeled with a 19-volume pipe. The axial nodalization is consistent with the axial nodalization inside the primary pressure vessel. Two heat structures are connected to this component: Structure 9500, which represents the surface facing the primary pressure vessel, and Structure 9501, which represents the back side of the panels, are connected to this component. Two heat structures are attached to this component: Structure 9500 (front panels) and Structure 9501 (back panels).

Component 955 represents the RCCS outlet lines leading to the outlet headers. They are modeled with a two-junction branch component. The first junction connects the outlet of the RCCS panels (Component 950) to the inlet of this component, and the second junction connects the outlet of this component to the inlet of Component 960 . Since the RCCS flow is being provided by a time-dependent junction, the pressure loss in the piping is not important (the flow rate does not depend on a balance between the pump head and the piping pressure loss), and loss coefficients of 0.0 are entered for the junctions for simplicity. There is no heat structure modeling the pipe wall, as heat transfer in this piping is not expected to be important to the RCCS behavior.

Component 960 represents the RCCS outlet headers. The two 1-in. headers are lumped together with the two 1.5-in. pipes into a single branch component with one junction connecting the outlet of this component to the middle of the fifth cell in Component 450, the RCCS water storage tank. If water is not being recirculated to the storage tank, flow is discharged to Component 965 . The hydraulic diameter of the 1-in. pipe is used, as the pressure drop through this piping is not important to the facility response. The junction loss coefficients represent the large area change between the piping and the tank. There is no heat structure modeling the pipe wall, as heat transfer in this piping is not expected to be important to the RCCS behavior.

Component 965 is the alternate sink volume for the RCCS flow, used when flow is not modeled as being recirculated to the water storage tank (Component 450). It is modeled using a time-dependent volume with constant conditions of $290 \mathrm{~K}$ water at a pressure of $100 \mathrm{kPa}$. This component is not active in the base input model. 


\section{HEAT STRUCTURES}

The core region is modeled with two heat structures in each channel. The first structure is centered on a coolant channel, and models the ceramic material. The second structure represents the heater rods, and is modeled as a solid cylinder that radiates heat to the outer surface of the ceramic structure. The "dog bone" shape of the individual heater rodlets is approximated by a cylinder of the same length that preserves the total mass of graphite. This results in about a $10 \%$ larger diameter than the actual diameter of the cylindrical portion of the rodlet. This will slightly distort the surface temperature of the rodlet (lower than expected) because of the larger surface area, but this is offset somewhat by modeling only radiation heat transfer, and not convection or conduction, from the heater rods to the ceramic.

The Gnielinski correlation is being used for the core coolant channels. This is implemented by using heat transfer package 160 on the 500/600 series input cards (Word 3). Two-dimensional (2-D) conduction is used in most vertical structures. Dummy values are usually entered for the input on the 800 and 900 series cards related to critical heat flux parameters. With a single-phase vapor coolant, critical heat flux will not be a concern; the exception is the secondary side of the steam generator tubes.

The thickness of the middle rings of the central and side reflectors will likely need to be adjusted based on system characterization data. The amount of material that is influenced by the coolant channels is just estimated in this original model development effort, as appropriate measured data are not yet available.

\subsection{Primary Pressure Vessel}

Structure 1000 is the cylindrical portion of the primary pressure vessel. It has 17 axial structures (cell 1 is at the bottom), is made of 304 stainless steel [Drawing OSU-HTTF-PRIM-DWG-002, Sheet 1, Rev. 0, items 2 and 3], and is connected to Components 100 and 115 on the left side and Component 900 on the right side. Axial conduction is turned on, and the node lengths are input on the 600 series cards. The left side is in a radiation enclosure (Enclosure 19) with the core barrel and the jacket shell, and the right side is in a radiation enclosure (Enclosure 21) with the RCCS.

Structure 1001 includes both the primary pressure vessel upper head and the upper plenum shield, since the volume between these two structures is filled with insulation. The upper head is made of 304 stainless steel [Drawing OSU-HTTF-PRIM-DWG-002, Sheet 1, Rev. 1, item 1]. The upper plenum shield is made of Haynes 230 [Drawing OSU-HTTF-PRIM-DWG-002, Sheet 6, Rev. 1, items 90-93]. The insulation is Cerablanket (alumina-silica). The structure is connected to Component 120 on the left side and Component 900 on the right side. The left side is in a radiation enclosure (Enclosure 16) with other structures in the upper plenum, and the right side is in a radiation enclosure (Enclosure 21) with the RCCS.

Structure 1002 is the primary pressure vessel lower head. It is modeled as a hemisphere, is made of 304 stainless steel [Drawing OSU-HTTF-PRIM-DWG-002, Sheet 1, Rev. 1, item 1], and is connected to Component 190 on the left side and Component 900 of the right side. The right side is in a radiation enclosure (Enclosure 21) with the RCCS.

Structure 1050 is the middle distributor plate in the coolant inlet region below the outlet plenum. It is a single, horizontal rectangular structure made of 304 stainless steel [Drawing OSU-HTTF-PRIMDWG-002, Sheet 6, Rev. 1, item 103], connected to volume 105-01 on the bottom and volume 105-02 on the top.

Structure 1100 is the jacket shell, the outer plate forming the coolant upcomer between the core barrel and the primary pressure vessel in the lower vessel region. It has one axial structure, is made of 304 stainless steel [Drawing OSU-HTTF-PRIM-DWG-002, Sheet 6, Rev. 1, item 85], and is connected to Component 110 on the left side and Component 100 on the right. Both sides of the structure are in a radiation enclosure (Enclosure 19) with the core barrel and primary pressure vessel shell. 
Structure 1150 is the core barrel. It has 16 axial structures (cell 1 is at the bottom), is made of 304 stainless steel [Drawing OSU-HTTF-PRIM-DWG-002, Sheet 6, Rev. 1, item 86], and is connected to Components 105, 166, and 175 on the left side and Components 100, 110, and 115 on the right side. Axial conduction is turned on. The left side of the structure is in a radiation enclosure (Enclosure 15) with the outer reflector, and the right side is in a radiation enclosure (Enclosure 19) with the primary pressure vessel barrel and the jacket shell.

Structure 1200 is the upper plenum cylinder. It has one axial structure, connected to Component 120 on the left side and Component 115, cell 15 on the right side. It is made of Haynes alloy 230 [Drawing OSU-HTTF-PRIM-DWG-002, Sheet 6, Rev. 1, item 90]. The height of the structure extends only to the top of the pressure vessel cylinder, as the remainder of the upper plenum cylinder is included in the upper head/upper plenum shield structure (Structure 1001). The left side of the structure is in a radiation enclosure (Enclosure 16) with other structures in the upper plenum. The right side of the structure is in a radiation enclosure (Enclosure 19) with the primary pressure vessel cylinder.

Structure 1201 is the upper plenum floor. It is made of graphite [Drawing OSU-HTTF-PRIMDWG-002, Sheet 6, Rev. 1, item 110], and is connected to Component 120 on the right side. The left side is not connected to a fluid volume, but is in a conduction enclosure (Enclosure 2) with the upper reflector portion of each of the core region heat structures; the right side is in a radiation enclosure (Enclosure 16) with other structures in the upper plenum.

Structure 1202 represents the upper plenum internals. It is made of 304 stainless steel, and is connected to Component 120 on the right side; the left side is adiabatic. The right side is in a radiation enclosure (Enclosure 16) with other structures in the upper plenum.

Structure 1300 is the center cylindrical region of the central reflector, which is made of Greencast ceramic. Its 14 axial cells (cell 1 is at the top) extend from the top of the upper reflector to the bottom of the lower reflector. Neither side of the structure is connected to a fluid volume. Steady-state initialization is turned off to avoid convergence problems during input processing. The right side of the structure is in a conduction enclosure (Enclosure 1) with the other two sections of the central reflector, Structures 1320 and 1340. 2-D conduction is turned on, with heat structure lengths input on the 600 series cards.

Structure 1320 is the middle ring of the central reflector, which is made of Greencast ceramic. Its 14 axial cells (cell 1 is at the top) extend from the top of the upper reflector to the bottom of the lower reflector. The left side of the structure is connected to Component 132. Steady-state initialization is turned off to avoid convergence problems during input processing. The left side of cell 14 is in a radiation enclosure (Enclosure 18) with other structures in the outlet plenum. The right side is in a conduction enclosure (Enclosure 1) with Structures 1300 and 1340. 2-D conduction is turned on.

Structure 1340 is the outer ring of the central reflector, which is made of Greencast ceramic. Its 14 axial cells (cell 1 is at the top) extend from the top of the upper reflector to the bottom of the lower reflector. Neither side of the structure is connected to a fluid volume. Steady-state initialization is turned off to avoid convergence problems during input processing. The left side of the structure is in a conduction enclosure (Enclosure 1) with Structures 1300 and 1320. The right side is in a conduction enclosure (Enclosure 2) with the three core channels and the inner ring of the outer reflector. 2-D conduction is turned on, with heat structure lengths input on the 500 series cards.

Structure 1400 is the upper reflector above the inner core ring. It is made of Greencast ceramic, and has two axial cells. 2-D conduction is turned on. The left side of the structure is connected to Component 140 and the right side is adiabatic. The left side is in a conduction enclosure (Enclosure 2) with the other core channels, the outer ring of the inner reflector, the inner ring of the outer reflector, and the upper plenum plate.

Structure 1401 is the ceramic in the heated region of the inner core ring. It is made of Greencast ceramic, and has 10 axial cells (cell 1 is at the top) extending over the heated length of the core. 2-D conduction is turned on. The left side of the structure is connected to Component 140, and the right side is 
connected to Component 141. The left side is in a conduction enclosure (Enclosure 2) with the other core channels, the outer ring of the inner reflector, the inner ring of the outer reflector, and the upper plenum plate; the only axial conduction modeled in the enclosure for this structure is from the ends to the top and bottom reflectors. The right side of the structure is in a radiation enclosure (Enclosure 11) with the heater rod, Structure 1403.

Structure 1402 is the bottom reflector below the inner core ring. It is made of Greencast ceramic, and has two axial cells. 2-D conduction is turned on. The left side of the structure is connected to Component 140. The left side is in a conduction enclosure (Enclosure 2) with the other core channels, the outer ring of the inner reflector, the inner ring of the outer reflector, and the upper plenum plate. The right side of the second cell is in a radiation enclosure (Enclosure 18) with other structures in the outlet plenum.

Structure 1403 represents the heater rods in the inner core ring. It is made of graphite and has 10 axial cells. 2-D conduction is turned on. Both sides of the structure are adiabatic, but the right side is in a radiation enclosure (Enclosure 11) with Structure 1401. The internal heat source is provided by CV 940.

Structure 1450 is the upper reflector above the middle core ring. It is made of Greencast ceramic, and has two axial cells. 2-D conduction is turned on. The left side of the structure is connected to Component 145 and the right side is adiabatic. The left side is in a conduction enclosure (Enclosure 2) with the other core channels, the outer ring of the inner reflector, the inner ring of the outer reflector, and the upper plenum plate.

Structure 1451 is the ceramic in the heated region of the middle core ring. It is made of Greencast ceramic, and has 10 axial cells (cell 1 is at the top) extending over the heated length of the core. 2-D conduction is turned on. The left side of the structure is connected to Component 145, and the right side is connected to Component 146. The left side is in a conduction enclosure (Enclosure 2) with the other core channels, the outer ring of the inner reflector, the inner ring of the outer reflector, and the upper plenum plate; the only axial conduction modeled in the enclosure for this structure is from the ends to the top and bottom reflectors. The right side of the structure is in a radiation enclosure (Enclosure 12) with the heater rod, Structure 1453.

Structure 1452 is the bottom reflector below the middle core ring. It is made of Greencast ceramic, and has two axial cells. 2-D conduction is turned on. The left side of the structure is connected to Component 145. The left side is in a conduction enclosure (Enclosure 2) with the other core channels, the outer ring of the inner reflector, the inner ring of the outer reflector, and the upper plenum plate. The right side of the second cell is in a radiation enclosure (Enclosure 18) with other structures in the outlet plenum.

Structure 1453 represents the heater rods in the middle core ring. It is made of graphite and has 10 axial cells. 2-D conduction is turned on. Both sides of the structure are adiabatic, but the right side is in a radiation enclosure (Enclosure 12) with Structure 1451. The internal heat source is provided by CV 945.

Structure 1500 is the upper reflector above the outer core ring. It is made of Greencast ceramic, and has two axial cells. 2-D conduction is turned on. The left side of the structure is connected to Component 150 and the right side is adiabatic. The left side is in a conduction enclosure (Enclosure 2) with the other core channels, the outer ring of the inner reflector, the inner ring of the outer reflector, and the upper plenum plate.

Structure 1501 is the ceramic in the heated region of the inner core ring. It is made of Greencast ceramic, and has 10 axial cells (cell 1 is at the top) extending over the heated length of the core. 2-D conduction is turned on. The left side of the structure is connected to Component 150, and the right side is connected to Component 151. The left side is in a conduction enclosure (Enclosure 2) with the other core channels, the outer ring of the inner reflector, the inner ring of the outer reflector, and the upper plenum plate; the only axial conduction modeled in the enclosure for this structure is from the ends to the top and bottom reflectors. The right side of the structure is in a radiation enclosure (Enclosure 13) with the heater rod, Structure 1503. 
Structure 1502 is the bottom reflector below the outer core ring. It is made of Greencast ceramic, and has two axial cells. 2-D conduction is turned on. The left side of the structure is connected to Component 150. The left side is in a conduction enclosure (Enclosure 2) with the other core channels, the outer ring of the inner reflector, the inner ring of the outer reflector, and the upper plenum plate. The right side of the second cell is in a radiation enclosure (Enclosure 18) with other structures in the outlet plenum.

Structure 1503 represents the heater rods in the outer core ring. It is made of graphite and has 10 axial cells. 2-D conduction is turned on. Both sides of the structure are adiabatic, but the right side is in a radiation enclosure (Enclosure 13) with Structure 1501. The internal heat source is provided by CV 950.

Structure 1600 is the inner ring of the side reflector, which is made of Greencast ceramic. Its 14 axial cells (cell 1 is at the top) extend from the top of the upper reflector to the bottom of the lower reflector. Neither side of the structure is connected to a fluid volume. Steady-state initialization is turned off to avoid convergence problems during input processing. The left side of the structure is in a conduction enclosure (Enclosure 2) with the three core channels and the outer ring of the central reflector. The right side of the structure is in a conduction enclosure (Enclosure 3 ) with the other two sections of the side reflector, Structures 1620 and 1640. 2-D conduction is turned on, with heat structure lengths input on the 500 series cards.

Structure 1620 is the middle ring of the side reflector, which is made of Greencast ceramic. Its 14 axial cells (cell 1 is at the top) extend from the top of the upper reflector to the bottom of the lower reflector. The left side of the structure is connected to Component 132. Steady-state initialization is turned off to avoid convergence problems during input processing. The left side of cell 14 is in a radiation enclosure (Enclosure 18) with other structures in the outlet plenum. The right side is in a conduction enclosure (Enclosure 3) with structures 1300 and 1340. 2-D conduction is turned on.

Structure 1640 is the outer ring of the side reflector, which is made of Greencast ceramic. Its 14 axial cells (cell 1 is at the top) extend from the top of the upper reflector to the bottom of the lower reflector. The right side of the structure is connected to Component 164. Steady-state initialization is turned off to avoid convergence problems during input processing. 2-D conduction is turned on. The left side of the structure is in a conduction enclosure (Enclosure 3) with Structures 1600 and 1620. The right side is in a radiation enclosure (Enclosure 14) with the outer reflector, Structure 1660.

Structure 1660 is the outer reflector, which is made of Shot-Tech SiC 80 ceramic. Its 15 axial cells (cell 1 is at the top) extend from the top of the upper reflector to the bottom of the outlet plenum. 2-D conduction is turned on. The left side of the structure is connected to Components 164 and 175, and the right side is connected to Component 166. Most of the left side is in a radiation enclosure (Enclosure 14) with the outer surface of the side reflector, Structure 1640, and the right side is in a radiation enclosure (Enclosure 15) with the core barrel, Structure 110; the left side of cell 15 is in a radiation enclosure (Enclosure 18) with other structures in the outlet plenum.

Structure 1750 represents the outlet plenum bottom plate, which is a composite horizontal structure that includes the outlet plenum bottom plate on the top, the upper bulkhead plate on the bottom, and insulation in between. The top of the structure is connected to Component 175, and the bottom is connected to Component 105. The top surface is in a radiation enclosure (Enclosure 18) with other structures in the outlet plenum.

Structure 1751 represents the support posts in the outlet plenum, which are made of Greencast ceramic. The right side of this solid cylinder is connected to Component 175 and is in a radiation enclosure (Enclosure 18) with other structures in the outlet plenum.

\subsection{Primary Coolant System}

Structure 2000 is the structure separating the hot and cold ducts. It is connected to Component 200 on the left side and to Component 270 on the right side. It consists of two cylinders of 304 stainless steel with a $3 / 8$ in. layer of alumina silica insulation between them [Drawing OSU-HTTF-PRIM-DWG-005A, 
Rev. 0, items 8-13].

Structure 2001 is the section of the hot duct from the end of the cold duct to the outlet of the isolation/break valve. It is a cylindrical structure with 304 stainless steel on the inside and insulation on the outside. It is connected to cells 5 and 6 of Component 200 on the left side, with a natural convection heat transfer coefficient from Table 951 on the right side and a heat sink temperature provided by Table 950.

Structure 2100 is the section of hot duct between the isolation/break valve and the RCST. It is a cylindrical structure made of 304 stainless steel. Since most of this pipe is on the inside of the RCST, it is modeled without insulation on the outside. It is connected to Component 210 on the left side and Component 280 on the right side.

Structure 2150 is the pipe between the hot duct and the steam generator inlet plenum. The geometry of the structure in this region is complicated, including the check valve body and a gap between the liner and the nozzle. This will be approximated by a single 304 stainless steel [Drawing OSU-HTTF-PRIMDWG-005A, Rev. 0, items 5 and 6] cylindrical structure with an inner radius of that of the inner sleeve and an outer steel radius of the steam generator nozzle; a layer of insulation completes the structure. It is connected to Component 215 on the left side, with a natural convection heat transfer coefficient from Table 951 on the right side and a heat sink temperature provided by Table 950.

Structure 2200 is the inlet plenum portion of the steam generator shell. It is modeled as a 304 stainless steel [Drawing OSU-HTTF-SEC-DWG-003A, Rev. 0, items 8, 36, and 37] cylinder whose inner surface area and total volume are equal to those that of the inlet plenum, inlet nozzle stub, and inlet elbow. The left side is connected to Component 220, and the right side has a heat transfer coefficient boundary condition applied to the outside of the insulation (from Table 951) with a heat sink temperature provided by Table 950 . The thin (0.024 in.) aluminum jacket on the outside of the insulation is not modeled, as it will provide a negligible resistance to heat transfer compared to the low thermal conductivity of the insulating material.

Structure 2201 is the dividing plate ("pass partition") between the inlet and outlet plena of the steam generator. It is made of 304 stainless steel [Drawing OSU-HTTF-SEC-DWG-003A, Rev. 0, item 10]. It is modeled as a rectangular structure, connected to Component 220 on the left side and to Component 228 on the right side.

Structure 2250 represents the 188 steam generator tubes. The tubes are made of 304 stainless steel [Drawing OSU-HTTF-SEC-DWG-003A, Rev. 0, item 2]. The left side is connected to Component 225, and the right side is connected to Component 350. The right side uses the rod bundle with crossflow heat transfer package, as the baffle plates should force some flow across the tubes. Axial conduction is turned on in the tubes because large temperature gradients are expected along the tubes.

Structure 2251 represents the tube sheet. It is modeled as a 304 stainless steel [Drawing OSU-HTTFSEC-DWG-003A, Rev. 0, item 1] cylindrical structure with two axial nodes: the first models the half of the tube sheet connected to the inlet end of the steam generator tubes, and the second models the half connected to the outlet end of the tubes. The structure is built around a unit cell, the inner radius being the inner radius of the tubes and the outer radius determined by conservation of mass (area). There are 188 of these unit cells in each half of the tube sheet. Heat transfer from the faces of the tube sheet to the boiler region and to the plena is not modeled as it is expected to be much smaller than the heat transfer in the flow passages.

Structure 2280 is the outlet plenum portion of the steam generator shell. It is modeled as a 304 stainless steel [Drawing OSU-HTTF-SEC-DWG-003A, Rev. 0, items 8, 38, and 39] cylinder whose inner surface area and total volume are equal to those that of the outlet plenum, outlet nozzle stub, and outlet elbow. The left side is connected to Component 228, and the right side has a natural convection heat transfer coefficient boundary condition applied to the outside of the insulation (from Table 951) with a heat sink temperature provided by Table 950 . The thin $(0.024$ in.) aluminum jacket on the outside of the insulation is not modeled, as it will provide a negligible resistance to heat transfer compared to the low 
thermal conductivity of the insulating material.

Structure 2300 is the pipe between the steam generator outlet plenum and the circulator. It is a cylindrical structure with 304 stainless steel on the inside, insulation on the outside, and one axial structure. The left side is connected to Component 230, and the right side has a natural convection heat transfer coefficient from Table 951 and a heat sink temperature provided by Table 950.

Structure 2350 is the circulator body. It is a cylindrical structure with 304 stainless steel on the inside, insulation on the outside, and one axial structure. The left side is connected to Component 235, and the right side has a natural convection heat transfer coefficient from Table 951 and a heat sink temperature provided by Table 950 .

Structure 2400 is the pipe between the circulator outlet and valve V-203. It is a cylindrical structure with 304 stainless steel on the inside, insulation on the outside, and one axial structure. The left side is connected to Component 240, and the right side has a natural convection heat transfer coefficient from Table 951 and a heat sink temperature provided by Table 950 .

Structure 2500 is the pipe between valve V-203 and the cold leg break valve. It is a cylindrical structure with 304 stainless steel on the inside, insulation on the outside, and three axial structures. The left side is connected to Component 250, and the right side has a natural convection heat transfer coefficient from Table 951 and a heat sink temperature provided by Table 950 .

Structure 2580 is the section of cold leg between the break valve and the RCST. It is a cylindrical structure made of 304 stainless steel. Since most of this pipe is on the inside of the RCST, it is modeled without insulation on the outside. It is connected to Component 258 on the left side and Component 280 on the right side.

Structure 2600 is the crossover line between the cold leg and the cold duct. It is a cylindrical structure with 304 stainless steel on the inside, insulation on the outside, and one axial structure. The left side is connected to Component 260, and the right side has a natural convection heat transfer coefficient from Table 951 and a heat sink temperature provided by Table 950 .

Structure 2700 is the outer wall of the cold duct. It is a cylindrical structure with 304 stainless steel on the inside, insulation on the outside, and four axial structures. The left side is connected to Component 270, and the right side has a natural convection heat transfer coefficient from Table 951 and a heat sink temperature provided by Table 950.

Structure 2800 is the RCST wall. It is a cylindrical structure with 304 stainless steel on the inside [Drawing OSU-HTTF-RCSS-DWG-008A, Sheet 1, Rev. 0, items 1 and 2], insulation on the outside, and either one or two axial structures. The mass of the heads is not completely accounted for with this modeling approach. The left side of the structure is connected to Component 280. The right side has a natural convection heat transfer coefficient from Table 951 and a heat sink temperature provided by Table 950. The thin (0.024 in.) aluminum jacket on the outside of the insulation is not modeled, as it will provide a negligible resistance to heat transfer compared to the low thermal conductivity of the insulating material.

Structure 2820 is the hot duct break spool piece. It is a cylindrical structure with 304 stainless steel on the inside, insulation on the outside, and one axial structure. The left side of the structure is connected to Component 282, and the right side is connected to Component 280.

\subsection{Secondary Coolant System}

Structure 3400 is the steam generator outer cylindrical shell, modeled with 13 axial structures. It is made of 304 stainless steel [Drawing OSU-HTTF-SEC-DWG-003A, Rev. 0, items 4 and 5]. The thicker wall just above the tube sheet is ignored. Most of the left side is connected to Component 340, with the bottom node being connected to the first volume in Component 350 and the top node being connected to Component 360. The right side has a natural convection heat transfer coefficient from Table 951 and a heat sink temperature provided by Table 950 . The thin (0.024 in.) aluminum jacket on the outside of the 
insulation is not modeled, as it will provide a negligible resistance to heat transfer compared to the low thermal conductivity of the insulating material.

Structure 3500 is the steam generator inner cylindrical shell separating the downcomer from the boiler. The shell is made of 304 stainless steel [Drawing OSU-HTTF-SEC-DWG-003A, Rev. 0, item 11]. It has 11 axial nodes, and is connected to the boiler (Component 350) on the left side and the downcomer (Component 340) on the right side. The portion of the cylinder above the top of the downcomer is neglected, as there is expected to be little temperature difference between the top of the boiler and the steam annulus region, and stored energy in the steam generator structures is not expected to be important in the transients to be simulated.

Structure 3550 is the steam generator upper head. The head is made of 304 stainless steel [Drawing OSU-HTTF-SEC-DWG-003A, Rev. 0, item 7]. The left side is connected to Component 355, and the right side has a natural convection heat transfer coefficient from Table 951 and a heat sink temperature provided by Table 950 . The thin $(0.024$ in.) aluminum jacket on the outside of the insulation is not modeled, as it will provide a negligible resistance to heat transfer compared to the low thermal conductivity of the insulating material.

\subsection{Alternate Break Piping}

Structure 0100 is the pressure vessel control rod drive break nozzle. It is a cylindrical structure with 304 stainless steel on the inside, insulation on the outside, and the same number of axial structures as the attached pipe has volumes (25). The left side is connected to Component 10 , and the right side has a natural convection heat transfer coefficient from Table 951 and a heat sink temperature provided by Table 950.

Structure 0200 is the section of piping between the pressure vessel control rod drive break nozzle and valve V-332. It is a cylindrical structure with 304 stainless steel on the inside, insulation on the outside, and the same number of axial structures as the attached pipe has volumes (35). The left side is connected to Component 20, and the right side has a natural convection heat transfer coefficient from Table 951 and a heat sink temperature provided by Table 950 .

Structure 0300 is the first third of the piping between valve V-332 and the RCST. It is a cylindrical structure with 304 stainless steel on the inside, insulation on the outside, and the same number of axial structures as the attached pipe has volumes (92). The left side is connected to Component 30, and the right side has a natural convection heat transfer coefficient from Table 951 and a heat sink temperature provided by Table 950 .

Structure 0320 is the middle third of the piping between valve V-332 and the RCST. It is a cylindrical structure with 304 stainless steel on the inside, insulation on the outside, and the same number of axial structures as the attached pipe has volumes (92). The left side is connected to Component 32, and the right side has a natural convection heat transfer coefficient from Table 951 and a heat sink temperature provided by Table 950 .

Structure 0340 is the final third of the piping between valve V-332 and the RCST. It is a cylindrical structure with 304 stainless steel on the inside, insulation on the outside, and the same number of axial structures as the attached pipe has volumes (92). The left side is connected to Component 34, and the right side has a natural convection heat transfer coefficient from Table 951 and a heat sink temperature provided by Table 950 .

Structure 0700 is the first half of the piping between the pressure vessel bottom break nozzle stub and valve V-331. It is a cylindrical structure with 304 stainless steel on the inside, insulation on the outside, and the same number of axial structures as the attached pipe has volumes (73). The left side is connected to Component 70, and the right side has a natural convection heat transfer coefficient from Table 951 and a heat sink temperature provided by Table 950 . 
Structure 0720 is the second half of the piping between the pressure vessel bottom break nozzle stub and valve V-331. It is a cylindrical structure with 304 stainless steel on the inside, insulation on the outside, and the same number of axial structures as the attached pipe has volumes (73). The left side is connected to Component 72 , and the right side has a natural convection heat transfer coefficient from Table 951 and a heat sink temperature provided by Table 950 .

Structure 0800 is the section of piping between valve V-331 and the RCST. It is a cylindrical structure with 304 stainless steel on the inside, insulation on the outside, and the same number of axial structures as the attached pipe has volumes (96). The left side is connected to Component 80, and the right side has a natural convection heat transfer coefficient from Table 951 and a heat sink temperature provided by Table 950 .

\subsection{Reactor Cavity Cooling System}

Structure 9500 is the front wall of the RCCS panels. The left side is connected to Component 900, and is in a radiation enclosure (Enclosure 21) with the primary pressure vessel. The right side is connected to Component 950.

Structure 9501 is the back wall of the RCCS panels. The left side is connected to Component 950, and the right side has a natural convection heat transfer coefficient from Table 951 and a heat sink temperature provided by Table 950 . The thin $(0.024$ in.) aluminum jacket on the outside of the insulation is not modeled, as it will provide a negligible resistance to heat transfer compared to the low thermal conductivity of the insulating material. 


\section{ENCLOSURES}

Both radiation and conduction enclosures are used in the model. The view factors in the radiation enclosures with concentric vertical structures are strictly radial, assuming that the cross-product terms between different axial levels will balance out enough to make them a second-order effect.

Enclosure 1 (601xxxxx cards) models the radial conduction between the three structures in the central reflector (Structures 1300, 1320, and 1340). It uses a temperature-dependent conductance from Table 601.

Enclosure 2 (602xxxxx cards) models the conduction in the core (heater rod) region. It includes radial conduction between the ceramic structures in the three core channels (Structures 1401, 1451, and 1501), as well from the core to the adjacent central and side reflector structures (Structures 1340 and 1600, respectively). It models axial conduction from the core ceramic structures to the top and bottom reflector structures (Structures 1400, 1402, 1450, 1452, 1500, and 1502). It also models conduction from the upper reflector structures to the upper plenum plate (Structure 1201). It uses a temperature-dependent conductance from Table 601.

Enclosure 3 (603xxxxx cards) models the radial conduction between the three structures in the side reflector (Structures 1600, 1620, and 1640). It uses a temperature-dependent conductance from Table 601.

Enclosure 11 (611xxxxx cards) models the radiation from the heater rods (Structure 1403) to the ceramic (Structure 1401) in the inner core ring.

Enclosure 12 (612xxxxx cards) models the radiation from the heater rods (Structure 1453) to the ceramic (Structure 1451) in the middle core ring.

Enclosure 13 (613xxxxx cards) models the radiation from the heater rods (Structure 1503) to the ceramic (Structure 1501) in the outer core ring.

Enclosure 14 (614xxxxx cards) models the radiation from the side reflector (Structure 1640) to the outer reflector (Structure 1660).

Enclosure 15 (615xxxxx cards) models the radiation from the outer reflector (Structure 1660) to the core barrel (Structure 1150).

Enclosure 16 (616xxxxx cards) models the radiation between the upper plenum plate (Structure 1201), upper plenum internals (Structure 1202), upper plenum shield (Structure 1001), and upper plenum cylinder (Structure 1200).

Enclosure 18 (618xxxxx cards) models the radiation between the core bottom reflector (Structures 1320, 1402, 1452, 1502, 1620), outlet plenum side reflector (Structure 1660), lower plenum bottom plate (Structure 1750), and lower plenum posts (Structure 1751).

Enclosure 19 (619xxxxx cards) models the radiation from the core barrel (Structure 1150) and upper plenum cylinder (Structure 1200) to the primary pressure vessel wall (Structure 1000). In the outlet plenum region, the core barrel radiates to the inner surface of the jacket shell (Structure 1100), and the outer surface of the jacket shell then radiates to the primary pressure vessel wall. Although the jacket shell extends below the outlet plenum, its total length is included in the radiation at the outlet plenum level.

Enclosure 21 (621xxxxx cards) models the radiation from the primary pressure vessel (Structures 1000, 1001, and 1002) to the RCCS panels (Structure 9500). 


\section{MATERIALS}

Material 1 is Greencast-94F Plus ceramic. It is used in the core, central and side reflectors, top and bottom reflectors, and the posts in the outlet plenum. The product data sheet ${ }^{\mathrm{a}}$ had thermal conductivity values for five temperatures, but temperatures both above and below the range of these data are expected. A third-order curve fit was used ( $\mathrm{R}^{2}$ value of 0.9994$)$ to extrapolate the measured data. Data for specific heat capacity and emissivity were contracted by Oregon State University (Larsen 2012) and are used in the input model. Only four emissivity data points are available, with a maximum temperature of $150^{\circ} \mathrm{C}$, which is well below the normal operating temperature of the facility. Extrapolating these data using a quadratic or cubic fit resulted in negative emissivities near the nominal steady state operating temperatures. A linear fit was therefore used to extrapolate the data to higher temperatures; although the curve fit statistics were not particularly good $\left(\mathrm{R}^{2}\right.$ value of 0.977$)$, the values were positive over the entire expected temperature range.

Material 2 is G320 graphite. It is used in the heater rods and the upper plenum floor. Density and thermal conductivity values were taken from the data provided in Figures 10-3 and 10-4 of Cadell 2011. Specific heat capacity values were obtained from Table A6.1 of ASTM International 2014. The emissivity used is the value for unoxidized carbon from Engineering Toolbox 2017.

Material 3 is Type 304 stainless steel. It is used in the pressure vessel, piping, and steam generator. Thermodynamic properties were obtained from Siefken et al. 2001. The emissivity used is the value for polished stainless steel from Engineering ToolBox 2017.

Material 4 is Haynes 230 alloy. It is used in the upper plenum cylinder. The emissivity used is the value for polished nickel from Engineering ToolBox 2017.

Material 5 is Shot-Tech $\mathrm{SiC} 80$ ceramic. It is used in the outer reflector. The only needed property information on the ceramic product data sheet ${ }^{\mathrm{a}}$ was the density. The value of $2.37 \mathrm{~g} / \mathrm{cm}^{3}$ is used for the constant density. Thermal conductivity and specific heat capacity values are not available. With no other information, these data are taken from measurements of Thor 80 ceramic, which has a similar chemical composition, with somewhat more alumina and less silica than the Shot-Tech. No measurements of the emissivity of Shot-Tech were made; therefore data for Thor 80 will be used. Only four emissivity data points are available, with a maximum temperature of $150^{\circ} \mathrm{C}$, which is well below the normal operating temperature of the facility. As for the Greencast ceramic, a linear fit of the four data points $\left(\mathrm{R}^{2}\right.$ value of 0.979) was used to extrapolate to higher temperatures.

Material 6 is Enerwrap MA 960 insulation (Roxul 2014). It is used for the permanent insulation on the outside of the large tanks and on the back side of the RCCS panels. Heat capacity information was not provided by the manufacturer, so it is assumed to be the same as that of mineral wool (Engineering Toolbox 2014).

Material 7 is structural insulation. It is used in the metallic core support structure.

Material 8 is alumina silica insulation. It is used in the upper plenum between the upper plenum shroud and the pressure vessel upper head and between the hot and cold ducts. The upper plenum insulation is McMaster-Carr Ultra-High Temperature Ceramic Insulation Roll; the associated safety data sheet identifies the product as Cerablanket from Morgan Advanced Materials. McMaster-Carr states the density is $4 \mathrm{lb} / \mathrm{ft}^{3}$, which corresponds to $64 \mathrm{~kg} / \mathrm{m}^{3}$.

Material 9 is Lewco Needled E Glass Blanket fiberglass insulation (Lewco undated). It is the removable insulation used on the outside of the piping. Heat capacity information was not provided by the manufacturer, so it is assumed to be the same as that of glass wool.

Additional information on insulation was provided in Hertel 2014, Hertel 2015, and Woods $2017 \mathrm{~b}$.

\footnotetext{
${ }^{a}$ Data sheets for the ceramics were provided to Idaho National Laboratory by HTTF personnel. 


\section{9. $\quad$ TRIPS}

Trip 25 manually opens the control rod drive break valve, V-332, Component 25 . It is set to be always false, and must be changed to open the valve.

Trip 75 manually opens the vessel bottom break valve, V-331, Component 75 . It is set to be always false, and must be changed to open the valve.

Trip 100 is the scram trip. It is set to be always false, and must be changed to initiate a power decrease.

Trip 205 opens the hot duct break valve, V-313, Component 205. It is set to be always false, and must be changed to initiate a break.

Trip 206 closes the hot duct break valve, V-313, Component 205. It is set to be always false, and must be changed to reclose a break.

Trip 245 opens the loop isolation valve, V-203, Component 245. It is set to be always false, and the valve is initialized to be fully open.

Trip 246 closes the loop isolation valve, V-203, Component 245. It is set to be always false, and must be changed to close the valve.

Trip 255 opens the cold leg break valve, V-311, Component 255. It is set to be always false, and must be changed to initiate a break.

Trip 256 closes the cold leg break valve, V-311, Component 255. It is set to be always false, and must be changed to reclose a break.

Trip 294 is the opening (setpoint) pressure for the PCS relief valve, PSV-100, Component 295.

Trip 295 is the closing (reseat) pressure for the PCS relief valve, PSV-100, Component 295.

Trip 296 manually opens the depressurization valve, PCV-400, Component 296. It is set to be always false, and must be changed to open the valve.

Trip 297 manually closes the depressurization valve, PCV-400, Component 296. It is set to be always false, and must be changed to close the valve.

Trip 394 is the opening (setpoint) pressure for the steam generator relief valve, PSV-600, Component 395.

Trip 395 is the closing (reseat) pressure for the steam generator relief valve, PSV-600, Component 395.

Trip 410 is the low liquid level setpoint on tank T-010 for the water supply control logic.

Trip 411 is the high liquid level setpoint on tank T-010 for the water supply control logic.

Trip 412 is true if the liquid level in tank T-010 is above mid-range (halfway between open and close setpoints)

Trip 1294 is true if valve Component 295 either should open or is already open.

Trip 1295 opens the PCS relief valve, PSV-100, Component 295.

Trip 1296 opens the depressurization valve, Component 296.

Trip 1394 is true if valve Component 395 either should open or is already open.

Trip 1395 opens the steam generator relief valve, PSV-600, Component 395.

Trip 1409 is true if the tank T-010 water supply valve, Component 410, either should open or is already open. 
Trip 1410 opens the tank T-010 water supply valve, Component 410, or maintains a higher flow until the liquid level is above mid-range.

Trip 1411 is true if the tank T-010 water supply valve, Component 410, either should close or is already closed.

Trip 1412 closes the tank T-010 water supply valve, Component 410 , or maintains a lower flow until the liquid level is below mid-range. 


\section{GENERAL TABLES}

Table 1 reproduces the volumetric heat capacity for Material 1. It is used in the calculation of the stored energy in the system.

Table 2 reproduces the volumetric heat capacity for Material 2. It is used in the calculation of the stored energy in the system.

Table 3 reproduces the volumetric heat capacity for Material 3. It is used in the calculation of the stored energy in the system.

Table 4 reproduces the volumetric heat capacity for Material 4. It is used in the calculation of the stored energy in the system.

Table 5 reproduces the volumetric heat capacity for Material 5. It is used in the calculation of the stored energy in the system.

Table 601 is the temperature-dependent conductance used in the core conduction enclosures.

Table 901 is the power in heater bank 101. It includes a normalized power decay curve that can be adjusted depending on the scaling factors on time and power that are appropriate for the transient being simulated. Alternatively, the measured power from an experiment could be input directly into this table.

Table 902 is the power in heater bank 102. It includes a normalized power decay curve that can be adjusted depending on the scaling factors on time and power that are appropriate for the transient being simulated. Alternatively, the measured power from an experiment could be input directly into this table.

Table 903 is the power in heater bank 103. It includes a normalized power decay curve that can be adjusted depending on the scaling factors on time and power that are appropriate for the transient being simulated. Alternatively, the measured power from an experiment could be input directly into this table.

Table 904 is the power in heater bank 104. It includes a normalized power decay curve that can be adjusted depending on the scaling factors on time and power that are appropriate for the transient being simulated. Alternatively, the measured power from an experiment could be input directly into this table.

Table 905 is the power in heater bank 105. It includes a normalized power decay curve that can be adjusted depending on the scaling factors on time and power that are appropriate for the transient being simulated. Alternatively, the measured power from an experiment could be input directly into this table.

Table 906 is the power in heater bank 106. It includes a normalized power decay curve that can be adjusted depending on the scaling factors on time and power that are appropriate for the transient being simulated. Alternatively, the measured power from an experiment could be input directly into this table.

Table 907 is the power in heater bank 107. It includes a normalized power decay curve that can be adjusted depending on the scaling factors on time and power that are appropriate for the transient being simulated. Alternatively, the measured power from an experiment could be input directly into this table.

Table 908 is the power in heater bank 108. It includes a normalized power decay curve that can be adjusted depending on the scaling factors on time and power that are appropriate for the transient being simulated. Alternatively, the measured power from an experiment could be input directly into this table.

Table 909 is the power in heater bank 109. It includes a normalized power decay curve that can be adjusted depending on the scaling factors on time and power that are appropriate for the transient being simulated. Alternatively, the measured power from an experiment could be input directly into this table.

Table 910 is the power in heater bank 110. It includes a normalized power decay curve that can be adjusted depending on the scaling factors on time and power that are appropriate for the transient being simulated. Alternatively, the measured power from an experiment could be input directly into this table.

Table 950 is the building temperature, used as a boundary temperature for the back side of the RCCS panels and for the outside of insulated structures. It is set to $300 \mathrm{~K}$. 
Table 951 is the convective heat transfer coefficient boundary condition for the back side of the RCCS panels and for the outside of insulated structures. It is set to a value of $15 \mathrm{~W} / \mathrm{m}^{2}-\mathrm{K}$, which is a representative natural convection value. 


\section{CONTROL VARIABLES}

CV 1 calculates the heat input (W) to the coolant in Component 140, the flow path through the core region inner ring.

CV 2 calculates the heat input (W) to the coolant in Component 145, the flow path through the core region middle ring.

CV 3 calculates the heat input (W) to the coolant in Component 150, the flow path through the core region outer ring.

$\mathrm{CV} 4$ calculates the heat input (W) to the coolant in Component 132, the flow path through the central reflector cooling channels.

CV 5 calculates the heat input (W) to the coolant in Component 162, the flow path through the side reflector cooling channels.

CV 6 calculates the heat input (W) to the coolant in Component 164, the gas gap between the side and outer reflectors.

CV 7 calculates the heat input (W) to the coolant in Component 166, the gas gap between the outer reflector and the core barrel.

CV 8 calculates the heat input (W) to the coolant in Component 141, the gas gap around the heater rod in the core region inner ring.

CV 9 calculates the heat input (W) to the coolant in Component 146, the gas gap around the heater rod in the core region middle ring.

CV 10 calculates the heat input (W) to the coolant in Component 151, the gas gap around the heater rod in the core region outer ring.

CV 11 calculates the total heat input (W) to the gas in the core region by adding CVs 1-10.

CV 12 integrates the total heat input (J) to the gas in the core region, CV 11.

CV 13 calculates the total heat input (W) to the gas in the primary pressure vessel by taking the difference between the flow enthalpy leaving the vessel (Junction 175-01) and that entering (Junction 100-01). This will generally only be a valid calculation under steady forced convection flow conditions.

$\mathrm{CV} 14$ calculates the total heat input $(\mathrm{J})$ to the gas in the primary pressure vessel by integrating CV 13.

CV 16 calculates the heat input (W) to the coolant in Component 115, the gap between the core barrel and the primary pressure vessel.

CV 20 mimics the total flow (kg/s) through the core by taking the mass flow through Junction 175-01. A minimum value of 0.001 is applied to prevent division by zero during subsequent use of this flow rate.

CV 21 calculates the flow fraction through the central reflector cooling channel by dividing the flow through the channel outlet, Junction 1700101, by the total flow, CV 20.

$\mathrm{CV} 22$ calculates the flow fraction through the core inner ring by dividing the flow through the channel outlet, Junction 1700102, by the total flow, CV 20.

$\mathrm{CV} 23$ calculates the flow fraction through the core middle ring by dividing the flow through the channel outlet, Junction 1700103, by the total flow, CV 20.

CV 24 calculates the flow fraction through the core outer ring by dividing the flow through the channel outlet, Junction 1700104, by the total flow, CV 20. 
CV 25 calculates the flow fraction through the side reflector cooling channel by dividing the flow through the channel outlet, Junction 1700105, by the total flow, CV 20.

CV 26 calculates the flow fraction through the gap between the side reflector and the outer reflector by dividing the flow through the channel outlet, Junction 1700106, by the total flow, CV 20.

CV 27 calculates the flow fraction through the gap between the outer reflector and the core barrel by dividing the flow through the channel outlet, Junction 1680000, by the total flow, CV 20.

CV 28 calculates the total core bypass flow fraction through the channels connected to the central and side reflectors.

CV 29 calculates the total core bypass flow fraction.

CV 31 calculates the total primary-to-secondary heat transfer rate (W) by summing the heat removal from the coolant in the steam generator tubes.

CV 32 calculates the total primary-to-secondary heat transfer rate (W) by summing the heat transfer out of the steam generator tube heat structures.

CV 33 calculates the total primary-to-secondary heat transfer rate (W) by summing the heat addition to the coolant in the steam generator boiler region.

CV 35 calculates the total energy transferred to the steam generator (W) by taking the difference between the flow enthalpy leaving the steam generator (Junction 360-02) and that entering (Junction 330-01). This will generally only be a valid calculation under steady forced convection flow conditions.

CV 36 integrates CV 35 to calculate the total net energy transferred to the steam generator secondary coolant $(\mathrm{J})$.

CV 45 calculates the heat added by the circulator (W) by taking the difference between the flow enthalpy downstream (Junction 245) and upstream (Junction 235-01) of the circulator. This will generally only be a valid calculation under steady forced convection flow conditions.

CV 46 integrates CV 45 to calculate the total energy (J) added to the coolant by the circulator.

CV 95 calculates the heat input (W) to the coolant in Component 950, the RCCS panels.

CV 96 integrates CV 95 to calculate the total net heat input (J) to the coolant in the RCCS panels.

CV 98 calculates the net heat transfer to the RCCS coolant in the RCCS panels (W) by taking the difference between the flow enthalpy downstream (Junction 955-01) and upstream (Junction 945-02) of the panels. This will generally only be a valid calculation under steady forced convection flow conditions.

CV 99 integrates CV 98 to calculate the total net energy deposition in the RCCS coolant (J).

$\mathrm{CV} 100$ calculates the maximum volume-average structure temperature $(\mathrm{K})$ for the primary pressure vessel cylinder.

CV 101 calculates the peak volume-average structure temperature $(\mathrm{K})$ for the primary pressure vessel cylinder.

CV 103 calculates the maximum volume-average structure temperature $(\mathrm{K})$ for the core barrel.

CV 104 calculates the peak volume-average structure temperature $(\mathrm{K})$ for the core barrel.

CV 120 calculates the maximum volume-average structure temperature $(\mathrm{K})$ for the central reflector inner cylinder over the heated length of the core.

CV 121 calculates the maximum volume-average structure temperature $(\mathrm{K})$ for the central reflector middle ring over the heated length of the core.

$\mathrm{CV} 122$ calculates the maximum volume-average structure temperature $(\mathrm{K})$ for the central reflector outer ring over the heated length of the core. 
$\mathrm{CV} 123$ calculates the maximum volume-average structure temperature $(\mathrm{K})$ for the core inner ring ceramic over the heated length of the core.

CV 124 calculates the maximum volume-average structure temperature $(\mathrm{K})$ for the core middle ring ceramic over the heated length of the core.

$\mathrm{CV} 125$ calculates the maximum volume-average structure temperature $(\mathrm{K})$ for the core outer ring ceramic over the heated length of the core.

$\mathrm{CV} 126$ calculates the maximum volume-average structure temperature $(\mathrm{K})$ for the side reflector inner ring over the heated length of the core.

CV 127 calculates the maximum volume-average structure temperature $(\mathrm{K})$ for the side reflector middle ring over the heated length of the core.

CV 128 calculates the maximum volume-average structure temperature $(\mathrm{K})$ for the side reflector outer ring over the heated length of the core.

CV 129 calculates the maximum volume-average structure temperature $(\mathrm{K})$ for the outer reflector over the heated length of the core.

CV 130 calculates the peak volume-average structure temperature $(\mathrm{K})$ achieved during the simulation for the central reflector center cylinder over the heated length of the core.

CV 131 calculates the peak volume-average structure temperature $(\mathrm{K})$ achieved during the simulation for the central reflector middle ring over the heated length of the core.

CV 132 calculates the peak volume-average structure temperature $(\mathrm{K})$ achieved during the simulation for the central reflector outer ring over the heated length of the core.

CV 133 calculates the peak volume-average structure temperature $(\mathrm{K})$ achieved during the simulation for the core inner ring ceramic over the heated length of the core.

$\mathrm{CV} 134$ calculates the peak volume-average structure temperature $(\mathrm{K})$ achieved during the simulation for the core middle ring ceramic over the heated length of the core.

CV 135 calculates the peak volume-average structure temperature $(\mathrm{K})$ achieved during the simulation for the core outer ring ceramic over the heated length of the core.

CV 136 calculates the peak volume-average structure temperature $(\mathrm{K})$ achieved during the simulation for the side reflector inner ring over the heated length of the core.

CV 137 calculates the peak volume-average structure temperature $(\mathrm{K})$ achieved during the simulation for the side reflector middle ring over the heated length of the core.

CV 138 calculates the peak volume-average structure temperature $(\mathrm{K})$ achieved during the simulation for the side reflector outer ring over the heated length of the core.

CV 139 calculates the peak volume-average structure temperature $(\mathrm{K})$ achieved during the simulation for the outer reflector over the heated length of the core.

$\mathrm{CV} 140$ calculates the maximum volume-average structure temperature $(\mathrm{K})$ for the heater rod in the core inner ring.

CV 145 calculates the maximum volume-average structure temperature $(\mathrm{K})$ for the heater rod in the core middle ring.

CV 150 calculates the maximum volume-average structure temperature $(\mathrm{K})$ for the heater rod in the core outer ring.

CV 156 calculates the maximum volume-average structure temperature $(\mathrm{K})$ for the heater rods. 
CV 157 calculates the peak volume-average structure temperature $(\mathrm{K})$ for the heater rods during the simulation.

CV 161 calculates the axial average structure temperature $(\mathrm{K})$ for the primary pressure vessel cylinder over the core heated length.

CV 162 calculates the axial average structure temperature $(\mathrm{K})$ for the core barrel over the core heated length.

CV 166 calculates the axial average structure temperature $(\mathrm{K})$ for the central reflector center cylinder over the core heated length.

CV 167 calculates the axial average structure temperature $(\mathrm{K})$ for the central reflector middle ring over the core heated length.

CV 168 calculates the axial average structure temperature $(\mathrm{K})$ for the central reflector outer ring over the core heated length.

CV 169 calculates the axial average structure temperature $(\mathrm{K})$ for the core inner ring ceramic over the core heated length.

CV 170 calculates the axial average structure temperature $(\mathrm{K})$ for the core inner ring heater rod over the core heated length.

CV 171 calculates the axial average structure temperature $(\mathrm{K})$ for the core middle ring ceramic over the core heated length.

CV 172 calculates the axial average structure temperature $(\mathrm{K})$ for the core middle ring heater rod over the core heated length.

CV 173 calculates the axial average structure temperature $(\mathrm{K})$ for the core outer ring ceramic over the core heated length.

CV 174 calculates the axial average structure temperature $(\mathrm{K})$ for the core outer ring heater rod over the core heated length.

CV 175 calculates the axial average structure temperature $(\mathrm{K})$ for the side reflector inner ring over the core heated length.

CV 176 calculates the axial average structure temperature $(\mathrm{K})$ for the side reflector outer ring over the core heated length.

CV 177 calculates the axial average structure temperature $(\mathrm{K})$ for the side reflector outer ring over the core heated length.

CV 178 calculates the axial average structure temperature $(\mathrm{K})$ for the outer reflector over the core heated length.

CV 183 calculates the axial average structure temperature $(\mathrm{K})$ for the front (primary pressure vessel) side of the RCCS cooling panels.

CV 184 calculates the axial average structure temperature $(\mathrm{K})$ for the back side of the RCCS cooling panels.

CV 233 calculates the primary pressure vessel inlet pressure error $(\mathrm{Pa})$, which is the difference between the calculated and desired steady-state pressure at the vessel inlet, Component 100.

CV 234 integrates CV 233, processing the pressure error signal. This processed signal is used to change the PCS pressure (Component 234) to achieve the desired steady-state conditions.

CV 236 calculates the primary pressure vessel outlet temperature error $(\mathrm{K})$, which is the difference between the calculated and desired steady-state gas temperature in the outlet plenum, Component 175. 
CV 237 integrates CV 236, processing the temperature error signal. This processed signal is used to change the PCS flow rate (Component 237) to achieve the desired steady-state conditions.

CV 275 calculates the pressure difference $(\mathrm{Pa})$ between the core inlet and outlet plenums.

CV 276 calculates the pressure drop $(\mathrm{Pa})$ across the primary pressure vessel.

CV 319 calculates the steam generator outlet temperature error $(\mathrm{K})$, which is the difference between the calculated and desired steady-state gas temperature in the cold duct near the primary pressure vessel, volume 4 of Component 270.

CV 320 integrates CV 319, processing the temperature error signal. This processed signal is used to change the steam generator feedwater flow rate (Component 320) to achieve the desired steady-state conditions.

CV 321 integrates the feedwater flow rate, the mass flow in Component 320, to calculate the total amount of water flowing into the steam generator secondary side $(\mathrm{kg})$.

CV 350 calculates the collapsed liquid level (m) in the steam generator boiler region.

CV 355 converts the collapsed liquid level from CV 350 to a level span (\%) corresponding to HTTF measurement LDP-601.

CV 369 calculates the steam generator secondary pressure error $(\mathrm{Pa})$, which is the difference between the calculated and desired steady-state pressure in the steam dome, Component 355.

CV 370 integrates CV 369, processing the pressure error signal. This processed signal is used to change the SCS pressure by modulating valve Component 370 to achieve the desired steady-state conditions.

CV 403 calculates the flow demand for the feedwater and RCCS systems.

CV 404 is a tripunit that has a value of 1.0 if the liquid level in the water storage tank is below the low setpoint.

CV 405 is a tripunit that has a value of -1.0 if the liquid level in the water storage tank is above the high setpoint.

CV 406 adds CV 404 and CV 405, which will provide a non-zero value if the tank liquid level is outof-range.

CV 407 calculates a liquid level out-of-range contribution to the water storage tank flow demand signal. The amount is assumed to be $25 \%$ of the value of CV 403.

CV 408 calculates the flow demand signal for the water storage tank makeup by adding CV 403 and CV 407.

CV 409 calculates the flow error for the water storage tank makeup by subtracting the flow in Component 410 from the demand value in CV 408.

CV 410 integrates the error signal in CV 409. CV 410 is then used to modulate the valve area in Component 410, a servo valve. Minimum and maximum values of $1.0 \mathrm{E}-5$ and 1.0 are specified, respectively.

CV 450 calculates the collapsed liquid level (m) in the water storage day tank (T-010).

CV 451 is a constant that provides the water storage tank low level setpoint (m).

$\mathrm{CV} 452$ is a constant that provides the water storage tank high level setpoint (m).

CV 453 calculates the mid-range of the tank level setpoints by averaging CV 451 and CV 452.

CV 501 is the core differential pressure ( $\mathrm{kPa})$. It corresponds to HTTF measurement DP-1001. 
CV 502 is the pressure difference $(\mathrm{kPa})$ between the pressure vessel inlet and the hot duct. It corresponds to HTTF measurement DP-4001.

$\mathrm{CV} 503$ is the pressure difference $(\mathrm{kPa})$ between the pressure vessel inlet and the upper plenum. It corresponds to HTTF measurement DP-7001.

$\mathrm{CV} 504$ is the pressure difference $(\mathrm{kPa})$ between the pressure vessel inlet and the lower plenum. It corresponds to HTTF measurement DP-8001.

CV 505 is the pressure difference $(\mathrm{kPa})$ between the pressure vessel inlet and the metallic core support structure. It corresponds to HTTF measurement DP-8002.

$\mathrm{CV} 506$ is the pressure difference $(\mathrm{kPa})$ between the pressure vessel inlet and the top of the upcomer. It corresponds to HTTF measurement DP-9001.

CV 507 is the pressure difference $(\mathrm{kPa})$ between the RCCS panel inlet lines and the outlet lines. It corresponds to HTTF measurement DP-801.

CV 901 obtains the power (W) for heater bank 101 from Table 901.

CV 902 obtains the power (W) for heater bank 102 from Table 902.

CV 903 obtains the power (W) for heater bank 103 from Table 903.

CV 904 obtains the power (W) for heater bank 104 from Table 904.

CV 905 obtains the power (W) for heater bank 105 from Table 905.

CV 906 obtains the power (W) for heater bank 106 from Table 906.

CV 907 obtains the power (W) for heater bank 107 from Table 907.

CV 908 obtains the power (W) for heater bank 108 from Table 908.

CV 909 obtains the power (W) for heater bank 109 from Table 909.

CV 910 obtains the power (W) for heater bank 110 from Table 910.

CV 911 calculates the total core power (W) by adding CVs 901-910.

CV 912 converts the core power from CV 911 into MW.

CV 913 calculates the total energy input (MJ) during the simulation by integrating CV 912.

CV 918 is a constant that provides the desired outlet temperature $(\mathrm{K})$ for the RCCS panels.

CV 919 calculates the RCCS panel coolant outlet temperature error (K).

CV 920 is a proportional-integral controller that processes the error in CV 919 to control the flow rate in the RCCS pump (Component 920).

CV 940 calculates the power input (W) to heat Structure 1403 by taking appropriate fractions of the power from the 10 heaters.

CV 945 calculates the power input (W) to heat Structure 1453 by taking appropriate fractions of the power from the 10 heaters.

CV 950 calculates the power input (W) to heat Structure 1503 by taking appropriate fractions of the power from the 10 heaters.

CV 1000 calculates the convective heat transfer (W) to the left side of the primary pressure vessel cylinder heat structure.

CV 1001 calculates the radiation heat transfer (W) to the left side of the primary pressure vessel cylinder heat structure. 
CV 1002 calculates the total heat transfer (W) to the left side of the primary pressure vessel cylinder heat structure.

CV 1003 calculates the integral energy transfer $(\mathrm{J})$ to the left side of the primary pressure vessel cylinder heat structure.

CV 1004 calculates the convective heat transfer (W) to the right side of the primary pressure vessel cylinder heat structure.

CV 1005 calculates the radiation heat transfer (W) to the right side of the primary pressure vessel cylinder heat structure.

CV 1006 calculates the total heat transfer (W) to the right side of the primary pressure vessel cylinder heat structure.

CV 1007 calculates the integral energy transfer $(J)$ to the right side of the primary pressure vessel cylinder heat structure.

CV 1008 calculates the net heat transfer (W) to the primary pressure vessel cylinder heat structure.

CV 1009 calculates the integral net heat transfer (J) to the primary pressure vessel cylinder heat structure.

CV 1010 calculates the convective heat transfer (W) to the left side of the primary pressure vessel upper head/upper plenum shield heat structure.

CV 1011 calculates the radiation heat transfer (W) to the left side of the primary pressure vessel upper head/upper plenum shield heat structure.

CV 1012 calculates the total heat transfer (W) to the left side of the primary pressure vessel upper head/upper plenum shield heat structure.

CV 1013 calculates the integral energy transfer $(\mathrm{J})$ to the left side of the primary pressure vessel upper head/upper plenum shield heat structure.

CV 1014 calculates the convective heat transfer (W) to the right side of the primary pressure vessel upper head/upper plenum shield heat structure.

CV 1015 calculates the radiation heat transfer (W) to the right side of the primary pressure vessel upper head/upper plenum shield heat structure.

CV 1016 calculates the total heat transfer (W) to the right side of the primary pressure vessel upper head/upper plenum shield heat structure.

CV 1017 calculates the integral energy transfer $(\mathrm{J})$ to the right side of the primary pressure vessel upper head/upper plenum shield heat structure.

CV 1018 calculates the net heat transfer (W) to the primary pressure vessel upper head/upper plenum shield heat structure.

CV 1019 calculates the integral net heat transfer $(\mathrm{J})$ to the primary pressure vessel upper head/upper plenum shield heat structure.

CV 1020 calculates the convective heat transfer (W) to the left side of the core barrel heat structure.

CV 1021 calculates the radiation heat transfer (W) to the left side of the core barrel heat structure.

CV 1022 calculates the total heat transfer (W) to the left side of the core barrel heat structure.

CV 1023 calculates the integral energy transfer (J) to the left side of the core barrel heat structure.

CV 1024 calculates the convective heat transfer (W) to the right side of the core barrel heat structure.

CV 1025 calculates the radiation heat transfer (W) to the right side of the core barrel heat structure. 
CV 1026 calculates the total heat transfer (W) to the right side of the core barrel heat structure.

CV 1027 calculates the integral energy transfer $(\mathrm{J})$ to the right side of the core barrel heat structure.

CV 1028 calculates the net heat transfer (W) to the core barrel heat structure.

CV 1029 calculates the integral net heat transfer $(\mathrm{J})$ to the core barrel heat structure.

CV 1030 calculates the convective heat transfer (W) to the left side of the upper plenum cylinder heat structure.

CV 1031 calculates the radiation heat transfer (W) to the left side of the upper plenum cylinder heat structure.

CV 1032 calculates the total heat transfer (W) to the left side of the upper plenum cylinder heat structure.

CV 1033 calculates the integral energy transfer $(\mathrm{J})$ to the left side of the upper plenum cylinder heat structure.

CV 1034 calculates the convective heat transfer (W) to the right side of the upper plenum cylinder heat structure.

CV 1035 calculates the radiation heat transfer (W) to the right side of the upper plenum cylinder heat structure.

CV 1036 calculates the total heat transfer (W) to the right side of the upper plenum cylinder heat structure.

CV 1037 calculates the integral energy transfer $(\mathrm{J})$ to the right side of the upper plenum cylinder heat structure.

CV 1038 calculates the net heat transfer (W) to the upper plenum cylinder heat structure.

CV 1039 calculates the integral net heat transfer (J) to the upper plenum cylinder heat structure.

CV 1041 calculates the conduction heat transfer (W) to the left side of the upper plenum floor heat structure.

CV 1042 calculates the total heat transfer (W) to the left side of the upper plenum floor heat structure.

CV 1043 calculates the integral energy transfer $(\mathrm{J})$ to the left side of the upper plenum floor heat structure.

CV 1044 calculates the convective heat transfer (W) to the right side of the upper plenum floor heat structure.

CV 1045 calculates the radiation heat transfer (W) to the right side of the upper plenum floor heat structure.

CV 1046 calculates the total heat transfer (W) to the right side of the upper plenum floor heat structure.

CV 1047 calculates the integral energy transfer $(\mathrm{J})$ to the right side of the upper plenum floor heat structure.

CV 1048 calculates the net heat transfer (W) to the upper plenum floor heat structure.

CV 1049 calculates the integral net heat transfer (J) to the upper plenum floor heat structure.

CV 1054 calculates the convective heat transfer (W) to the right side of the upper plenum internals heat structure.

CV 1055 calculates the radiation heat transfer (W) to the right side of the upper plenum internals heat structure. 
CV 1056 calculates the total heat transfer (W) to the right side of the upper plenum internals heat structure.

CV 1057 calculates the integral energy transfer $(J)$ to the right side of the upper plenum internals heat structure.

CV 1058 calculates the net heat transfer (W) to the upper plenum internals heat structure.

CV 1059 calculates the integral net heat transfer (J) to the upper plenum internals heat structure.

CV 1065 calculates the conduction heat transfer (W) to the right side of the central reflector center cylinder heat structure.

CV 1066 calculates the total heat transfer (W) to the right side of the central reflector center cylinder heat structure.

CV 1067 calculates the integral energy transfer $(\mathrm{J})$ to the right side of the central reflector center cylinder heat structure.

CV 1068 calculates the net heat transfer (W) to the central reflector center cylinder heat structure.

CV 1069 calculates the integral net heat transfer $(\mathrm{J})$ to the central reflector center cylinder heat structure.

CV 1070 calculates the convective heat transfer (W) to the left side of the central reflector middle ring heat structure.

CV 1071 calculates the radiation heat transfer (W) to the left side of the central reflector middle ring heat structure.

CV 1072 calculates the total heat transfer (W) to the left side of the central reflector middle ring heat structure.

CV 1073 calculates the integral energy transfer $(\mathrm{J})$ to the left side of the central reflector middle ring heat structure.

CV 1075 calculates the conduction heat transfer (W) to the right side of the central reflector middle ring heat structure.

CV 1076 calculates the total heat transfer $(\mathrm{W})$ to the right side of the central reflector middle ring heat structure.

CV 1077 calculates the integral energy transfer $(\mathrm{J})$ to the right side of the central reflector middle ring heat structure.

CV 1078 calculates the net heat transfer (W) to the central reflector middle ring heat structure.

CV 1079 calculates the integral net heat transfer $(\mathrm{J})$ to the central reflector middle ring heat structure.

CV 1081 calculates the conduction heat transfer (W) to the left side of the central reflector outer ring heat structure.

CV 1082 calculates the total heat transfer (W) to the left side of the central reflector outer ring heat structure.

CV 1083 calculates the integral energy transfer $(\mathrm{J})$ to the left side of the central reflector outer ring heat structure.

CV 1085 calculates the conduction heat transfer (W) to the right side of the central reflector outer ring heat structure.

CV 1086 calculates the total heat transfer (W) to the right side of the central reflector outer ring heat structure. 
CV 1087 calculates the integral energy transfer $(\mathrm{J})$ to the right side of the central reflector outer ring heat structure.

CV 1088 calculates the net heat transfer (W) to the central reflector outer ring heat structure.

CV 1089 calculates the integral net heat transfer $(\mathrm{J})$ to the central reflector outer ring heat structure.

CV 1090 calculates the convective heat transfer (W) to the left side of the inner core ring ceramic heat structure.

CV 1091 calculates the conduction heat transfer (W) to the left side of the inner core ring ceramic heat structure.

CV 1092 calculates the total heat transfer (W) to the left side of the inner core ring ceramic heat structure.

CV 1093 calculates the integral energy transfer $(\mathrm{J})$ to the left side of the inner core ring ceramic heat structure.

CV 1094 calculates the convective heat transfer (W) to the right side of the inner core ring ceramic heat structure.

CV 1095 calculates the radiation heat transfer (W) to the right side of the inner core ring ceramic heat structure.

CV 1096 calculates the total heat transfer (W) to the right side of the inner core ring ceramic heat structure.

CV 1097 calculates the integral energy transfer $(\mathrm{J})$ to the right side of the inner core ring ceramic heat structure.

CV 1098 calculates the net heat transfer (W) to the inner core ring ceramic heat structure.

CV 1099 calculates the integral net heat transfer $(\mathrm{J})$ to the inner core ring ceramic heat structure.

CV 1100 calculates the convective heat transfer (W) to the left side of the middle core ring ceramic heat structure.

CV 1101 calculates the conduction heat transfer (W) to the left side of the middle core ring ceramic heat structure.

CV 1102 calculates the total heat transfer (W) to the left side of the middle core ring ceramic heat structure.

CV 1103 calculates the integral energy transfer $(\mathrm{J})$ to the left side of the middle core ring ceramic heat structure.

CV 1104 calculates the convective heat transfer (W) to the right side of the middle core ring ceramic heat structure.

CV 1105 calculates the radiation heat transfer (W) to the right side of the middle core ring ceramic heat structure.

CV 1106 calculates the total heat transfer (W) to the right side of the middle core ring ceramic heat structure.

CV 1107 calculates the integral energy transfer $(\mathrm{J})$ to the right side of the middle core ring ceramic heat structure.

CV 1108 calculates the net heat transfer $(\mathrm{W})$ to the middle core ring ceramic heat structure.

CV 1109 calculates the integral net heat transfer $(\mathrm{J})$ to the middle core ring ceramic heat structure. 
CV 1110 calculates the convective heat transfer (W) to the left side of the outer core ring ceramic heat structure.

CV 1111 calculates the conduction heat transfer (W) to the left side of the outer core ring ceramic heat structure.

CV 1112 calculates the total heat transfer (W) to the left side of the outer core ring ceramic heat structure.

CV 1113 calculates the integral energy transfer $(\mathrm{J})$ to the left side of the outer core ring ceramic heat structure.

CV 1114 calculates the convective heat transfer (W) to the right side of the outer core ring ceramic heat structure.

CV 1115 calculates the radiation heat transfer (W) to the right side of the outer core ring ceramic heat structure.

CV 1116 calculates the total heat transfer (W) to the right side of the outer core ring ceramic heat structure.

CV 1117 calculates the integral energy transfer $(\mathrm{J})$ to the right side of the outer core ring ceramic heat structure.

CV 1118 calculates the net heat transfer (W) to the outer core ring ceramic heat structure.

CV 1119 calculates the integral net heat transfer $(\mathrm{J})$ to the outer core ring ceramic heat structure.

CV 1121 calculates the conduction heat transfer (W) to the left side of the side reflector inner ring heat structure.

CV 1122 calculates the total heat transfer (W) to the left side of the side reflector inner ring heat structure.

CV 1123 calculates the integral energy transfer $(\mathrm{J})$ to the left side of the side reflector inner ring heat structure.

CV 1125 calculates the conduction heat transfer (W) to the right side of the side reflector inner ring heat structure.

CV 1126 calculates the total heat transfer (W) to the right side of the side reflector inner ring heat structure.

CV 1127 calculates the integral energy transfer $(\mathrm{J})$ to the right side of the side reflector inner ring heat structure.

CV 1128 calculates the net heat transfer (W) to the side reflector inner ring heat structure.

CV 1129 calculates the integral net heat transfer $(\mathrm{J})$ to the side reflector inner ring heat structure.

CV 1130 calculates the convective heat transfer (W) to the left side of the side reflector middle ring heat structure.

CV 1131 calculates the conduction heat transfer (W) to the left side of the side reflector middle ring heat structure.

CV 1132 calculates the total heat transfer (W) to the left side of the side reflector middle ring heat structure.

CV 1133 calculates the integral energy transfer $(\mathrm{J})$ to the left side of the side reflector middle ring heat structure.

CV 1135 calculates the conduction heat transfer (W) to the right side of the side reflector middle ring heat structure. 
CV 1136 calculates the total heat transfer (W) to the right side of the side reflector middle ring heat structure.

CV 1137 calculates the integral energy transfer $(\mathrm{J})$ to the right side of the side reflector middle ring heat structure.

CV 1138 calculates the net heat transfer (W) to the side reflector middle ring heat structure.

CV 1139 calculates the integral net heat transfer $(\mathrm{J})$ to the side reflector middle ring heat structure.

CV 1141 calculates the conduction heat transfer (W) to the left side of the side reflector outer ring heat structure.

CV 1142 calculates the total heat transfer (W) to the left side of the side reflector outer ring heat structure.

CV 1143 calculates the integral energy transfer $(\mathrm{J})$ to the left side of the side reflector outer ring heat structure.

CV 1144 calculates the convective heat transfer (W) to the right side of the side reflector outer ring heat structure.

CV 1145 calculates the radiation heat transfer (W) to the right side of the side reflector outer ring heat structure.

CV 1146 calculates the total heat transfer (W) to the right side of the side reflector outer ring heat structure.

CV 1147 calculates the integral energy transfer $(\mathrm{J})$ to the right side of the side reflector outer ring heat structure.

CV 1148 calculates the net heat transfer $(\mathrm{W})$ to the side reflector outer ring heat structure.

CV 1149 calculates the integral net heat transfer $(\mathrm{J})$ to the side reflector outer ring heat structure.

CV 1150 calculates the convective heat transfer (W) to the left side of the outer reflector heat structure.

CV 1151 calculates the radiation heat transfer (W) to the left side of the outer reflector heat structure.

CV 1152 calculates the total heat transfer (W) to the left side of the outer reflector heat structure.

CV 1153 calculates the integral energy transfer $(\mathrm{J})$ to the left side of the outer reflector heat structure.

CV 1154 calculates the convective heat transfer (W) to the right side of the outer reflector heat structure.

CV 1155 calculates the radiation heat transfer (W) to the right side of the outer reflector heat structure.

CV 1156 calculates the total heat transfer (W) to the right side of the outer reflector heat structure.

CV 1157 calculates the integral energy transfer $(J)$ to the right side of the outer reflector heat structure.

CV 1158 calculates the net heat transfer (W) to the outer reflector heat structure.

CV 1159 calculates the integral net heat transfer (J) to the outer reflector heat structure.

CV 1160 calculates the convective heat transfer (W) to the left side of the outlet plenum bottom plate heat structure.

CV 1161 calculates the radiation heat transfer (W) to the left side of the outlet plenum bottom plate heat structure. 
CV 1162 calculates the total heat transfer (W) to the left side of the outlet plenum bottom plate heat structure.

CV 1163 calculates the integral energy transfer $(\mathrm{J})$ to the left side of the outlet plenum bottom plate heat structure.

CV 1164 calculates the convective heat transfer (W) to the right side of the outlet plenum bottom plate heat structure.

CV 1166 calculates the total heat transfer (W) to the right side of the outlet plenum bottom plate heat structure.

CV 1167 calculates the integral energy transfer $(\mathrm{J})$ to the right side of the outlet plenum bottom plate heat structure.

CV 1168 calculates the net heat transfer (W) to the outlet plenum bottom plate heat structure.

CV 1169 calculates the integral net heat transfer $(\mathrm{J})$ to the outlet plenum bottom plate heat structure.

CV 1174 calculates the convective heat transfer (W) to the right side of the outlet plenum support columns heat structure.

CV 1175 calculates the radiation heat transfer (W) to the right side of the outlet plenum support columns heat structure.

CV 1176 calculates the total heat transfer (W) to the right side of the outlet plenum support columns heat structure.

CV 1177 calculates the integral energy transfer $(\mathrm{J})$ to the right side of the outlet plenum support columns heat structure.

CV 1178 calculates the net heat transfer $(\mathrm{W})$ to the outlet plenum support columns heat structure.

CV 1179 calculates the integral net heat transfer $(\mathrm{J})$ to the outlet plenum support columns heat structure.

CV 1180 calculates the convective heat transfer (W) to the left side of the RCCS panels front (vessel) side heat structure.

CV 1181 calculates the radiation heat transfer (W) to the left side of the RCCS panels front (vessel) side heat structure.

CV 1182 calculates the total heat transfer (W) to the left side of the RCCS panels front (vessel) side heat structure.

CV 1183 calculates the integral energy transfer $(\mathrm{J})$ to the left side of the RCCS panels front (vessel) side heat structure.

CV 1184 calculates the convective heat transfer (W) to the right side of the RCCS panels front (vessel) side heat structure.

CV 1186 calculates the total heat transfer (W) to the right side of the RCCS panels front (vessel) side heat structure.

CV 1187 calculates the integral energy transfer (J) to the right side of the RCCS panels front (vessel) side heat structure.

CV 1188 calculates the net heat transfer (W) to the RCCS panels front (vessel) side heat structure.

CV 1189 calculates the integral net heat transfer (J) to the RCCS panels front (vessel) side heat structure.

CV 1190 calculates the convective heat transfer (W) to the left side of the RCCS panels back side heat structure. 
CV 1192 calculates the total heat transfer (W) to the left side of the RCCS panels back side heat structure.

CV 1193 calculates the integral energy transfer $(\mathrm{J})$ to the left side of the RCCS panels back side heat structure.

CV 1194 calculates the convective heat transfer (W) to the right side of the RCCS panels back side heat structure.

CV 1196 calculates the total heat transfer (W) to the right side of the RCCS panels back side heat structure.

CV 1197 calculates the integral energy transfer (J) to the right side of the RCCS panels back side heat structure.

CV 1198 calculates the net heat transfer (W) to the RCCS panels back side heat structure.

CV 1199 calculates the integral net heat transfer (J) to the RCCS panels back side heat structure.

CV 1200 calculates the convective heat transfer (W) to the left side of the primary pressure vessel lower head heat structure.

CV 1202 calculates the total heat transfer (W) to the left side of the primary pressure vessel lower head heat structure.

CV 1203 calculates the integral energy transfer $(\mathrm{J})$ to the left side of the primary pressure vessel lower head heat structure.

CV 1204 calculates the convective heat transfer (W) to the right side of the primary pressure vessel lower head heat structure.

CV 1205 calculates the radiation heat transfer (W) to the right side of the primary pressure vessel lower head heat structure.

CV 1206 calculates the total heat transfer (W) to the right side of the primary pressure vessel lower head heat structure.

CV 1207 calculates the integral energy transfer $(\mathrm{J})$ to the right side of the primary pressure vessel lower head heat structure.

CV 1208 calculates the net heat transfer (W) to the primary pressure vessel lower head heat structure.

CV 1209 calculates the integral net heat transfer $(\mathrm{J})$ to the primary pressure vessel lower head heat structure.

CV 1215 calculates the radiation heat transfer (W) to the right side of the inner core ring heater rod heat structure.

CV 1216 calculates the total heat transfer (W) to the right side of the inner core ring heater rod heat structure.

CV 1217 calculates the integral energy transfer $(\mathrm{J})$ to the right side of the inner core ring heater rod heat structure.

CV 1225 calculates the radiation heat transfer (W) to the right side of the middle core ring heater rod heat structure.

CV 1226 calculates the total heat transfer (W) to the right side of the middle core ring heater rod heat structure.

CV 1227 calculates the integral energy transfer $(\mathrm{J})$ to the right side of the middle core ring heater rod heat structure. 
CV 1235 calculates the radiation heat transfer (W) to the right side of the outer core ring heater rod heat structure.

CV 1236 calculates the total heat transfer (W) to the right side of the outer core ring heater rod heat structure.

CV 1237 calculates the integral energy transfer $(\mathrm{J})$ to the right side of the outer core ring heater rod heat structure.

CV 1301 calculates the net heat removal (W) from the heater rods.

CV 1302 calculates the net heat removal (W) from the ceramic around the heater rods.

CV 1303 calculates the net heat removal (W) from the core ceramic blocks.

CV 1304 calculates the net heat removal (W) from the core and reflectors.

CV 1305 calculates the net heat removal (W) from the core, reflectors, and core barrel.

CV 1306 calculates the net heat removal (W) from the primary pressure vessel and its internals.

CV 1401 calculates the environmental heat loss (W) from Structure 2001.

CV 1403 calculates the environmental heat loss (W) from Structure 2150.

CV 1404 calculates the environmental heat loss (W) from Structure 2200.

CV 1405 calculates the environmental heat loss (W) from Structure 2280.

CV 1406 calculates the environmental heat loss (W) from Structure 2300.

CV 1407 calculates the environmental heat loss (W) from Structure 2350.

CV 1408 calculates the environmental heat loss (W) from Structure 2400.

CV 1409 calculates the environmental heat loss (W) from Structure 2500.

CV 1411 calculates the environmental heat loss (W) from Structure 2600.

CV 1412 calculates the environmental heat loss (W) from Structure 2700.

CV 1413 calculates the environmental heat loss (W) from Structure 2800.

CV 1414 calculates the environmental heat loss (W) from Structure 3400.

CV 1415 calculates the environmental heat loss (W) from Structure 3550.

CV 1416 calculates the environmental heat loss (W) from Structure 0100. (Only used if the control rod drive break line is active in the input model.)

CV 1417 calculates the environmental heat loss (W) from Structure 0200. (Only used if the control rod drive break line is active in the input model.)

CV 1418 calculates the environmental heat loss (W) from cells 1-40 in Structure 0300. (Only used if the control rod drive break line is active in the input model.)

CV 1419 calculates the environmental heat loss (W) from cells 41-80 in Structure 0300. (Only used if the control rod drive break line is active in the input model.)

CV 1420 calculates the environmental heat loss (W) from cells 81-92 in Structure 0300. (Only used if the control rod drive break line is active in the input model.)

CV 1421 calculates the total environmental heat loss (W) from Structure 0300. (Only used if the control rod drive break line is active in the input model.)

CV 1422 calculates the environmental heat loss (W) from cells 1-40 in Structure 0320. (Only used if the control rod drive break line is active in the input model.) 
CV 1423 calculates the environmental heat loss (W) from cells 41-80 in Structure 0320. (Only used if the control rod drive break line is active in the input model.)

CV 1424 calculates the environmental heat loss (W) from cells 81-92 in Structure 0320. (Only used if the control rod drive break line is active in the input model.)

CV 1425 calculates the total environmental heat loss (W) from Structure 0320. (Only used if the control rod drive break line is active in the input model.)

CV 1426 calculates the environmental heat loss (W) from cells 1-40 in Structure 0340. (Only used if the control rod drive break line is active in the input model.)

CV 1427 calculates the environmental heat loss (W) from cells 41-80 in Structure 0340. (Only used if the control rod drive break line is active in the input model.)

CV 1428 calculates the environmental heat loss (W) from cells 81-92 in Structure 0340. (Only used if the control rod drive break line is active in the input model.)

CV 1429 calculates the total environmental heat loss (W) from Structure 0340. (Only used if the control rod drive break line is active in the input model.)

CV 1430 calculates the total environmental heat loss (W) from the control rod drive break piping. (Only used if the control rod drive break line is active in the input model.)

CV 1431 calculates the environmental heat loss (W) from cells 1-40 in Structure 0700. (Only used if the vessel bottom break line is active in the input model.)

CV 1432 calculates the environmental heat loss (W) from cells 41-73 in Structure 0700. (Only used if the vessel bottom break line is active in the input model.)

CV 1433 calculates the total environmental heat loss (W) from Structure 0700. (Only used if the vessel bottom break line is active in the input model.)

CV 1434 calculates the environmental heat loss (W) from cells 1-40 in Structure 0720. (Only used if the vessel bottom break line is active in the input model.)

CV 1435 calculates the environmental heat loss (W) from cells 41-73 in Structure 0720. (Only used if the vessel bottom break line is active in the input model.)

CV 1436 calculates the total environmental heat loss (W) from Structure 0720. (Only used if the vessel bottom break line is active in the input model.)

CV 1437 calculates the environmental heat loss (W) from cells 1-40 in Structure 0800. (Only used if the vessel bottom break line is active in the input model.)

CV 1438 calculates the environmental heat loss (W) from cells 41-80 in Structure 0800. (Only used if the vessel bottom break line is active in the input model.)

CV 1439 calculates the environmental heat loss (W) from cells 81-96 in Structure 0800. (Only used if the vessel bottom break line is active in the input model.)

CV 1440 calculates the total environmental heat loss (W) from Structure 0800. (Only used if the vessel bottom break line is active in the input model.)

CV 1441 calculates the total environmental heat loss (W) from the vessel bottom break piping. (Only used if the vessel bottom break line is active in the input model.)

CV 1444 calculates the total environmental heat loss (W) from the loop piping.

CV 1445 calculates the total environmental heat loss (W) from the steam generator body.

CV 1446 calculates the total environmental heat loss (W) from the PCS.

CV 1447 calculates the total environmental heat loss (W) from the SCS. 
CV 1449 calculates the total environmental heat loss (W).

CV 1450 integrates the total environmental heat loss (J).

CV 1601 calculates the total fluid mass $(\mathrm{kg})$ in Component 140.

CV 1602 calculates the total fluid mass $(\mathrm{kg})$ in Component 145.

CV 1603 calculates the total fluid mass $(\mathrm{kg})$ in Component 150.

CV 1604 calculates the total fluid mass $(\mathrm{kg})$ in Component 132.

CV 1605 calculates the total fluid mass $(\mathrm{kg})$ in Component 162.

CV 1606 calculates the total fluid mass $(\mathrm{kg})$ in Component 164.

CV 1607 calculates the total fluid mass $(\mathrm{kg})$ in Component 166.

CV 1608 calculates the total fluid mass $(\mathrm{kg})$ in the core region.

CV 1609 calculates the total fluid mass $(\mathrm{kg})$ in Component 115.

CV 1610 calculates the total fluid mass $(\mathrm{kg})$ in the remaining components in the primary pressure vessel $(100,105,110,120,175)$.

CV 1611 calculates the total fluid mass $(\mathrm{kg})$ in the primary pressure vessel.

CV 1615 calculates the total fluid mass (kg) in the hot leg, Components 200 and 215.

CV 1616 calculates the total fluid mass $(\mathrm{kg})$ on the primary side of the steam generator, Components 220,225 , and 228 .

CV 1617 calculates the total fluid mass $(\mathrm{kg})$ in the cold leg, Components 230, 235, 240, 250, 260, 270 , and 293.

CV 1618 calculates the total fluid mass $(\mathrm{kg})$ in the PCS piping.

CV 1619 calculates the total fluid mass $(\mathrm{kg})$ in the PCS inside of the break valves (does not include the piping between the valves and the RCST or the RCST itself).

CV 1621 calculates the total fluid mass $(\mathrm{kg})$ in the RCST, Components 210, 258, and 280.

CV 1626 calculates the total fluid mass $(\mathrm{kg})$ in the secondary side of the steam generator, Components 340, 350, 355, and 360 .

CV 1627 calculates the total fluid mass $(\mathrm{kg})$ in the SCS.

CV 1631 calculates the total fluid mass $(\mathrm{kg})$ in the RCCS cooling panels, Component 950.

CV 1632 calculates the total fluid mass $(\mathrm{kg})$ in the RCCS.

CV 1636 calculates the total fluid mass $(\mathrm{kg})$ in the water storage tank, Component 450.

CV 1637 calculates the total fluid mass $(\mathrm{kg})$ in the potable water system.

CV 1640 calculates the total fluid mass $(\mathrm{kg})$ in the water systems.

The CVs in the 2000s calculate various scaling parameters that can be used for comparison with the reference plant or other experiment facilities. The parameters below are taken from McEligot and McCreery 2004.

Non-dimensional heat flux: $\mathrm{q}^{+}=\beta \mathrm{q}^{\prime \prime}$ wall $/\left(\mathrm{G} \mathrm{c}_{\mathrm{p}}\right)$

Acceleration parameter: $\quad \mathrm{K}_{\mathrm{v}}=4 \mathrm{q}^{+} / \mathrm{Re}_{\mathrm{D}}$

Buoyancy parameter: $\quad \mathrm{Bo}^{*}=\mathrm{Gr}^{*} /\left(\operatorname{Re}_{\mathrm{Dh}^{3}}{ }^{3.425} \operatorname{Pr}^{0.8}\right)$ 
Some of these require average values over the heated length. These averages are calculated as the simple average of the values of those parameters in the first and last cells over the heated length.

CV 2001 calculates the pressure difference (Pa) across the heated length of Component 115.

CV 2002 calculates the average pressure $(\mathrm{Pa})$ along the heated length of Component 115.

CV 2003 calculates the gas temperature difference (K) across the heated length of Component 115.

CV 2004 calculates the average gas temperature (K) along the heated length of Component 115.

CV 2005 calculates the average gas density $\left(\mathrm{kg} / \mathrm{m}^{3}\right)$ along the heated length of Component 115 .

CV 2006 calculates the gas specific heat capacity $(\mathrm{J} / \mathrm{kg}-\mathrm{K})$ at the inlet of the heated length of Component 115.

CV 2007 calculates the gas specific heat capacity $(\mathrm{J} / \mathrm{kg}-\mathrm{K})$ at the outlet of the heated length of Component 115.

CV 2008 calculates the average gas specific heat capacity $(\mathrm{J} / \mathrm{kg}-\mathrm{K})$ along the heated length of Component 115.

CV 2009 calculates the gas viscosity $(\mathrm{kg} / \mathrm{m}-\mathrm{s})$ near the middle of the heated length of Component 115.

CV 2010 calculates the reciprocal gas viscosity $(\mathrm{m}-\mathrm{s} / \mathrm{kg})$ near the middle of the heated length of Component 115.

CV 2011 calculates the gas thermal expansion coefficient (1/ K) near the middle of the heated length of Component 115.

CV 2012 calculates the gas specific heat capacity $(\mathrm{J} / \mathrm{kg}-\mathrm{K})$ near the middle of the heated length of Component 115.

CV 2013 calculates the gas thermal conductivity $(\mathrm{W} / \mathrm{m}-\mathrm{K})$ near the middle of the heated length of Component 115.

CV 2014 calculates the reciprocal gas thermal conductivity $(\mathrm{m}-\mathrm{K} / \mathrm{W})$ near the middle of the heated length of Component 115.

CV 2015 calculates the wall-to-gas temperature difference $(\mathrm{K})$ near the middle of the heated length of Component 115.

CV 2016 calculates the gas mass flux $\left(\mathrm{kg} / \mathrm{m}^{2}-\mathrm{s}\right)$ near the middle of the heated length of Component 115.

CV 2017 calculates the gas Reynolds number near the middle of the heated length of Component 115.

CV 2018 calculates the gas Nusselt number near the middle of the heated length of Component 115.

CV 2019 calculates the gas Prandtl number near the middle of the heated length of Component 115.

CV 2020 calculates the gas Grashof number near the middle of the heated length of Component 115.

CV 2021 calculates the gas Froude number near the middle of the heated length of Component 115.

CV 2022 calculates the numerator for the non-dimensional heat flux parameter $\mathrm{q}^{+}$.

CV 2023 calculates the denominator for the non-dimensional heat flux parameter $\mathrm{q}^{+}$.

CV 2024 calculates the non-dimensional heat flux parameter $\mathrm{q}^{+}$near the middle of the heated length of Component 115.

CV 2025 calculates the acceleration parameter $K_{v}$ near the middle of the heated length of Component 115.

54 
CV 2026 calculates the square of the gas Reynolds number near the middle of the heated length of Component 115.

CV 2027 calculates the gas Richardson number near the middle of the heated length of Component 115.

CV 2028 calculates the gas $\mathrm{Re}^{3.425}$ near the middle of the heated length of Component 115. It does this by raising the square of the gas $\operatorname{Re}(\mathrm{CV} 2026)$ to the $1.7125(=3.425 / 2)$ power to protect against trying to raise a negative number to a real power.

CV 2029 calculates the gas $\operatorname{Pr}^{0.8}$ near the middle of the heated length of Component 115 .

CV 2030 calculates the denominator for the buoyancy parameter Bo*.

CV 2031 calculates the buoyancy parameter Bo* near the middle of the heated length of Component 115.

CV 2051 calculates the pressure difference $(\mathrm{Pa})$ across the heated length of Component 132.

CV 2052 calculates the average pressure $(\mathrm{Pa})$ along the heated length of Component 132.

CV 2053 calculates the gas temperature difference (K) across the heated length of Component 132.

CV 2054 calculates the average gas temperature (K) along the heated length of Component 132.

CV 2055 calculates the average gas density $\left(\mathrm{kg} / \mathrm{m}^{3}\right)$ along the heated length of Component 132 .

CV 2056 calculates the gas specific heat capacity $(\mathrm{J} / \mathrm{kg}-\mathrm{K})$ at the inlet of the heated length of Component 132.

CV 2057 calculates the gas specific heat capacity $(\mathrm{J} / \mathrm{kg}-\mathrm{K})$ at the outlet of the heated length of Component 132.

CV 2058 calculates the average gas specific heat capacity $(\mathrm{J} / \mathrm{kg}-\mathrm{K})$ along the heated length of Component 132.

CV 2059 calculates the gas viscosity $(\mathrm{kg} / \mathrm{m}$-s) near the middle of the heated length of Component 132.

CV 2060 calculates the reciprocal gas viscosity (m-s/kg) near the middle of the heated length of Component 132.

CV 2061 calculates the gas thermal expansion coefficient (1/ K) near the middle of the heated length of Component 132.

CV 2062 calculates the gas specific heat capacity $(\mathrm{J} / \mathrm{kg}-\mathrm{K})$ near the middle of the heated length of Component 132.

CV 2063 calculates the gas thermal conductivity (W/m-K) near the middle of the heated length of Component 132.

CV 2064 calculates the reciprocal gas thermal conductivity $(\mathrm{m}-\mathrm{K} / \mathrm{W})$ near the middle of the heated length of Component 132.

CV 2065 calculates the wall-to-gas temperature difference $(\mathrm{K})$ near the middle of the heated length of Component 132.

CV 2066 calculates the gas mass flux $\left(\mathrm{kg} / \mathrm{m}^{2}-\mathrm{s}\right)$ near the middle of the heated length of Component 132.

CV 2067 calculates the gas Reynolds number near the middle of the heated length of Component 132.

CV 2068 calculates the gas Nusselt number near the middle of the heated length of Component 132.

CV 2069 calculates the gas Prandtl number near the middle of the heated length of Component 132. 55 
CV 2070 calculates the gas Grashof number near the middle of the heated length of Component 132.

CV 2071 calculates the gas Froude number near the middle of the heated length of Component 132.

CV 2072 calculates the numerator for the non-dimensional heat flux parameter $\mathrm{q}^{+}$.

CV 2073 calculates the denominator for the non-dimensional heat flux parameter $\mathrm{q}^{+}$.

CV 2074 calculates the non-dimensional heat flux parameter $\mathrm{q}^{+}$near the middle of the heated length of Component 132.

CV 2075 calculates the acceleration parameter $\mathrm{K}_{\mathrm{v}}$ near the middle of the heated length of Component 132.

CV 2076 calculates the square of the gas Reynolds number near the middle of the heated length of Component 132.

CV 2077 calculates the gas Richardson number near the middle of the heated length of Component 132.

CV 2078 calculates the gas $\mathrm{Re}^{3.425}$ near the middle of the heated length of Component 132. It does this by raising the square of the gas $\operatorname{Re}(\mathrm{CV} 2076)$ to the $1.7125(=3.425 / 2)$ power to protect against trying to raise a negative number to a real power.

CV 2079 calculates the gas $\operatorname{Pr}^{0.8}$ near the middle of the heated length of Component 132.

CV 2080 calculates the denominator for the buoyancy parameter Bo*.

CV 2081 calculates the buoyancy parameter Bo* near the middle of the heated length of Component 132.

CV 2101 calculates the pressure difference (Pa) across the heated length of Component 140.

CV 2102 calculates the average pressure $(\mathrm{Pa})$ along the heated length of Component 140.

CV 2103 calculates the gas temperature difference $(\mathrm{K})$ across the heated length of Component 140.

CV 2104 calculates the average gas temperature $(\mathrm{K})$ along the heated length of Component 140.

CV 2105 calculates the average gas density $\left(\mathrm{kg} / \mathrm{m}^{3}\right)$ along the heated length of Component 140 .

CV 2106 calculates the gas specific heat capacity $(\mathrm{J} / \mathrm{kg}-\mathrm{K})$ at the inlet of the heated length of Component 140 .

CV 2107 calculates the gas specific heat capacity $(\mathrm{J} / \mathrm{kg}-\mathrm{K})$ at the outlet of the heated length of Component 140.

CV 2108 calculates the average gas specific heat capacity $(\mathrm{J} / \mathrm{kg}-\mathrm{K})$ along the heated length of Component 140 .

CV 2109 calculates the gas viscosity $(\mathrm{kg} / \mathrm{m}-\mathrm{s})$ near the middle of the heated length of Component 140.

CV 2110 calculates the reciprocal gas viscosity $(\mathrm{m}-\mathrm{s} / \mathrm{kg})$ near the middle of the heated length of Component 140.

CV 2111 calculates the gas thermal expansion coefficient $(1 / \mathrm{K})$ near the middle of the heated length of Component 140.

CV 2112 calculates the gas specific heat capacity $(\mathrm{J} / \mathrm{kg}-\mathrm{K})$ near the middle of the heated length of Component 140.

CV 2113 calculates the gas thermal conductivity $(\mathrm{W} / \mathrm{m}-\mathrm{K})$ near the middle of the heated length of Component 140 . 
CV 2114 calculates the reciprocal gas thermal conductivity $(\mathrm{m}-\mathrm{K} / \mathrm{W})$ near the middle of the heated length of Component 140.

CV 2115 calculates the wall-to-gas temperature difference (K) near the middle of the heated length of Component 140.

CV 2116 calculates the gas mass flux $\left(\mathrm{kg} / \mathrm{m}^{2}-\mathrm{s}\right)$ near the middle of the heated length of Component 140 .

CV 2117 calculates the gas Reynolds number near the middle of the heated length of Component 140.

CV 2118 calculates the gas Nusselt number near the middle of the heated length of Component 140.

CV 2119 calculates the gas Prandtl number near the middle of the heated length of Component 140.

CV 2120 calculates the gas Grashof number near the middle of the heated length of Component 140.

CV 2121 calculates the gas Froude number near the middle of the heated length of Component1140.

CV 2122 calculates the numerator for the non-dimensional heat flux parameter $\mathrm{q}^{+}$.

CV 2123 calculates the denominator for the non-dimensional heat flux parameter $\mathrm{q}^{+}$.

CV 2124 calculates the non-dimensional heat flux parameter $\mathrm{q}^{+}$near the middle of the heated length of Component 140.

CV 2125 calculates the acceleration parameter $K_{v}$ near the middle of the heated length of Component 140.

CV 2126 calculates the square of the gas Reynolds number near the middle of the heated length of Component 140.

CV 2127 calculates the gas Richardson number near the middle of the heated length of Component 140.

CV 2128 calculates the gas $\mathrm{Re}^{3.425}$ near the middle of the heated length of Component 140. It does this by raising the square of the gas $\operatorname{Re}(\mathrm{CV} 2126)$ to the $1.7125(=3.425 / 2)$ power to protect against trying to raise a negative number to a real power.

CV 2129 calculates the gas $\operatorname{Pr}^{0.8}$ near the middle of the heated length of Component 140.

CV 2130 calculates the denominator for the buoyancy parameter Bo*.

CV 2131 calculates the buoyancy parameter Bo* near the middle of the heated length of Component 140.

CV 2151 calculates the pressure difference $(\mathrm{Pa})$ across the heated length of Component 145.

CV 2152 calculates the average pressure $(\mathrm{Pa})$ along the heated length of Component 145.

CV 2153 calculates the gas temperature difference $(\mathrm{K})$ across the heated length of Component 145.

CV 2154 calculates the average gas temperature (K) along the heated length of Component 145.

CV 2155 calculates the average gas density $\left(\mathrm{kg} / \mathrm{m}^{3}\right)$ along the heated length of Component 145 .

CV 2156 calculates the gas specific heat capacity $(\mathrm{J} / \mathrm{kg}-\mathrm{K})$ at the inlet of the heated length of Component 145.

CV 2157 calculates the gas specific heat capacity $(\mathrm{J} / \mathrm{kg}-\mathrm{K})$ at the outlet of the heated length of Component 145.

CV 2158 calculates the average gas specific heat capacity $(\mathrm{J} / \mathrm{kg}-\mathrm{K})$ along the heated length of Component 145. 
CV 2159 calculates the gas viscosity $(\mathrm{kg} / \mathrm{m}-\mathrm{s})$ near the middle of the heated length of Component 145.

CV 2160 calculates the reciprocal gas viscosity (m-s/kg) near the middle of the heated length of Component 145.

CV 2161 calculates the gas thermal expansion coefficient $(1 / \mathrm{K})$ near the middle of the heated length of Component 145.

CV 2162 calculates the gas specific heat capacity $(\mathrm{J} / \mathrm{kg}-\mathrm{K})$ near the middle of the heated length of Component 145.

CV 2163 calculates the gas thermal conductivity $(\mathrm{W} / \mathrm{m}-\mathrm{K})$ near the middle of the heated length of Component 145.

CV 2164 calculates the reciprocal gas thermal conductivity $(\mathrm{m}-\mathrm{K} / \mathrm{W})$ near the middle of the heated length of Component 145.

CV 2165 calculates the wall-to-gas temperature difference $(\mathrm{K})$ near the middle of the heated length of Component 145.

CV 2166 calculates the gas mass flux $\left(\mathrm{kg} / \mathrm{m}^{2}-\mathrm{s}\right)$ near the middle of the heated length of Component 145.

CV 2167 calculates the gas Reynolds number near the middle of the heated length of Component 145.

CV 2168 calculates the gas Nusselt number near the middle of the heated length of Component 145.

CV 2169 calculates the gas Prandtl number near the middle of the heated length of Component 145.

CV 2170 calculates the gas Grashof number near the middle of the heated length of Component 145.

CV 2171 calculates the gas Froude number near the middle of the heated length of Component 1132.

CV 2172 calculates the numerator for the non-dimensional heat flux parameter $\mathrm{q}^{+}$.

CV 2173 calculates the denominator for the non-dimensional heat flux parameter $\mathrm{q}^{+}$.

CV 2174 calculates the non-dimensional heat flux parameter $\mathrm{q}^{+}$near the middle of the heated length of Component 145.

CV 2175 calculates the acceleration parameter $\mathrm{K}_{\mathrm{v}}$ near the middle of the heated length of Component 145.

CV 2176 calculates the square of the gas Reynolds number near the middle of the heated length of Component 145.

CV 2177 calculates the gas Richardson number near the middle of the heated length of Component 145.

CV 2178 calculates the gas $\operatorname{Re}^{3.425}$ near the middle of the heated length of Component 145. It does this by raising the square of the gas $\operatorname{Re}(\mathrm{CV} 2176)$ to the $1.7125(=3.425 / 2)$ power to protect against trying to raise a negative number to a real power.

CV 2179 calculates the gas $\operatorname{Pr}^{0.8}$ near the middle of the heated length of Component 145.

CV 2180 calculates the denominator for the buoyancy parameter Bo*.

CV 2181 calculates the buoyancy parameter Bo* near the middle of the heated length of Component 145.

CV 2201 calculates the pressure difference $(\mathrm{Pa})$ across the heated length of Component 150.

CV 2202 calculates the average pressure $(\mathrm{Pa})$ along the heated length of Component 150. 
CV 2203 calculates the gas temperature difference (K) across the heated length of Component 150.

CV 2204 calculates the average gas temperature (K) along the heated length of Component 150.

CV 2205 calculates the average gas density $\left(\mathrm{kg} / \mathrm{m}^{3}\right)$ along the heated length of Component 150 .

CV 2206 calculates the gas specific heat capacity $(\mathrm{J} / \mathrm{kg}-\mathrm{K})$ at the inlet of the heated length of Component 150.

CV 2207 calculates the gas specific heat capacity $(\mathrm{J} / \mathrm{kg}-\mathrm{K})$ at the outlet of the heated length of Component 150.

CV 2208 calculates the average gas specific heat capacity $(\mathrm{J} / \mathrm{kg}-\mathrm{K})$ along the heated length of Component 150.

CV 2209 calculates the gas viscosity $(\mathrm{kg} / \mathrm{m}-\mathrm{s})$ near the middle of the heated length of Component 150.

CV 2210 calculates the reciprocal gas viscosity $(\mathrm{m}-\mathrm{s} / \mathrm{kg})$ near the middle of the heated length of Component 150.

CV 2211 calculates the gas thermal expansion coefficient $(1 / \mathrm{K})$ near the middle of the heated length of Component 150.

CV 2212 calculates the gas specific heat capacity $(\mathrm{J} / \mathrm{kg}-\mathrm{K})$ near the middle of the heated length of Component 150.

CV 2213 calculates the gas thermal conductivity $(\mathrm{W} / \mathrm{m}-\mathrm{K})$ near the middle of the heated length of Component 150.

CV 2214 calculates the reciprocal gas thermal conductivity $(\mathrm{m}-\mathrm{K} / \mathrm{W})$ near the middle of the heated length of Component 150.

CV 2215 calculates the wall-to-gas temperature difference $(\mathrm{K})$ near the middle of the heated length of Component 150.

CV 2216 calculates the gas mass flux $\left(\mathrm{kg} / \mathrm{m}^{2}-\mathrm{s}\right)$ near the middle of the heated length of Component 150.

CV 2217 calculates the gas Reynolds number near the middle of the heated length of Component 150.

CV 2218 calculates the gas Nusselt number near the middle of the heated length of Component 150.

CV 2219 calculates the gas Prandtl number near the middle of the heated length of Component 150.

CV 2220 calculates the gas Grashof number near the middle of the heated length of Component 150.

CV 2221 calculates the gas Froude number near the middle of the heated length of Component 1150.

CV 2222 calculates the numerator for the non-dimensional heat flux parameter $\mathrm{q}^{+}$.

CV 2223 calculates the denominator for the non-dimensional heat flux parameter $\mathrm{q}^{+}$.

CV 2224 calculates the non-dimensional heat flux parameter $\mathrm{q}^{+}$near the middle of the heated length of Component 150.

CV 2225 calculates the acceleration parameter $\mathrm{K}_{\mathrm{v}}$ near the middle of the heated length of Component 150.

CV 2226 calculates the square of the gas Reynolds number near the middle of the heated length of Component 150.

CV 2227 calculates the gas Richardson number near the middle of the heated length of Component 150. 
CV 2228 calculates the gas $\mathrm{Re}^{3.425}$ near the middle of the heated length of Component 150. It does this by raising the square of the gas $\operatorname{Re}(\mathrm{CV} 2226)$ to the $1.7125(=3.425 / 2)$ power to protect against trying to raise a negative number to a real power.

CV 2229 calculates the gas $\operatorname{Pr}^{0.8}$ near the middle of the heated length of Component 150 .

CV 2230 calculates the denominator for the buoyancy parameter Bo*.

CV 2231 calculates the buoyancy parameter Bo* near the middle of the heated length of Component 150.

CV 2251 calculates the pressure difference $(\mathrm{Pa})$ across the heated length of Component 162.

CV 2252 calculates the average pressure $(\mathrm{Pa})$ along the heated length of Component 162.

CV 2253 calculates the gas temperature difference (K) across the heated length of Component 162.

CV 2254 calculates the average gas temperature $(\mathrm{K})$ along the heated length of Component 162.

CV 2255 calculates the average gas density $\left(\mathrm{kg} / \mathrm{m}^{3}\right)$ along the heated length of Component 162 .

CV 2256 calculates the gas specific heat capacity $(\mathrm{J} / \mathrm{kg}-\mathrm{K})$ at the inlet of the heated length of Component 162.

CV 2257 calculates the gas specific heat capacity $(\mathrm{J} / \mathrm{kg}-\mathrm{K})$ at the outlet of the heated length of Component 162 .

CV 2258 calculates the average gas specific heat capacity $(\mathrm{J} / \mathrm{kg}-\mathrm{K})$ along the heated length of Component 162.

CV 2259 calculates the gas viscosity ( $\mathrm{kg} / \mathrm{m}$-s) near the middle of the heated length of Component 162.

CV 2260 calculates the reciprocal gas viscosity (m-s/kg) near the middle of the heated length of Component 162.

CV 2261 calculates the gas thermal expansion coefficient $(1 / \mathrm{K})$ near the middle of the heated length of Component 162.

CV 2262 calculates the gas specific heat capacity $(\mathrm{J} / \mathrm{kg}-\mathrm{K})$ near the middle of the heated length of Component 162.

CV 2263 calculates the gas thermal conductivity (W/m-K) near the middle of the heated length of Component 162.

CV 2264 calculates the reciprocal gas thermal conductivity $(\mathrm{m}-\mathrm{K} / \mathrm{W})$ near the middle of the heated length of Component 162.

CV 2265 calculates the wall-to-gas temperature difference $(\mathrm{K})$ near the middle of the heated length of Component 162.

CV 2266 calculates the gas mass flux $\left(\mathrm{kg} / \mathrm{m}^{2}-\mathrm{s}\right)$ near the middle of the heated length of Component 162.

CV 2267 calculates the gas Reynolds number near the middle of the heated length of Component 162.

CV 2268 calculates the gas Nusselt number near the middle of the heated length of Component 162.

CV 2269 calculates the gas Prandtl number near the middle of the heated length of Component 162.

CV 2270 calculates the gas Grashof number near the middle of the heated length of Component 162.

CV 2271 calculates the gas Froude number near the middle of the heated length of Component 1132.

CV 2272 calculates the numerator for the non-dimensional heat flux parameter $\mathrm{q}^{+}$. 
CV 2273 calculates the denominator for the non-dimensional heat flux parameter $\mathrm{q}^{+}$.

CV 2274 calculates the non-dimensional heat flux parameter $\mathrm{q}^{+}$near the middle of the heated length of Component 162.

CV 2275 calculates the acceleration parameter $K_{v}$ near the middle of the heated length of Component 162.

CV 2276 calculates the square of the gas Reynolds number near the middle of the heated length of Component 162.

CV 2277 calculates the gas Richardson number near the middle of the heated length of Component 162.

CV 2278 calculates the gas $\mathrm{Re}^{3.425}$ near the middle of the heated length of Component 162. It does this by raising the square of the gas $\operatorname{Re}(\mathrm{CV} 2276)$ to the $1.7125(=3.425 / 2)$ power to protect against trying to raise a negative number to a real power.

CV 2279 calculates the gas $\operatorname{Pr}^{0.8}$ near the middle of the heated length of Component 162 .

CV 2280 calculates the denominator for the buoyancy parameter Bo*.

CV 2281 calculates the buoyancy parameter Bo* near the middle of the heated length of Component 162.

CV 2301 calculates the pressure difference (Pa) across the heated length of Component 164.

CV 2302 calculates the average pressure $(\mathrm{Pa})$ along the heated length of Component 164.

CV 2303 calculates the gas temperature difference $(\mathrm{K})$ across the heated length of Component 164.

CV 2304 calculates the average gas temperature $(\mathrm{K})$ along the heated length of Component 164.

CV 2305 calculates the average gas density $\left(\mathrm{kg} / \mathrm{m}^{3}\right)$ along the heated length of Component 164 .

CV 2306 calculates the gas specific heat capacity $(\mathrm{J} / \mathrm{kg}-\mathrm{K})$ at the inlet of the heated length of Component 164.

CV 2307 calculates the gas specific heat capacity $(\mathrm{J} / \mathrm{kg}-\mathrm{K})$ at the outlet of the heated length of Component 164.

CV 2308 calculates the average gas specific heat capacity $(\mathrm{J} / \mathrm{kg}-\mathrm{K})$ along the heated length of Component 164.

CV 2309 calculates the gas viscosity $(\mathrm{kg} / \mathrm{m}-\mathrm{s})$ near the middle of the heated length of Component 164.

CV 2310 calculates the reciprocal gas viscosity $(\mathrm{m}-\mathrm{s} / \mathrm{kg})$ near the middle of the heated length of Component 164.

CV 2311 calculates the gas thermal expansion coefficient $(1 / \mathrm{K})$ near the middle of the heated length of Component 164.

CV 2312 calculates the gas specific heat capacity $(\mathrm{J} / \mathrm{kg}-\mathrm{K})$ near the middle of the heated length of Component 164.

CV 2313 calculates the gas thermal conductivity $(\mathrm{W} / \mathrm{m}-\mathrm{K})$ near the middle of the heated length of Component 164.

CV 2314 calculates the reciprocal gas thermal conductivity $(\mathrm{m}-\mathrm{K} / \mathrm{W})$ near the middle of the heated length of Component 164.

CV 2315 calculates the wall-to-gas temperature difference (K) near the middle of the heated length of Component 164. 
CV 2316 calculates the gas mass flux $\left(\mathrm{kg} / \mathrm{m}^{2}-\mathrm{s}\right)$ near the middle of the heated length of Component 164.

CV 2317 calculates the gas Reynolds number near the middle of the heated length of Component 164.

CV 2318 calculates the gas Nusselt number near the middle of the heated length of Component 164.

CV 2319 calculates the gas Prandtl number near the middle of the heated length of Component 164.

CV 2320 calculates the gas Grashof number near the middle of the heated length of Component 164.

CV 2321 calculates the gas Froude number near the middle of the heated length of Component 1150.

CV 2322 calculates the numerator for the non-dimensional heat flux parameter $\mathrm{q}^{+}$.

CV 2323 calculates the denominator for the non-dimensional heat flux parameter $\mathrm{q}^{+}$.

CV 2324 calculates the non-dimensional heat flux parameter $\mathrm{q}^{+}$near the middle of the heated length of Component 164.

CV 2325 calculates the acceleration parameter $K_{v}$ near the middle of the heated length of Component 164.

CV 2326 calculates the square of the gas Reynolds number near the middle of the heated length of Component 164.

CV 2327 calculates the gas Richardson number near the middle of the heated length of Component 164.

CV 2328 calculates the gas $\mathrm{Re}^{3.425}$ near the middle of the heated length of Component 164. It does this by raising the square of the gas $\operatorname{Re}(\mathrm{CV} 2326)$ to the $1.7125(=3.425 / 2)$ power to protect against trying to raise a negative number to a real power.

CV 2329 calculates the gas $\operatorname{Pr}^{0.8}$ near the middle of the heated length of Component 164 .

CV 2330 calculates the denominator for the buoyancy parameter $\mathrm{Bo}^{*}$.

CV 2331 calculates the buoyancy parameter Bo* near the middle of the heated length of Component 164.

CV 2351 calculates the pressure difference $(\mathrm{Pa})$ across the heated length of Component 166.

CV 2352 calculates the average pressure $(\mathrm{Pa})$ along the heated length of Component 166.

CV 2353 calculates the gas temperature difference $(\mathrm{K})$ across the heated length of Component 166.

CV 2354 calculates the average gas temperature (K) along the heated length of Component 166.

CV 2355 calculates the average gas density $\left(\mathrm{kg} / \mathrm{m}^{3}\right)$ along the heated length of Component 166.

CV 2356 calculates the gas specific heat capacity $(\mathrm{J} / \mathrm{kg}-\mathrm{K})$ at the inlet of the heated length of Component 166.

CV 2357 calculates the gas specific heat capacity $(\mathrm{J} / \mathrm{kg}-\mathrm{K})$ at the outlet of the heated length of Component 166.

CV 2358 calculates the average gas specific heat capacity $(\mathrm{J} / \mathrm{kg}-\mathrm{K})$ along the heated length of Component 166.

CV 2359 calculates the gas viscosity ( $\mathrm{kg} / \mathrm{m}-\mathrm{s})$ near the middle of the heated length of Component 166.

CV 2360 calculates the reciprocal gas viscosity $(\mathrm{m}-\mathrm{s} / \mathrm{kg})$ near the middle of the heated length of Component 166. 
CV 2361 calculates the gas thermal expansion coefficient $(1 / \mathrm{K})$ near the middle of the heated length of Component 166.

CV 2362 calculates the gas specific heat capacity $(\mathrm{J} / \mathrm{kg}-\mathrm{K})$ near the middle of the heated length of Component 166.

CV 2363 calculates the gas thermal conductivity $(\mathrm{W} / \mathrm{m}-\mathrm{K})$ near the middle of the heated length of Component 166.

CV 2364 calculates the reciprocal gas thermal conductivity $(\mathrm{m}-\mathrm{K} / \mathrm{W})$ near the middle of the heated length of Component 166.

CV 2365 calculates the wall-to-gas temperature difference $(\mathrm{K})$ near the middle of the heated length of Component 166.

CV 2366 calculates the gas mass flux $\left(\mathrm{kg} / \mathrm{m}^{2}-\mathrm{s}\right)$ near the middle of the heated length of Component 166.

CV 2367 calculates the gas Reynolds number near the middle of the heated length of Component 166.

CV 2368 calculates the gas Nusselt number near the middle of the heated length of Component 166.

CV 2369 calculates the gas Prandtl number near the middle of the heated length of Component 166.

CV 2370 calculates the gas Grashof number near the middle of the heated length of Component 166.

CV 2371 calculates the gas Froude number near the middle of the heated length of Component1132.

CV 2372 calculates the numerator for the non-dimensional heat flux parameter $\mathrm{q}^{+}$.

CV 2373 calculates the denominator for the non-dimensional heat flux parameter $\mathrm{q}^{+}$.

CV 2374 calculates the non-dimensional heat flux parameter $\mathrm{q}^{+}$near the middle of the heated length of Component 166.

CV 2375 calculates the acceleration parameter $K_{v}$ near the middle of the heated length of Component 166.

CV 2376 calculates the square of the gas Reynolds number near the middle of the heated length of Component 166.

CV 2377 calculates the gas Richardson number near the middle of the heated length of Component 166.

CV 2378 calculates the gas $\mathrm{Re}^{3.425}$ near the middle of the heated length of Component 166. It does this by raising the square of the gas $\operatorname{Re}(\mathrm{CV} 2376)$ to the $1.7125(=3.425 / 2)$ power to protect against trying to raise a negative number to a real power.

CV 2379 calculates the gas $\operatorname{Pr}^{0.8}$ near the middle of the heated length of Component 166 .

CV 2380 calculates the denominator for the buoyancy parameter Bo*.

CV 2381 calculates the buoyancy parameter Bo* near the middle of the heated length of Component 166.

CV 2401 calculates the pressure difference (Pa) across the heated length of Component 950.

CV 2402 calculates the average pressure $(\mathrm{Pa})$ along the heated length of Component 950.

CV 2403 calculates the gas temperature difference (K) across the heated length of Component 950.

CV 2404 calculates the average gas temperature $(\mathrm{K})$ along the heated length of Component 950.

CV 2405 calculates the average gas density $\left(\mathrm{kg} / \mathrm{m}^{3}\right)$ along the heated length of Component 950. 
CV 2406 calculates the gas specific heat capacity $(\mathrm{J} / \mathrm{kg}-\mathrm{K})$ at the inlet of the heated length of Component 950.

CV 2407 calculates the gas specific heat capacity $(\mathrm{J} / \mathrm{kg}-\mathrm{K})$ at the outlet of the heated length of Component 950.

CV 2408 calculates the average gas specific heat capacity $(\mathrm{J} / \mathrm{kg}-\mathrm{K})$ along the heated length of Component 950.

CV 2409 calculates the gas viscosity $(\mathrm{kg} / \mathrm{m}-\mathrm{s})$ near the middle of the heated length of Component 950.

CV 2410 calculates the reciprocal gas viscosity $(\mathrm{m}-\mathrm{s} / \mathrm{kg})$ near the middle of the heated length of Component 950.

CV 2411 calculates the gas thermal expansion coefficient $(1 / \mathrm{K})$ near the middle of the heated length of Component 950.

CV 2412 calculates the gas specific heat capacity $(\mathrm{J} / \mathrm{kg}-\mathrm{K})$ near the middle of the heated length of Component 950.

CV 2413 calculates the gas thermal conductivity $(\mathrm{W} / \mathrm{m}-\mathrm{K})$ near the middle of the heated length of Component 950.

CV 2414 calculates the reciprocal gas thermal conductivity $(\mathrm{m}-\mathrm{K} / \mathrm{W})$ near the middle of the heated length of Component 950.

CV 2415 calculates the wall-to-gas temperature difference $(\mathrm{K})$ near the middle of the heated length of Component 950.

CV 2416 calculates the gas mass flux $\left(\mathrm{kg} / \mathrm{m}^{2}-\mathrm{s}\right)$ near the middle of the heated length of Component 950.

CV 2417 calculates the gas Reynolds number near the middle of the heated length of Component 950.

CV 2418 calculates the gas Nusselt number near the middle of the heated length of Component 950.

CV 2419 calculates the gas Prandtl number near the middle of the heated length of Component 950.

CV 2420 calculates the gas Grashof number near the middle of the heated length of Component 950.

CV 2421 calculates the gas Froude number near the middle of the heated length of Component 1150.

CV 2422 calculates the numerator for the non-dimensional heat flux parameter $\mathrm{q}^{+}$.

CV 2423 calculates the denominator for the non-dimensional heat flux parameter $\mathrm{q}^{+}$.

CV 2424 calculates the non-dimensional heat flux parameter $\mathrm{q}^{+}$near the middle of the heated length of Component 950.

CV 2425 calculates the acceleration parameter $K_{v}$ near the middle of the heated length of Component 950.

CV 2426 calculates the square of the gas Reynolds number near the middle of the heated length of Component 950.

CV 2427 calculates the gas Richardson number near the middle of the heated length of Component 950.

CV 2428 calculates the gas $\mathrm{Re}^{3.425}$ near the middle of the heated length of Component 950. It does this by raising the square of the gas $\operatorname{Re}(\mathrm{CV} 2426)$ to the $1.7125(=3.425 / 2)$ power to protect against trying to raise a negative number to a real power.

CV 2429 calculates the gas $\operatorname{Pr}^{0.8}$ near the middle of the heated length of Component 950 . 
CV 2430 calculates the denominator for the buoyancy parameter Bo*.

CV 2431 calculates the buoyancy parameter Bo* near the middle of the heated length of Component 950.

The 3000 series CVs are intended to provide an approximation of the stored energy of the system. The volumetric heat capacity is in $\mathrm{MJ} / \mathrm{m}^{3}-\mathrm{K}$ and the stored energy is in $\mathrm{MJ}$.

CV 3001 calculates the volumetric heat capacity $\left(\mathrm{MJ} / \mathrm{m}^{3}-\mathrm{K}\right)$ in Structure 1000, axial node 1.

CV 3002 calculates the stored energy (MJ) in Structure 1000, axial node 1.

CV 3003 calculates the volumetric heat capacity $\left(\mathrm{MJ} / \mathrm{m}^{3}-\mathrm{K}\right)$ in Structure 1000, axial node 2.

CV 3004 calculates the stored energy (MJ) in Structure 1000, axial node 2.

CV 3005 calculates the volumetric heat capacity $\left(\mathrm{MJ} / \mathrm{m}^{3}-\mathrm{K}\right)$ in Structure 1000, axial node 3.

CV 3006 calculates the stored energy (MJ) in Structure 1000, axial node 3.

CV 3007 calculates the volumetric heat capacity $\left(\mathrm{MJ} / \mathrm{m}^{3}-\mathrm{K}\right)$ in Structure 1000, axial node 4.

CV 3008 calculates the stored energy (MJ) in Structure 1000, axial node 4.

CV 3009 calculates the volumetric heat capacity $\left(\mathrm{MJ} / \mathrm{m}^{3}-\mathrm{K}\right)$ in Structure 1000, axial node 5.

CV 3010 calculates the stored energy (MJ) in Structure 1000, axial node 5.

CV 3011 calculates the volumetric heat capacity $\left(\mathrm{MJ} / \mathrm{m}^{3}-\mathrm{K}\right)$ in Structure 1000, axial node 6.

CV 3012 calculates the stored energy (MJ) in Structure 1000, axial node 6.

CV 3013 calculates the volumetric heat capacity $\left(\mathrm{MJ} / \mathrm{m}^{3}-\mathrm{K}\right)$ in Structure 1000, axial node 7.

CV 3014 calculates the stored energy (MJ) in Structure 1000, axial node 7.

CV 3015 calculates the volumetric heat capacity $\left(\mathrm{MJ} / \mathrm{m}^{3}-\mathrm{K}\right)$ in Structure 1000 , axial node 8.

CV 3016 calculates the stored energy (MJ) in Structure 1000, axial node 8.

CV 3017 calculates the volumetric heat capacity $\left(\mathrm{MJ} / \mathrm{m}^{3}-\mathrm{K}\right)$ in Structure 1000, axial node 9.

CV 3018 calculates the stored energy (MJ) in Structure 1000, axial node 9.

CV 3019 calculates the volumetric heat capacity $\left(\mathrm{MJ} / \mathrm{m}^{3}-\mathrm{K}\right)$ in Structure 1000, axial node 10.

CV 3020 calculates the stored energy (MJ) in Structure 1000, axial node 10.

CV 3021 calculates the volumetric heat capacity $\left(\mathrm{MJ} / \mathrm{m}^{3}-\mathrm{K}\right)$ in Structure 1000, axial node 11.

CV 3022 calculates the stored energy (MJ) in Structure 1000, axial node 11.

CV 3023 calculates the volumetric heat capacity $\left(\mathrm{MJ} / \mathrm{m}^{3}-\mathrm{K}\right)$ in Structure 1000, axial node 12.

CV 3024 calculates the stored energy (MJ) in Structure 1000, axial node 12.

CV 3025 calculates the volumetric heat capacity $\left(\mathrm{MJ} / \mathrm{m}^{3}-\mathrm{K}\right)$ in Structure 1000, axial node 13.

CV 3026 calculates the stored energy (MJ) in Structure 1000, axial node 13.

CV 3027 calculates the volumetric heat capacity $\left(\mathrm{MJ} / \mathrm{m}^{3}-\mathrm{K}\right)$ in Structure 1000, axial node 14.

CV 3028 calculates the stored energy (MJ) in Structure 1000, axial node 14.

CV 3029 calculates the volumetric heat capacity $\left(\mathrm{MJ} / \mathrm{m}^{3}-\mathrm{K}\right)$ in Structure 1000, axial node 15.

CV 3030 calculates the stored energy (MJ) in Structure 1000, axial node 15.

CV 3031 calculates the volumetric heat capacity $\left(\mathrm{MJ} / \mathrm{m}^{3}-\mathrm{K}\right)$ in Structure 1000, axial node 16. 
CV 3032 calculates the stored energy (MJ) in Structure 1000, axial node 16.

CV 3033 calculates the volumetric heat capacity $\left(\mathrm{MJ} / \mathrm{m}^{3}-\mathrm{K}\right)$ in Structure 1000, axial node 17.

CV 3034 calculates the stored energy (MJ) in Structure 1000, axial node 17.

CV 3035 calculates the volumetric heat capacity $\left(\mathrm{MJ} / \mathrm{m}^{3}-\mathrm{K}\right)$ in Structure 1001, axial node 1.

CV 3036 calculates the stored energy (MJ) in Structure 1001, axial node 1.

CV 3038 calculates the stored energy (MJ) in the pressure vessel cylinder and head, Structures 1000 and 1001 .

CV 3041 calculates the volumetric heat capacity $\left(\mathrm{MJ} / \mathrm{m}^{3}-\mathrm{K}\right)$ in Structure 1050, axial node 1.

CV 3042 calculates the stored energy (MJ) in Structure 1050, axial node 1.

CV 3043 calculates the volumetric heat capacity $\left(\mathrm{MJ} / \mathrm{m}^{3}-\mathrm{K}\right)$ in Structure 1100, axial node 1.

CV 3044 calculates the stored energy (MJ) in Structure 1100, axial node 1.

CV 3049 calculates the volumetric heat capacity $\left(\mathrm{MJ} / \mathrm{m}^{3}-\mathrm{K}\right)$ in Structure 1150, axial node 1.

CV 3050 calculates the stored energy (MJ) in Structure 1150, axial node 1.

CV 3051 calculates the volumetric heat capacity $\left(\mathrm{MJ} / \mathrm{m}^{3}-\mathrm{K}\right)$ in Structure 1150, axial node 2.

CV 3052 calculates the stored energy (MJ) in Structure 1150, axial node 2.

CV 3053 calculates the volumetric heat capacity $\left(\mathrm{MJ} / \mathrm{m}^{3}-\mathrm{K}\right)$ in Structure 1150, axial node 3.

CV 3054 calculates the stored energy (MJ) in Structure 1150, axial node 3.

CV 3055 calculates the volumetric heat capacity $\left(\mathrm{MJ} / \mathrm{m}^{3}-\mathrm{K}\right)$ in Structure 1150, axial node 4.

CV 3056 calculates the stored energy (MJ) in Structure 1150, axial node 4.

CV 3057 calculates the volumetric heat capacity $\left(\mathrm{MJ} / \mathrm{m}^{3}-\mathrm{K}\right)$ in Structure 1150, axial node 5.

CV 3058 calculates the stored energy (MJ) in Structure 1150, axial node 5.

CV 3059 calculates the volumetric heat capacity $\left(\mathrm{MJ} / \mathrm{m}^{3}-\mathrm{K}\right)$ in Structure 1150, axial node 6.

CV 3060 calculates the stored energy (MJ) in Structure 1150, axial node 6.

CV 3061 calculates the volumetric heat capacity $\left(\mathrm{MJ} / \mathrm{m}^{3}-\mathrm{K}\right)$ in Structure 1150, axial node 7.

CV 3062 calculates the stored energy (MJ) in Structure 1150, axial node 7.

CV 3063 calculates the volumetric heat capacity $\left(\mathrm{MJ} / \mathrm{m}^{3}-\mathrm{K}\right)$ in Structure 1150, axial node 8.

CV 3064 calculates the stored energy (MJ) in Structure 1150, axial node 8.

CV 3065 calculates the volumetric heat capacity $\left(\mathrm{MJ} / \mathrm{m}^{3}-\mathrm{K}\right)$ in Structure 1150, axial node 9.

CV 3066 calculates the stored energy (MJ) in Structure 1150, axial node 9.

CV 3067 calculates the volumetric heat capacity $\left(\mathrm{MJ} / \mathrm{m}^{3}-\mathrm{K}\right)$ in Structure 1150, axial node 10.

CV 3068 calculates the stored energy (MJ) in Structure 1150, axial node 10.

CV 3069 calculates the volumetric heat capacity $\left(\mathrm{MJ} / \mathrm{m}^{3}-\mathrm{K}\right)$ in Structure 1150, axial node 11.

CV 3070 calculates the stored energy (MJ) in Structure 1150, axial node 11.

CV 3071 calculates the volumetric heat capacity $\left(\mathrm{MJ} / \mathrm{m}^{3}-\mathrm{K}\right)$ in Structure 1150, axial node 12.

CV 3072 calculates the stored energy (MJ) in Structure 1150, axial node 12.

CV 3073 calculates the volumetric heat capacity $\left(\mathrm{MJ} / \mathrm{m}^{3}-\mathrm{K}\right)$ in Structure 1150, axial node 13. 
CV 3074 calculates the stored energy (MJ) in Structure 1150, axial node 13.

CV 3075 calculates the volumetric heat capacity $\left(\mathrm{MJ} / \mathrm{m}^{3}-\mathrm{K}\right)$ in Structure 1150, axial node 14. CV 3076 calculates the stored energy (MJ) in Structure 1150, axial node 14.

CV 3077 calculates the volumetric heat capacity $\left(\mathrm{MJ} / \mathrm{m}^{3}-\mathrm{K}\right)$ in Structure 1150, axial node 15. CV 3078 calculates the stored energy (MJ) in Structure 1150, axial node 15.

CV 3079 calculates the volumetric heat capacity $\left(\mathrm{MJ} / \mathrm{m}^{3}-\mathrm{K}\right)$ in Structure 1150, axial node 16. CV 3080 calculates the stored energy (MJ) in Structure 1150, axial node 16.

CV 3081 calculates the stored energy (MJ) in the core barrel, Structure 1150.

CV 3083 calculates the volumetric heat capacity $\left(\mathrm{MJ} / \mathrm{m}^{3}-\mathrm{K}\right)$ in Structure 1200, axial node 1.

CV 3084 calculates the stored energy (MJ) in Structure 1200, axial node 1.

CV 3085 calculates the volumetric heat capacity $\left(\mathrm{MJ} / \mathrm{m}^{3}-\mathrm{K}\right)$ in Structure 1201, axial node 1.

CV 3086 calculates the stored energy (MJ) in Structure 1201, axial node 1.

CV 3087 calculates the volumetric heat capacity $\left(\mathrm{MJ} / \mathrm{m}^{3}-\mathrm{K}\right)$ in Structure 1202, axial node 1.

CV 3088 calculates the stored energy (MJ) in Structure 1202, axial node 1.

CV 3091 calculates the volumetric heat capacity $\left(\mathrm{MJ} / \mathrm{m}^{3}-\mathrm{K}\right)$ in Structure 1300, axial node 1.

CV 3092 calculates the stored energy (MJ) in Structure 1300, axial node 1.

CV 3093 calculates the volumetric heat capacity $\left(\mathrm{MJ} / \mathrm{m}^{3}-\mathrm{K}\right)$ in Structure 1300, axial node 2.

CV 3094 calculates the stored energy (MJ) in Structure 1300, axial node 2.

CV 3095 calculates the volumetric heat capacity $\left(\mathrm{MJ} / \mathrm{m}^{3}-\mathrm{K}\right)$ in Structure 1300, axial node 3.

CV 3096 calculates the stored energy (MJ) in Structure 1300, axial node 3.

CV 3097 calculates the volumetric heat capacity $\left(\mathrm{MJ} / \mathrm{m}^{3}-\mathrm{K}\right)$ in Structure 1300, axial node 4.

CV 3098 calculates the stored energy (MJ) in Structure 1300, axial node 4.

CV 3099 calculates the volumetric heat capacity $\left(\mathrm{MJ} / \mathrm{m}^{3}-\mathrm{K}\right)$ in Structure 1300, axial node 5.

CV 3100 calculates the stored energy (MJ) in Structure 1300, axial node 5.

CV 3101 calculates the volumetric heat capacity $\left(\mathrm{MJ} / \mathrm{m}^{3}-\mathrm{K}\right)$ in Structure 1300, axial node 6.

CV 3102 calculates the stored energy (MJ) in Structure 1300, axial node 6.

CV 3103 calculates the volumetric heat capacity $\left(\mathrm{MJ} / \mathrm{m}^{3}-\mathrm{K}\right)$ in Structure 1300, axial node 7.

CV 3104 calculates the stored energy (MJ) in Structure 1300, axial node 7.

CV 3105 calculates the volumetric heat capacity $\left(\mathrm{MJ} / \mathrm{m}^{3}-\mathrm{K}\right)$ in Structure 1300, axial node 8.

CV 3106 calculates the stored energy (MJ) in Structure 1300, axial node 8.

CV 3107 calculates the volumetric heat capacity $\left(\mathrm{MJ} / \mathrm{m}^{3}-\mathrm{K}\right)$ in Structure 1300, axial node 9.

CV 3108 calculates the stored energy (MJ) in Structure 1300, axial node 9.

CV 3109 calculates the volumetric heat capacity $\left(\mathrm{MJ} / \mathrm{m}^{3}-\mathrm{K}\right)$ in Structure 1300, axial node 10.

CV 3110 calculates the stored energy (MJ) in Structure 1300, axial node 10.

CV 3111 calculates the volumetric heat capacity $\left(\mathrm{MJ} / \mathrm{m}^{3}-\mathrm{K}\right)$ in Structure 1300, axial node 11. 
CV 3112 calculates the stored energy (MJ) in Structure 1300, axial node 11.

CV 3113 calculates the volumetric heat capacity $\left(\mathrm{MJ} / \mathrm{m}^{3}-\mathrm{K}\right)$ in Structure 1300, axial node 12. CV 3114 calculates the stored energy (MJ) in Structure 1300, axial node 12.

CV 3115 calculates the volumetric heat capacity $\left(\mathrm{MJ} / \mathrm{m}^{3}-\mathrm{K}\right)$ in Structure 1300, axial node 13. CV 3116 calculates the stored energy (MJ) in Structure 1300, axial node 13.

CV 3117 calculates the volumetric heat capacity $\left(\mathrm{MJ} / \mathrm{m}^{3}-\mathrm{K}\right)$ in Structure 1300, axial node 14. CV 3118 calculates the stored energy (MJ) in Structure 1300, axial node 14.

CV 3121 calculates the volumetric heat capacity $\left(\mathrm{MJ} / \mathrm{m}^{3}-\mathrm{K}\right)$ in Structure 1320, axial node 1. CV 3122 calculates the stored energy (MJ) in Structure 1320, axial node 1.

CV 3123 calculates the volumetric heat capacity $\left(\mathrm{MJ} / \mathrm{m}^{3}-\mathrm{K}\right)$ in Structure 1320, axial node 2.

CV 3124 calculates the stored energy (MJ) in Structure 1320, axial node 2.

CV 3125 calculates the volumetric heat capacity $\left(\mathrm{MJ} / \mathrm{m}^{3}-\mathrm{K}\right)$ in Structure 1320, axial node 3.

CV 3126 calculates the stored energy (MJ) in Structure 1320, axial node 3.

CV 3127 calculates the volumetric heat capacity $\left(\mathrm{MJ} / \mathrm{m}^{3}-\mathrm{K}\right)$ in Structure 1320, axial node 4.

CV 3128 calculates the stored energy (MJ) in Structure 1320, axial node 4.

CV 3129 calculates the volumetric heat capacity $\left(\mathrm{MJ} / \mathrm{m}^{3}-\mathrm{K}\right)$ in Structure 1320, axial node 5.

CV 3130 calculates the stored energy (MJ) in Structure 1320, axial node 5.

CV 3131 calculates the volumetric heat capacity $\left(\mathrm{MJ} / \mathrm{m}^{3}-\mathrm{K}\right)$ in Structure 1320, axial node 6.

CV 3132 calculates the stored energy (MJ) in Structure 1320, axial node 6.

CV 3133 calculates the volumetric heat capacity $\left(\mathrm{MJ} / \mathrm{m}^{3}-\mathrm{K}\right)$ in Structure 1320, axial node 7.

CV 3134 calculates the stored energy (MJ) in Structure 1320, axial node 7.

CV 3135 calculates the volumetric heat capacity $\left(\mathrm{MJ} / \mathrm{m}^{3}-\mathrm{K}\right)$ in Structure 1320, axial node 8.

CV 3136 calculates the stored energy (MJ) in Structure 1320, axial node 8.

CV 3137 calculates the volumetric heat capacity $\left(\mathrm{MJ} / \mathrm{m}^{3}-\mathrm{K}\right)$ in Structure 1320, axial node 9.

CV 3138 calculates the stored energy (MJ) in Structure 1320, axial node 9.

CV 3139 calculates the volumetric heat capacity $\left(\mathrm{MJ} / \mathrm{m}^{3}-\mathrm{K}\right)$ in Structure 1320, axial node 10.

CV 3140 calculates the stored energy (MJ) in Structure 1320, axial node 10.

CV 3141 calculates the volumetric heat capacity $\left(\mathrm{MJ} / \mathrm{m}^{3}-\mathrm{K}\right)$ in Structure 1320, axial node 11.

CV 3142 calculates the stored energy (MJ) in Structure 1320, axial node 11.

CV 3143 calculates the volumetric heat capacity $\left(\mathrm{MJ} / \mathrm{m}^{3}-\mathrm{K}\right)$ in Structure 1320, axial node 12.

CV 3144 calculates the stored energy (MJ) in Structure 1320, axial node 12.

CV 3145 calculates the volumetric heat capacity $\left(\mathrm{MJ} / \mathrm{m}^{3}-\mathrm{K}\right)$ in Structure 1320, axial node 13.

CV 3146 calculates the stored energy (MJ) in Structure 1320, axial node 13.

CV 3147 calculates the volumetric heat capacity $\left(\mathrm{MJ} / \mathrm{m}^{3}-\mathrm{K}\right)$ in Structure 1320, axial node 14.

CV 3148 calculates the stored energy (MJ) in Structure 1320, axial node 14. 
CV 3151 calculates the volumetric heat capacity $\left(\mathrm{MJ} / \mathrm{m}^{3}-\mathrm{K}\right)$ in Structure 1340, axial node 1.

CV 3152 calculates the stored energy (MJ) in Structure 1340, axial node 1.

CV 3153 calculates the volumetric heat capacity $\left(\mathrm{MJ} / \mathrm{m}^{3}-\mathrm{K}\right)$ in Structure 1340, axial node 2.

CV 3154 calculates the stored energy (MJ) in Structure 1340, axial node 2.

CV 3155 calculates the volumetric heat capacity $\left(\mathrm{MJ} / \mathrm{m}^{3}-\mathrm{K}\right)$ in Structure 1340, axial node 3.

CV 3156 calculates the stored energy (MJ) in Structure 1340, axial node 3.

CV 3157 calculates the volumetric heat capacity $\left(\mathrm{MJ} / \mathrm{m}^{3}-\mathrm{K}\right)$ in Structure 1340, axial node 4.

CV 3158 calculates the stored energy (MJ) in Structure 1340, axial node 4.

CV 3159 calculates the volumetric heat capacity $\left(\mathrm{MJ} / \mathrm{m}^{3}-\mathrm{K}\right)$ in Structure 1340, axial node 5.

CV 3160 calculates the stored energy (MJ) in Structure 1340, axial node 5.

CV 3161 calculates the volumetric heat capacity $\left(\mathrm{MJ} / \mathrm{m}^{3}-\mathrm{K}\right)$ in Structure 1340, axial node 6 .

CV 3162 calculates the stored energy (MJ) in Structure 1340, axial node 6.

CV 3163 calculates the volumetric heat capacity $\left(\mathrm{MJ} / \mathrm{m}^{3}-\mathrm{K}\right)$ in Structure 1340, axial node 7.

CV 3164 calculates the stored energy (MJ) in Structure 1340, axial node 7.

CV 3165 calculates the volumetric heat capacity $\left(\mathrm{MJ} / \mathrm{m}^{3}-\mathrm{K}\right)$ in Structure 1340, axial node 8.

CV 3166 calculates the stored energy (MJ) in Structure 1340, axial node 8.

CV 3167 calculates the volumetric heat capacity $\left(\mathrm{MJ} / \mathrm{m}^{3}-\mathrm{K}\right)$ in Structure 1340, axial node 9.

CV 3168 calculates the stored energy (MJ) in Structure 1340, axial node 9.

CV 3169 calculates the volumetric heat capacity $\left(\mathrm{MJ} / \mathrm{m}^{3}-\mathrm{K}\right)$ in Structure 1340, axial node 10.

CV 3170 calculates the stored energy (MJ) in Structure 1340, axial node 10.

CV 3171 calculates the volumetric heat capacity $\left(\mathrm{MJ} / \mathrm{m}^{3}-\mathrm{K}\right)$ in Structure 1340, axial node 11.

CV 3172 calculates the stored energy (MJ) in Structure 1340, axial node 11.

CV 3173 calculates the volumetric heat capacity $\left(\mathrm{MJ} / \mathrm{m}^{3}-\mathrm{K}\right)$ in Structure 1340, axial node 12.

CV 3174 calculates the stored energy (MJ) in Structure 1340, axial node 12.

CV 3175 calculates the volumetric heat capacity $\left(\mathrm{MJ} / \mathrm{m}^{3}-\mathrm{K}\right)$ in Structure 1340, axial node 13.

CV 3176 calculates the stored energy (MJ) in Structure 1340, axial node 13.

CV 3177 calculates the volumetric heat capacity $\left(\mathrm{MJ} / \mathrm{m}^{3}-\mathrm{K}\right)$ in Structure 1340, axial node 14.

CV 3178 calculates the stored energy (MJ) in Structure 1340, axial node 14.

CV 3179 calculates the stored energy (MJ) in the central reflector, Structures 1300, 1320, and 1340.

CV 3181 calculates the volumetric heat capacity $\left(\mathrm{MJ} / \mathrm{m}^{3}-\mathrm{K}\right)$ in Structure 1400, axial node 1.

CV 3182 calculates the stored energy (MJ) in Structure 1400, axial node 1.

CV 3183 calculates the volumetric heat capacity $\left(\mathrm{MJ} / \mathrm{m}^{3}-\mathrm{K}\right)$ in Structure 1400, axial node 2.

CV 3184 calculates the stored energy (MJ) in Structure 1400, axial node 2.

CV 3185 calculates the volumetric heat capacity $\left(\mathrm{MJ} / \mathrm{m}^{3}-\mathrm{K}\right)$ in Structure 1401, axial node 1.

CV 3186 calculates the stored energy (MJ) in Structure 1401, axial node 1. 
CV 3187 calculates the volumetric heat capacity $\left(\mathrm{MJ} / \mathrm{m}^{3}-\mathrm{K}\right)$ in Structure 1401, axial node 2.

CV 3188 calculates the stored energy (MJ) in Structure 1401, axial node 2.

CV 3189 calculates the volumetric heat capacity $\left(\mathrm{MJ} / \mathrm{m}^{3}-\mathrm{K}\right)$ in Structure 1401, axial node 3. CV 3190 calculates the stored energy (MJ) in Structure 1401, axial node 3.

CV 3191 calculates the volumetric heat capacity $\left(\mathrm{MJ} / \mathrm{m}^{3}-\mathrm{K}\right)$ in Structure 1401, axial node 4.

CV 3192 calculates the stored energy (MJ) in Structure 1401, axial node 4.

CV 3193 calculates the volumetric heat capacity $\left(\mathrm{MJ} / \mathrm{m}^{3}-\mathrm{K}\right)$ in Structure 1401, axial node 5.

CV 3194 calculates the stored energy (MJ) in Structure 1401, axial node 5.

CV 3195 calculates the volumetric heat capacity $\left(\mathrm{MJ} / \mathrm{m}^{3}-\mathrm{K}\right)$ in Structure 1401, axial node 6.

CV 3196 calculates the stored energy (MJ) in Structure 1401, axial node 6.

CV 3197 calculates the volumetric heat capacity $\left(\mathrm{MJ} / \mathrm{m}^{3}-\mathrm{K}\right)$ in Structure 1401, axial node 7.

CV 3198 calculates the stored energy (MJ) in Structure 1401, axial node 7.

CV 3199 calculates the volumetric heat capacity $\left(\mathrm{MJ} / \mathrm{m}^{3}-\mathrm{K}\right)$ in Structure 1401, axial node 8.

CV 3200 calculates the stored energy (MJ) in Structure 1401, axial node 8.

CV 3201 calculates the volumetric heat capacity $\left(\mathrm{MJ} / \mathrm{m}^{3}-\mathrm{K}\right)$ in Structure 1401, axial node 9.

CV 3202 calculates the stored energy (MJ) in Structure 1401, axial node 9.

CV 3203 calculates the volumetric heat capacity $\left(\mathrm{MJ} / \mathrm{m}^{3}-\mathrm{K}\right)$ in Structure 1401, axial node 10.

CV 3204 calculates the stored energy (MJ) in Structure 1401, axial node 10.

CV 3205 calculates the volumetric heat capacity $\left(\mathrm{MJ} / \mathrm{m}^{3}-\mathrm{K}\right)$ in Structure 1402, axial node 1.

CV 3206 calculates the stored energy (MJ) in Structure 1402, axial node 1.

CV 3207 calculates the volumetric heat capacity $\left(\mathrm{MJ} / \mathrm{m}^{3}-\mathrm{K}\right)$ in Structure 1402, axial node 2.

CV 3208 calculates the stored energy (MJ) in Structure 1402, axial node 2.

CV 3211 calculates the volumetric heat capacity $\left(\mathrm{MJ} / \mathrm{m}^{3}-\mathrm{K}\right)$ in Structure 1450, axial node 1.

CV 3212 calculates the stored energy (MJ) in Structure 1450, axial node 1.

CV 3213 calculates the volumetric heat capacity $\left(\mathrm{MJ} / \mathrm{m}^{3}-\mathrm{K}\right)$ in Structure 1450, axial node 2.

CV 3214 calculates the stored energy (MJ) in Structure 1450, axial node 2.

CV 3215 calculates the volumetric heat capacity $\left(\mathrm{MJ} / \mathrm{m}^{3}-\mathrm{K}\right)$ in Structure 1451, axial node 1.

CV 3216 calculates the stored energy (MJ) in Structure 1451, axial node 1.

CV 3217 calculates the volumetric heat capacity $\left(\mathrm{MJ} / \mathrm{m}^{3}-\mathrm{K}\right)$ in Structure 1451, axial node 2.

CV 3218 calculates the stored energy (MJ) in Structure 1451, axial node 2.

CV 3219 calculates the volumetric heat capacity $\left(\mathrm{MJ} / \mathrm{m}^{3}-\mathrm{K}\right)$ in Structure 1451, axial node 3.

CV 3220 calculates the stored energy (MJ) in Structure 1451, axial node 3.

CV 3221 calculates the volumetric heat capacity $\left(\mathrm{MJ} / \mathrm{m}^{3}-\mathrm{K}\right)$ in Structure 1451, axial node 4.

CV 3222 calculates the stored energy (MJ) in Structure 1451, axial node 4.

CV 3223 calculates the volumetric heat capacity $\left(\mathrm{MJ} / \mathrm{m}^{3}-\mathrm{K}\right)$ in Structure 1451, axial node 5. 
CV 3224 calculates the stored energy (MJ) in Structure 1451, axial node 5.

CV 3225 calculates the volumetric heat capacity $\left(\mathrm{MJ} / \mathrm{m}^{3}-\mathrm{K}\right)$ in Structure 1451, axial node 6. CV 3226 calculates the stored energy (MJ) in Structure 1451, axial node 6.

CV 3227 calculates the volumetric heat capacity $\left(\mathrm{MJ} / \mathrm{m}^{3}-\mathrm{K}\right)$ in Structure 1451, axial node 7. CV 3228 calculates the stored energy (MJ) in Structure 1451, axial node 7.

CV 3229 calculates the volumetric heat capacity $\left(\mathrm{MJ} / \mathrm{m}^{3}-\mathrm{K}\right)$ in Structure 1451 , axial node 8 . CV 3230 calculates the stored energy (MJ) in Structure 1451, axial node 8.

CV 3231 calculates the volumetric heat capacity $\left(\mathrm{MJ} / \mathrm{m}^{3}-\mathrm{K}\right)$ in Structure 1451, axial node 9. CV 3232 calculates the stored energy (MJ) in Structure 1451, axial node 9.

CV 3233 calculates the volumetric heat capacity $\left(\mathrm{MJ} / \mathrm{m}^{3}-\mathrm{K}\right)$ in Structure 1451, axial node 10. CV 3234 calculates the stored energy (MJ) in Structure 1451, axial node 10.

CV 3235 calculates the volumetric heat capacity $\left(\mathrm{MJ} / \mathrm{m}^{3}-\mathrm{K}\right)$ in Structure 1452, axial node 1. CV 3236 calculates the stored energy (MJ) in Structure 1452, axial node 1.

CV 3237 calculates the volumetric heat capacity $\left(\mathrm{MJ} / \mathrm{m}^{3}-\mathrm{K}\right)$ in Structure 1452, axial node 2. CV 3238 calculates the stored energy (MJ) in Structure 1452, axial node 2.

CV 3241 calculates the volumetric heat capacity $\left(\mathrm{MJ} / \mathrm{m}^{3}-\mathrm{K}\right)$ in Structure 1500 , axial node 1. CV 3242 calculates the stored energy (MJ) in Structure 1500, axial node 1.

CV 3243 calculates the volumetric heat capacity $\left(\mathrm{MJ} / \mathrm{m}^{3}-\mathrm{K}\right)$ in Structure 1500, axial node 2. CV 3244 calculates the stored energy (MJ) in Structure 1500, axial node 2.

CV 3245 calculates the volumetric heat capacity $\left(\mathrm{MJ} / \mathrm{m}^{3}-\mathrm{K}\right)$ in Structure 1501, axial node 1. CV 3246 calculates the stored energy (MJ) in Structure 1501, axial node 1.

CV 3247 calculates the volumetric heat capacity $\left(\mathrm{MJ} / \mathrm{m}^{3}-\mathrm{K}\right)$ in Structure 1501, axial node 2. CV 3248 calculates the stored energy (MJ) in Structure 1501, axial node 2.

CV 3249 calculates the volumetric heat capacity $\left(\mathrm{MJ} / \mathrm{m}^{3}-\mathrm{K}\right)$ in Structure 1501, axial node 3. CV 3250 calculates the stored energy (MJ) in Structure 1501, axial node 3.

CV 3251 calculates the volumetric heat capacity $\left(\mathrm{MJ} / \mathrm{m}^{3}-\mathrm{K}\right)$ in Structure 1501 , axial node 4. CV 3252 calculates the stored energy (MJ) in Structure 1501, axial node 4.

CV 3253 calculates the volumetric heat capacity $\left(\mathrm{MJ} / \mathrm{m}^{3}-\mathrm{K}\right)$ in Structure 1501, axial node 5. CV 3254 calculates the stored energy (MJ) in Structure 1501, axial node 5.

CV 3255 calculates the volumetric heat capacity $\left(\mathrm{MJ} / \mathrm{m}^{3}-\mathrm{K}\right)$ in Structure 1501, axial node 6. CV 3256 calculates the stored energy (MJ) in Structure 1501, axial node 6.

CV 3257 calculates the volumetric heat capacity $\left(\mathrm{MJ} / \mathrm{m}^{3}-\mathrm{K}\right)$ in Structure 1501, axial node 7. CV 3258 calculates the stored energy (MJ) in Structure 1501, axial node 7.

CV 3259 calculates the volumetric heat capacity $\left(\mathrm{MJ} / \mathrm{m}^{3}-\mathrm{K}\right)$ in Structure 1501 , axial node 8 . CV 3260 calculates the stored energy (MJ) in Structure 1501, axial node 8. 
CV 3261 calculates the volumetric heat capacity $\left(\mathrm{MJ} / \mathrm{m}^{3}-\mathrm{K}\right)$ in Structure 1501, axial node 9.

CV 3262 calculates the stored energy (MJ) in Structure 1501, axial node 9.

CV 3263 calculates the volumetric heat capacity $\left(\mathrm{MJ} / \mathrm{m}^{3}-\mathrm{K}\right)$ in Structure 1501, axial node 10. CV 3264 calculates the stored energy (MJ) in Structure 1501, axial node 10.

CV 3265 calculates the volumetric heat capacity $\left(\mathrm{MJ} / \mathrm{m}^{3}-\mathrm{K}\right)$ in Structure 1502, axial node 1.

CV 3266 calculates the stored energy (MJ) in Structure 1502, axial node 1.

CV 3267 calculates the volumetric heat capacity $\left(\mathrm{MJ} / \mathrm{m}^{3}-\mathrm{K}\right)$ in Structure 1502, axial node 2.

CV 3268 calculates the stored energy (MJ) in Structure 1502, axial node 2.

CV 3269 calculates the stored energy (MJ) in the core ceramic, Structures 1400, 1401, 1402, 1450, $1451,1452,1500,1501$, and 1502 .

CV 3271 calculates the volumetric heat capacity $\left(\mathrm{MJ} / \mathrm{m}^{3}-\mathrm{K}\right)$ in Structure 1403, axial node 1.

CV 3272 calculates the stored energy (MJ) in Structure 1403, axial node 1.

CV 3273 calculates the volumetric heat capacity $\left(\mathrm{MJ} / \mathrm{m}^{3}-\mathrm{K}\right)$ in Structure 1403, axial node 2.

CV 3274 calculates the stored energy (MJ) in Structure 1403, axial node 2.

CV 3275 calculates the volumetric heat capacity $\left(\mathrm{MJ} / \mathrm{m}^{3}-\mathrm{K}\right)$ in Structure 1403, axial node 3.

CV 3276 calculates the stored energy (MJ) in Structure 1403, axial node 3.

CV 3277 calculates the volumetric heat capacity $\left(\mathrm{MJ} / \mathrm{m}^{3}-\mathrm{K}\right)$ in Structure 1403, axial node 4.

CV 3278 calculates the stored energy (MJ) in Structure 1403, axial node 4.

CV 3279 calculates the volumetric heat capacity $\left(\mathrm{MJ} / \mathrm{m}^{3}-\mathrm{K}\right)$ in Structure 1403, axial node 5.

CV 3280 calculates the stored energy (MJ) in Structure 1403, axial node 5.

CV 3281 calculates the volumetric heat capacity $\left(\mathrm{MJ} / \mathrm{m}^{3}-\mathrm{K}\right)$ in Structure 1403, axial node 6.

CV 3282 calculates the stored energy (MJ) in Structure 1403, axial node 6.

CV 3283 calculates the volumetric heat capacity $\left(\mathrm{MJ} / \mathrm{m}^{3}-\mathrm{K}\right)$ in Structure 1403, axial node 7.

CV 3284 calculates the stored energy (MJ) in Structure 1403, axial node 7.

CV 3285 calculates the volumetric heat capacity $\left(\mathrm{MJ} / \mathrm{m}^{3}-\mathrm{K}\right)$ in Structure 1403, axial node 8.

CV 3286 calculates the stored energy (MJ) in Structure 1403, axial node 8.

CV 3287 calculates the volumetric heat capacity $\left(\mathrm{MJ} / \mathrm{m}^{3}-\mathrm{K}\right)$ in Structure 1403, axial node 9.

CV 3288 calculates the stored energy (MJ) in Structure 1403, axial node 9.

CV 3289 calculates the volumetric heat capacity $\left(\mathrm{MJ} / \mathrm{m}^{3}-\mathrm{K}\right)$ in Structure 1403, axial node 10.

CV 3290 calculates the stored energy (MJ) in Structure 1403, axial node 10.

CV 3291 calculates the volumetric heat capacity $\left(\mathrm{MJ} / \mathrm{m}^{3}-\mathrm{K}\right)$ in Structure 1453, axial node 1.

CV 3292 calculates the stored energy (MJ) in Structure 1453, axial node 1.

CV 3293 calculates the volumetric heat capacity $\left(\mathrm{MJ} / \mathrm{m}^{3}-\mathrm{K}\right)$ in Structure 1453, axial node 2.

CV 3294 calculates the stored energy (MJ) in Structure 1453, axial node 2.

CV 3295 calculates the volumetric heat capacity $\left(\mathrm{MJ} / \mathrm{m}^{3}-\mathrm{K}\right)$ in Structure 1453, axial node 3.

CV 3296 calculates the stored energy (MJ) in Structure 1453, axial node 3. 
CV 3297 calculates the volumetric heat capacity $\left(\mathrm{MJ} / \mathrm{m}^{3}-\mathrm{K}\right)$ in Structure 1453, axial node 4. CV 3298 calculates the stored energy (MJ) in Structure 1453, axial node 4.

CV 3299 calculates the volumetric heat capacity $\left(\mathrm{MJ} / \mathrm{m}^{3}-\mathrm{K}\right)$ in Structure 1453, axial node 5. CV 3300 calculates the stored energy (MJ) in Structure 1453, axial node 5.

CV 3301 calculates the volumetric heat capacity $\left(\mathrm{MJ} / \mathrm{m}^{3}-\mathrm{K}\right)$ in Structure 1453, axial node 6 . CV 3302 calculates the stored energy (MJ) in Structure 1453, axial node 6.

CV 3303 calculates the volumetric heat capacity $\left(\mathrm{MJ} / \mathrm{m}^{3}-\mathrm{K}\right)$ in Structure 1453, axial node 7. CV 3304 calculates the stored energy (MJ) in Structure 1453, axial node 7.

CV 3305 calculates the volumetric heat capacity $\left(\mathrm{MJ} / \mathrm{m}^{3}-\mathrm{K}\right)$ in Structure 1453 , axial node 8. CV 3306 calculates the stored energy (MJ) in Structure 1453, axial node 8.

CV 3307 calculates the volumetric heat capacity $\left(\mathrm{MJ} / \mathrm{m}^{3}-\mathrm{K}\right)$ in Structure 1453, axial node 9.

CV 3308 calculates the stored energy (MJ) in Structure 1453, axial node 9.

CV 3309 calculates the volumetric heat capacity $\left(\mathrm{MJ} / \mathrm{m}^{3}-\mathrm{K}\right)$ in Structure 1453, axial node 10. CV 3310 calculates the stored energy (MJ) in Structure 1453, axial node 10.

CV 3311 calculates the volumetric heat capacity $\left(\mathrm{MJ} / \mathrm{m}^{3}-\mathrm{K}\right)$ in Structure 1503, axial node 1. CV 3312 calculates the stored energy (MJ) in Structure 1503, axial node 1.

CV 3313 calculates the volumetric heat capacity $\left(\mathrm{MJ} / \mathrm{m}^{3}-\mathrm{K}\right)$ in Structure 1503, axial node 2.

CV 3314 calculates the stored energy (MJ) in Structure 1503, axial node 2.

CV 3315 calculates the volumetric heat capacity $\left(\mathrm{MJ} / \mathrm{m}^{3}-\mathrm{K}\right)$ in Structure 1503, axial node 3.

CV 3316 calculates the stored energy (MJ) in Structure 1503, axial node 3.

CV 3317 calculates the volumetric heat capacity $\left(\mathrm{MJ} / \mathrm{m}^{3}-\mathrm{K}\right)$ in Structure 1503, axial node 4.

CV 3318 calculates the stored energy (MJ) in Structure 1503, axial node 4.

CV 3319 calculates the volumetric heat capacity $\left(\mathrm{MJ} / \mathrm{m}^{3}-\mathrm{K}\right)$ in Structure 1503 , axial node 5.

CV 3320 calculates the stored energy (MJ) in Structure 1503, axial node 5.

CV 3321 calculates the volumetric heat capacity $\left(\mathrm{MJ} / \mathrm{m}^{3}-\mathrm{K}\right)$ in Structure 1503, axial node 6.

CV 3322 calculates the stored energy (MJ) in Structure 1503, axial node 6.

CV 3323 calculates the volumetric heat capacity $\left(\mathrm{MJ} / \mathrm{m}^{3}-\mathrm{K}\right)$ in Structure 1503, axial node 7.

CV 3324 calculates the stored energy (MJ) in Structure 1503, axial node 7.

CV 3325 calculates the volumetric heat capacity $\left(\mathrm{MJ} / \mathrm{m}^{3}-\mathrm{K}\right)$ in Structure 1503 , axial node 8.

CV 3326 calculates the stored energy (MJ) in Structure 1503, axial node 8.

CV 3327 calculates the volumetric heat capacity $\left(\mathrm{MJ} / \mathrm{m}^{3}-\mathrm{K}\right)$ in Structure 1503, axial node 9.

CV 3328 calculates the stored energy (MJ) in Structure 1503, axial node 9.

CV 3329 calculates the volumetric heat capacity $\left(\mathrm{MJ} / \mathrm{m}^{3}-\mathrm{K}\right)$ in Structure 1503, axial node 10 .

CV 3330 calculates the stored energy (MJ) in Structure 1503, axial node 10.

CV 3331 calculates the stored energy (MJ) in the heater rods, Structures 1403, 1453, and 1503. 
CV 3341 calculates the volumetric heat capacity $\left(\mathrm{MJ} / \mathrm{m}^{3}-\mathrm{K}\right)$ in Structure 1600, axial node 1.

CV 3342 calculates the stored energy (MJ) in Structure 1600, axial node 1.

CV 3343 calculates the volumetric heat capacity $\left(\mathrm{MJ} / \mathrm{m}^{3}-\mathrm{K}\right)$ in Structure 1600, axial node 2.

CV 3344 calculates the stored energy (MJ) in Structure 1600, axial node 2.

CV 3345 calculates the volumetric heat capacity $\left(\mathrm{MJ} / \mathrm{m}^{3}-\mathrm{K}\right)$ in Structure 1600, axial node 3.

CV 3346 calculates the stored energy (MJ) in Structure 1600, axial node 3.

CV 3347 calculates the volumetric heat capacity $\left(\mathrm{MJ} / \mathrm{m}^{3}-\mathrm{K}\right)$ in Structure 1600, axial node 4.

CV 3348 calculates the stored energy (MJ) in Structure 1600, axial node 4.

CV 3349 calculates the volumetric heat capacity $\left(\mathrm{MJ} / \mathrm{m}^{3}-\mathrm{K}\right)$ in Structure 1600, axial node 5.

CV 3350 calculates the stored energy (MJ) in Structure 1600, axial node 5.

CV 3351 calculates the volumetric heat capacity $\left(\mathrm{MJ} / \mathrm{m}^{3}-\mathrm{K}\right)$ in Structure 1600, axial node 6 .

CV 3352 calculates the stored energy (MJ) in Structure 1600, axial node 6.

CV 3353 calculates the volumetric heat capacity $\left(\mathrm{MJ} / \mathrm{m}^{3}-\mathrm{K}\right)$ in Structure 1600, axial node 7.

CV 3354 calculates the stored energy (MJ) in Structure 1600, axial node 7.

CV 3355 calculates the volumetric heat capacity $\left(\mathrm{MJ} / \mathrm{m}^{3}-\mathrm{K}\right)$ in Structure 1600 , axial node 8.

CV 3356 calculates the stored energy (MJ) in Structure 1600, axial node 8.

CV 3357 calculates the volumetric heat capacity $\left(\mathrm{MJ} / \mathrm{m}^{3}-\mathrm{K}\right)$ in Structure 1600, axial node 9.

CV 3358 calculates the stored energy (MJ) in Structure 1600, axial node 9.

CV 3359 calculates the volumetric heat capacity $\left(\mathrm{MJ} / \mathrm{m}^{3}-\mathrm{K}\right)$ in Structure 1600 , axial node 10.

CV 3360 calculates the stored energy (MJ) in Structure 1600, axial node 10.

CV 3361 calculates the volumetric heat capacity $\left(\mathrm{MJ} / \mathrm{m}^{3}-\mathrm{K}\right)$ in Structure 1600, axial node 11.

CV 3362 calculates the stored energy (MJ) in Structure 1600, axial node 11.

CV 3363 calculates the volumetric heat capacity $\left(\mathrm{MJ} / \mathrm{m}^{3}-\mathrm{K}\right)$ in Structure 1600, axial node 12.

CV 3364 calculates the stored energy (MJ) in Structure 1600, axial node 12.

CV 3365 calculates the volumetric heat capacity $\left(\mathrm{MJ} / \mathrm{m}^{3}-\mathrm{K}\right)$ in Structure 1600, axial node 13.

CV 3366 calculates the stored energy (MJ) in Structure 1600, axial node 13.

CV 3367 calculates the volumetric heat capacity $\left(\mathrm{MJ} / \mathrm{m}^{3}-\mathrm{K}\right)$ in Structure 1600, axial node 14.

CV 3368 calculates the stored energy (MJ) in Structure 1600, axial node 14.

CV 3371 calculates the volumetric heat capacity $\left(\mathrm{MJ} / \mathrm{m}^{3}-\mathrm{K}\right)$ in Structure 1620 , axial node 1.

CV 3372 calculates the stored energy (MJ) in Structure 1620, axial node 1.

CV 3373 calculates the volumetric heat capacity $\left(\mathrm{MJ} / \mathrm{m}^{3}-\mathrm{K}\right)$ in Structure 1620, axial node 2.

CV 3374 calculates the stored energy (MJ) in Structure 1620, axial node 2.

CV 3375 calculates the volumetric heat capacity $\left(\mathrm{MJ} / \mathrm{m}^{3}-\mathrm{K}\right)$ in Structure 1620, axial node 3.

CV 3376 calculates the stored energy (MJ) in Structure 1620, axial node 3.

CV 3377 calculates the volumetric heat capacity $\left(\mathrm{MJ} / \mathrm{m}^{3}-\mathrm{K}\right)$ in Structure 1620, axial node 4. 
CV 3378 calculates the stored energy (MJ) in Structure 1620, axial node 4.

CV 3379 calculates the volumetric heat capacity $\left(\mathrm{MJ} / \mathrm{m}^{3}-\mathrm{K}\right)$ in Structure 1620, axial node 5. CV 3380 calculates the stored energy (MJ) in Structure 1620, axial node 5.

CV 3381 calculates the volumetric heat capacity $\left(\mathrm{MJ} / \mathrm{m}^{3}-\mathrm{K}\right)$ in Structure 1620, axial node 6.

CV 3382 calculates the stored energy (MJ) in Structure 1620, axial node 6.

CV 3383 calculates the volumetric heat capacity $\left(\mathrm{MJ} / \mathrm{m}^{3}-\mathrm{K}\right)$ in Structure 1620 , axial node 7 .

CV 3384 calculates the stored energy (MJ) in Structure 1620, axial node 7.

CV 3385 calculates the volumetric heat capacity $\left(\mathrm{MJ} / \mathrm{m}^{3}-\mathrm{K}\right)$ in Structure 1620 , axial node 8.

CV 3386 calculates the stored energy (MJ) in Structure 1620, axial node 8.

CV 3387 calculates the volumetric heat capacity $\left(\mathrm{MJ} / \mathrm{m}^{3}-\mathrm{K}\right)$ in Structure 1620, axial node 9.

CV 3388 calculates the stored energy (MJ) in Structure 1620, axial node 9.

CV 3389 calculates the volumetric heat capacity $\left(\mathrm{MJ} / \mathrm{m}^{3}-\mathrm{K}\right)$ in Structure 1620, axial node 10.

CV 3390 calculates the stored energy (MJ) in Structure 1620, axial node 10.

CV 3391 calculates the volumetric heat capacity $\left(\mathrm{MJ} / \mathrm{m}^{3}-\mathrm{K}\right)$ in Structure 1620, axial node 11.

CV 3392 calculates the stored energy (MJ) in Structure 1620, axial node 11.

CV 3393 calculates the volumetric heat capacity $\left(\mathrm{MJ} / \mathrm{m}^{3}-\mathrm{K}\right)$ in Structure 1620, axial node 12.

CV 3394 calculates the stored energy (MJ) in Structure 1620, axial node 12.

CV 3395 calculates the volumetric heat capacity $\left(\mathrm{MJ} / \mathrm{m}^{3}-\mathrm{K}\right)$ in Structure 1620, axial node 13.

CV 3396 calculates the stored energy (MJ) in Structure 1620, axial node 13.

CV 3397 calculates the volumetric heat capacity $\left(\mathrm{MJ} / \mathrm{m}^{3}-\mathrm{K}\right)$ in Structure 1620, axial node 14.

CV 3398 calculates the stored energy (MJ) in Structure 1620, axial node 14.

CV 3401 calculates the volumetric heat capacity $\left(\mathrm{MJ} / \mathrm{m}^{3}-\mathrm{K}\right)$ in Structure 1640, axial node 1.

CV 3402 calculates the stored energy (MJ) in Structure 1640, axial node 1.

CV 3403 calculates the volumetric heat capacity $\left(\mathrm{MJ} / \mathrm{m}^{3}-\mathrm{K}\right)$ in Structure 1640, axial node 2.

CV 3404 calculates the stored energy (MJ) in Structure 1640, axial node 2.

CV 3405 calculates the volumetric heat capacity $\left(\mathrm{MJ} / \mathrm{m}^{3}-\mathrm{K}\right)$ in Structure 1640, axial node 3.

CV 3406 calculates the stored energy (MJ) in Structure 1640, axial node 3.

CV 3407 calculates the volumetric heat capacity $\left(\mathrm{MJ} / \mathrm{m}^{3}-\mathrm{K}\right)$ in Structure 1640, axial node 4.

CV 3408 calculates the stored energy (MJ) in Structure 1640, axial node 4.

CV 3409 calculates the volumetric heat capacity $\left(\mathrm{MJ} / \mathrm{m}^{3}-\mathrm{K}\right)$ in Structure 1640, axial node 5.

CV 3410 calculates the stored energy (MJ) in Structure 1640, axial node 5.

CV 3411 calculates the volumetric heat capacity $\left(\mathrm{MJ} / \mathrm{m}^{3}-\mathrm{K}\right)$ in Structure 1640, axial node 6.

CV 3412 calculates the stored energy (MJ) in Structure 1640, axial node 6.

CV 3413 calculates the volumetric heat capacity $\left(\mathrm{MJ} / \mathrm{m}^{3}-\mathrm{K}\right)$ in Structure 1640, axial node 7.

CV 3414 calculates the stored energy (MJ) in Structure 1640, axial node 7. 
CV 3415 calculates the volumetric heat capacity $\left(\mathrm{MJ} / \mathrm{m}^{3}-\mathrm{K}\right)$ in Structure 1640, axial node 8.

CV 3416 calculates the stored energy (MJ) in Structure 1640, axial node 8.

CV 3417 calculates the volumetric heat capacity $\left(\mathrm{MJ} / \mathrm{m}^{3}-\mathrm{K}\right)$ in Structure 1640, axial node 9.

CV 3418 calculates the stored energy (MJ) in Structure 1640, axial node 9.

CV 3419 calculates the volumetric heat capacity $\left(\mathrm{MJ} / \mathrm{m}^{3}-\mathrm{K}\right)$ in Structure 1640, axial node 10.

CV 3420 calculates the stored energy (MJ) in Structure 1640, axial node 10.

CV 3421 calculates the volumetric heat capacity $\left(\mathrm{MJ} / \mathrm{m}^{3}-\mathrm{K}\right)$ in Structure 1640, axial node 11.

CV 3422 calculates the stored energy (MJ) in Structure 1640, axial node 11.

CV 3423 calculates the volumetric heat capacity $\left(\mathrm{MJ} / \mathrm{m}^{3}-\mathrm{K}\right)$ in Structure 1640, axial node 12.

CV 3424 calculates the stored energy (MJ) in Structure 1640, axial node 12.

CV 3425 calculates the volumetric heat capacity $\left(\mathrm{MJ} / \mathrm{m}^{3}-\mathrm{K}\right)$ in Structure 1640, axial node 13.

CV 3426 calculates the stored energy (MJ) in Structure 1640, axial node 13.

CV 3427 calculates the volumetric heat capacity $\left(\mathrm{MJ} / \mathrm{m}^{3}-\mathrm{K}\right)$ in Structure 1640, axial node 14.

CV 3428 calculates the stored energy (MJ) in Structure 1640, axial node 14.

CV 3429 calculates the stored energy (MJ) in the side reflector, Structures 1600, 1620, and 1640.

CV 3431 calculates the volumetric heat capacity $\left(\mathrm{MJ} / \mathrm{m}^{3}-\mathrm{K}\right)$ in Structure 1660, axial node 1.

CV 3432 calculates the stored energy (MJ) in Structure 1660, axial node 1.

CV 3433 calculates the volumetric heat capacity $\left(\mathrm{MJ} / \mathrm{m}^{3}-\mathrm{K}\right)$ in Structure 1660, axial node 2.

CV 3434 calculates the stored energy (MJ) in Structure 1660, axial node 2.

CV 3435 calculates the volumetric heat capacity $\left(\mathrm{MJ} / \mathrm{m}^{3}-\mathrm{K}\right)$ in Structure 1660, axial node 3.

CV 3436 calculates the stored energy (MJ) in Structure 1660, axial node 3.

CV 3437 calculates the volumetric heat capacity $\left(\mathrm{MJ} / \mathrm{m}^{3}-\mathrm{K}\right)$ in Structure 1660, axial node 4.

CV 3438 calculates the stored energy (MJ) in Structure 1660, axial node 4.

CV 3439 calculates the volumetric heat capacity $\left(\mathrm{MJ} / \mathrm{m}^{3}-\mathrm{K}\right)$ in Structure 1660, axial node 5.

CV 3440 calculates the stored energy (MJ) in Structure 1660, axial node 5.

CV 3441 calculates the volumetric heat capacity $\left(\mathrm{MJ} / \mathrm{m}^{3}-\mathrm{K}\right)$ in Structure 1660, axial node 6.

CV 3442 calculates the stored energy (MJ) in Structure 1660, axial node 6.

CV 3443 calculates the volumetric heat capacity $\left(\mathrm{MJ} / \mathrm{m}^{3}-\mathrm{K}\right)$ in Structure 1660, axial node 7.

CV 3444 calculates the stored energy (MJ) in Structure 1660, axial node 7.

CV 3445 calculates the volumetric heat capacity $\left(\mathrm{MJ} / \mathrm{m}^{3}-\mathrm{K}\right)$ in Structure 1660 , axial node 8.

CV 3446 calculates the stored energy (MJ) in Structure 1660, axial node 8.

CV 3447 calculates the volumetric heat capacity $\left(\mathrm{MJ} / \mathrm{m}^{3}-\mathrm{K}\right)$ in Structure 1660, axial node 9.

CV 3448 calculates the stored energy (MJ) in Structure 1660, axial node 9.

CV 3449 calculates the volumetric heat capacity $\left(\mathrm{MJ} / \mathrm{m}^{3}-\mathrm{K}\right)$ in Structure 1660, axial node 10.

CV 3450 calculates the stored energy (MJ) in Structure 1660, axial node 10. 
CV 3451 calculates the volumetric heat capacity $\left(\mathrm{MJ} / \mathrm{m}^{3}-\mathrm{K}\right)$ in Structure 1660, axial node 11. CV 3452 calculates the stored energy (MJ) in Structure 1660, axial node 11.

CV 3453 calculates the volumetric heat capacity $\left(\mathrm{MJ} / \mathrm{m}^{3}-\mathrm{K}\right)$ in Structure 1660, axial node 12. CV 3454 calculates the stored energy (MJ) in Structure 1660, axial node 12.

CV 3455 calculates the volumetric heat capacity $\left(\mathrm{MJ} / \mathrm{m}^{3}-\mathrm{K}\right)$ in Structure 1660, axial node 13. CV 3456 calculates the stored energy (MJ) in Structure 1660, axial node 13.

CV 3457 calculates the volumetric heat capacity $\left(\mathrm{MJ} / \mathrm{m}^{3}-\mathrm{K}\right)$ in Structure 1660, axial node 14. CV 3458 calculates the stored energy (MJ) in Structure 1660, axial node 14.

CV 3459 calculates the stored energy (MJ) in the outer reflector, Structure 1660.

CV 3461 calculates the volumetric heat capacity $\left(\mathrm{MJ} / \mathrm{m}^{3}-\mathrm{K}\right)$ in Structure 1750, axial node 1.

CV 3462 calculates the stored energy (MJ) in Structure 1750, axial node 1.

CV 3463 calculates the volumetric heat capacity $\left(\mathrm{MJ} / \mathrm{m}^{3}-\mathrm{K}\right)$ in Structure 1751, axial node 1.

CV 3464 calculates the stored energy (MJ) in Structure 1751, axial node 1.

CV 3466 calculates the stored energy (MJ) in the core region inside the core barrel.

CV 3468 calculates the stored energy (MJ) in the primary pressure vessel.

CV 3471 calculates the volumetric heat capacity $\left(\mathrm{MJ} / \mathrm{m}^{3}-\mathrm{K}\right)$ in Structure 2000, axial node 1.

CV 3472 calculates the stored energy (MJ) in Structure 2000, axial node 1.

CV 3473 calculates the volumetric heat capacity $\left(\mathrm{MJ} / \mathrm{m}^{3}-\mathrm{K}\right)$ in Structure 2000, axial node 2.

CV 3474 calculates the stored energy (MJ) in Structure 2000, axial node 2.

CV 3475 calculates the volumetric heat capacity $\left(\mathrm{MJ} / \mathrm{m}^{3}-\mathrm{K}\right)$ in Structure 2000, axial node 3.

CV 3476 calculates the stored energy (MJ) in Structure 2000, axial node 3.

CV 3477 calculates the volumetric heat capacity $\left(\mathrm{MJ} / \mathrm{m}^{3}-\mathrm{K}\right)$ in Structure 2000, axial node 4.

CV 3478 calculates the stored energy (MJ) in Structure 2000, axial node 4.

CV 3479 calculates the volumetric heat capacity $\left(\mathrm{MJ} / \mathrm{m}^{3}-\mathrm{K}\right)$ in Structure 2001, axial node 1.

CV 3480 calculates the stored energy (MJ) in Structure 2001, axial node 1.

CV 3481 calculates the volumetric heat capacity $\left(\mathrm{MJ} / \mathrm{m}^{3}-\mathrm{K}\right)$ in Structure 2001, axial node 2.

CV 3482 calculates the stored energy (MJ) in Structure 2001, axial node 2.

CV 3483 calculates the volumetric heat capacity $\left(\mathrm{MJ} / \mathrm{m}^{3}-\mathrm{K}\right)$ in Structure 2100, axial node 1.

CV 3484 calculates the stored energy (MJ) in Structure 2100, axial node 1.

CV 3485 calculates the volumetric heat capacity $\left(\mathrm{MJ} / \mathrm{m}^{3}-\mathrm{K}\right)$ in Structure 2150, axial node 1.

CV 3486 calculates the stored energy (MJ) in Structure 2150, axial node 1.

CV 3487 calculates the volumetric heat capacity $\left(\mathrm{MJ} / \mathrm{m}^{3}-\mathrm{K}\right)$ in Structure 2200, axial node 1.

CV 3488 calculates the stored energy (MJ) in Structure 2200, axial node 1.

CV 3489 calculates the volumetric heat capacity $\left(\mathrm{MJ} / \mathrm{m}^{3}-\mathrm{K}\right)$ in Structure 2201, axial node 1.

CV 3490 calculates the stored energy (MJ) in Structure 2201, axial node 1. 
CV 3501 calculates the volumetric heat capacity $\left(\mathrm{MJ} / \mathrm{m}^{3}-\mathrm{K}\right)$ in Structure 2250, axial node 1.

CV 3502 calculates the stored energy (MJ) in Structure 2250, axial node 1.

CV 3503 calculates the volumetric heat capacity $\left(\mathrm{MJ} / \mathrm{m}^{3}-\mathrm{K}\right)$ in Structure 2250, axial node 2.

CV 3504 calculates the stored energy (MJ) in Structure 2250, axial node 2.

CV 3505 calculates the volumetric heat capacity $\left(\mathrm{MJ} / \mathrm{m}^{3}-\mathrm{K}\right)$ in Structure 2250, axial node 3.

CV 3506 calculates the stored energy (MJ) in Structure 2250, axial node 3.

CV 3507 calculates the volumetric heat capacity $\left(\mathrm{MJ} / \mathrm{m}^{3}-\mathrm{K}\right)$ in Structure 2250, axial node 4.

CV 3508 calculates the stored energy (MJ) in Structure 2250, axial node 4.

CV 3509 calculates the volumetric heat capacity $\left(\mathrm{MJ} / \mathrm{m}^{3}-\mathrm{K}\right)$ in Structure 2250, axial node 5.

CV 3510 calculates the stored energy (MJ) in Structure 2250, axial node 5.

CV 3511 calculates the volumetric heat capacity $\left(\mathrm{MJ} / \mathrm{m}^{3}-\mathrm{K}\right)$ in Structure 2250, axial node 6.

CV 3512 calculates the stored energy (MJ) in Structure 2250, axial node 6.

CV 3513 calculates the volumetric heat capacity $\left(\mathrm{MJ} / \mathrm{m}^{3}-\mathrm{K}\right)$ in Structure 2250, axial node 7.

CV 3514 calculates the stored energy (MJ) in Structure 2250, axial node 7.

CV 3515 calculates the volumetric heat capacity $\left(\mathrm{MJ} / \mathrm{m}^{3}-\mathrm{K}\right)$ in Structure 2250, axial node 8.

CV 3516 calculates the stored energy (MJ) in Structure 2250, axial node 8.

CV 3517 calculates the volumetric heat capacity $\left(\mathrm{MJ} / \mathrm{m}^{3}-\mathrm{K}\right)$ in Structure 2250, axial node 9.

CV 3518 calculates the stored energy (MJ) in Structure 2250, axial node 9.

CV 3519 calculates the volumetric heat capacity $\left(\mathrm{MJ} / \mathrm{m}^{3}-\mathrm{K}\right)$ in Structure 2250, axial node 10.

CV 3520 calculates the stored energy (MJ) in Structure 2250, axial node 10.

CV 3521 calculates the volumetric heat capacity $\left(\mathrm{MJ} / \mathrm{m}^{3}-\mathrm{K}\right)$ in Structure 2250, axial node 11.

CV 3522 calculates the stored energy (MJ) in Structure 2250, axial node 11.

CV 3523 calculates the volumetric heat capacity $\left(\mathrm{MJ} / \mathrm{m}^{3}-\mathrm{K}\right)$ in Structure 2250, axial node 12.

CV 3524 calculates the stored energy (MJ) in Structure 2250, axial node 12.

CV 3525 calculates the volumetric heat capacity $\left(\mathrm{MJ} / \mathrm{m}^{3}-\mathrm{K}\right)$ in Structure 2250, axial node 13.

CV 3526 calculates the stored energy (MJ) in Structure 2250, axial node 13.

CV 3527 calculates the volumetric heat capacity $\left(\mathrm{MJ} / \mathrm{m}^{3}-\mathrm{K}\right)$ in Structure 2250, axial node 14.

CV 3528 calculates the stored energy (MJ) in Structure 2250, axial node 14.

CV 3529 calculates the volumetric heat capacity $\left(\mathrm{MJ} / \mathrm{m}^{3}-\mathrm{K}\right)$ in Structure 2250, axial node 15.

CV 3530 calculates the stored energy (MJ) in Structure 2250, axial node 15.

CV 3531 calculates the volumetric heat capacity $\left(\mathrm{MJ} / \mathrm{m}^{3}-\mathrm{K}\right)$ in Structure 2250, axial node 16.

CV 3532 calculates the stored energy (MJ) in Structure 2250, axial node 16.

CV 3533 calculates the volumetric heat capacity $\left(\mathrm{MJ} / \mathrm{m}^{3}-\mathrm{K}\right)$ in Structure 2250, axial node 17.

CV 3534 calculates the stored energy (MJ) in Structure 2250, axial node 17.

CV 3535 calculates the volumetric heat capacity $\left(\mathrm{MJ} / \mathrm{m}^{3}-\mathrm{K}\right)$ in Structure 2250, axial node 18. 
CV 3536 calculates the stored energy (MJ) in Structure 2250, axial node 18.

CV 3537 calculates the volumetric heat capacity $\left(\mathrm{MJ} / \mathrm{m}^{3}-\mathrm{K}\right)$ in Structure 2250, axial node 19. CV 3538 calculates the stored energy (MJ) in Structure 2250, axial node 19.

CV 3539 calculates the volumetric heat capacity $\left(\mathrm{MJ} / \mathrm{m}^{3}-\mathrm{K}\right)$ in Structure 2250, axial node 20. CV 3540 calculates the stored energy (MJ) in Structure 2250, axial node 20.

CV 3541 calculates the volumetric heat capacity $\left(\mathrm{MJ} / \mathrm{m}^{3}-\mathrm{K}\right)$ in Structure 2250, axial node 21. CV 3542 calculates the stored energy (MJ) in Structure 2250, axial node 21.

CV 3543 calculates the volumetric heat capacity $\left(\mathrm{MJ} / \mathrm{m}^{3}-\mathrm{K}\right)$ in Structure 2250, axial node 22. CV 3544 calculates the stored energy (MJ) in Structure 2250, axial node 22.

CV 3546 calculates the stored energy (MJ) in the steam generator tubes, Structure 2250.

CV 3547 calculates the volumetric heat capacity $\left(\mathrm{MJ} / \mathrm{m}^{3}-\mathrm{K}\right)$ in Structure 2251, axial node 1. CV 3548 calculates the stored energy (MJ) in Structure 2251, axial node 1.

CV 3549 calculates the volumetric heat capacity $\left(\mathrm{MJ} / \mathrm{m}^{3}-\mathrm{K}\right)$ in Structure 2251, axial node 2. CV 3550 calculates the stored energy (MJ) in Structure 2251, axial node 2.

CV 3551 calculates the volumetric heat capacity $\left(\mathrm{MJ} / \mathrm{m}^{3}-\mathrm{K}\right)$ in Structure 2280, axial node 1. CV 3552 calculates the stored energy (MJ) in Structure 2280, axial node 1.

CV 3553 calculates the volumetric heat capacity $\left(\mathrm{MJ} / \mathrm{m}^{3}-\mathrm{K}\right)$ in Structure 2300, axial node 1. CV 3554 calculates the stored energy (MJ) in Structure 2300, axial node 1.

CV 3555 calculates the volumetric heat capacity $\left(\mathrm{MJ} / \mathrm{m}^{3}-\mathrm{K}\right)$ in Structure 2350, axial node 1. CV 3556 calculates the stored energy (MJ) in Structure 2350, axial node 1.

CV 3557 calculates the volumetric heat capacity $\left(\mathrm{MJ} / \mathrm{m}^{3}-\mathrm{K}\right)$ in Structure 2400, axial node 1. CV 3558 calculates the stored energy (MJ) in Structure 2400, axial node 1.

CV 3559 calculates the volumetric heat capacity $\left(\mathrm{MJ} / \mathrm{m}^{3}-\mathrm{K}\right)$ in Structure 2500, axial node 1. CV 3560 calculates the stored energy (MJ) in Structure 2500, axial node 1.

CV 3561 calculates the volumetric heat capacity $\left(\mathrm{MJ} / \mathrm{m}^{3}-\mathrm{K}\right)$ in Structure 2500, axial node 2. CV 3562 calculates the stored energy (MJ) in Structure 2500, axial node 2.

CV 3563 calculates the volumetric heat capacity $\left(\mathrm{MJ} / \mathrm{m}^{3}-\mathrm{K}\right)$ in Structure 2500, axial node 3. CV 3564 calculates the stored energy (MJ) in Structure 2500, axial node 3.

CV 3565 calculates the volumetric heat capacity $\left(\mathrm{MJ} / \mathrm{m}^{3}-\mathrm{K}\right)$ in Structure 2580, axial node 1. CV 3566 calculates the stored energy (MJ) in Structure 2580, axial node 1.

CV 3567 calculates the volumetric heat capacity $\left(\mathrm{MJ} / \mathrm{m}^{3}-\mathrm{K}\right)$ in Structure 2600, axial node 1. CV 3568 calculates the stored energy (MJ) in Structure 2600, axial node 1.

CV 3569 calculates the volumetric heat capacity $\left(\mathrm{MJ} / \mathrm{m}^{3}-\mathrm{K}\right)$ in Structure 2700, axial node 1.

CV 3570 calculates the stored energy (MJ) in Structure 2700, axial node 1.

CV 3571 calculates the volumetric heat capacity $\left(\mathrm{MJ} / \mathrm{m}^{3}-\mathrm{K}\right)$ in Structure 2700, axial node 2. 
CV 3572 calculates the stored energy (MJ) in Structure 2700, axial node 2.

CV 3573 calculates the volumetric heat capacity $\left(\mathrm{MJ} / \mathrm{m}^{3}-\mathrm{K}\right)$ in Structure 2700, axial node 3.

CV 3574 calculates the stored energy (MJ) in Structure 2700, axial node 3.

CV 3575 calculates the volumetric heat capacity $\left(\mathrm{MJ} / \mathrm{m}^{3}-\mathrm{K}\right)$ in Structure 2700, axial node 4.

CV 3576 calculates the stored energy (MJ) in Structure 2700, axial node 4.

CV 3577 calculates the stored energy (MJ) in the PCS piping.

CV 3578 calculates the stored energy (MJ) in the PCS.

\section{SPLIT HOT DUCT MODEL}

An alternate model of the hot duct, outlet plenum, and RCST was developed for use in the doubleended hot duct break simulations. The phenomenon of interest in this scenario is single-phase countercurrent flow in the hot duct, with hot (or lighter) gas flowing from the pressure vessel outlet plenum to the RCST along the top of the pipe, with colder (or denser) gas returning from the RCST to the outlet plenum along the bottom of the pipe. Since the code cannot simulate this directly in a single control volume, the nodalization must be changed. Figure 7 shows the revised nodalization.

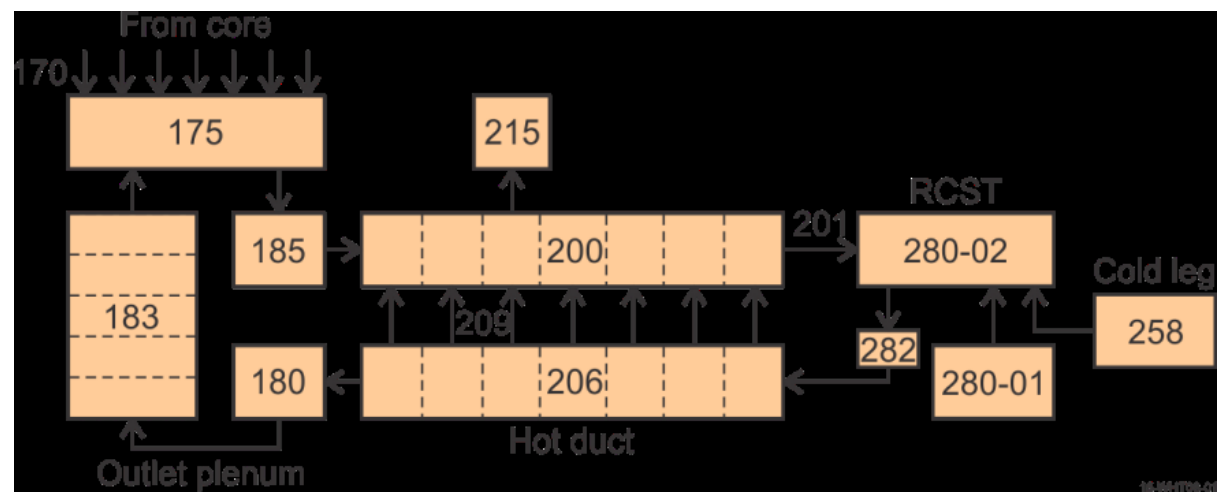

Figure 7. Revised nodalization for the split hot duct input model.

The basic approach is to split the hot duct into top and bottom halves (Components 200 and 206). The break valve (Component 205) is removed from the model, and the piping between the valve and the RCST (Component 210) is now included in the pipe. Each of the cells in the two pipes is connected by crossflow junctions (Component 209) to allow the pressure to equalize along the pipe. The pipe heat structures are also split into top and bottom halves; conduction between the two halves is not modeled.

The outlet plenum is changed from one component to four, with the objective being to allow the plenum to fill with the returning gas before it interacts with the hotter gas in the core. The existing volume (Component 175) is reduced in length so that no changes in the core channel connections are needed. Component 185 represents a small portion of the outlet plenum volume, and connects Component 175 to the top of the hot duct. Component 180 represents a small portion of the outlet plenum volume and is connected to the bottom half of the hot duct. There is no direct connection between Components 180 and 185. Component 183 represents most of the outlet plenum volume. It is connected to Component 180 at the inlet and Component 175 at the outlet. Only one heat structure, the plenum bottom plate, is changed. Other structures were not changed in that their response was not expected to be significant enough to warrant the effort of splitting them into a number of axial cells corresponding to the nodalization of pipe Component 183.

The second volume in the RCST is modified so that it connects to the top half of the hot duct while maintaining the connection to the cold leg side of the break (which is not renodalized). A small volume (Component 282) is added to make the connection from this second volume to the bottom half of the hot 
duct. The intent of the original model was for the second volume in the RCST to include all of the tank volume involved in the fluid mixing. This nodalization maintains that. By making the added component very small, its conditions should be very close to those in the mixing volume. No changes are needed for the heat structures.

A number of control variables were changed or added as a result of the renodalization.

Brief descriptions of the altered components are provided below.

Component 175 represents the top $2 \mathrm{~cm}$ of the pressure vessel outlet plenum. It is modeled as a branch with two junctions, both connected to the outlet. The first connects the outlet of this component to the inlet of Component 185, and the second connects the outlet of Component 183 to the outlet of this component. This component is also connected to all of the core channels by Component 170 .

Component 180 represents a portion of the outlet plenum near the bottom half of the hot duct. It is modeled as a branch component with two junctions. The first junction connects the outlet of the bottom half of the hot duct, Component 206, to the middle of this component, and the second junction connects the outlet of this component to the inlet of Component 183.

Component 183 is a five-volume pipe representing the bulk of the outlet plenum. The number of pipe cells can be altered to try to reduce the effect of numerical diffusion in the calculations.

Component 185 represents a portion of the outlet plenum near the top half of the hot duct. It is modeled as a branch with one junction, connecting the middle of this component to the inlet of the top half of the hot duct, Component 200.

Component 200 is a pipe representing the top half of the hot duct connecting the pressure vessel outlet plenum to the RCST. It has seven internal volumes, the third of which is connected to the hot leg piping leading to the steam generator. The flow area is half that of the full pipe, the hydraulic diameter is the same as that of the full pipe, and the z-direction length is half the pipe diameter. The break valve loss coefficient is maintained at the fifth internal junction.

Component 201 connects the outlet of Component 200 to the middle of Component 280-02. It is modeled as a single junction. The smooth area change model is used, with forward and reverse loss coefficients of 1.0 and 0.5 , respectively.

Component 206 is a pipe representing the bottom half of the hot duct. It has seven internal volumes, and is oriented so that positive flow is from the RCST to the outlet plenum. The flow area is half that of the full pipe, and the hydraulic diameter is the same as that of the full pipe. The z-direction length is less than half the pipe diameter, so that elevation closure is maintained with the connection to the outlet plenum. The break valve loss coefficient is maintained at the second internal junction.

Component 209 is a multiple junction component connecting the two halves of the hot duct. The seven junctions are oriented from the top of the volumes in Component 206 to the bottom of the volumes in Component 200. The junction area is set to the product of the pipe cell length and the diameter. Small loss coefficients of 0.1 are included to provide some resistance to unphysical recirculating flows that the code has had a tendency to predict in some previous calculations with similar geometry.

Component 280 is the RCST. The second volume has been compressed with this renodalization; it has the same volume as before, but now has a height of $0.14898 \mathrm{~m}$ instead of $4.0831 \mathrm{~m}$. This allows the top of the hot duct to connect to the middle of the volume while the cold leg break connects to the bottom of the volume. All other input for the component is unchanged.

Component 282 is a small portion of the RCST between the inlet to Volume 280-02 and the inlet to the bottom half of the hot duct. It is modeled as a branch with two junctions: the first junction connects the inlet of Component 280-02 to the inlet of this component, and the second junction connects the outlet of this component to the inlet of Component 206. The area of this component is arbitrarily set to a small value, so that its fluid conditions should be nearly the same as those in Component 280-02, the mixed volume of the RCST, but not so small that its Courant limit affects the time step during the transient. 
Forward and reverse loss coefficients of 0.5 and 1.0, respectively, are used at the connection to the hot duct. No heat structures are associated with this component.

Structure 1750 represents the outlet plenum lower plate. The only change from the original structure is that the left boundary volume is changed to 183010000 (from 175010000).

Structure 2000 represents a portion of the top half of the hot duct. It is identical to the original structure, except that the area factor is cut in half.

Structure 2001 represents a portion of the top half of the hot duct. It is identical to the original structure, except that the area factor is cut in half.

Structure 2002 represents the portion of the top half of the hot duct between the break valve and the RCST. It is identical to Structure 2100, except that the area factor is cut in half.

Structure 2060 represents the portion of the bottom half of the hot duct between the break valve and the RCST. It is identical to Structure 2100, except that the area factor is cut in half.

Structure 2061 represents a portion of the bottom half of the hot duct. It is identical to Structure 2001, except for the left boundary volumes.

Structure 2062 represents a portion of the bottom half of the hot duct. It is identical to Structure 2000, except for the left boundary volumes.

CV 1401 calculates the environmental heat loss (W) from Structures 2001 and 2061.

CV 1615 calculates the total fluid mass $(\mathrm{kg})$ in the hot leg, Components 200 and 206.

CV 1621 calculates the total fluid mass (kg) in the RCST, Components 258, 280, and 282.

CV 3472 calculates the stored energy (MJ) in Structure 2000, axial node 1.

CV 3474 calculates the stored energy (MJ) in Structure 2000, axial node 2.

CV 3476 calculates the stored energy (MJ) in Structure 2000, axial node 3.

CV 3478 calculates the stored energy (MJ) in Structure 2000, axial node 4.

CV 3480 calculates the stored energy (MJ) in Structure 2001, axial node 1.

CV 3482 calculates the stored energy (MJ) in Structure 2001, axial node 2.

CV 3483 calculates the volumetric heat capacity $\left(\mathrm{MJ} / \mathrm{m}^{3}-\mathrm{K}\right)$ in Structure 2002, axial node 1.

CV 3484 calculates the stored energy (MJ) in Structure 2002, axial node 1.

CV 3577 calculates the stored energy (MJ) in the primary coolant system piping.

CV 3581 calculates the volumetric heat capacity $\left(\mathrm{MJ} / \mathrm{m}^{3}-\mathrm{K}\right)$ in Structure 2060, axial node 1.

CV 3582 calculates the stored energy (MJ) in Structure 2060, axial node 1.

CV 3583 calculates the volumetric heat capacity $\left(\mathrm{MJ} / \mathrm{m}^{3}-\mathrm{K}\right)$ in Structure 2061, axial node 1.

CV 3584 calculates the stored energy (MJ) in Structure 2061, axial node 1.

CV 3585 calculates the volumetric heat capacity $\left(\mathrm{MJ} / \mathrm{m}^{3}-\mathrm{K}\right)$ in Structure 2061, axial node 2.

CV 3586 calculates the stored energy (MJ) in Structure 2061, axial node 2.

CV 3587 calculates the volumetric heat capacity $\left(\mathrm{MJ} / \mathrm{m}^{3}-\mathrm{K}\right)$ in Structure 2062, axial node 1.

CV 3588 calculates the stored energy (MJ) in Structure 2062, axial node 1.

CV 3589 calculates the volumetric heat capacity $\left(\mathrm{MJ} / \mathrm{m}^{3}-\mathrm{K}\right)$ in Structure 2062, axial node 2.

CV 3590 calculates the stored energy (MJ) in Structure 2062, axial node 2. 
CV 3591 calculates the volumetric heat capacity $\left(\mathrm{MJ} / \mathrm{m}^{3}-\mathrm{K}\right)$ in Structure 2062, axial node 3. CV 3592 calculates the stored energy (MJ) in Structure 2062, axial node 3.

CV 3593 calculates the volumetric heat capacity $\left(\mathrm{MJ} / \mathrm{m}^{3}-\mathrm{K}\right)$ in Structure 2062, axial node 4. CV 3594 calculates the stored energy (MJ) in Structure 2062, axial node 4. 


\section{NODALIZATION STUDY}

All of the calculations have been performed at full power $(2.2 \mathrm{MW})$ with helium as the primary coolant.

The steam generator was originally nodalized with 12 volumes in the tubes, six up and six down, with the bend in the tubes in Cells 6 and 7. The boiler and downcomer regions of the secondary side of the steam generator were modeled with node boundaries at the same elevations. A sensitivity calculation was performed in which the number of cells in the tubes was increased to 22, by doubling the number of nodes in the straight sections and leaving the bend alone; this region of the tubes was in single-phase vapor convection heat transfer on the secondary side anyway, so doubling the nodes here would provide no benefit, but would further reduce the Courant limit. The boiler and downcomer nodalizations were also increased to match the node boundaries on the primary side. For the first and last cells in the tubes, rather than dividing the tube cell length in two, the cell boundary was located at an elevation that divided the first cell in the boiler into equal length cells. This makes the first cell in the tubes longer than the second, because the first cell includes the length of tube in the tube sheet, and results in the system Courant limit being located in the second tube cell. The more detailed model produced more stable results than the coarser nodalization.

With the steam generator modeled, the Courant limit is a little above $0.002 \mathrm{~s}$, determined by the second volume in the tubes. Without the steam generator, the Courant limit is about $0.0047 \mathrm{~s}$. 


\section{COMPUTER FILES}

Computer files associated with the input file are listed in Table 1. In addition to the file name, a description of the file is included, along with the checksum value (gnu command "cksum").

Table 1. Listing of computer files.

\begin{tabular}{|l|l|l|}
\hline File name & Description & Checksum value \\
\hline httf-base.i & RELAP5-3D input file & 2319698913 \\
\hline $\begin{array}{l}\text { HTTF base } \\
\text { 2018-05-30QA.xlsx }\end{array}$ & $\begin{array}{l}\text { Workbook containing the final version of the model and } \\
\text { supporting calculations }\end{array}$ & 2084154050 \\
\hline $\begin{array}{l}\text { HTTF base } \\
\text { 2015-02-10QA.xlsx }\end{array}$ & $\begin{array}{l}\text { Excel workbook containing the version of the model and } \\
\text { supporting calculations for the initial quality assurance } \\
\text { review }\end{array}$ & 3765750314 \\
\hline HTTF base & $\begin{array}{l}\text { Excel workbook containing the version of the model and } \\
\text { supporting calculations after the initial quality assurance } \\
\text { review }\end{array}$ & 392234047 \\
\hline $\begin{array}{l}\text { HTTF base } \\
\text { 2017-03-23QA.xlsx }\end{array}$ & $\begin{array}{l}\text { Excel workbook containing the version of the model and } \\
\text { supporting calculations for the second quality assurance } \\
\text { review }\end{array}$ & 2735886914 \\
\hline $\begin{array}{l}\text { HTTF base } \\
\text { 2017-03-30QA.xlsx }\end{array}$ & $\begin{array}{l}\text { Excel workbook containing the version of the model and } \\
\text { supporting calculations after the second quality assurance } \\
\text { review }\end{array}$ & 1132593988 \\
\hline $\begin{array}{l}\text { HTTF base } \\
\text { 2018-05-16QA.xlsx }\end{array}$ & $\begin{array}{l}\text { Excel workbook containing the version of the model and } \\
\text { supporting calculations for the final quality assurance } \\
\text { review }\end{array}$ & 921649429 \\
\hline
\end{tabular}




\section{REFERENCES}

ASTM International, 2014, Standard Practice for Testing Graphite and Boronated Graphite Materials for High-Temperature Gas-Cooled Nuclear Reactor Components, C781-08, July 2014.

Baumeister, T., E. A. Avallone, and T. Baumeister III, eds., 1978, Marks' Standard Handbook for Mechanical Engineers, Eighth Edition, New York: McGraw-Hill, 1978.

Cadell, S. R., 2011, HTTF Ceramic Component Analysis and Experimental Test Apparatus, January 4, 2011.

Crane Co., 1988, Flow of Fluids through Valves, Fittings, and Pipe, Technical Paper No. 410, 1988.

DOE, 1986, Preliminary Safety Information Document for the Standard MHTGR, Stone \& Webster Engineering Corp., report HTGR-86-024.

Gutowska, Izabela (izabela.gutowska@oregonstate.edu), “HTTF figures,” Paul Bayless (paul.bayless@inl.gov), May 24, 2018.

Hertel, Matthew A. (hertelm@onid.oregonstate.edu), "Insulation Info for HTTF," Brian Woods (woodsb@engr.orst.edu), December 12, 2014.

Hertel, Matthew A. (hertelm@onid.oregonstate.edu), "Insulation Info for HTTF," Paul Bayless (paul.bayless@inl.gov), January 6, 2015.

Idelchik, I. E., 1994, Handbook of Hydraulic Resistance, $3^{\text {rd }}$ Edition, Boca Raton: CRC Press, 1994.

INL, 2018, RELAP5-3D Code Manual, Volumes I-V, INL/MIS-15-36723, Rev. 4.4, June 2018.

Larsen, R., 2012, Normal Emissivity of Two Samples - A Report to Oregon State University, TPRL 4813, Thermophysical Properties Research Laboratory, Inc., January 2012.

Lewco Specialty Products, Inc., High Temperature Insulation Textiles \& Accessories for Industry, undated.

McEligot, D.M. and G.E. McCreery, 2004, Scaling Studies and Conceptual Experiment Designs for NGNP CFD Assessment, INEEL/EXT-04-02502, November 2004.

Mueller Temp-Plate purchase order, Quote \# T17039-3.1, April 25, 2011.

Paul Mueller Co., 2011, All About Temp-Plate ${ }^{\circledR}$, TP-108-15, 2011.

Roxul Inc., 2014, Enerwrap ${ }^{\circledR}$ MA 960 Product Data Sheet, June 5, 2014.

Siefken, L. J. et al., 2001, SCDAP/RELAP5/MOD 3.3 Code Manual: MATPRO - A Library of Materials Properties for Light-Water-Reactor Accident Analysis, NUREG/CR-6150, INEL-96-0422, Vol. 4, Rev. 2, January 2001.

Woods, Brian, 2017, OSU High Temperature Test Facility Technical Design Report, OSU-HTTFTECH-003-R1, Rev. 1, February 2017.

Woods, Brian (woodsb@engr.orst.edu), “Upper Head Insulation,” Paul Bayless (paul.bayless@inl.gov), May 17, 2017.

Woods, Brian, 2018, Instrumentation Plan for the OSU High Temperature Test Facility, OSU-HTTFTECH-002-R3, Rev. 3, March 2018.

http://www.EngineeringToolBox.com, "Solids - Specific Heats," Web page visited December 15, 2014.

https://www.engineeringtoolbox.com/emissivity-coefficients-d_447.html, web page visited October 19, 2017. 
Table 2. HTTF drawings used in developing the input model.

\begin{tabular}{|c|c|c|c|}
\hline Drawing Number & Sheet & Revision & Date \\
\hline OSU-HTTF-CORE-DWG-001-R1 & 1 & 1 & $3 / 13 / 2018$ \\
\hline OSU-HTTF-CORE-DWG-004-R0 & 1 & A & $4 / 1 / 2013$ \\
\hline OSU-HTTF-CORE-DWG-004-R0 & 2 & $\mathrm{~A}$ & $4 / 1 / 2013$ \\
\hline OSU-HTTF-CORE-DWG-005-R0 & 1 & A & $4 / 1 / 2013$ \\
\hline OSU-HTTF-CORE-DWG-005-R0 & 4 & A & $4 / 1 / 2013$ \\
\hline OSU-HTTF-CORE-DWG-006-R0 & 1 & A & $4 / 1 / 2013$ \\
\hline OSU-HTTF-CORE-DWG-006-R0 & 1 & A & $4 / 1 / 2013$ \\
\hline OSU-HTTF-CORE-DWG-011-R0 & 1 & A & $4 / 1 / 2013$ \\
\hline OSU-HTTF-CORE-DWG-012-R0 & 1 & A & $4 / 1 / 2013$ \\
\hline OSU-HTTF-CORE-DWG-013-R0 & 1 & A & $4 / 1 / 2013$ \\
\hline OSU-HTTF-CORE-DWG-014-R0 & 1 & A & $4 / 1 / 2013$ \\
\hline OSU-HTTF-CORE-DWG-015-R0 & 1 & A & $4 / 1 / 2013$ \\
\hline OSU-HTTF-CORE-DWG-016-R0 & 1 & A & $4 / 1 / 2013$ \\
\hline OSU-HTTF-CORE-DWG-016-R0 & 2 & A & $4 / 1 / 2013$ \\
\hline OSU-HTTF-CORE-DWG-016-R0 & 3 & A & $4 / 1 / 2013$ \\
\hline OSU-HTTF-CORE-DWG-017-R0 & 1 & A & $4 / 1 / 2013$ \\
\hline OSU-HTTF-CORE-DWG-019-R0 & 1 & A & $4 / 1 / 2013$ \\
\hline OSU-HTTF-CORE-DWG-021-R0 & 1 & A & $4 / 1 / 2013$ \\
\hline OSU-HTTF-CORE-DWG-021-R0 & 2 & A & $4 / 1 / 2013$ \\
\hline OSU-HTTF-CORE-DWG-021-R0 & 3 & A & $4 / 1 / 2013$ \\
\hline OSU-HTTF-CORE-DWG-026-R0 & 1 & 0 & $4 / 19 / 2018$ \\
\hline OSU-HTTF-GEN-DWG-001B & 2 & 1 & $6 / 1 / 2017$ \\
\hline OSU-HTTF-GEN-DWG-009A & 1 & 0 & $11 / 21 / 2016$ \\
\hline OSU-HTTF-GEN-DWG-009C & 3 & 0 & $11 / 21 / 2016$ \\
\hline OSU-HTTF-GEN-DWG-009D & 4 & 0 & $11 / 21 / 2016$ \\
\hline OSU-HTTF-GEN-DWG-009E & 5 & 0 & $11 / 21 / 2016$ \\
\hline OSU-HTTF-GEN-DWG-009F & 6 & 0 & $11 / 21 / 2016$ \\
\hline OSU-HTTF-GEN-DWG-009G & 7 & 0 & $11 / 21 / 2016$ \\
\hline OSU-HTTF-GEN-DWG-009H & 8 & 0 & $11 / 21 / 2016$ \\
\hline OSU-HTTF-PRIM-DWG-002 & 1 & 1 & $2 / 15 / 2018$ \\
\hline OSU-HTTF-PRIM-DWG-002 & 3 & 1 & $2 / 15 / 2018$ \\
\hline OSU-HTTF-PRIM-DWG-002 & 5 & 1 & $2 / 15 / 2018$ \\
\hline OSU-HTTF-PRIM-DWG-002 & 6 & 1 & $2 / 15 / 2018$ \\
\hline OSU-HTTF-PRIM-DWG-002 & 7 & 1 & $2 / 15 / 2018$ \\
\hline OSU-HTTF-PRIM-DWG-002 & 8 & 1 & $2 / 15 / 2018$ \\
\hline OSU-HTTF-PRIM-DWG-002 & 9 & 1 & $2 / 15 / 2018$ \\
\hline OSU-HTTF-PRIM-DWG-004A & 1 & 0 & $11 / 21 / 2016$ \\
\hline OSU-HTTF-PRIM-DWG-005A & 1 & 0 & $11 / 21 / 2016$ \\
\hline
\end{tabular}


Table 2. continued

\begin{tabular}{cccc}
\hline Drawing Number & Sheet & Revision & Date \\
\hline OSU-HTTF-PRIM-DWG-011 & 1 & 2 & $3 / 14 / 2018$ \\
OSU-HTTF-PRIM-DWG-012 & 1 & 1 & $3 / 1 / 2018$ \\
OSU-HTTF-PRIM-DWG-019 & 1 & 0 & $11 / 20 / 2017$ \\
OSU-HTTF-RCCS-DWG-006A & 1 & 0 & $11 / 21 / 2016$ \\
OSU-HTTF-RCCS-DWG-007A & 1 & 0 & $11 / 21 / 2016$ \\
OSU-HTTF-RCSS-DWG-008A & 1 & 0 & $11 / 21 / 2016$ \\
OSU-HTTF-RCSS-DWG-008C & 3 & 0 & $11 / 21 / 2016$ \\
OSU-HTTF-SEC-DWG-003A & 1 & 0 & $11 / 21 / 2016$ \\
OSU-HTTF-SEC-DWG-003B & 2 & 0 & $11 / 21 / 2016$ \\
OSU-HTTF-SEC-DWG-003C & 3 & 0 & $11 / 21 / 2016$ \\
\hline
\end{tabular}


Appendix A

Input Model Listing 


\section{Appendix A. Input Model Listing}

$=$ HTTF system model

* base model

*

* This model represents the High Temperature Test Facility (HTTF) (prismatic core

* design), which is being built at Oregon State University to support the Advanced

* Reactor Technologies program.

* This is a full system model developed to perform assessment calculations using

* experiment data from the facility. The model includes the primary pressure vessel

* and internals, the primary coolant system, the secondary coolant system, and

* the reactor cavity cooling system (RCCS).

* The core is modeled with three parallel channels, each representing one of the

* three rings in the annular heated region. The heater rods radiate to the

* surrounding ceramic material. The helium gap between the rods and the

* ceramic is included.

$\star$

* The central reflector is modeled in three pieces: a solid inner ring, a middle ring

* with coolant holes, and an outer solid ring next to the heated region.

* The side reflector is also modeled with a solid ring next to the heated portion of

* the core, a middle ring with coolant holes, and a solid ring outside it. The

* permanent side reflector is also modeled as a solid ring.

* The primary coolant system includes the hot and cold ducts, the steam

* generator plenums and tubes, the gas circulator, pressure relief and

* depressurization valves, the check valve at the steam generator inlet, the loop

* isolation valve, and connecting piping. Break valves at the end of the hot duct and

* in the cold leg piping connect to the reactor cavity simulation tank (RCST).

* The secondary coolant system includes the feedwater pump, steam generator,

* the steam line pressure control valve, the pressure relief valve, and associated

* piping. The feedwater piping is not modeled explicitly: the approximate length and

* correct elevation change are input, as the flow resistance of the feedwater piping

* is not important to the plant response.

*

* The RCCS is modeled as a set of panels completely surrounding the primary

* pressure vessel. Flowing water cools the front side of the panels, and natural

* convection heat transfer cools the back side.

* The tank that provides water to the feedwater and RCCS pumps is modeled,

* along with its water supply, drain valve, and vent line.

* The air cavity between the primary pressure vessel and the RCCS panels is

* also included in the model.

* Trips and control systems are provided for the circulator, the feedwater and RCCS

* pumps, the break and loop isolation valves, the pressure relief and depressurization

* valves, and the tank water supply and drain valves.

$\star$

* All of the vertically-oriented heat structures have 2-D conduction turned on where

* possible. Axial conduction between the core and the top and

* bottom reflectors, and in three of the four solid reflector regions, is modeled

* using conduction enclosures.

*

* Core power of $2.2 \mathrm{MW}$.

* Inlet coolant temperature of $258.6 \mathrm{C}$.

* Outlet coolant temperature of $687 \mathrm{C}$. 


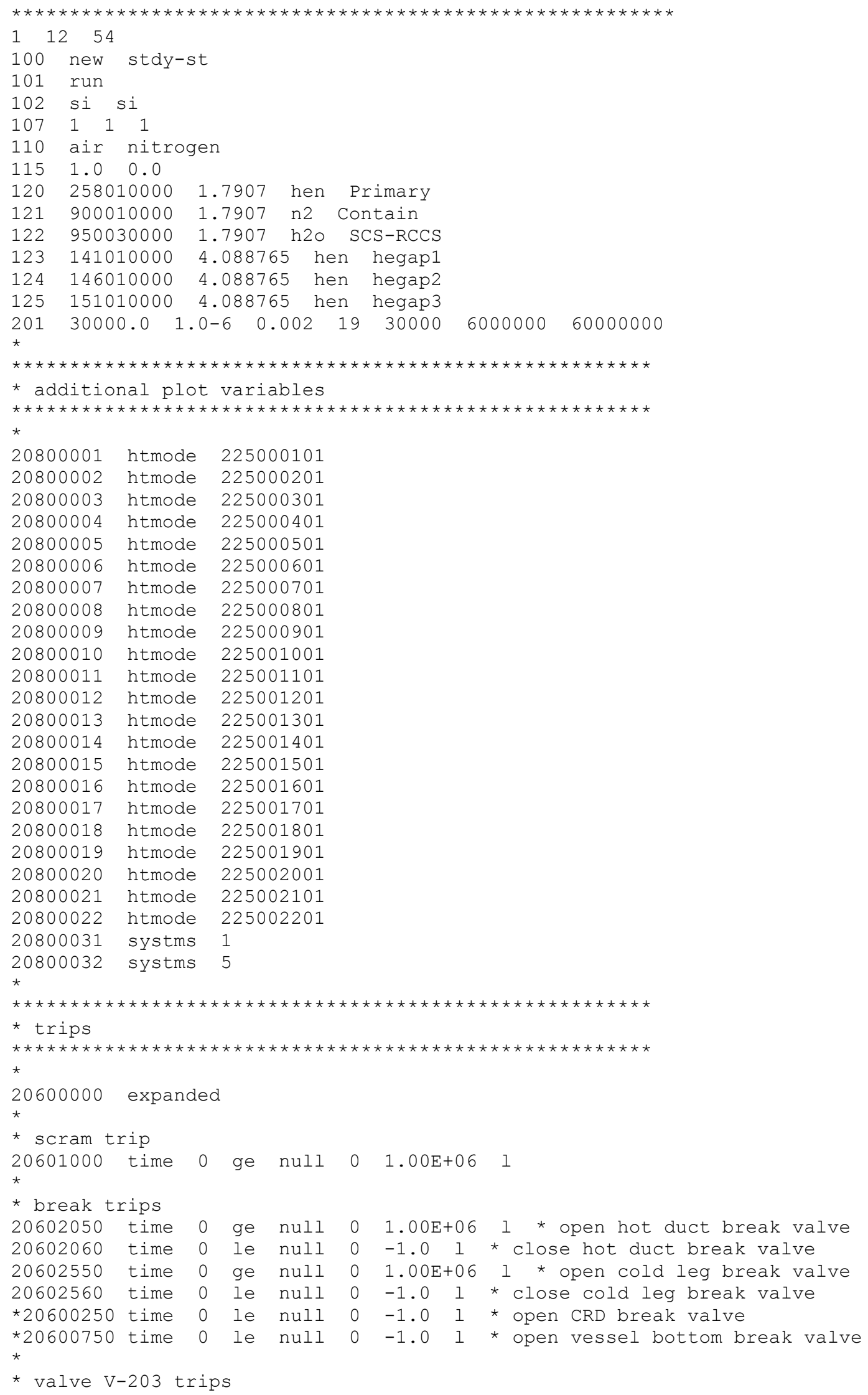




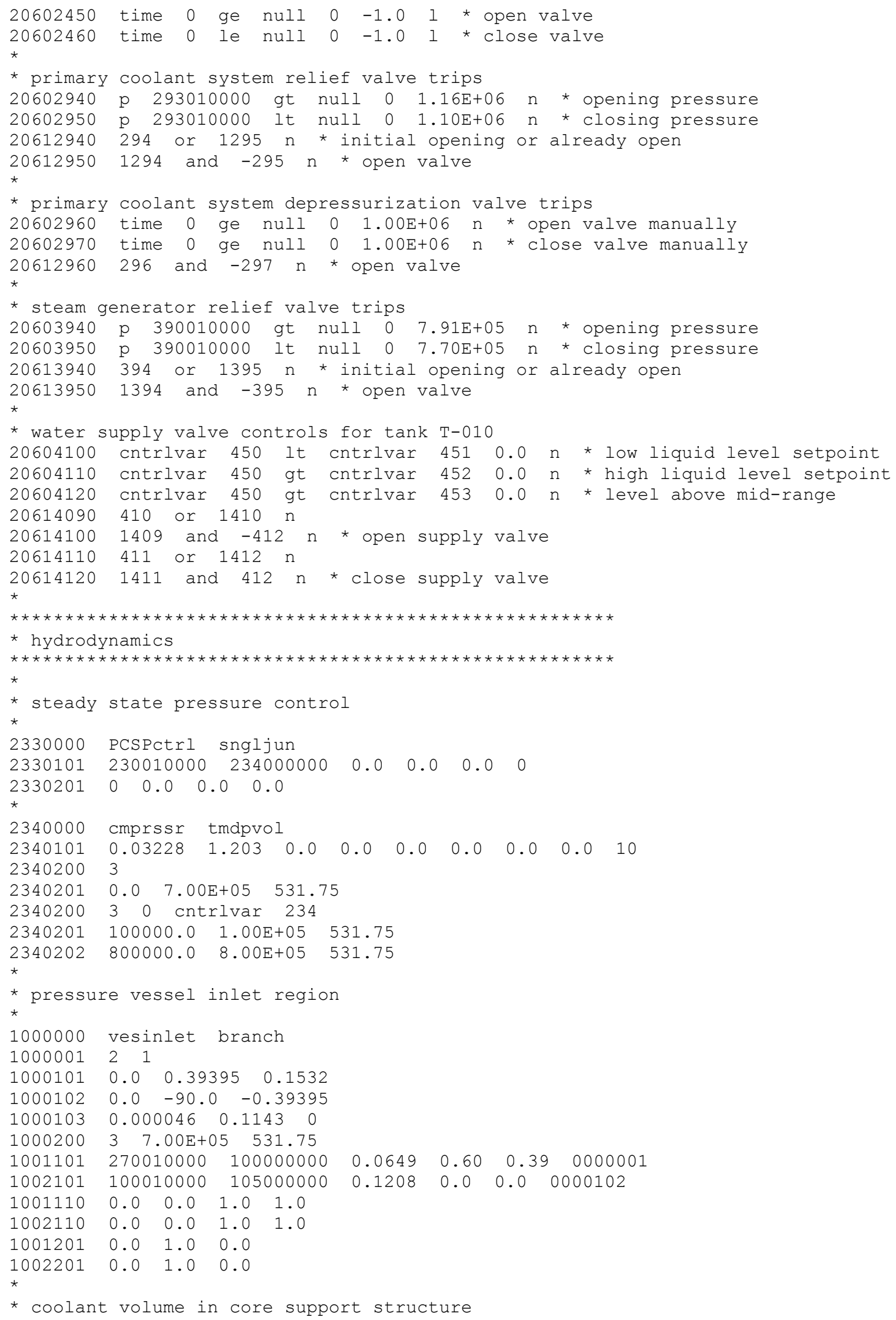




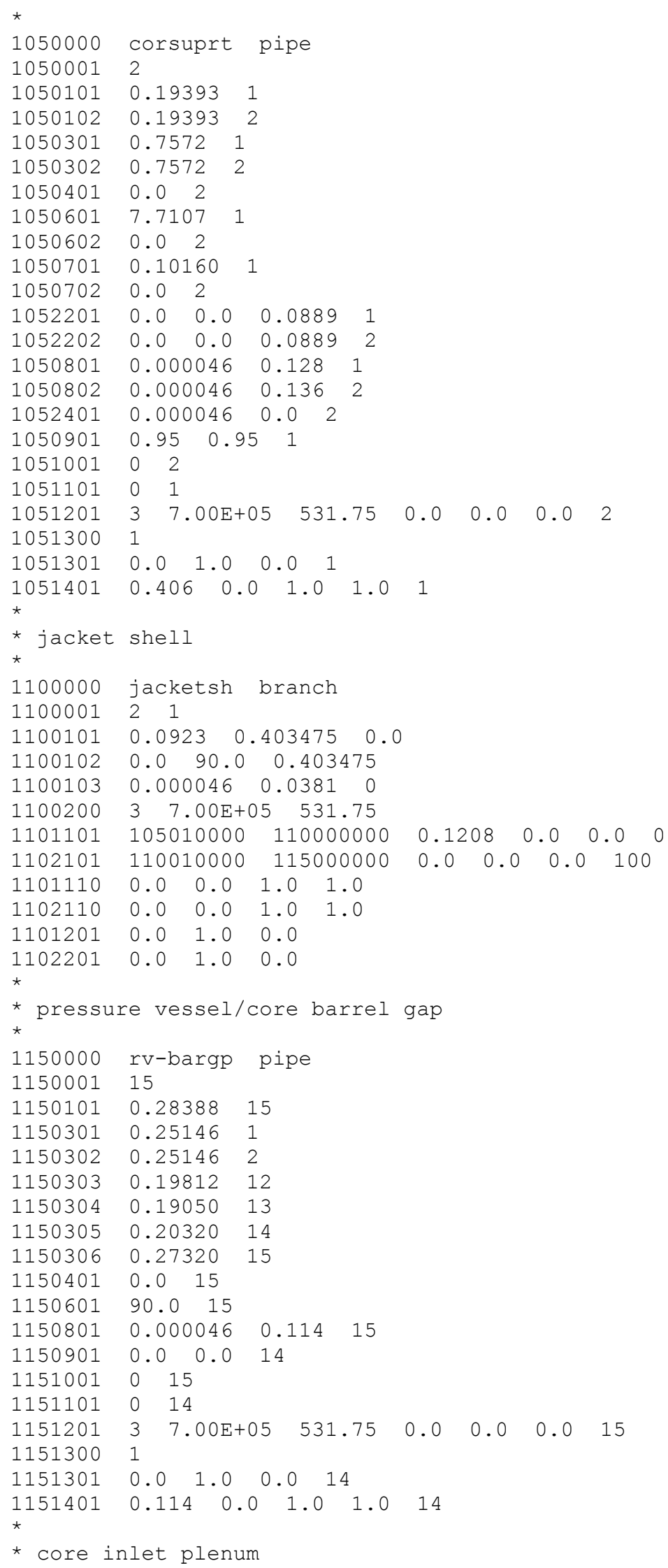




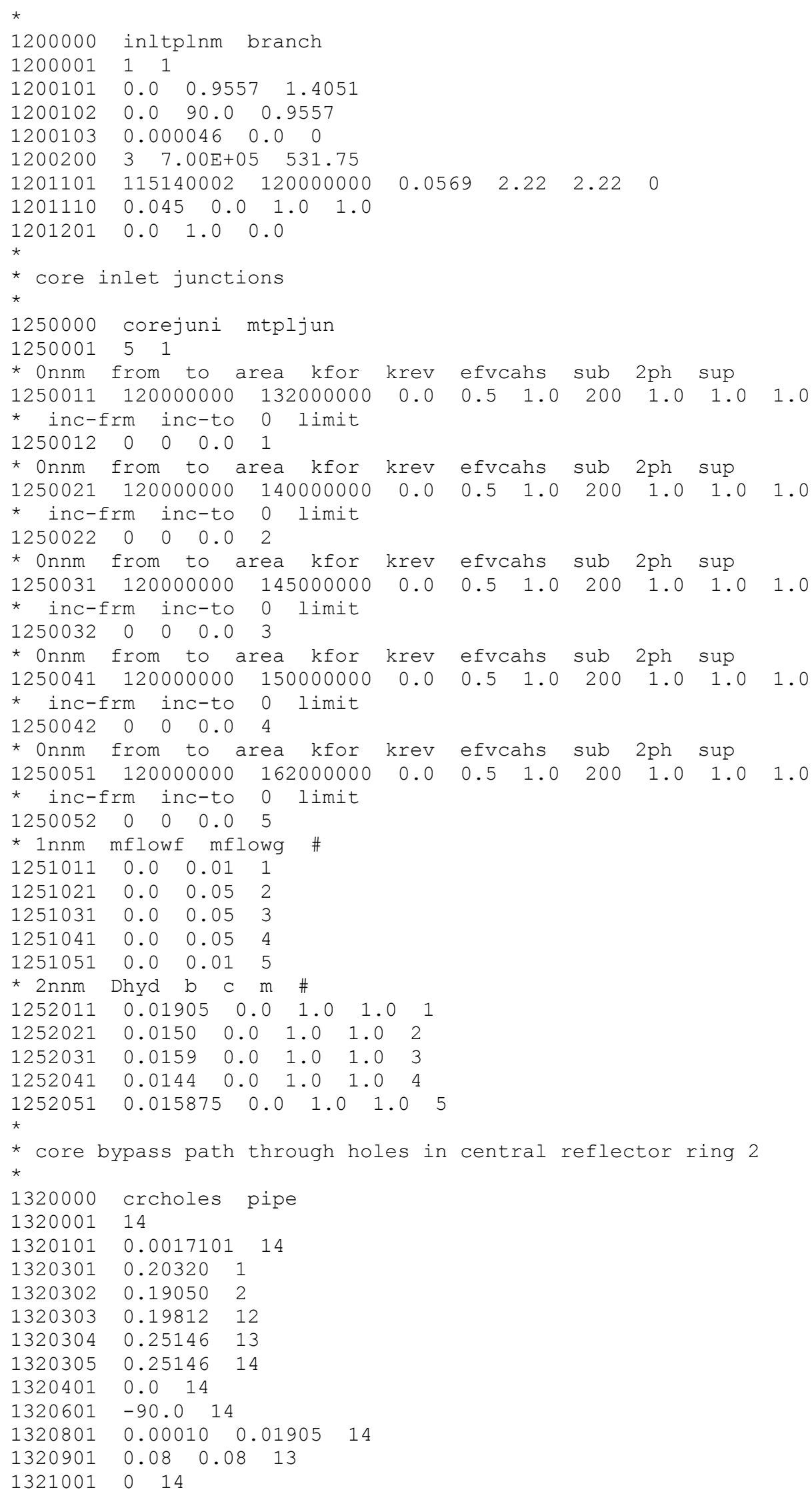




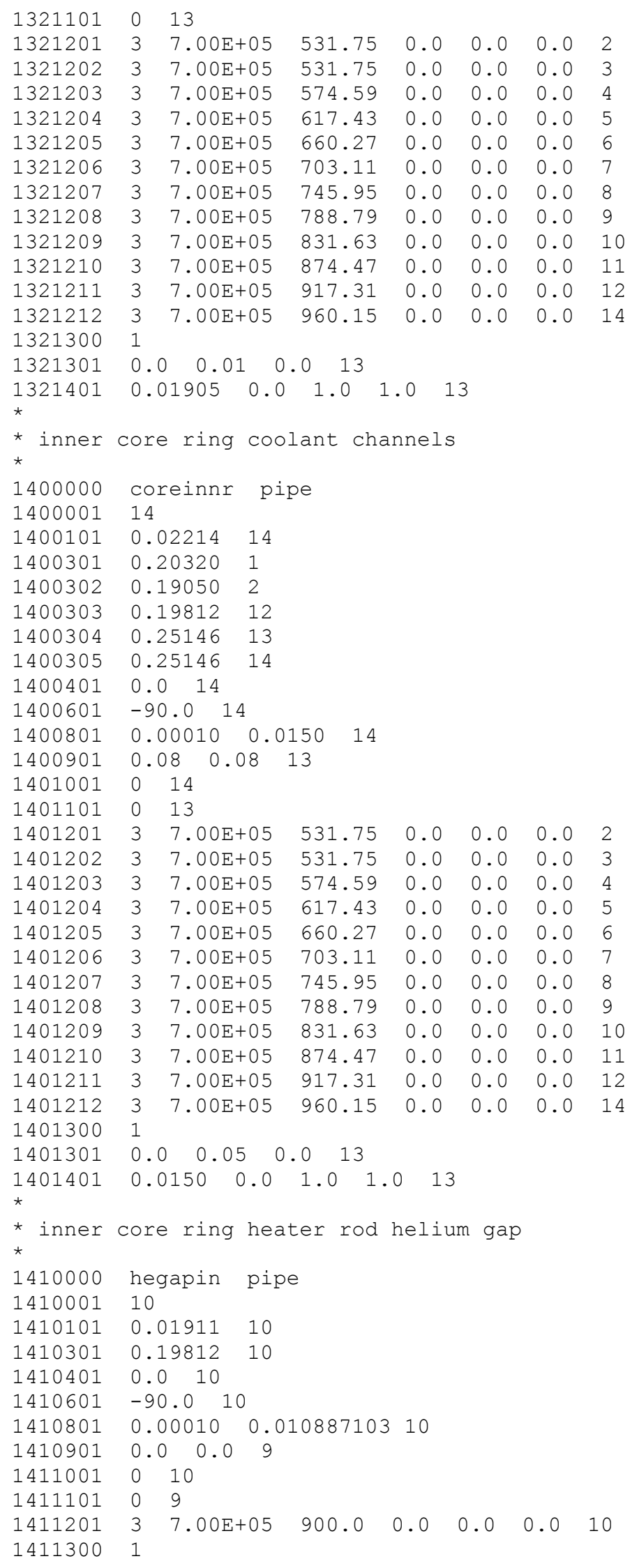




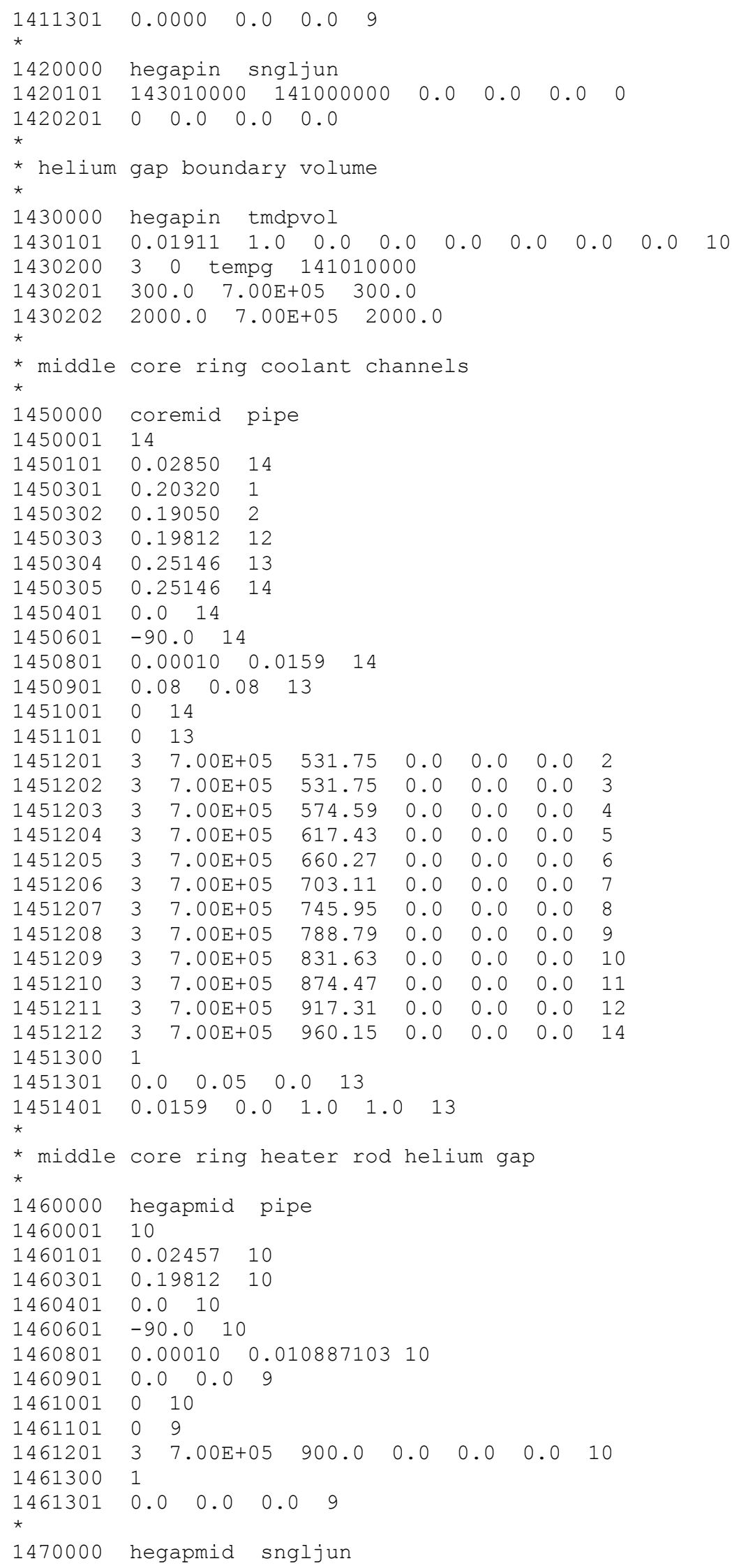




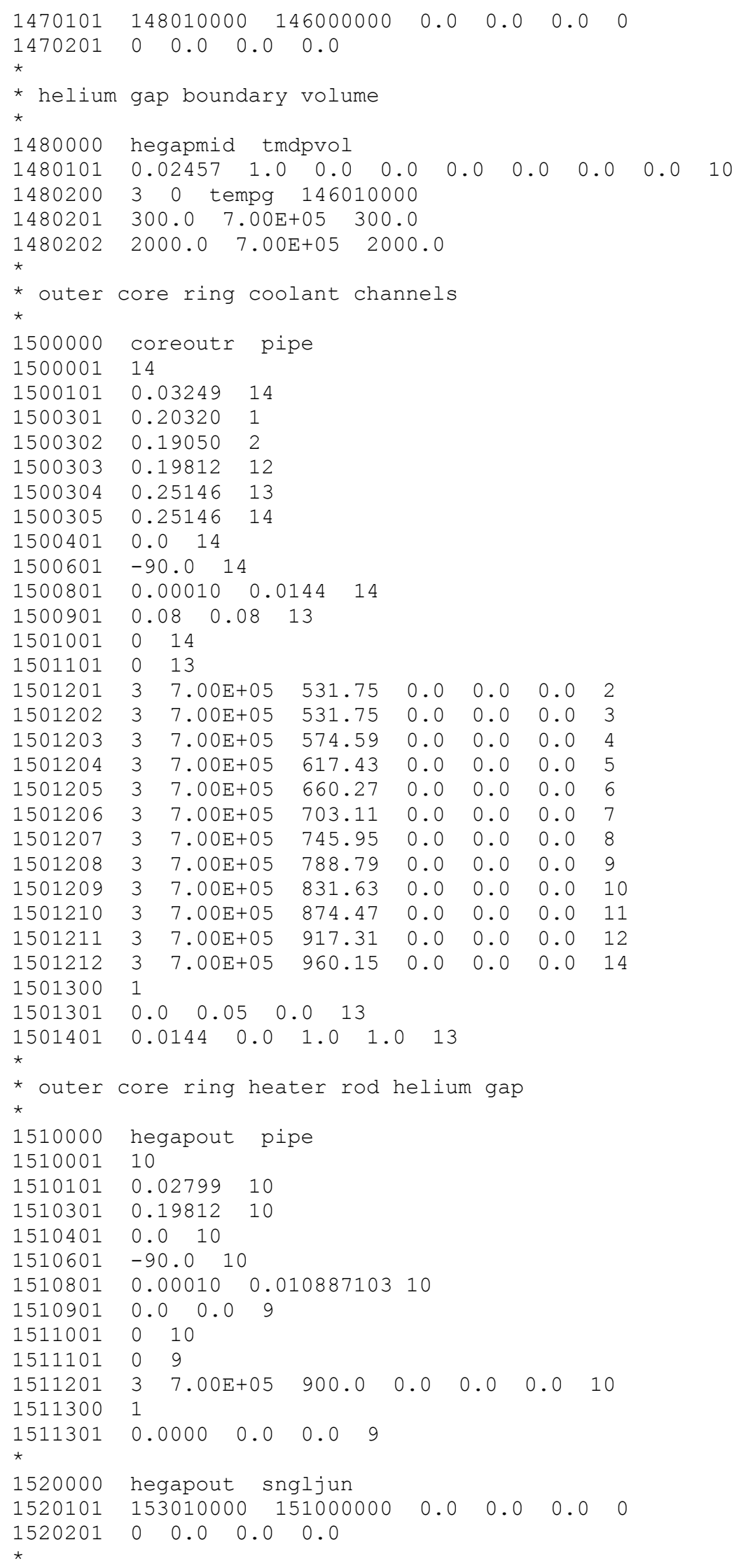




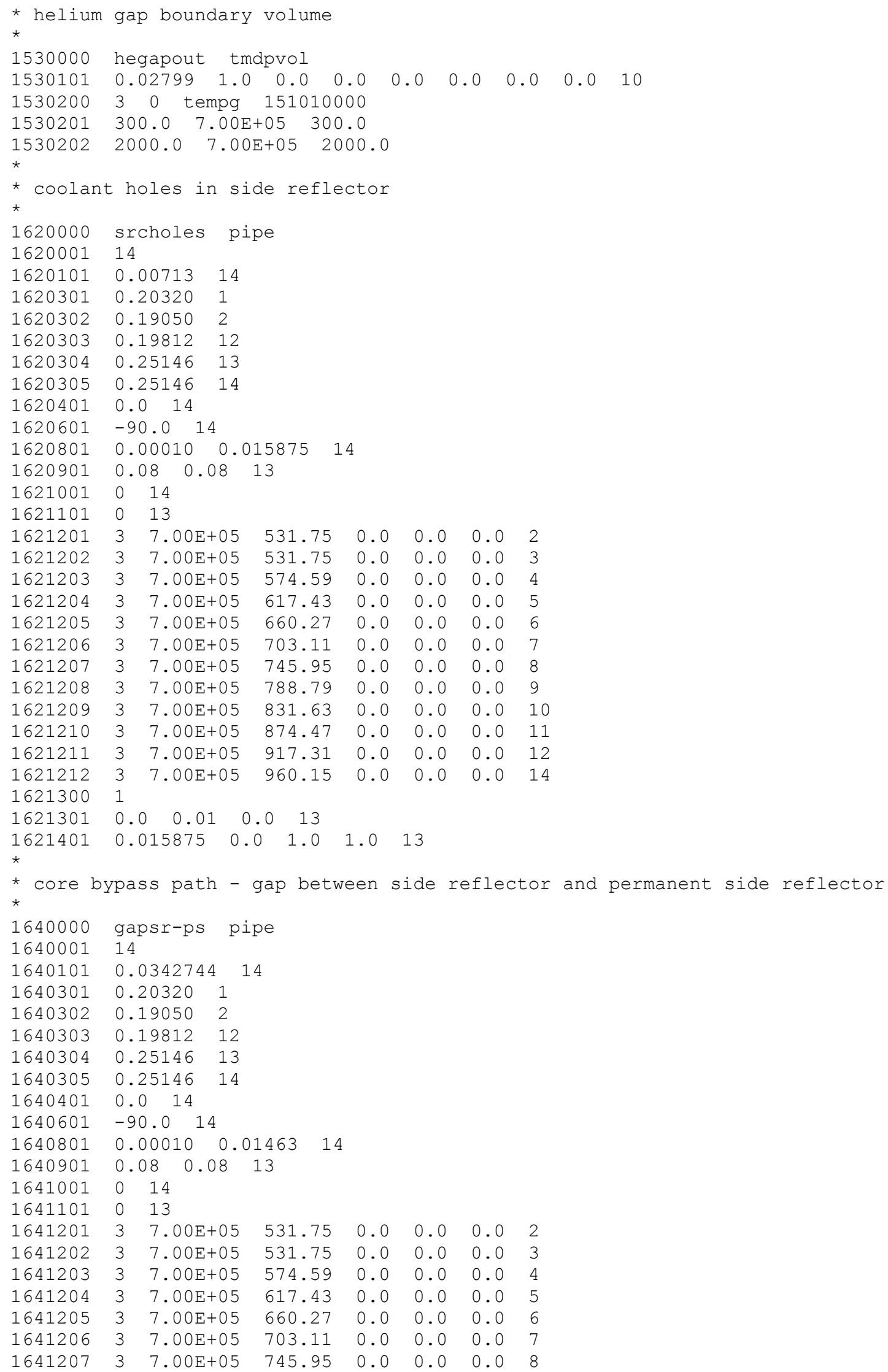




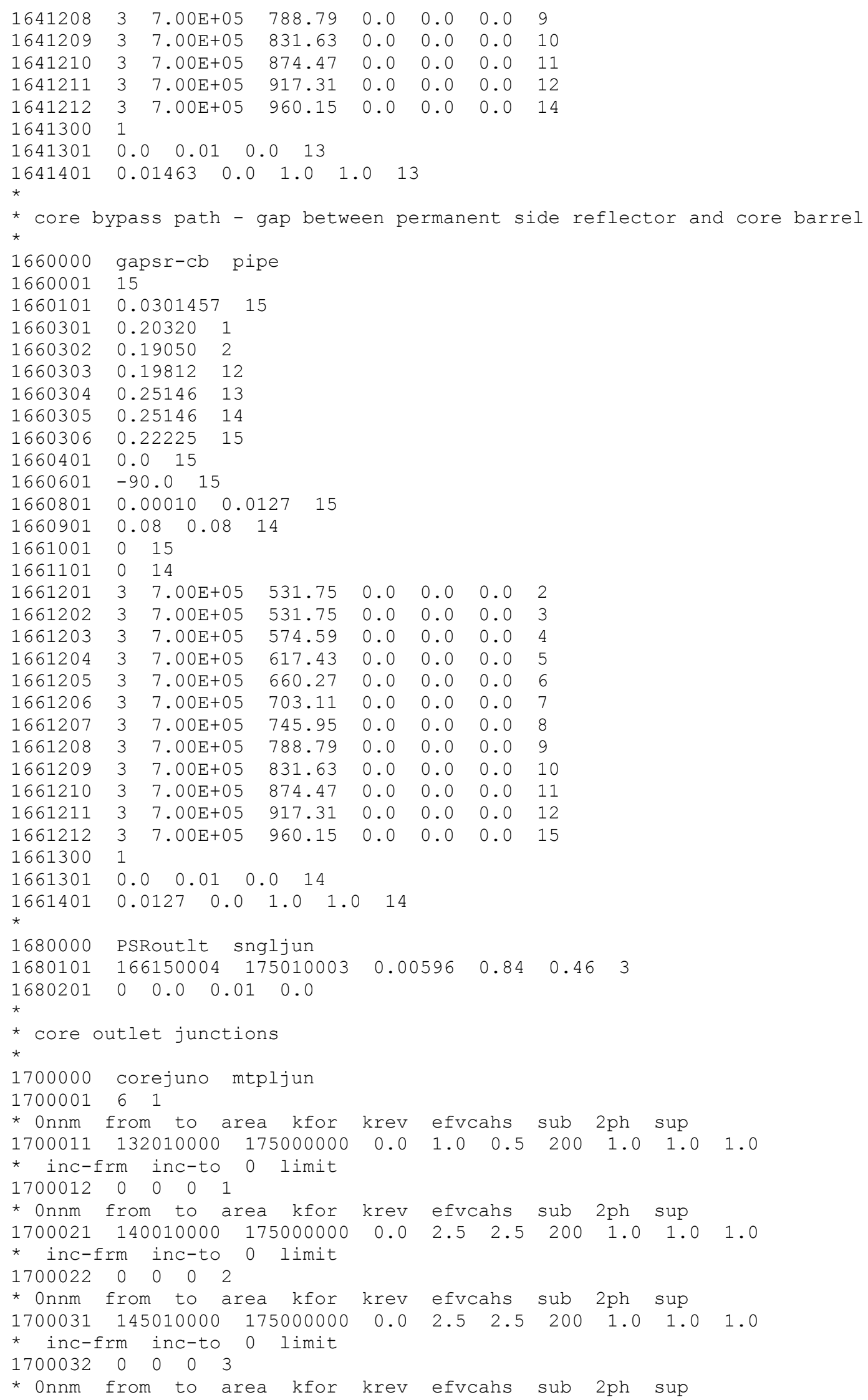




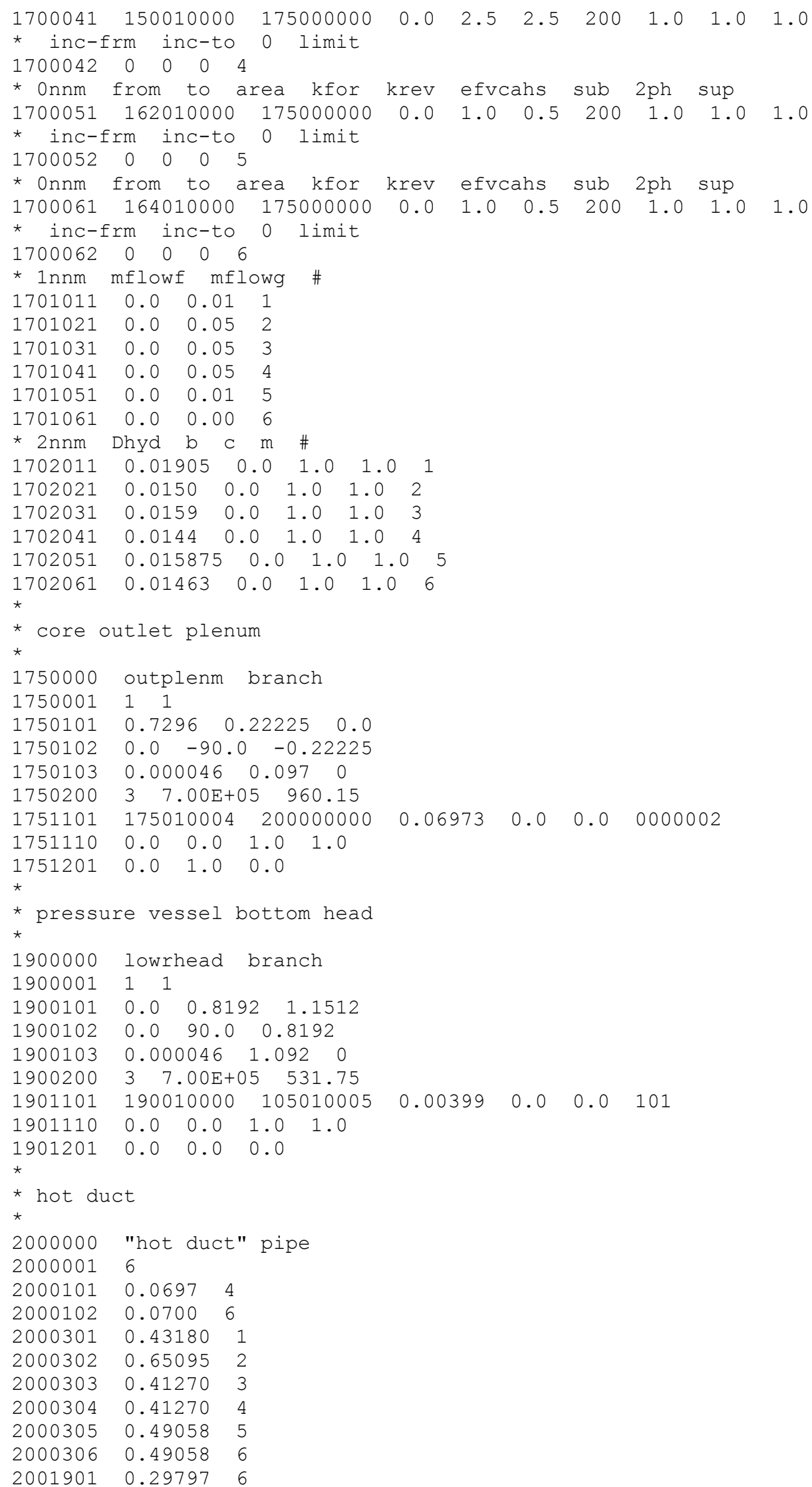




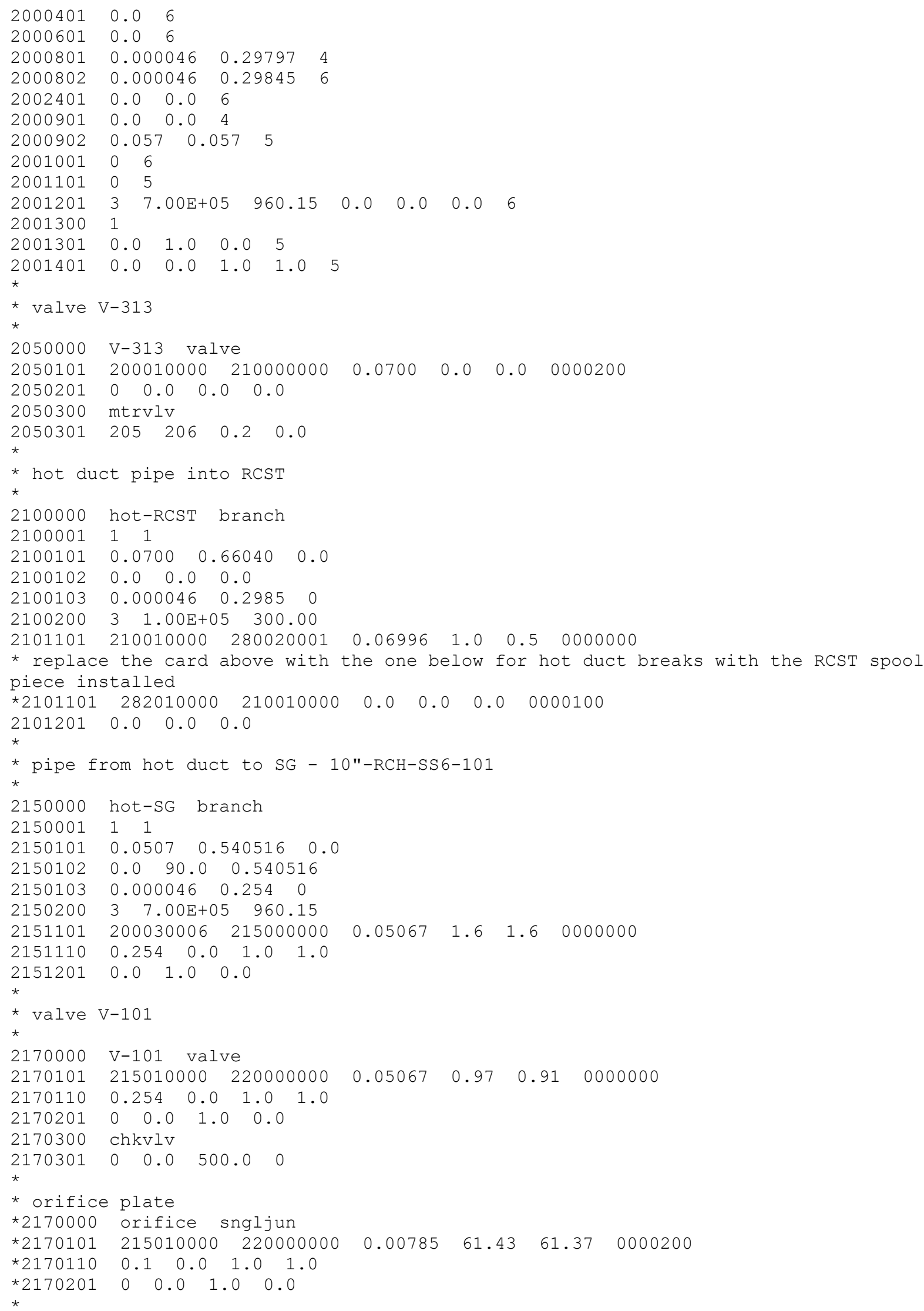




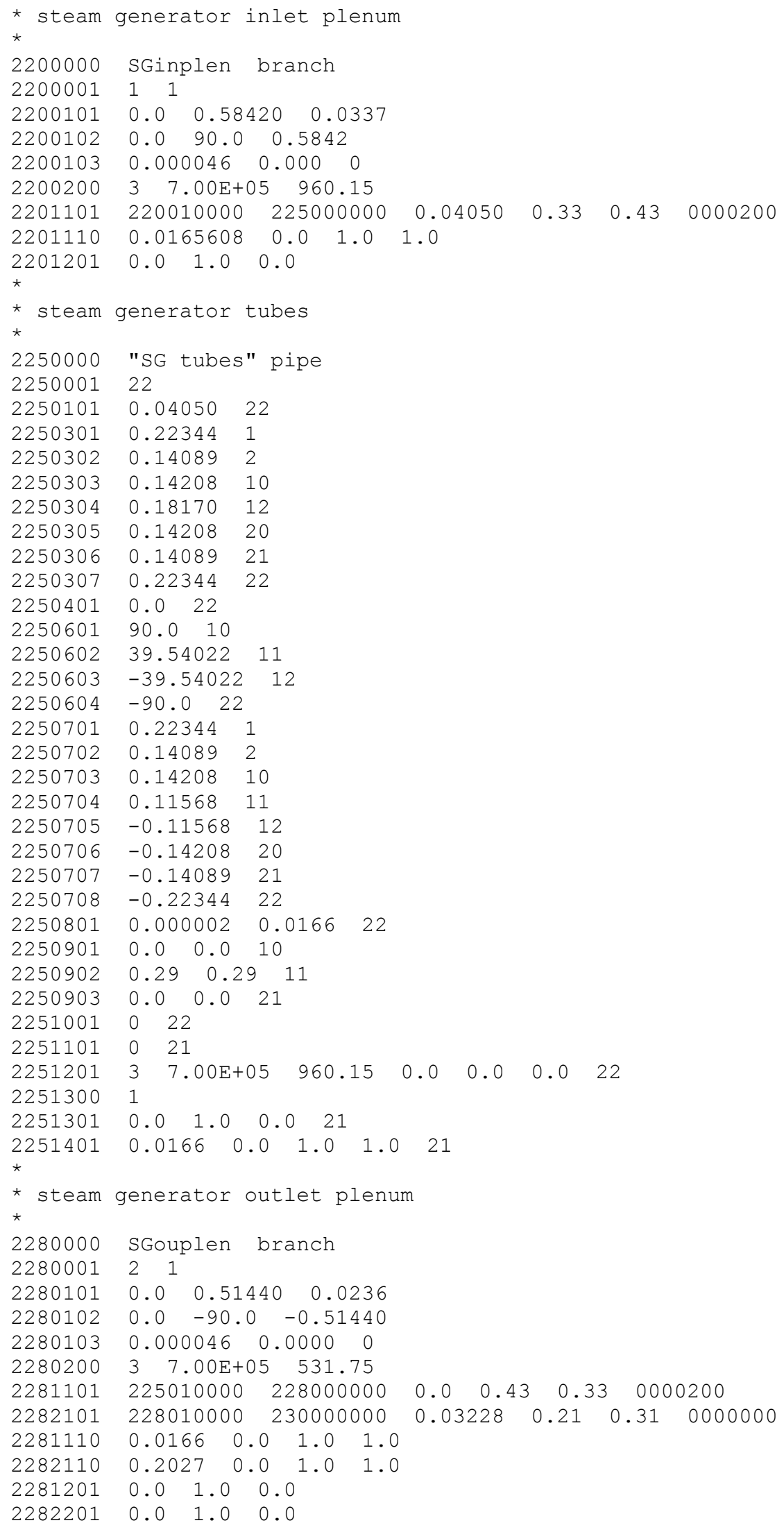




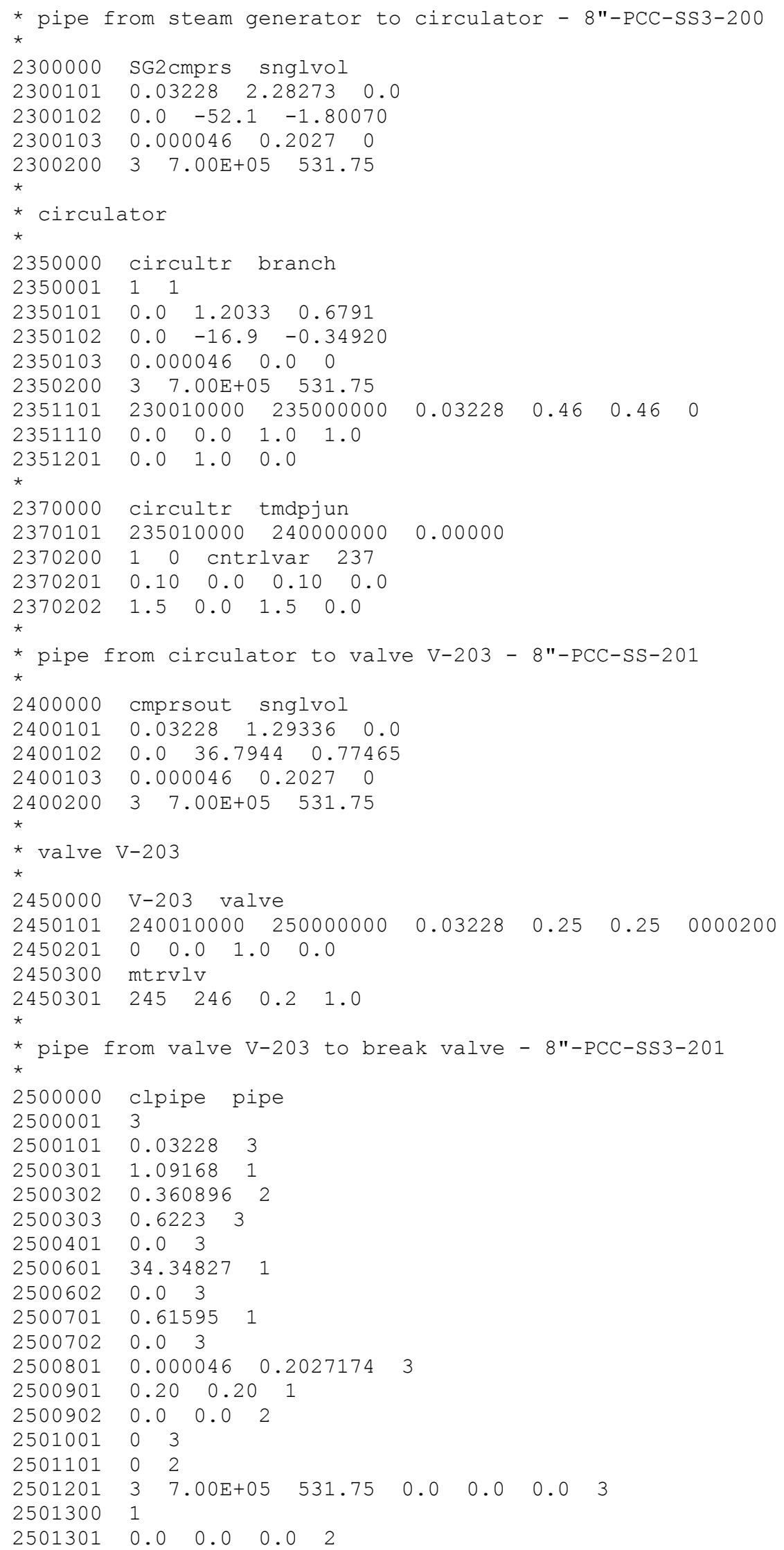




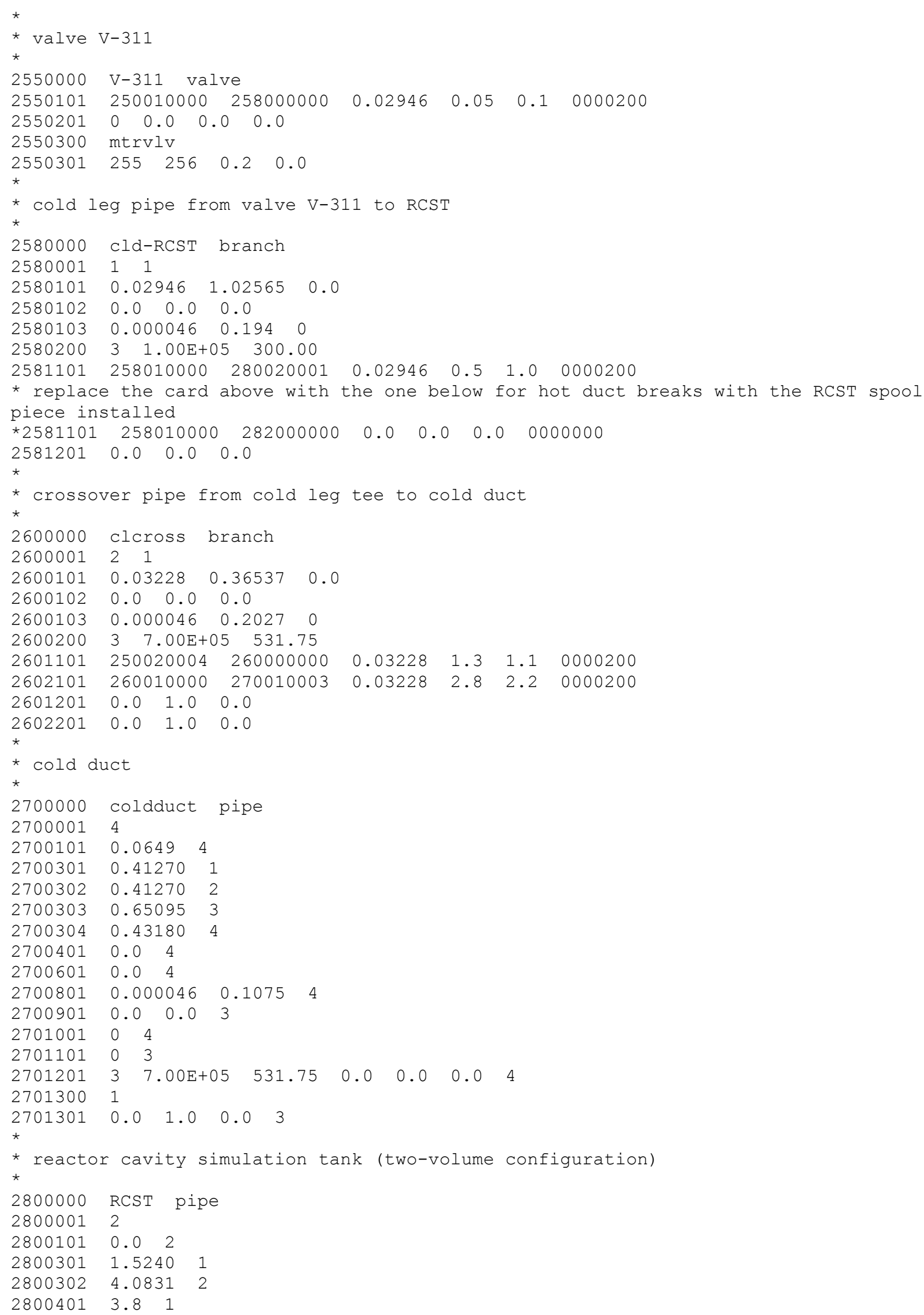




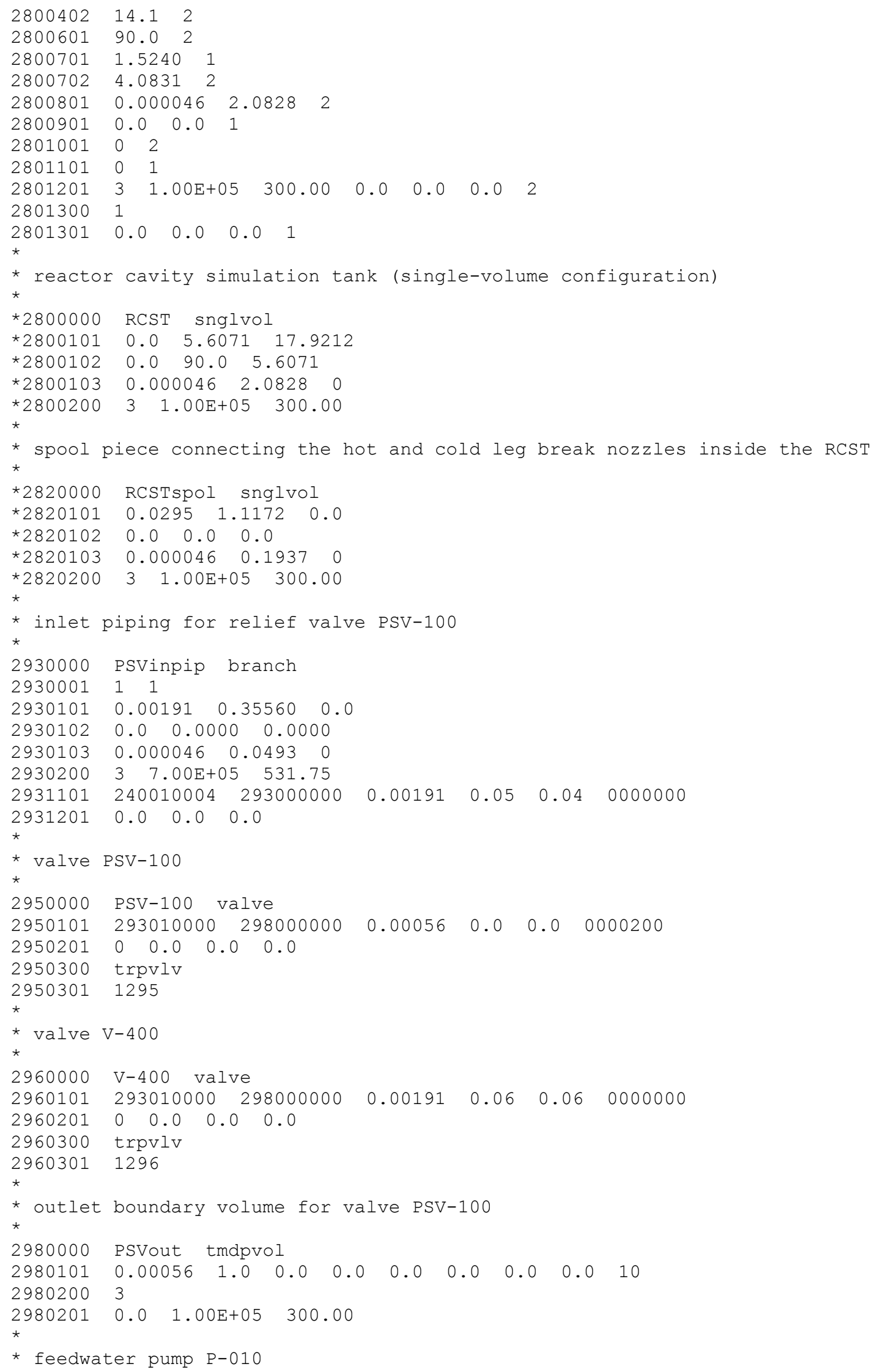




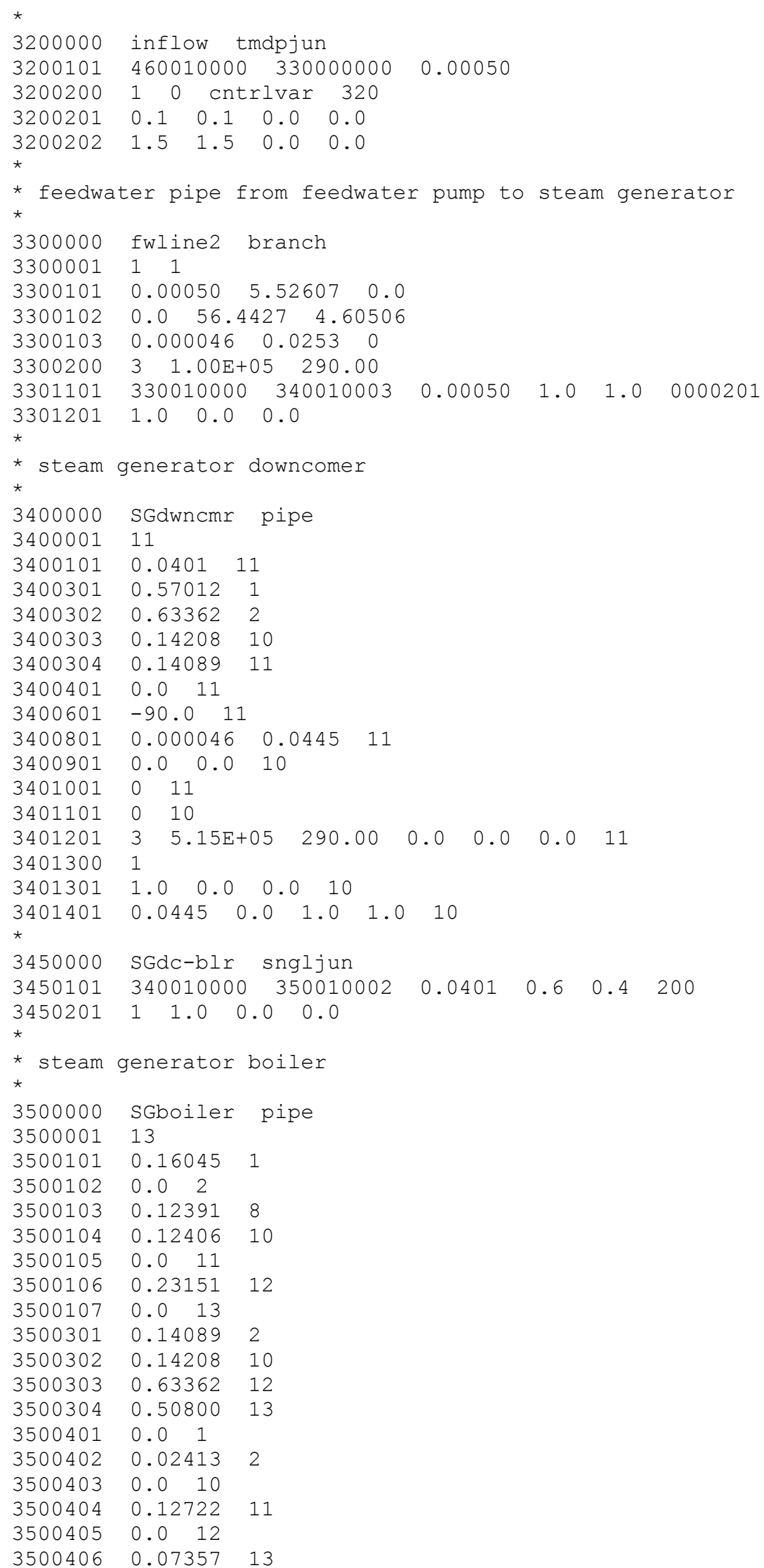




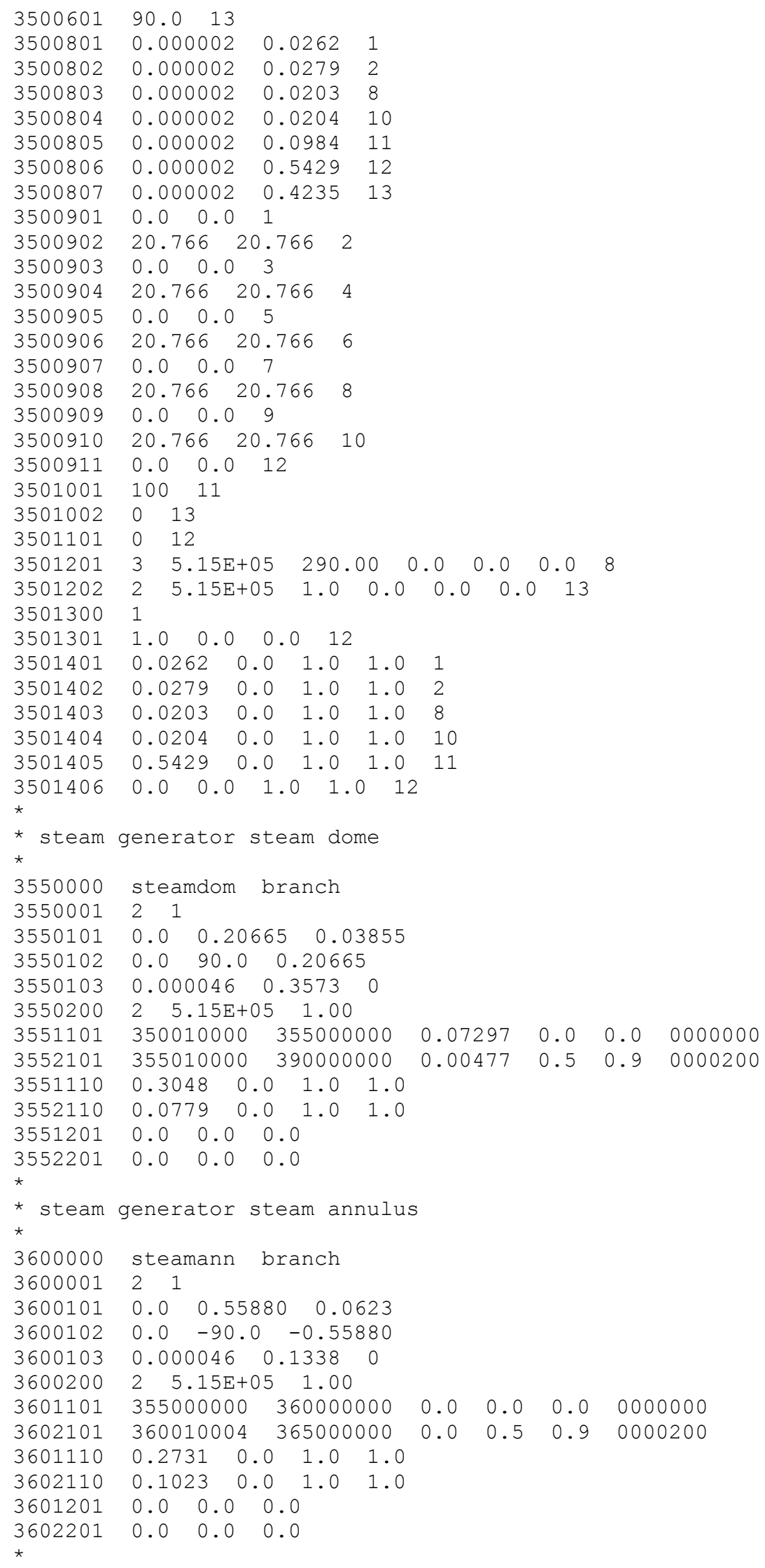




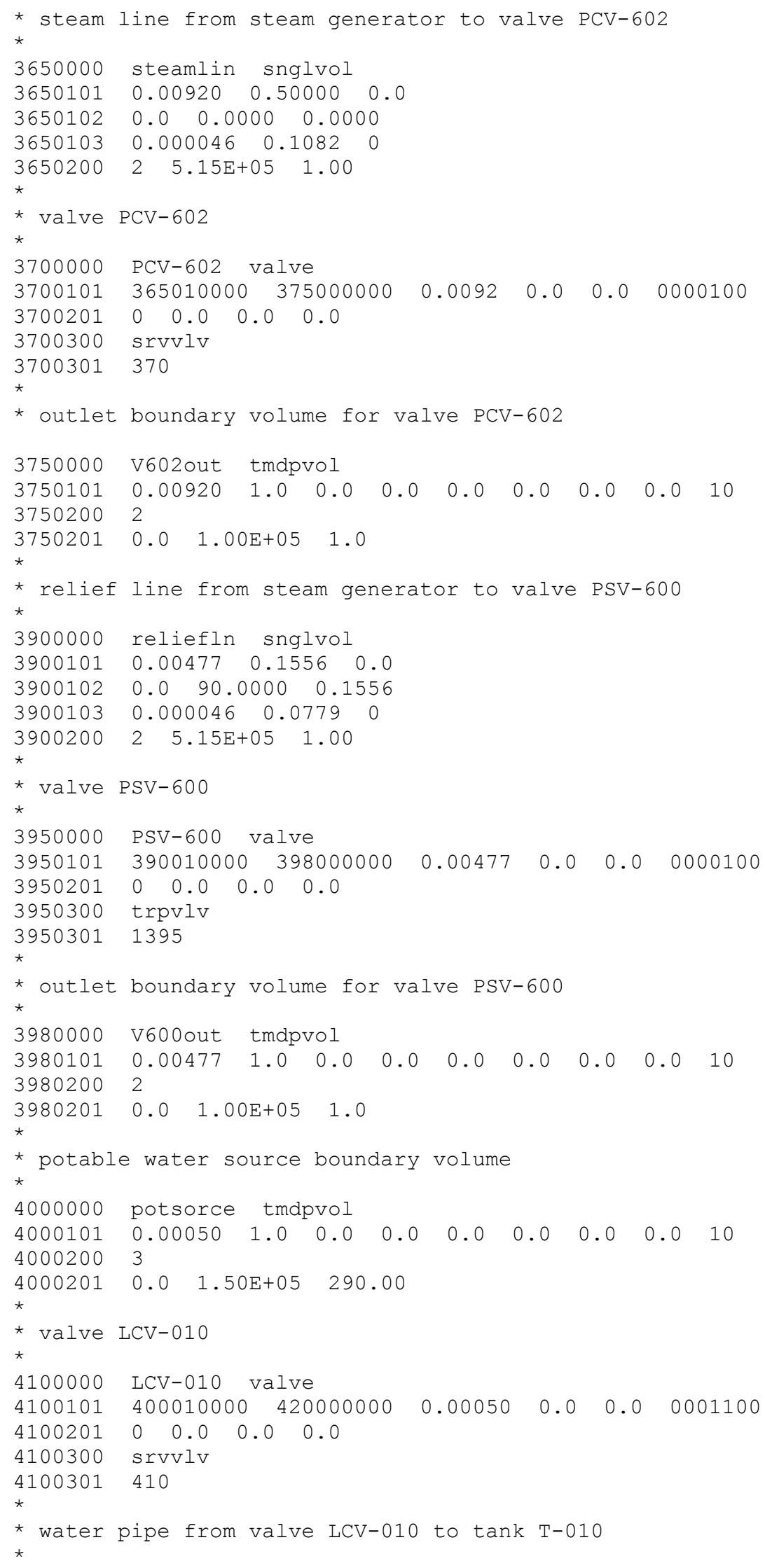




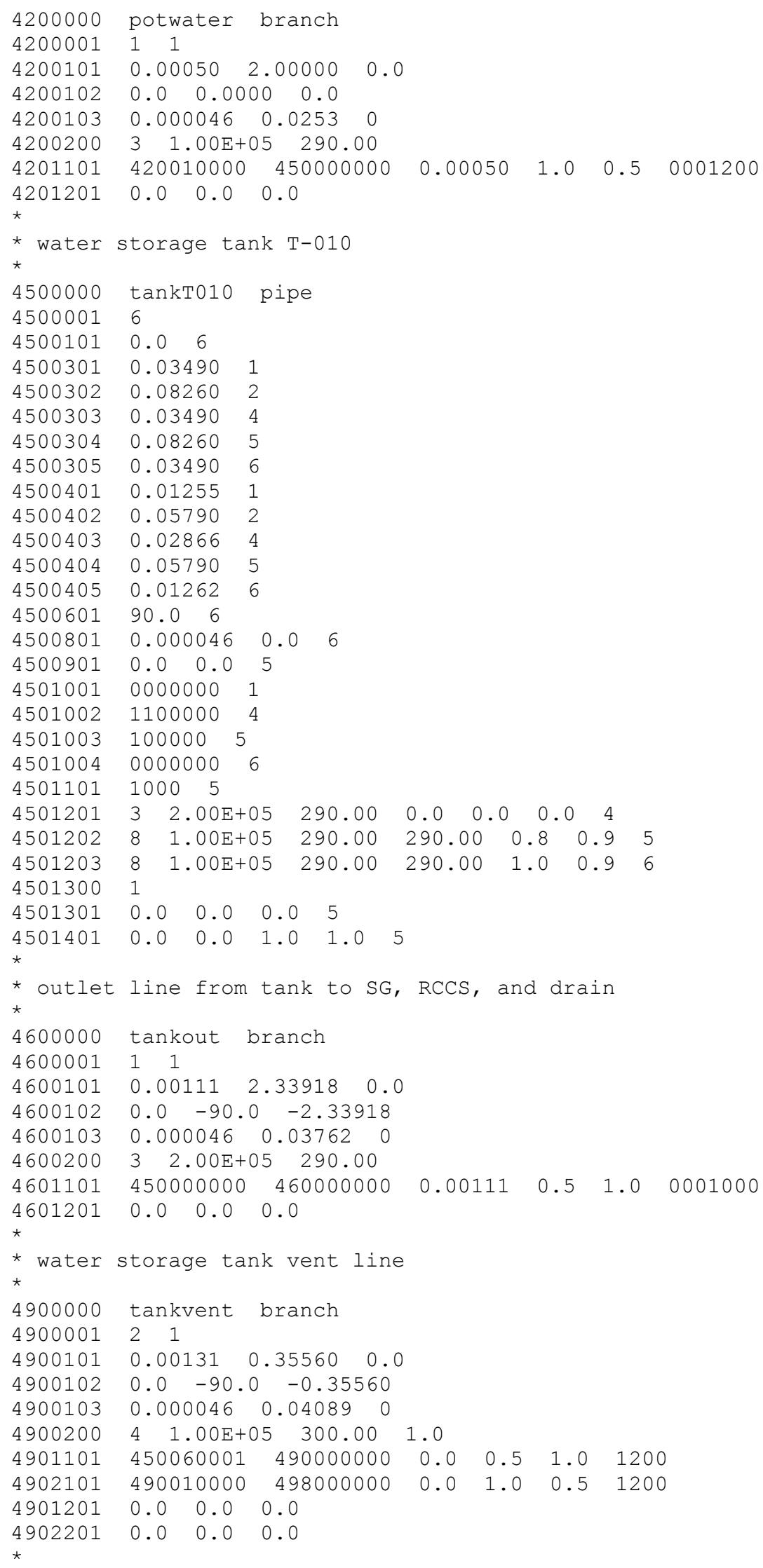




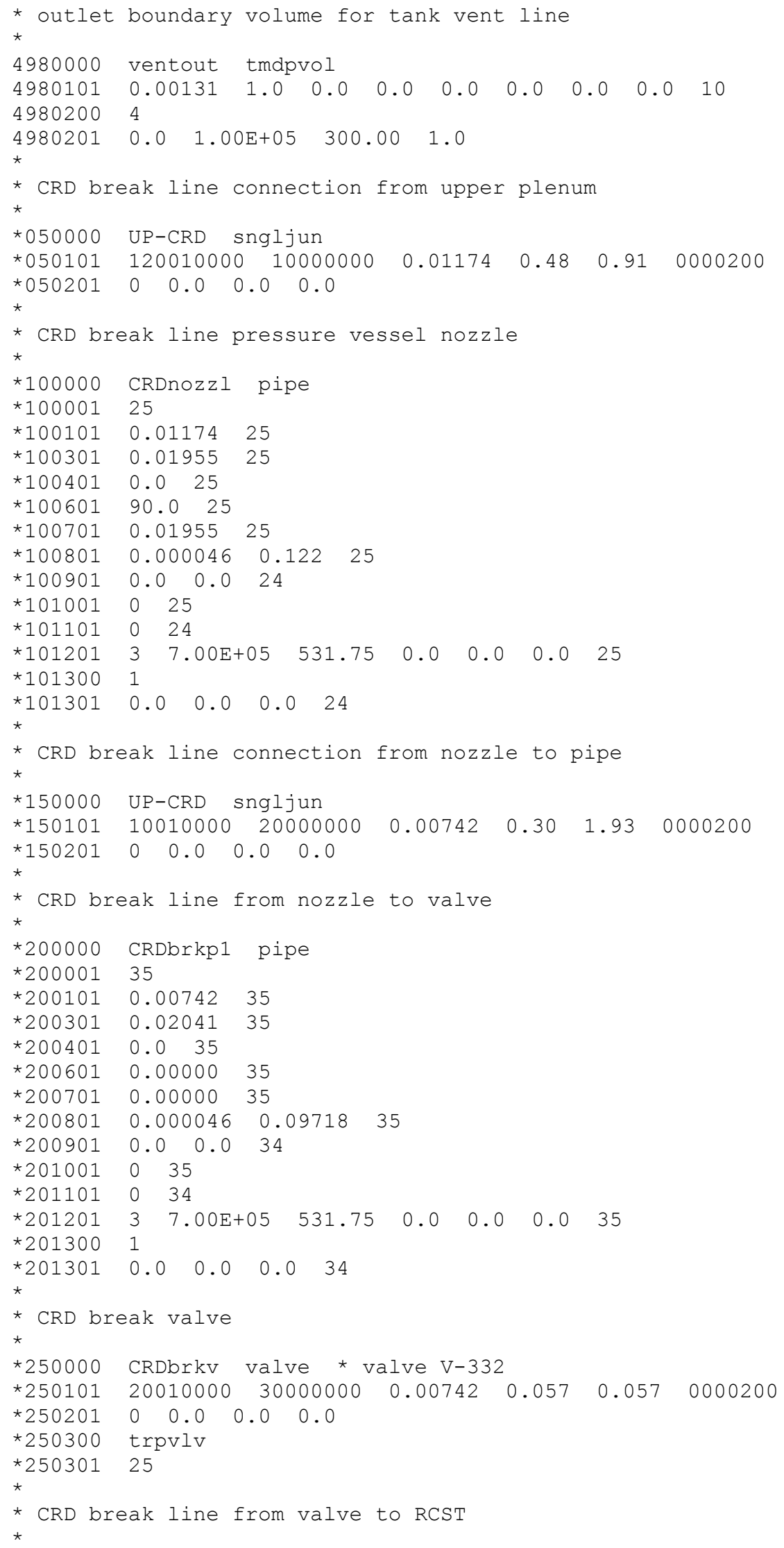




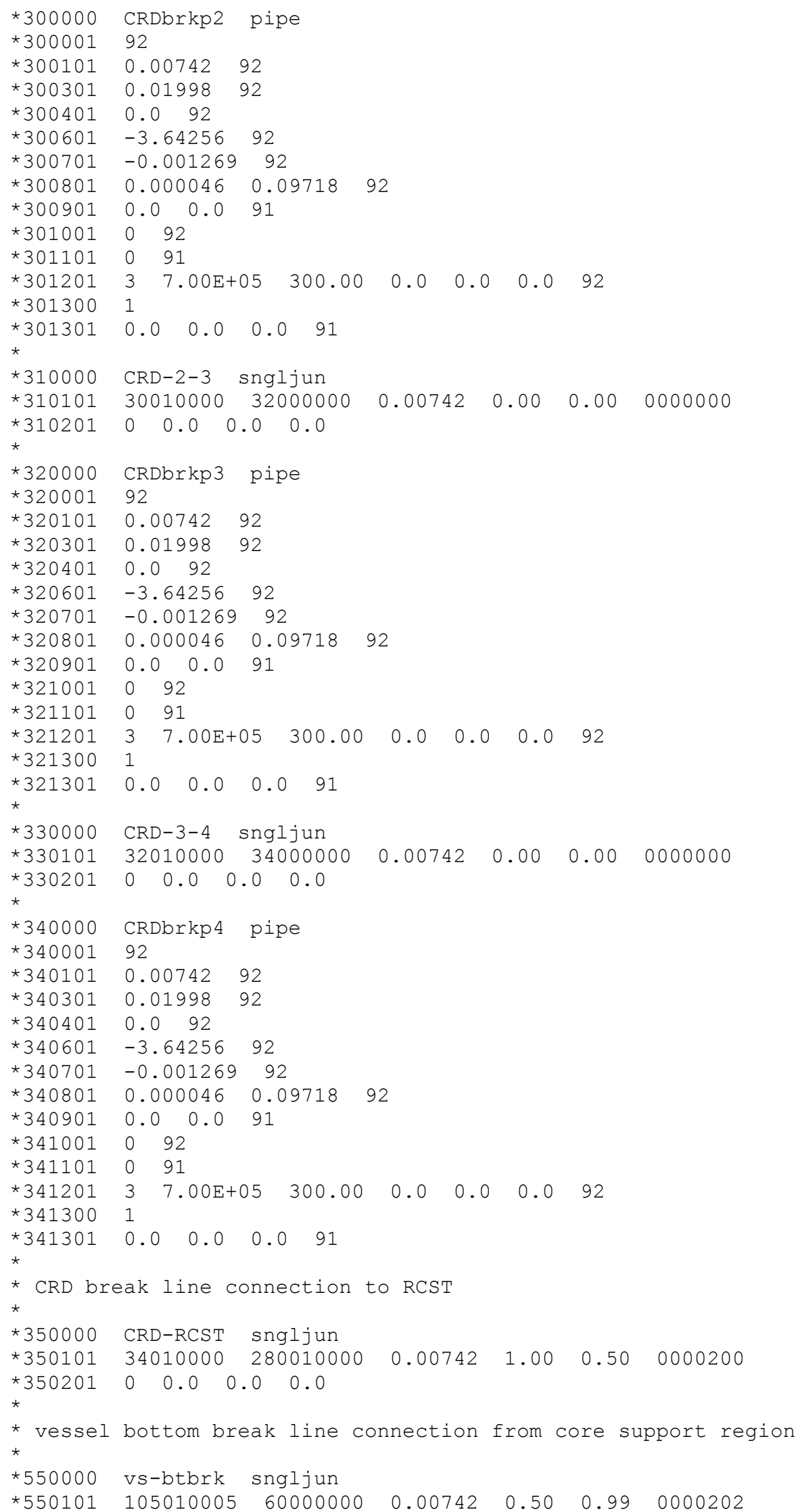




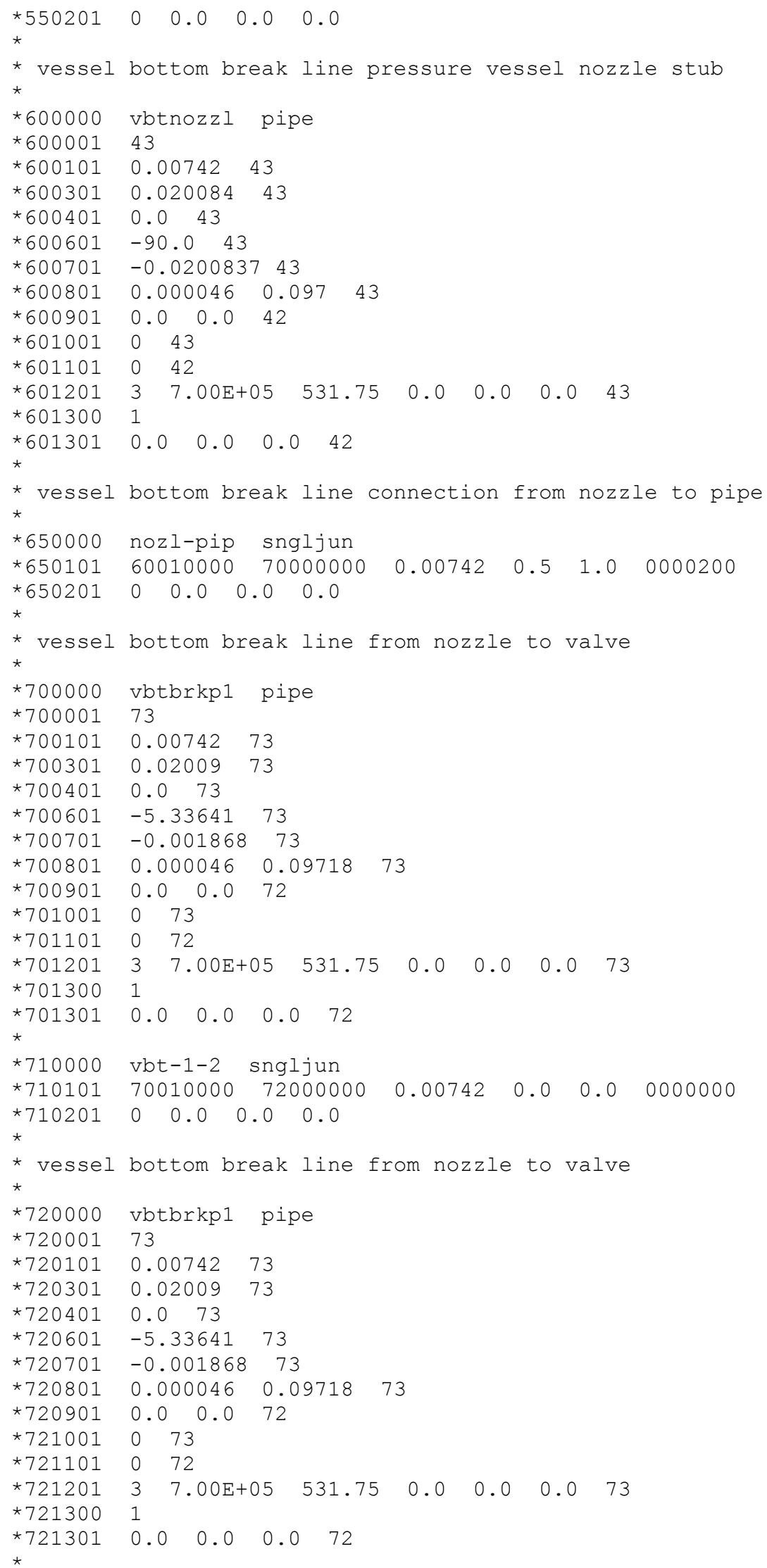




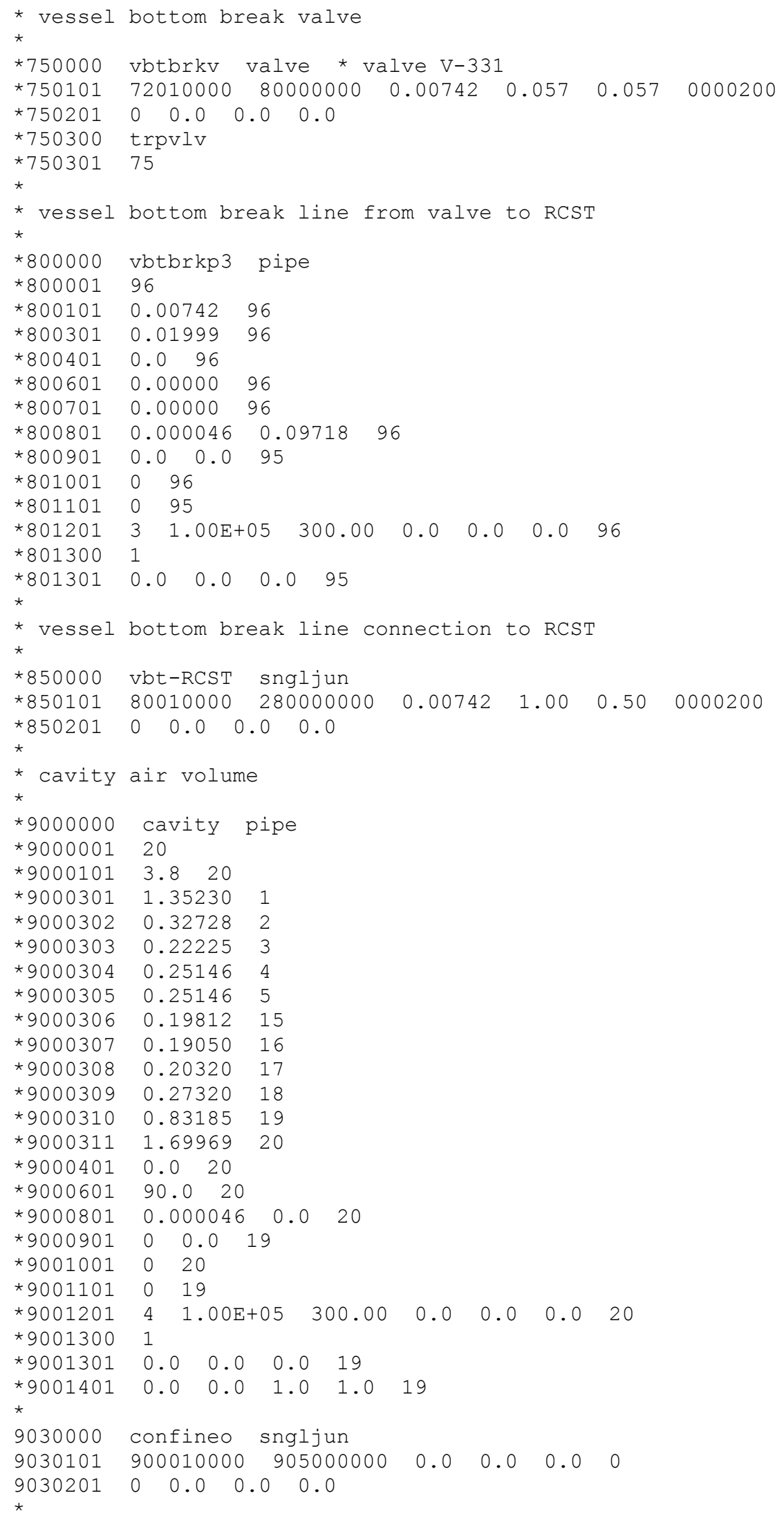




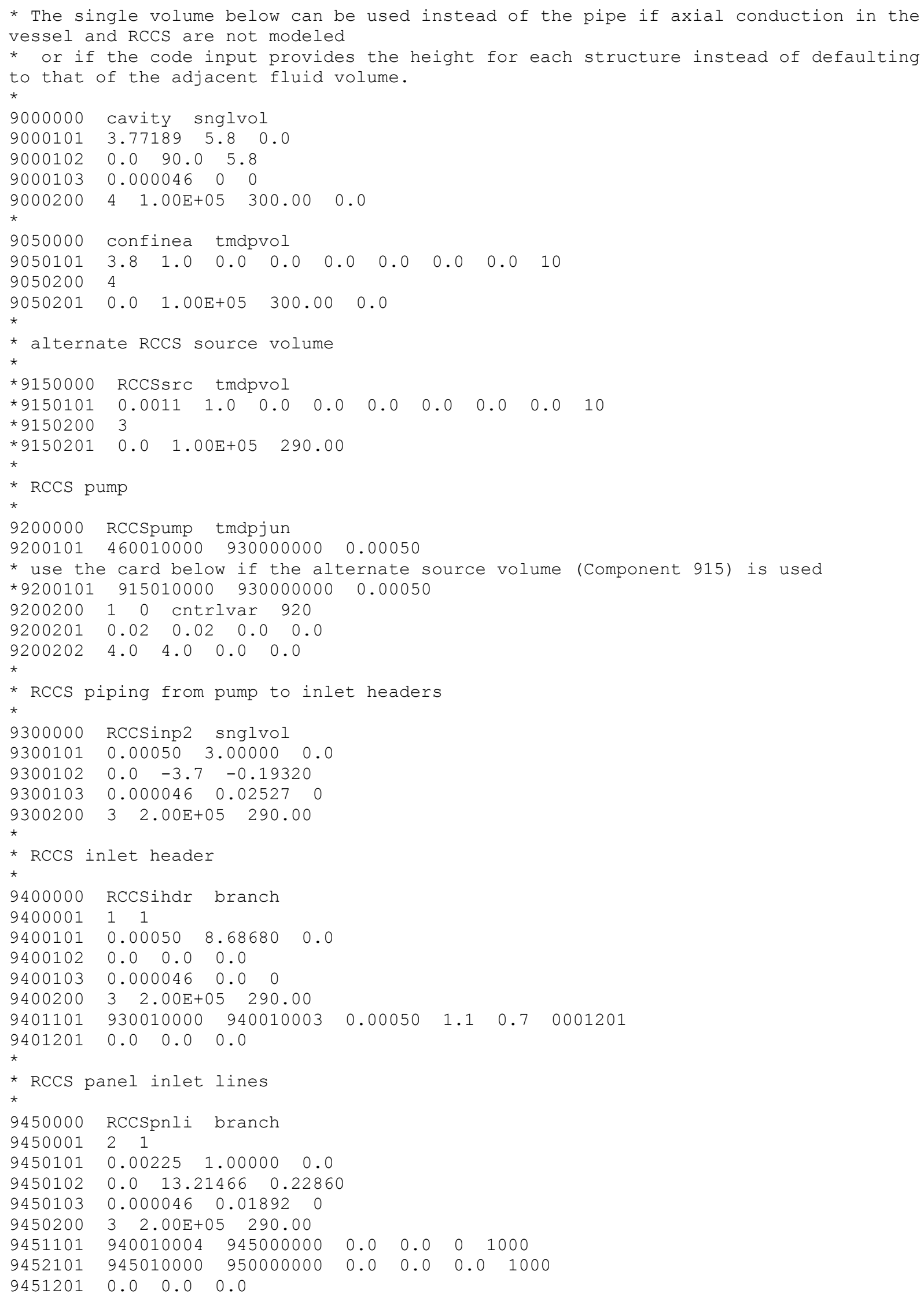




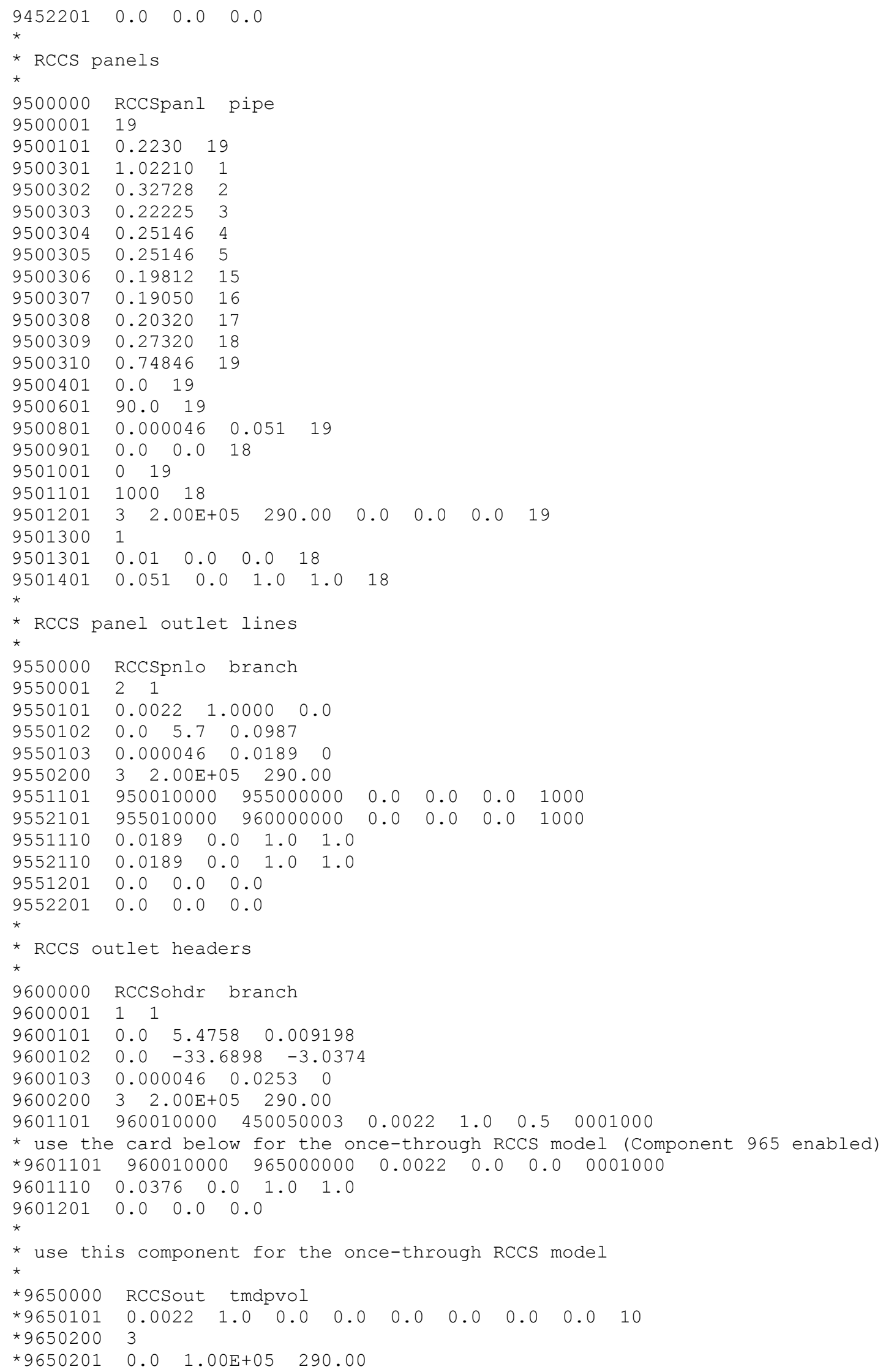




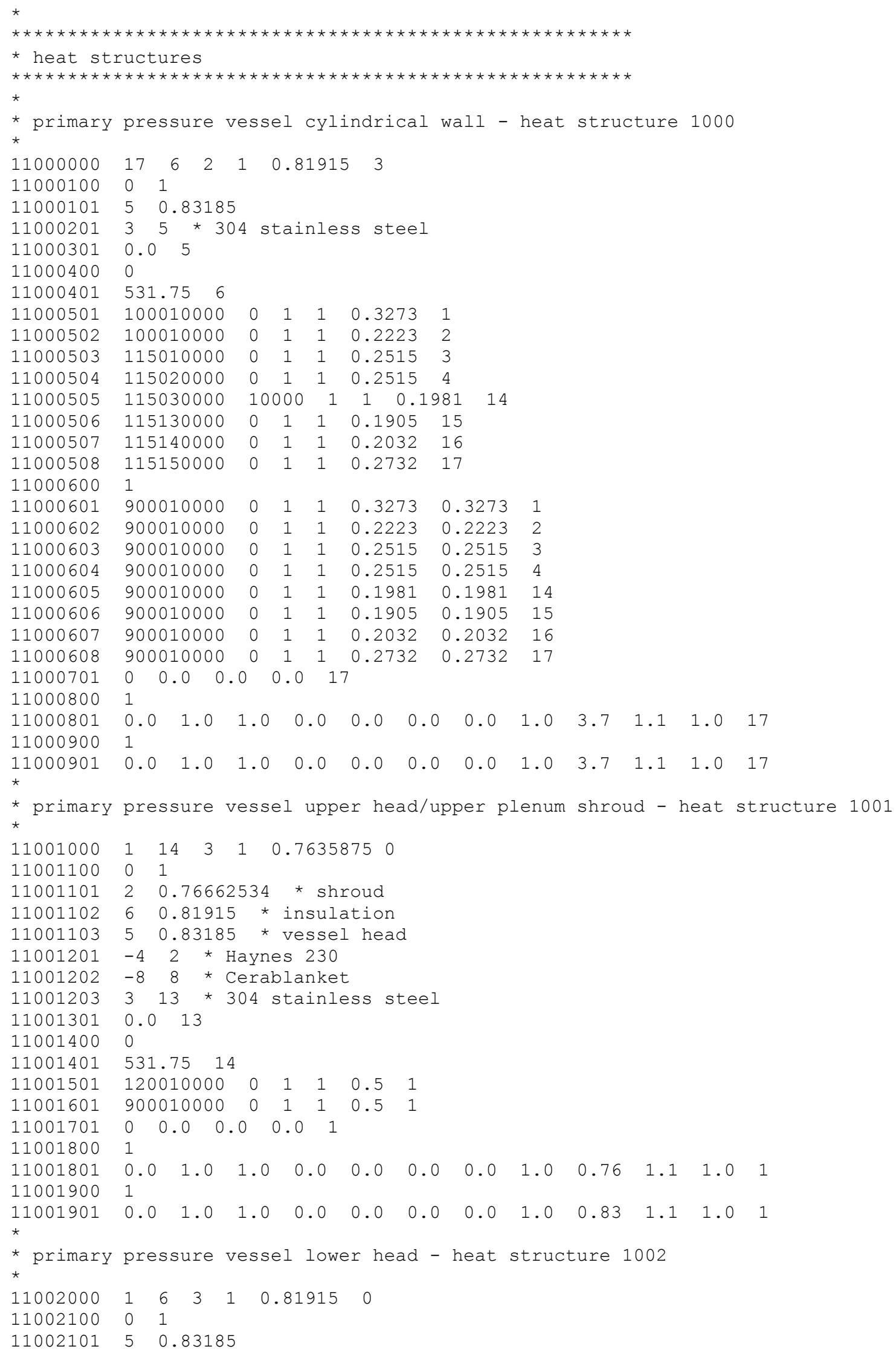




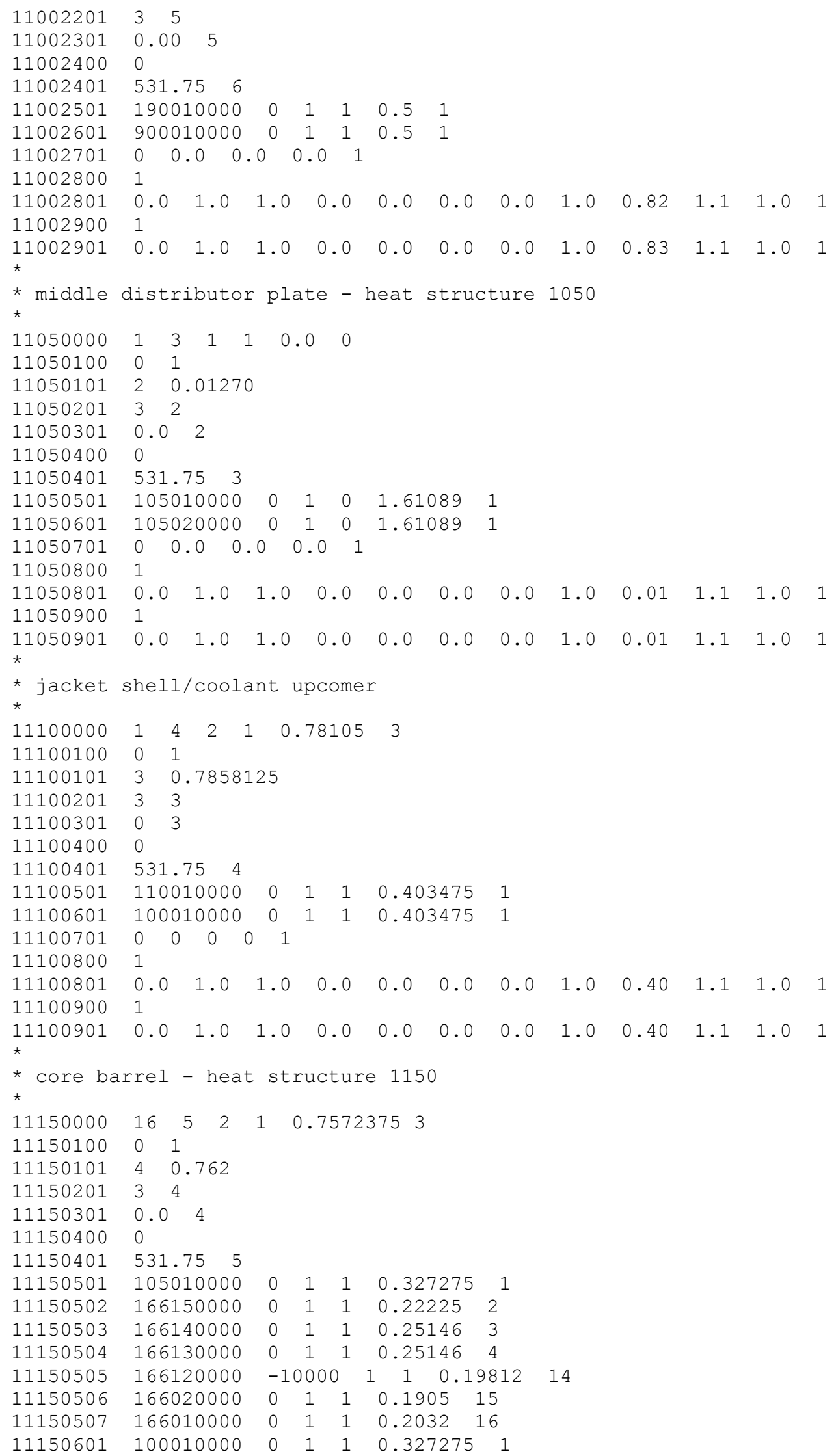




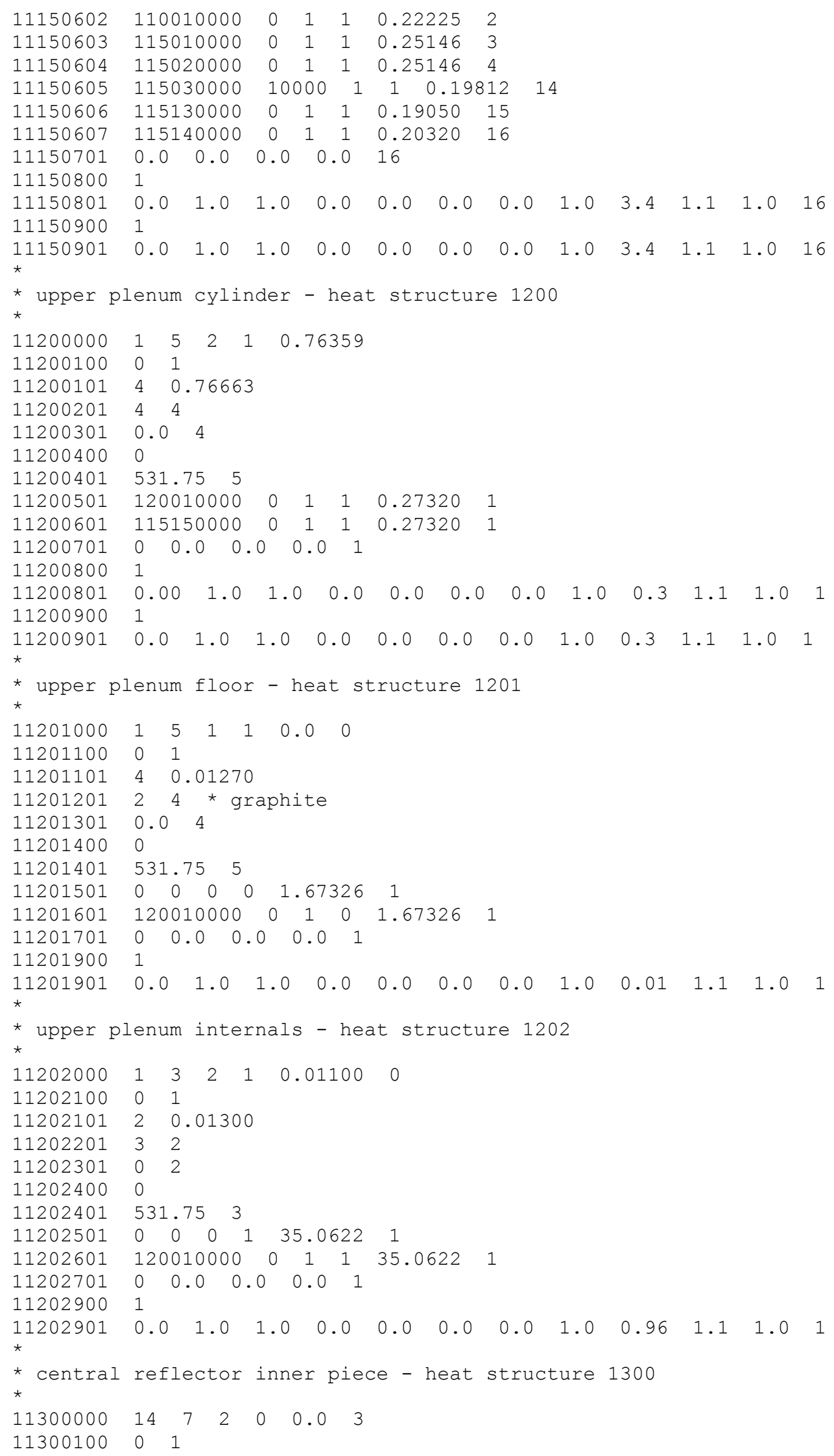




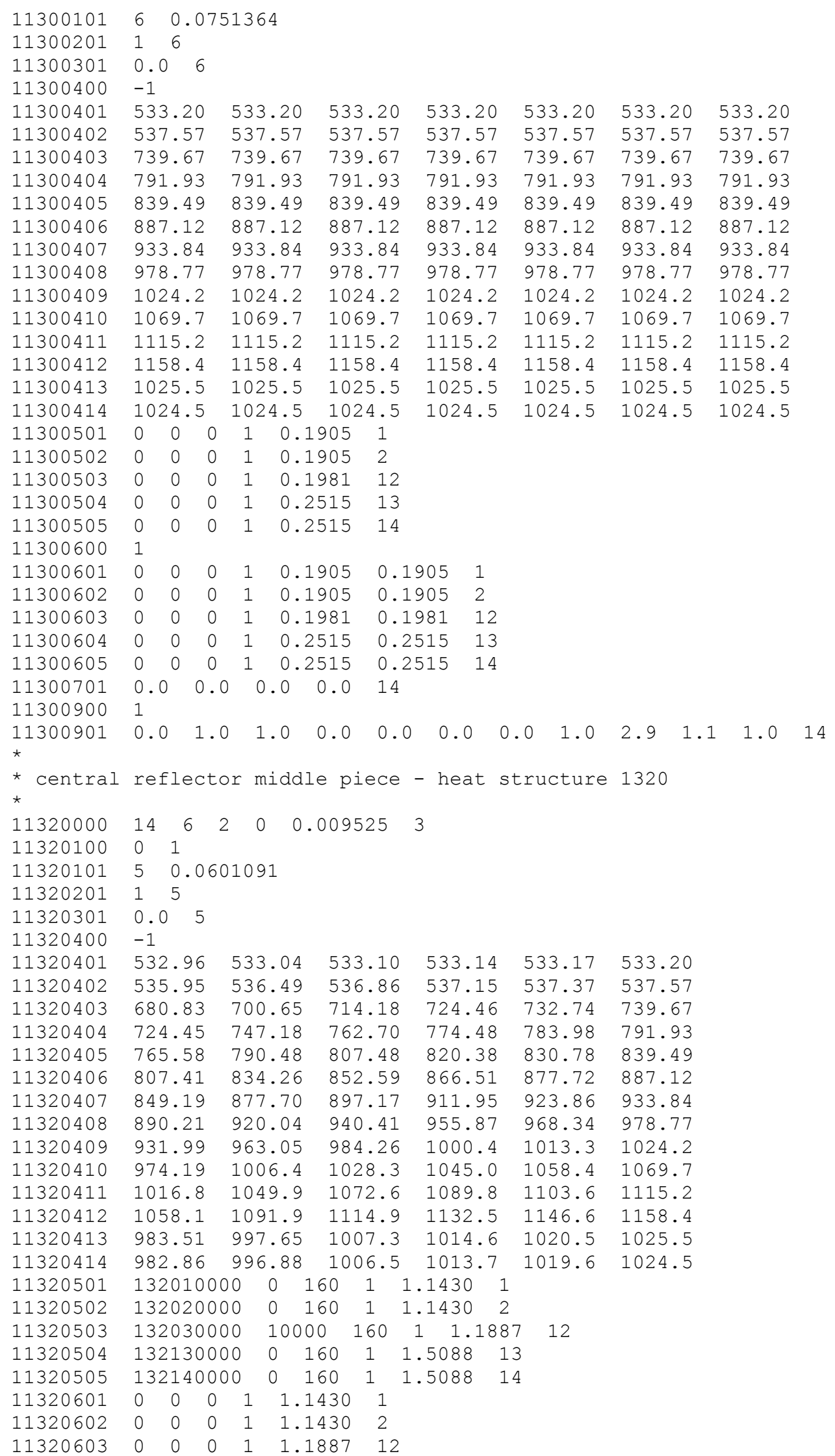




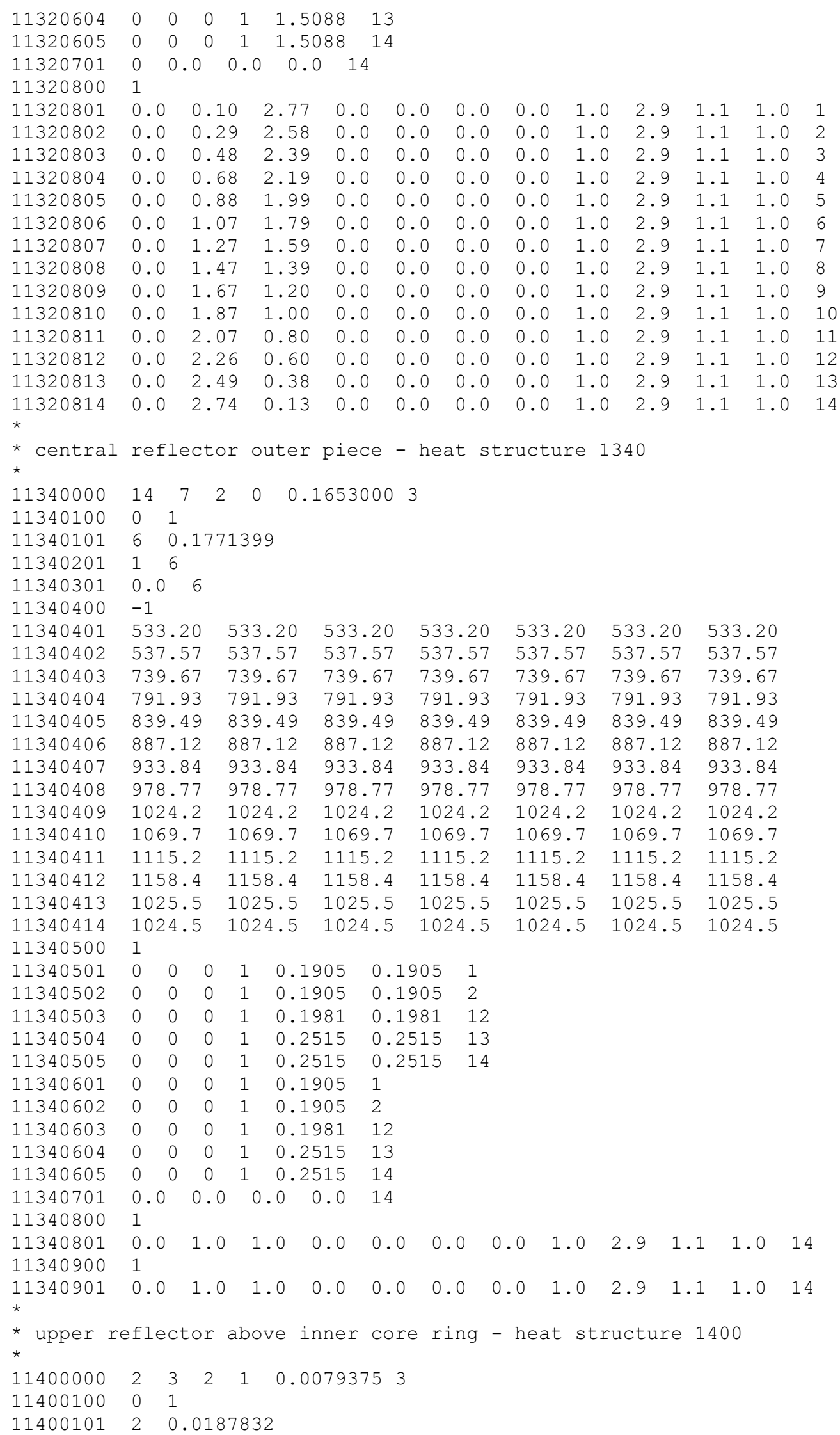




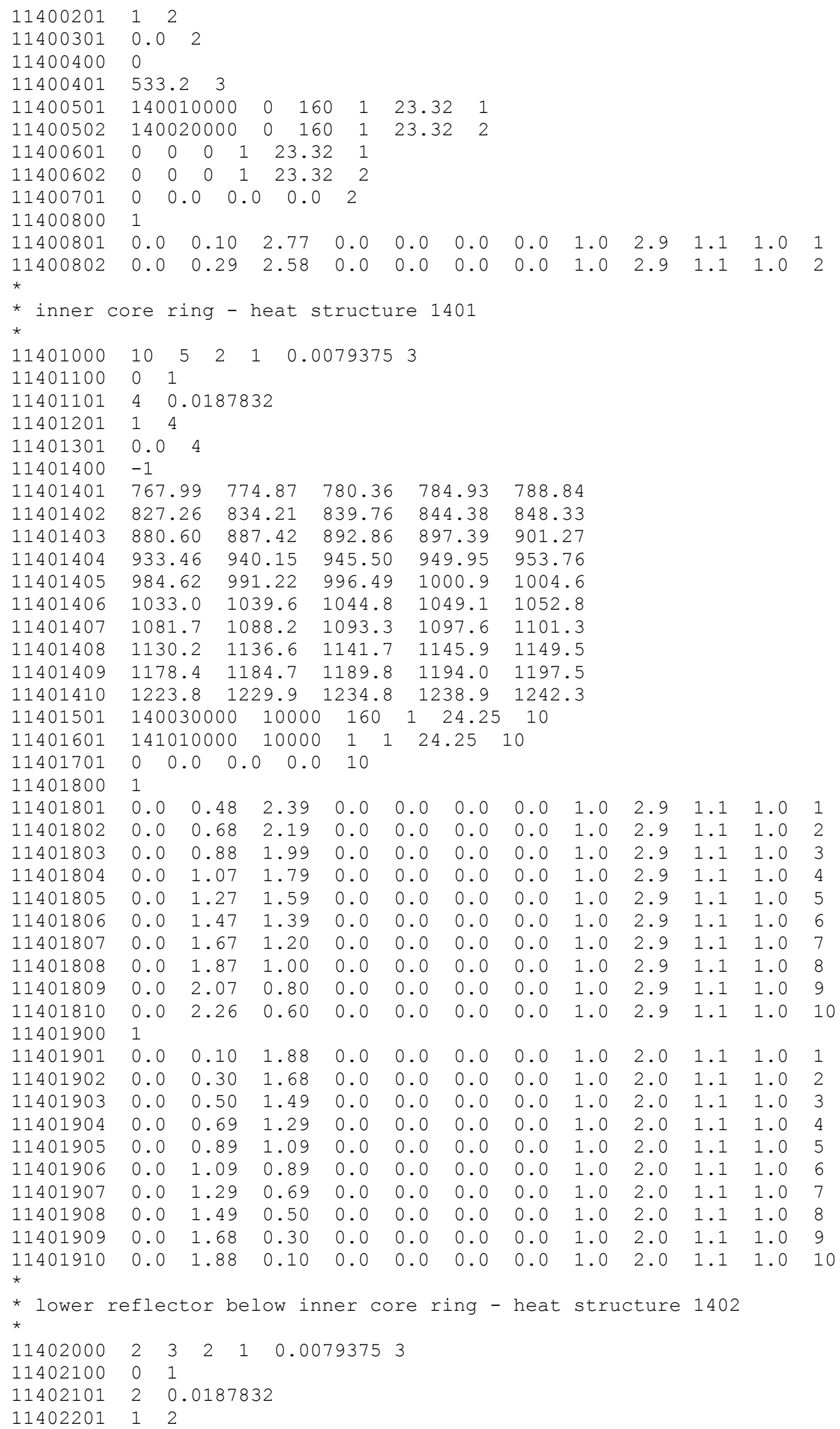




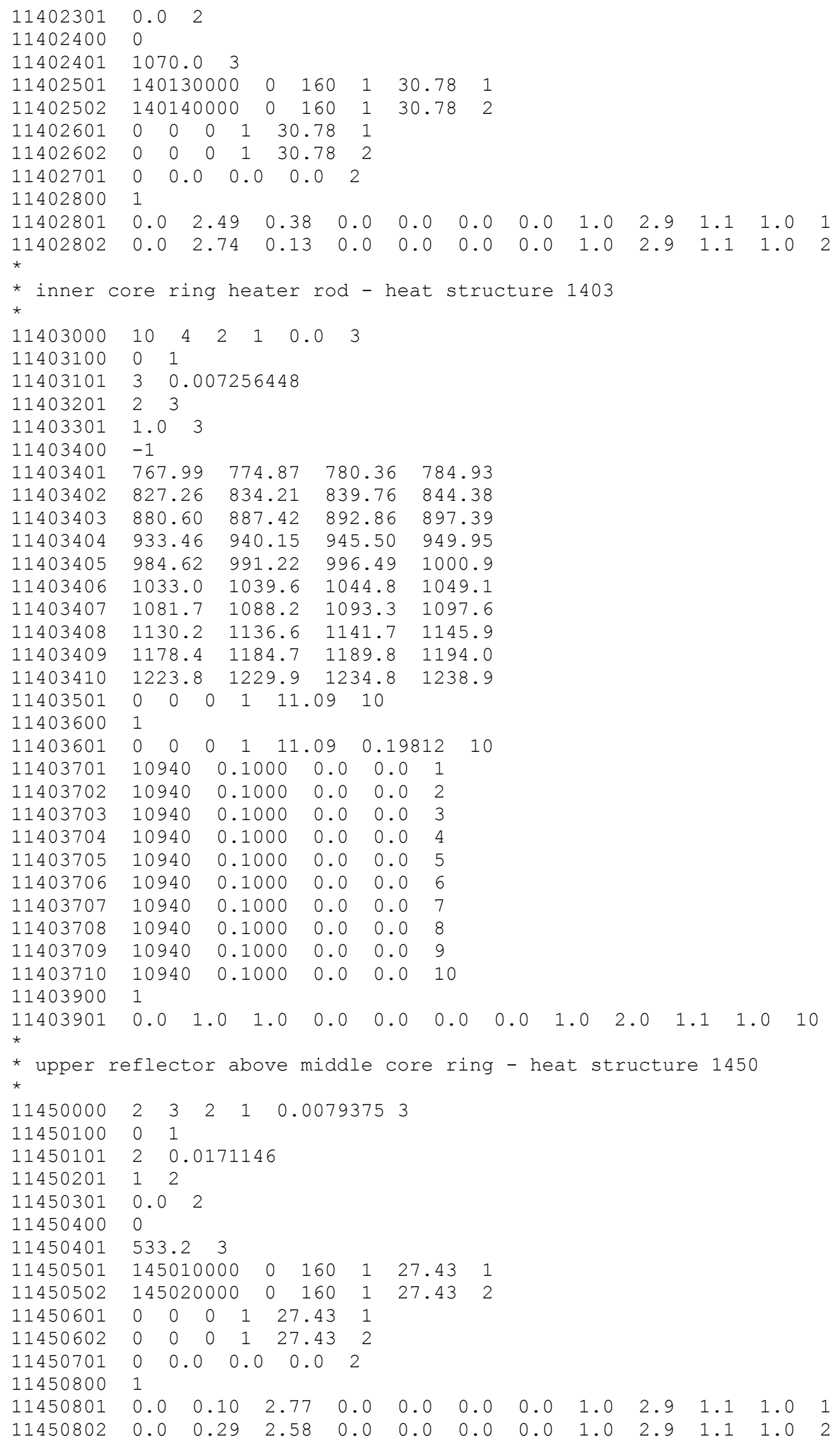




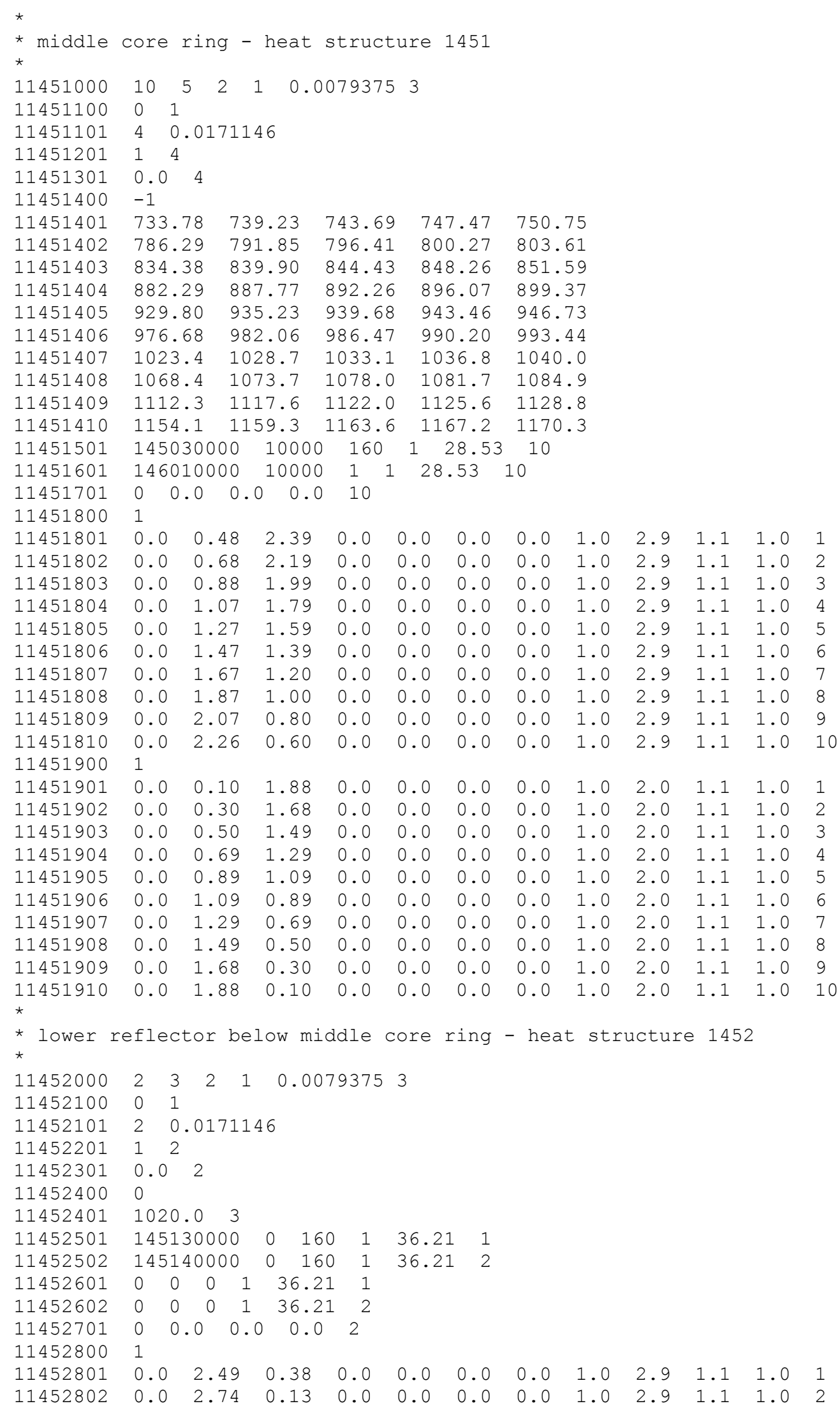




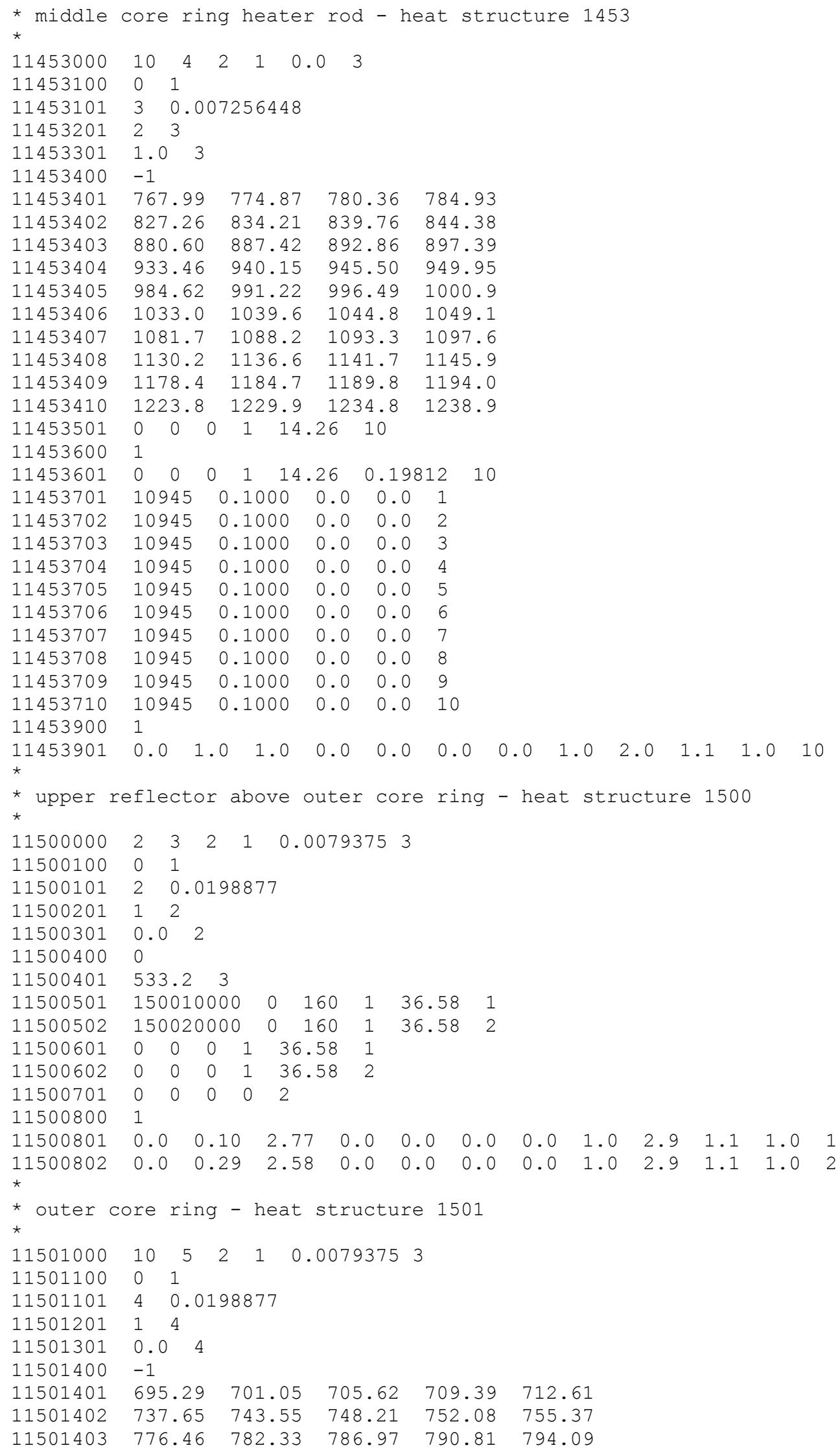




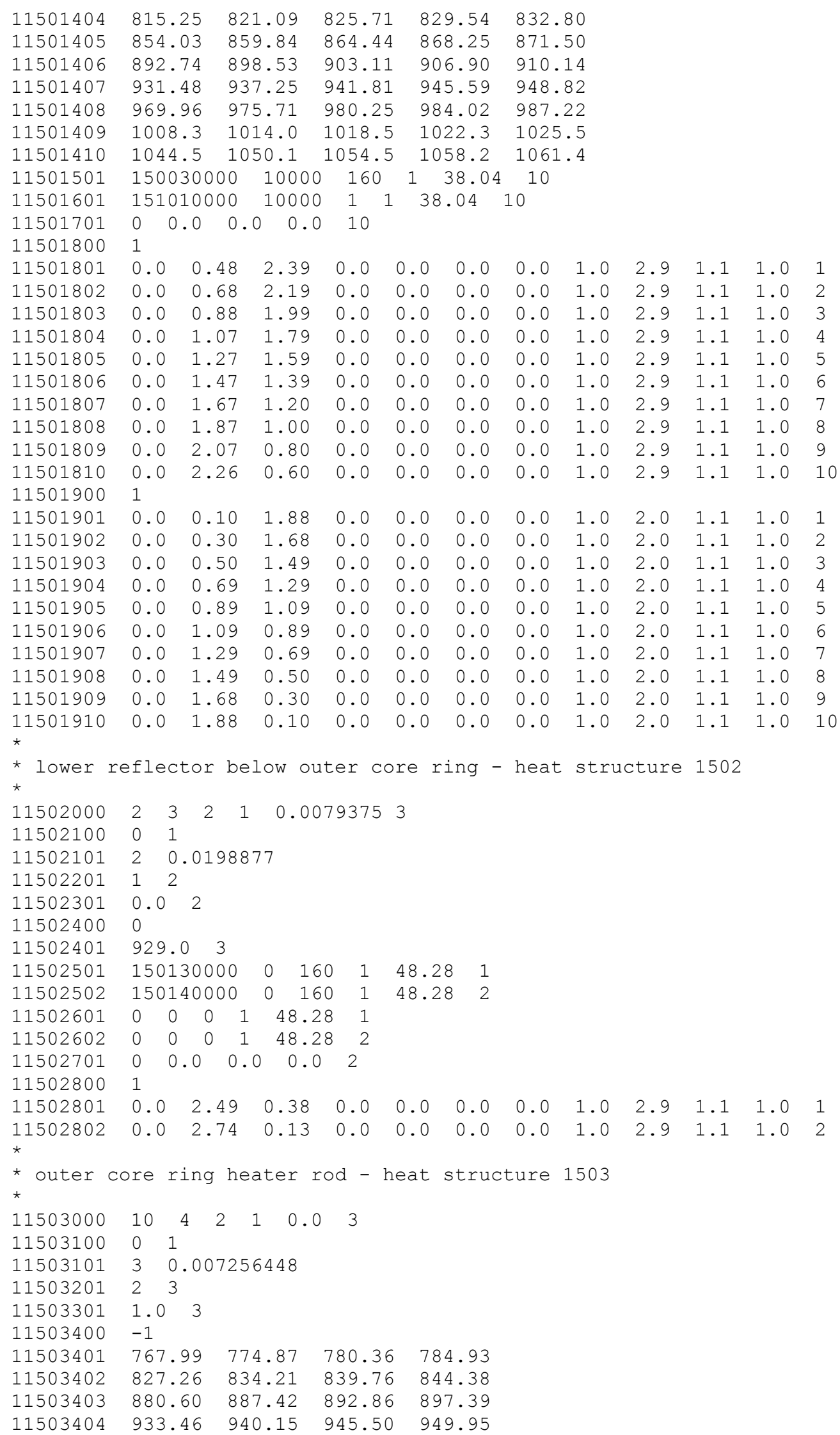




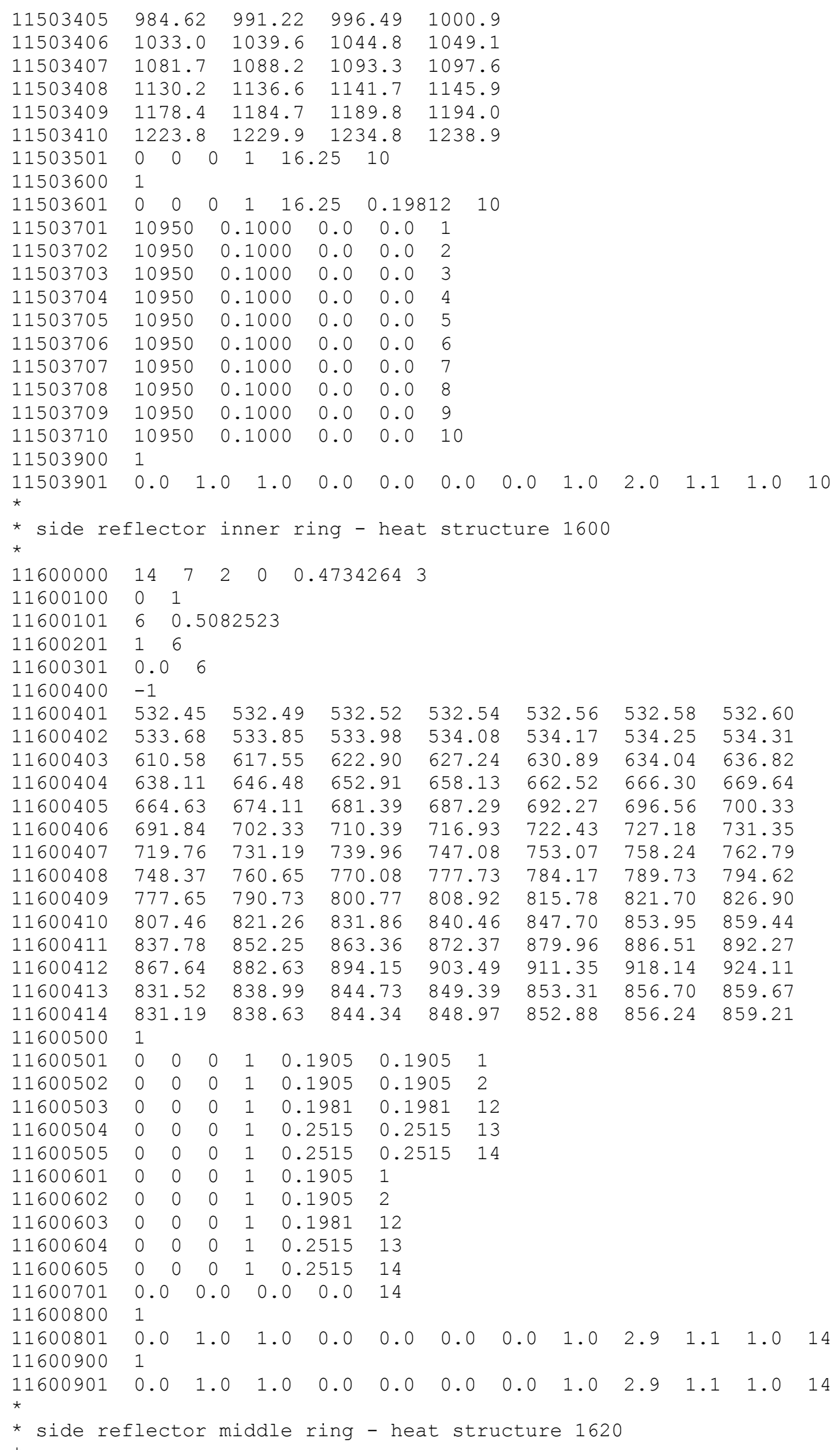




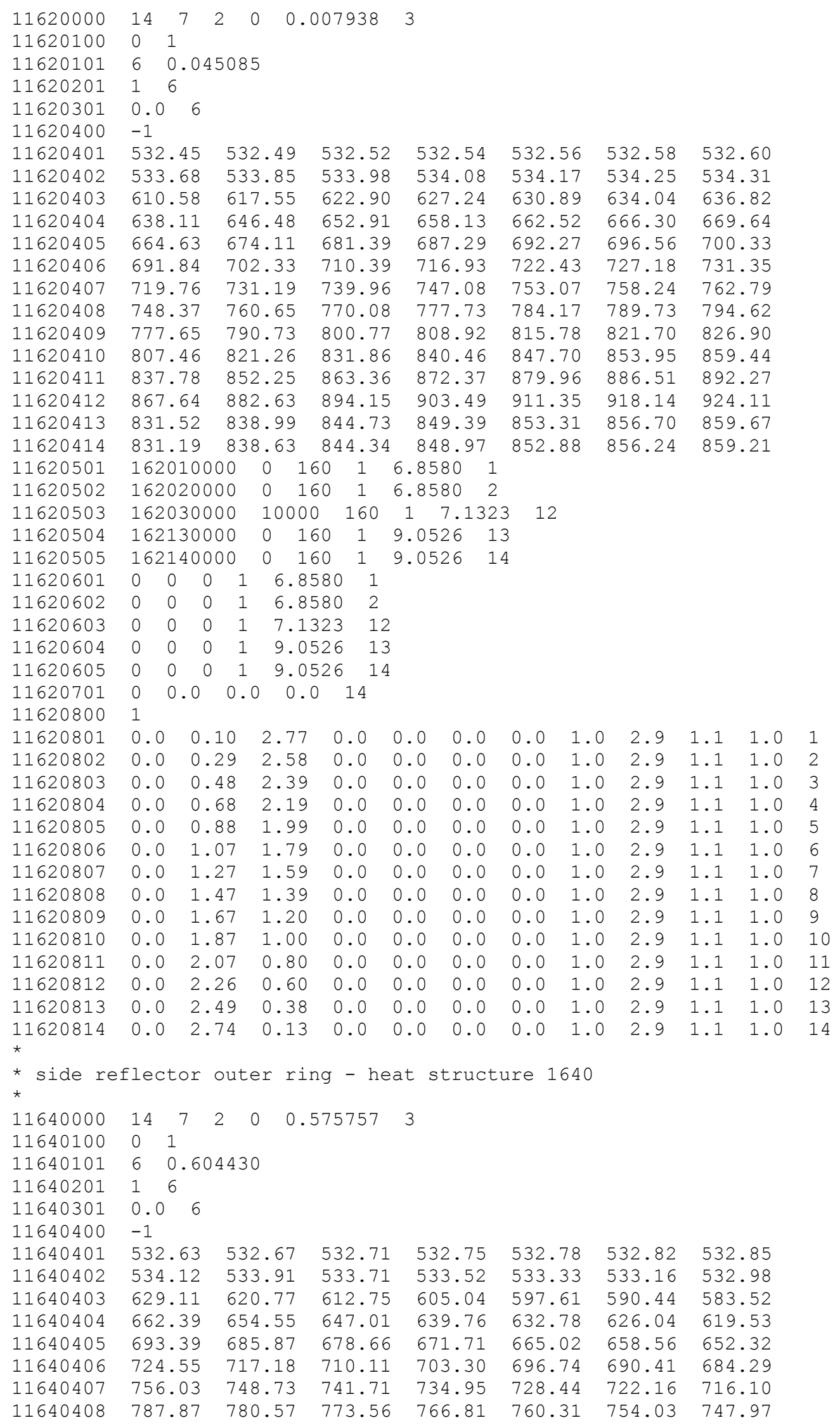




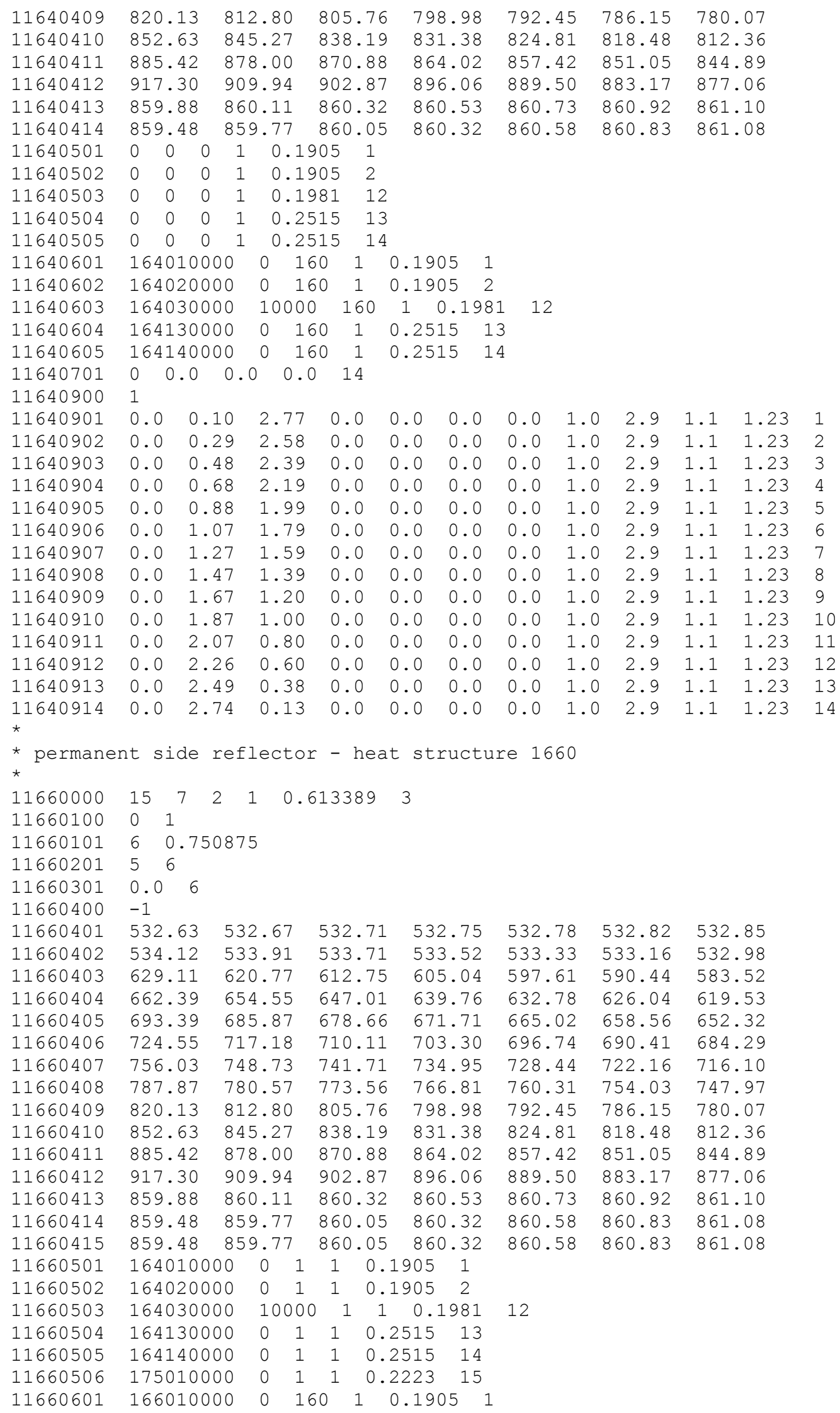




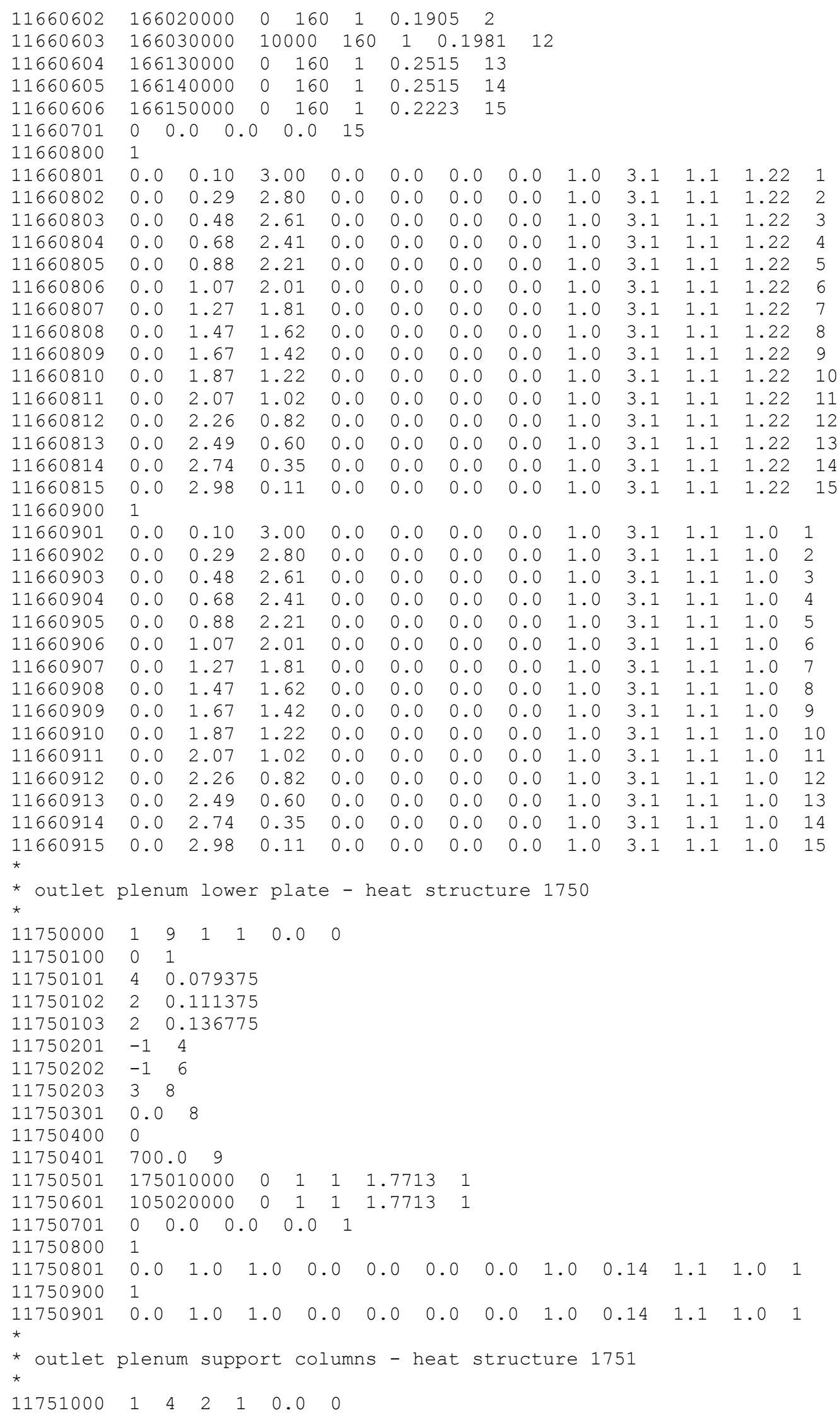




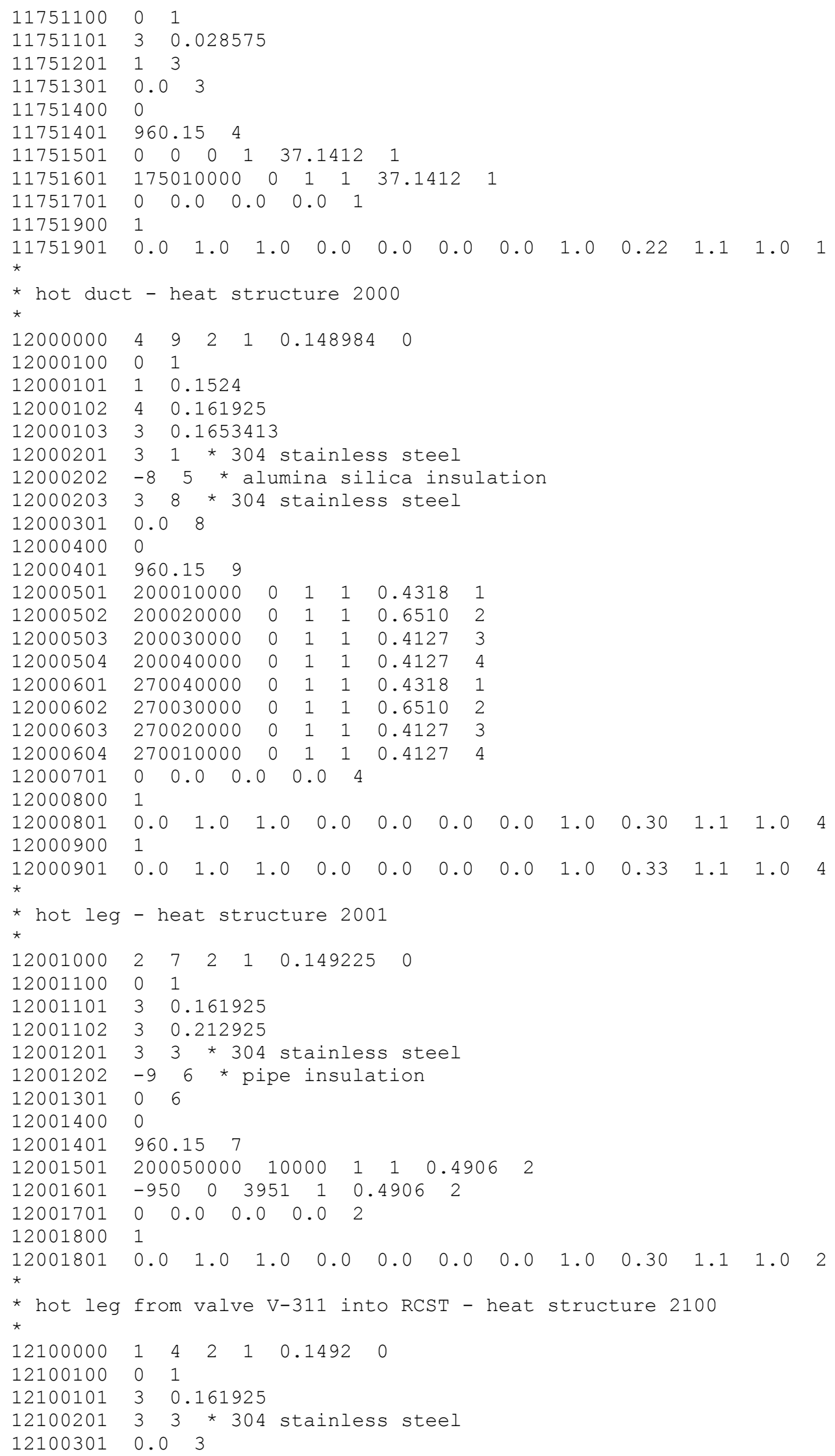




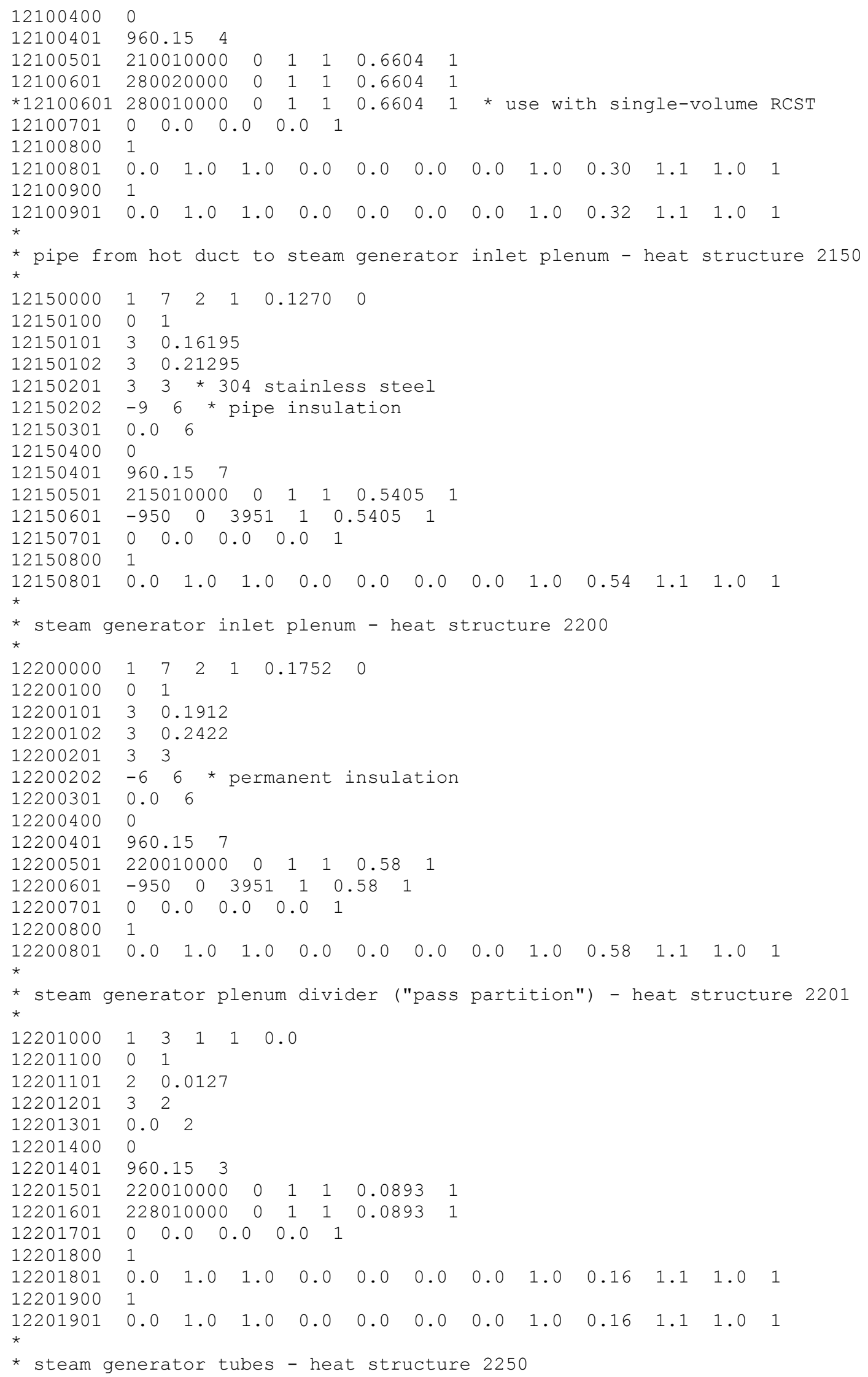




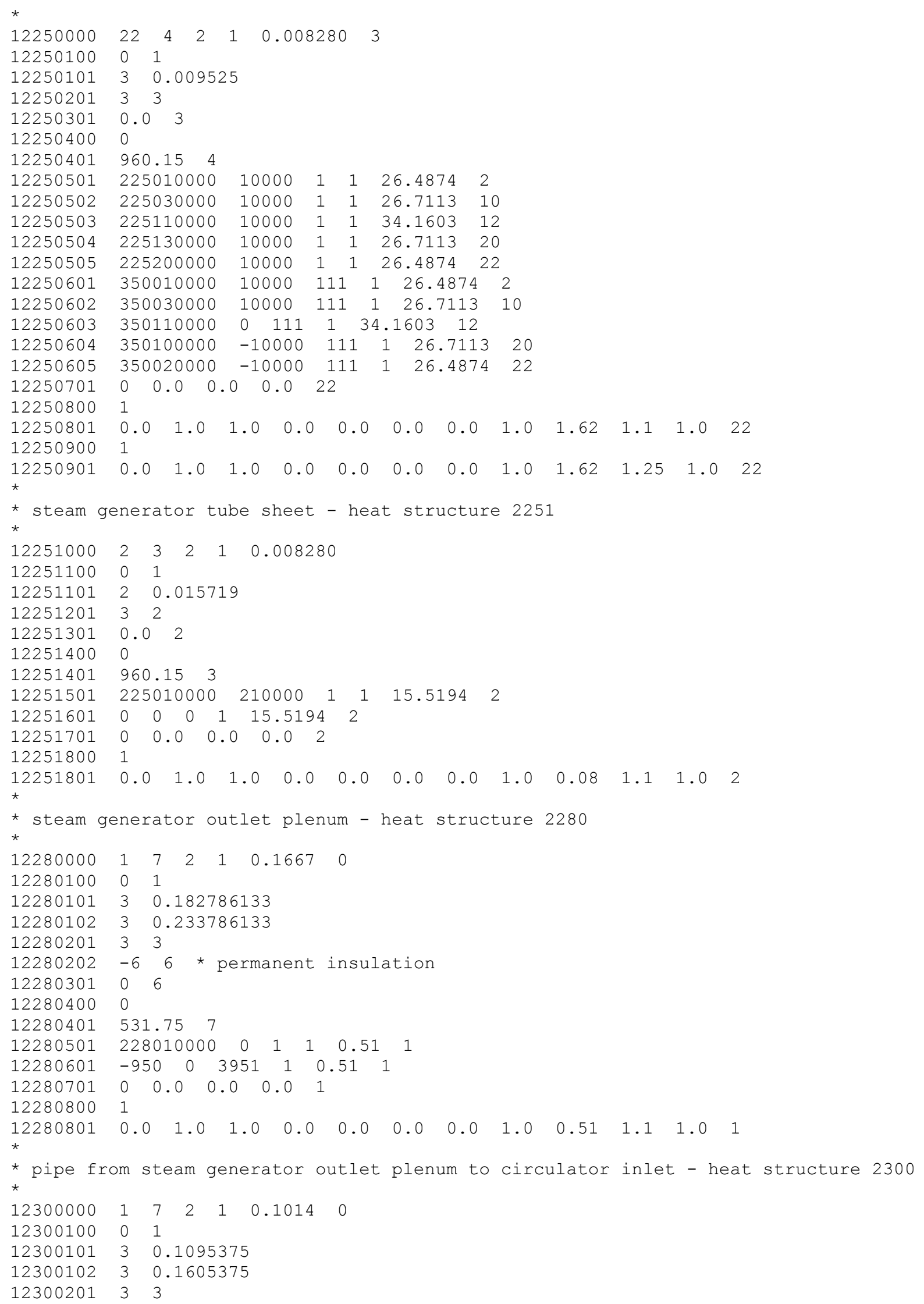




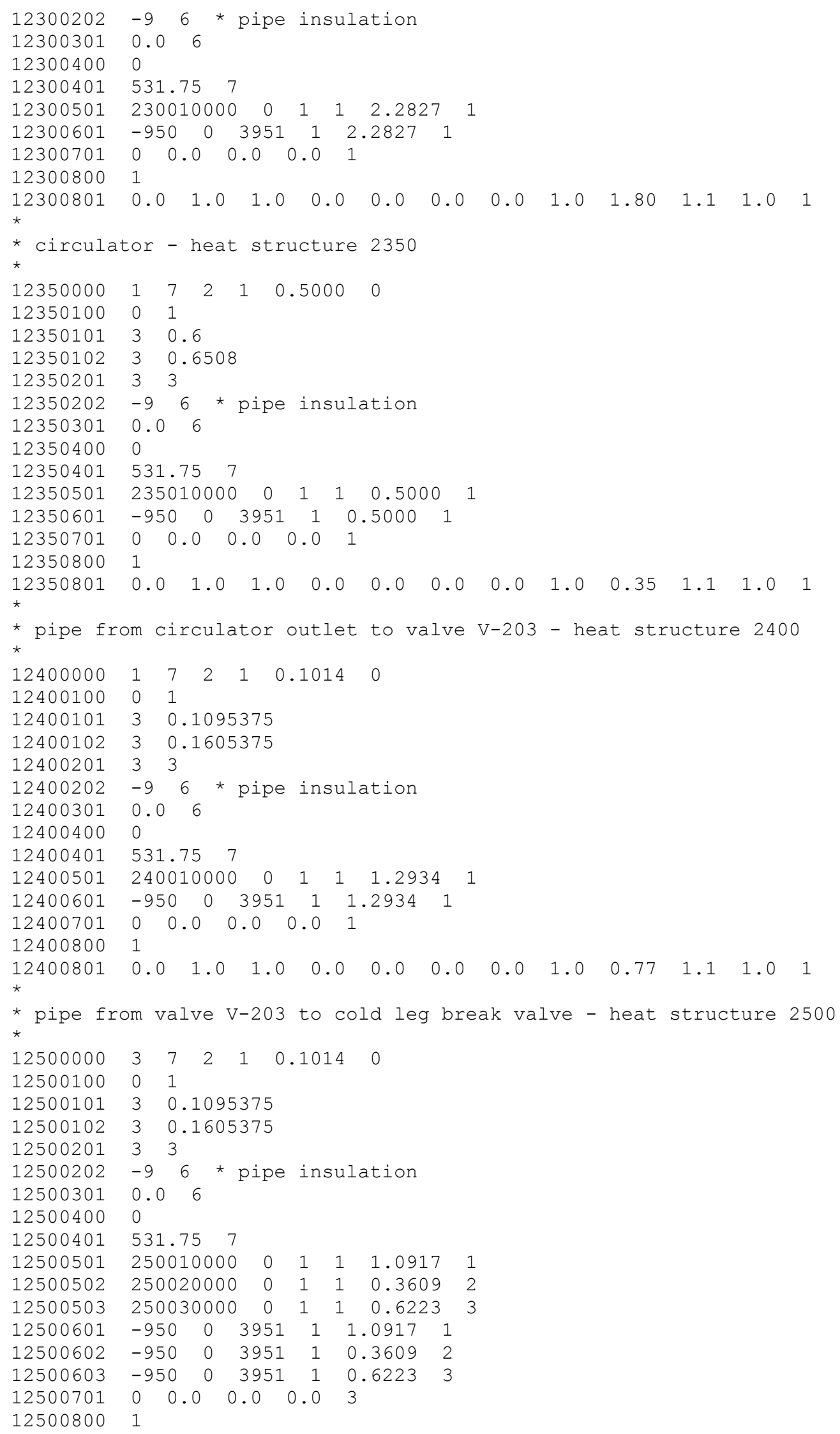




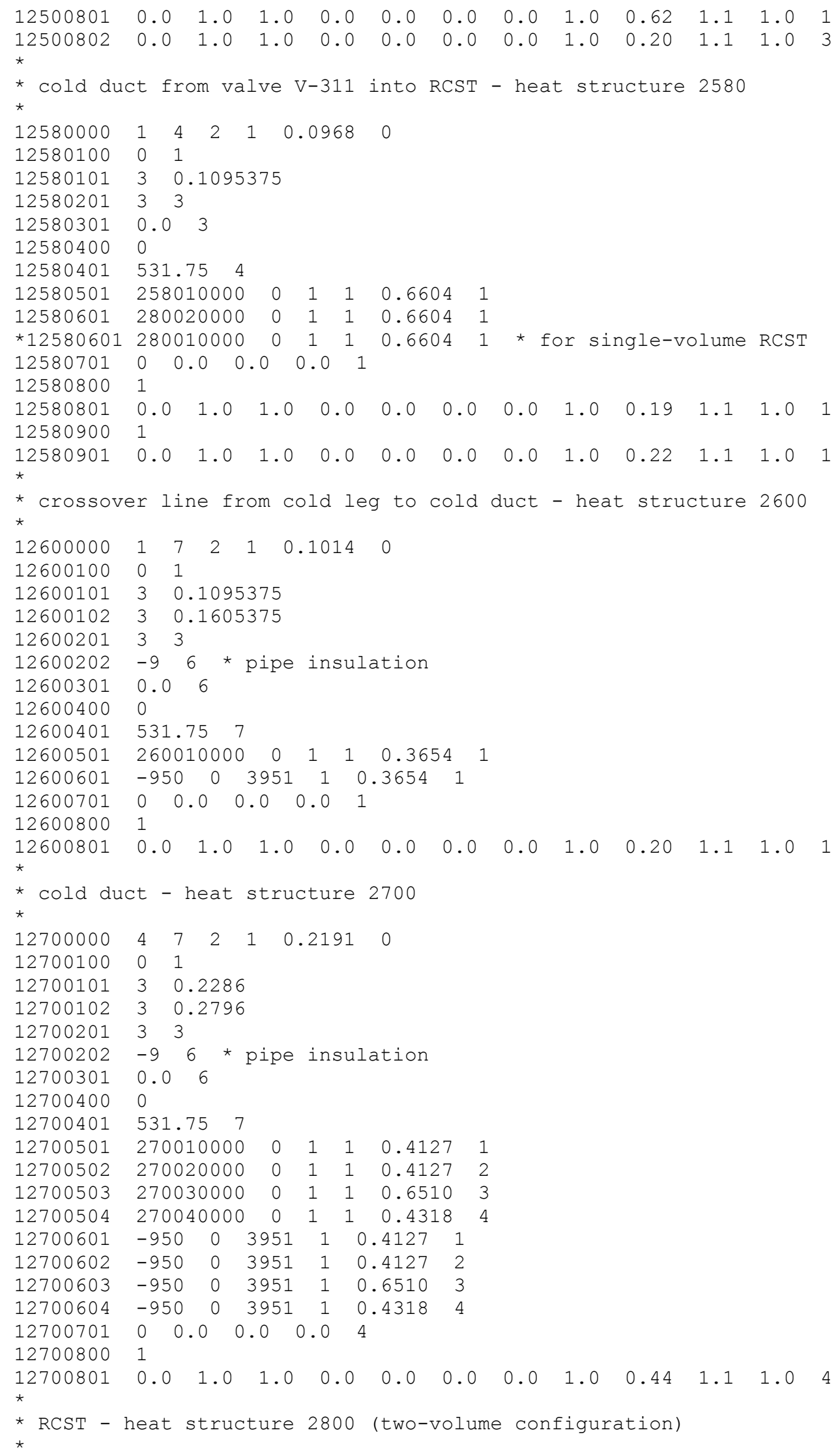




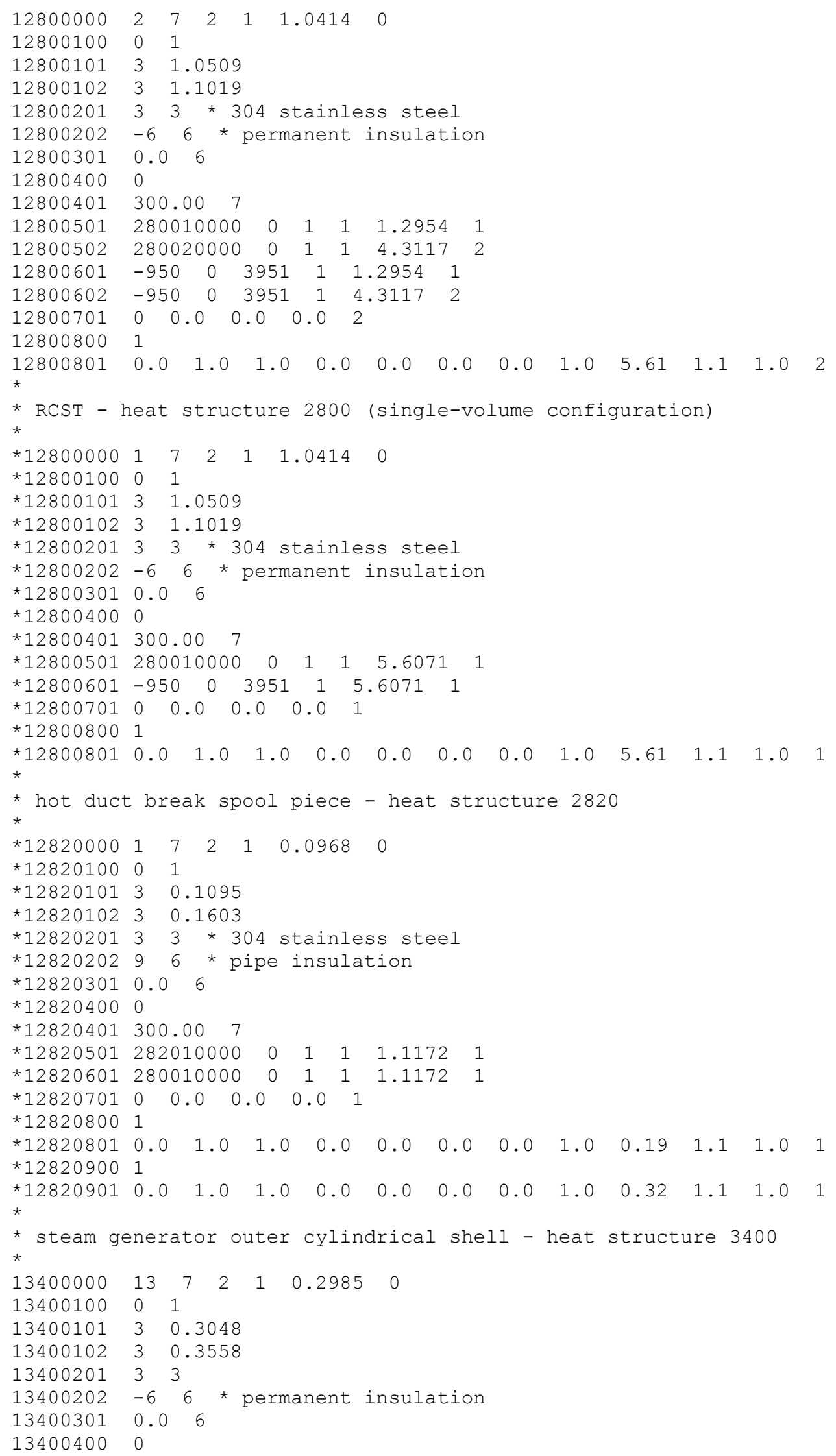




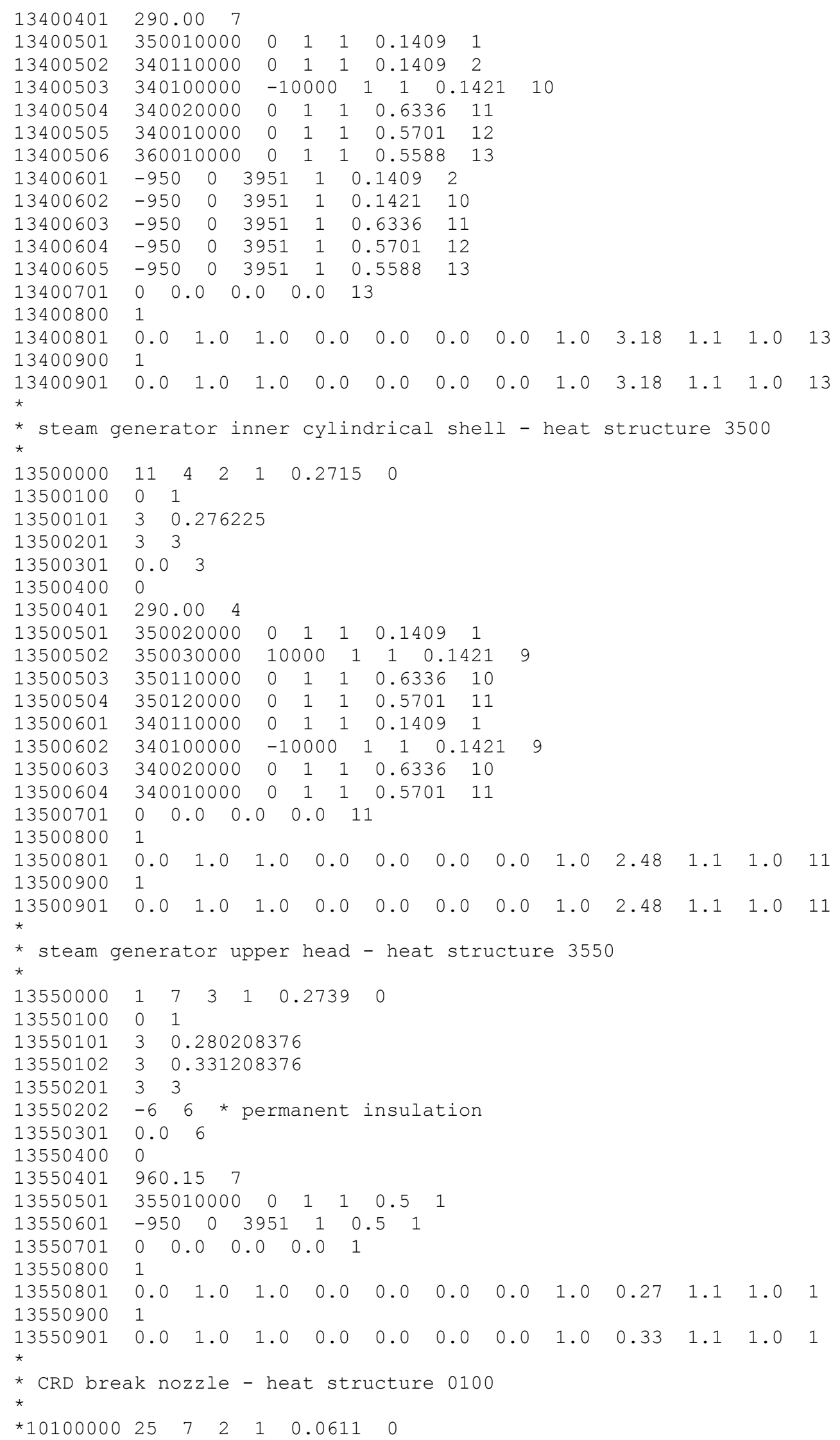




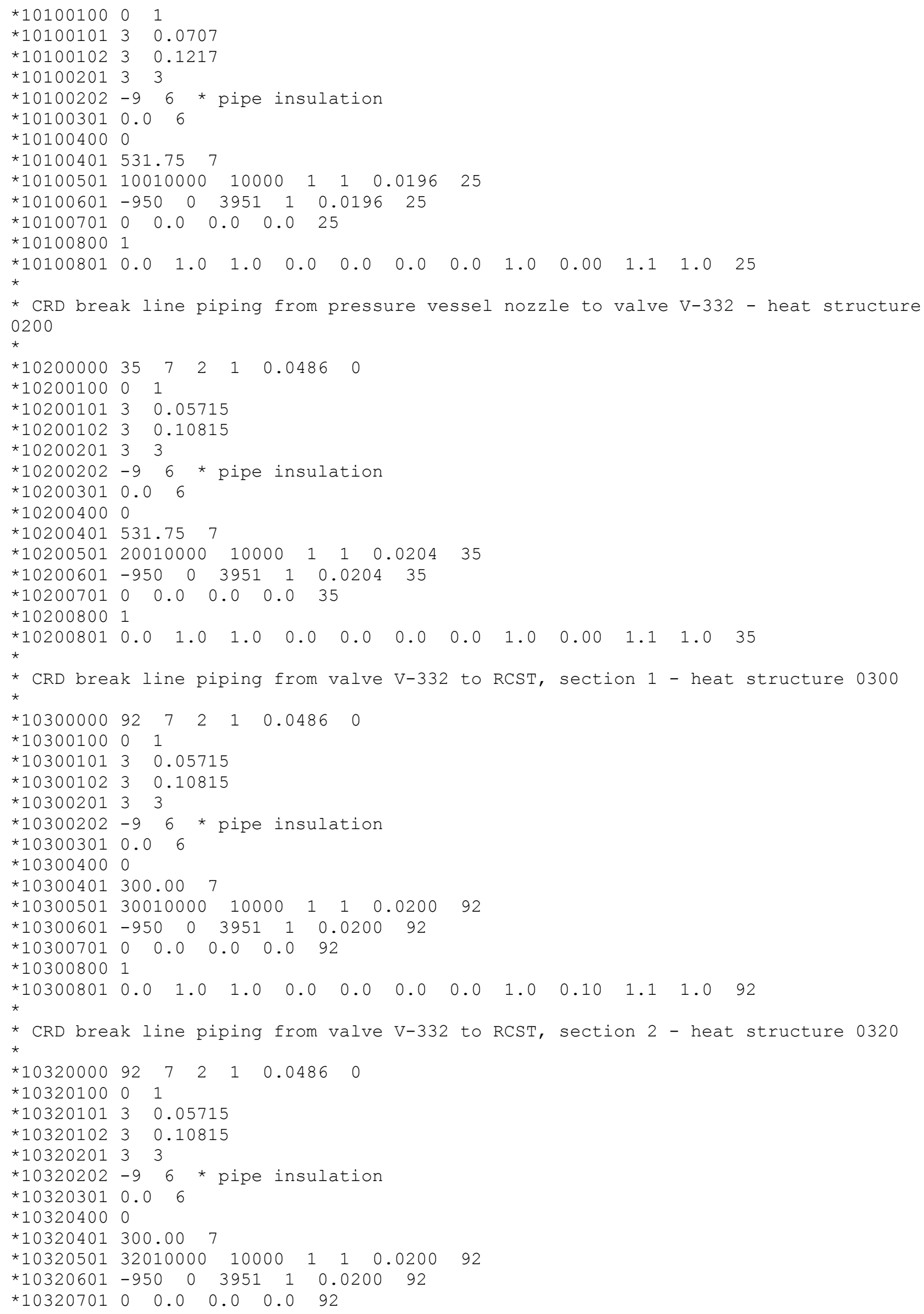




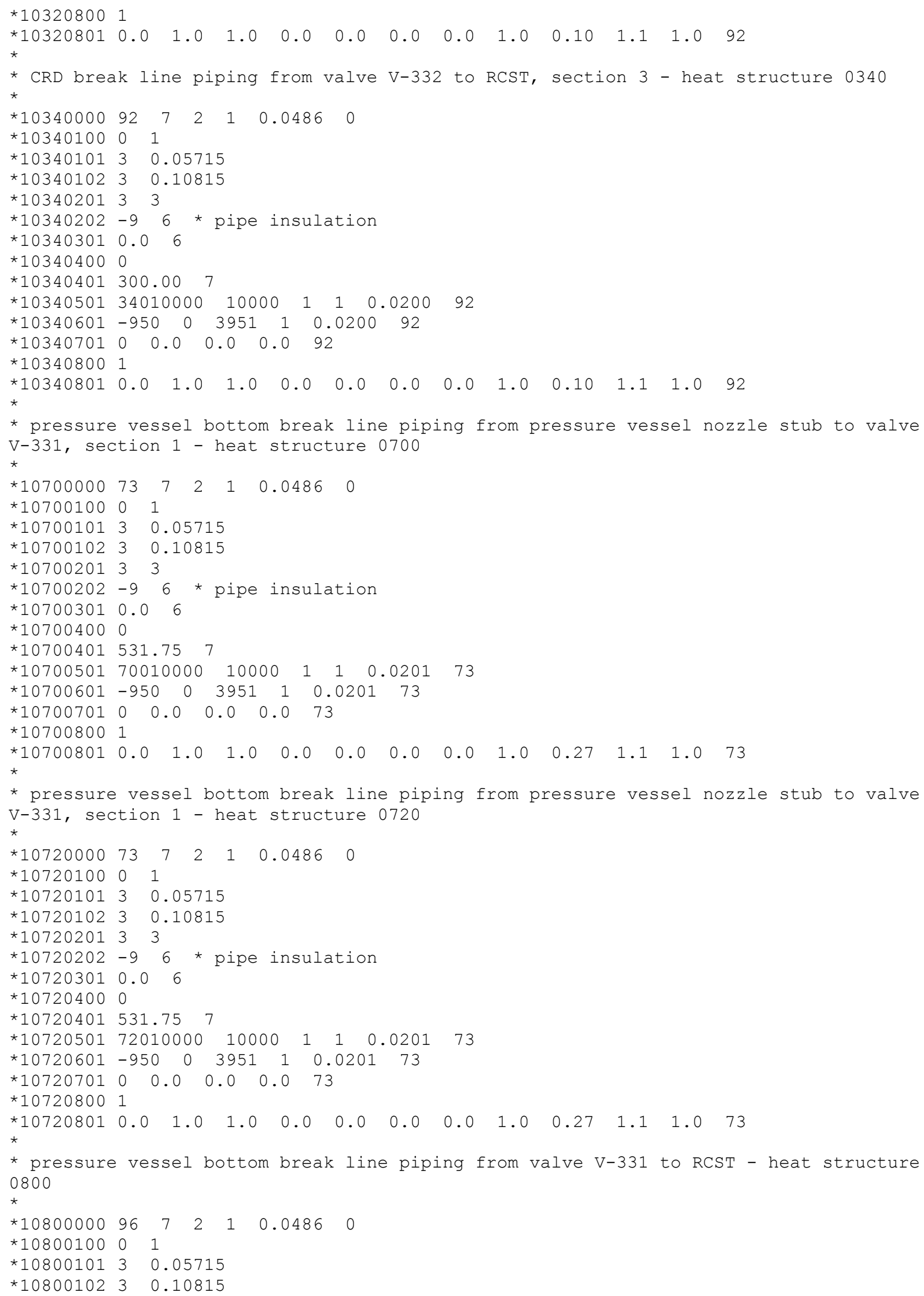




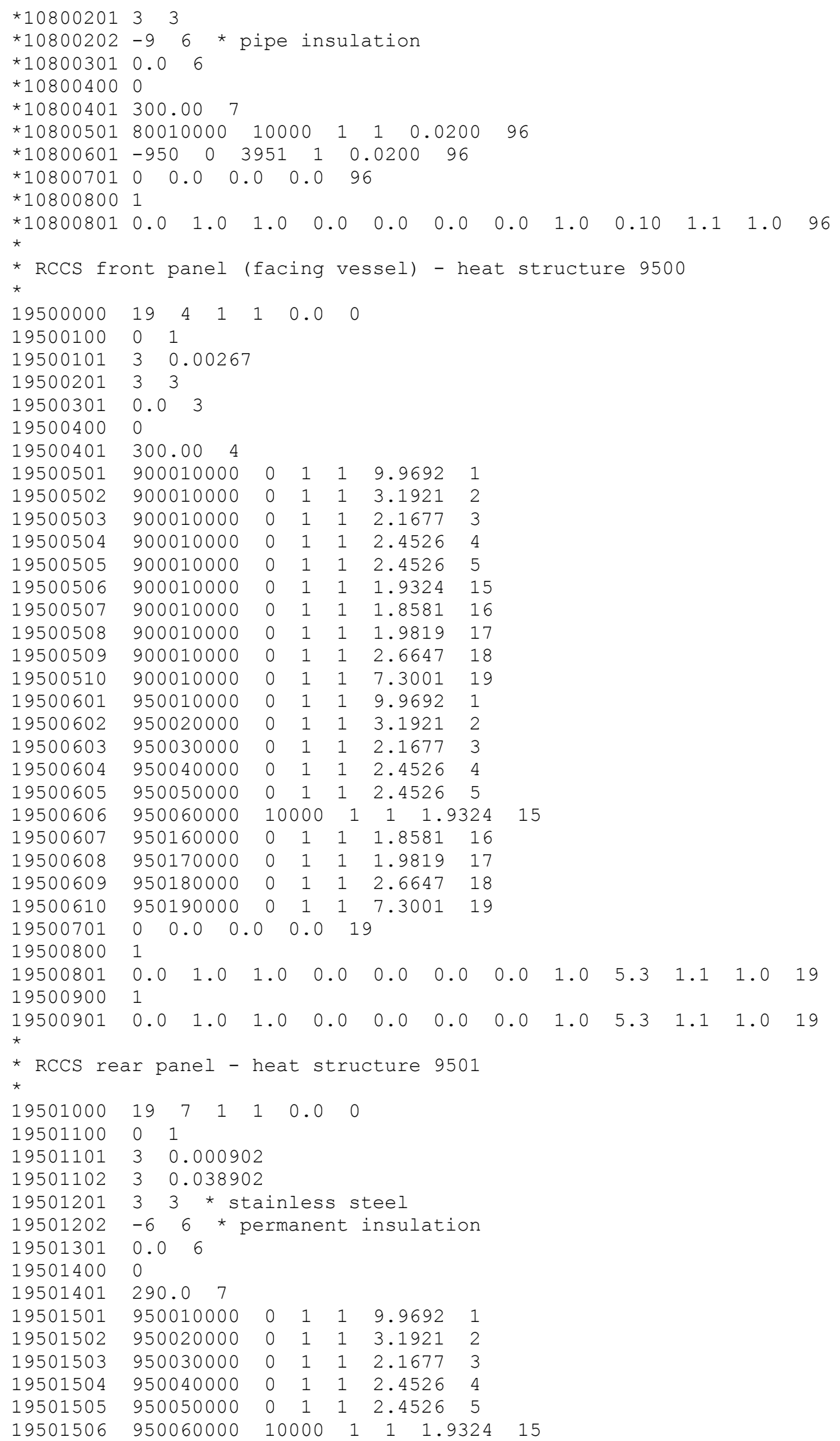




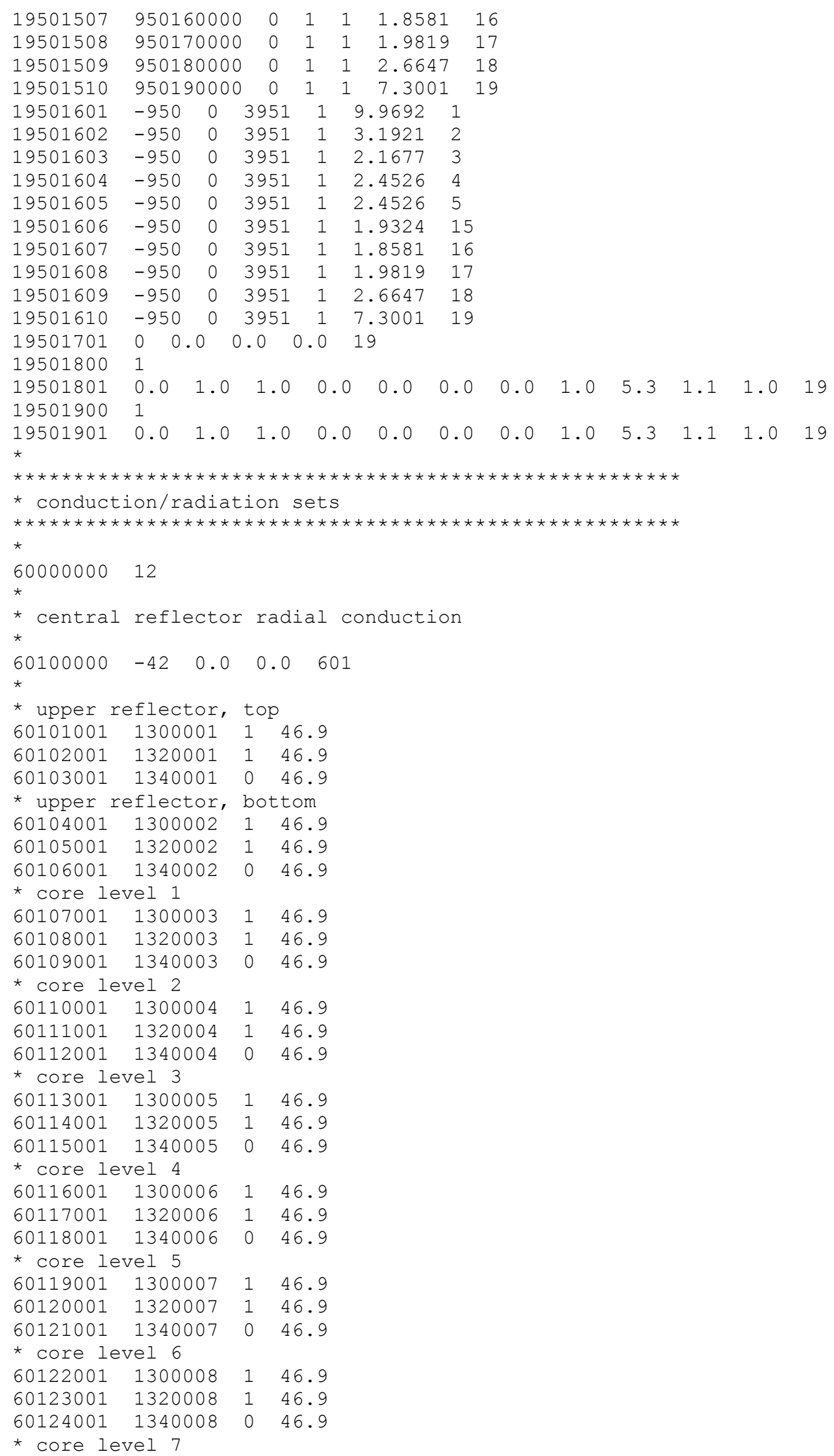




\begin{tabular}{|c|c|c|c|c|c|c|c|c|c|c|c|}
\hline 60125001 & 1300 & 009 & 1 & 46.9 & & & & & & & \\
\hline 60126001 & 1320 & 009 & 1 & 46.9 & & & & & & & \\
\hline 60127001 & 1340 & 009 & 0 & 46.9 & & & & & & & \\
\hline * core le & vel 8 & & & & & & & & & & \\
\hline 60128001 & 1300 & 010 & 1 & 46.9 & & & & & & & \\
\hline 60129001 & 1320 & 010 & 1 & 46.9 & & & & & & & \\
\hline 60130001 & 1340 & 010 & 0 & 46.9 & & & & & & & \\
\hline * core le & vel 9 & & & & & & & & & & \\
\hline 60131001 & 1300 & 011 & 1 & 46.9 & & & & & & & \\
\hline 60132001 & 1320 & 011 & 1 & 46.9 & & & & & & & \\
\hline 60133001 & 1340 & 011 & 0 & 46.9 & & & & & & & \\
\hline * core le & vel 1 & & & & & & & & & & \\
\hline 60134001 & 1300 & 012 & 1 & 46.9 & & & & & & & \\
\hline 60135001 & 1320 & 012 & 1 & 46.9 & & & & & & & \\
\hline 60136001 & 1340 & 012 & 0 & 46.9 & & & & & & & \\
\hline * bottom & refle & ctor & $=$, up & pper & & & & & & & \\
\hline 60137001 & 1300 & 013 & 1 & 46.9 & & & & & & & \\
\hline 60138001 & 1320 & 013 & 1 & 46.9 & & & & & & & \\
\hline 60139001 & 1340 & 013 & 0 & 46.9 & & & & & & & \\
\hline * bottom & refle & ctor & $=1$ & ower & & & & & & & \\
\hline 60140001 & 1300 & 014 & 1 & 46.9 & & & & & & & \\
\hline 60141001 & 1320 & 014 & 1 & 46.9 & & & & & & & \\
\hline 60142001 & 1340 & 014 & 0 & 46.9 & & & & & & & \\
\hline * conduct & ion a & rea & fact & tors & & & & & & & \\
\hline * upper & eflec & tor, & tor & & & & & & & & \\
\hline 60101101 & 0.0 & 1 & 1.3 & 40979 & 2 & 0.0 & 42 & & & & \\
\hline 60102101 & 0.27 & 9371 & 1 & 0.0 & 2 & 0.6146 & 615 & 0.0 & 42 & & \\
\hline 60103101 & 0.0 & 1 & 1.3 & 40979 & 2 & $0.0 \quad 4$ & 42 & & & & \\
\hline * upper & eflec & tor, & bot & ttom & & & & & & & \\
\hline 60104101 & 0.0 & 4 & 1.3 & 40979 & 5 & 0.0 & 42 & & & & \\
\hline 60105101 & 0.0 & 3 & $0.2^{\prime}$ & 79371 & 4 & 0.0 & 0 & .614615 & 0.0 & 42 & \\
\hline 60106101 & 0.0 & 4 & 1.3 & 40979 & 5 & 0.0 & 42 & & & & \\
\hline * core le & vel 1 & & & & & & & & & & \\
\hline 60107101 & 0.0 & 7 & 1.3 & 40979 & 8 & 0.0 & 42 & & & & \\
\hline 60108101 & 0.0 & 6 & 0.2 & 79371 & 7 & 0.0 & 0 & .614615 & 0.0 & 42 & \\
\hline 60109101 & 0.0 & 7 & 1.3 & 40979 & 8 & 0.0 & 42 & & & & \\
\hline * core le & vel 2 & & & & & & & & & & \\
\hline 60110101 & 0.0 & 10 & 1. & 340979 & 11 & 0.0 & 42 & & & & \\
\hline 60111101 & 0.0 & 9 & 0.2 & 79371 & 10 & 0.0 & 11 & 0.614615 & 12 & 0.0 & 42 \\
\hline 60112101 & 0.0 & 10 & 1 & 340979 & 11 & 0.0 & 42 & & & & \\
\hline * core le & vel 3 & & & & & & & & & & \\
\hline 60113101 & 0.0 & 13 & 1. & 340979 & 14 & 0.0 & 42 & & & & \\
\hline 60114101 & 0.0 & 12 & 0.2 & 279371 & 13 & 0.0 & 14 & 0.614615 & 15 & 0.0 & 42 \\
\hline 60115101 & 0.0 & 13 & 1. & 340979 & 14 & 0.0 & 42 & & & & \\
\hline * core le & vel 4 & & & & & & & & & & \\
\hline 60116101 & 0.0 & 16 & 1. & 340979 & 17 & 0.0 & 42 & & & & \\
\hline 60117101 & 0.0 & 15 & 0.2 & 279371 & 16 & 0.0 & 17 & 0.614615 & 18 & 0.0 & 42 \\
\hline 60118101 & 0.0 & 16 & 1. & 340979 & 17 & 0.0 & 42 & & & & \\
\hline * core le & vel 5 & & & & & & & & & & \\
\hline 60119101 & 0.0 & 19 & 1. & 340979 & 20 & 0.0 & 42 & & & & \\
\hline 60120101 & 0.0 & 18 & 0.2 & 279371 & 19 & 0.0 & 20 & 0.61461 & 21 & 0.0 & 42 \\
\hline 60121101 & 0.0 & 19 & & 340979 & 20 & 0.0 & 42 & & & & \\
\hline * core le & vel 6 & & & & & & & & & & \\
\hline 60122101 & 0.0 & 22 & 1. & 340979 & 23 & 0.0 & 42 & & & & \\
\hline 60123101 & 0.0 & 21 & 0. & 279371 & 22 & 0.0 & 23 & 0.61461 & 24 & 0.0 & 42 \\
\hline 60124101 & 0.0 & 22 & 1. & 340979 & 23 & 0.0 & 42 & & & & \\
\hline * core le & vel 7 & & & & & & & & & & \\
\hline 60125101 & 0.0 & 25 & 1. & 340979 & 26 & 0.0 & 42 & & & & \\
\hline 60126101 & 0.0 & 24 & 0. & 279371 & 25 & 0.0 & 26 & 0.614615 & 27 & 0.0 & 42 \\
\hline 60127101 & 0.0 & 25 & & 340979 & 26 & 0.0 & 42 & & & & \\
\hline * core le & vel 8 & & & & & & & & & & \\
\hline 60128101 & 0.0 & 28 & & 340979 & 29 & 0.0 & 42 & & & & \\
\hline 60129101 & 0.0 & 27 & 0.2 & 279371 & 28 & 0.0 & 29 & 0.614615 & 30 & 0.0 & 42 \\
\hline
\end{tabular}




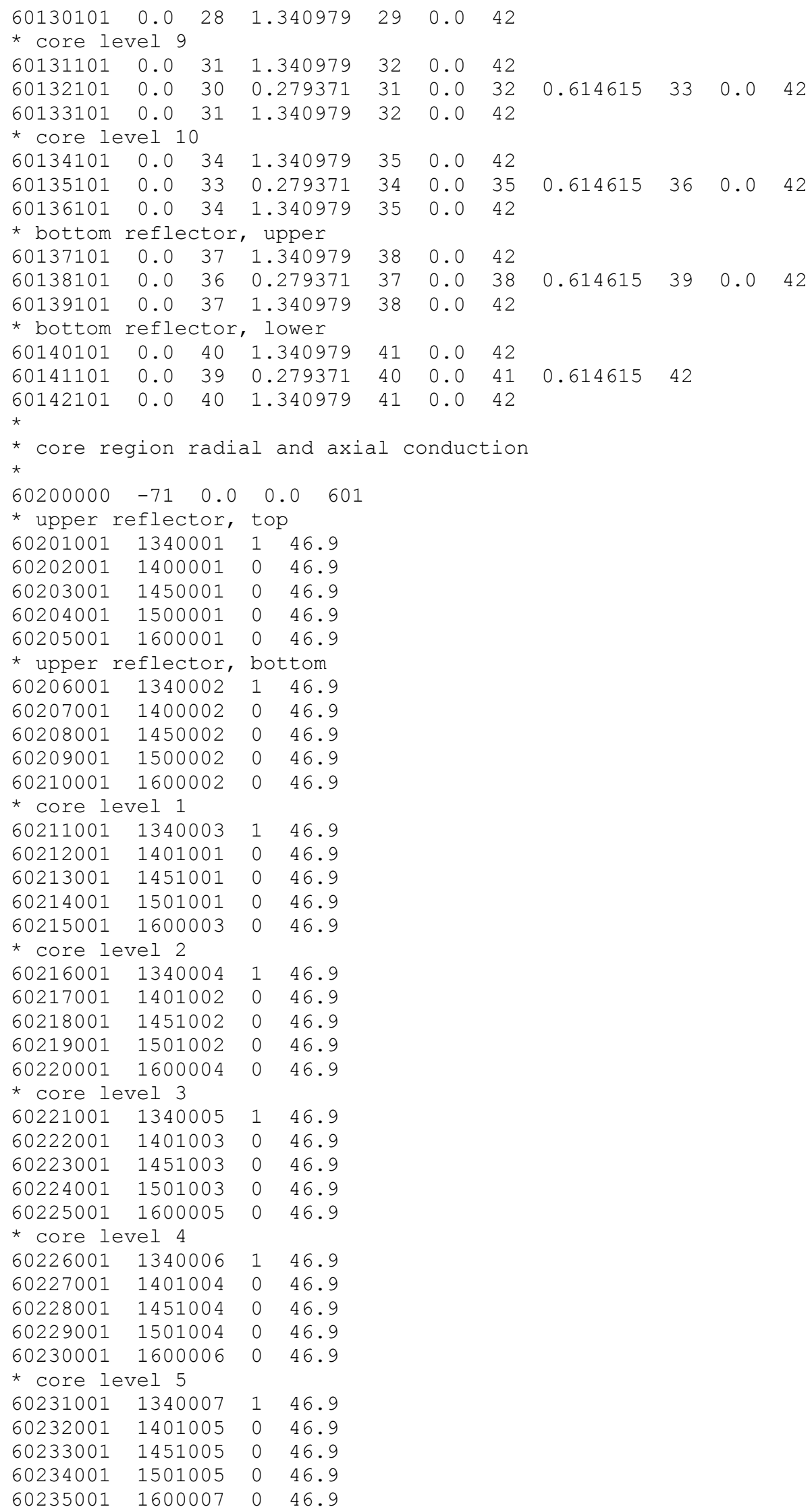




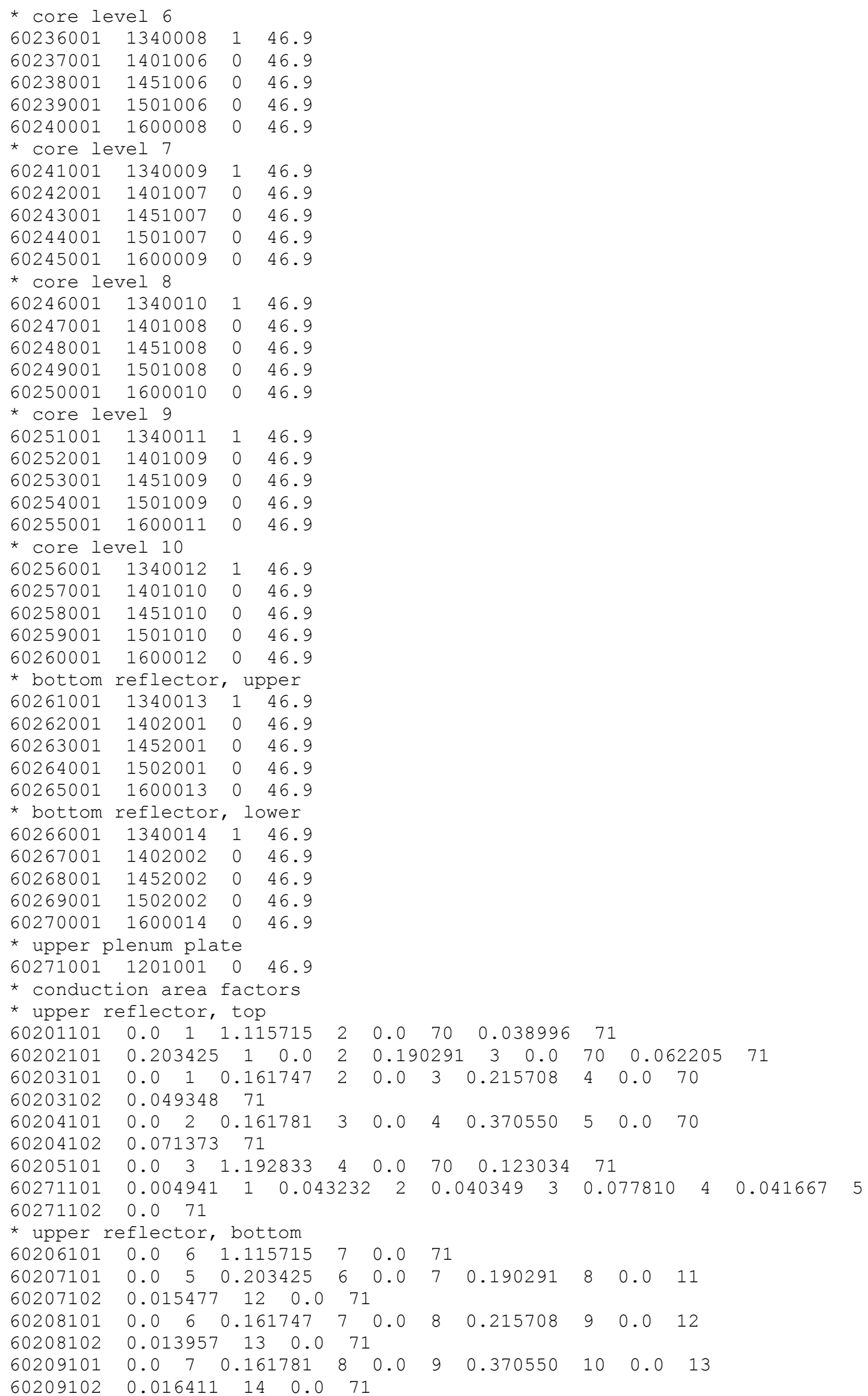




\begin{tabular}{|c|c|c|c|c|c|c|c|c|c|c|}
\hline $\begin{array}{l}60210101 \\
* \quad \text { core l }\end{array}$ & $\begin{array}{c}0.0 \\
\text { vel } 1\end{array}$ & 8 & 1.192833 & 9 & .0 & & & & & \\
\hline 60211101 & 0.0 & 11 & 1.661174 & 12 & 0.0 & 71 & & & & \\
\hline 60212101 & 0.0 & 6 & 0.014881 & 70 & .0 & & 0.302877 & 11 & 0.0 & 12 \\
\hline 60212102 & 0.293 & 3809 & $\begin{array}{lll}9 & 13 & 0.0\end{array}$ & 71 & & & & & & \\
\hline 60213101 & 0.0 & 7 & 0.013421 & 80 & .0 & & 0.249738 & 12 & 0.0 & 13 \\
\hline 60213102 & 0.323 & 3498 & 0.0 & 71 & & & & & & \\
\hline 60214101 & 0.0 & 8 & 0.015780 & & .0 & & 0.242623 & 13 & 0.0 & 14 \\
\hline 60214102 & 0.523 & 3730 & 15 & 71 & & & & & & \\
\hline 60215101 & 0.0 & 13 & 1.685933 & 14 & 0.0 & 71 & & & & \\
\hline core 1 & vel 2 & & & & & & & & & \\
\hline 60216101 & 0.0 & 16 & 1.661174 & 17 & 0.0 & 71 & & & & \\
\hline 60217101 & 0.0 & 15 & 0.302877 & 16 & 0.0 & 17 & 0.293809 & 18 & 0.0 & 71 \\
\hline 60218101 & 0.0 & 16 & 0.249738 & 17 & 0.0 & 18 & 0.323498 & 19 & 0.0 & 71 \\
\hline 60219101 & 0.0 & 17 & 0.242623 & 18 & 0.0 & 19 & 0.523730 & 20 & 0.0 & 71 \\
\hline 60220101 & 0.0 & 18 & 1.685933 & 19 & 0.0 & 71 & & & & \\
\hline core 1 & vel 3 & & & & & & & & & \\
\hline 60221101 & 0.0 & 21 & 1.661174 & 22 & 0.0 & 71 & & & & \\
\hline 60222101 & 0.0 & 20 & 0.302877 & 21 & 0.0 & 22 & 0.293809 & 23 & 0.0 & 71 \\
\hline 60223101 & 0.0 & 21 & 0.249738 & 22 & 0.0 & 23 & 0.323498 & 24 & 0.0 & 71 \\
\hline 60224101 & 0.0 & 22 & 0.242623 & 23 & 0.0 & 24 & 0.523730 & 25 & 0.0 & 71 \\
\hline 60225101 & 0.0 & 23 & 1.685933 & 24 & 0.0 & 71 & & & & \\
\hline * core 1 & vel 4 & & & & & & & & & \\
\hline 60226101 & 0.0 & 26 & 1.661174 & 27 & 0.0 & 71 & & & & \\
\hline 60227101 & 0.0 & 25 & 0.302877 & 26 & 0.0 & 27 & 0.293809 & 28 & 0.0 & 71 \\
\hline 60228101 & 0.0 & 26 & 0.249738 & 27 & 0.0 & 28 & 0.323498 & 29 & 0.0 & 71 \\
\hline 60229101 & 0.0 & 27 & 0.242623 & 28 & 0.0 & 29 & 0.523730 & 30 & 0.0 & 71 \\
\hline 60230101 & 0.0 & 28 & 1.685933 & 29 & 0.0 & 71 & & & & \\
\hline * core 1 & vel 5 & & & & & & & & & \\
\hline 60231101 & 0.0 & 31 & 1.661174 & 32 & 0.0 & 71 & & & & \\
\hline 60232101 & 0.0 & 30 & 0.302877 & 31 & 0.0 & 32 & 0.293809 & 33 & 0.0 & 71 \\
\hline 60233101 & 0.0 & 31 & 0.249738 & 32 & 0.0 & 33 & 0.323498 & 34 & 0.0 & 71 \\
\hline 60234101 & 0.0 & 32 & 0.242623 & 33 & 0.0 & 34 & 0.523730 & 35 & 0.0 & 71 \\
\hline $\begin{array}{l}60235101 \\
* \quad \text { core } 1\end{array}$ & $\begin{array}{c}0.0 \\
\text { vel } 6\end{array}$ & 33 & 1.685933 & 34 & 0.0 & 71 & & & & \\
\hline 60236101 & 0.0 & 36 & 1.661174 & 37 & 0.0 & 71 & & & & \\
\hline 60237101 & 0.0 & 35 & 0.302877 & 36 & 0.0 & 37 & 0.293809 & 38 & 0.0 & 71 \\
\hline 60238101 & 0.0 & 36 & 0.249738 & 37 & 0.0 & 38 & 0.323498 & 39 & 0.0 & 71 \\
\hline 60239101 & 0.0 & 37 & 0.242623 & 38 & 0.0 & 39 & 0.523730 & 40 & 0.0 & 71 \\
\hline 60240101 & 0.0 & 38 & 1.685933 & 39 & 0.0 & 71 & & & & \\
\hline * core 1 & vel 7 & & & & & & & & & \\
\hline 60241101 & 0.0 & 41 & 1.661174 & 42 & 0.0 & 71 & & & & \\
\hline 60242101 & 0.0 & 40 & 0.302877 & 41 & 0.0 & 42 & 0.293809 & 43 & 0.0 & 71 \\
\hline 60243101 & 0.0 & 41 & 0.249738 & 42 & 0.0 & 43 & 0.323498 & 44 & 0.0 & 71 \\
\hline 60244101 & 0.0 & 42 & 0.242623 & 43 & 0.0 & 44 & 0.523730 & 45 & 0.0 & 71 \\
\hline 60245101 & 0.0 & 43 & 1.685933 & 44 & 0.0 & 71 & & & & \\
\hline * core 1 & vel 8 & & & & & & & & & \\
\hline 60246101 & 0.0 & 46 & 1.661174 & 47 & 0.0 & 71 & & & & \\
\hline 60247101 & 0.0 & 45 & 0.302877 & 46 & 0.0 & 47 & 0.293809 & 48 & 0.0 & 71 \\
\hline 60248101 & 0.0 & 46 & 0.249738 & 47 & 0.0 & 48 & 0.323498 & 49 & 0.0 & 71 \\
\hline 60249101 & 0.0 & 47 & 0.242623 & 48 & 0.0 & 49 & 0.523730 & 50 & 0.0 & 71 \\
\hline 60250101 & 0.0 & 48 & 1.685933 & 49 & 0.0 & 71 & & & & \\
\hline * core l & vel 9 & & & & & & & & & \\
\hline 60251101 & 0.0 & 51 & 1.661174 & 52 & 0.0 & 71 & & & & \\
\hline 60252101 & 0.0 & 50 & 0.302877 & 51 & 0.0 & 52 & 0.293809 & 53 & 0.0 & 71 \\
\hline 60253101 & 0.0 & 51 & 0.249738 & 52 & 0.0 & 53 & 0.323498 & 54 & 0.0 & 71 \\
\hline 60254101 & 0.0 & 52 & 0.242623 & 53 & 0.0 & 54 & 0.523730 & 55 & 0.0 & 71 \\
\hline 60255101 & 0.0 & 53 & 1.685933 & 54 & 0.0 & 71 & & & & \\
\hline * core 1 & vel 1 & & & & & & & & & \\
\hline 60256101 & 0.0 & 56 & 1.661174 & 57 & 0.0 & 71 & & & & \\
\hline 60257101 & 0.0 & 55 & 0.302877 & 56 & 0.0 & 57 & 0.293809 & 58 & 0.0 & 61 \\
\hline 60257102 & 0.01 & 2522 & $2 \quad 62 \quad 0.0$ & 71 & & & & & & \\
\hline 60258101 & 0.0 & 56 & 0.249738 & 57 & 0.0 & 58 & 0.323498 & 59 & 0.0 & 62 \\
\hline
\end{tabular}




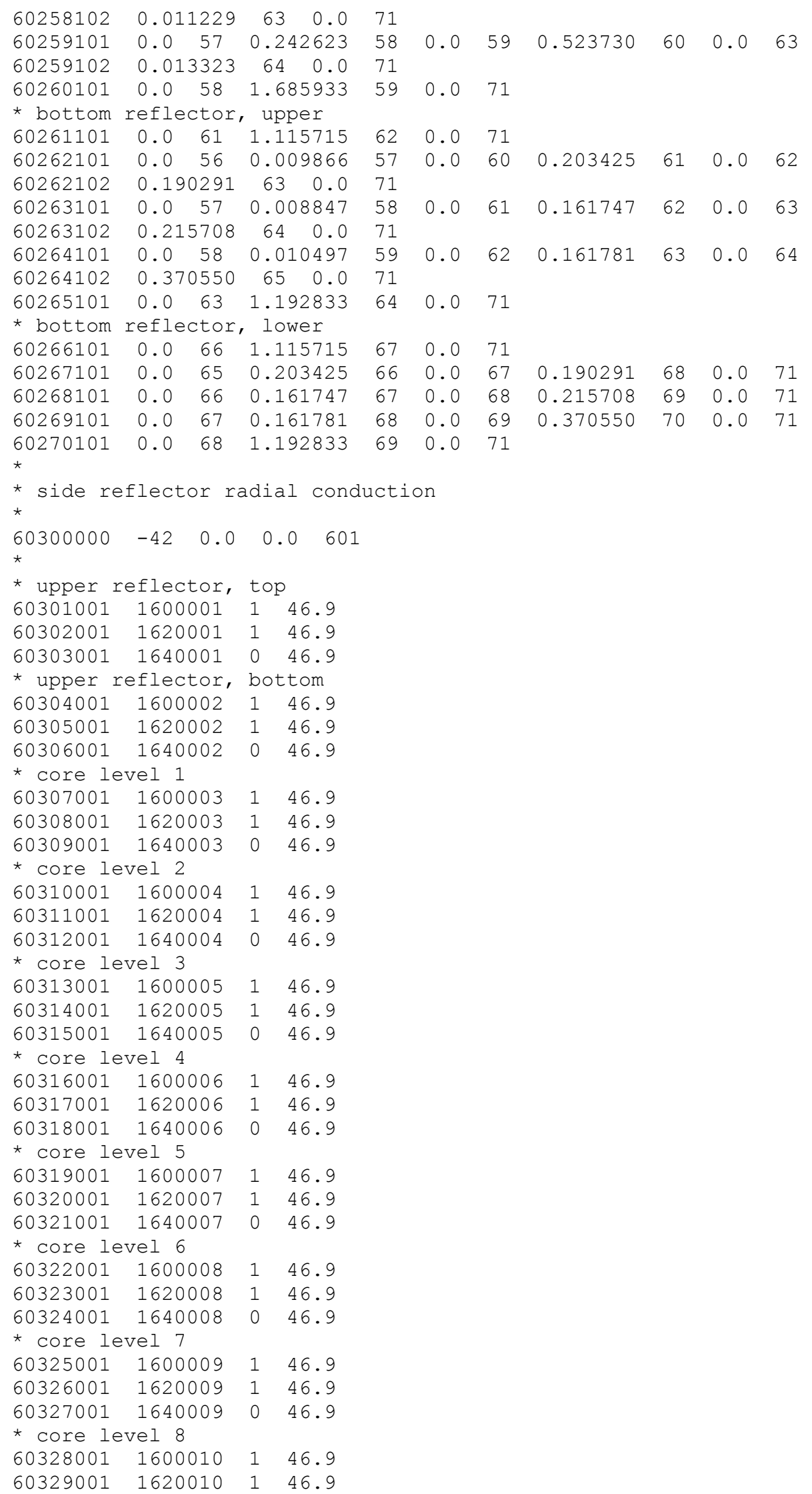




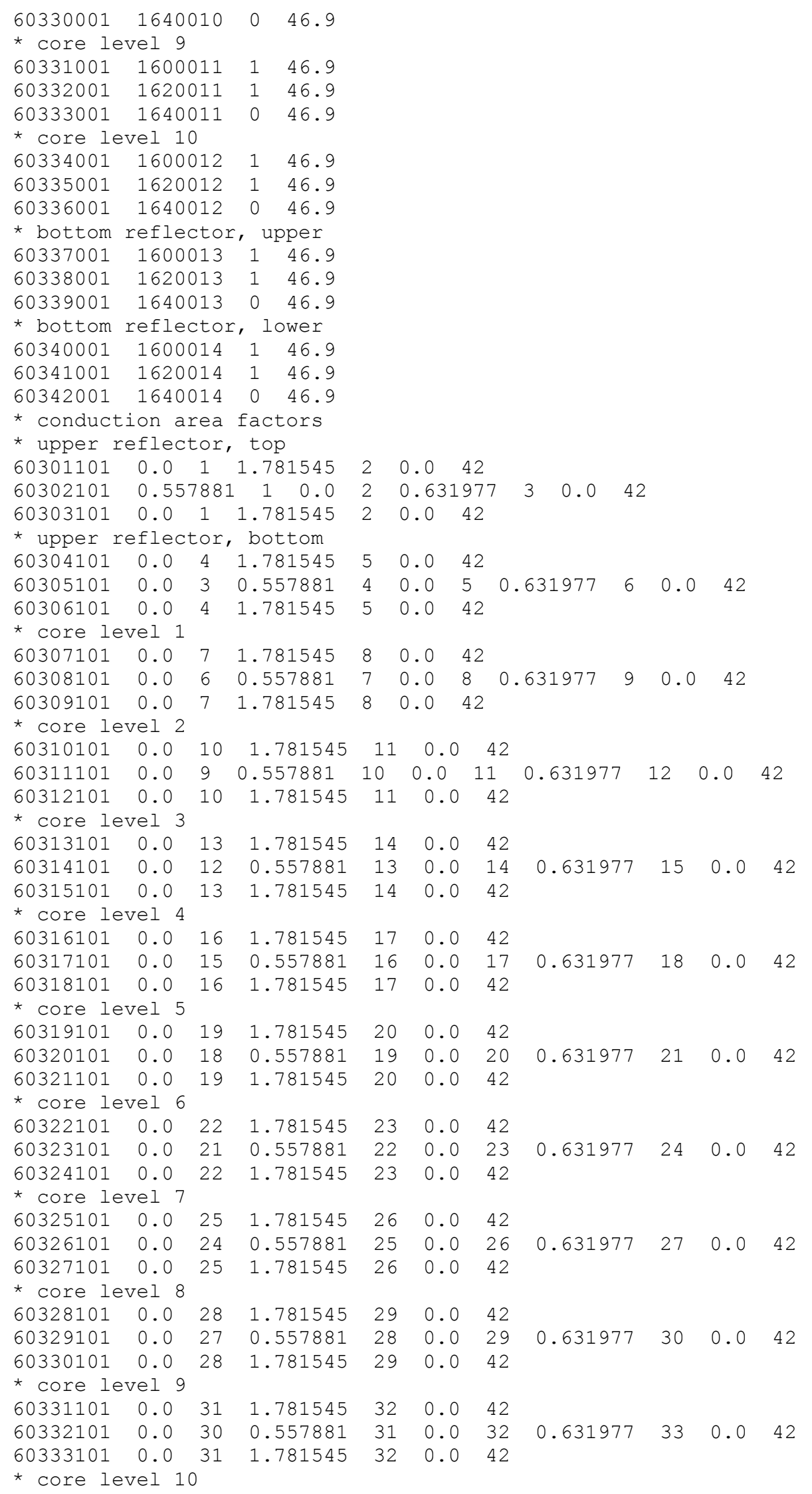




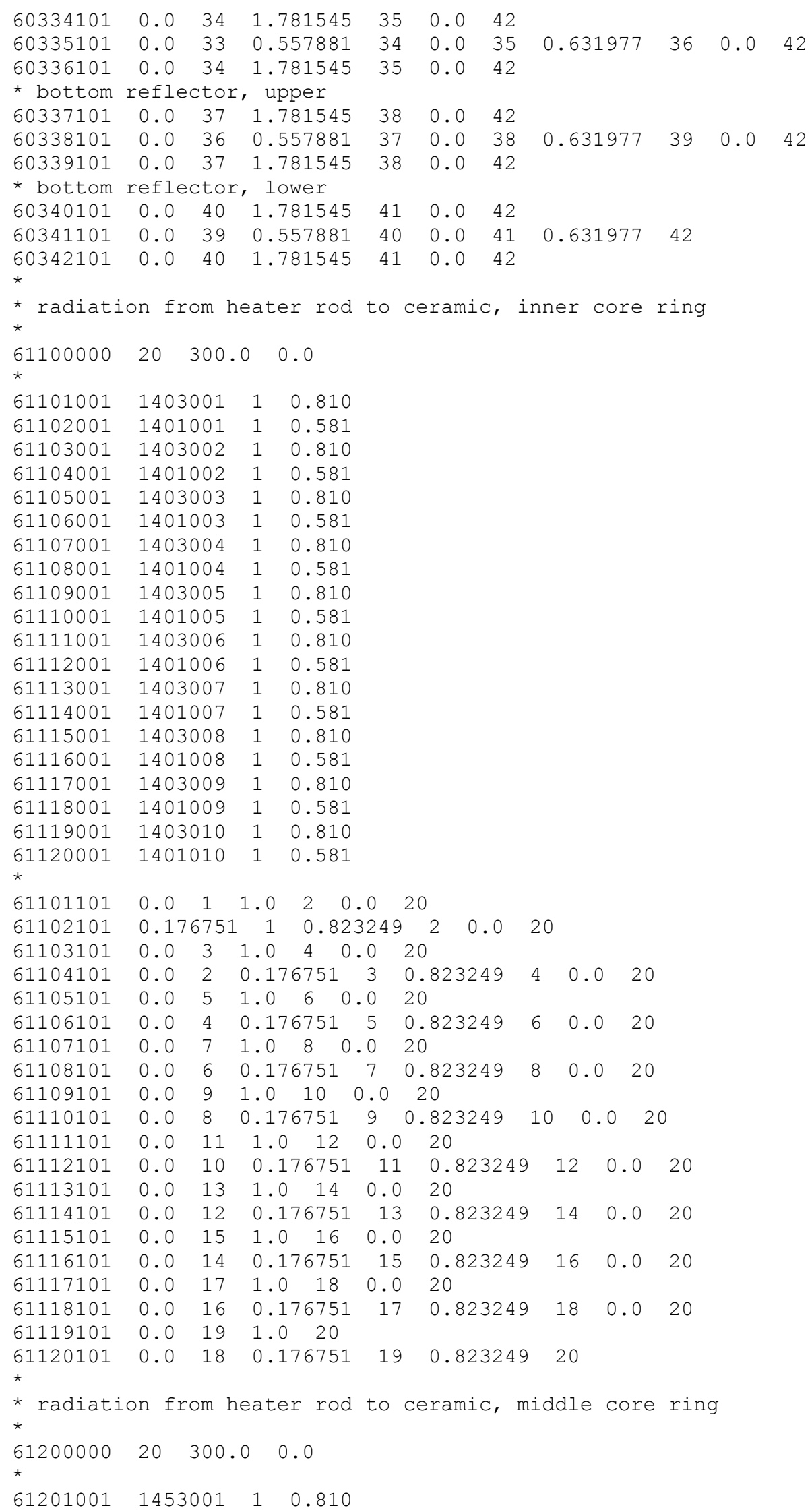




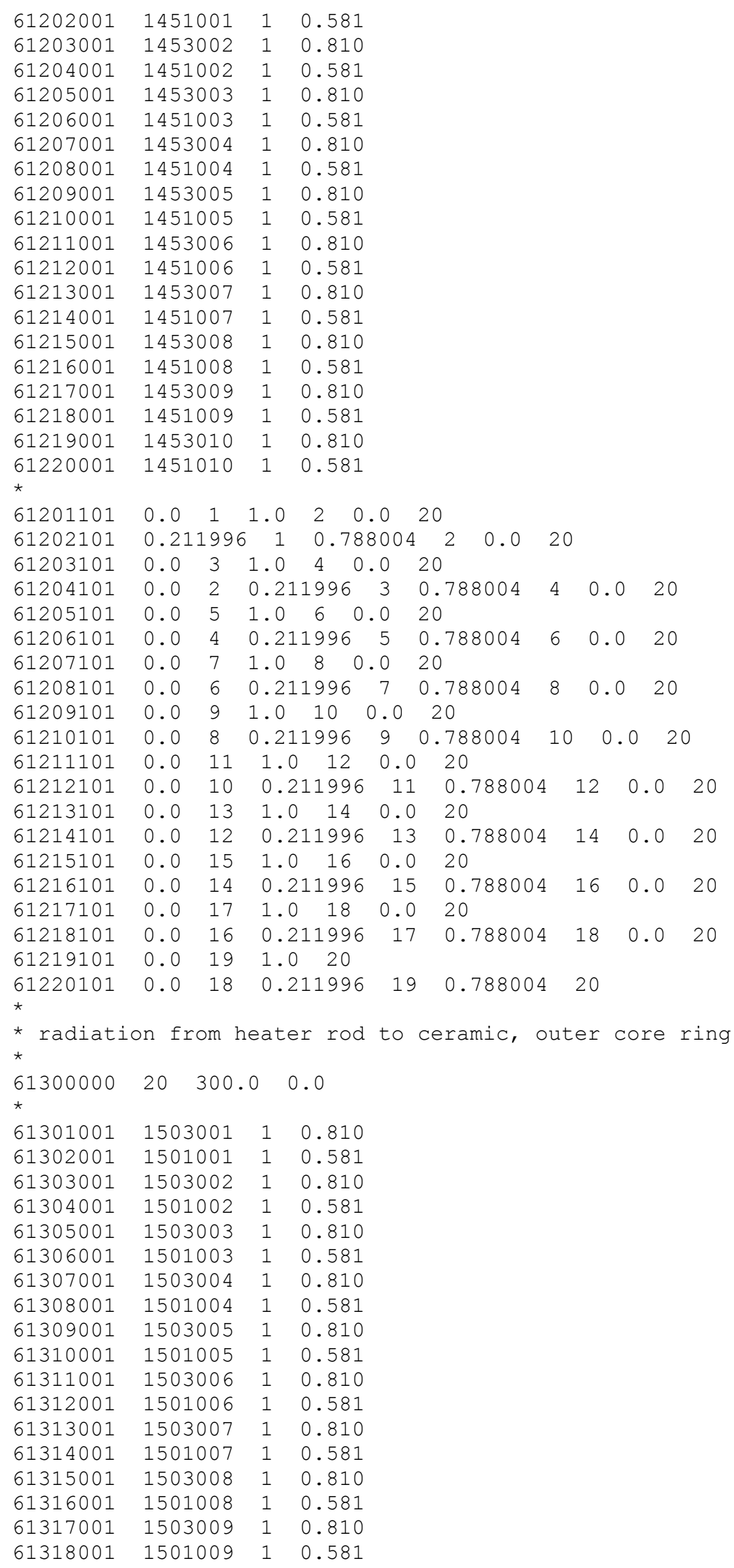




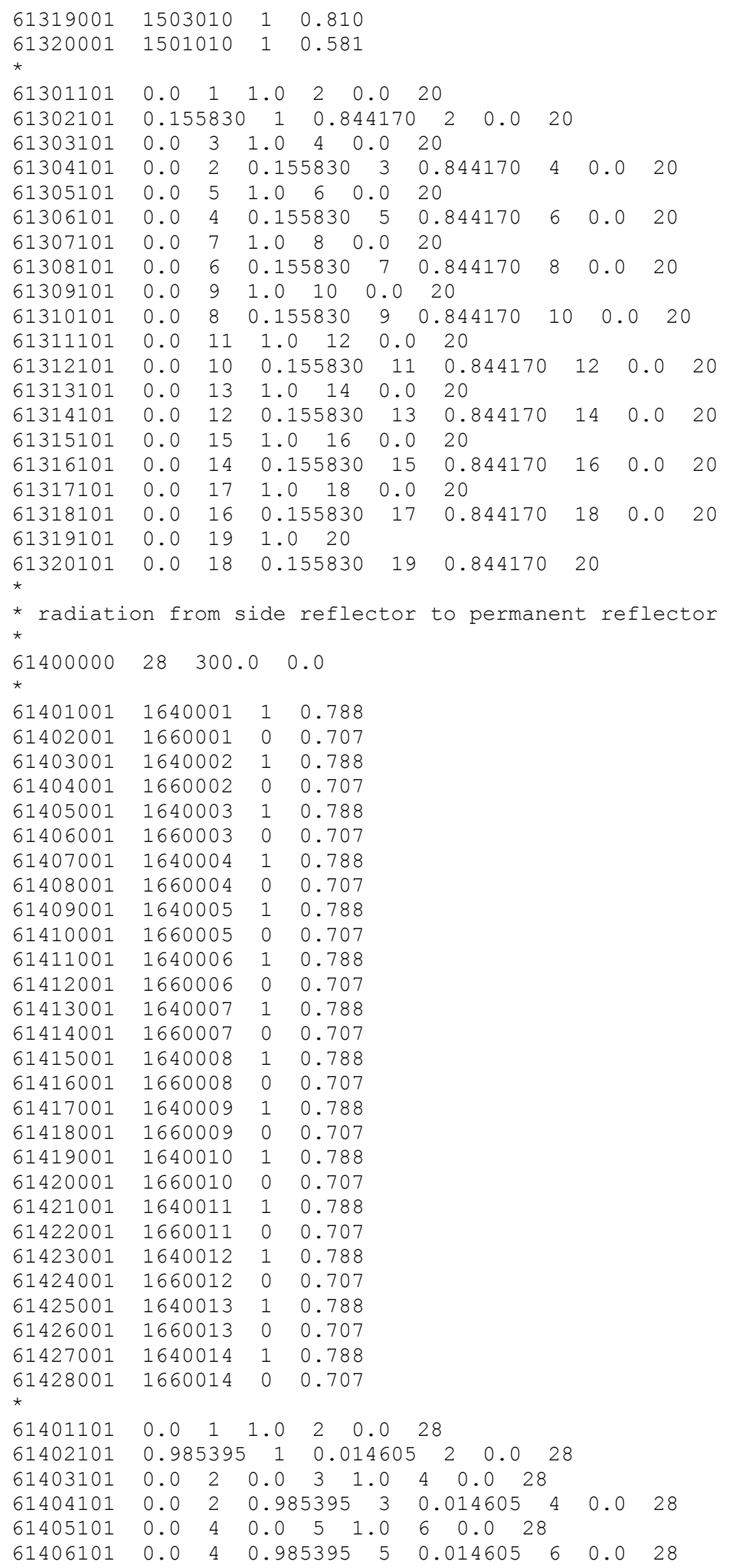




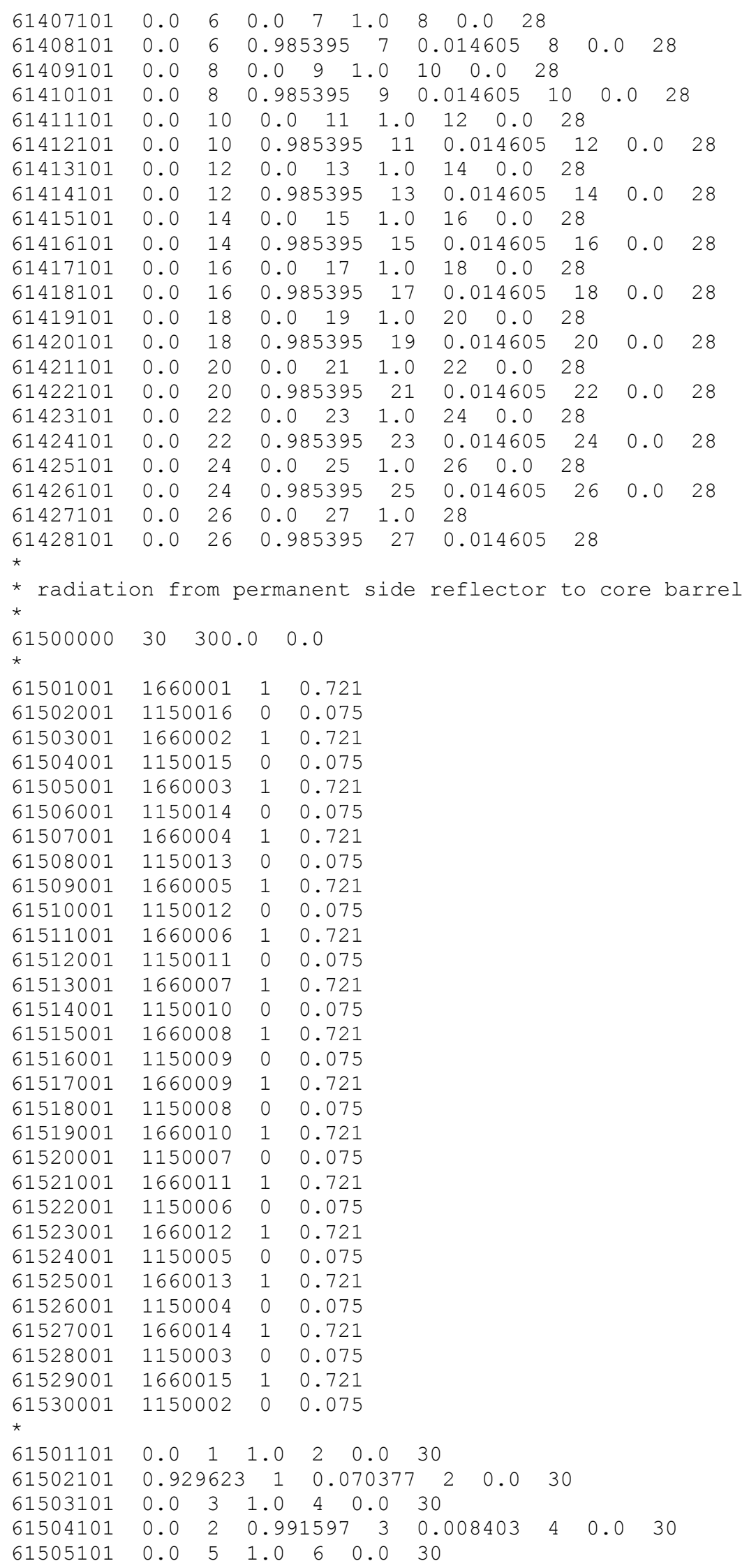




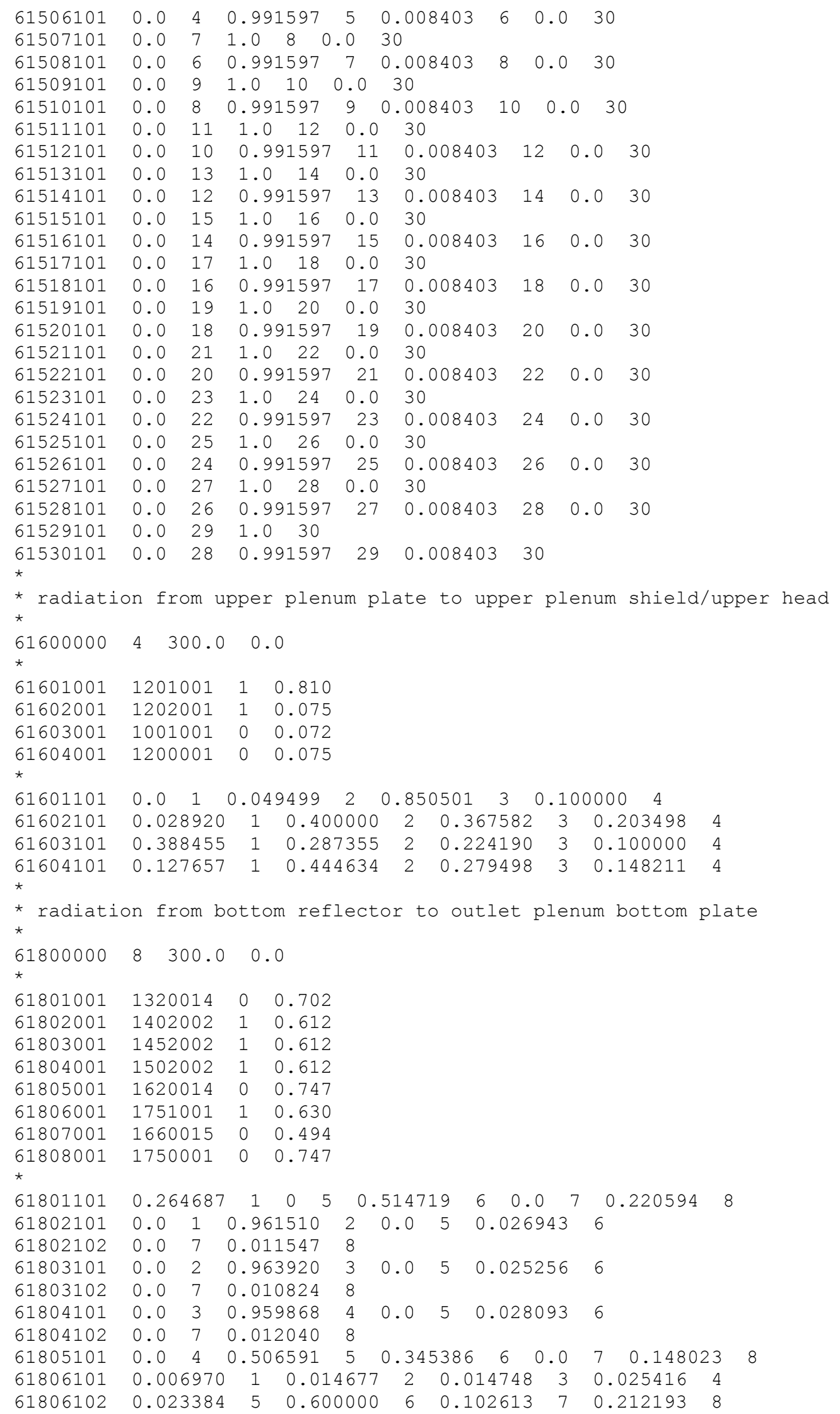




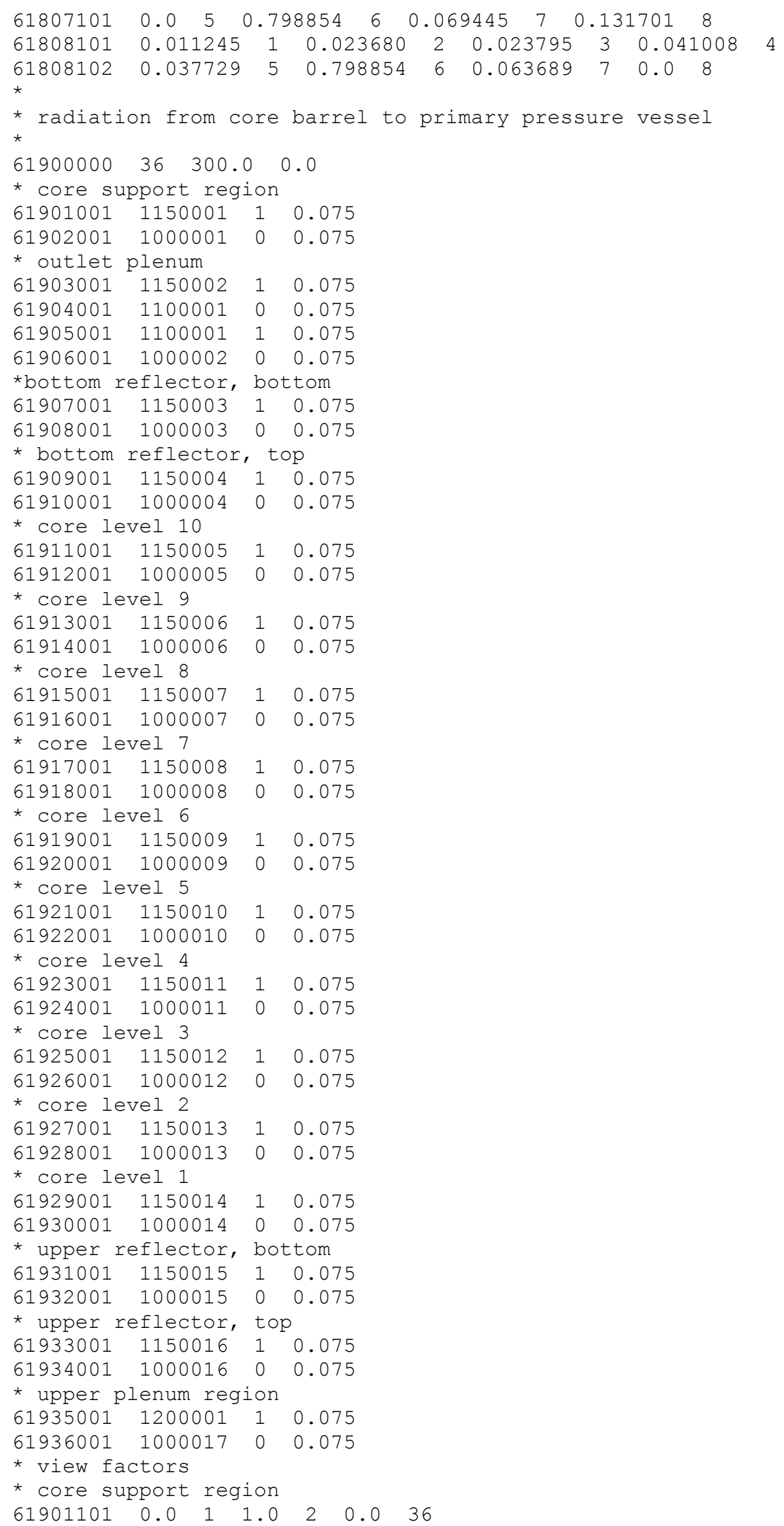




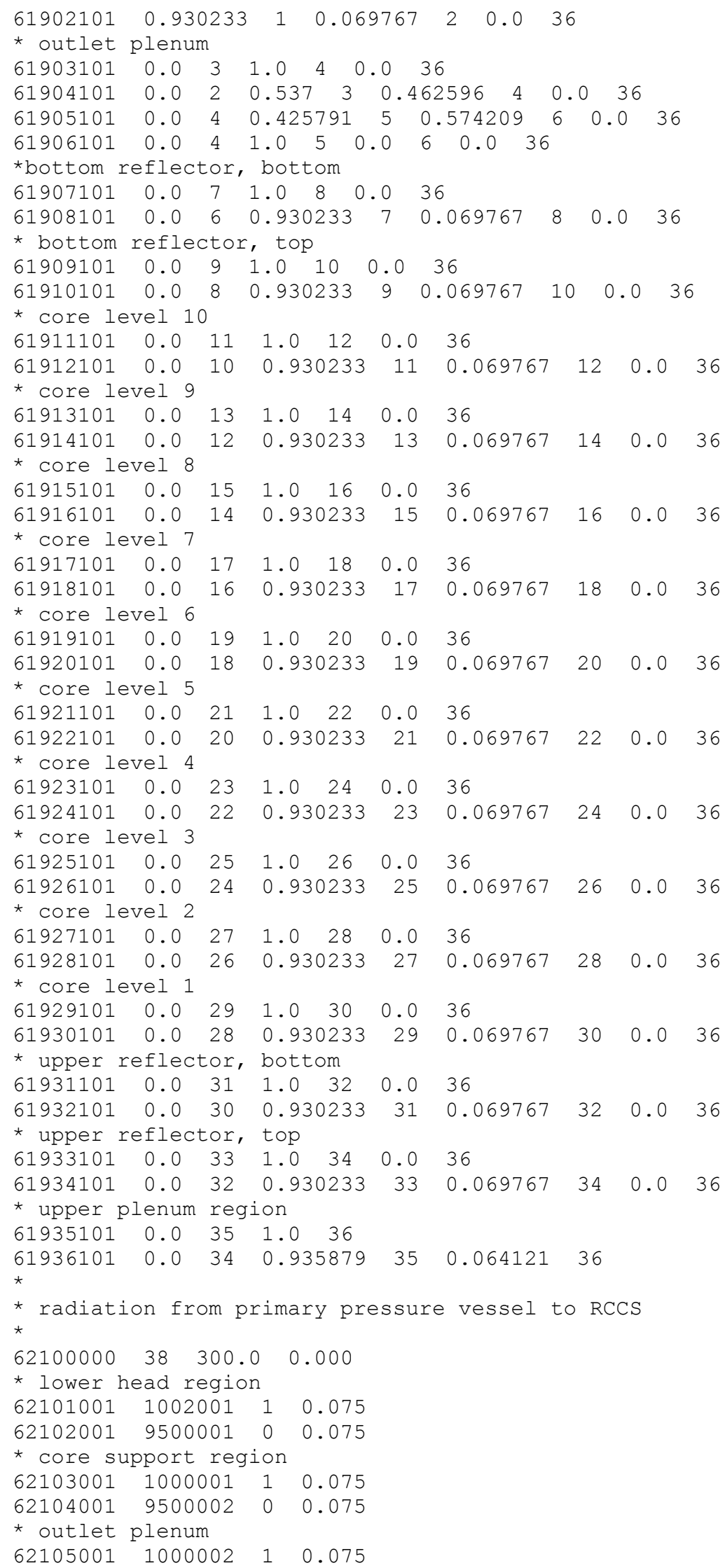




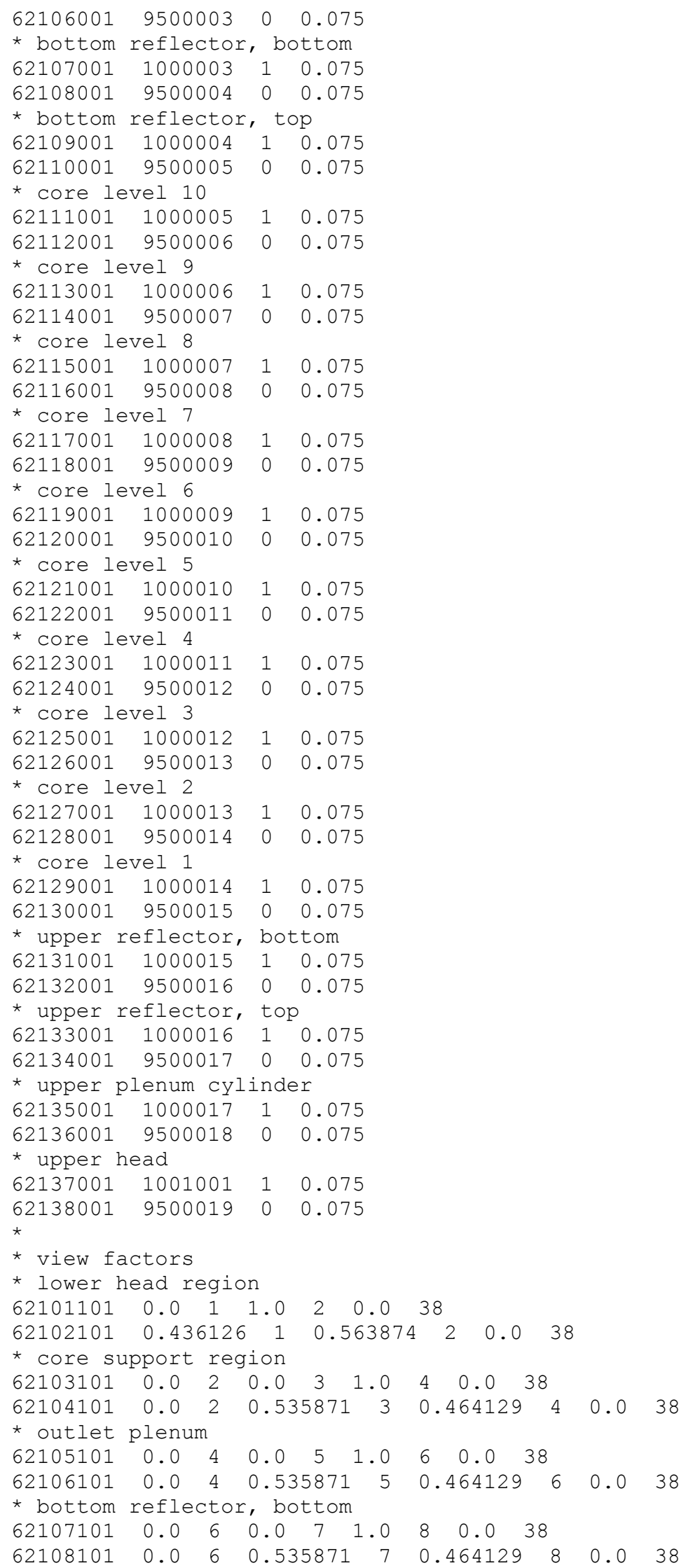




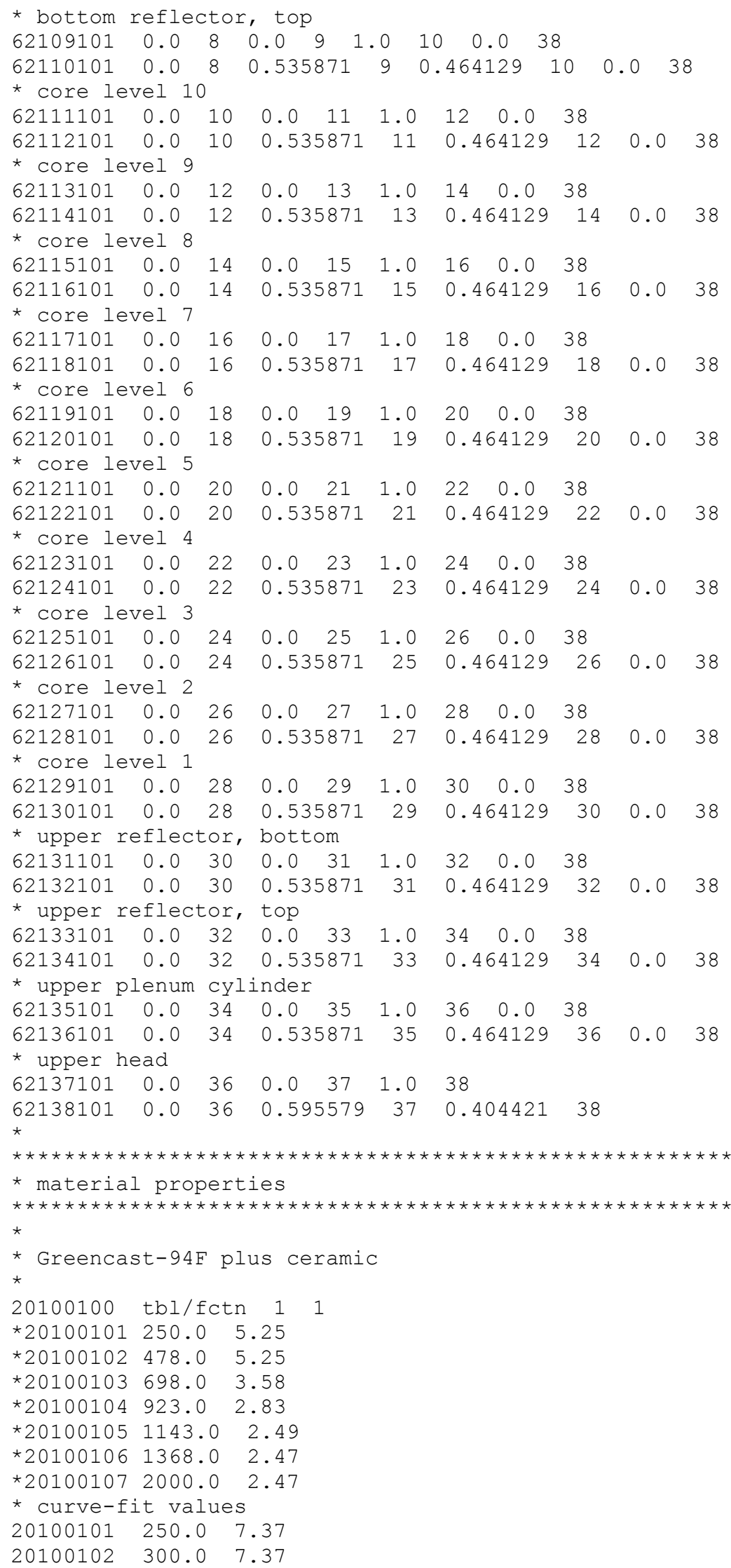




\begin{tabular}{|c|c|c|}
\hline 20100103 & 400.0 & 6.06 \\
\hline 20100104 & 500.0 & 5.01 \\
\hline 20100105 & 600.0 & 4.18 \\
\hline 20100106 & 700.0 & 3.56 \\
\hline 20100107 & 800.0 & 3.10 \\
\hline 20100108 & 900.0 & 2.78 \\
\hline 20100109 & 1000.0 & 2.58 \\
\hline 20100110 & 1100.0 & 2.46 \\
\hline 20100111 & 1200.0 & 2.40 \\
\hline 20100112 & 1300.0 & 2.37 \\
\hline 20100113 & 1400.0 & 2.33 \\
\hline 20100114 & 1500.0 & 2.27 \\
\hline 20100115 & 1600.0 & 2.15 \\
\hline 20100116 & 1700.0 & 1.95 \\
\hline 20100117 & 1800.0 & 1.63 \\
\hline 20100118 & 1900.0 & 1.17 \\
\hline $\begin{array}{l}20100119 \\
*\end{array}$ & 2000.0 & 0.54 \\
\hline 20100151 & 250.0 & $2.74 \mathrm{E}+06$ \\
\hline 20100152 & 335.5 & $2.74 E+06$ \\
\hline 20100153 & 422.1 & $3.21 E+06$ \\
\hline 20100154 & 506.4 & $3.65 \mathrm{E}+06$ \\
\hline 20100155 & 589.3 & $3.68 \mathrm{E}+06$ \\
\hline 20100156 & 671.3 & $3.45 E+06$ \\
\hline 20100157 & 752.4 & $3.45 E+06$ \\
\hline 20100158 & 832.8 & $3.47 E+06$ \\
\hline 20100159 & 912.5 & $3.50 \mathrm{E}+06$ \\
\hline 20100160 & 991.4 & $3.53 \mathrm{E}+06$ \\
\hline 20100161 & 1069.8 & $3.65 \mathrm{E}+06$ \\
\hline 20100162 & 1147.5 & $3.50 \mathrm{E}+06$ \\
\hline 20100163 & 1224.6 & $3.50 \mathrm{E}+06$ \\
\hline 20100164 & 1301.3 & $3.45 E+06$ \\
\hline 20100165 & 1377.7 & $3.47 E+06$ \\
\hline 20100166 & 1453.9 & $3.56 \mathrm{E}+06$ \\
\hline 20100167 & 1530.0 & $3.77 \mathrm{E}+06$ \\
\hline 20100168 & 1606.1 & $3.77 \mathrm{E}+06$ \\
\hline 20100169 & 1682.3 & $3.77 \mathrm{E}+06$ \\
\hline 20100170 & 1758.2 & $8.91 E+06$ \\
\hline 20100171 & 1834.3 & $3.71 E+06$ \\
\hline 20100172 & 2000.0 & $3.71 \mathrm{E}+06$ \\
\hline \\
\hline \multicolumn{3}{|c|}{ * heater rod } \\
\hline 20100200 & \multicolumn{2}{|c|}{ tbl/fctn 11} \\
\hline 20100201 & 250.0 & 93.00 \\
\hline 20100202 & 293.2 & 93.00 \\
\hline 20100203 & 443.2 & 81.84 \\
\hline 20100204 & 593.2 & 69.75 \\
\hline 20100205 & 773.2 & 61.38 \\
\hline 20100206 & 1003.2 & 51.15 \\
\hline 20100207 & 1123.2 & 46.50 \\
\hline 20100208 & 1273.2 & 42.78 \\
\hline 20100209 & 1673.2 & 29.76 \\
\hline $\begin{array}{l}20100210 \\
*\end{array}$ & 3000.0 & 29.76 \\
\hline 20100251 & 250.0 & $1.25 \mathrm{E}+06$ \\
\hline 20100252 & 300.0 & $1.25 \mathrm{E}+06$ \\
\hline 20100253 & 400.0 & $1.68 \mathrm{E}+06$ \\
\hline 20100254 & 500.0 & $2.08 E+06$ \\
\hline 20100255 & 600.0 & $2.40 \mathrm{E}+06$ \\
\hline 20100256 & 700.0 & $2.65 \mathrm{E}+06$ \\
\hline 20100257 & 800.0 & $2.86 \mathrm{E}+06$ \\
\hline 20100258 & 900.0 & $3.02 E+06$ \\
\hline
\end{tabular}




\begin{tabular}{|c|c|c|}
\hline 20100259 & 1000.0 & $3.14 E+06$ \\
\hline 100260 & 1100.0 & $3.24 E+06$ \\
\hline 100261 & 1200.0 & $3.33 E+06$ \\
\hline 0100262 & 1300.0 & $3.40 \mathrm{E}+06$ \\
\hline 20100263 & 1400.0 & $3.45 \mathrm{E}+06$ \\
\hline 0100264 & 1500.0 & $3.50 \mathrm{E}+06$ \\
\hline 0100265 & 1600.0 & $3.54 E+06$ \\
\hline 0100266 & 1700.0 & $3.58 E+06$ \\
\hline 100267 & 1800.0 & $3.62 \mathrm{E}+06$ \\
\hline 100268 & 1900.0 & $3.65 E+06$ \\
\hline 20100269 & 2000.0 & $3.68 \mathrm{E}+06$ \\
\hline 0100270 & 2100.0 & $3.70 E+06$ \\
\hline 0100271 & 2200.0 & $3.73 E+06$ \\
\hline 20100272 & 2300.0 & $3.75 E+06$ \\
\hline 20100273 & 2400.0 & $3.77 E+06$ \\
\hline 0100274 & 2500.0 & $3.79 \mathrm{E}+06$ \\
\hline 20100275 & 2600.0 & $3.80 E+06$ \\
\hline 20100276 & 2700.0 & $3.82 \mathrm{E}+06$ \\
\hline 20100277 & 2800.0 & $3.84 E+06$ \\
\hline 20100278 & 2900.0 & $3.85 E+06$ \\
\hline 20100279 & 3000.0 & $3.87 \mathrm{E}+06$ \\
\hline 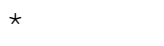 & & \\
\hline * 304 sta & less st & teel \\
\hline 20100300 & tbl/fctr & 1 \\
\hline 20100301 & 250.0 & 13.25 \\
\hline 20100302 & 300.0 & 13.25 \\
\hline 20100303 & 1671.0 & 39.1619 \\
\hline 20100304 & 1727.0 & 20.0 \\
\hline $\begin{array}{l}20100305 \\
*\end{array}$ & 3000.0 & 20.0 \\
\hline 20100351 & 250.0 & $3.72 E+06$ \\
\hline 20100352 & 300.0 & $3.72 E+06$ \\
\hline 20100353 & 400.0 & $3.94 \mathrm{E}+06$ \\
\hline 100354 & 500.0 & $4.12 E+06$ \\
\hline 20100355 & 600.0 & $4.29 E+06$ \\
\hline 20100356 & 700.0 & $4.44 E+06$ \\
\hline 20100357 & 800.0 & $4.57 E+06$ \\
\hline 20100358 & 900.0 & $4.69 E+06$ \\
\hline 20100359 & 1000.0 & $4.81 E+06$ \\
\hline 20100360 & 1100.0 & $4.92 \mathrm{E}+06$ \\
\hline 20100361 & 1200.0 & $5.01 E+06$ \\
\hline 20100362 & 1300.0 & $5.11 \mathrm{E}+06$ \\
\hline 20100363 & 1400.0 & $5.19 \mathrm{E}+06$ \\
\hline 20100364 & 1500.0 & $5.27 E+06$ \\
\hline 20100365 & 1600.0 & $5.35 E+06$ \\
\hline 20100366 & 1671.0 & $5.40 \mathrm{E}+0$ \\
\hline 20100367 & 3000.0 & $5.40 \mathrm{E}+0$ \\
\hline * & & \\
\hline * Haynes & 230 & \\
\hline * & & \\
\hline 20100400 & tbl/fctr & n 1 \\
\hline 20100401 & 250.0 & 8.9 \\
\hline 20100402 & 293.0 & 8.9 \\
\hline 20100403 & 373.0 & 10.4 \\
\hline 20100404 & 473.0 & 12.4 \\
\hline 20100405 & 573.0 & 14.4 \\
\hline 20100406 & 673.0 & 16.4 \\
\hline 20100407 & 773.0 & 18.4 \\
\hline 20100408 & 873.0 & 20.4 \\
\hline 20100409 & 973.0 & 22.4 \\
\hline 20100410 & 1073.0 & 24.4 \\
\hline 20100411 & 1173.0 & 26.4 \\
\hline
\end{tabular}




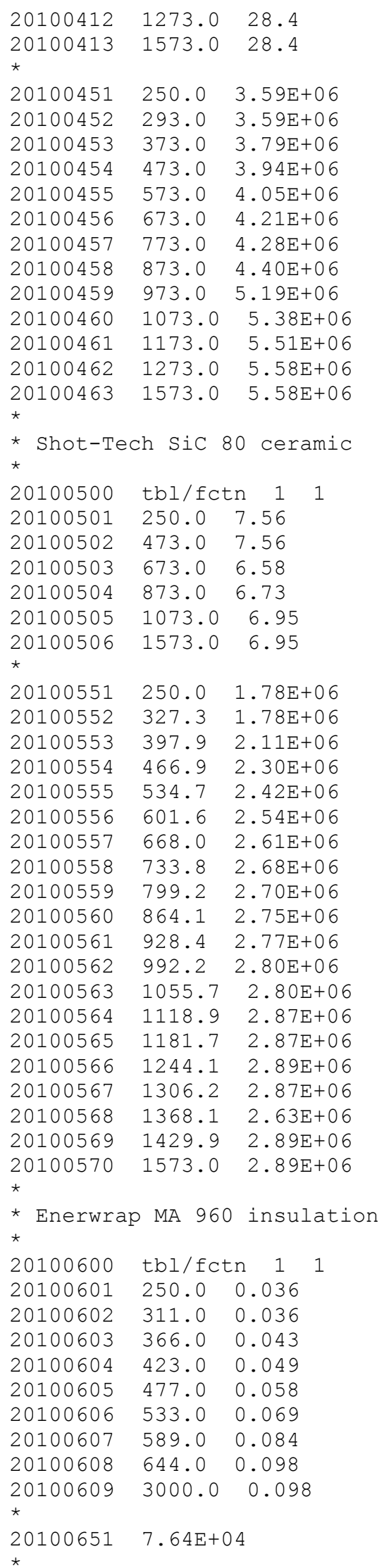




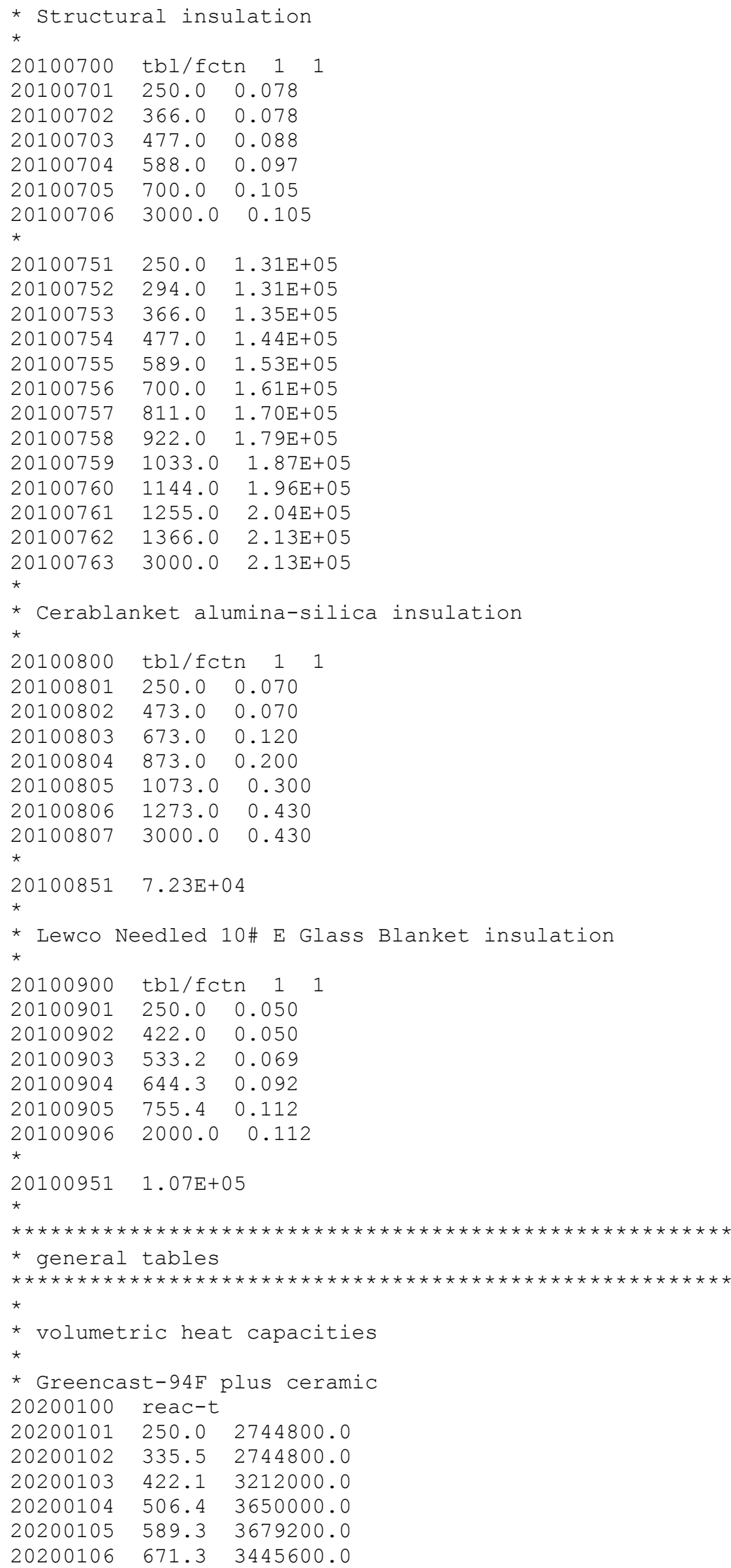




\begin{tabular}{|c|c|c|}
\hline 07 & 752.4 & .0 \\
\hline 年 & 832.8 & 800.0 \\
\hline 10 & 912.5 & 4000.0 \\
\hline 11 & 991.4 & 33200.0 \\
\hline 200111 & 1069.8 & 50000 \\
\hline 0112 & 1147.5 & 04000.0 \\
\hline 200113 & 1224.6 & 04000 \\
\hline 0114 & 1301.3 & \\
\hline 011 & 1377.7 & \\
\hline 11 & 1453.9 & 0 \\
\hline 200117 & 1530.0 & 6800.0 \\
\hline 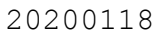 & 1606.1 & 3 \\
\hline 11 & 1682.3 & 6800.0 \\
\hline 012 & 1758.2 & \\
\hline 20012 & 1834.3 & \\
\hline 2 & 2000.0 & \\
\hline & & \\
\hline ter & rod & \\
\hline مחم2 & $r e a c-t$ & \\
\hline 20 & 300.0 & 0.0 \\
\hline 020 & 400.0 & 0.0 \\
\hline & 500.0 & 0.0 \\
\hline 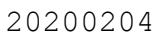 & 600.0 & 0 \\
\hline & 700.0 & 0.0 \\
\hline & 800.0 & 0.0 \\
\hline 0207 & 900.0 & 3015250.0 \\
\hline 0208 & 1000.0 & 3143000.0 \\
\hline 020 & 1100.0 & 3 \\
\hline 021 & 1200.0 & 0.0 \\
\hline 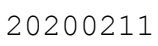 & 1300.0 & 0.0 \\
\hline 0212 & 1400.0 & 00.0 \\
\hline 0213 & 1500.0 & 0000 . \\
\hline 0214 & 1600.0 & \\
\hline 2 & 1700.0 & .0 \\
\hline 21 & 1800.0 & 0.0 \\
\hline 2 & 1900.0 & 0.0 \\
\hline 218 & 2000.0 & 00.0 \\
\hline 021 & 2100.0 & 3701250 . \\
\hline 0220 & 2200.0 & 372 \\
\hline 022 & 2300.0 & 500.0 \\
\hline 2 & 2400.0 & 0. \\
\hline 3 & 2500.0 & 37 \\
\hline 0224 & 2600.0 & 00.0 \\
\hline 200225 & 2700.0 & 3822000.0 \\
\hline 20200226 & 2800.0 & 3837750. \\
\hline 20200227 & 2900.0 & 3853500. \\
\hline 28 & 3000.0 & 3872750 . \\
\hline * & & \\
\hline * $304 \mathrm{st}$ & ess & el \\
\hline 0200300 & reac-t & \\
\hline 0200301 & 250.0 & 3724428.5 \\
\hline 200302 & 300.0 & 3724428.5 \\
\hline 303 & 400.0 & 3937320.4 \\
\hline 304 & 500.0 & 4122643.2 \\
\hline 200305 & 600.0 & 4287368.5 \\
\hline 20200306 & 700.0 & 4435836.2 \\
\hline 200307 & 800.0 & 4570983.8 \\
\hline 20200308 & 900.0 & 4694918.8 \\
\hline 309 & 1000.0 & 4809219. \\
\hline 20200310 & 1100.0 & 4915106. \\
\hline 20200311 & 1200.0 & 5013550 . \\
\hline 20200312 & 1300.0 & 5105338.8 \\
\hline 20200313 & 1400.0 & 5191121 \\
\hline
\end{tabular}




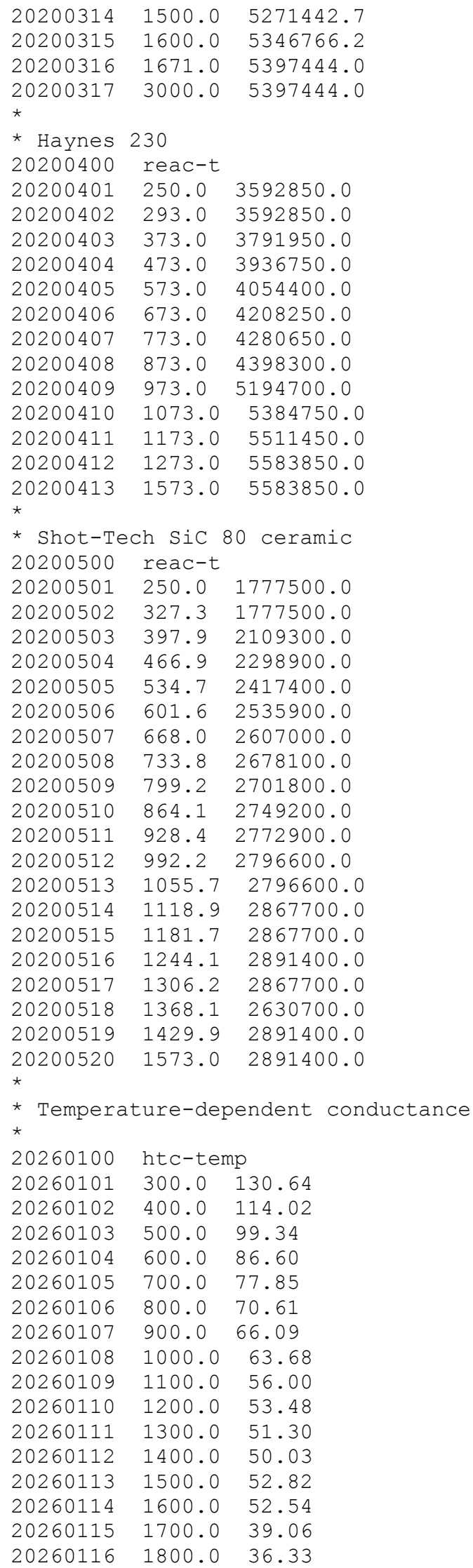




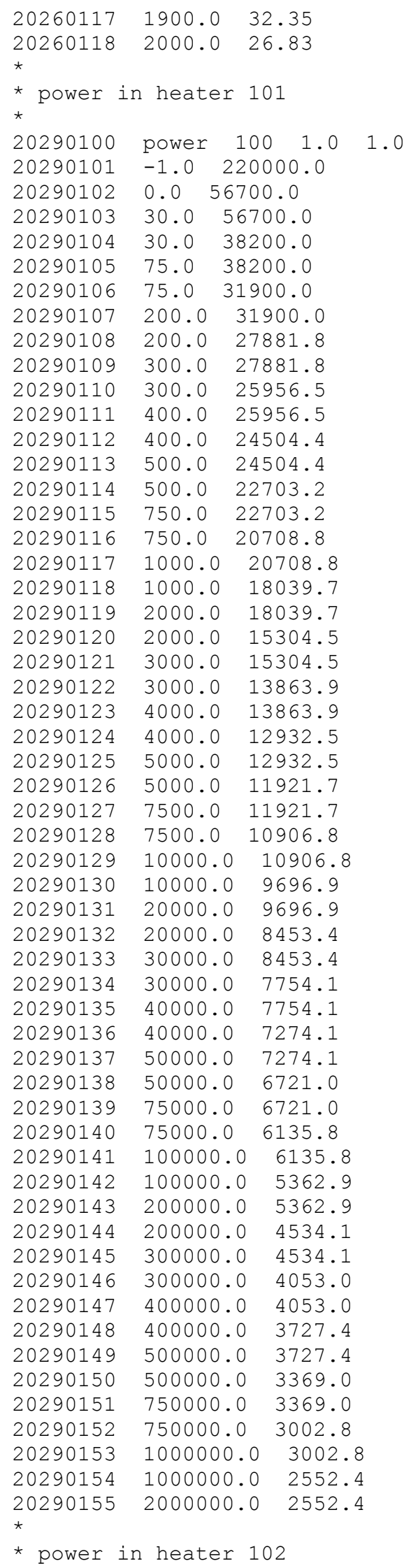




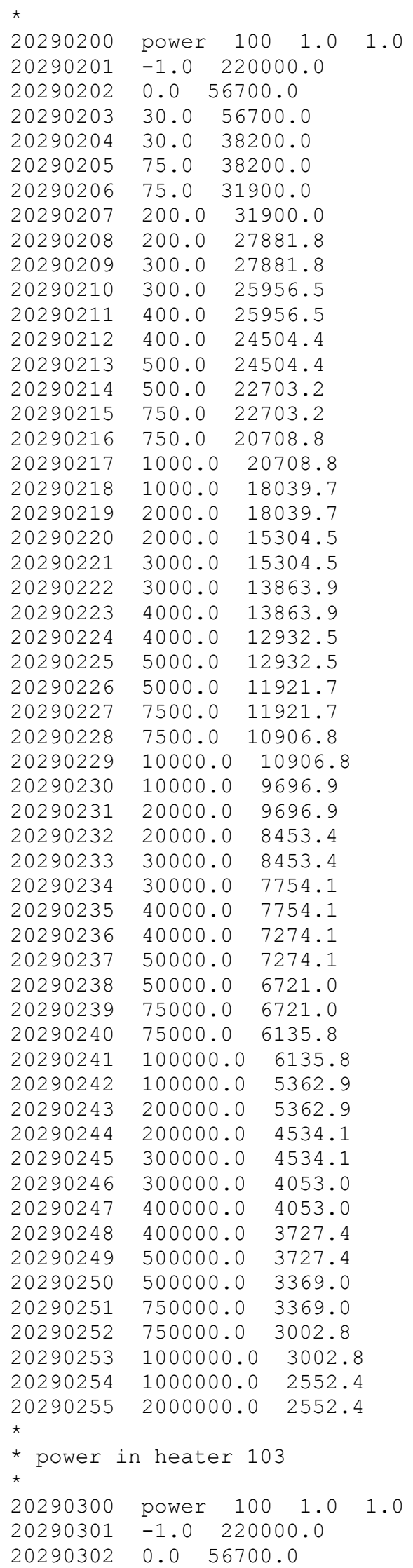




\begin{tabular}{|c|c|c|c|}
\hline 20290303 & 30.0 & 00.0 & \\
\hline 20290304 & 30.0 & 00.0 & \\
\hline 20290305 & 75.0 & 00.0 & \\
\hline 20290306 & 75.0 & 00.0 & \\
\hline 20290307 & 200.0 & 900.0 & \\
\hline 20290308 & 200.0 & 881.8 & \\
\hline 20290309 & 300.0 & 881.8 & \\
\hline 20290310 & 300.0 & 956.5 & \\
\hline 20290311 & 400.0 & 956.5 & \\
\hline 20290312 & 400.0 & 504.4 & \\
\hline 20290313 & 500.0 & 504.4 & \\
\hline 20290314 & 500.0 & 703.2 & \\
\hline 20290315 & 750.0 & 703.2 & \\
\hline 20290316 & 750.0 & 708.8 & \\
\hline 20290317 & 1000.0 & 0708.8 & \\
\hline 20290318 & 1000.0 & 8039.7 & \\
\hline 20290319 & 2000.0 & 8039.7 & \\
\hline 20290320 & 2000.0 & 5304.5 & \\
\hline 20290321 & 3000.0 & 5304.5 & \\
\hline 20290322 & 3000.0 & 3863.9 & \\
\hline 20290323 & 4000.0 & 3863.9 & \\
\hline 20290324 & 4000.0 & 2932.5 & \\
\hline 20290325 & 5000.0 & 2932.5 & \\
\hline 20290326 & 5000.0 & 1921.7 & \\
\hline 20290327 & 7500.0 & 1921.7 & \\
\hline 20290328 & 7500.0 & 0906.8 & \\
\hline 20290329 & 10000.0 & 10906.8 & \\
\hline 20290330 & 10000.0 & 9696.9 & \\
\hline 20290331 & 20000.0 & 9696.9 & \\
\hline 20290332 & 20000.0 & 8453.4 & \\
\hline 20290333 & 30000.0 & 8453.4 & \\
\hline 20290334 & 30000.0 & 7754.1 & \\
\hline 20290335 & 40000.0 & 7754.1 & \\
\hline 20290336 & 40000.0 & 7274.1 & \\
\hline 20290337 & 50000.0 & 7274.1 & \\
\hline 20290338 & 50000.0 & 6721.0 & \\
\hline 20290339 & 75000.0 & 6721.0 & \\
\hline 20290340 & 75000.0 & 6135.8 & \\
\hline 20290341 & 100000.0 & 6135.8 & \\
\hline 20290342 & 100000.0 & 5362.9 & \\
\hline 20290343 & 200000.0 & 5362.9 & \\
\hline 20290344 & 200000.0 & 4534.1 & \\
\hline 20290345 & 300000.0 & 4534.1 & \\
\hline 20290346 & 300000.0 & 4053.0 & \\
\hline 20290347 & 400000.0 & 4053.0 & \\
\hline 20290348 & 400000.0 & 3727.4 & \\
\hline 20290349 & 500000.0 & 3727.4 & \\
\hline 20290350 & 500000.0 & 3369.0 & \\
\hline 20290351 & 750000.0 & 3369.0 & \\
\hline 20290352 & 750000.0 & 3002.8 & \\
\hline 20290353 & 1000000.0 & 3002 . & \\
\hline 20290354 & 1000000.0 & 2552 . & \\
\hline 20290355 & 2000000.0 & 2552 . & \\
\hline \multicolumn{4}{|c|}{2000000.0280 .4} \\
\hline \multicolumn{4}{|c|}{ * power in heater 104} \\
\hline 20290400 & power 100 & $0 \quad 1.0$ & 1.0 \\
\hline 20290401 & $-1.0 \quad 2200$ & 000.0 & \\
\hline 20290402 & $0.0 \quad 56700$ & 0.0 & \\
\hline 20290403 & 30.0 & 00.0 & \\
\hline 20290404 & 30.0 & 00.0 & \\
\hline 20290405 & 75.0 & 00.0 & \\
\hline 20290406 & 75.0 & 00.0 & \\
\hline
\end{tabular}




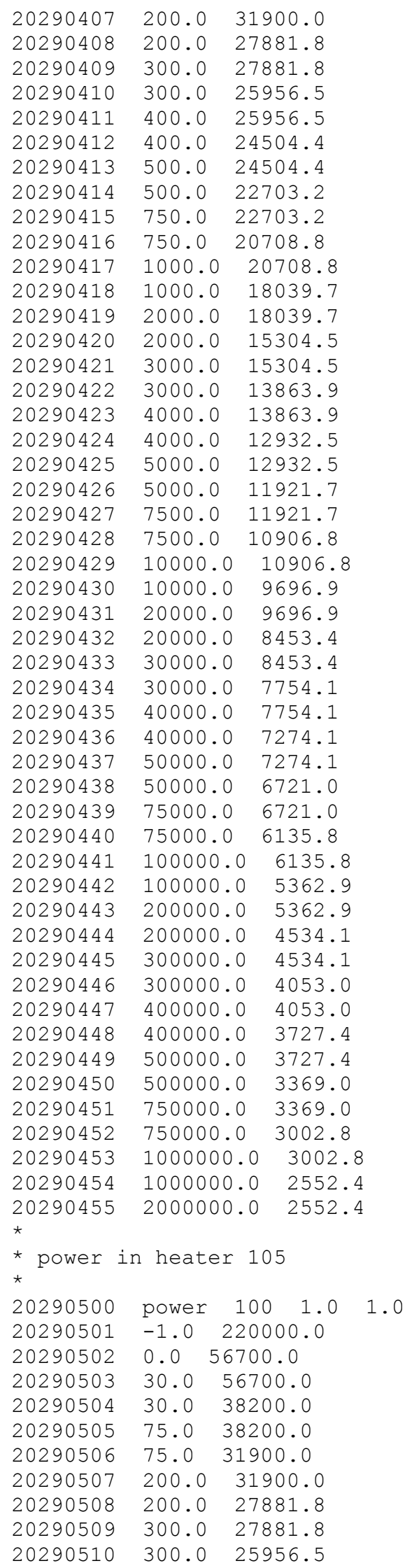




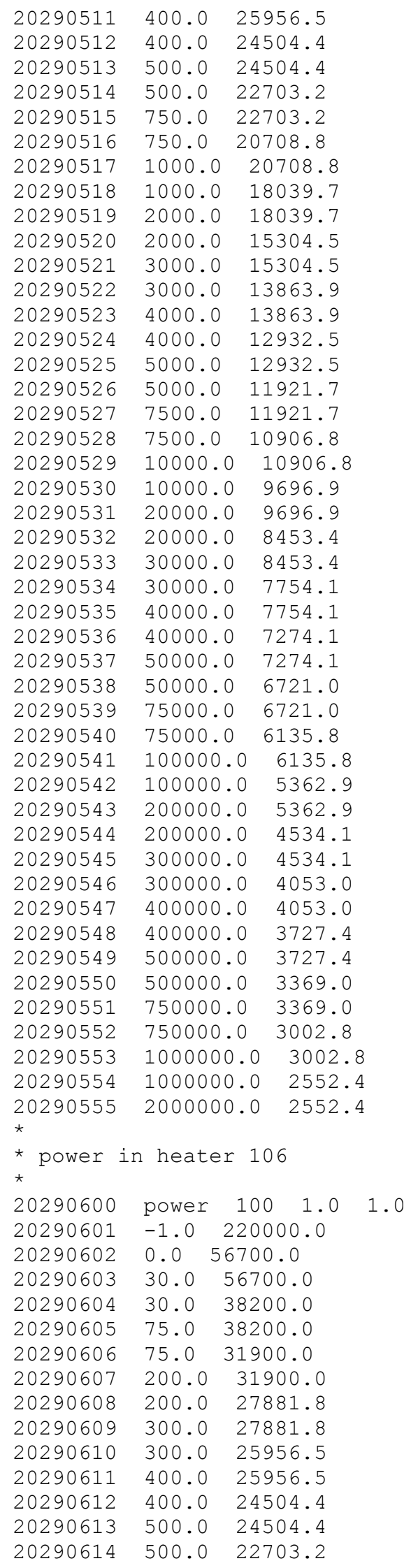




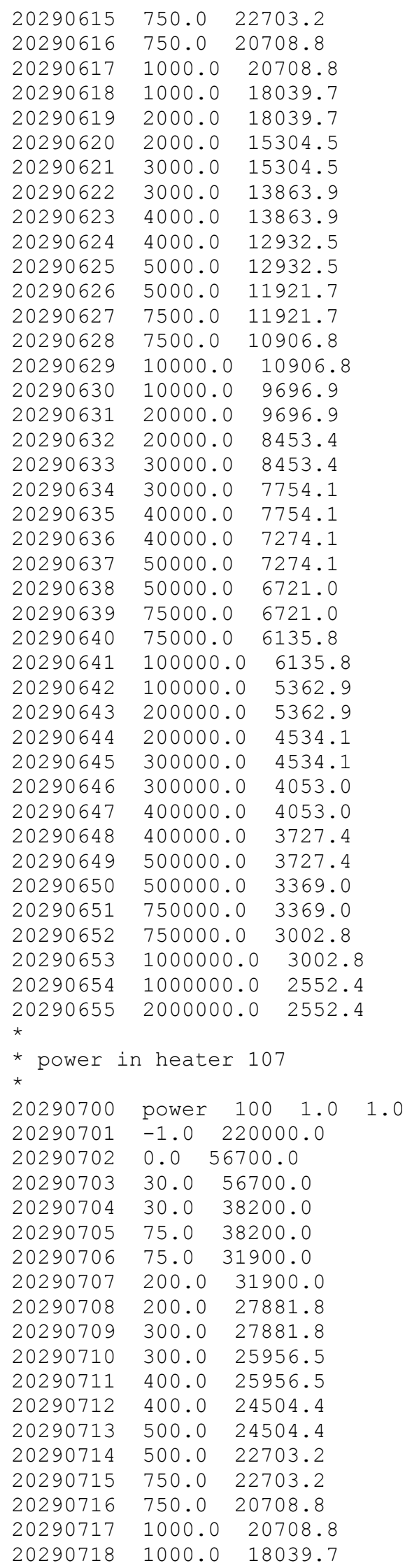




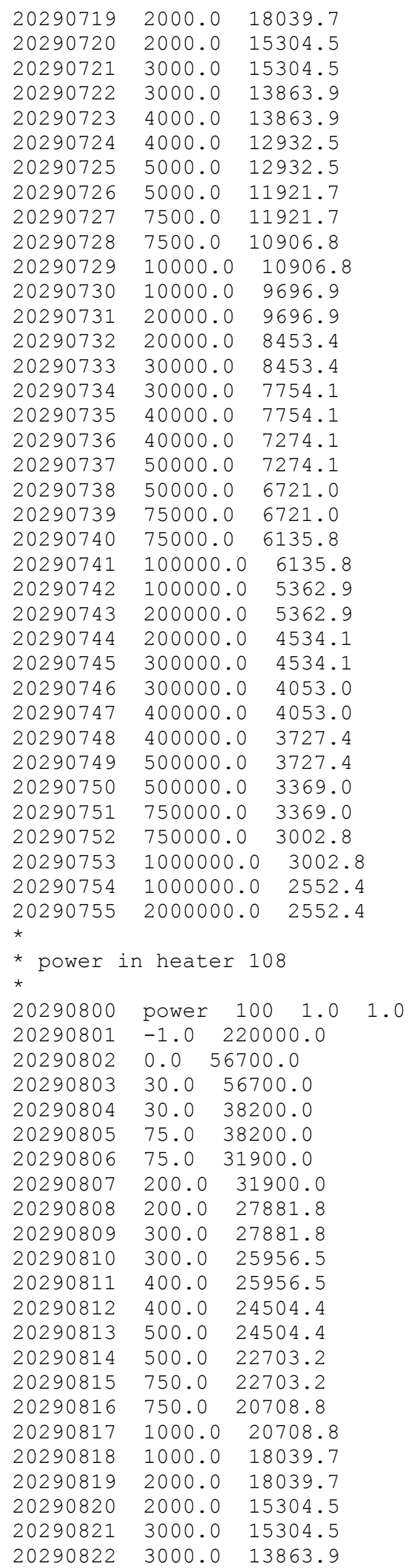




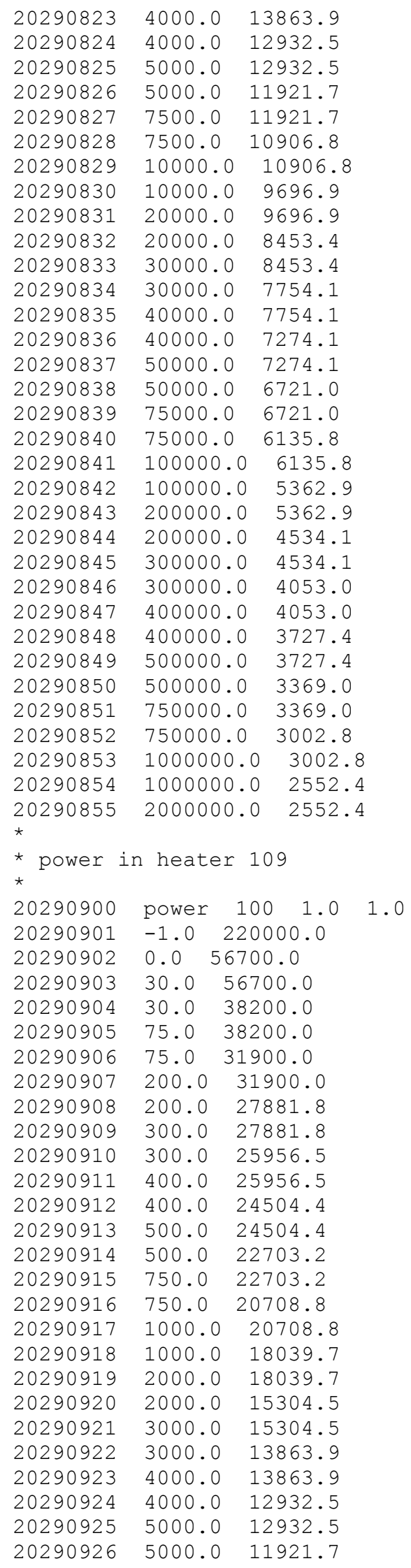




\begin{tabular}{|c|c|c|c|}
\hline 20290927 & 7500.0 & 11921.7 & \\
\hline 0290928 & 7500.0 & 10906.8 & \\
\hline 20290929 & 10000. & 10906.8 & \\
\hline 20290930 & 10000. & 9696.9 & \\
\hline 20290931 & 20000 & 9696.9 & \\
\hline 20290932 & 20000 & 8453.4 & \\
\hline 0290933 & 30000. & 8453.4 & \\
\hline 0290934 & 30000. & 7754.1 & \\
\hline 20290935 & 40000. & 7754.1 & \\
\hline 20290936 & 40000. & 7274.1 & \\
\hline 20290937 & 50000 & 7274.1 & \\
\hline 20290938 & 50000. & 6721.0 & \\
\hline 0290939 & 75000. & 6721.0 & \\
\hline 0290940 & 75000 & 6135.8 & \\
\hline 20290941 & 100000 & $0 \quad 6135.8$ & \\
\hline 20290942 & 100000 & 5362.9 & \\
\hline 20290943 & 200000 & 5362.9 & \\
\hline 20290944 & 200000 & 4534.1 & \\
\hline 20290945 & 300000 & 4534.1 & \\
\hline 20290946 & 300000 & 4053.0 & \\
\hline 20290947 & 400000 & 4053.0 & \\
\hline 20290948 & 400000 & 3727.4 & \\
\hline 20290949 & 500000 & 3727.4 & \\
\hline 20290950 & 500000 & 3369.0 & \\
\hline 20290951 & 750000 & 3369.0 & \\
\hline 20290952 & 750000 & 3002.8 & \\
\hline 20290953 & 1000000 & 3002. & \\
\hline 20290954 & 1000000 & .02552. & \\
\hline $\begin{array}{l}20290955 \\
*\end{array}$ & 2000000 & .02552 & \\
\hline \multicolumn{4}{|c|}{ * power in heater 110} \\
\hline 20291000 & power & $100 \quad 1.0$ & 1.0 \\
\hline 20291001 & -1.0 & 20000.0 & \\
\hline 20291002 & $0.0 \quad 56$ & 8700.0 & \\
\hline 20291003 & 30.0 & 6700.0 & \\
\hline 20291004 & 30.0 & 38200.0 & \\
\hline 20291005 & 75.0 & 38200.0 & \\
\hline 20291006 & 75.0 & 31900.0 & \\
\hline 20291007 & 200.0 & 31900.0 & \\
\hline 20291008 & 200.0 & 27881.8 & \\
\hline 20291009 & 300.0 & 27881.8 & \\
\hline 20291010 & 300.0 & 25956.5 & \\
\hline 20291011 & 400.0 & 25956.5 & \\
\hline 20291012 & 400.0 & 24504.4 & \\
\hline 20291013 & 500.0 & 24504.4 & \\
\hline 20291014 & 500.0 & 22703.2 & \\
\hline 20291015 & 750.0 & 22703.2 & \\
\hline 20291016 & 750.0 & 20708.8 & \\
\hline 20291017 & 1000.0 & 20708.8 & \\
\hline 20291018 & 1000.0 & 18039.7 & \\
\hline 20291019 & 2000.0 & 18039.7 & \\
\hline 20291020 & 2000.0 & 15304.5 & \\
\hline 20291021 & 3000.0 & 15304.5 & \\
\hline 20291022 & 3000.0 & 13863.9 & \\
\hline 20291023 & 4000.0 & 13863.9 & \\
\hline 20291024 & 4000.0 & 12932.5 & \\
\hline 20291025 & 5000.0 & 12932.5 & \\
\hline 20291026 & 5000.0 & 11921.7 & \\
\hline 20291027 & 7500.0 & 11921.7 & \\
\hline 20291028 & 7500.0 & 10906.8 & \\
\hline 20291029 & 10000 & 10906.8 & \\
\hline 20291030 & 10000 & 9696.9 & \\
\hline
\end{tabular}




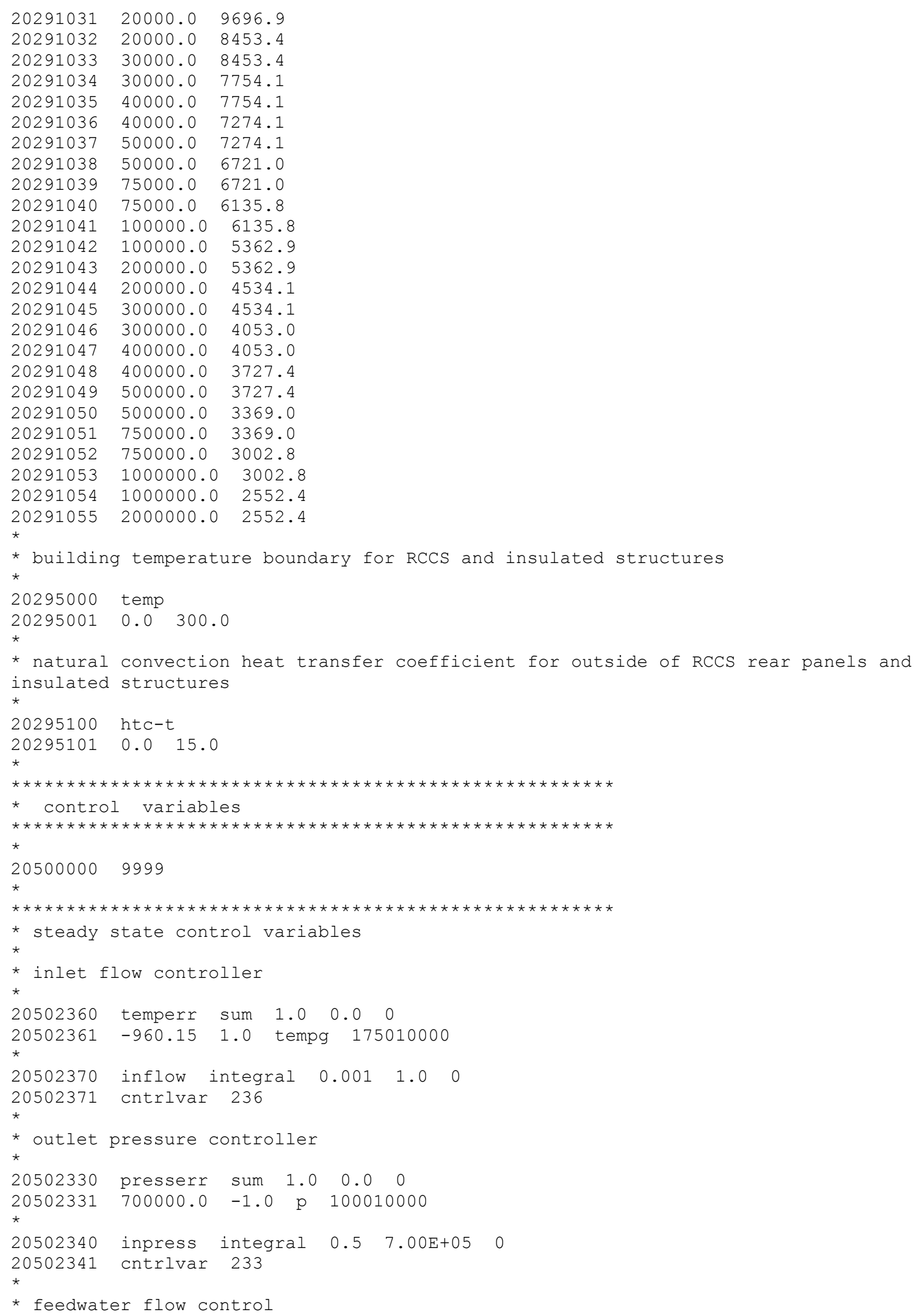




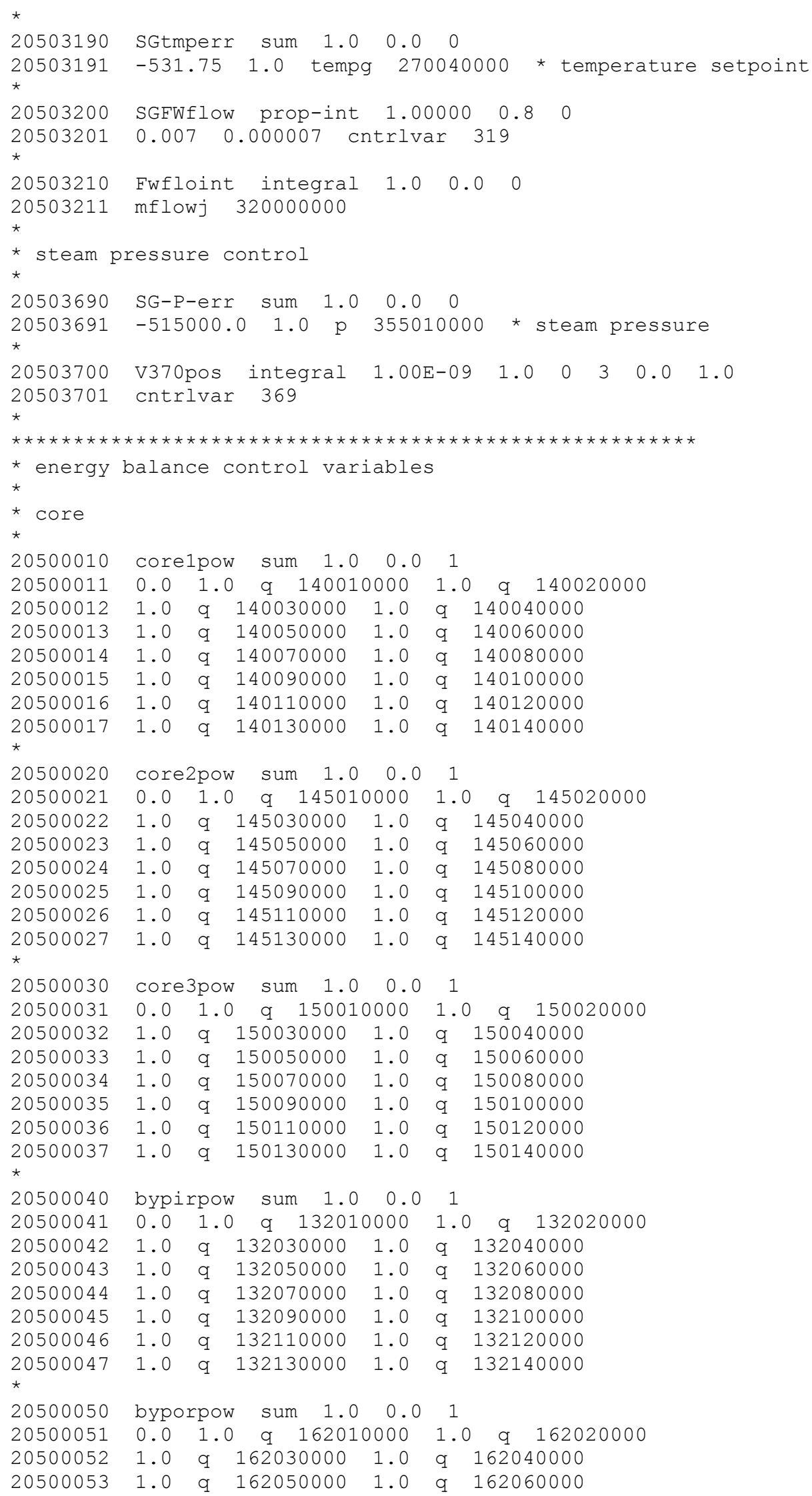




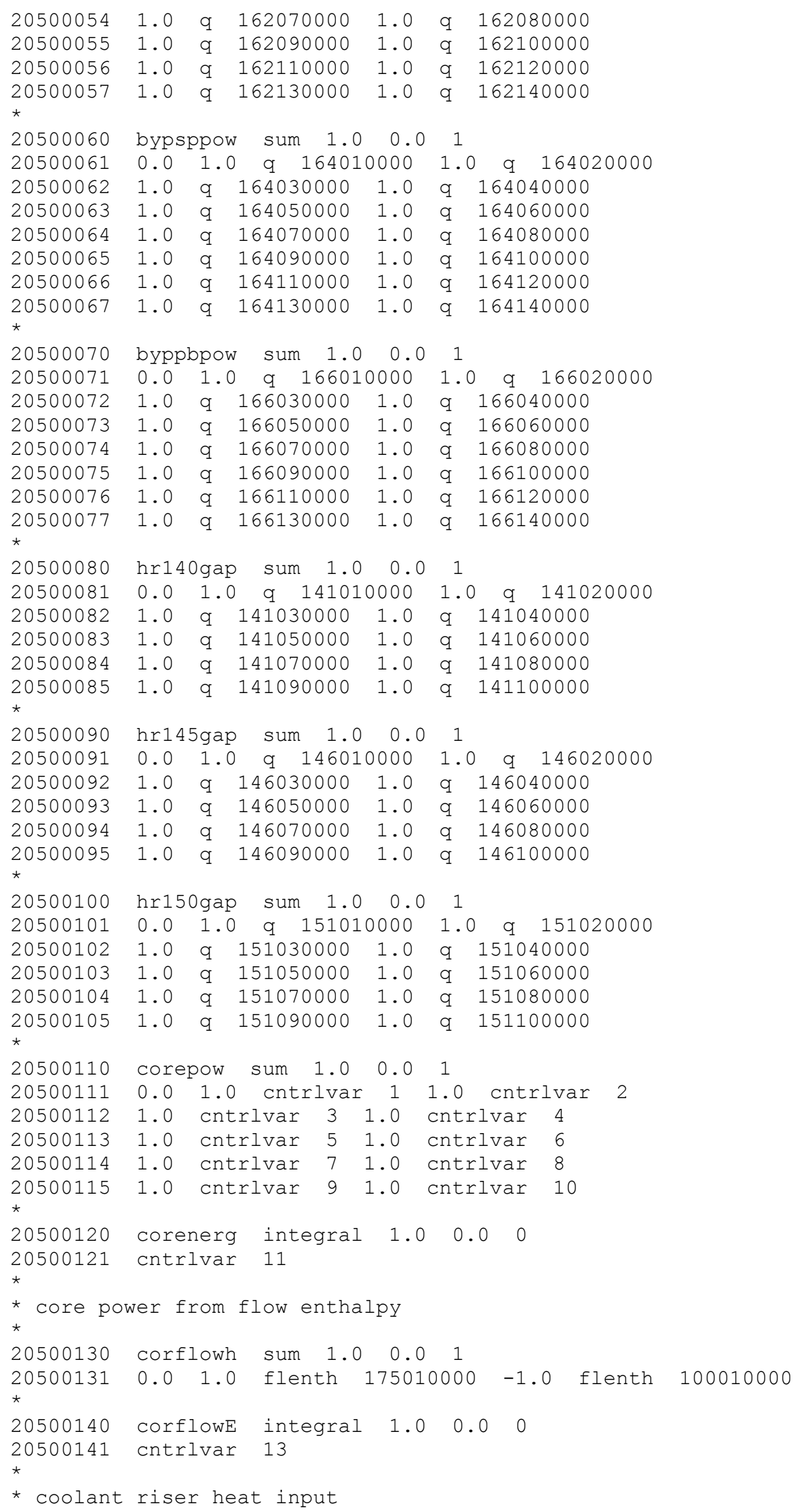




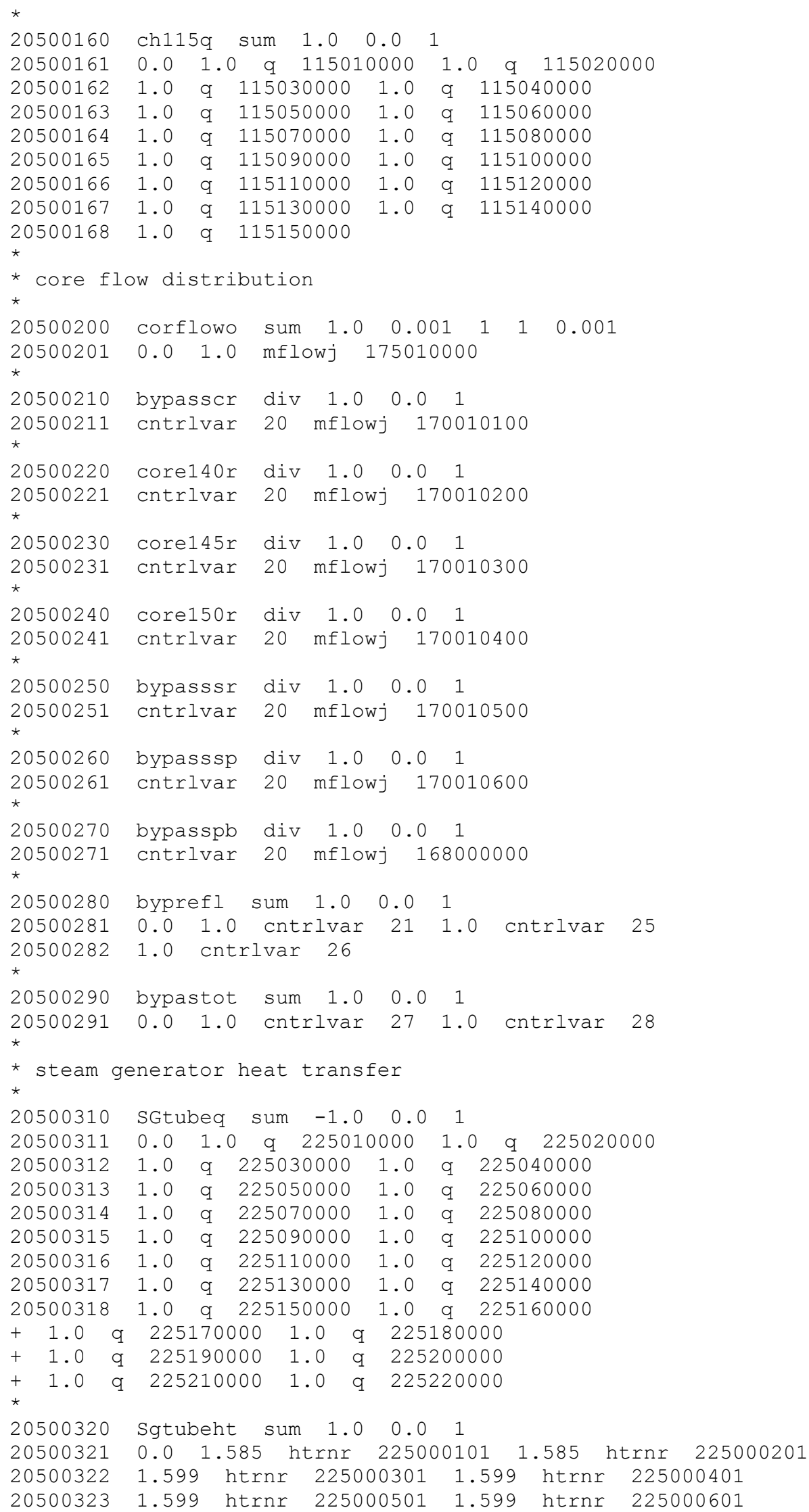




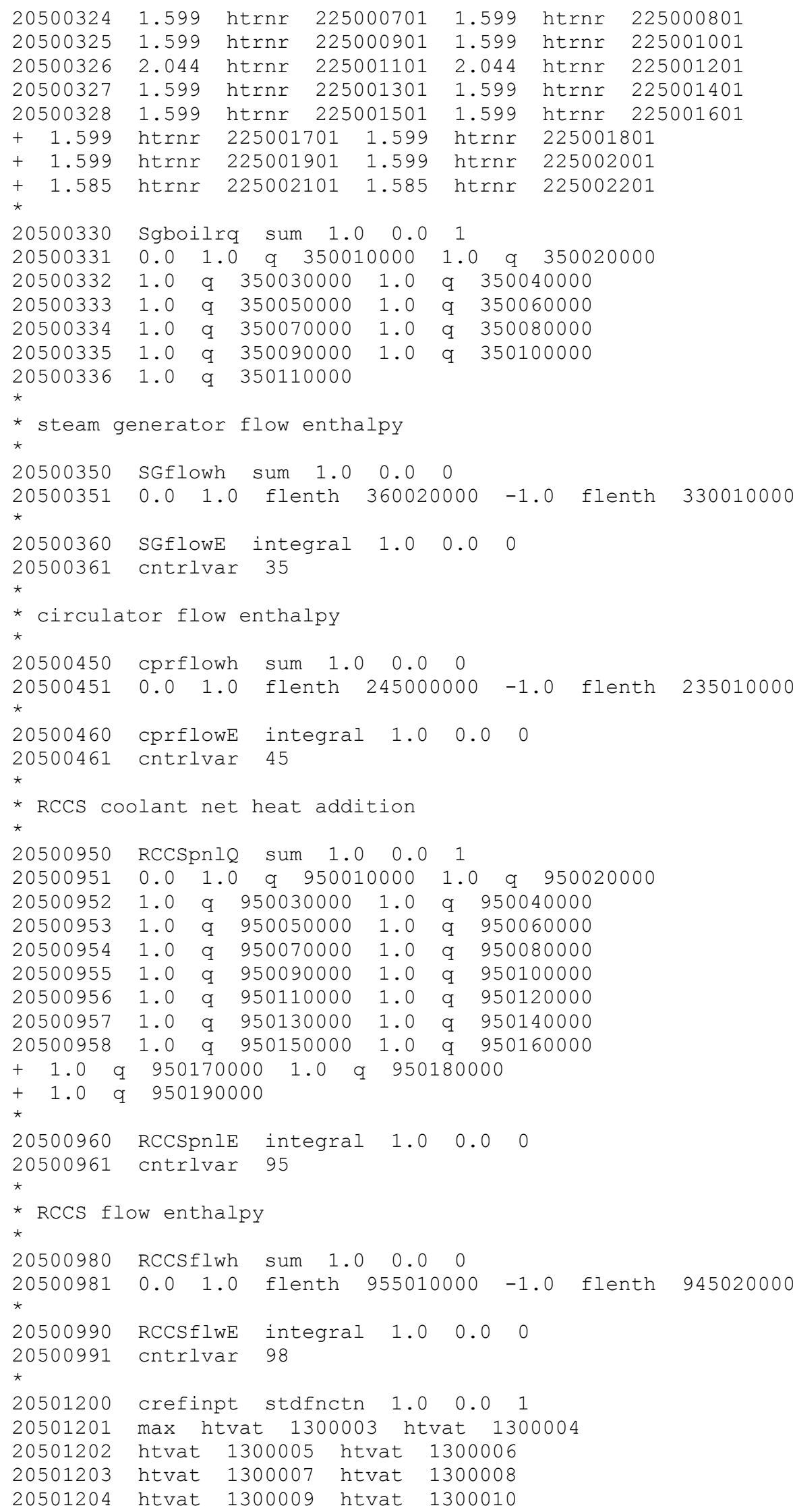




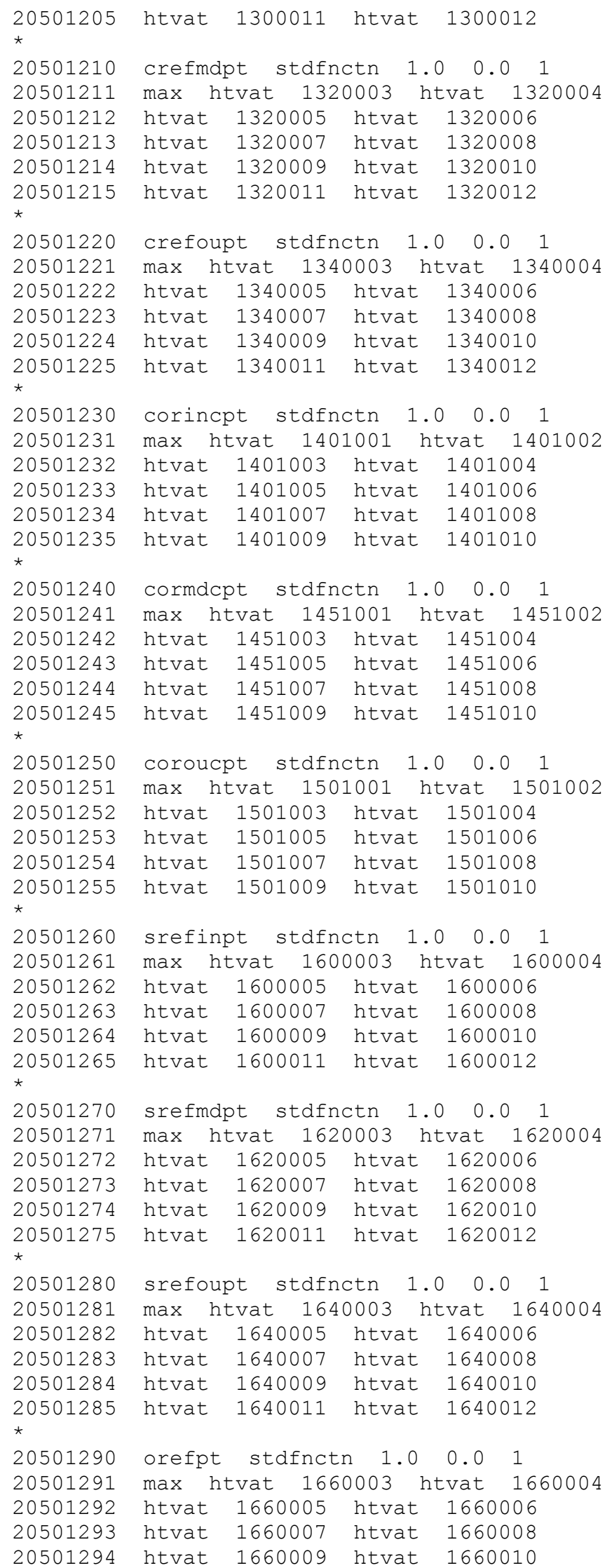




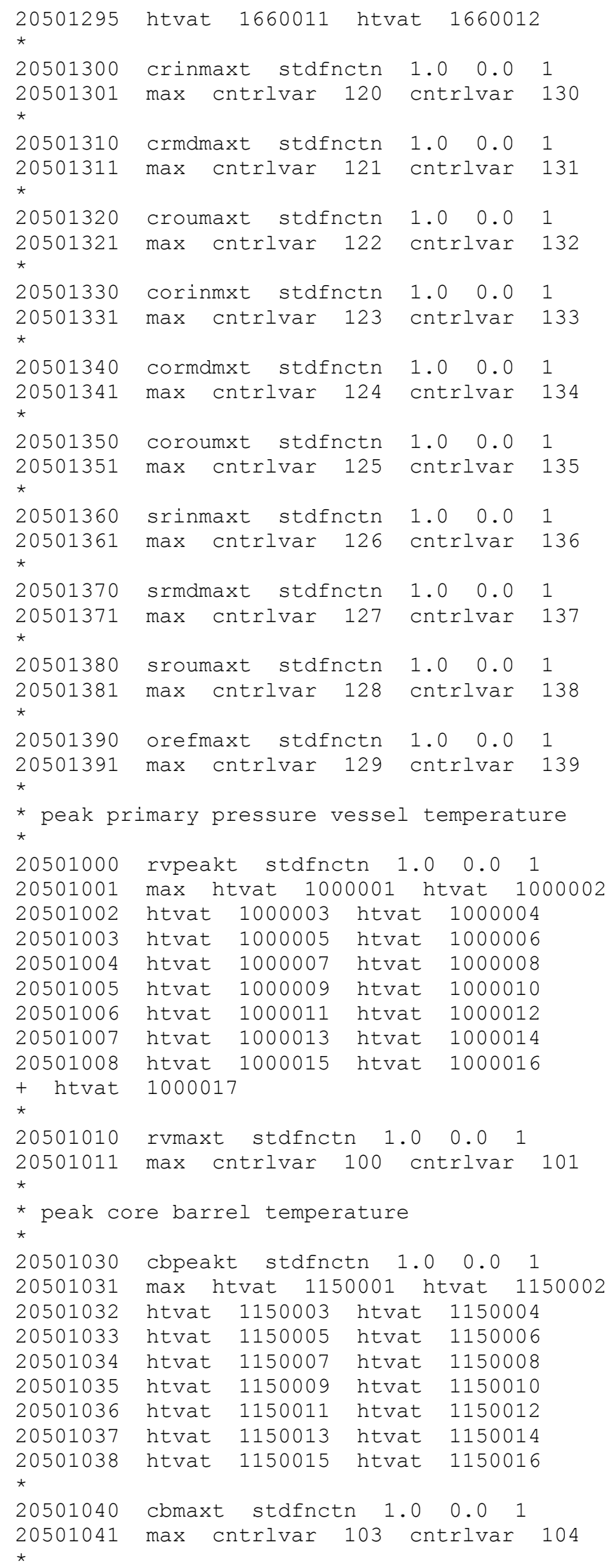




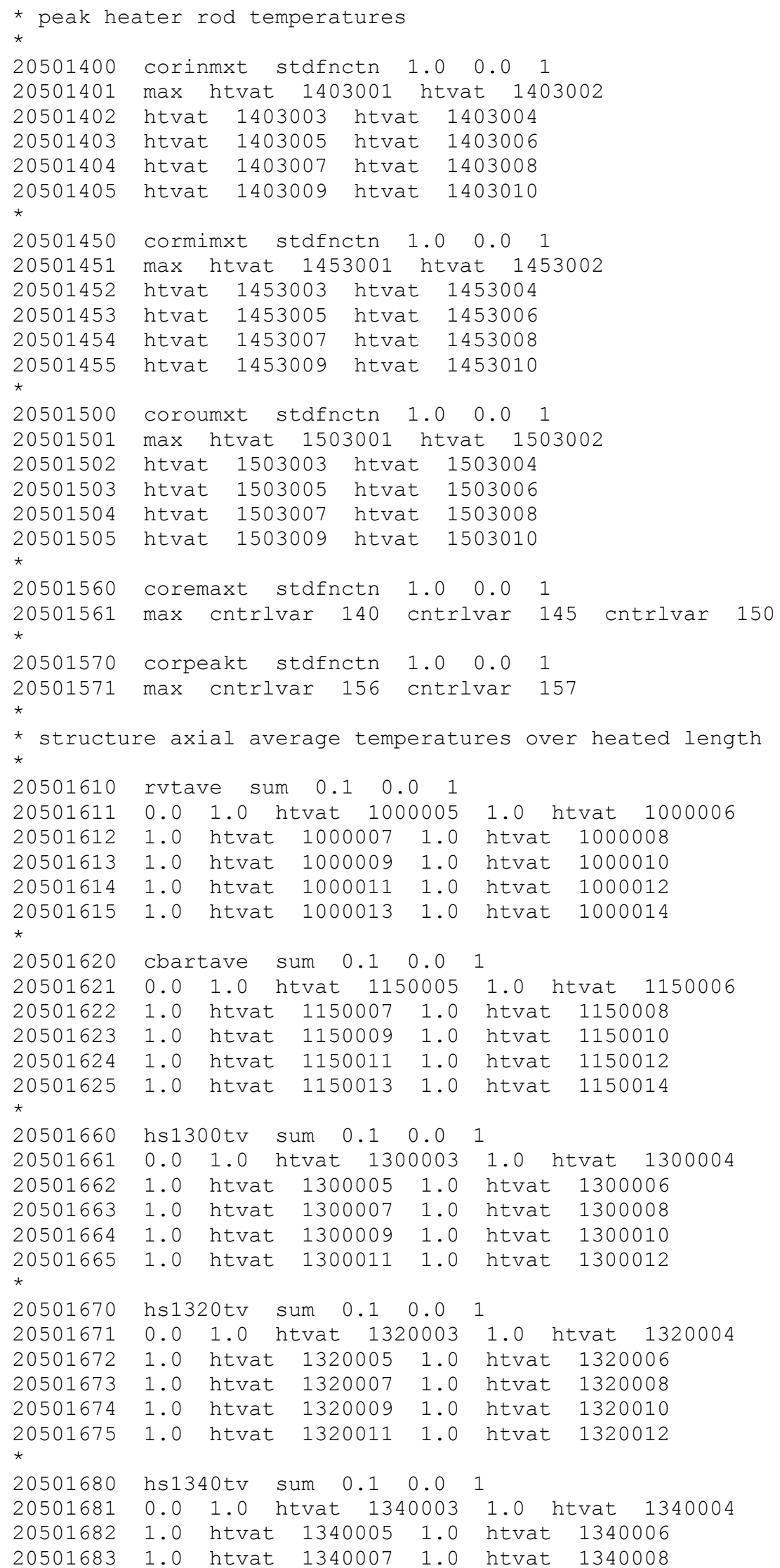




\begin{tabular}{|c|c|c|c|c|c|c|}
\hline 20501684 & 1.0 & htvat & 1340009 & 1.0 & htvat & 1340010 \\
\hline $\begin{array}{l}20501685 \\
\star\end{array}$ & 1.0 & htvat & 1340011 & 1.0 & htvat & 1340012 \\
\hline 0501690 & hs14 & $01 \mathrm{tv}$ & sum & 0.0 & 1 & \\
\hline 1691 & 0.0 & 1.0 & htvat & 1001 & 1.0 & 1401002 \\
\hline 501692 & 1.0 & htvat & 1401003 & 1.0 & htvat & 1401004 \\
\hline 01693 & 1.0 & htvat & 1401005 & 1.0 & htvat & 1401006 \\
\hline 1694 & 1.0 & htvat & 1401007 & 1.0 & htvat & 1401008 \\
\hline 0501695 & 1.0 & htvat & 1401009 & 1.0 & htvat & 1401010 \\
\hline 501700 & hs 14 & $03 t v$ & sum & 0.0 & 1 & \\
\hline & 0.0 & 1.0 & htvat 140 & 3001 & 1.0 & 1403002 \\
\hline 501702 & 1.0 & htvat & 1403003 & 1.0 & htvat & $=1403004$ \\
\hline 1703 & 1.0 & htvat & 1403005 & 1.0 & htvat & 1403006 \\
\hline 04 & 1.0 & htvat & 1403007 & 1.0 & htvat & 1403008 \\
\hline 20501705 & 1.0 & htvat & 1403009 & 1.0 & htvat & 1403010 \\
\hline 501710 & hs14 & $51 \mathrm{tv}$ & sum & 0.0 & 1 & \\
\hline 11 & 0.0 & 1.0 & htvat 145 & $\$ 1001$ & 1.0 & 1451002 \\
\hline 2 & 1.0 & htvat & 1451003 & 1.0 & htvat & $=1451004$ \\
\hline 3 & 1.0 & htvat & 1451005 & 1.0 & htvat & 1451006 \\
\hline 14 & 1.0 & htvat & 1451007 & 1.0 & htvat & 1451008 \\
\hline 20501715 & 1.0 & htvat & 1451009 & 1.0 & htvat & 1451010 \\
\hline 20 & hs14 & $53 t v$ & 0.1 & 0.0 & 1 & \\
\hline & 0.0 & 1.0 & htvat 145 & 53001 & 1.0 & htvat \\
\hline 2 & 1.0 & htvat & 1453003 & 1.0 & htvat & $=1453004$ \\
\hline 1723 & 1.0 & htvat & 1453005 & 1.0 & htvat & 1453006 \\
\hline 501724 & 1.0 & htvat & 1453007 & 1.0 & htvat & 1453008 \\
\hline 20501725 & 1.0 & htvat & 1453009 & 1.0 & htvat & 1453010 \\
\hline 0 & hs 15 & $01 t v$ & 0.1 & 0.0 & 1 & \\
\hline & 0.0 & 1.0 & htvat 150 & 1001 & 1.0 & htvat \\
\hline 732 & 1.0 & htvat & 1501003 & 1.0 & htvat & 1501004 \\
\hline 0501733 & 1.0 & htvat & 1501005 & 1.0 & htvat & 1501006 \\
\hline 0501734 & 1.0 & htvat & 1501007 & 1.0 & htvat & 1501008 \\
\hline 20501735 & 1.0 & htvat & 1501009 & 1.0 & htvat & 1501010 \\
\hline 40 & hs 15 & $03 t v$ & sum & 0.0 & 1 & \\
\hline 41 & 0.0 & 1.0 & htvat 150 & 3001 & 1.0 & 1503002 \\
\hline 501742 & 1.0 & htvat & 1503003 & 1.0 & htvat & 1503004 \\
\hline 501743 & 1.0 & htvat & 1503005 & 1.0 & htvat & 1503006 \\
\hline 20501744 & 1.0 & htvat & 1503007 & 1.0 & htvat & 1503008 \\
\hline $\begin{array}{l}20501745 \\
\star\end{array}$ & 1.0 & htvat & 1503009 & 1.0 & htvat & 1503010 \\
\hline 501750 & hs16 & $00 t v$ & sum & 0.0 & 1 & \\
\hline 51 & 0.0 & 1.0 & htvat 160 & 0003 & 1.0 & 1600004 \\
\hline 0501752 & 1.0 & htvat & 1600005 & 1.0 & htvat & 1600006 \\
\hline 501753 & 1.0 & htvat & 1600007 & 1.0 & htvat & 1600008 \\
\hline 20501754 & 1.0 & htvat & 1600009 & 1.0 & htvat & 1600010 \\
\hline 20501755 & 1.0 & htvat & 1600011 & 1.0 & htvat & 1600012 \\
\hline 01760 & hs 16 & $20 t v$ & sum & 0.0 & 1 & \\
\hline 1761 & 0.0 & 1.0 & htvat 162 & 20003 & 1.0 & htvat \\
\hline 501762 & 1.0 & htvat & 1620005 & 1.0 & htvat & 1620006 \\
\hline 501763 & 1.0 & htvat & 1620007 & 1.0 & htvat & 1620008 \\
\hline 20501764 & 1.0 & htvat & 1620009 & 1.0 & htvat & 1620010 \\
\hline $\begin{array}{l}20501765 \\
\star\end{array}$ & 1.0 & htvat & 1620011 & 1.0 & htvat & 1620012 \\
\hline 20501770 & hs16 & $40 \mathrm{tv}$ & 0.1 & 0.0 & 1 & \\
\hline 501771 & 0.0 & 1.0 & htvat 164 & 10003 & 1.0 & 164000 \\
\hline 501772 & 1.0 & htvat & 1640005 & 1.0 & htvat & 1640006 \\
\hline 0501773 & 1.0 & htvat & 1640007 & 1.0 & htvat & 1640008 \\
\hline
\end{tabular}




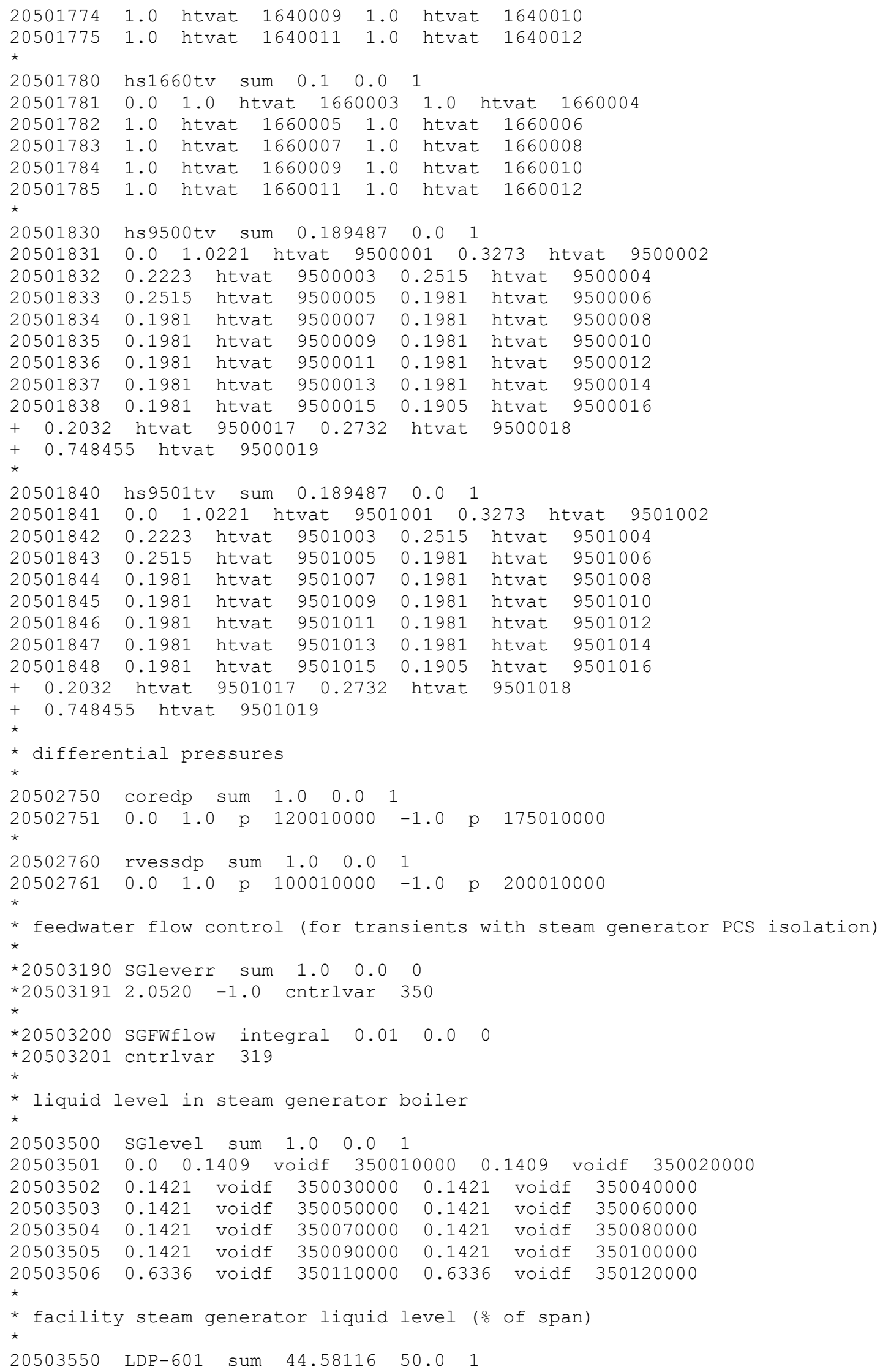




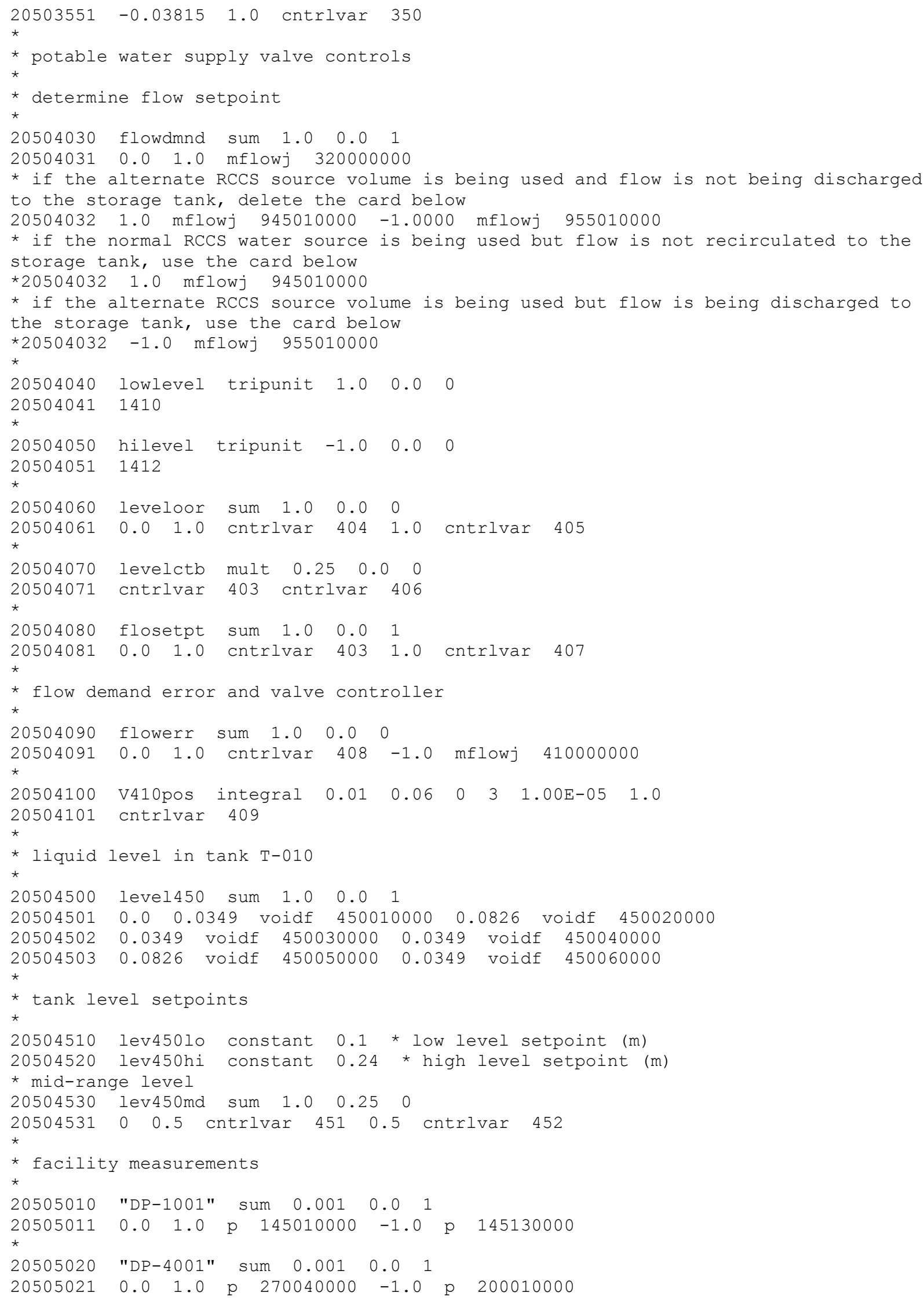




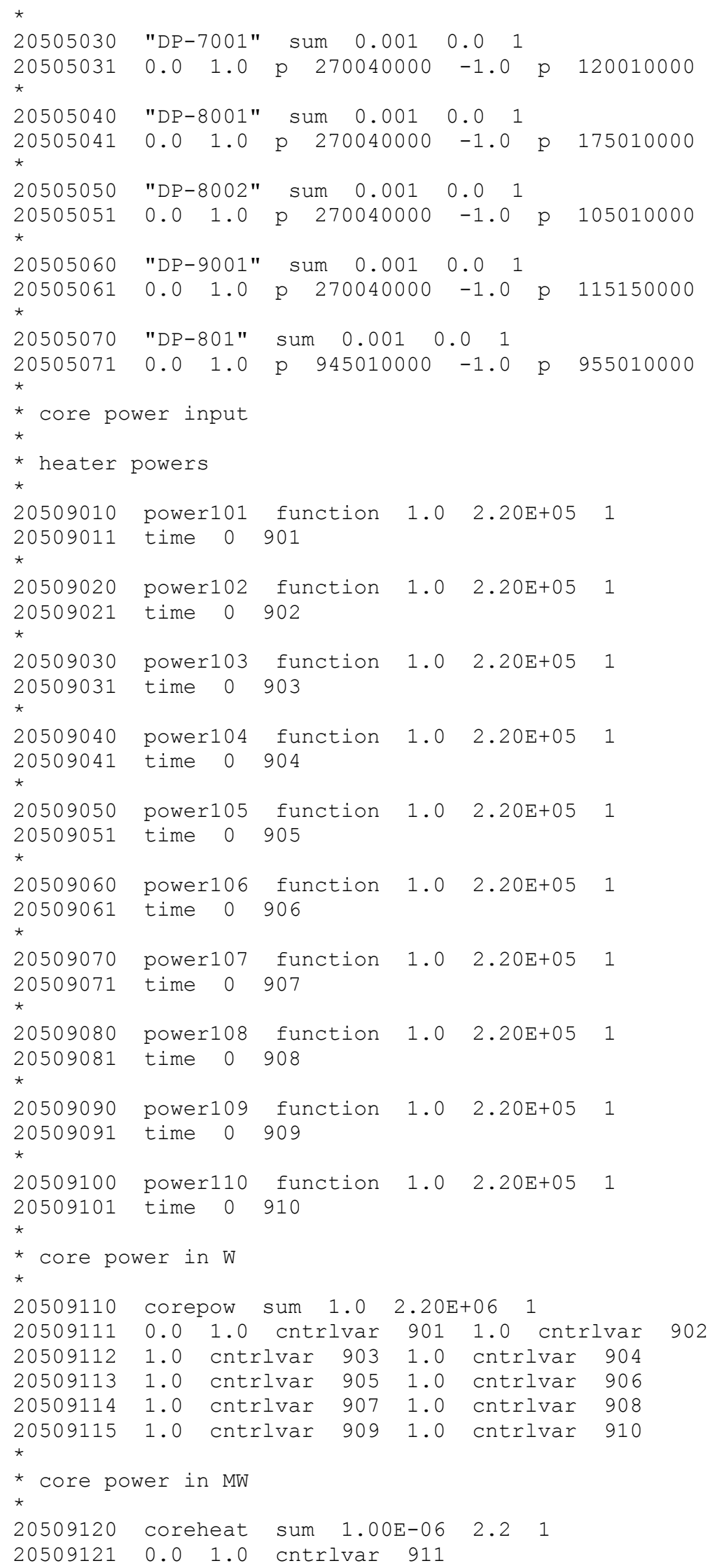




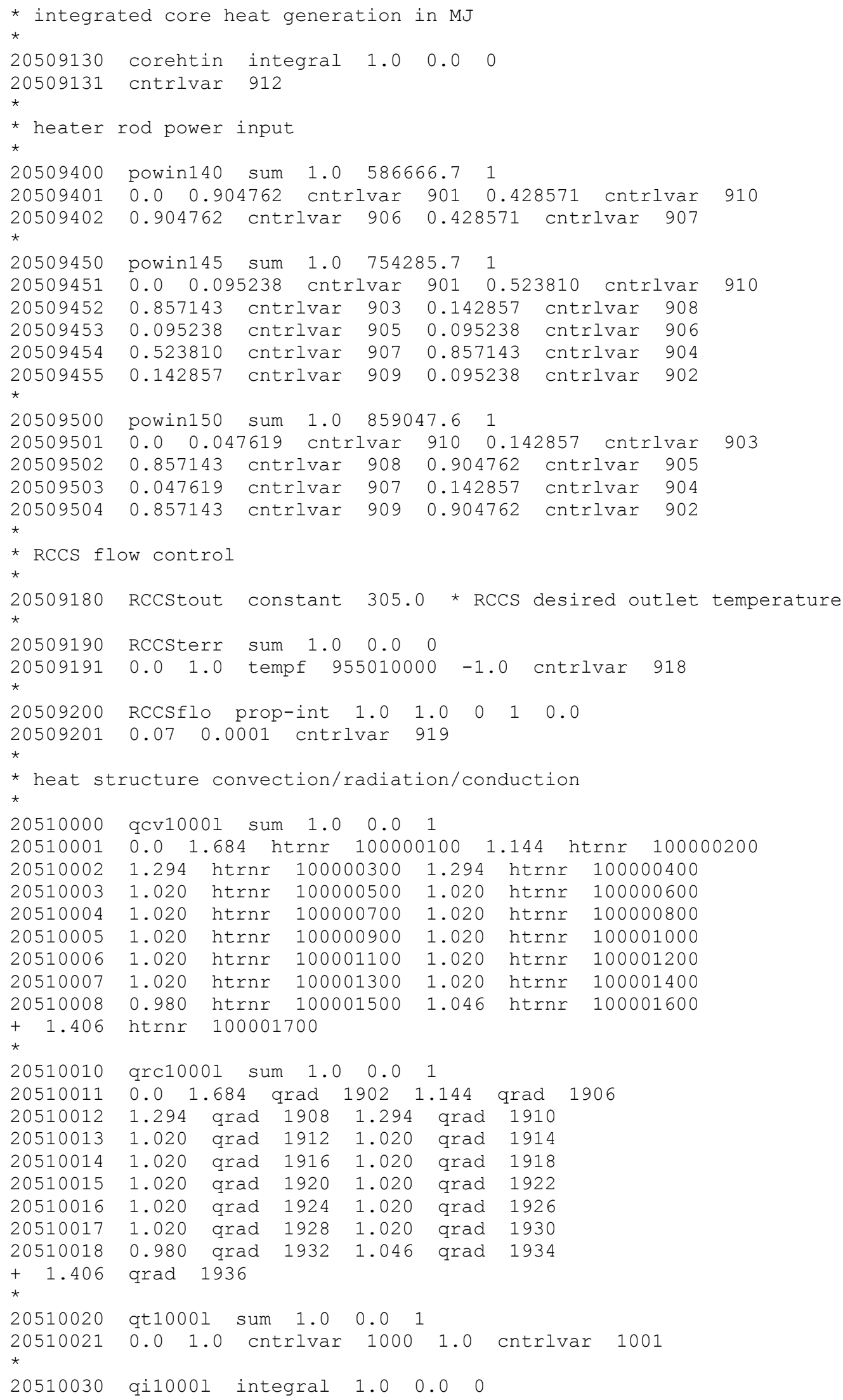




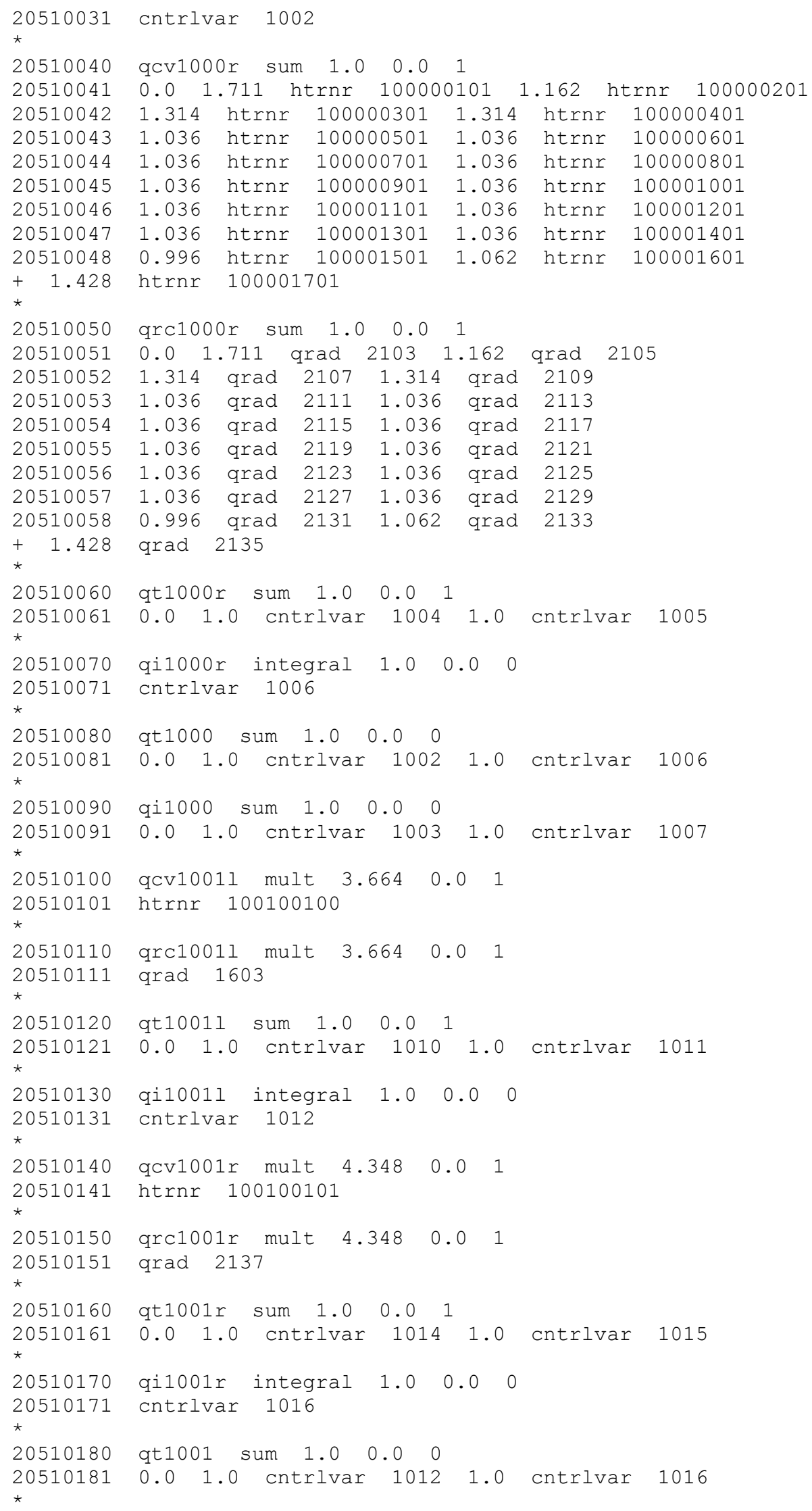




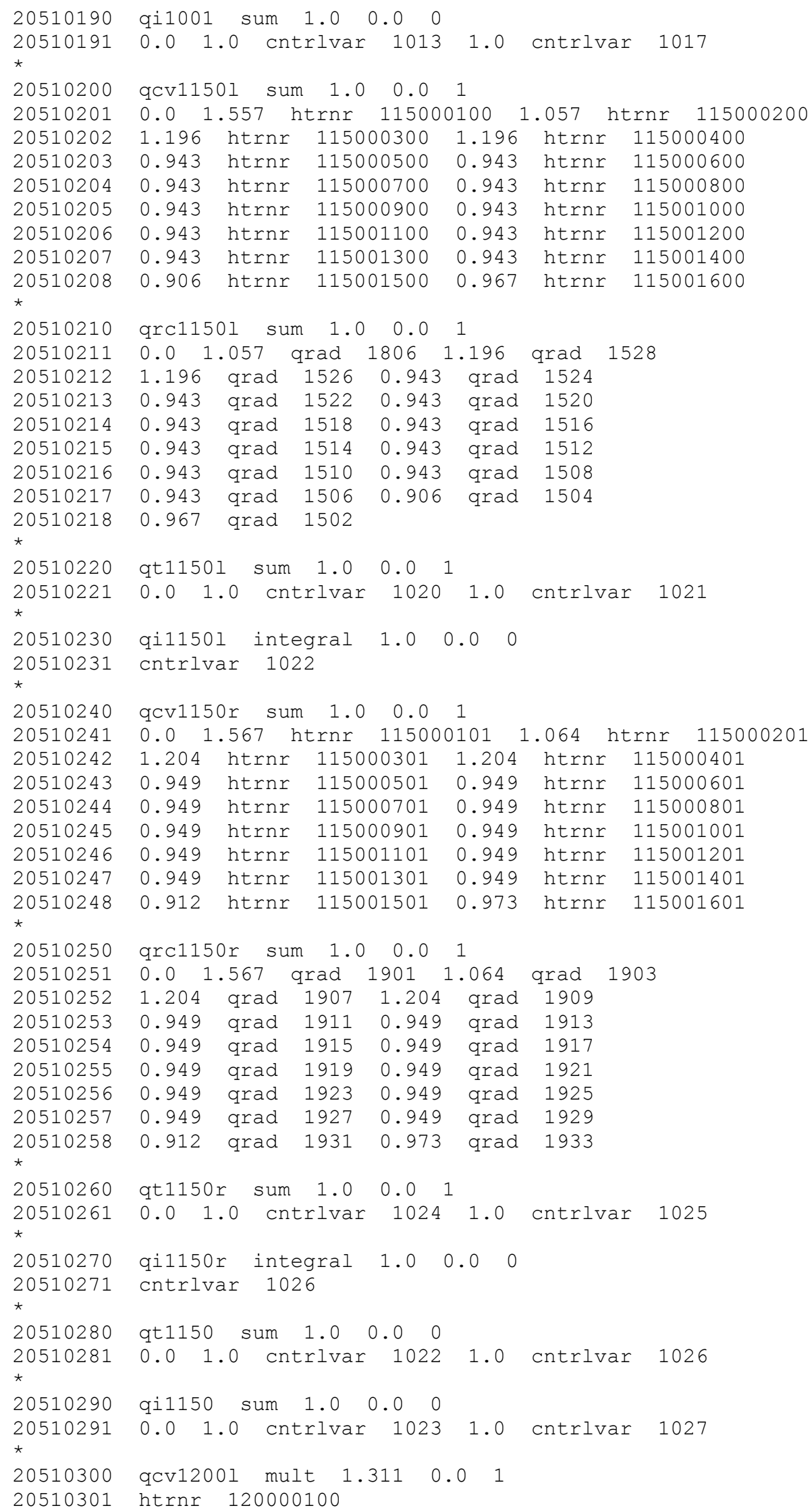




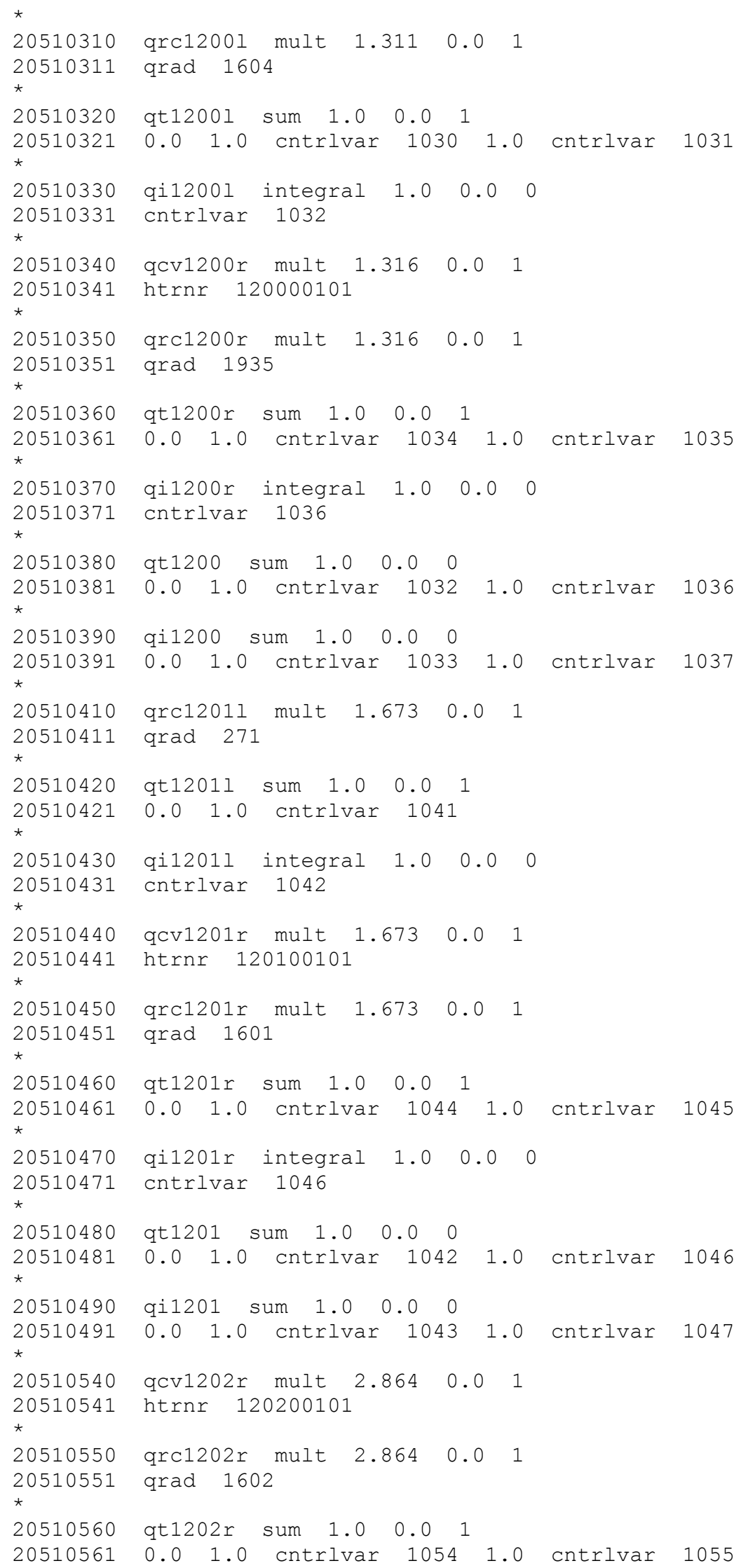




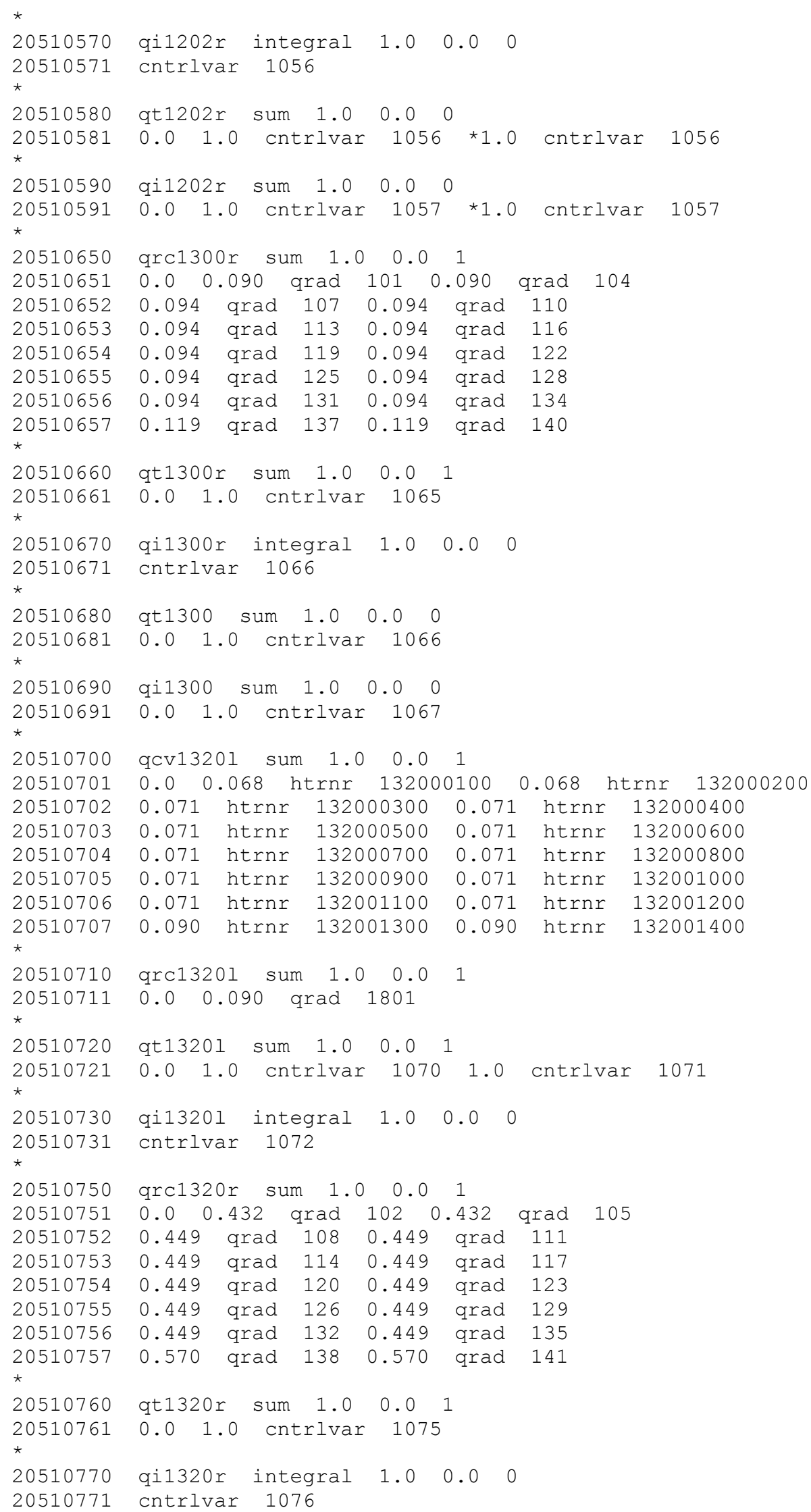




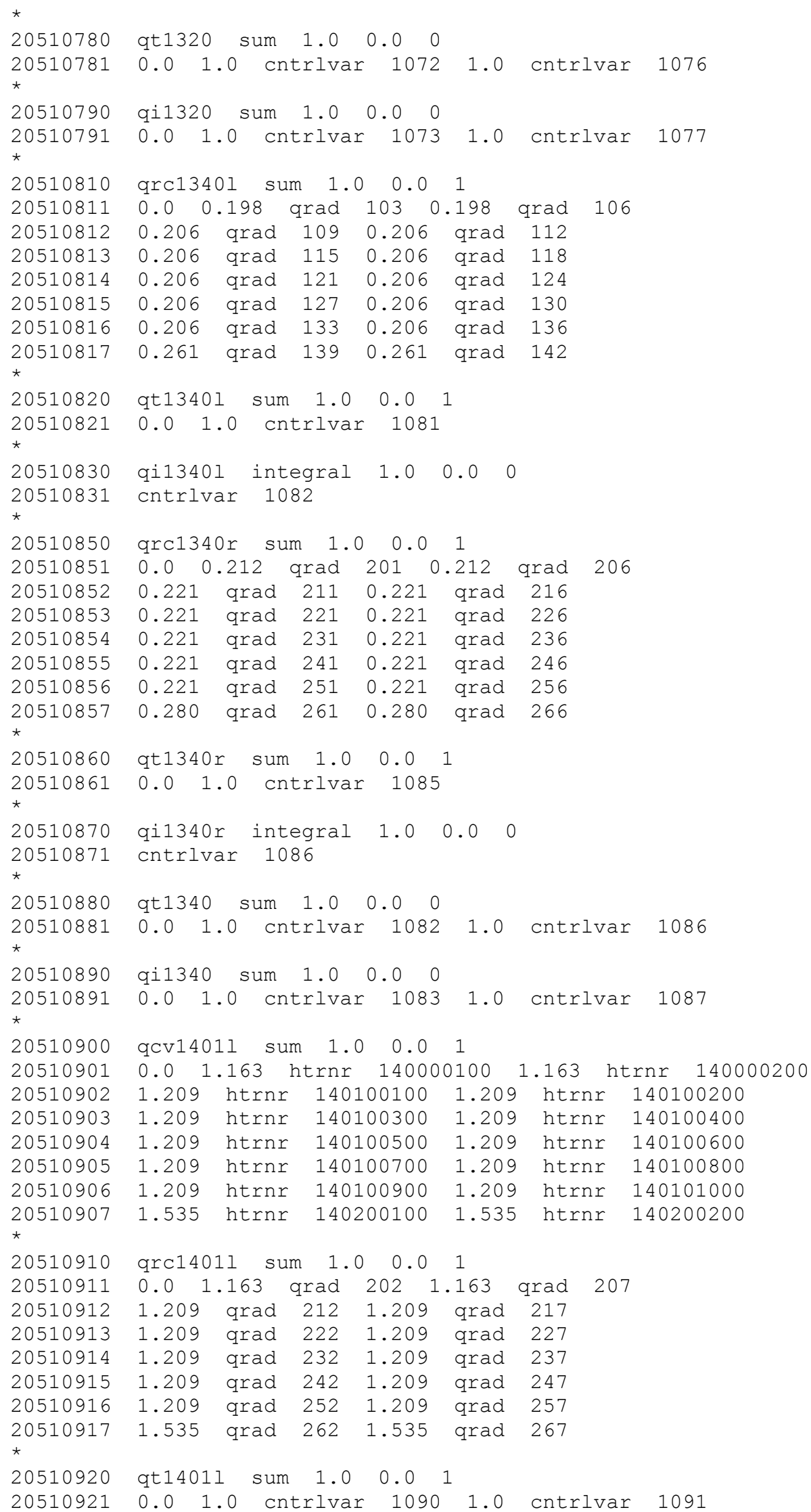




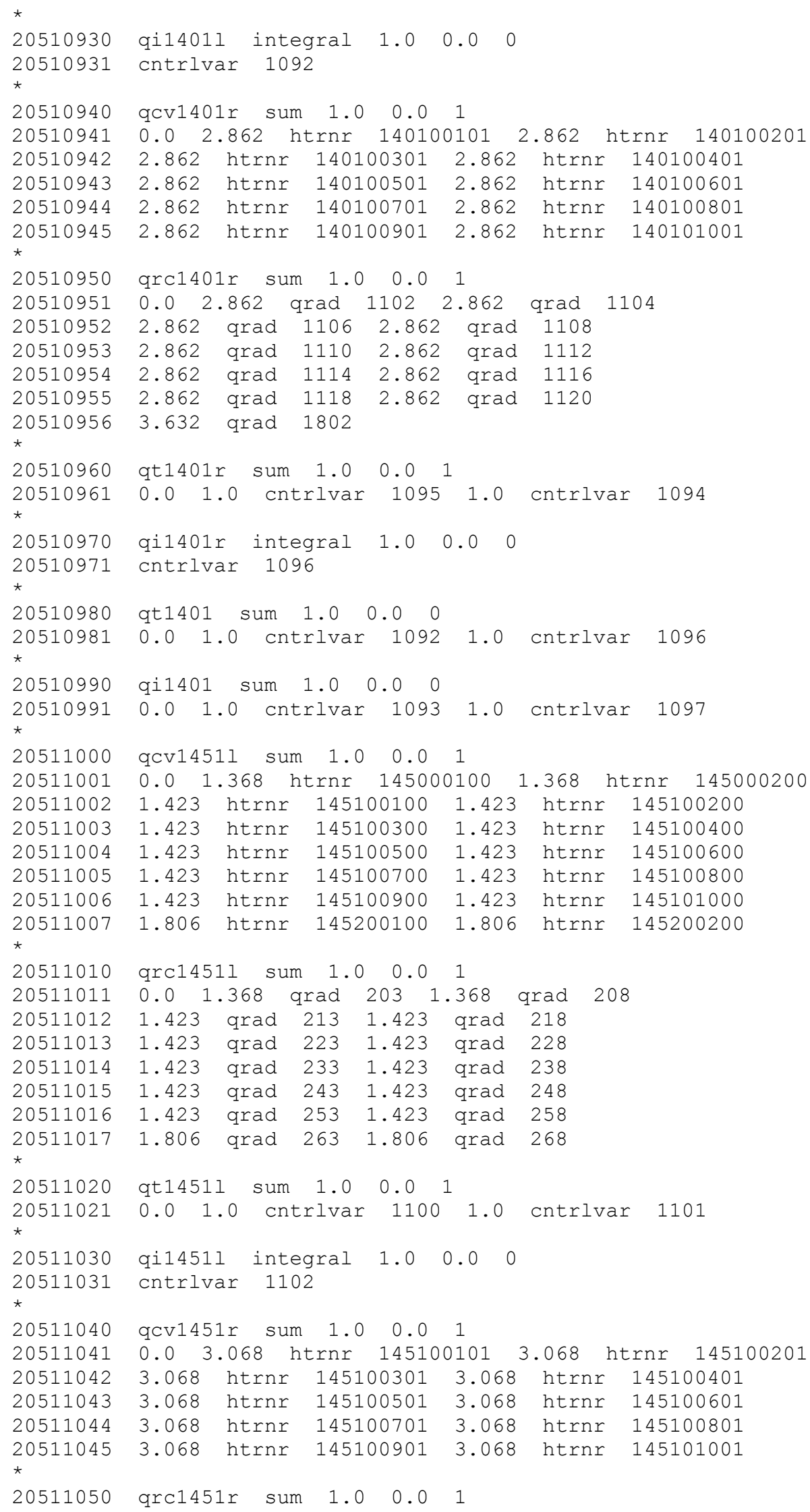




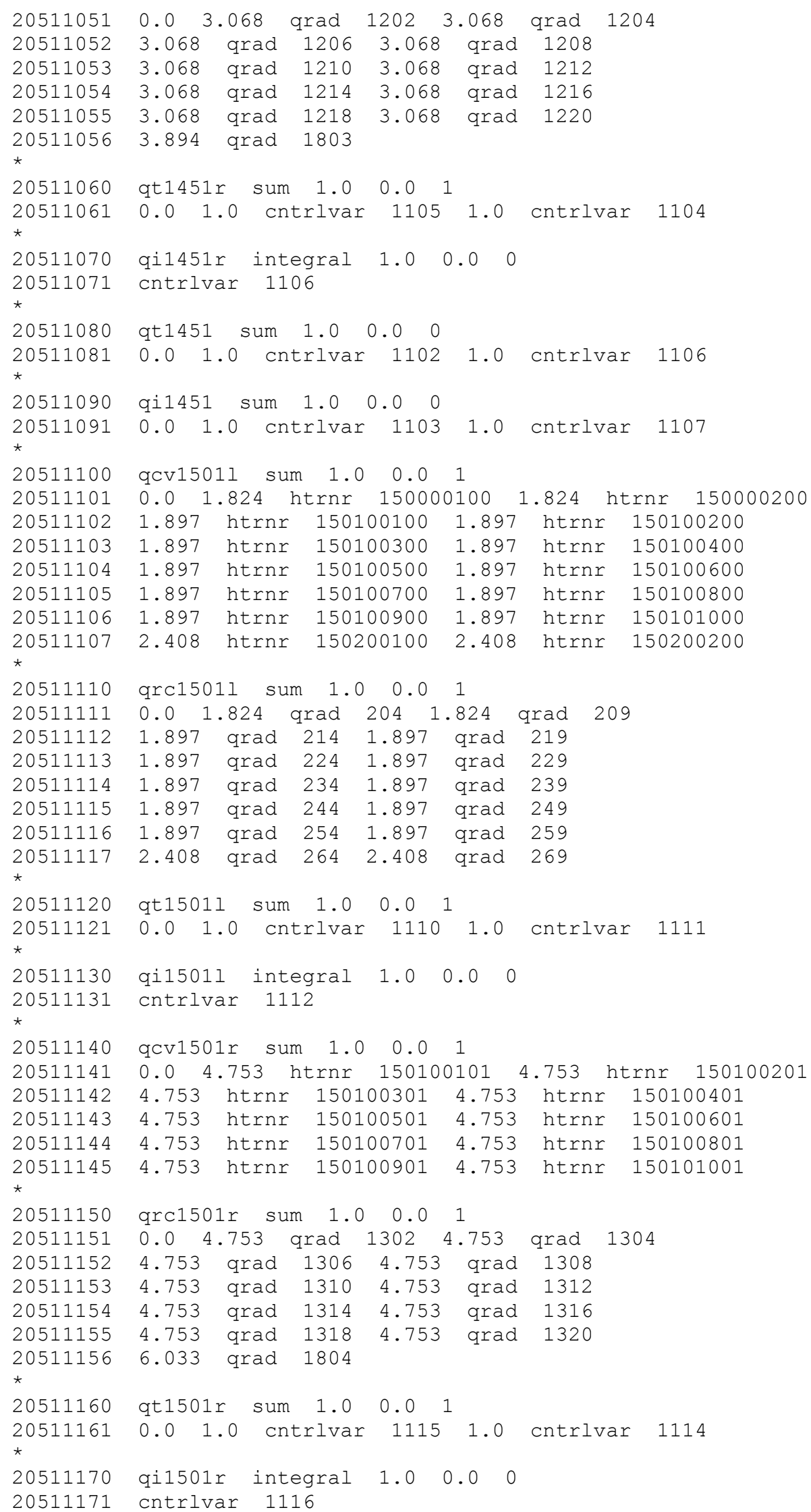




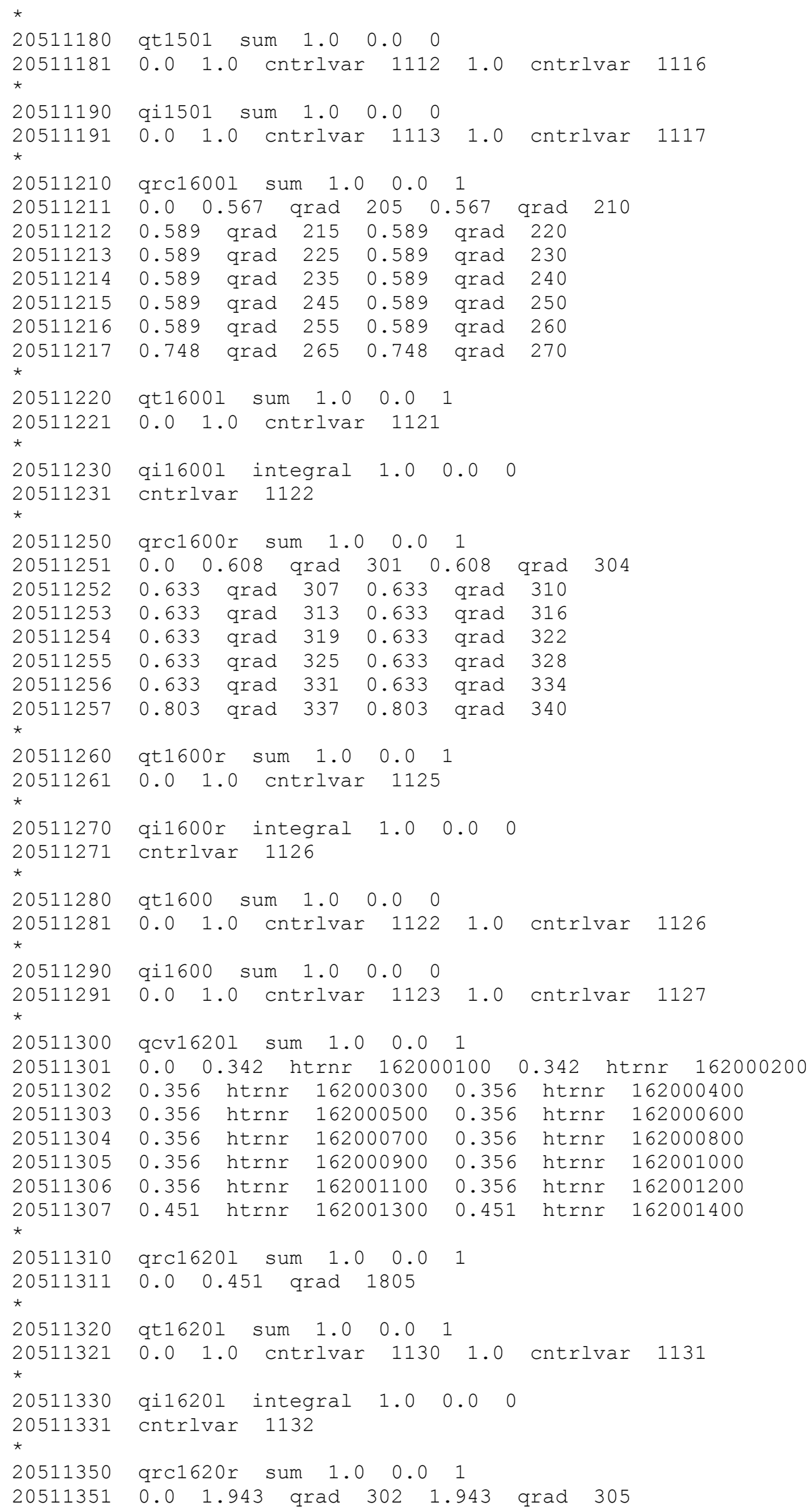




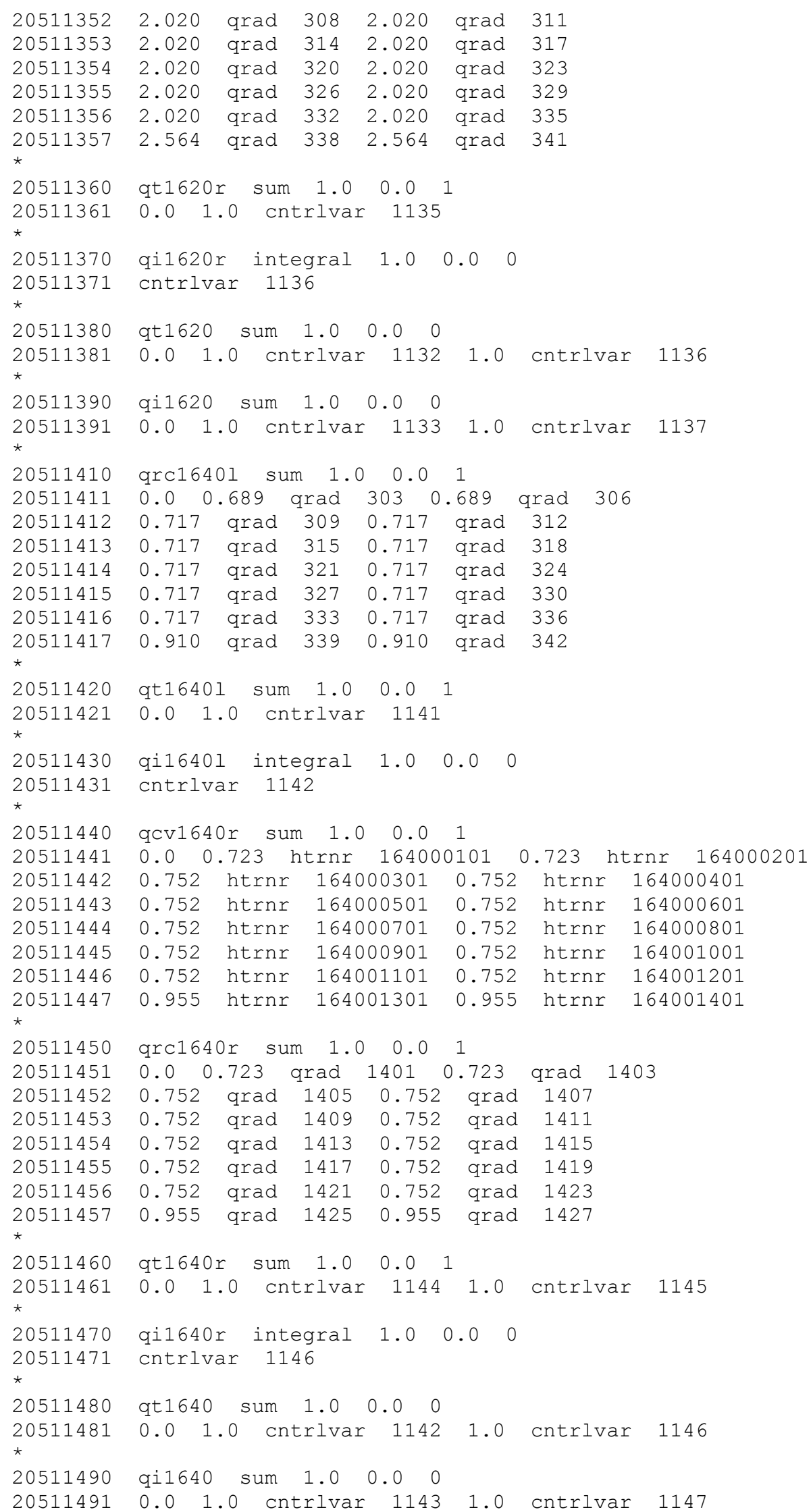




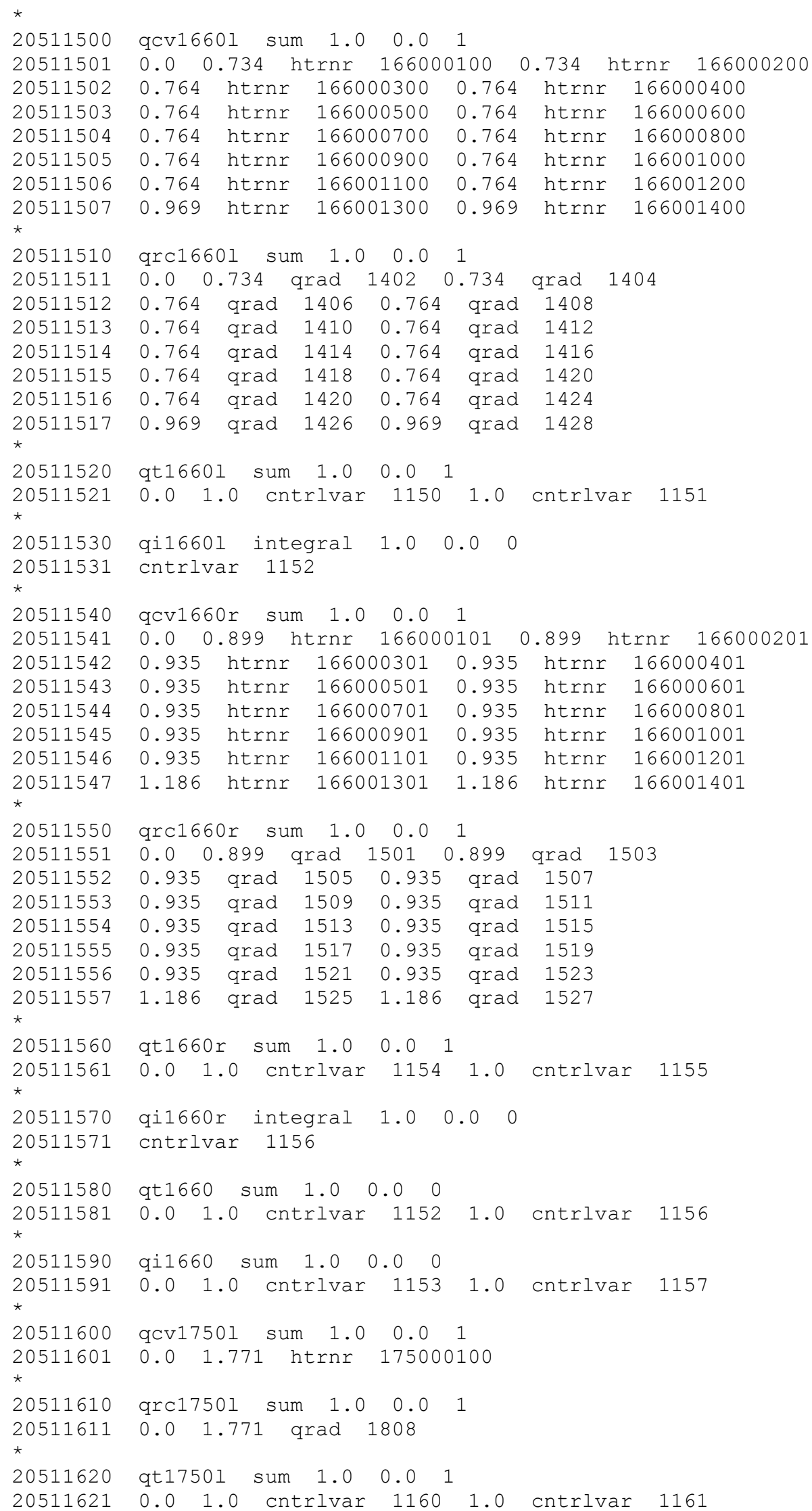




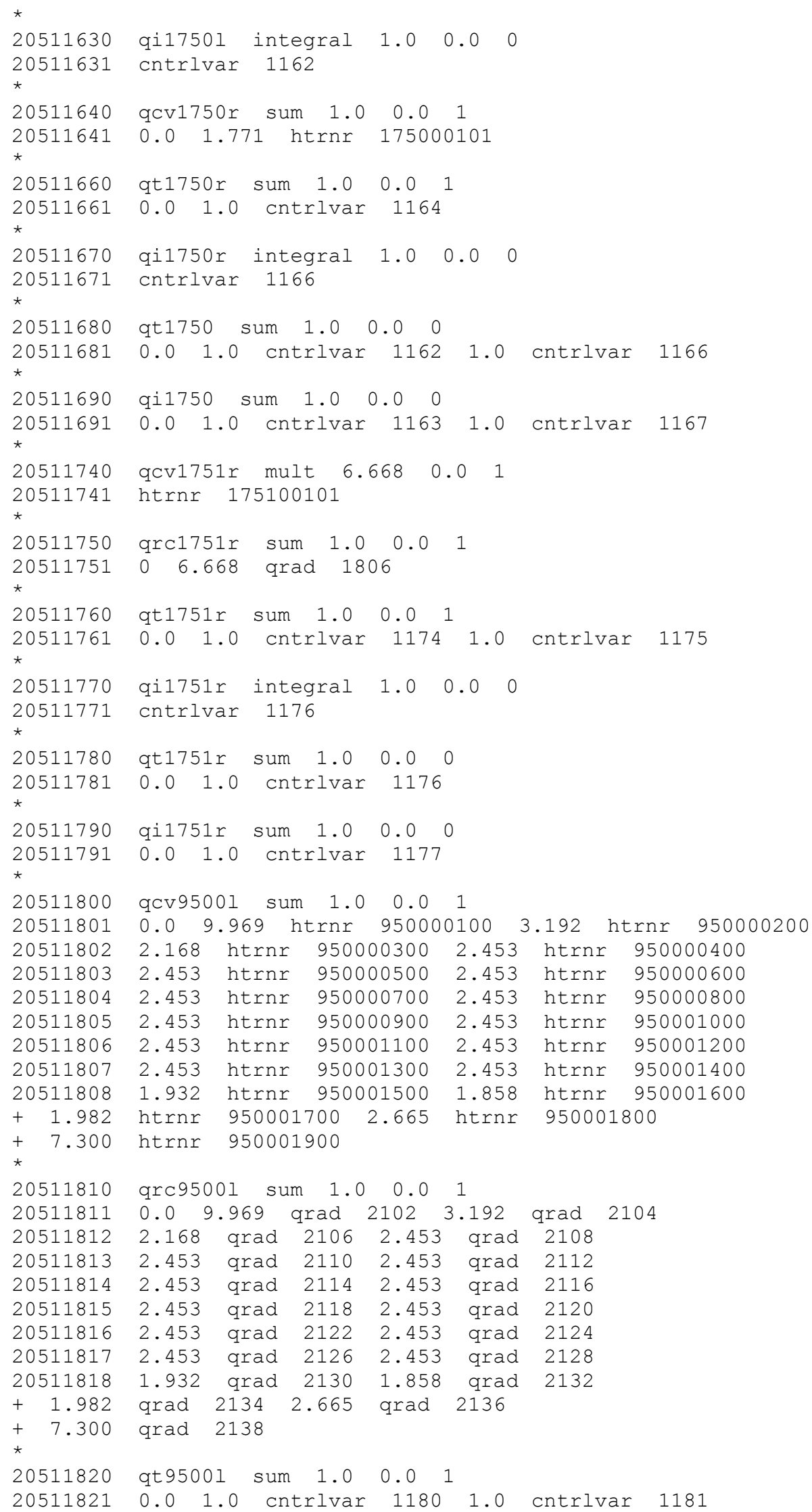




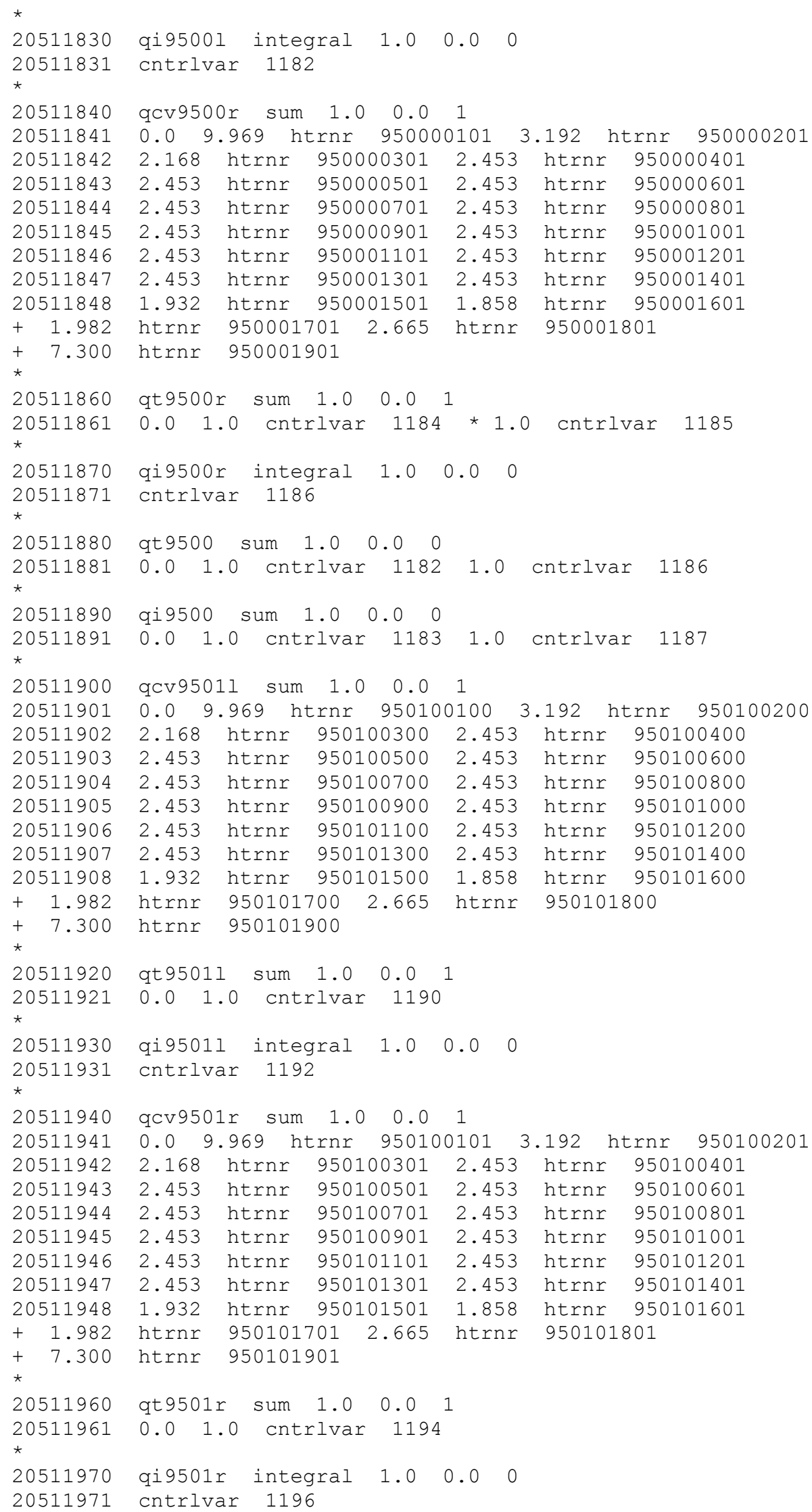




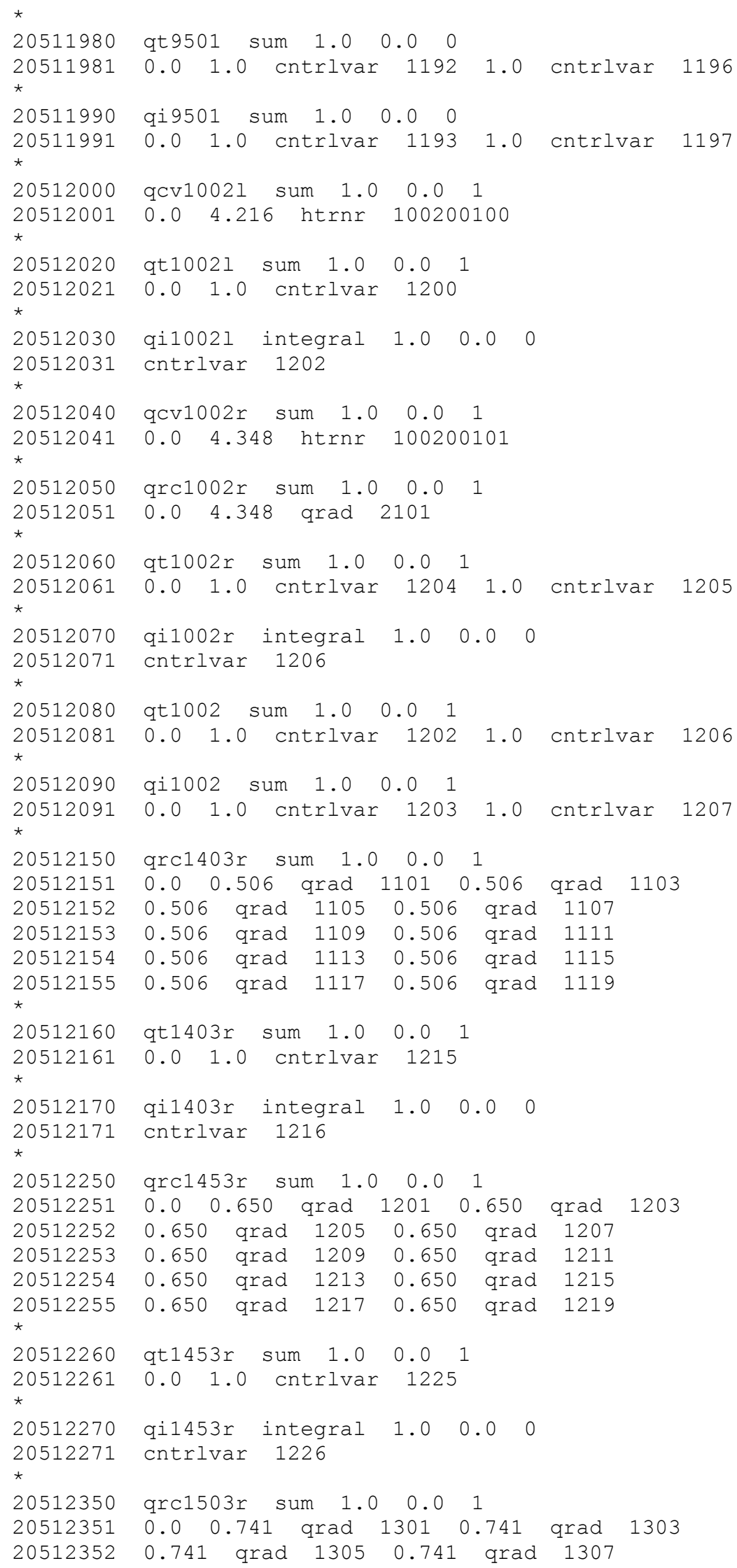




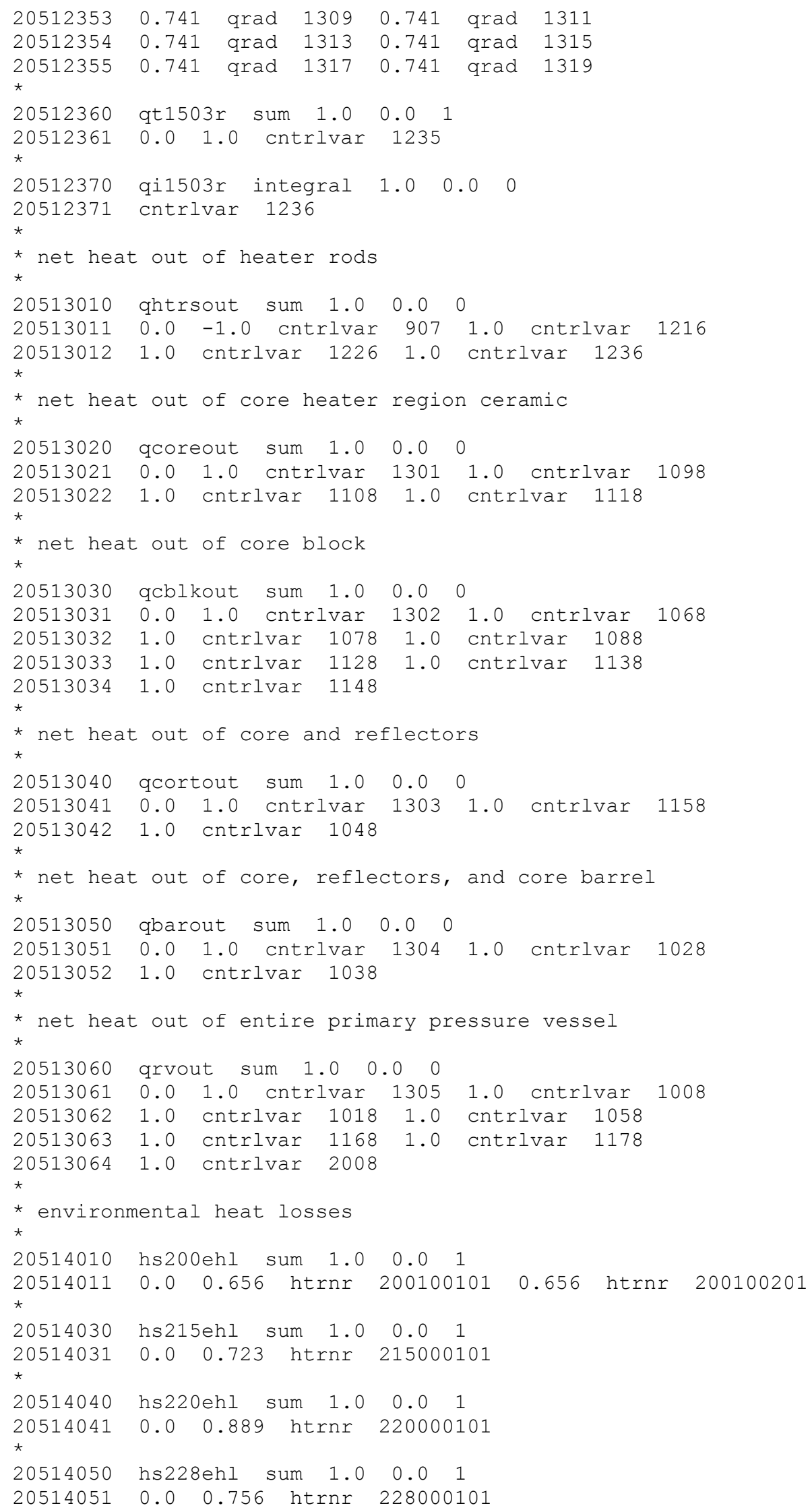




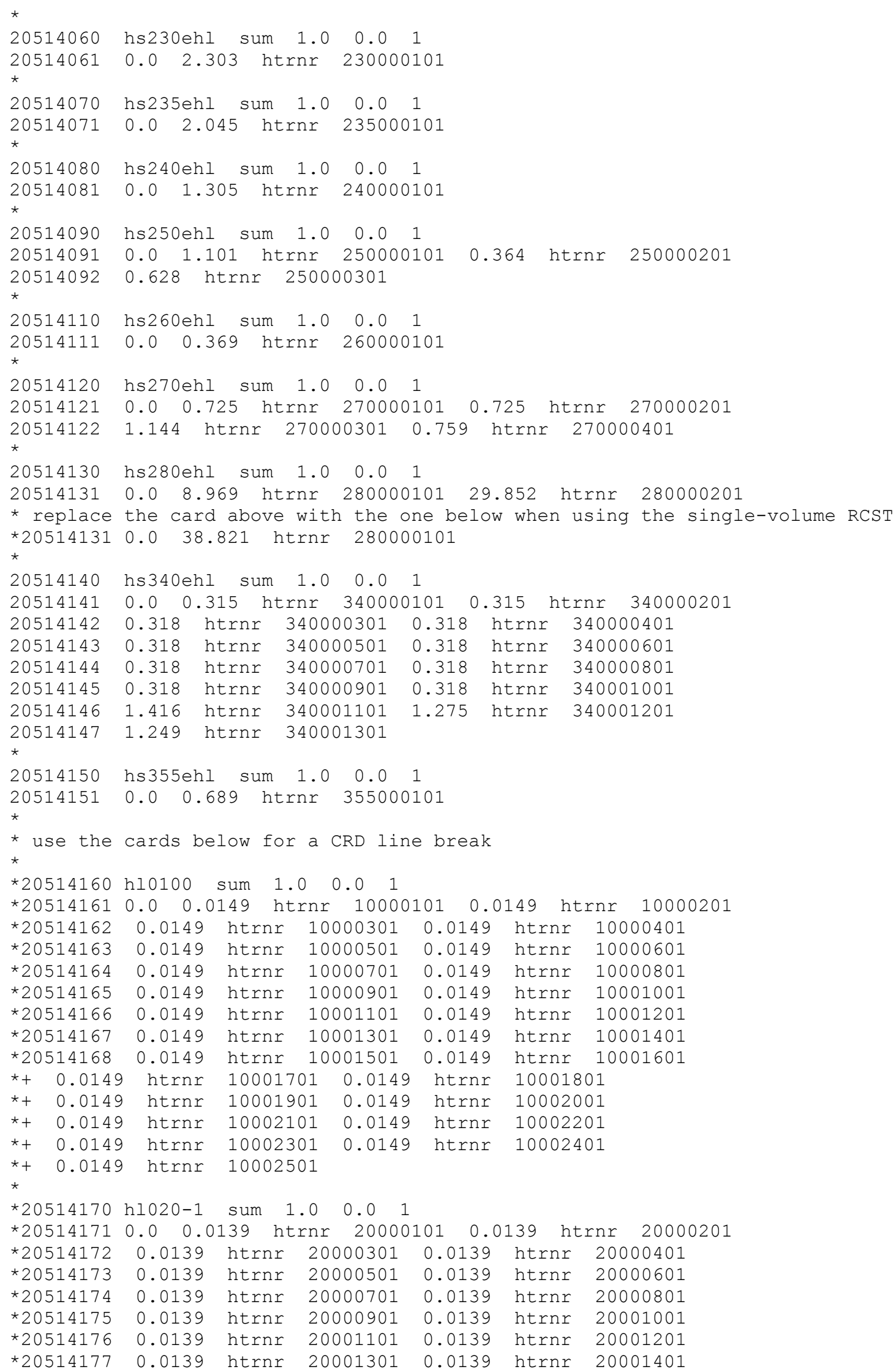




\begin{tabular}{|c|c|c|c|c|c|c|}
\hline *20 & 4178 & 0.0139 & htrnr & & .0139 & htrnr \\
\hline$\star+$ & 0.0139 & htrnr & 20001701 & 0.0139 & htrnr & 20001801 \\
\hline$\star+$ & 0.0139 & htrnr & 20001901 & 0.0139 & htrnr & 20002001 \\
\hline$\star+$ & 0.0139 & htrnr & 20002101 & 0.0139 & htrnr & 20002201 \\
\hline$\star+$ & 0.0139 & htrnr & 20002301 & 0.0139 & htrnr & 20002401 \\
\hline *+ & 0.0139 & htrne & 20002501 & 0.0139 & htrnr & 20002601 \\
\hline *+ & 0.0139 & htrnr & 20002701 & 0.0139 & htrnr & 20002801 \\
\hline$\star+$ & 0.0139 & htrnr & 20002901 & 0.0139 & htrnr & 20003001 \\
\hline$\star+$ & 0.0139 & htrnr & 20003101 & 0.0139 & htrnr & 20003201 \\
\hline *+ & 0.0139 & htrnr & 20003301 & 0.0139 & htrnr & 20003401 \\
\hline $\begin{array}{l}\star+ \\
\star\end{array}$ & 0.0139 & htrnr & 20003501 & & & \\
\hline$\star 20$ & 4180 & n1030-1 & sum & 0.0 & & \\
\hline$\star 20$ & 4181 & 0.0 & htrnr & 300001 & 01 & htrnr \\
\hline$\star 20$ & 514182 & 0.0136 & htrnr 30 & 000301 & 0.0136 & htrnr $\quad 30000401$ \\
\hline$\star 20$ & 514183 & 0.0136 & htrnr & 000501 & 0.0136 & 30000601 \\
\hline$\star 20$ & 514184 & 0.0136 & htrne & 000701 & 0.0136 & 30000801 \\
\hline$\star 20$ & 514185 & 0.0136 & htrne & 000901 & 0.0136 & 30001001 \\
\hline$\star 20$ & 514186 & 0.0136 & htrne & 001101 & 0.0136 & 30001201 \\
\hline$\star 20$ & 514187 & 0.0136 & htrne & 001301 & 0.0136 & 30001401 \\
\hline$\star 20$ & 514188 & 0.0136 & htrnr & 001501 & 0.0136 & 30001601 \\
\hline$\star+$ & 0.0136 & htrne & 30001701 & 0.0136 & htrnr & 30001801 \\
\hline$\star+$ & 0.0136 & htrnr & 30001901 & 0.0136 & htrnr & 30002001 \\
\hline$\star+$ & 0.0136 & htrnr & 30002101 & 0.0136 & htrnr & 30002201 \\
\hline$\star+$ & 0.0136 & htrnr & 30002301 & 0.0136 & htrnr & 30002401 \\
\hline$\star+$ & 0.0136 & htrnr & 30002501 & 0.0136 & htrnr & 30002601 \\
\hline$\star+$ & 0.0136 & htrnr & 30002701 & 0.0136 & htrnr & 30002801 \\
\hline$\star+$ & 0.0136 & htrnr & 30002901 & 0.0136 & htrnr & 30003001 \\
\hline *+ & 0.0136 & htrnr & 30003101 & 0.0136 & htrnr & 30003201 \\
\hline$\star+$ & 0.0136 & htrnr & 30003301 & 0.0136 & htrnr & 30003401 \\
\hline$\star+$ & 0.0136 & htrnr & 30003501 & 0.0136 & htrnr & 30003601 \\
\hline *+ & 0.0136 & htrnr & 30003701 & 0.0136 & htrnr & 30003801 \\
\hline$\star+$ & 0.0136 & htrnr & 30003901 & 0.0136 & htrnr & 30004001 \\
\hline$\star$ & & & & & & \\
\hline$\star 20$ & 190 & h1030-2 & sum & 0.0 & & \\
\hline$\star 20$ & 514191 & 0.0 & 136 htrnr & 300041 & 01 & htrnr \\
\hline$\star 20$ & 514192 & 0.0136 & htrne & 004301 & 0.0136 & htrne \\
\hline$\star 20$ & 514193 & 0.0136 & htrne & 004501 & 0.0136 & 30004601 \\
\hline$\star 20$ & 514194 & 0.0136 & htrne & 004701 & 0.0136 & 30004801 \\
\hline *20 & 514195 & 0.0136 & htrnr & 004901 & 0.0136 & htrnr \\
\hline$\star 20$ & 514196 & 0.0136 & htrnr & 005101 & 0.0136 & htrnr \\
\hline$\star 20$ & 514197 & 0.0136 & htrne & 005301 & 0.0136 & htrne \\
\hline *20 & 514198 & 0.0136 & htrnr & 005501 & 0.0136 & 30005601 \\
\hline$\star+$ & 0.0136 & htrnr & 30005701 & 0.0136 & htrnr & 30005801 \\
\hline *+ & 0.0136 & htrnr & 30005901 & 0.0136 & htrnr & 30006001 \\
\hline *+ & 0.0136 & htrne & 30006101 & 0.0136 & htrnr & 30006201 \\
\hline *+ & 0.0136 & htrnr & 30006301 & 0.0136 & htrnr & 30006401 \\
\hline$\star+$ & 0.0136 & htrnr & 30006501 & 0.0136 & htrnr & 30006601 \\
\hline$\star+$ & 0.0136 & htrnr & 30006701 & 0.0136 & htrnr & 30006801 \\
\hline$\star+$ & 0.0136 & htrnr & 30006901 & 0.0136 & htrnr & 30007001 \\
\hline$\star+$ & 0.0136 & htrnr & 30007101 & 0.0136 & htrnr & 30007201 \\
\hline$\star+$ & 0.0136 & htrnr & 30007301 & 0.0136 & htrnr & 30007401 \\
\hline *+ & 0.0136 & htrnr & 30007501 & 0.0136 & htrnr & 30007601 \\
\hline *+ & 0.0136 & htrnr & 30007701 & 0.0136 & htrnr & 30007801 \\
\hline $\begin{array}{l}\star+ \\
\star\end{array}$ & 0.0136 & htrnr & 30007901 & 0.0136 & htrnr & 30008001 \\
\hline$\star 20$ & 4200 & h1030-3 & sum & 0.0 & & \\
\hline$\star 20$ & 514201 & 0.0 & 136 htrnr & 300081 & 01 & htrne \\
\hline *20 & 514202 & 0.0136 & htrne 30 & 008301 & 0.0136 & htrnr 30008401 \\
\hline$\star 20$ & 514203 & 0.0136 & htrne & 008501 & 0.0136 & 30008601 \\
\hline$\star 20$ & 514204 & 0.0136 & htrne & 008701 & 0.0136 & 30008801 \\
\hline$\star 20$ & 514205 & 0.0136 & htrnr & 008901 & 0.0136 & 30009001 \\
\hline$\star 20$ & 514206 & 0.0136 & htrne & 009101 & 0.0136 & 30009201 \\
\hline
\end{tabular}




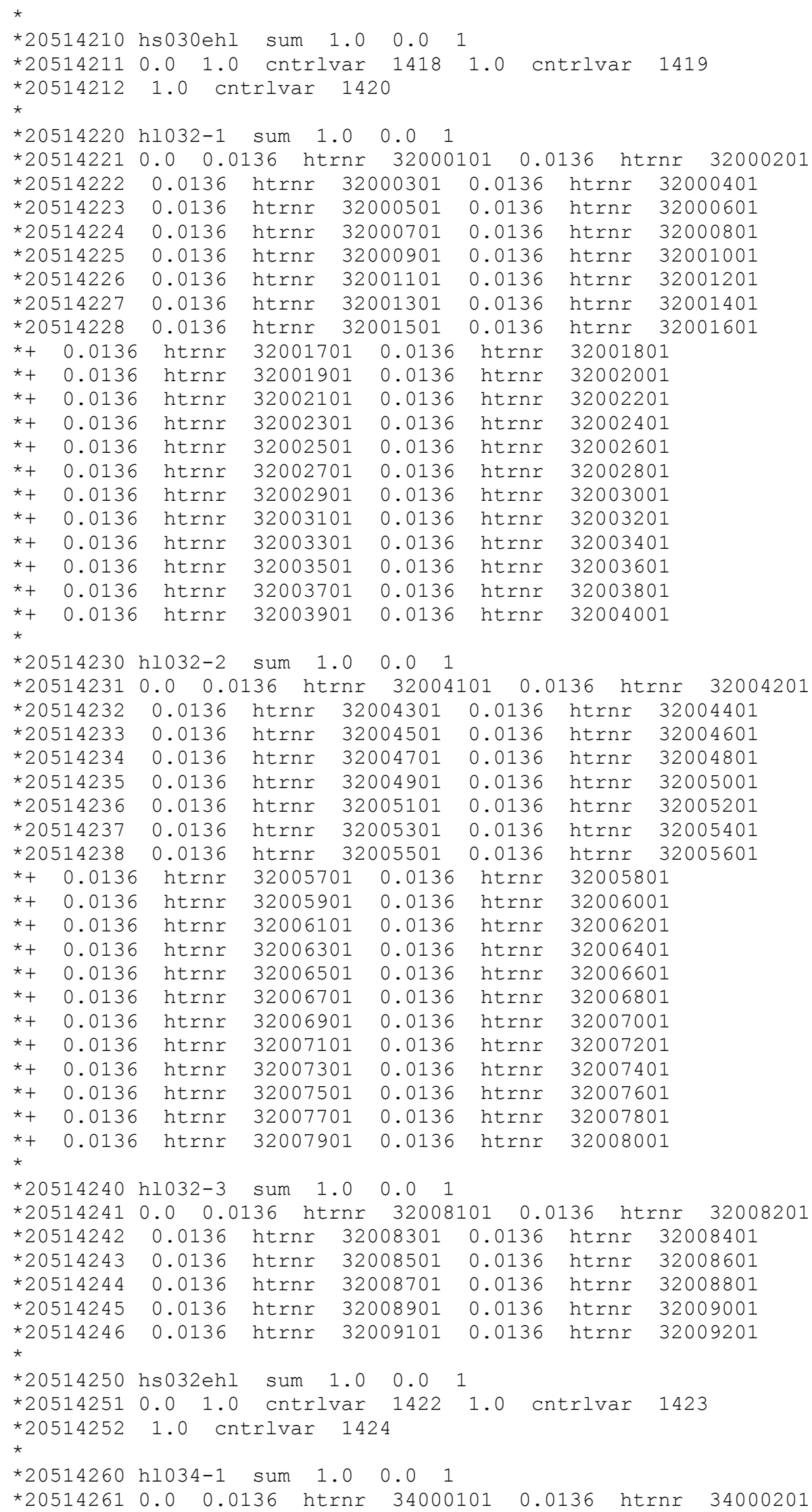




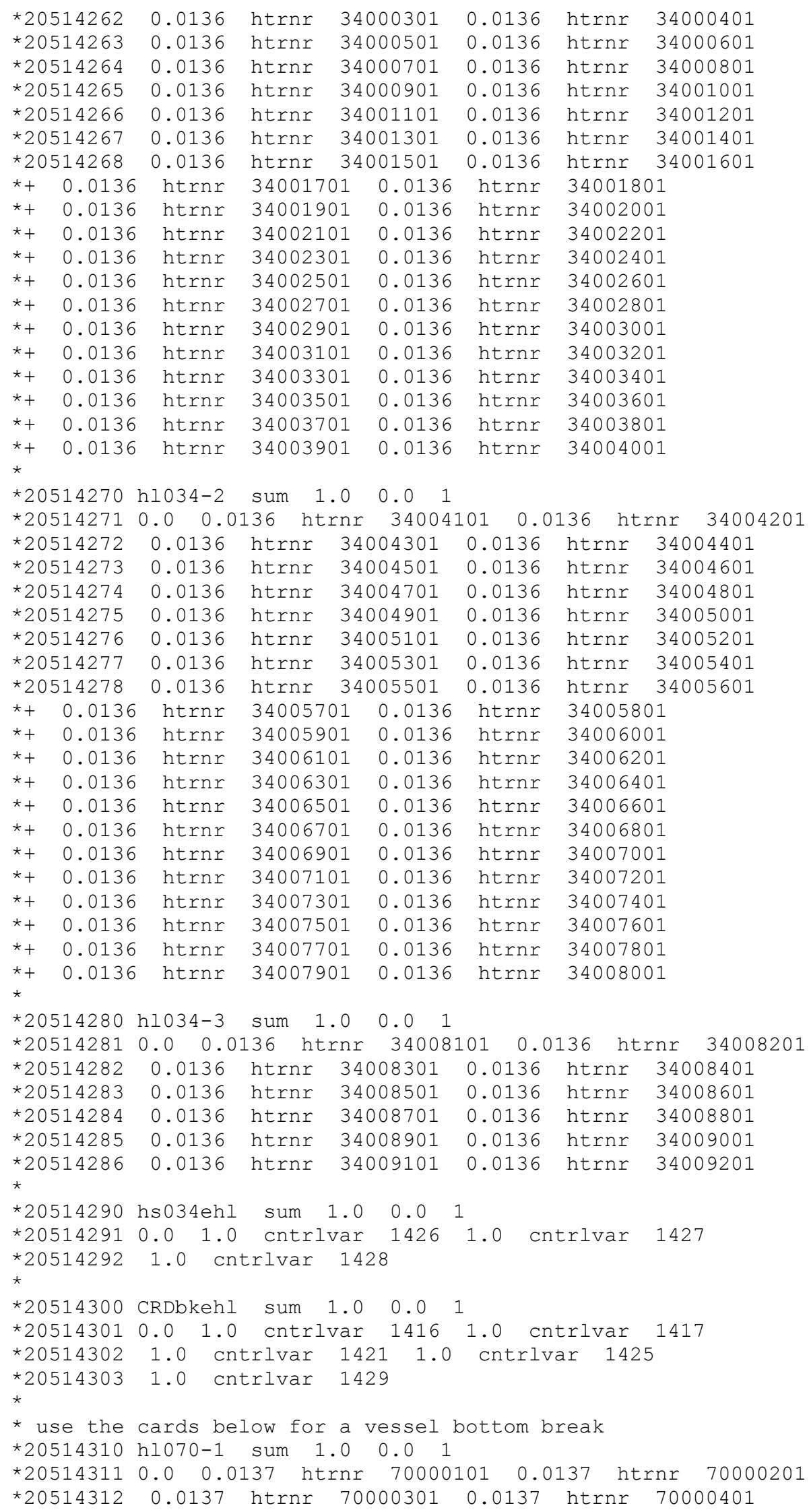




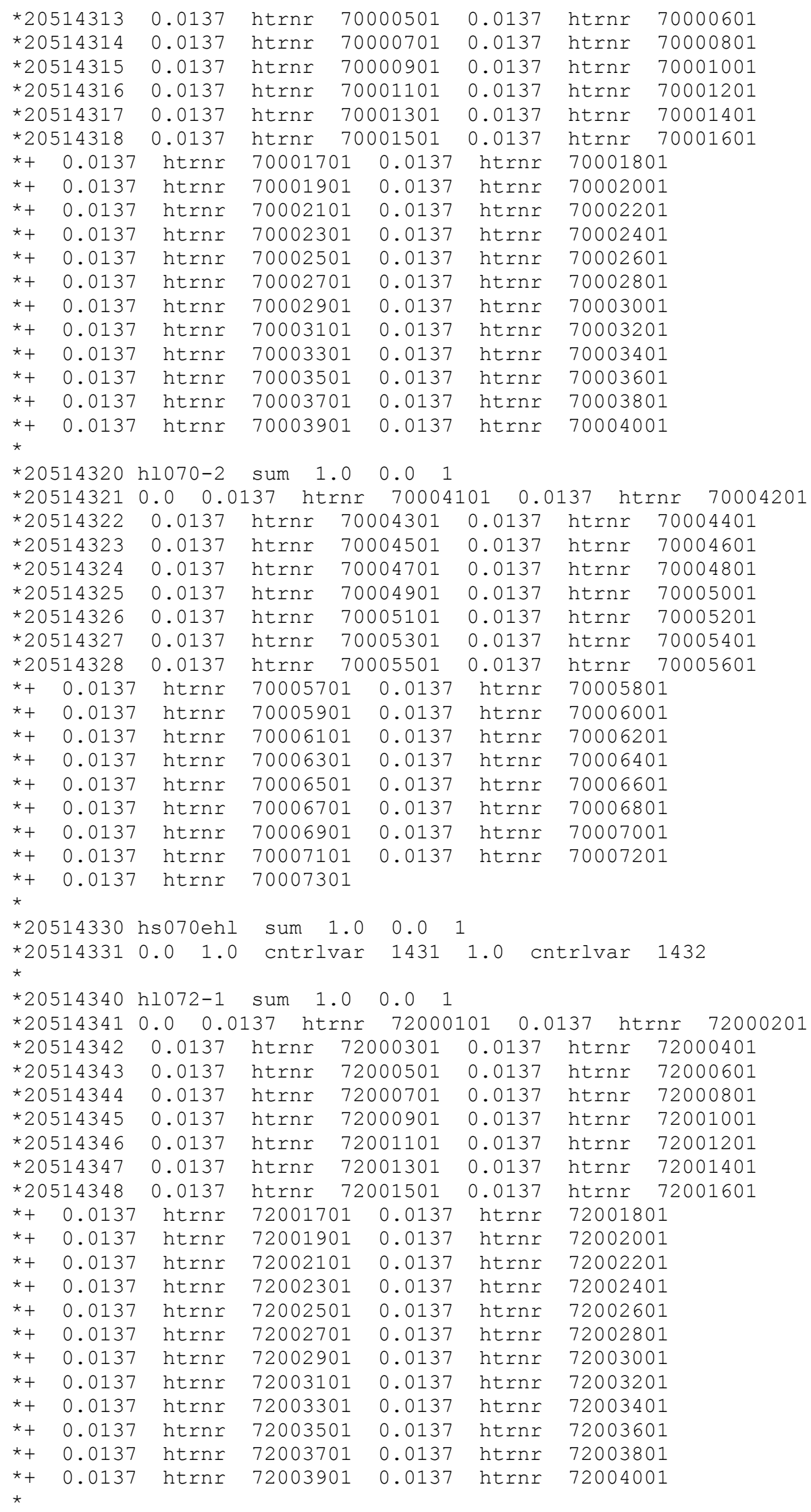




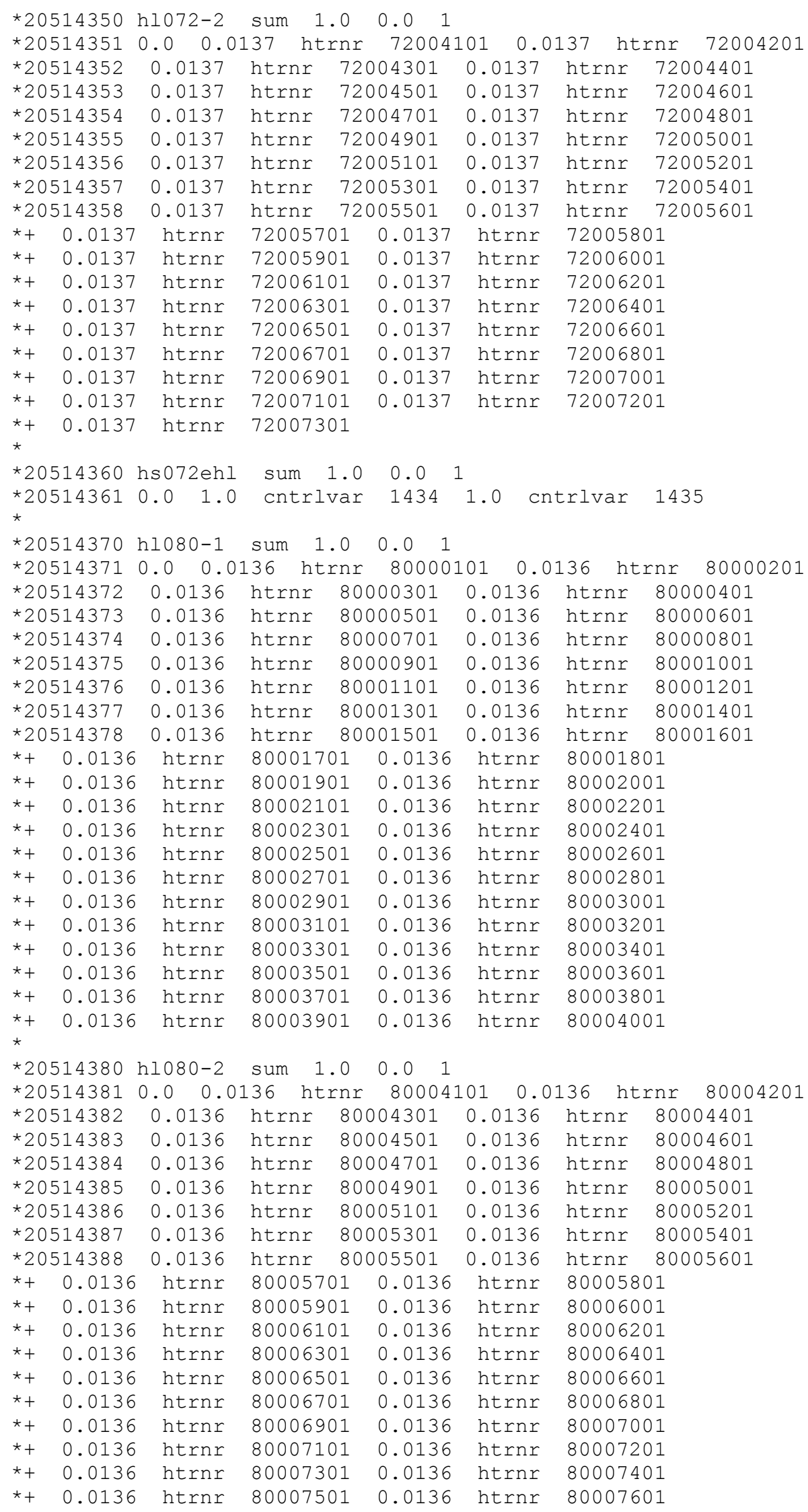




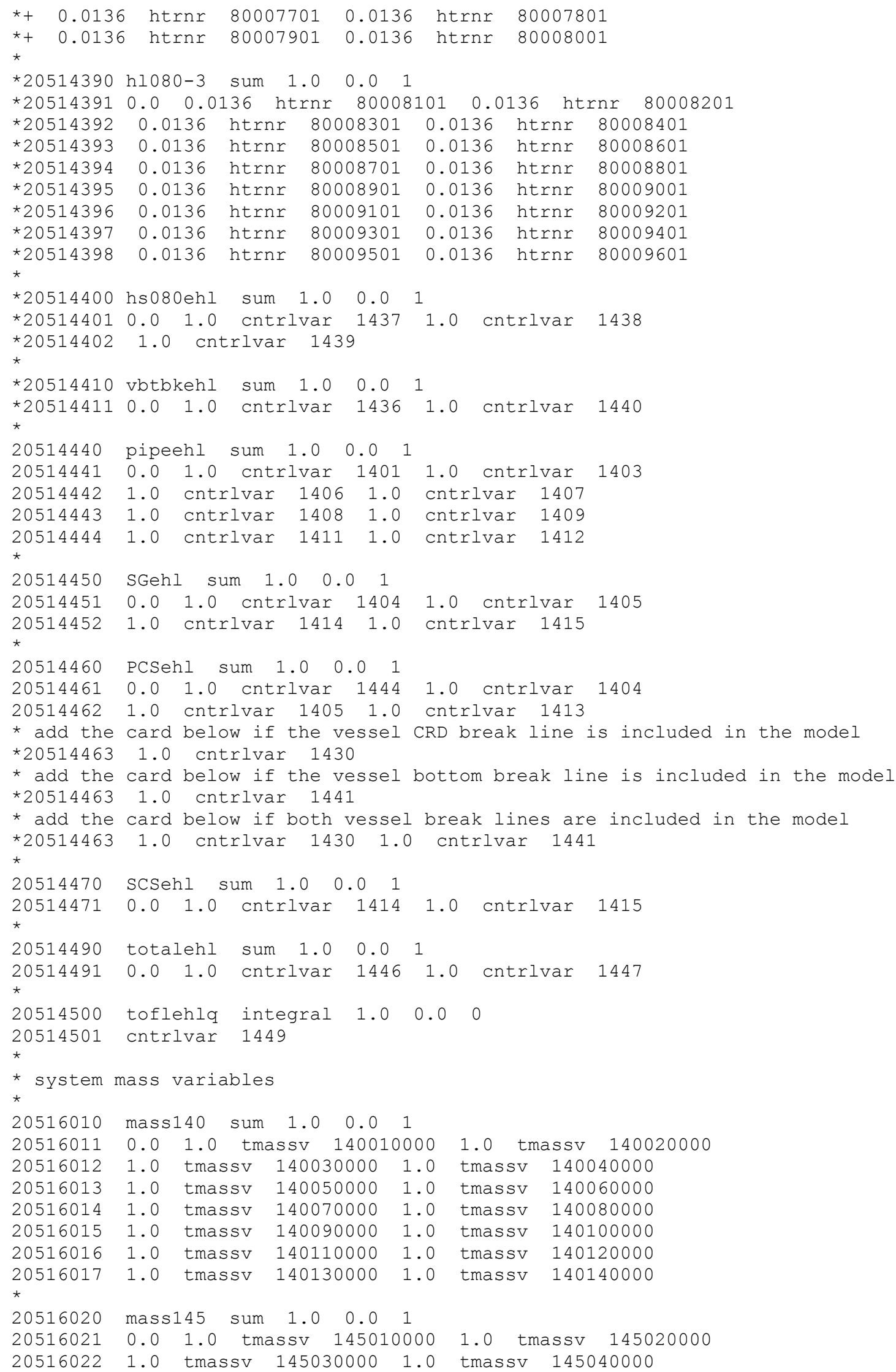




\begin{tabular}{|c|c|c|c|c|c|c|}
\hline 20516023 & 1.0 & tmassv & 145050000 & 1.0 & tmassv & 145060000 \\
\hline 20516024 & 1.0 & tmassv & 145070000 & 1.0 & tmassv & 145080000 \\
\hline 20516025 & 1.0 & tmassv & 145090000 & 1.0 & tmassv & 145100000 \\
\hline 20516026 & 1.0 & tmassv & 145110000 & 1.0 & tmassv & 145120000 \\
\hline $\begin{array}{l}20516027 \\
\star\end{array}$ & 1.0 & tmassv & 145130000 & 1.0 & tmassv & 145140000 \\
\hline 516030 & $\operatorname{mass} 1$ & sum & 1.0 & 1 & & \\
\hline 516031 & 0.0 & 1.0 & 150010 & 0000 & 1.0 & 150020000 \\
\hline 16032 & 1.0 & tmassv & 150030000 & 1.0 & tmassv & V $\quad 150040000$ \\
\hline 0516033 & 1.0 & tmassv & 150050000 & 1.0 & tmassv & 150060000 \\
\hline 516034 & 1.0 & tmassv & 150070000 & 1.0 & tmassv & 150080000 \\
\hline 516035 & 1.0 & tmassv & 150090000 & 1.0 & tmassv & 150100000 \\
\hline 516036 & 1.0 & tmassv & 150110000 & 1.0 & tmassv & 150120000 \\
\hline $\begin{array}{l}20516037 \\
\star\end{array}$ & 1.0 & tmassv & 150130000 & 1.0 & tmassv & 150140000 \\
\hline 516040 & $\operatorname{mass} 1$ & sum & 1.0 & 1 & & \\
\hline 16041 & 0.0 & 1.0 tma & 132010 & 0000 & 1.0 & 132020000 \\
\hline 516042 & 1.0 & tmassv & 132030000 & 1.0 & tmassv & 132040000 \\
\hline 516043 & 1.0 & tmassv & 132050000 & 1.0 & tmassv & 132060000 \\
\hline 516044 & 1.0 & tmassv & 132070000 & 1.0 & tmassv & 132080000 \\
\hline 16045 & 1.0 & tmassv & 132090000 & 1.0 & tmassv & 132100000 \\
\hline 516046 & 1.0 & tmassv & 132110000 & 1.0 & tmassv & 132120000 \\
\hline $\begin{array}{l}20516047 \\
\text { * }\end{array}$ & 1.0 & tmassv & 132130000 & 1.0 & tmassv & 132140000 \\
\hline 516050 & mass 1 & sum & 1.0 & 1 & & \\
\hline 0516051 & 0.0 & 1.0 tma & SSV 162010 & 0000 & 1.0 & 162020000 \\
\hline 20516052 & 1.0 & tmassv & 162030000 & 1.0 & tmassv & 162040000 \\
\hline 16053 & 1.0 & tmassv & 162050000 & 1.0 & tmassv & 162060000 \\
\hline 0516054 & 1.0 & tmassv & 162070000 & 1.0 & tmassv & 162080000 \\
\hline 20516055 & 1.0 & tmassv & 162090000 & 1.0 & tmassv & 162100000 \\
\hline 20516056 & 1.0 & tmassv & 162110000 & 1.0 & tmassv & 162120000 \\
\hline $\begin{array}{l}20516057 \\
\star\end{array}$ & 1.0 & tmassv & 162130000 & 1.0 & tmassv & 162140000 \\
\hline 0516060 & $\operatorname{mass} 1$ & sum & 1.0 & 1 & & \\
\hline 20516061 & 0.0 & 1.0 tma & SSV 164010 & 0000 & 1.0 & 164020000 \\
\hline 20516062 & 1.0 & tmassv & 164030000 & 1.0 & tmassv & 164040000 \\
\hline 20516063 & 1.0 & tmassv & 164050000 & 1.0 & tmassv & 164060000 \\
\hline 20516064 & 1.0 & tmassv & 164070000 & 1.0 & tmassv & 164080000 \\
\hline 20516065 & 1.0 & tmassv & 164090000 & 1.0 & tmassv & 164100000 \\
\hline 20516066 & 1.0 & tmassv & 164110000 & 1.0 & tmassv & 164120000 \\
\hline $\begin{array}{l}20516067 \\
\star\end{array}$ & 1.0 & tmassv & 164130000 & 1.0 & tmassv & 164140000 \\
\hline 20516070 & $\operatorname{mass} 1$ & sum & 1.0 & 1 & & \\
\hline 20516071 & 0.0 & 1.0 tma & 166010 & 0000 & 1.0 & 166020000 \\
\hline 20516072 & 1.0 & tmassv & 166030000 & 1.0 & tmassv & 166040000 \\
\hline 20516073 & 1.0 & tmassv & 166050000 & 1.0 & tmassv & 166060000 \\
\hline 20516074 & 1.0 & tmassv & 166070000 & 1.0 & tmassv & 166080000 \\
\hline 20516075 & 1.0 & tmassv & 166090000 & 1.0 & tmassv & 166100000 \\
\hline 20516076 & 1.0 & tmassv & 166110000 & 1.0 & tmassv & 166120000 \\
\hline $\begin{array}{l}20516077 \\
\star\end{array}$ & 1.0 & tmassv & 166130000 & 1.0 & tmassv & 166140000 \\
\hline 20516080 & massc & core sum & 1.0 & 1 & & \\
\hline 20516081 & 0.0 & $1.0 \mathrm{cnt}$ & rlvar & 1.0 & cntr & rlvar \\
\hline 20516082 & 1.0 & cntrlvar & 1603 & & trlvar & 1604 \\
\hline 20516083 & 1.0 & cntrlvar & 1605 & cnt & trlvar & 1606 \\
\hline $\begin{array}{l}20516084 \\
\star\end{array}$ & 1.0 & cntrlvar & 1607 & & & \\
\hline 20516090 & mass 1 & sum & 0.0 & 1 & & \\
\hline 20516091 & 0.0 & 1.0 tma & SSV 115010 & 000 & 1.0 & 115020000 \\
\hline 20516092 & 1.0 & tmassv & 115030000 & 1.0 & tmassv & V 115040000 \\
\hline 20516093 & 1.0 & tmassv & 115050000 & 1.0 & tmassv & 115060000 \\
\hline 20516094 & 1.0 & tmassv & 115070000 & 1.0 & tmassv & 115080000 \\
\hline 20516095 & 1.0 & tmassv & 115090000 & 1.0 & tmassv & 115100000 \\
\hline
\end{tabular}




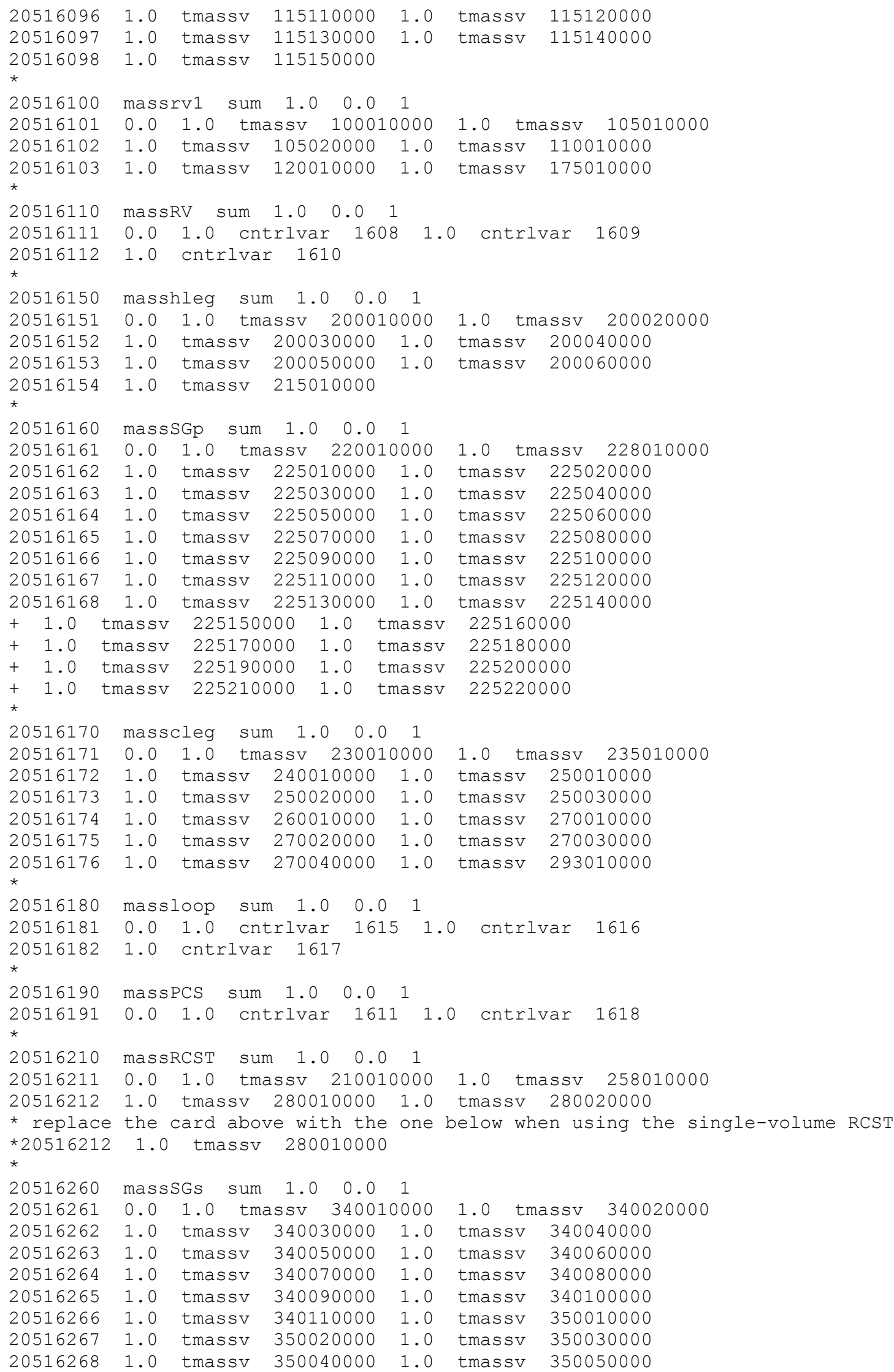




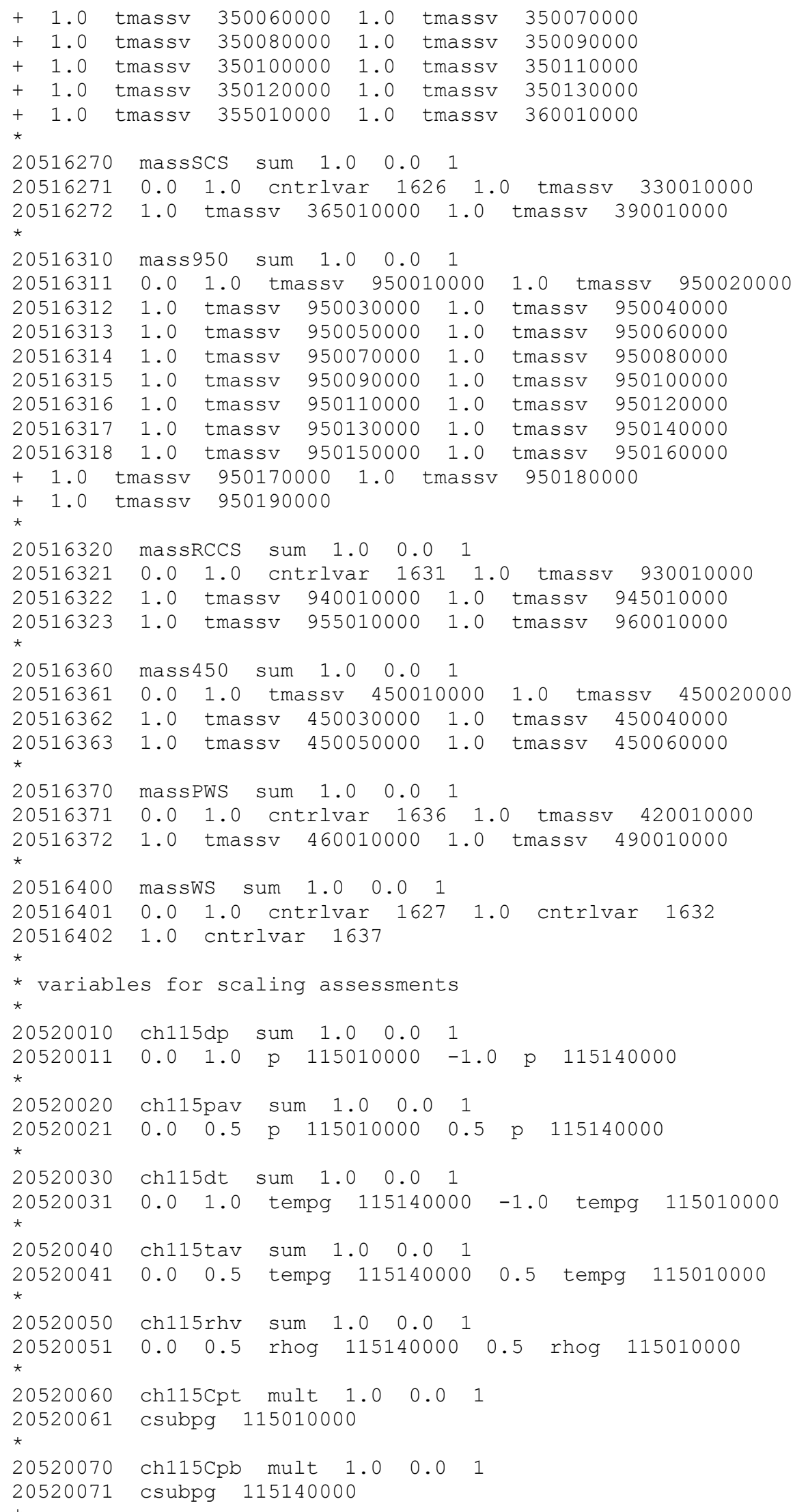




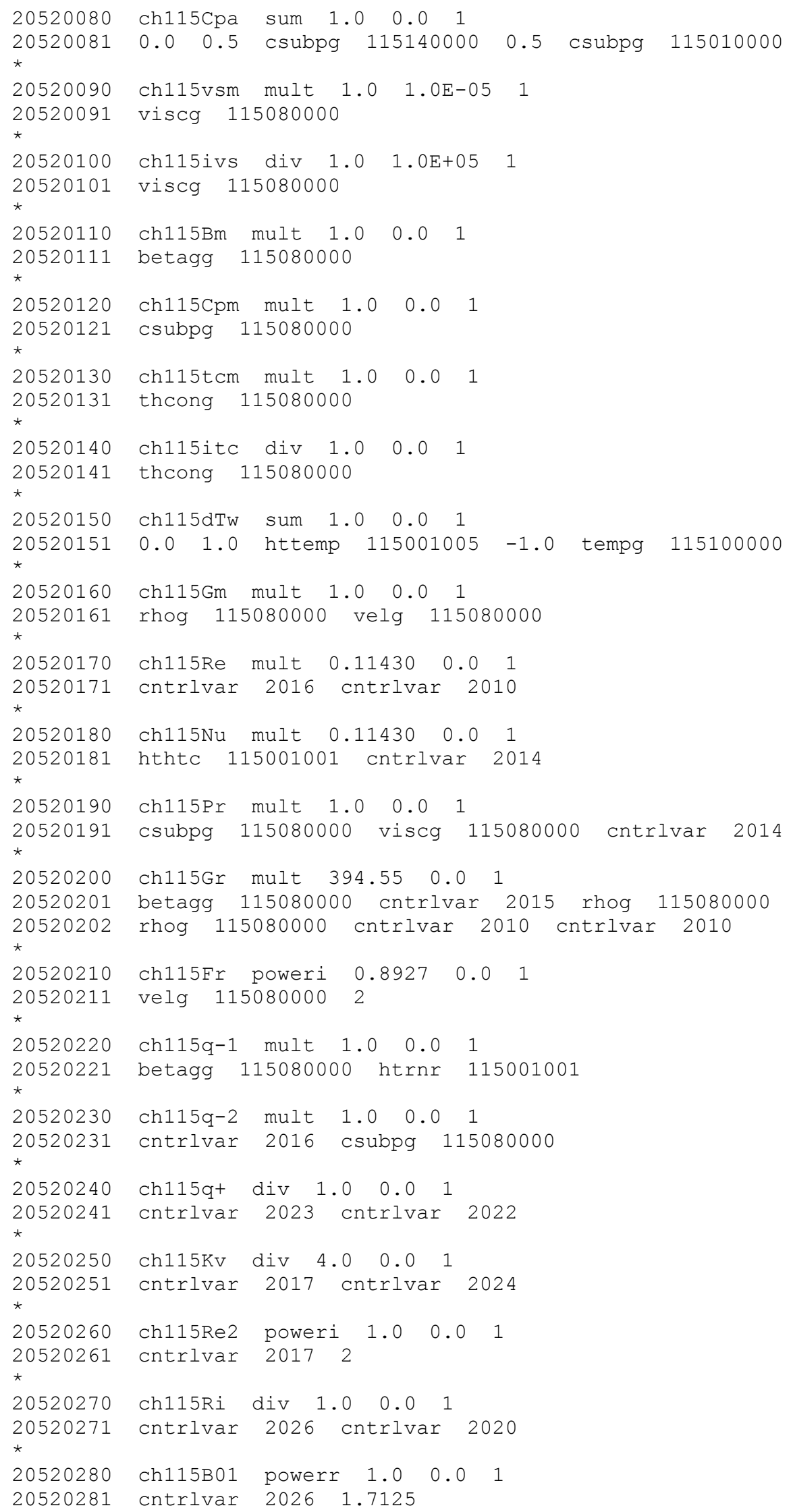




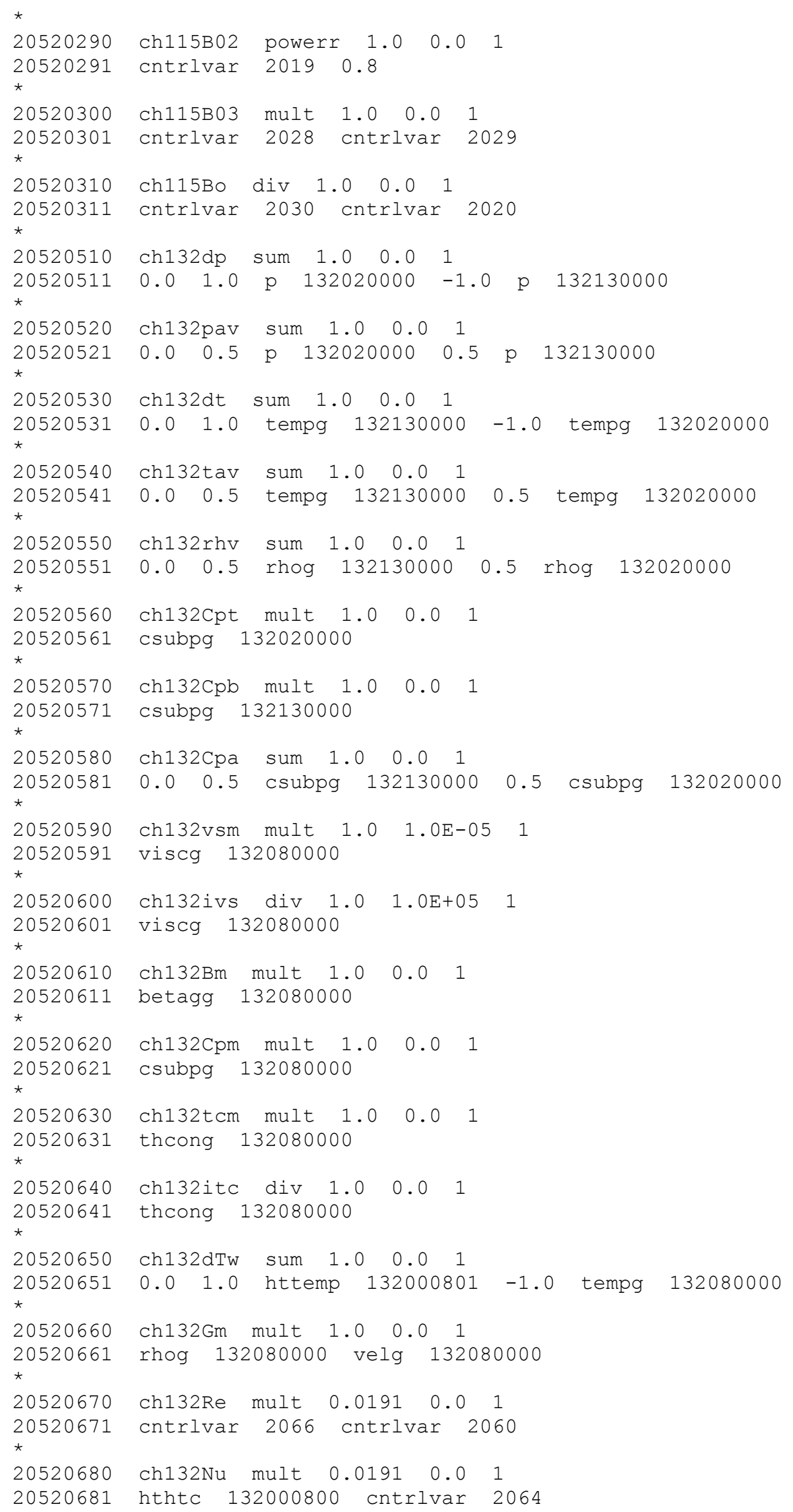




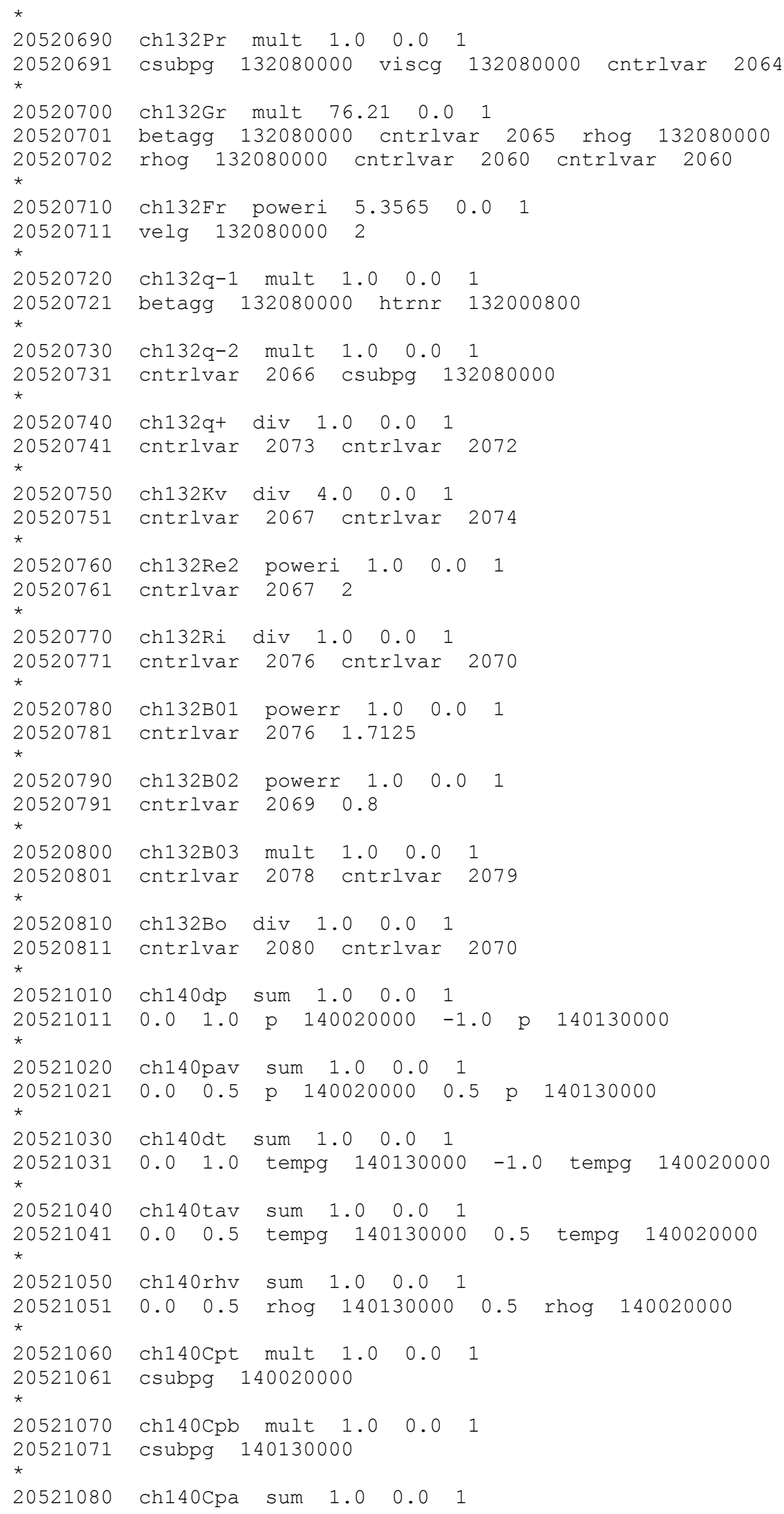




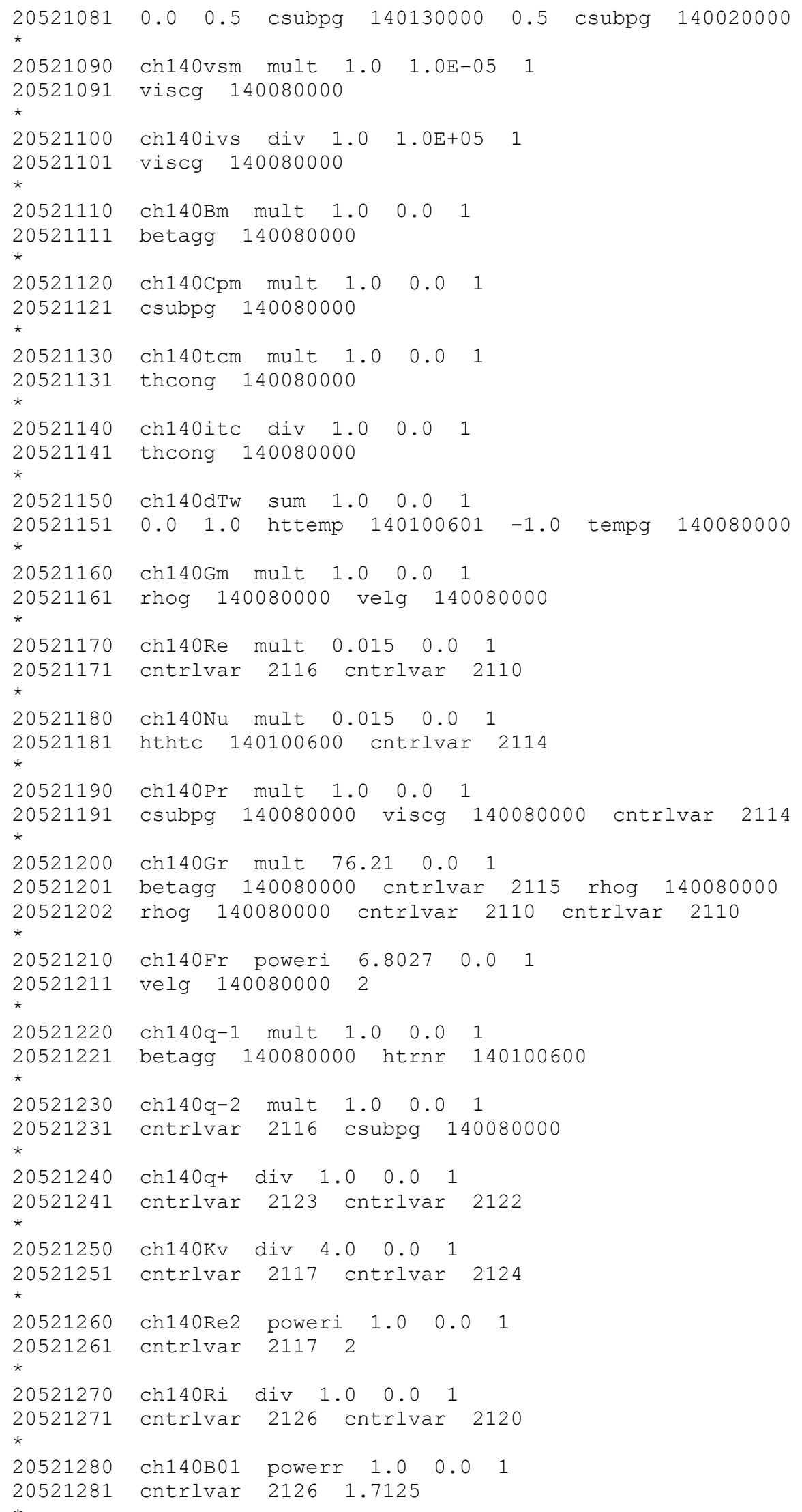




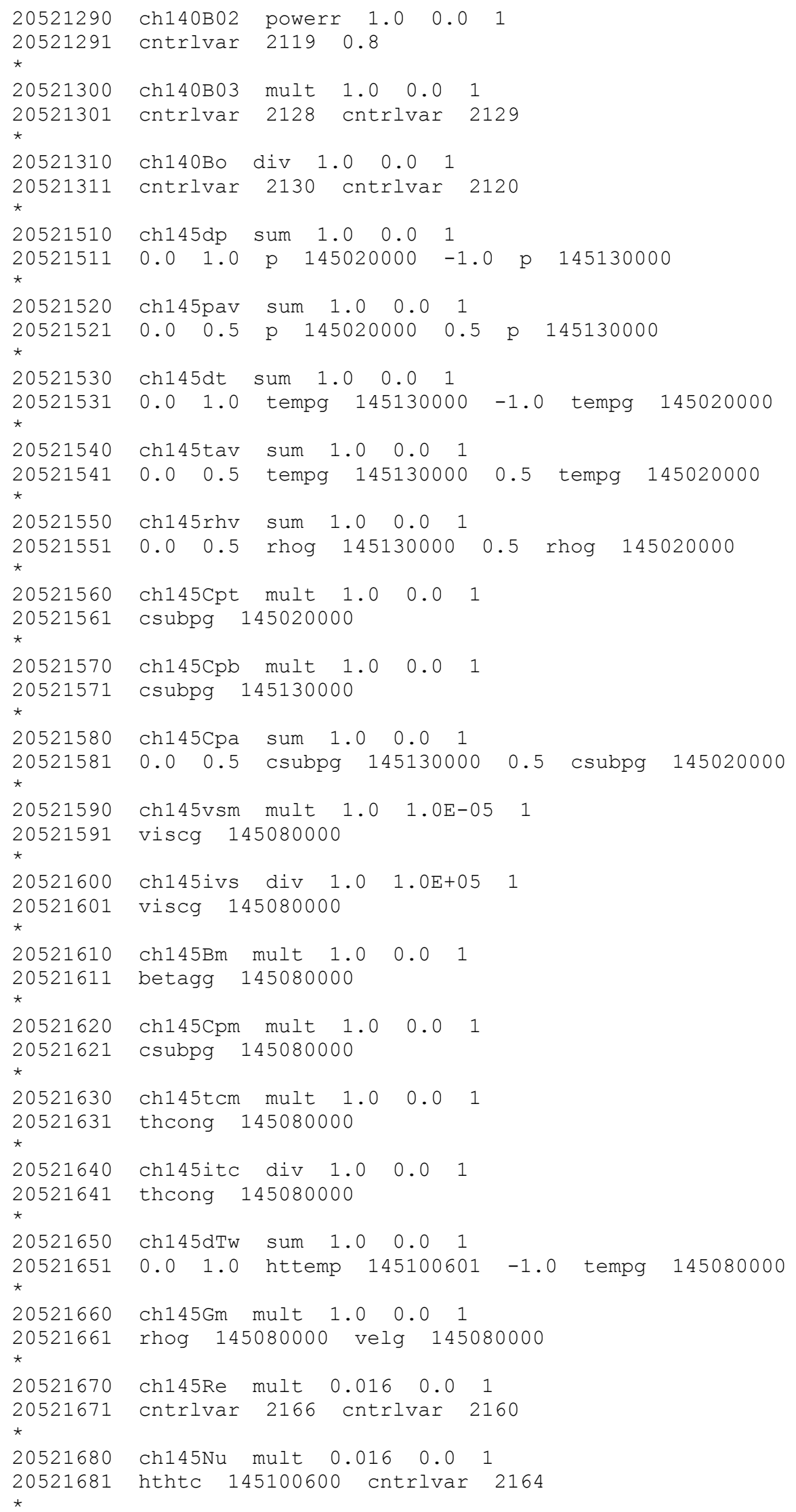




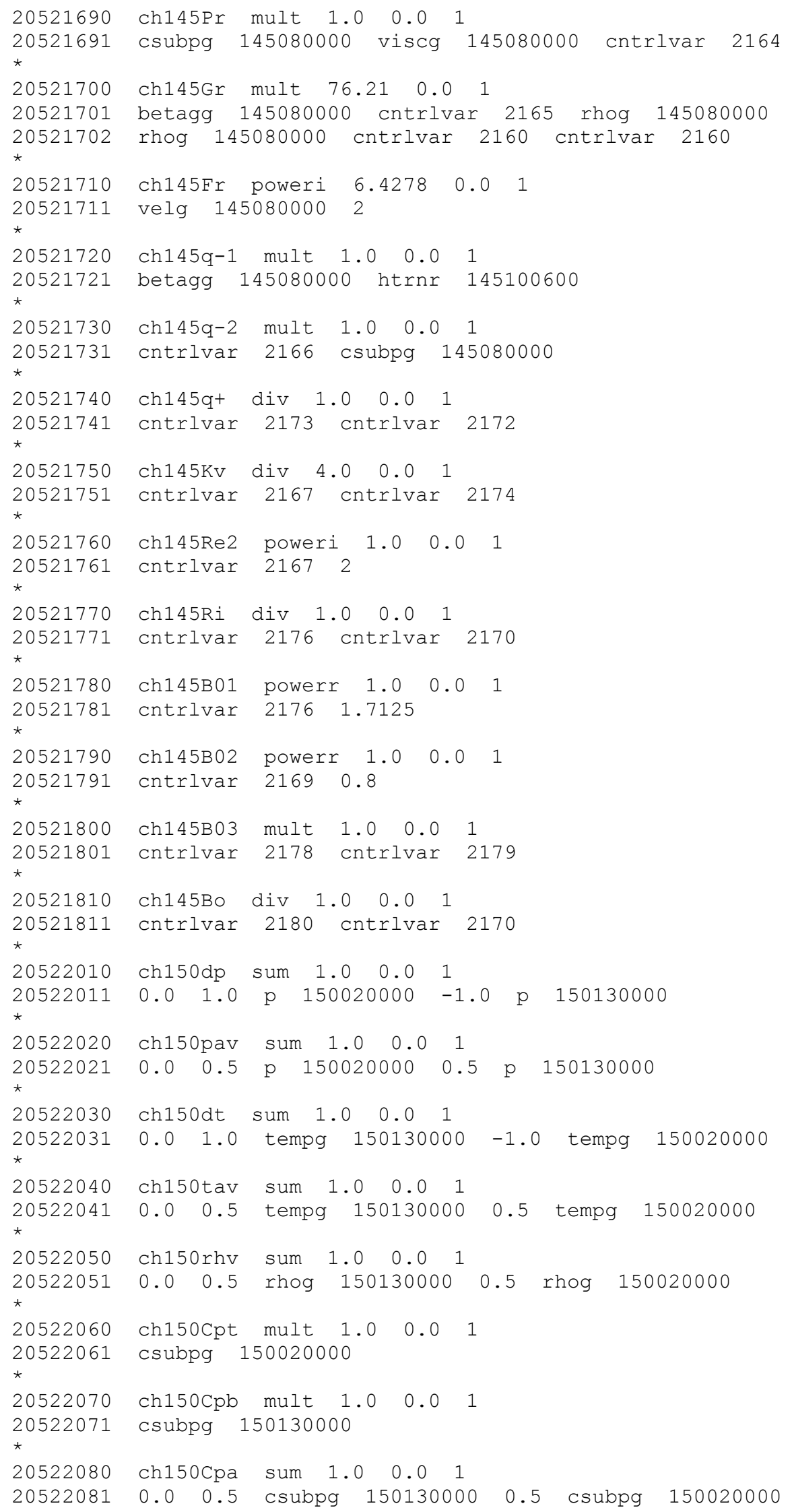




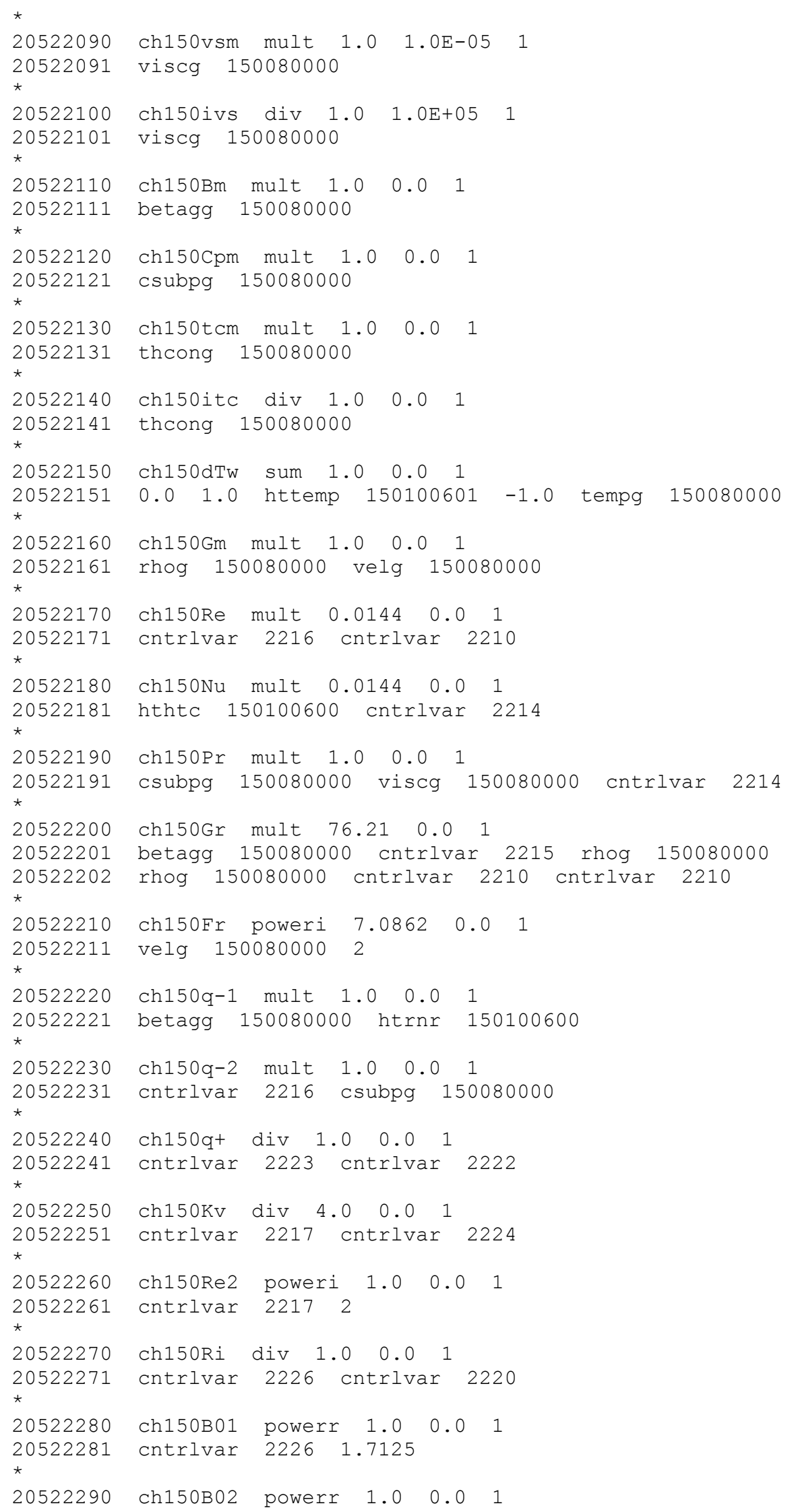




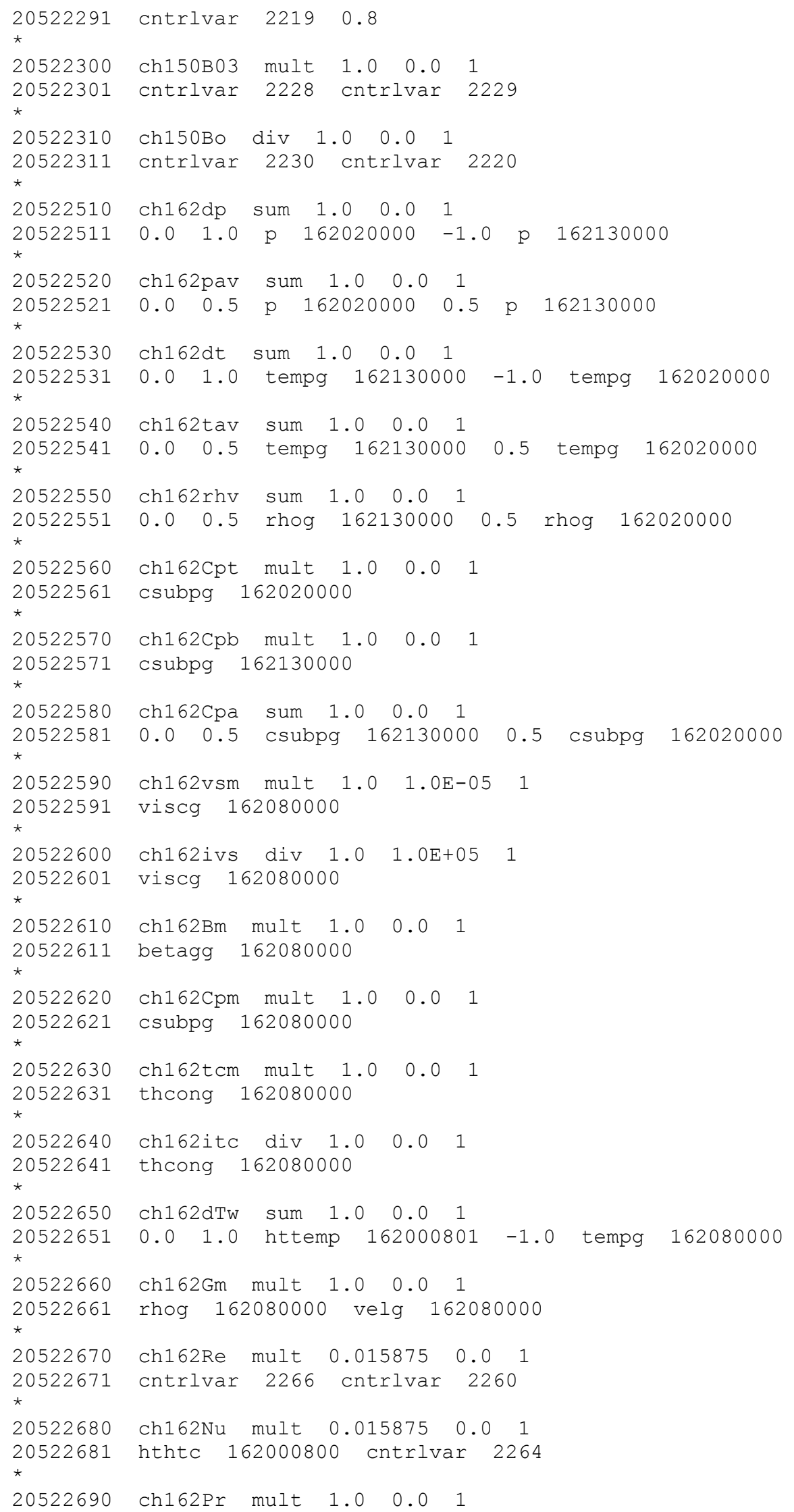




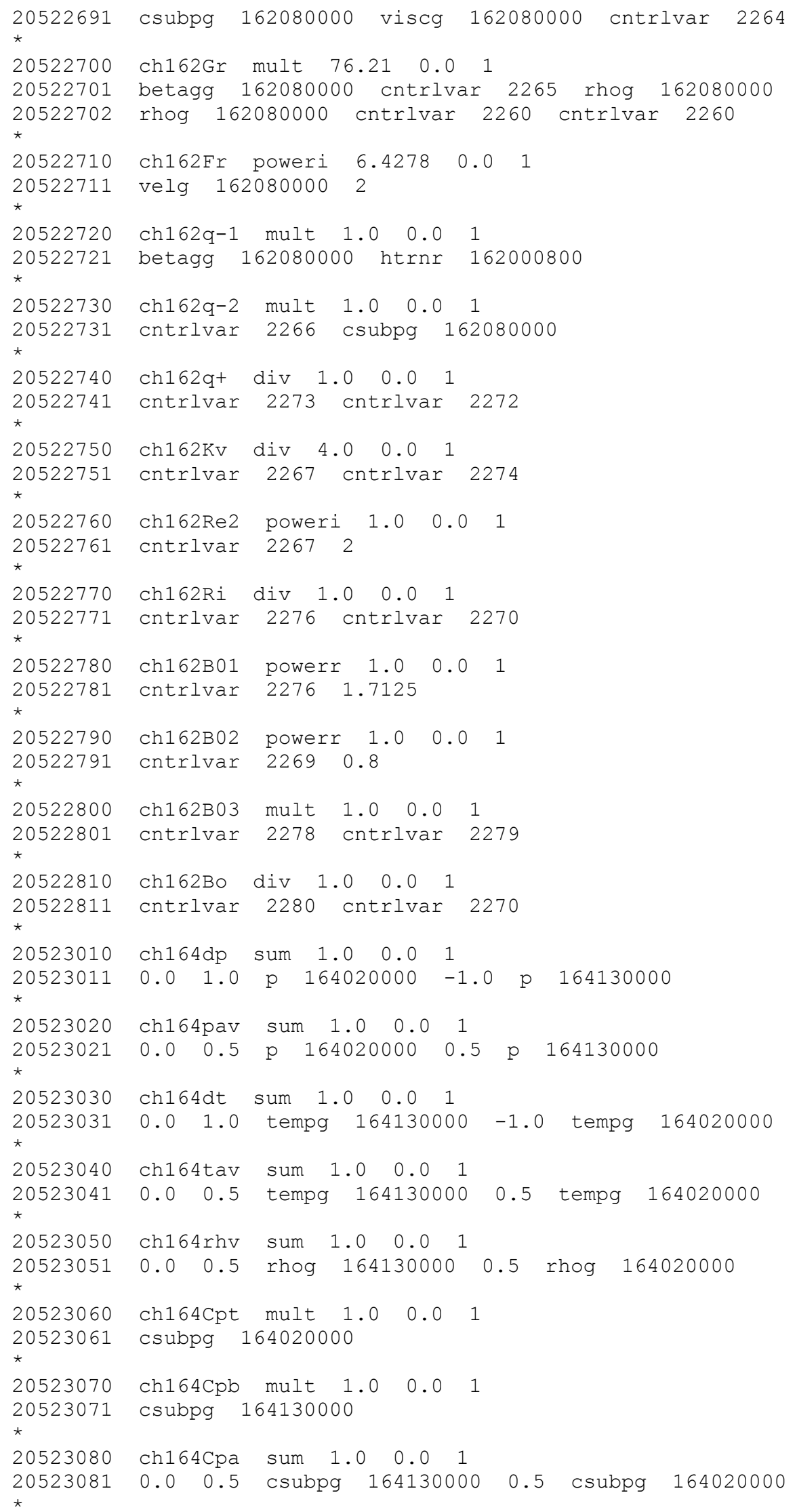




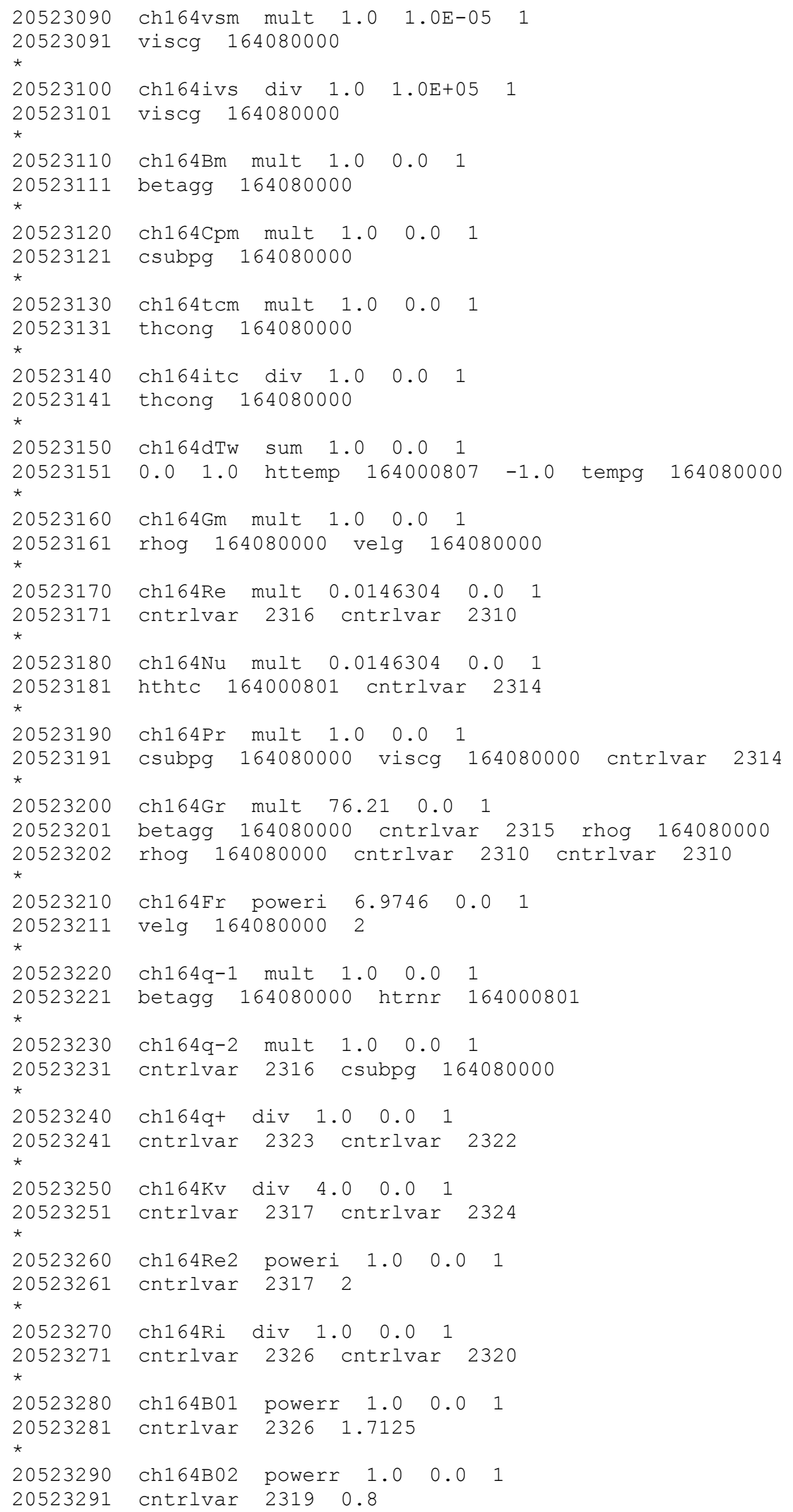




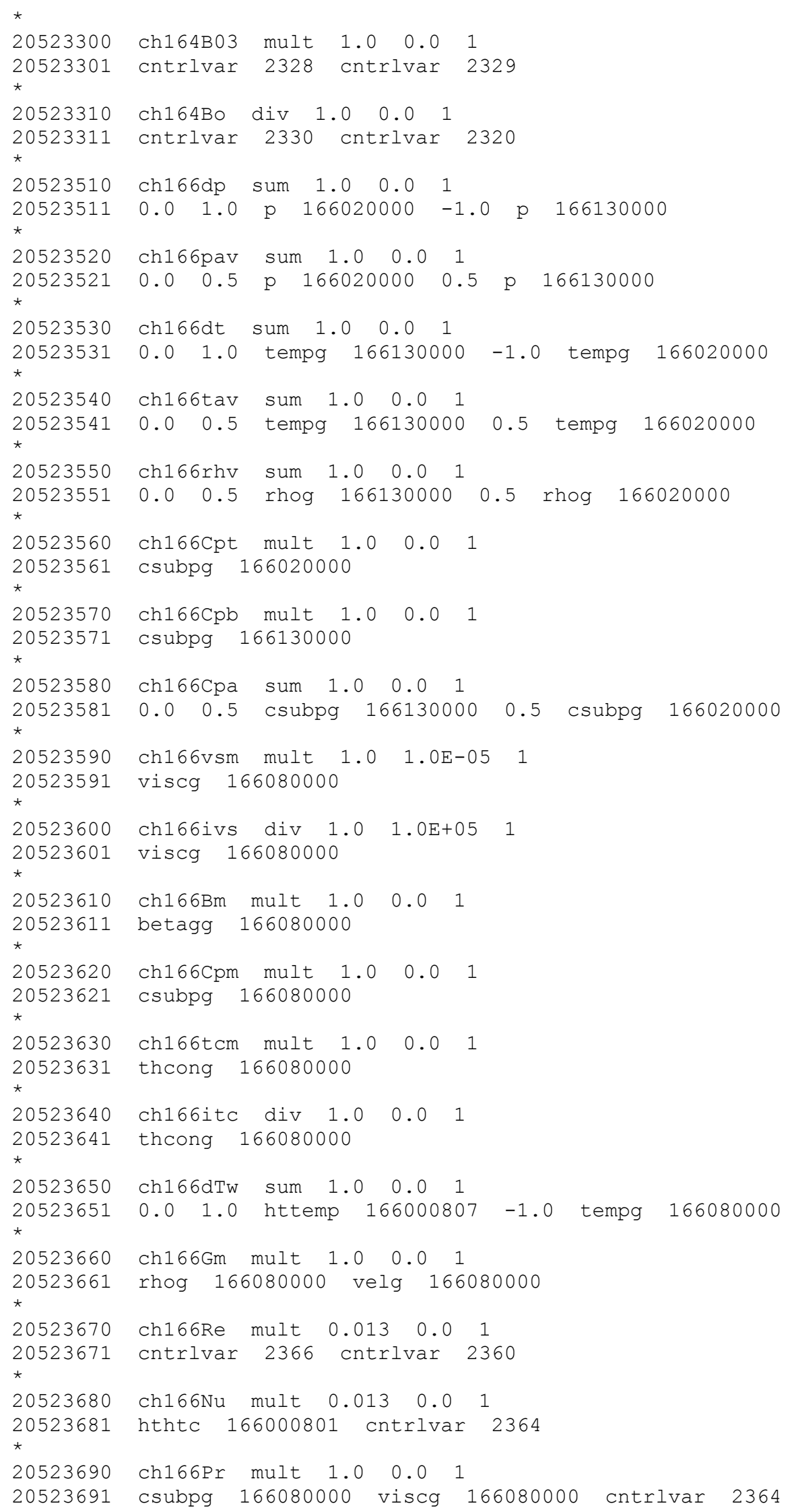




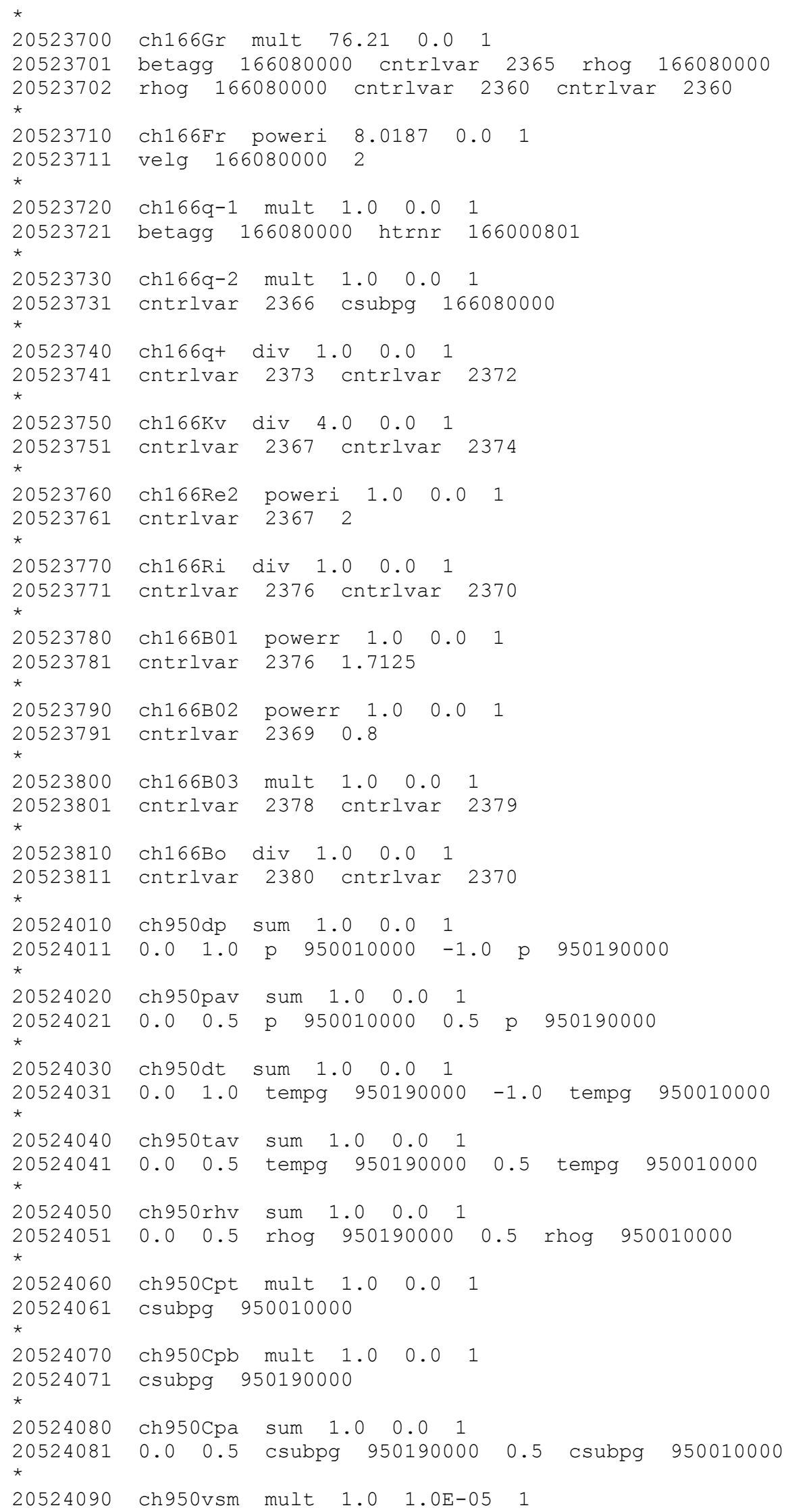




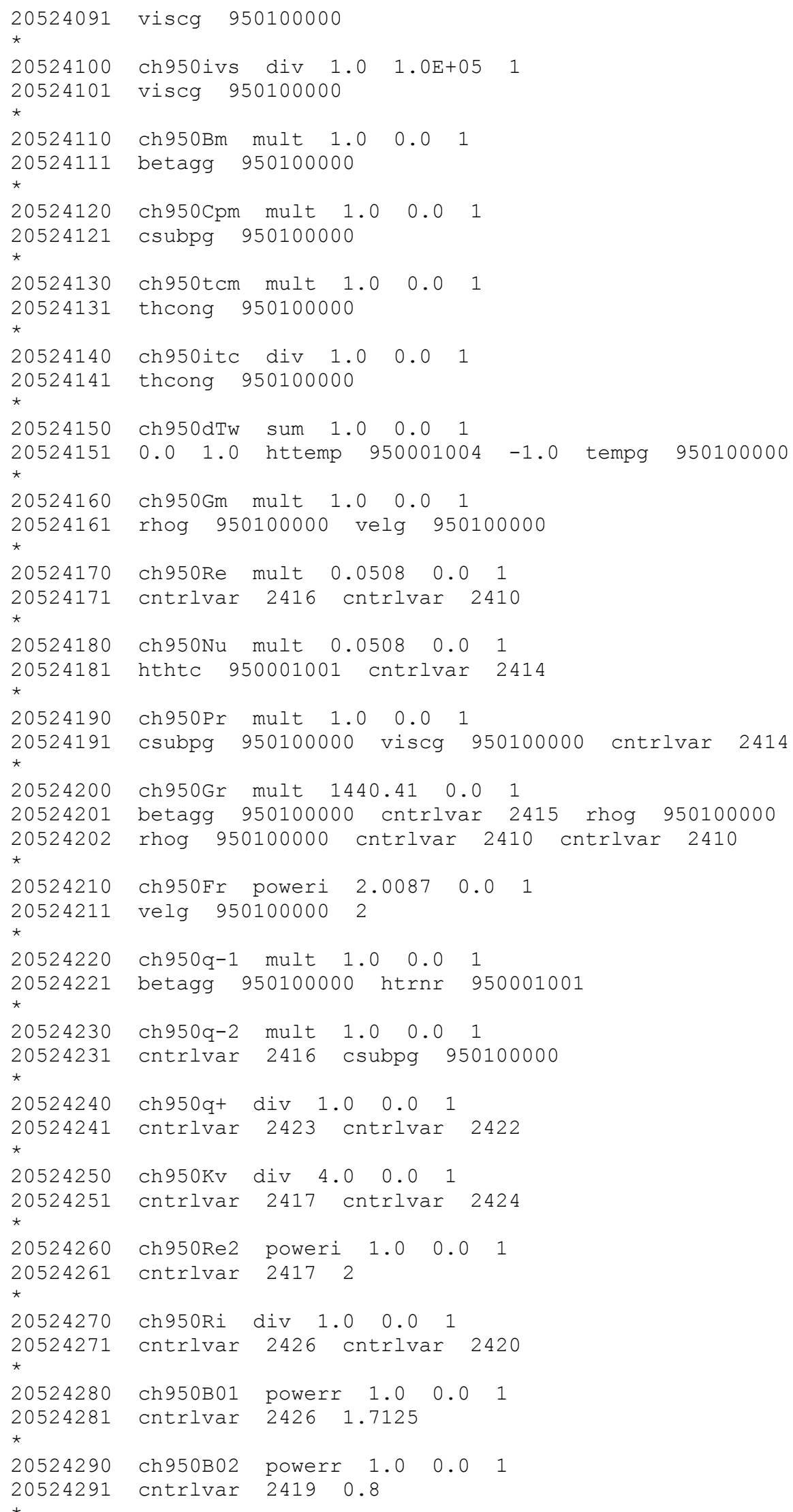




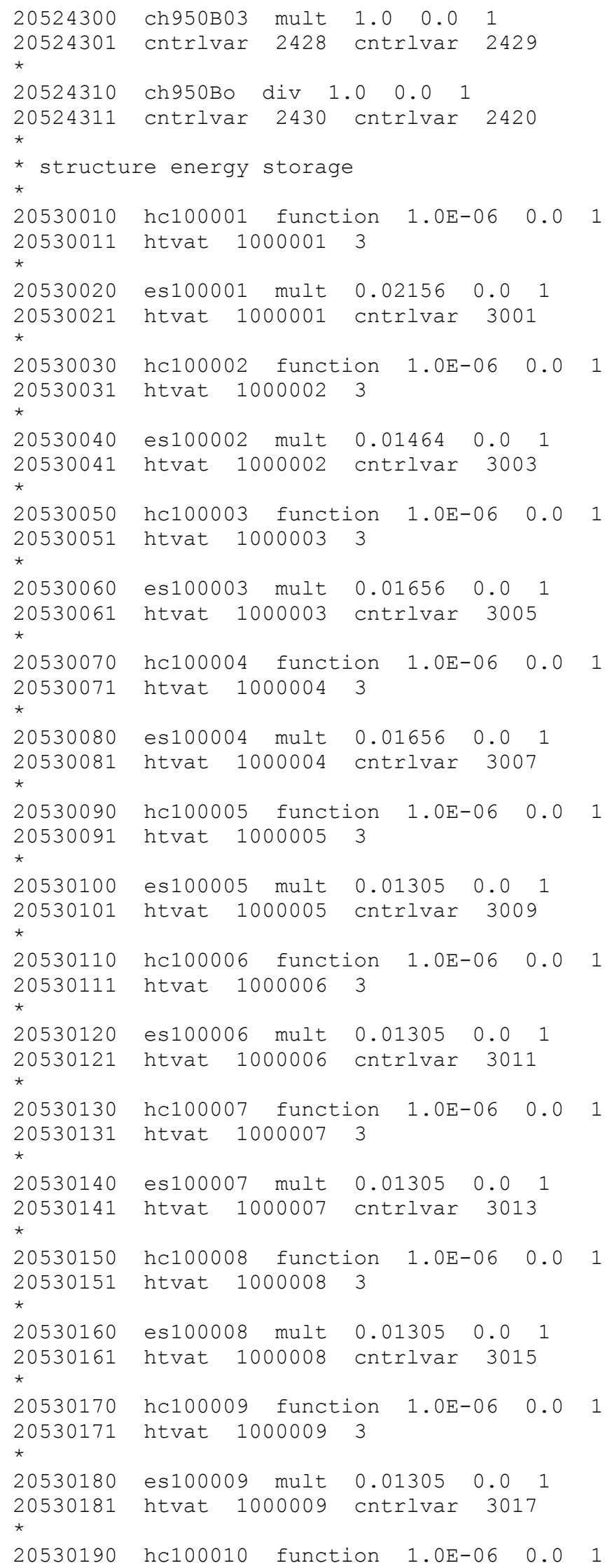




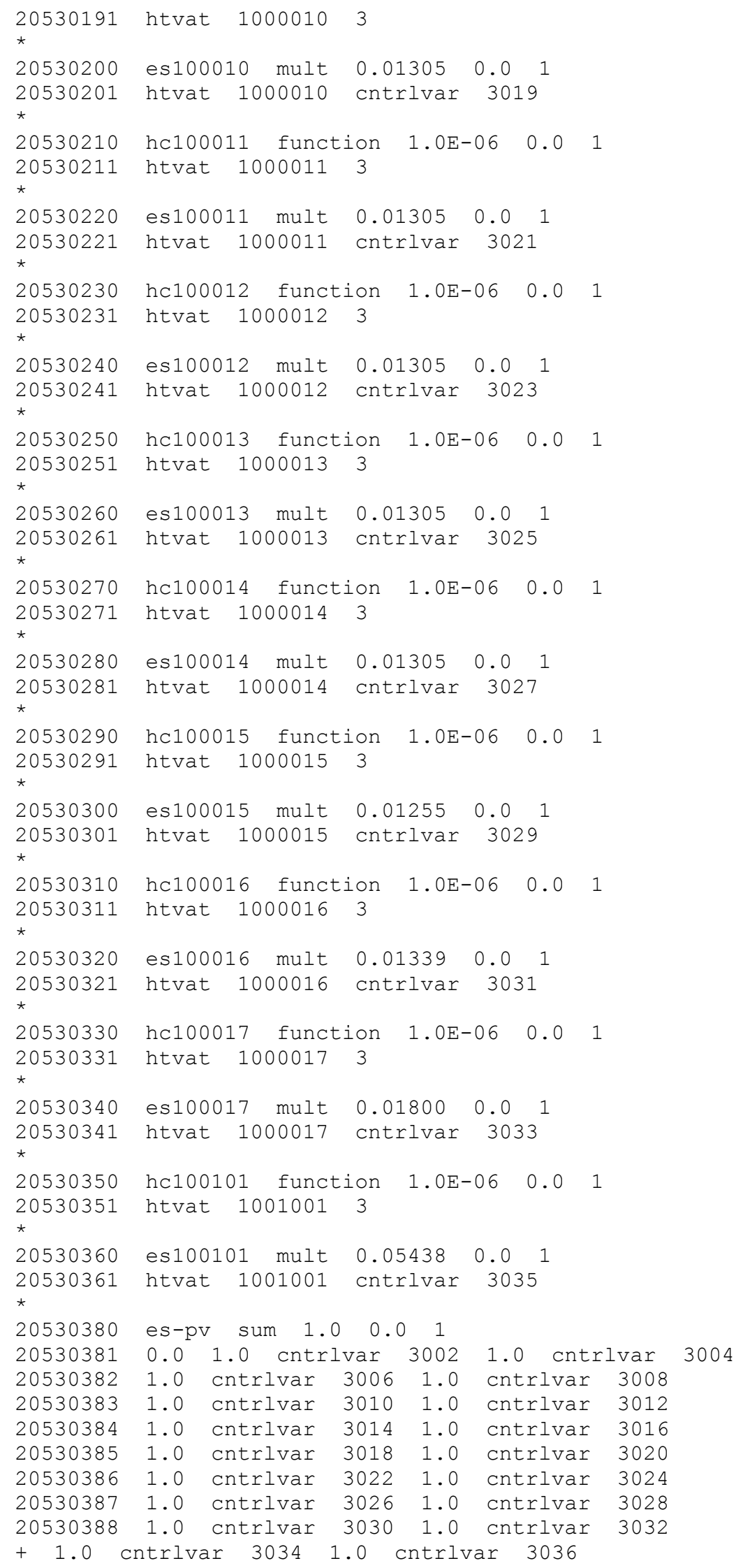




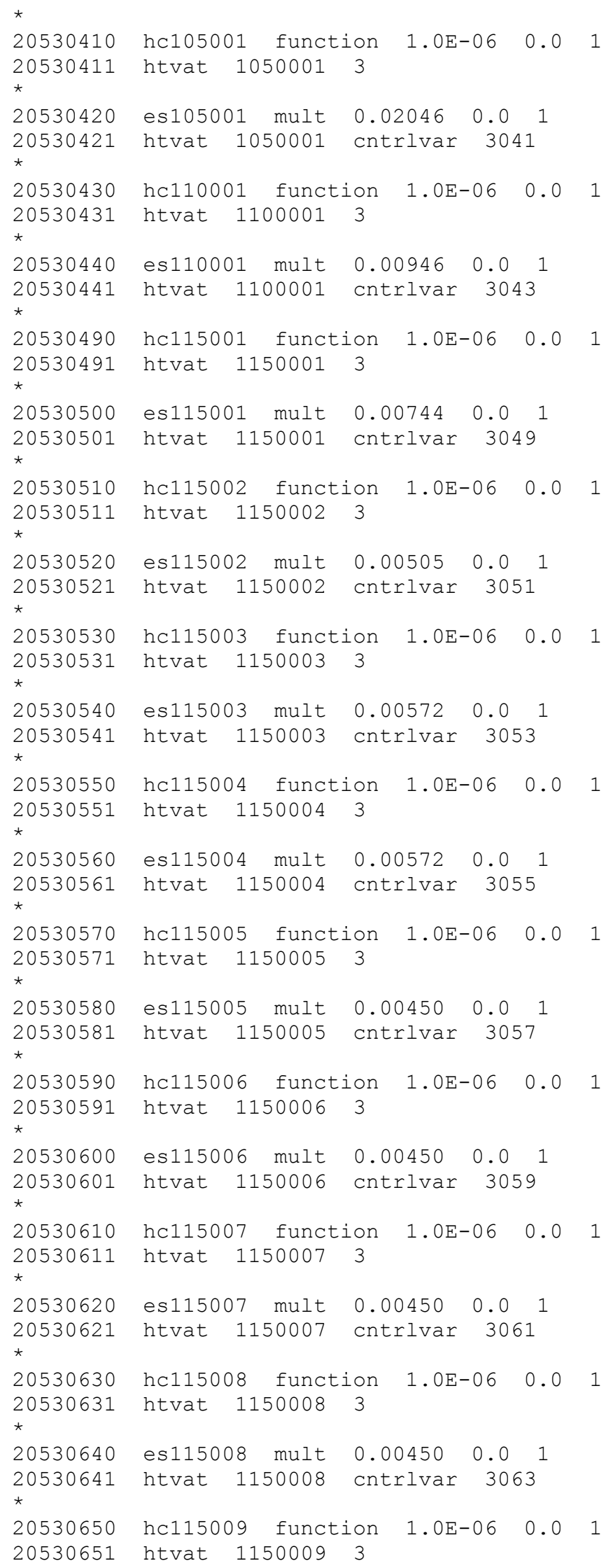




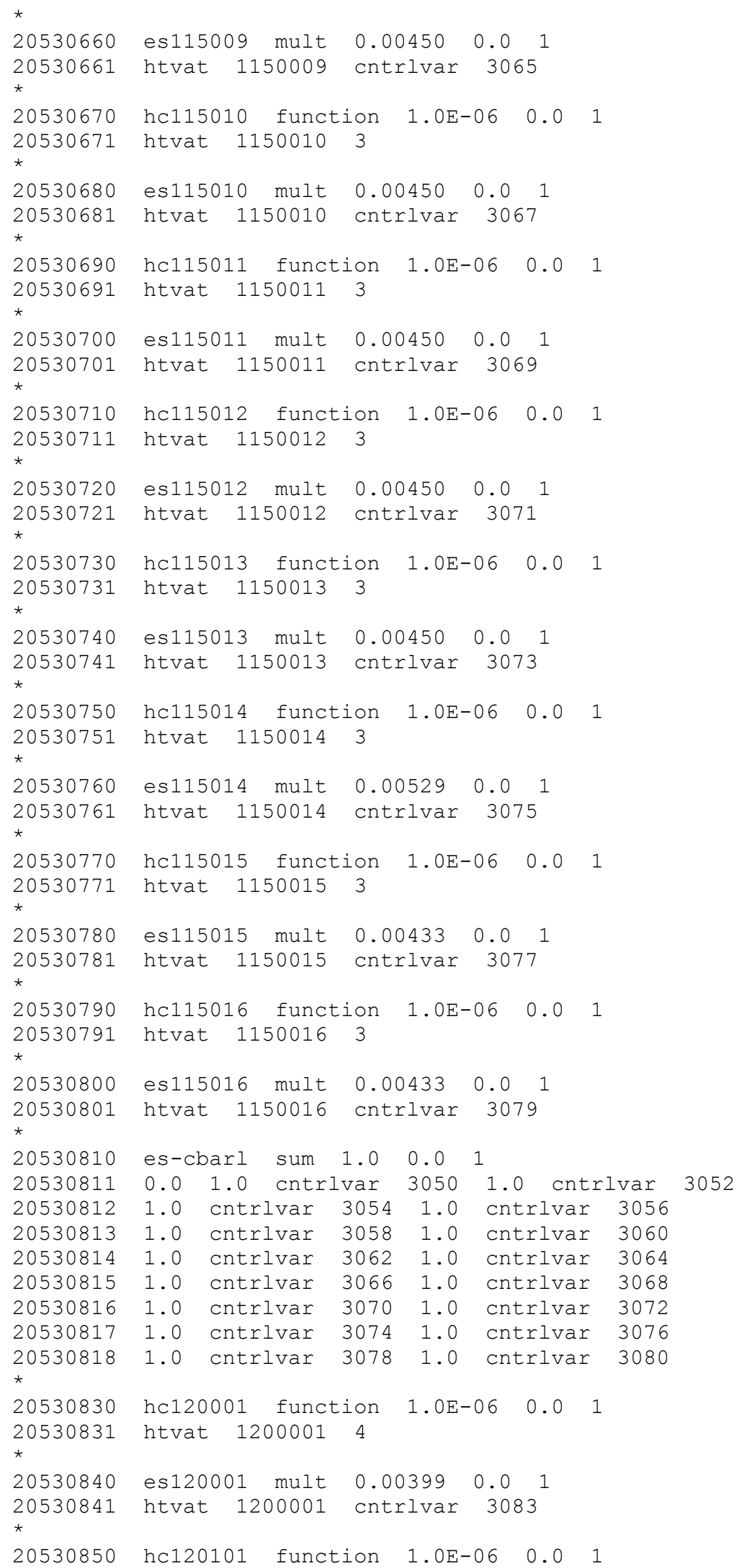




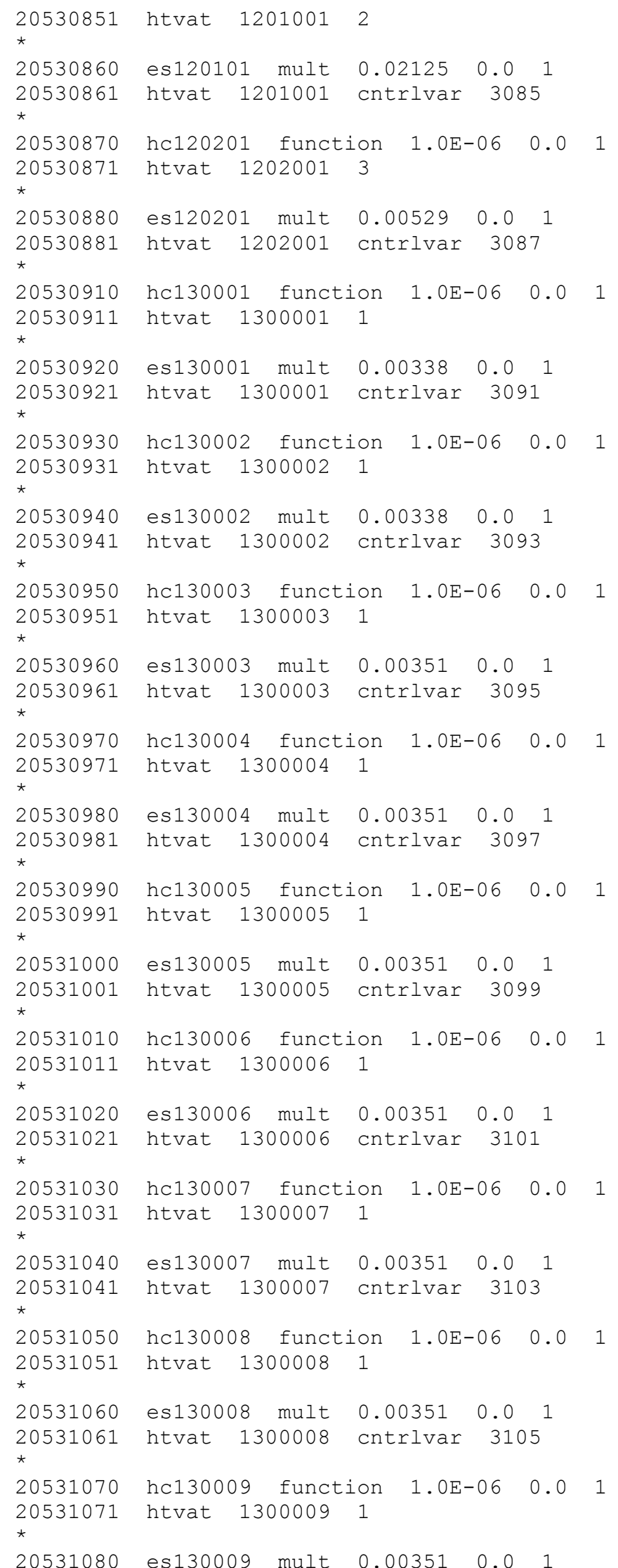




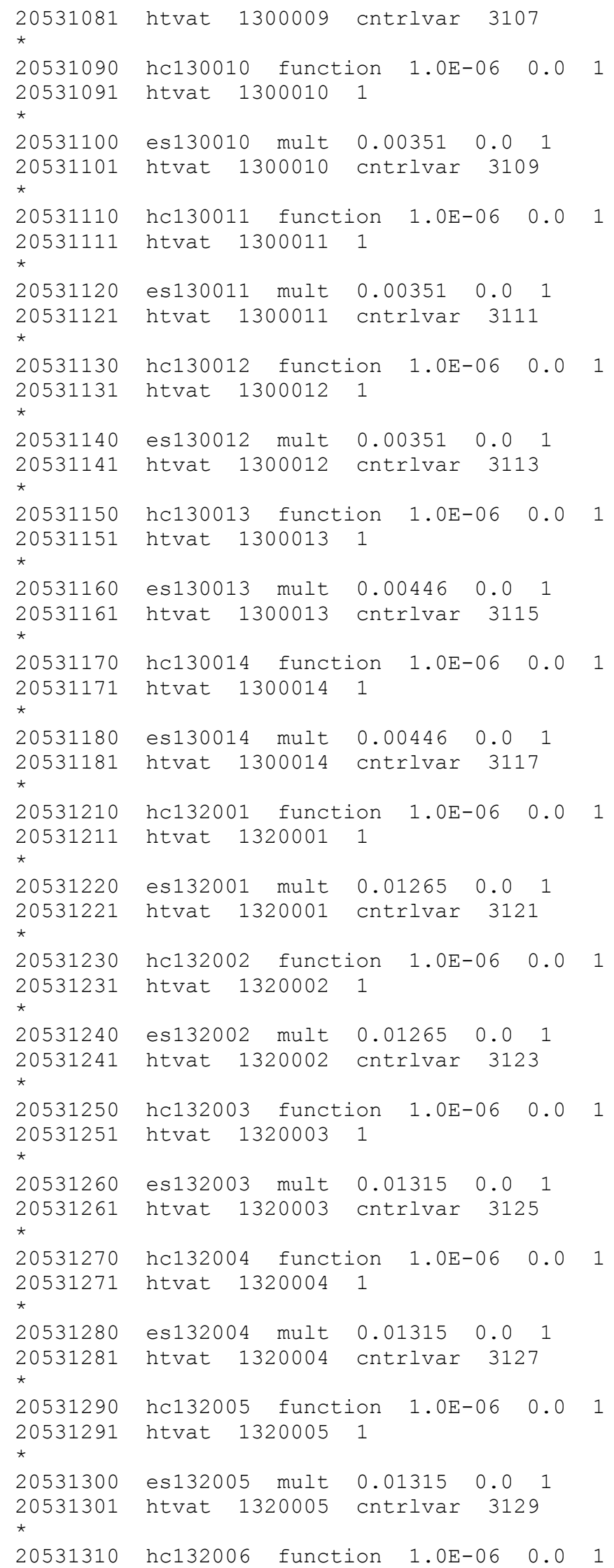




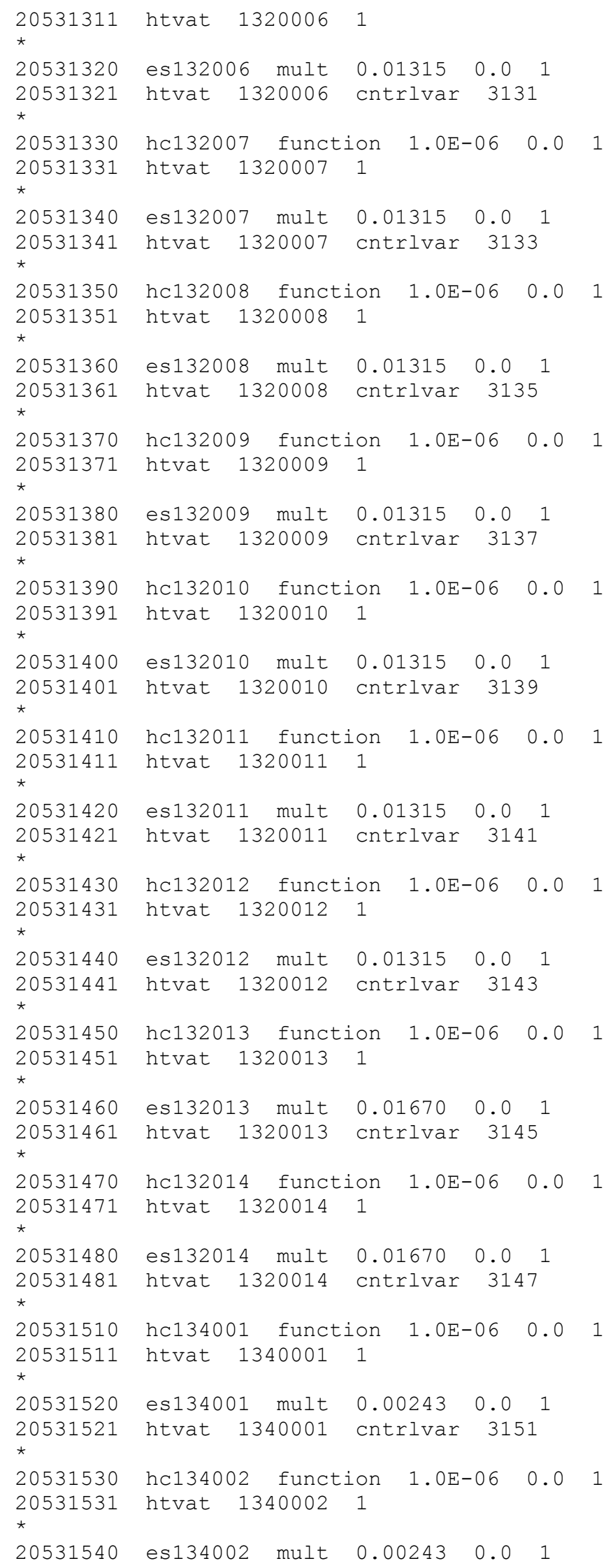




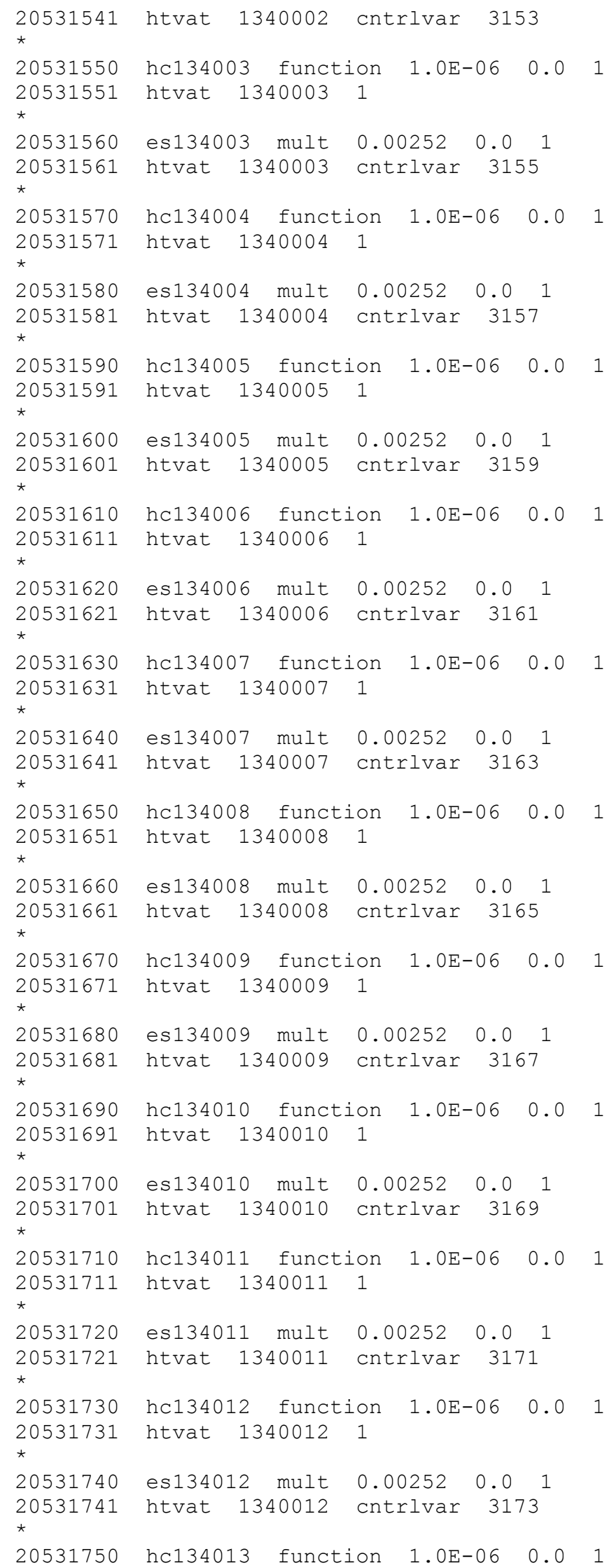




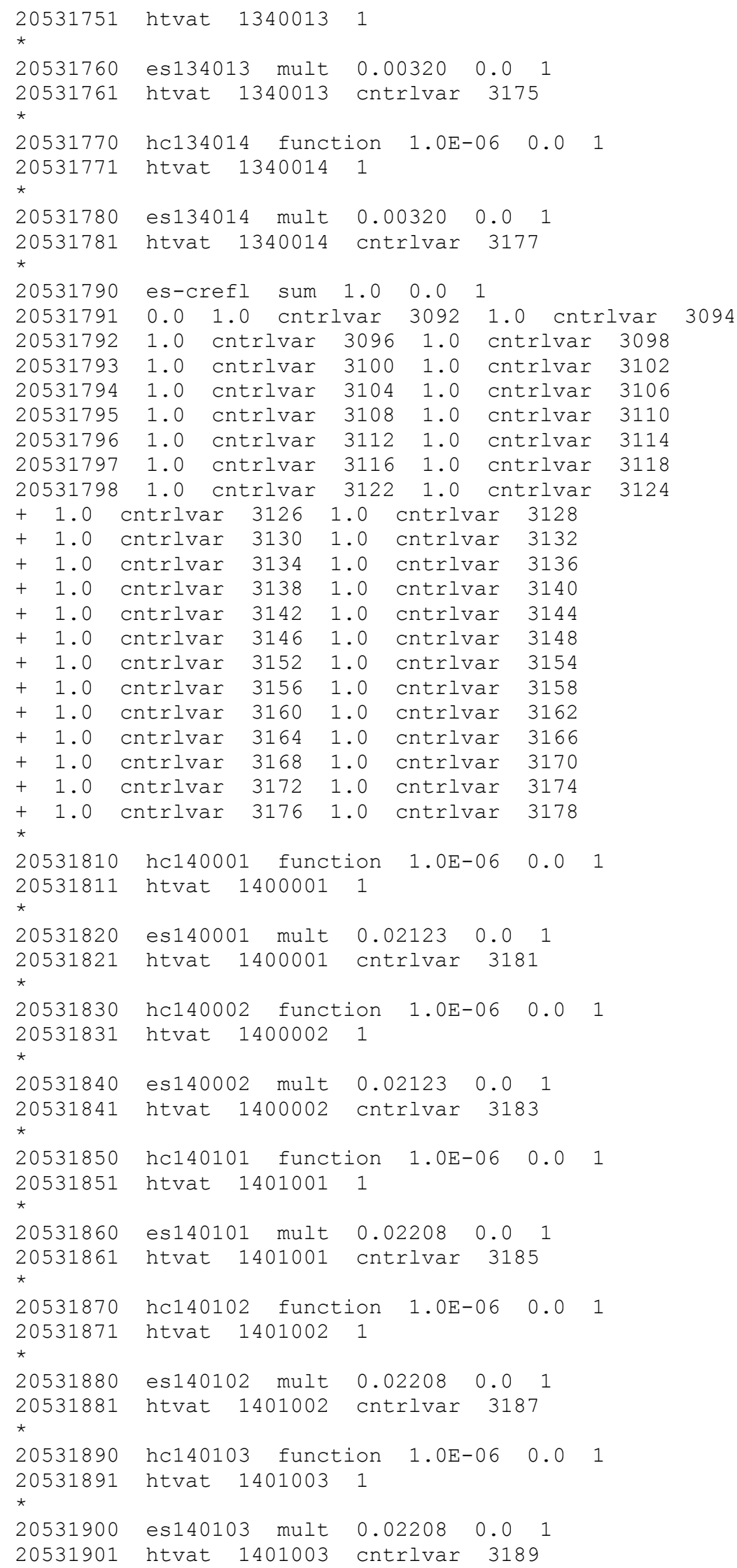




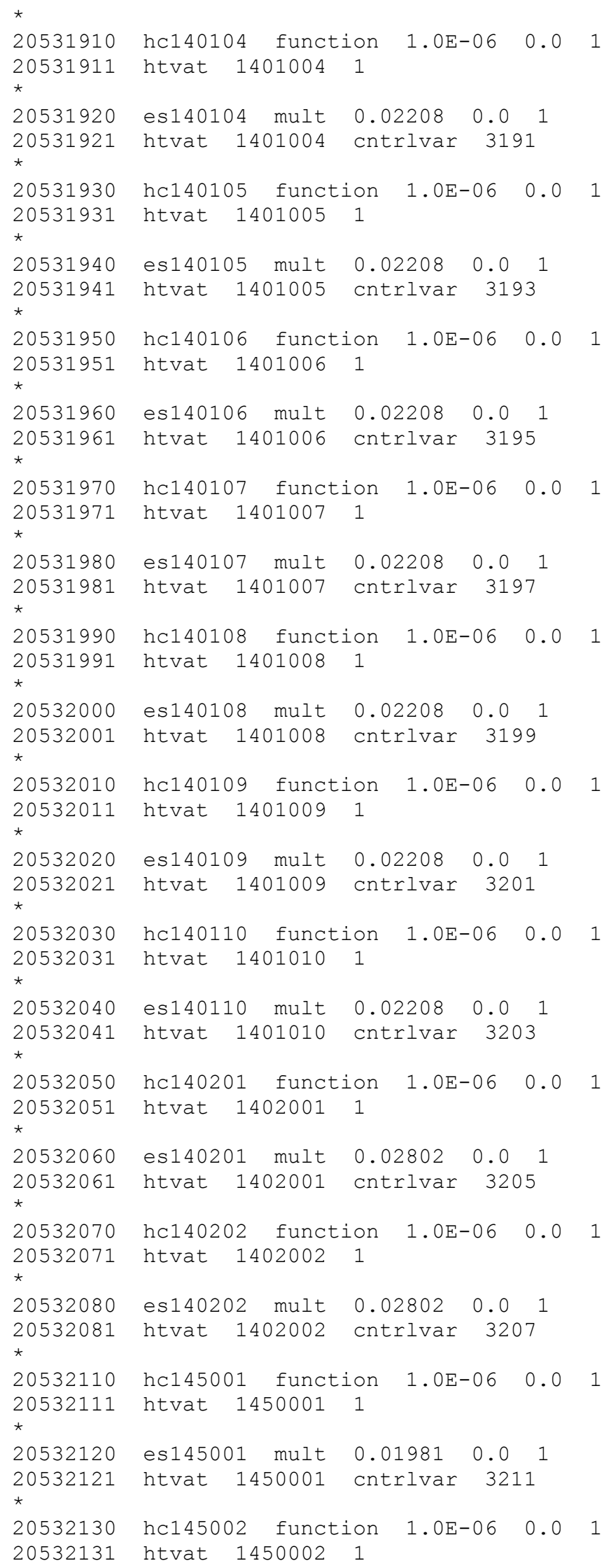




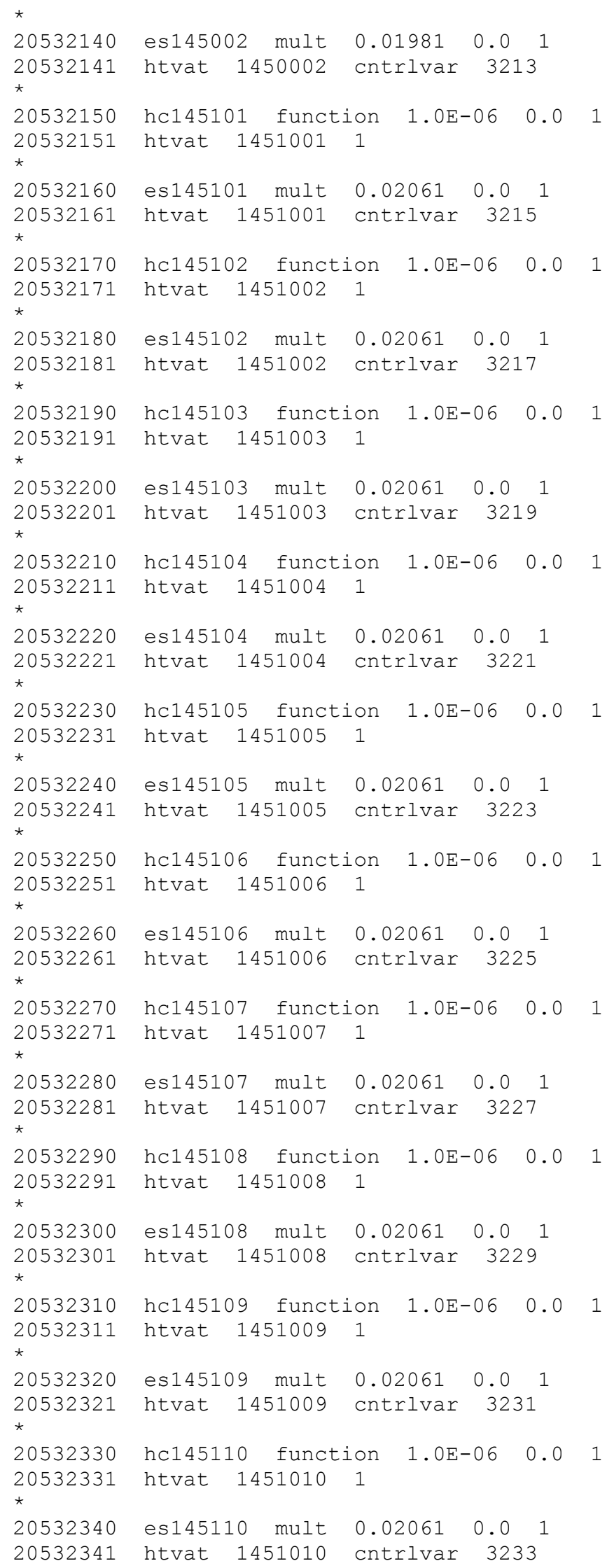




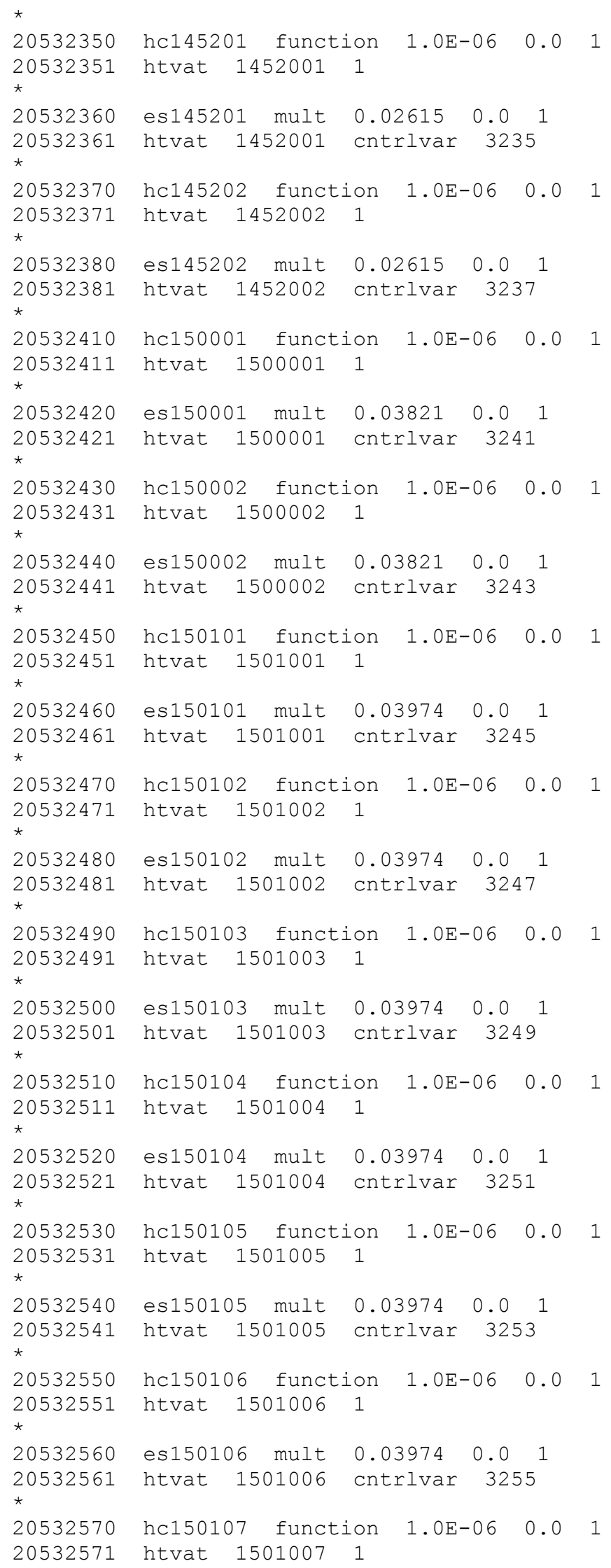




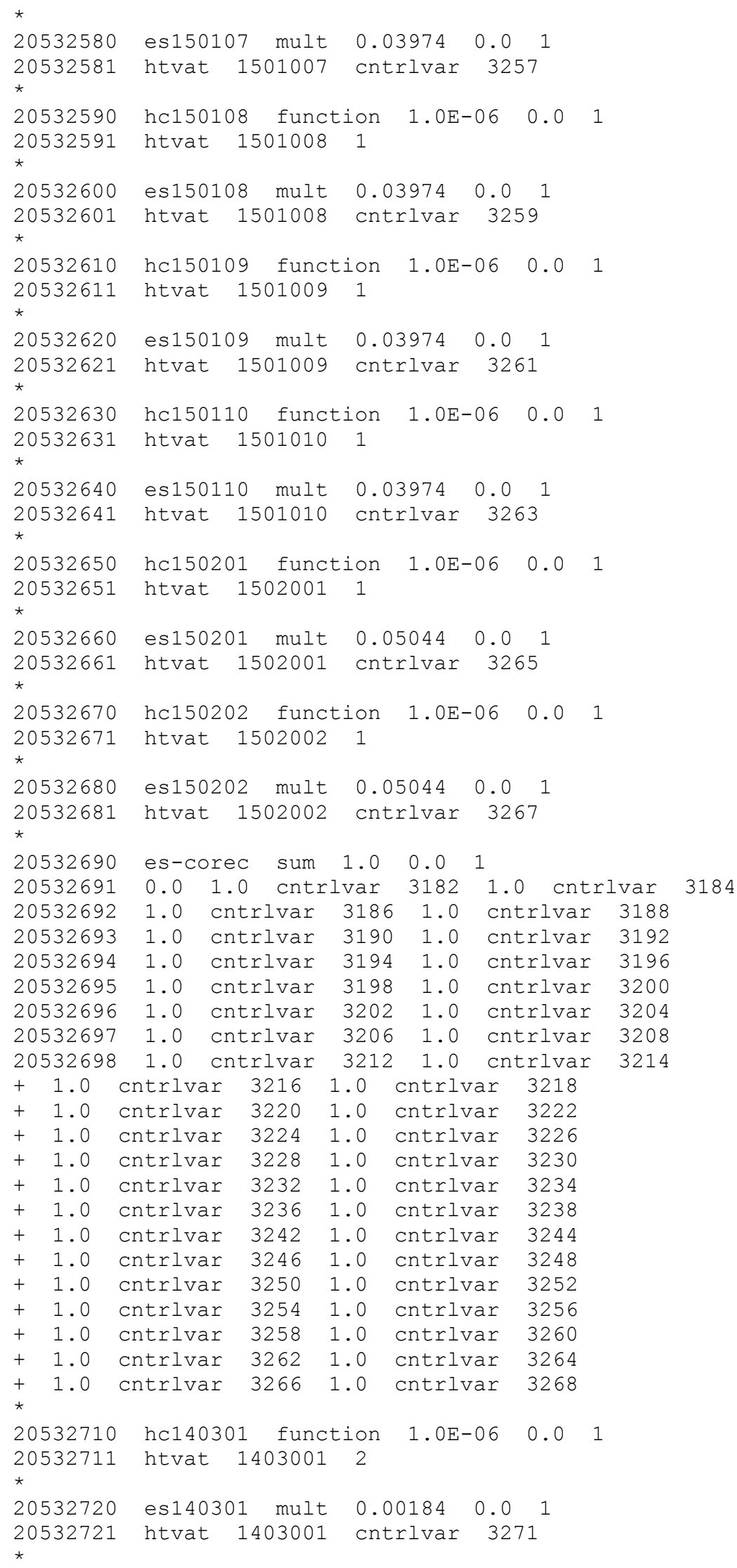




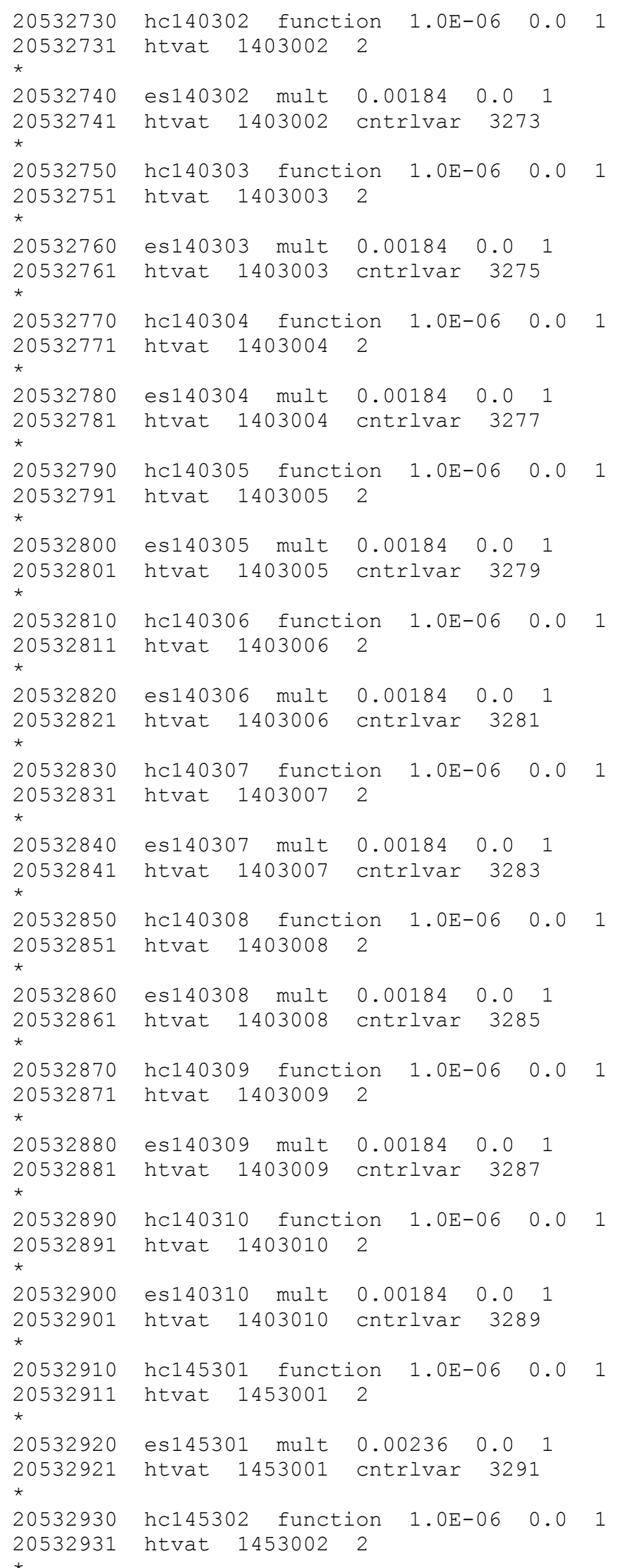




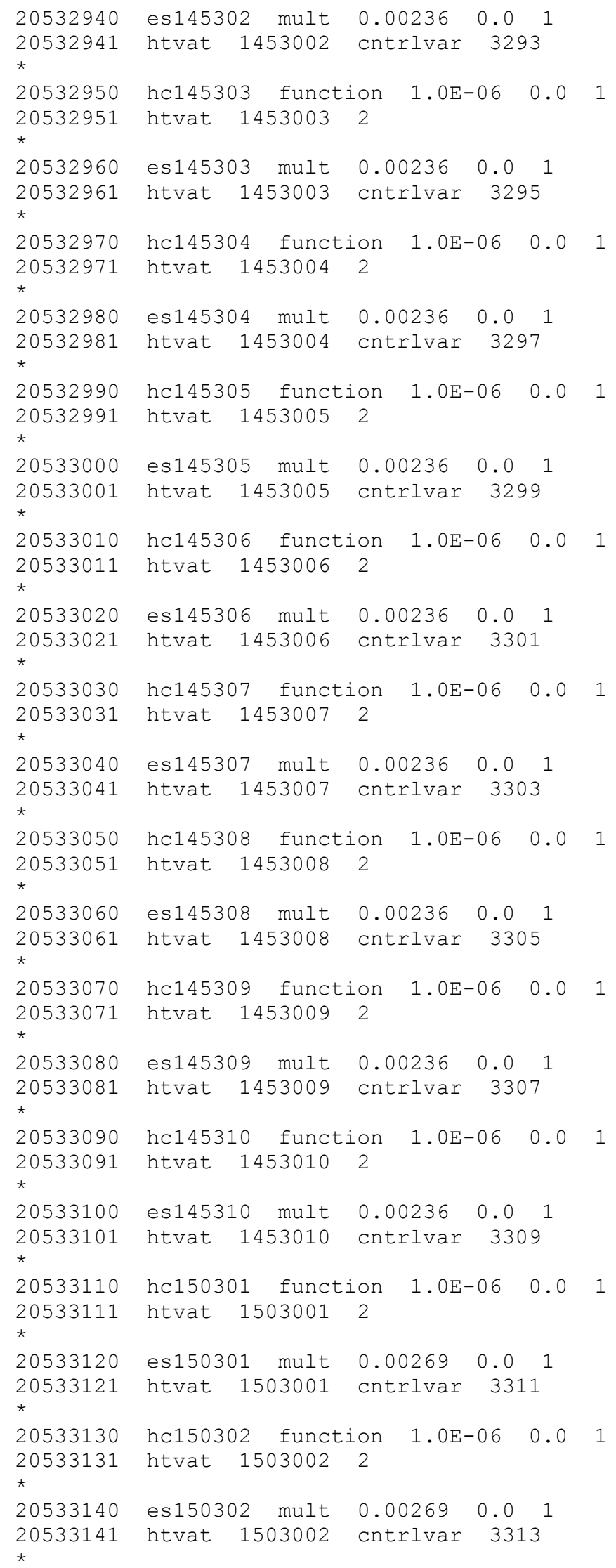




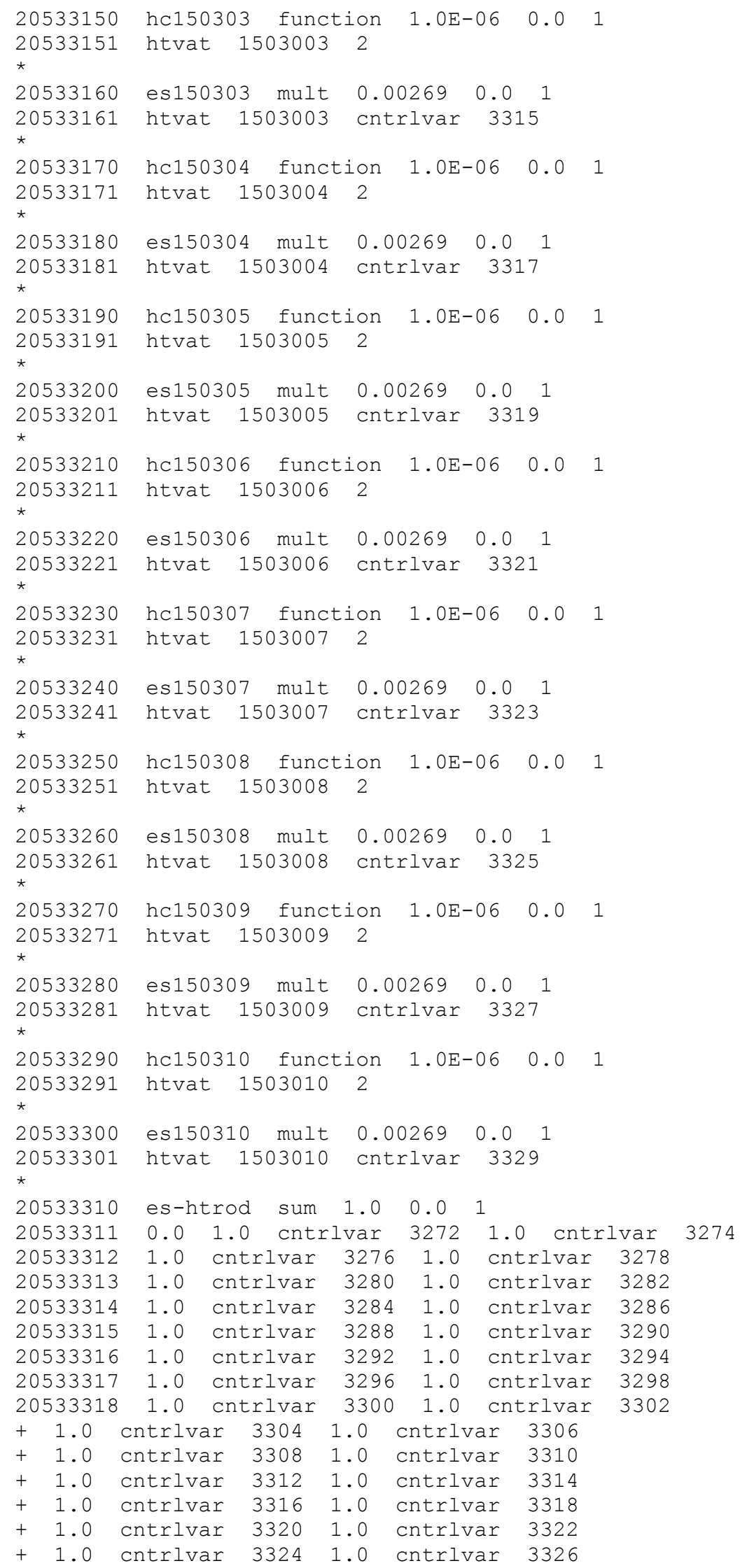




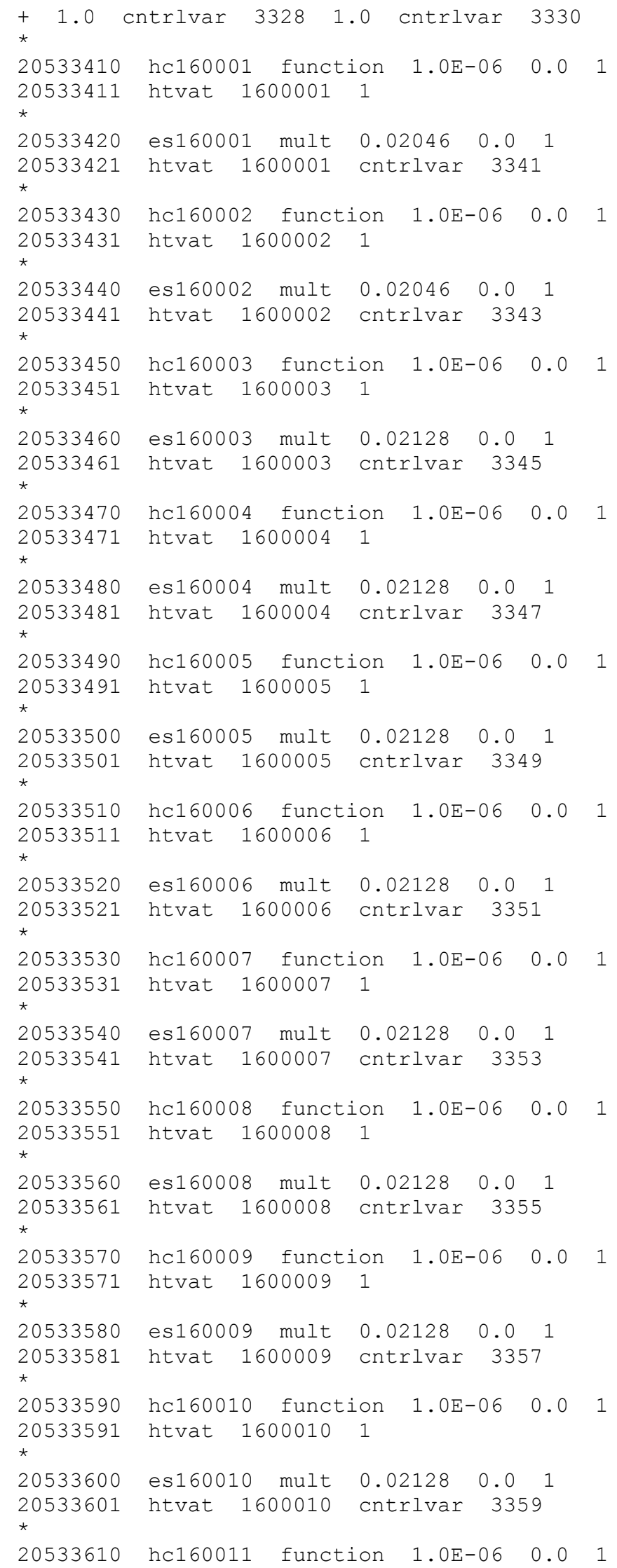




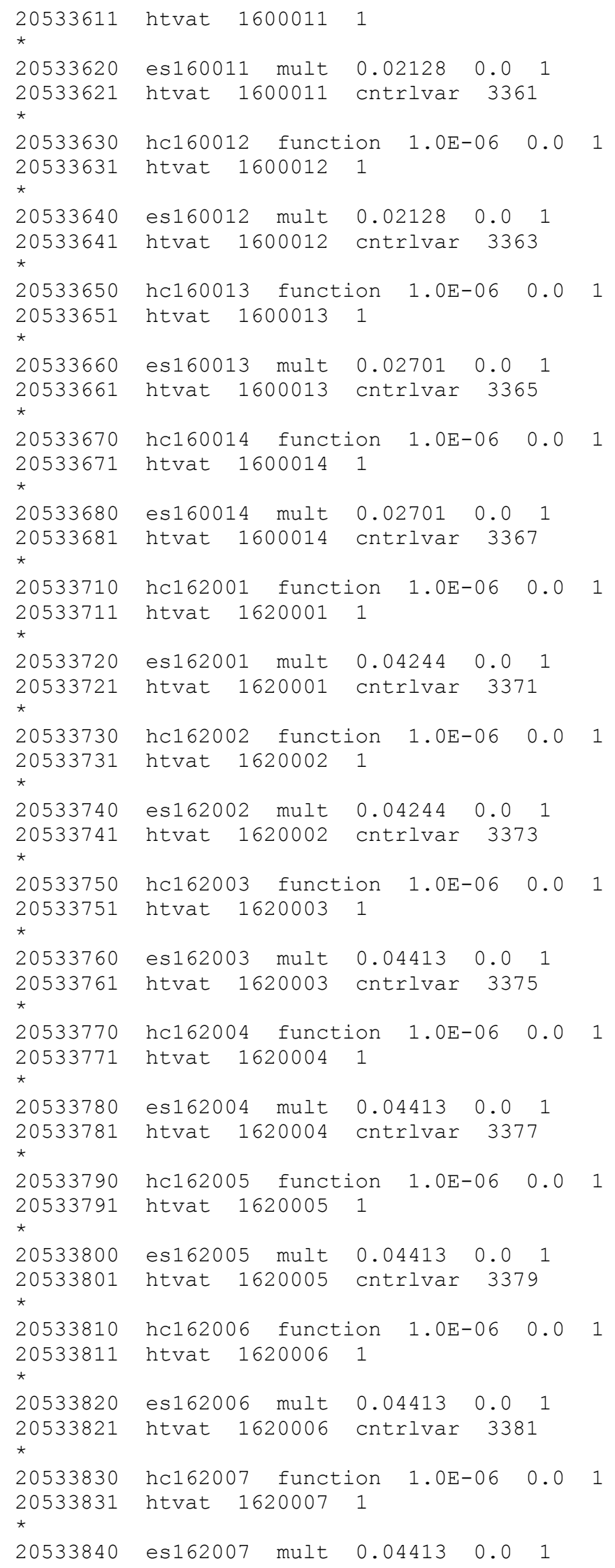




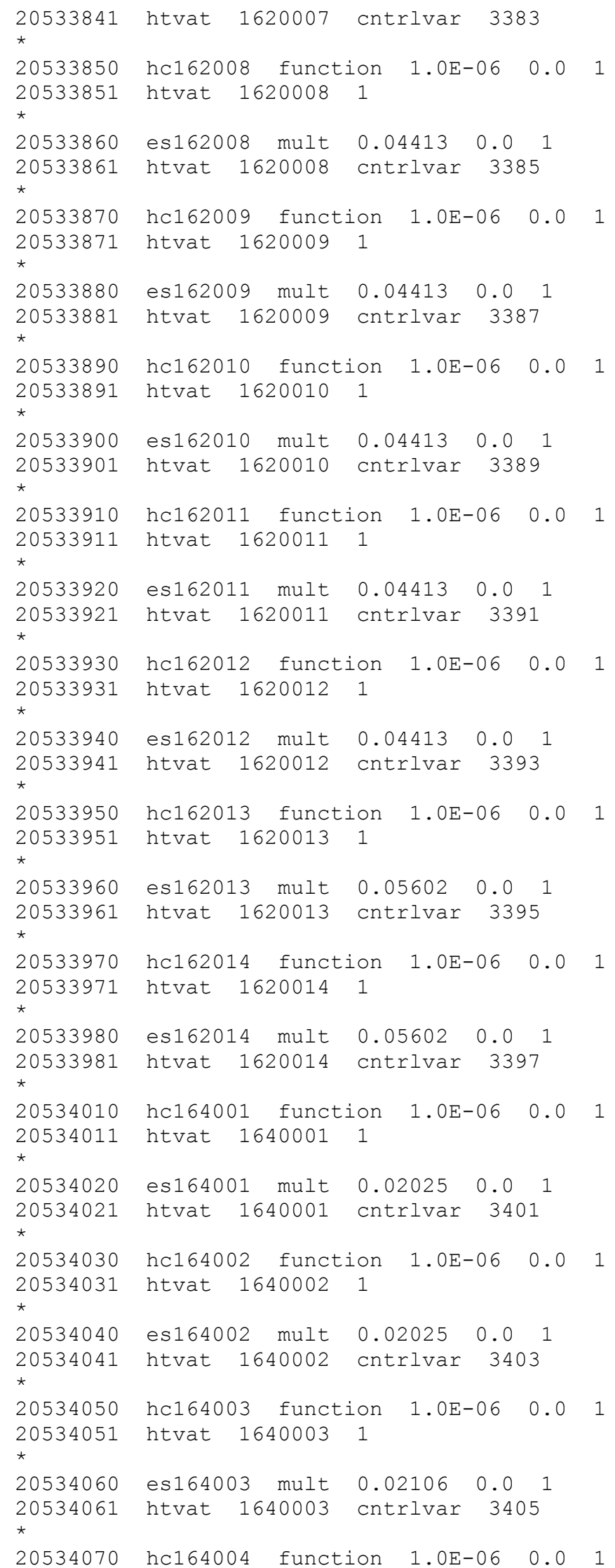




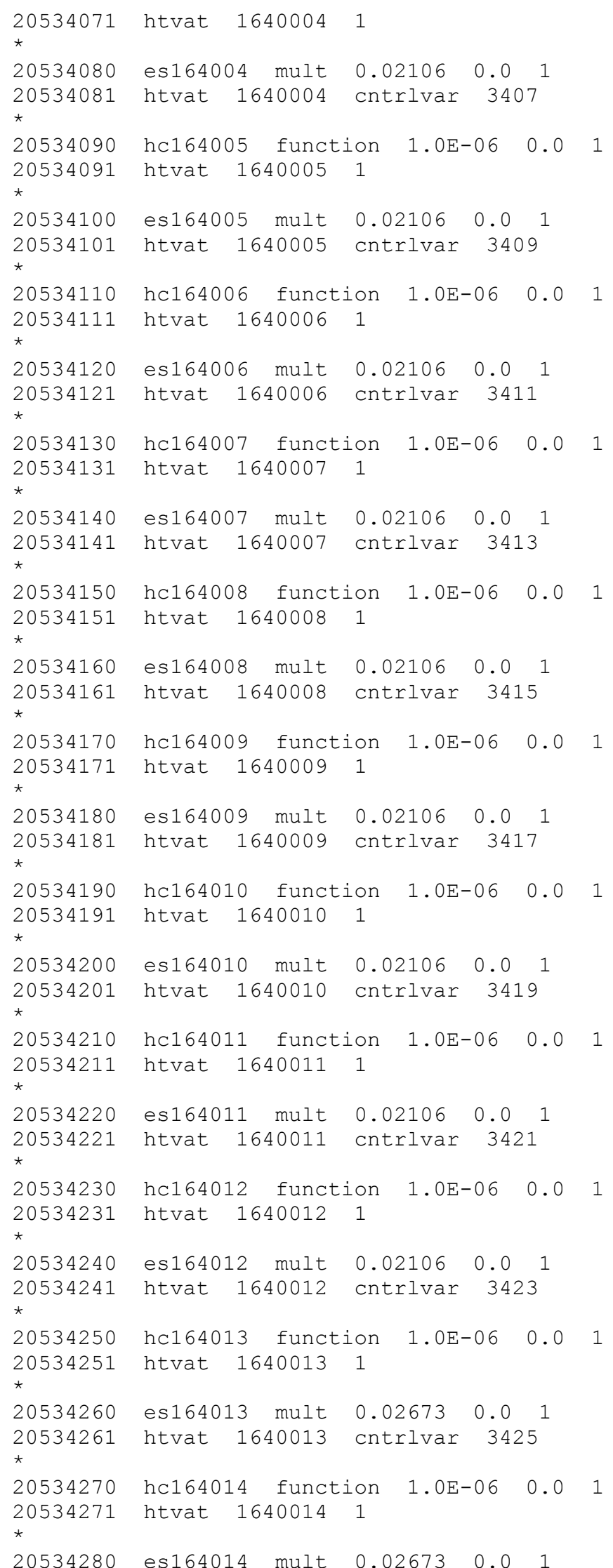




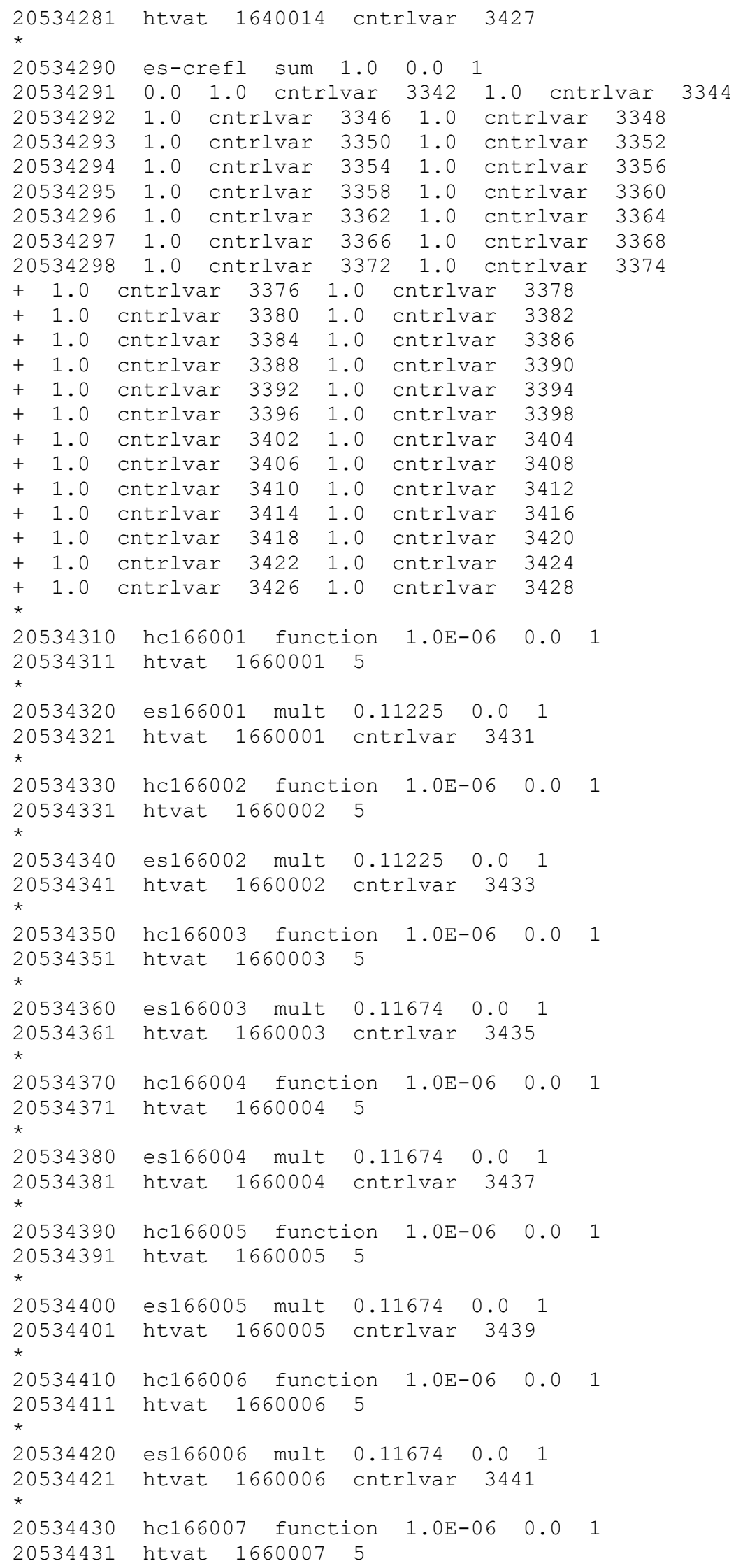




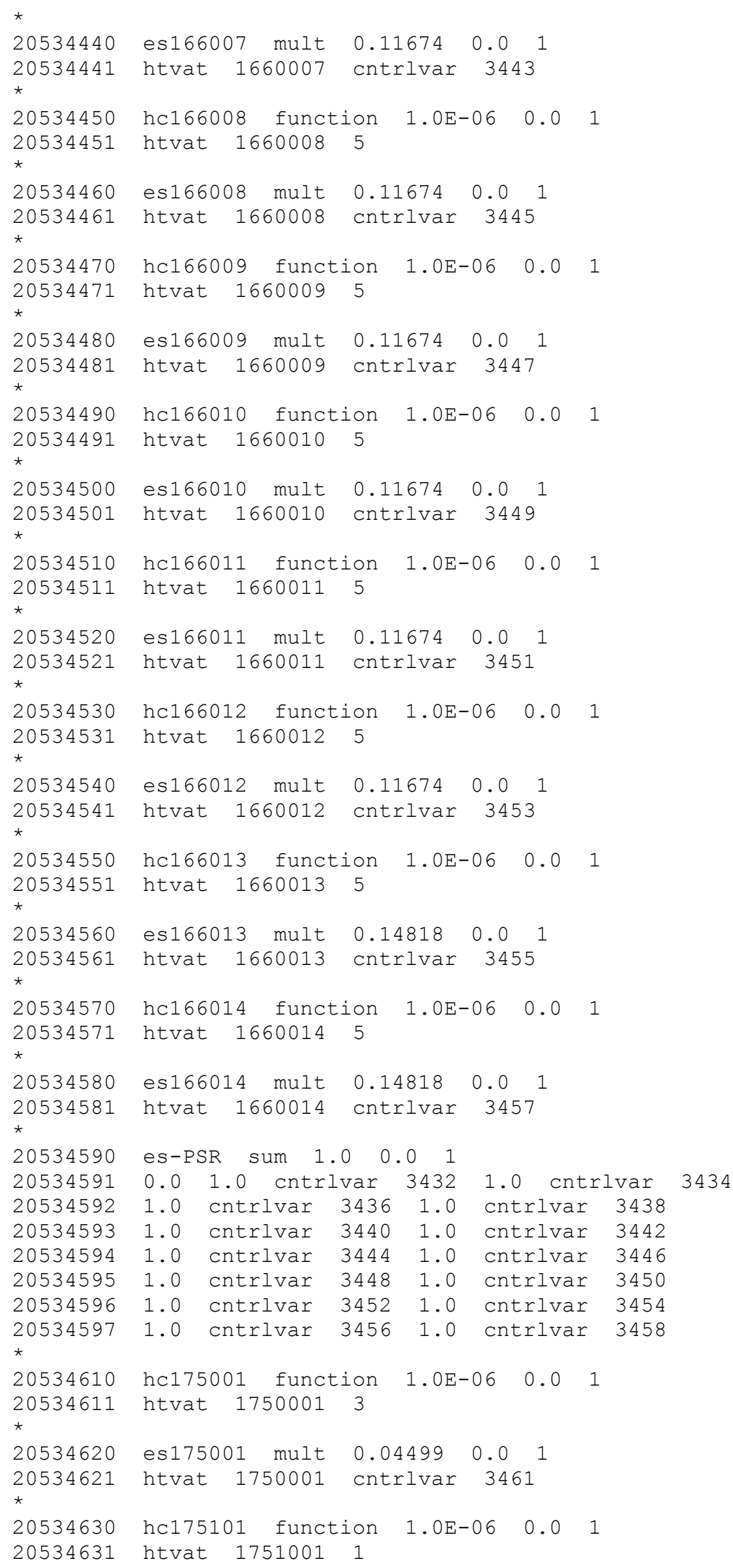




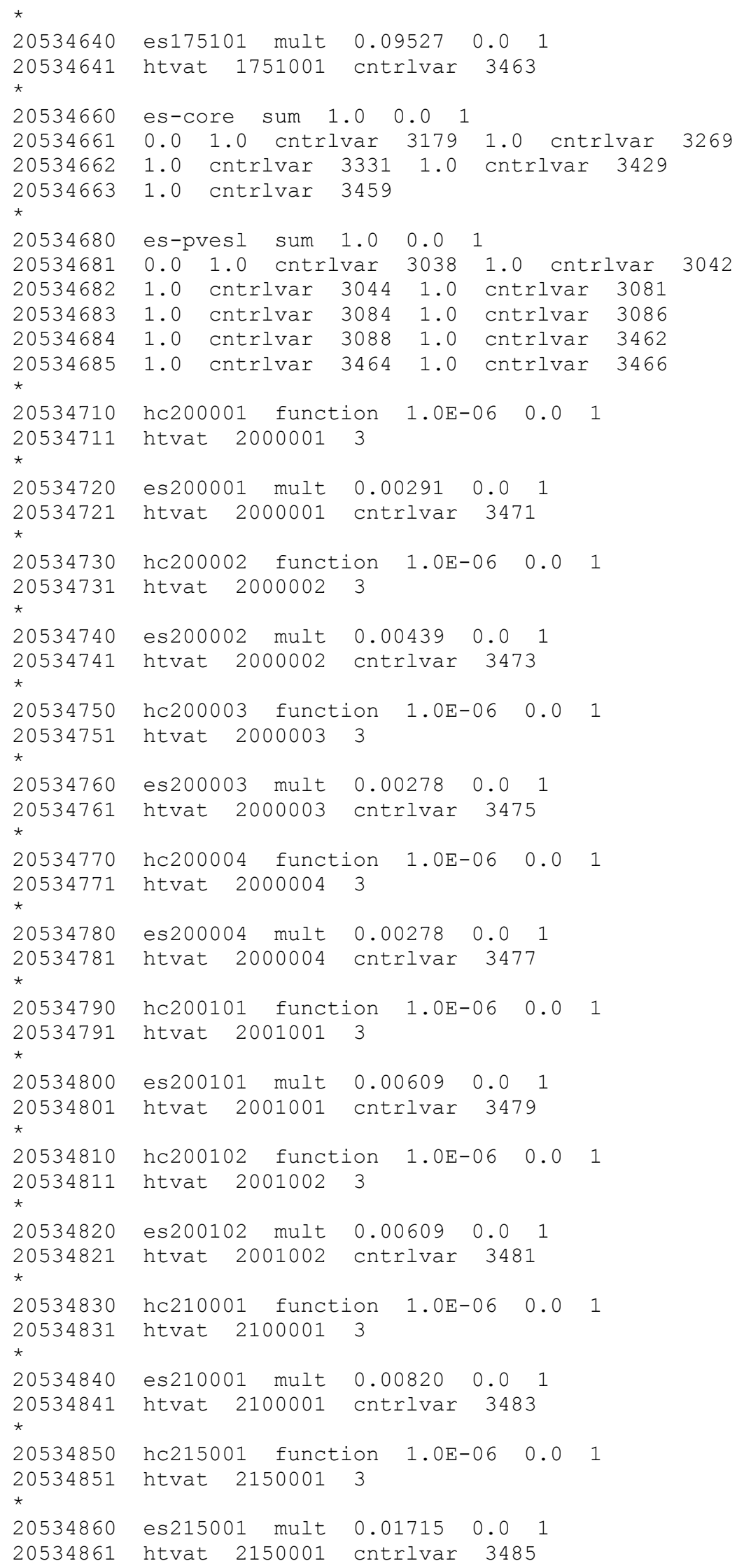




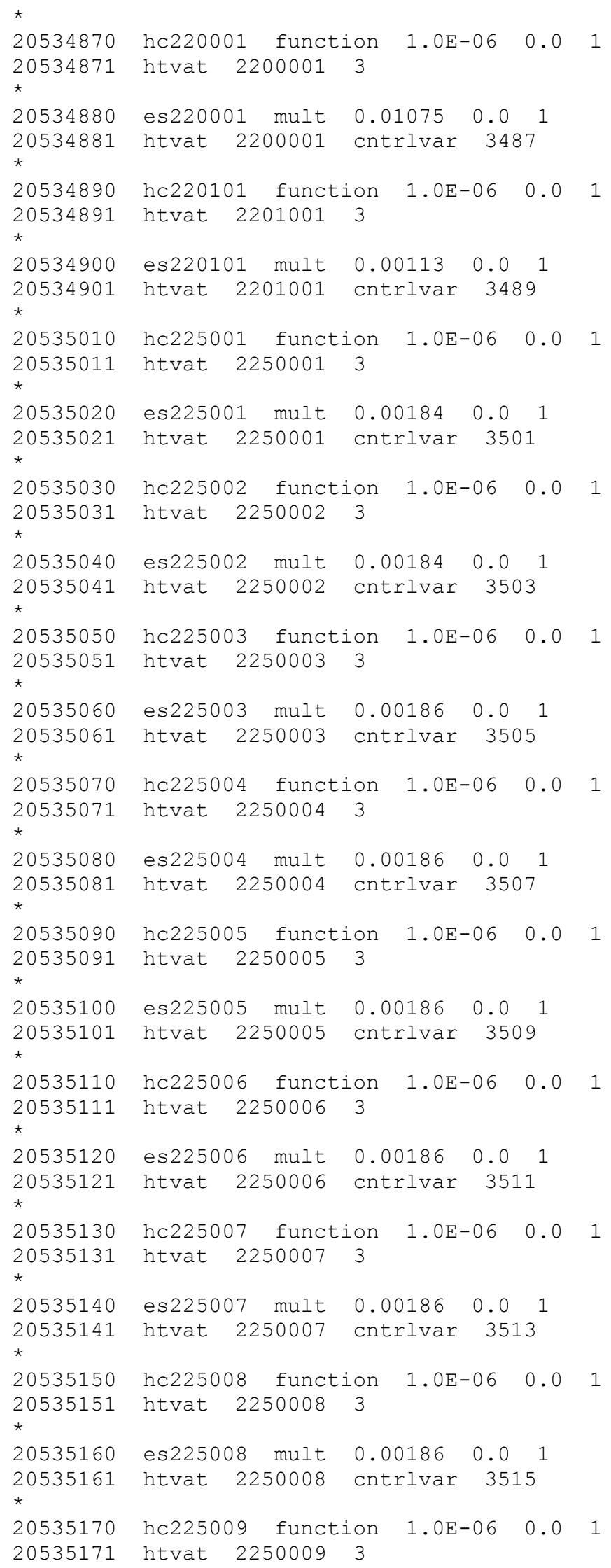




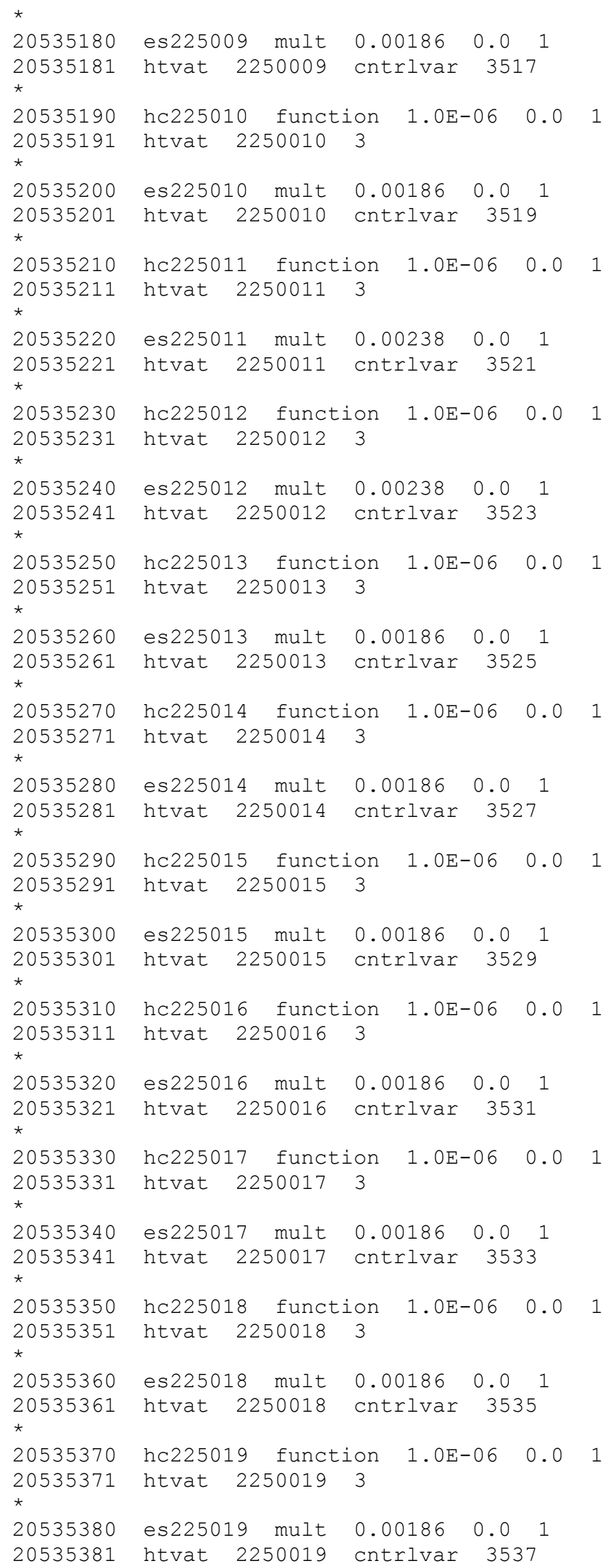




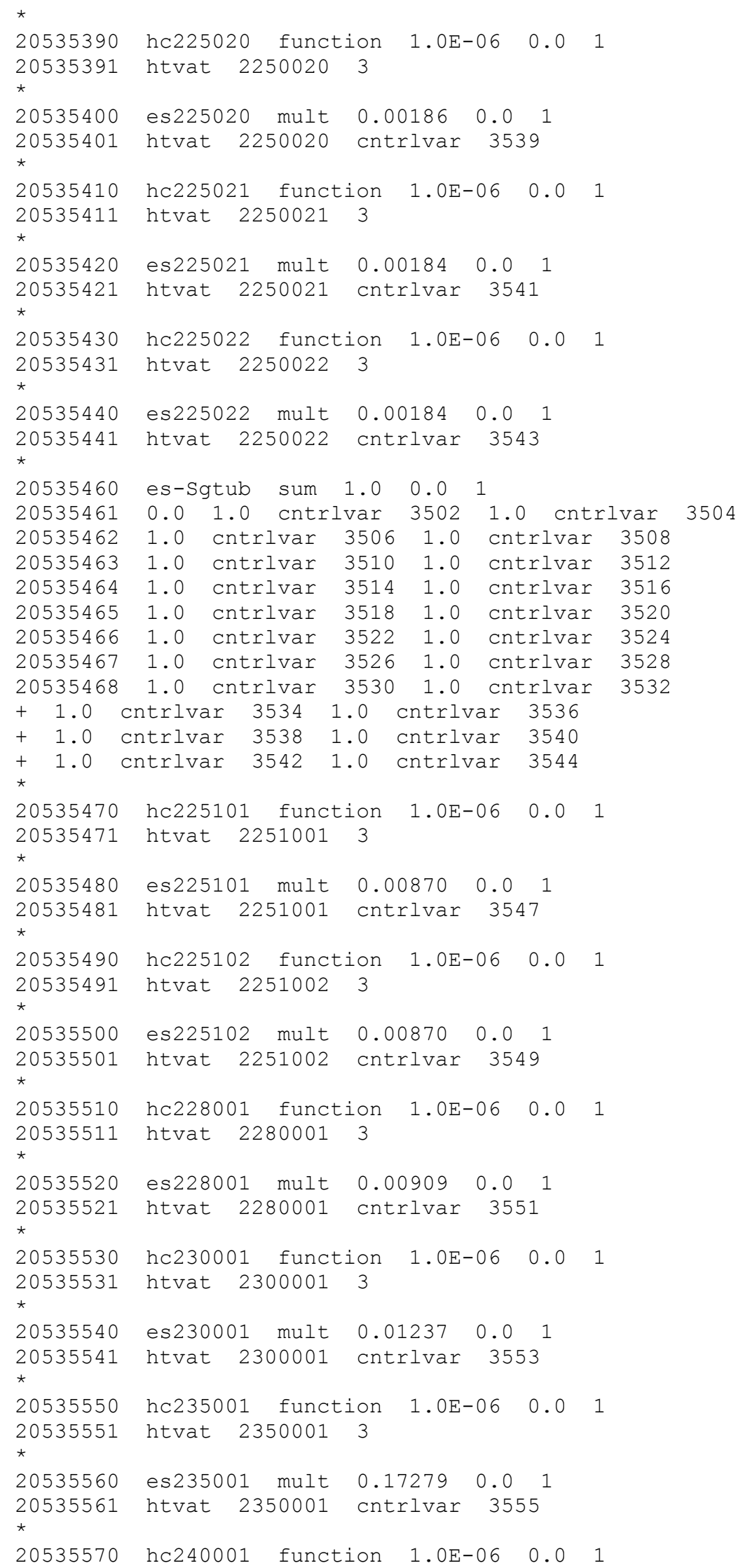




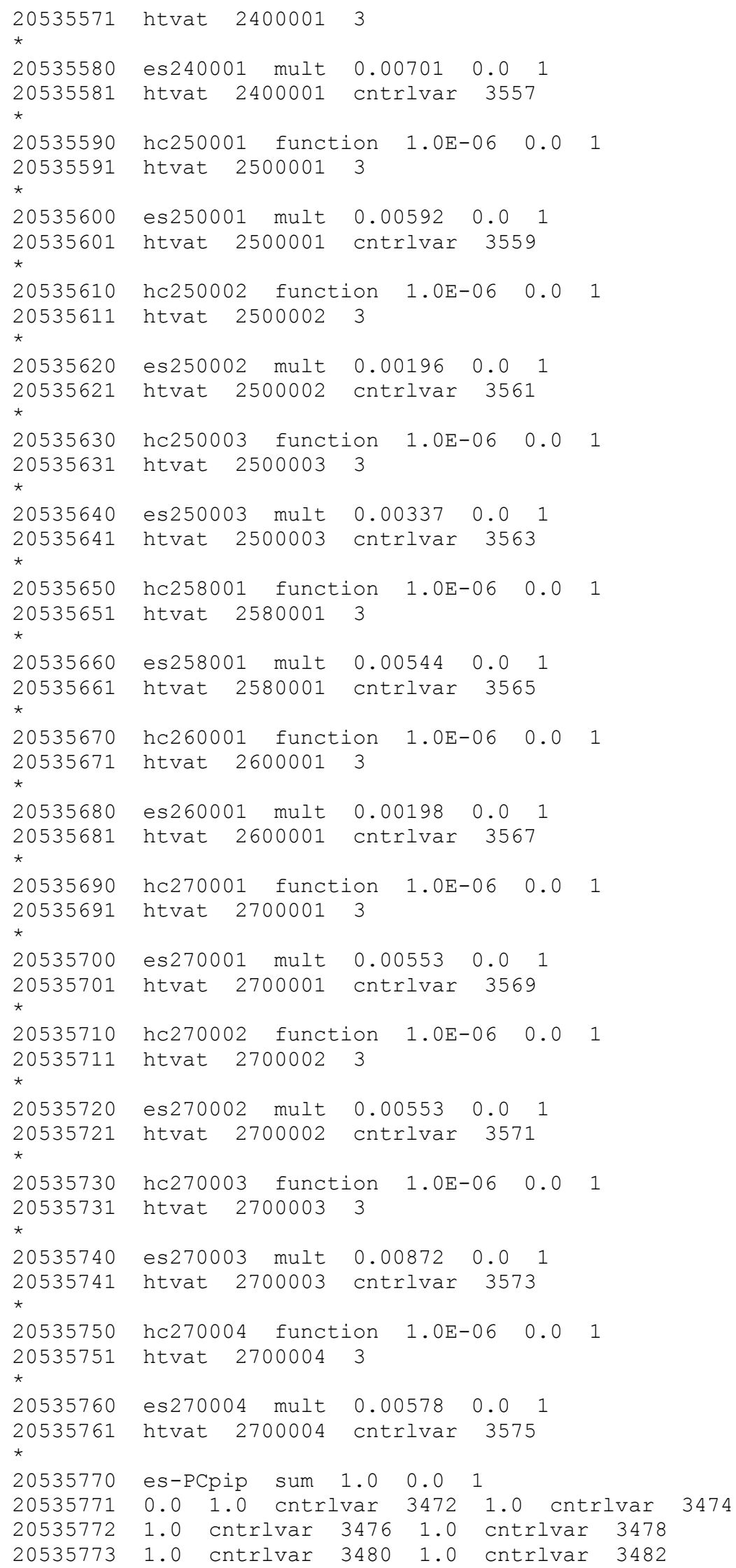




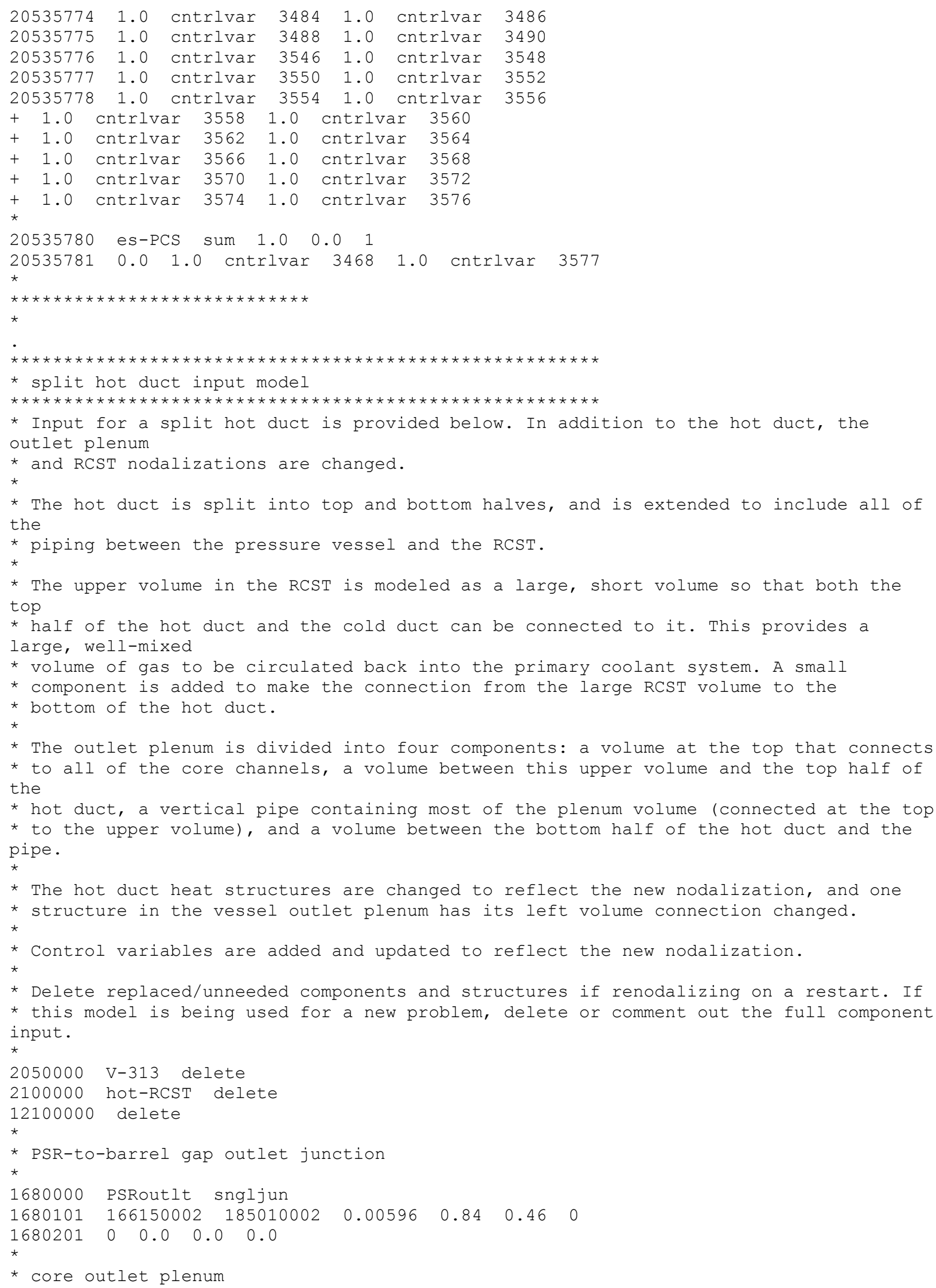




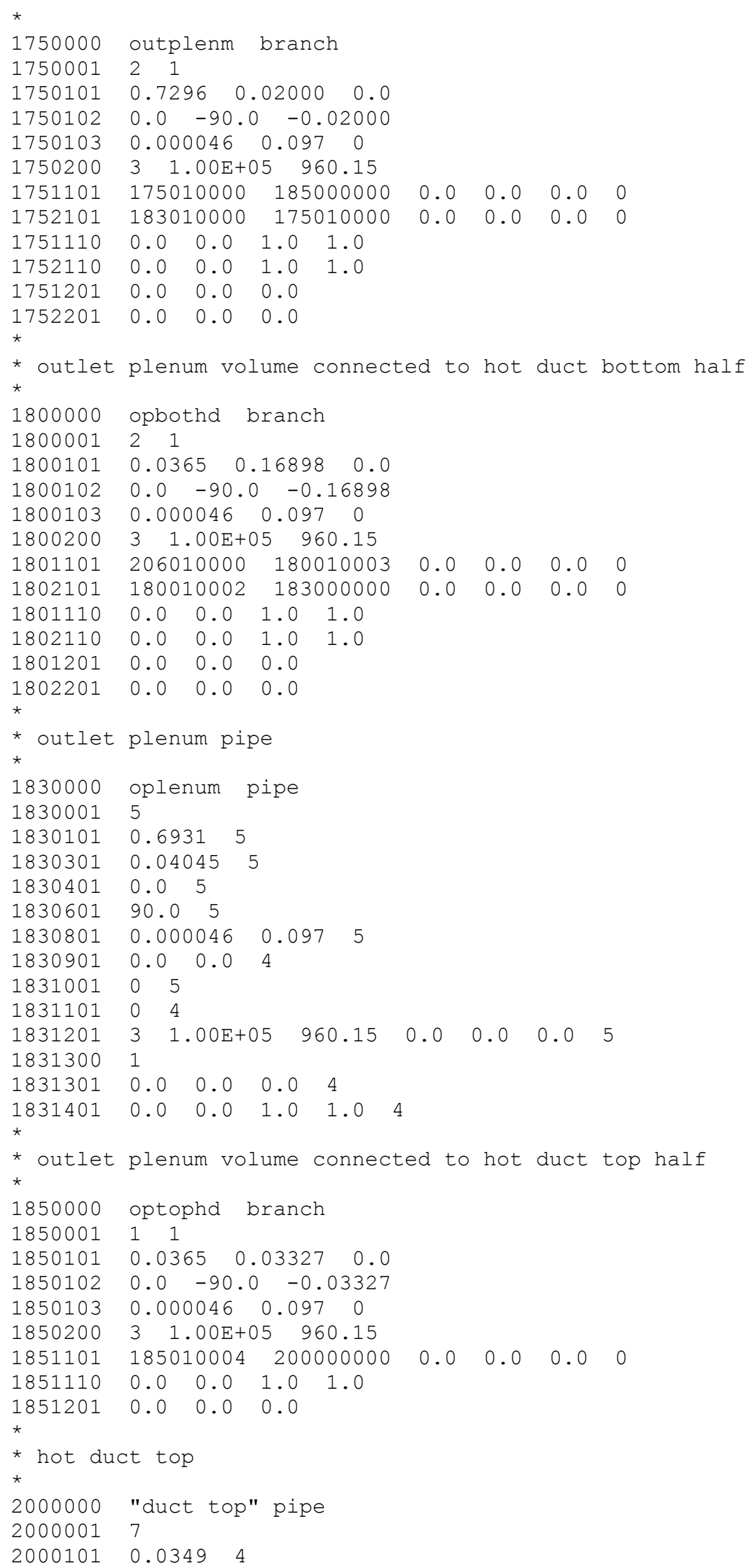




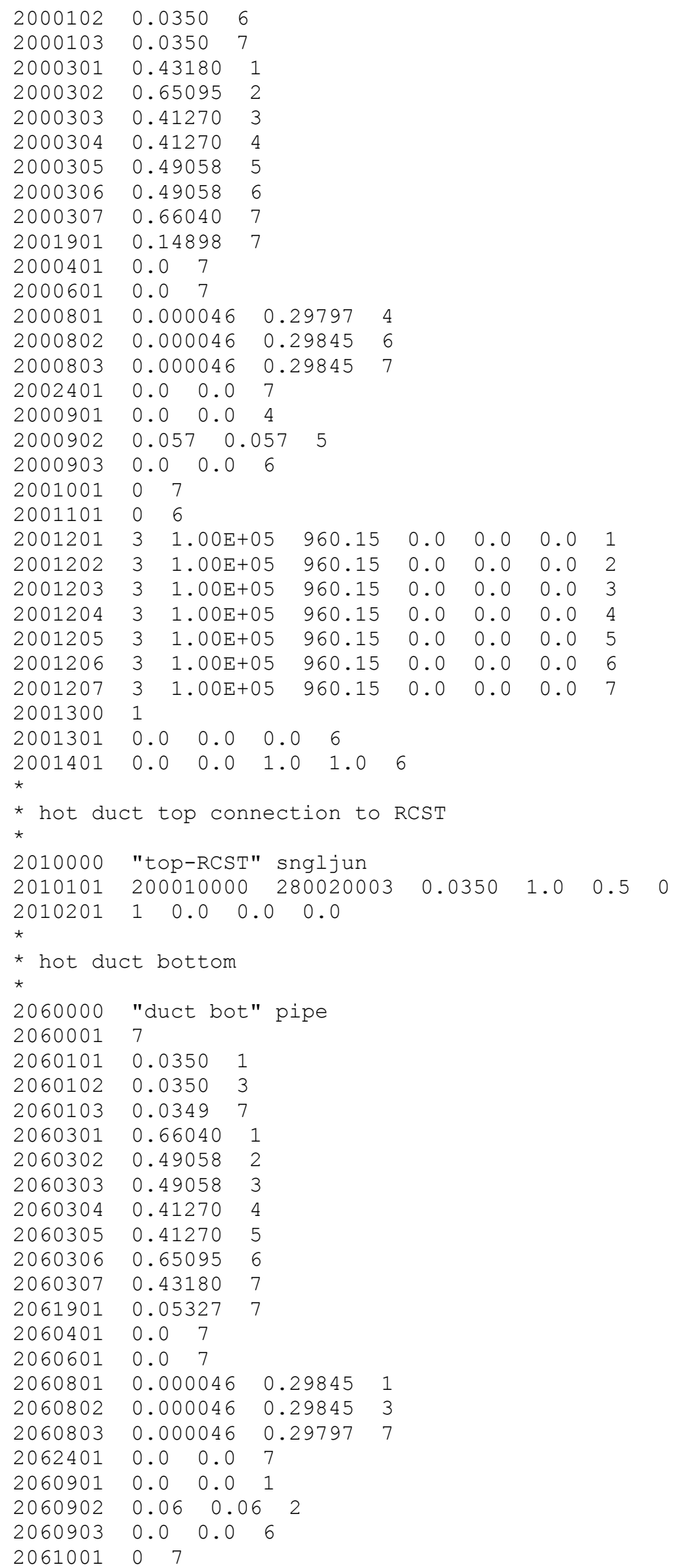




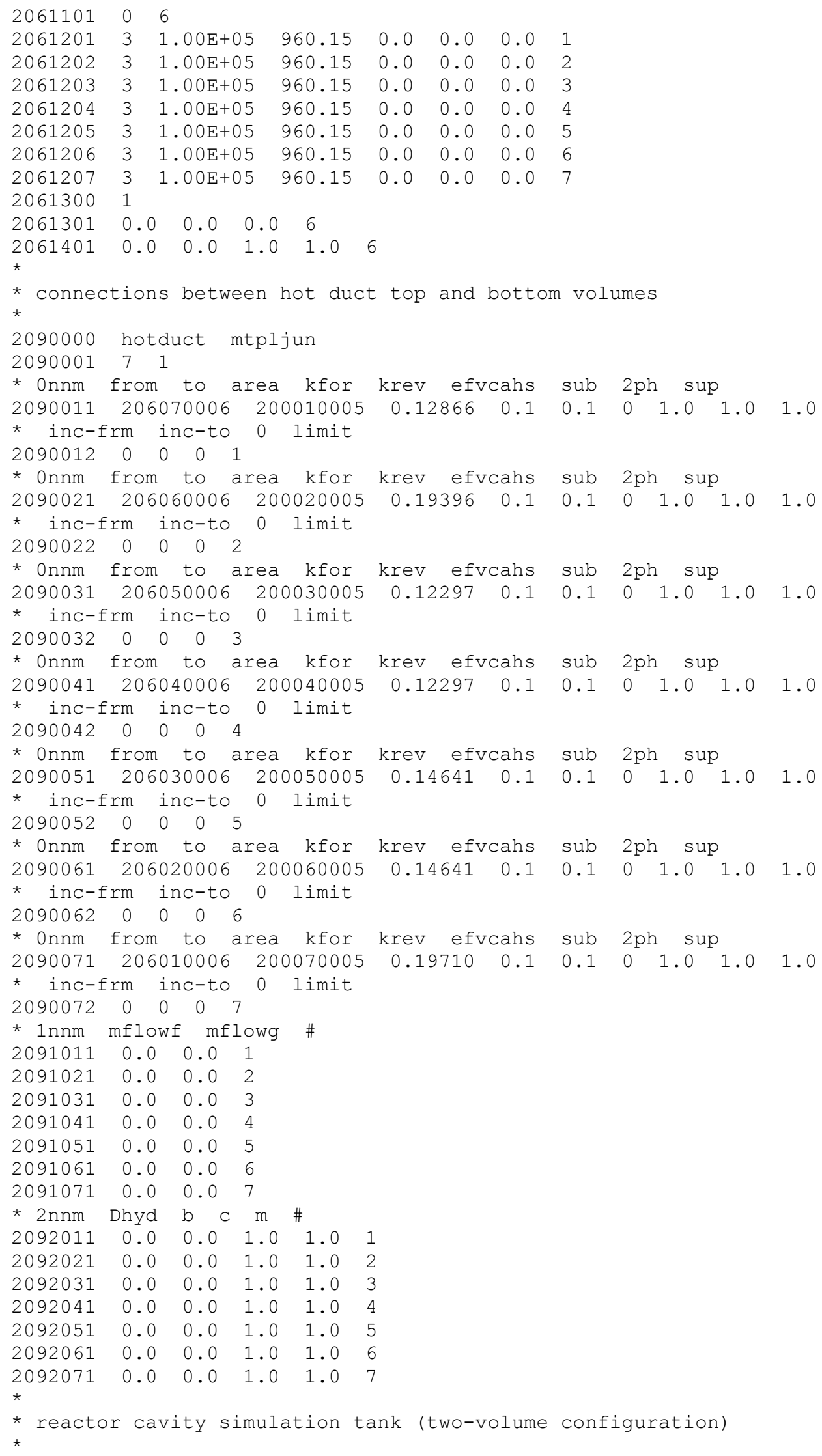




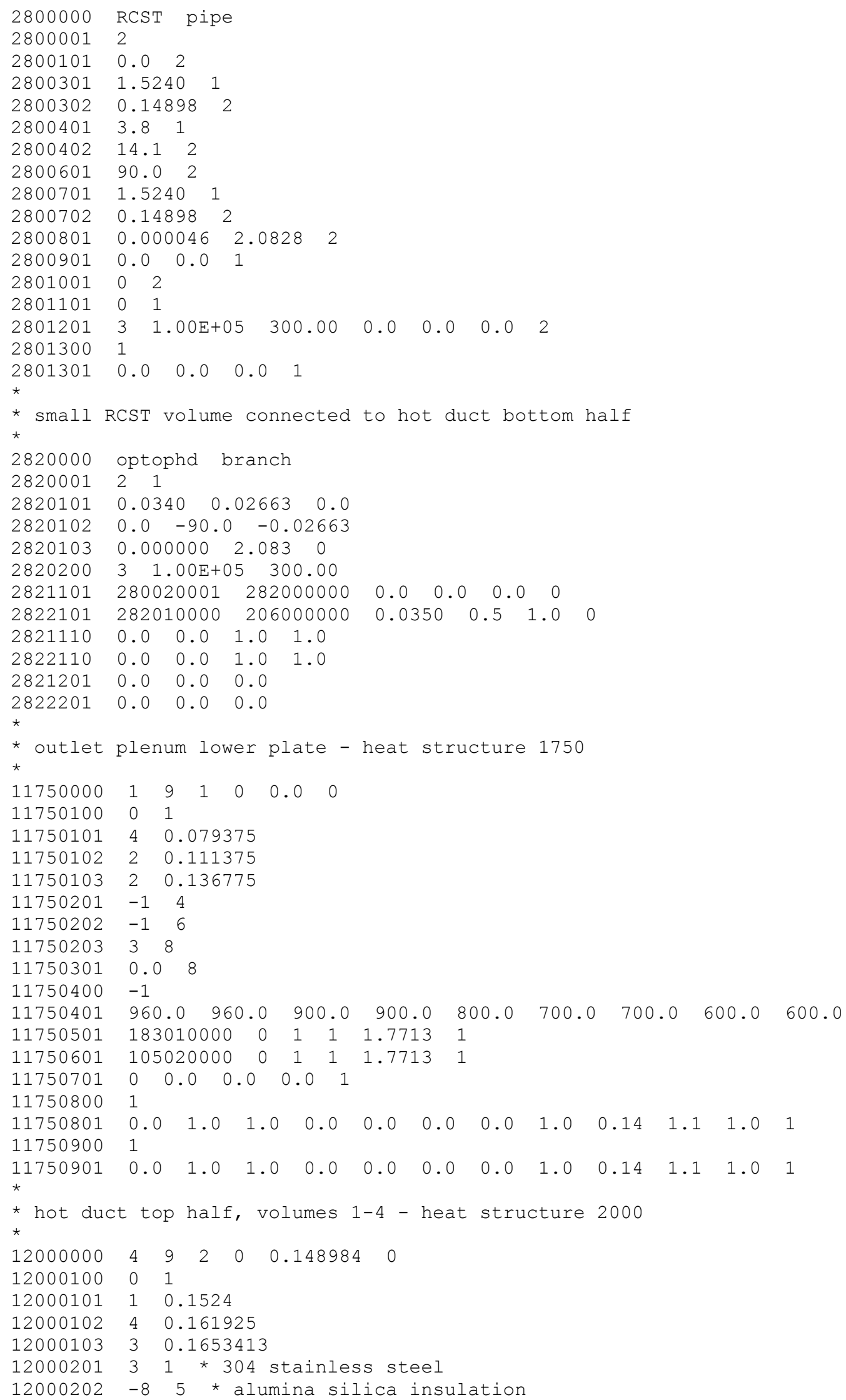




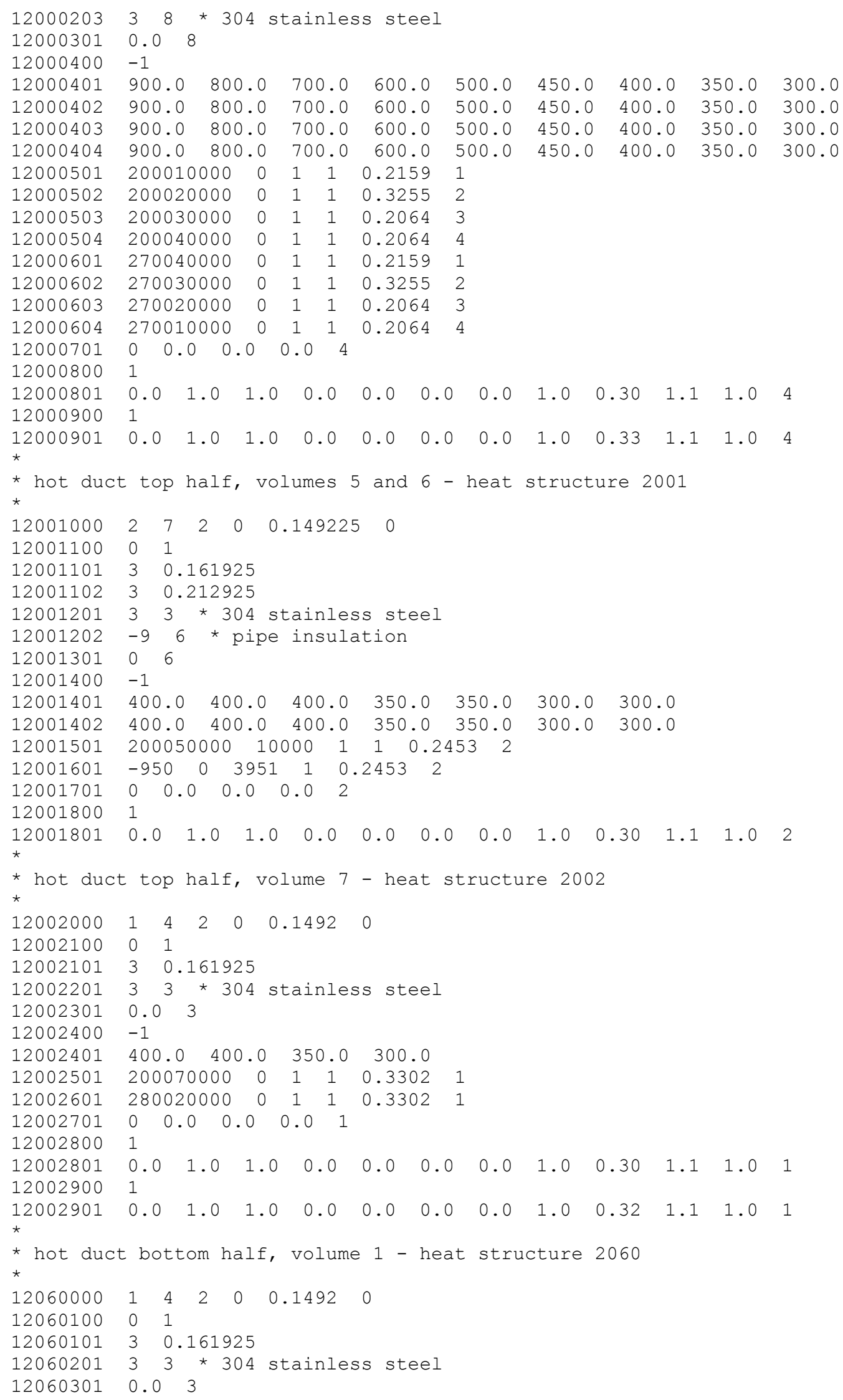




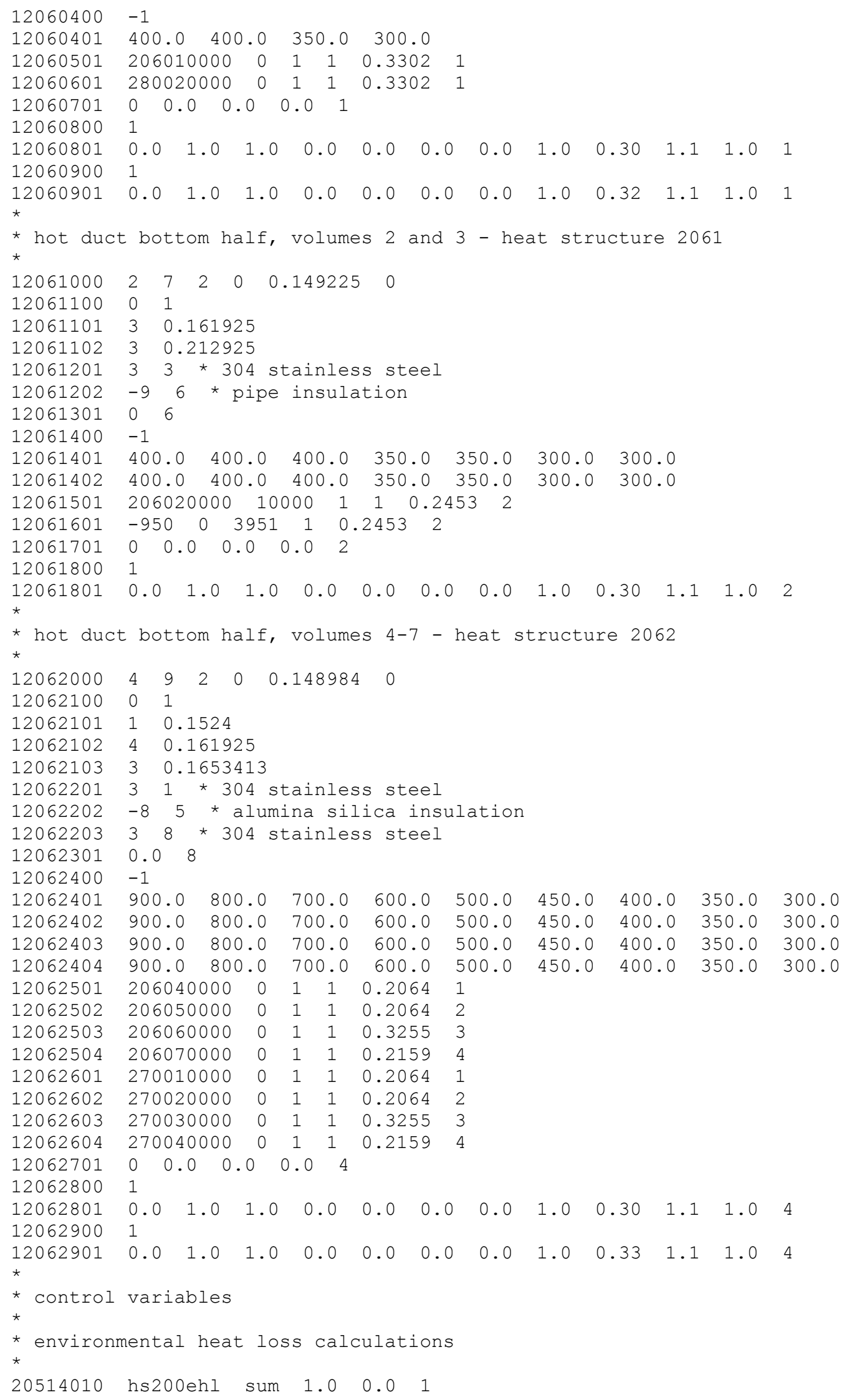




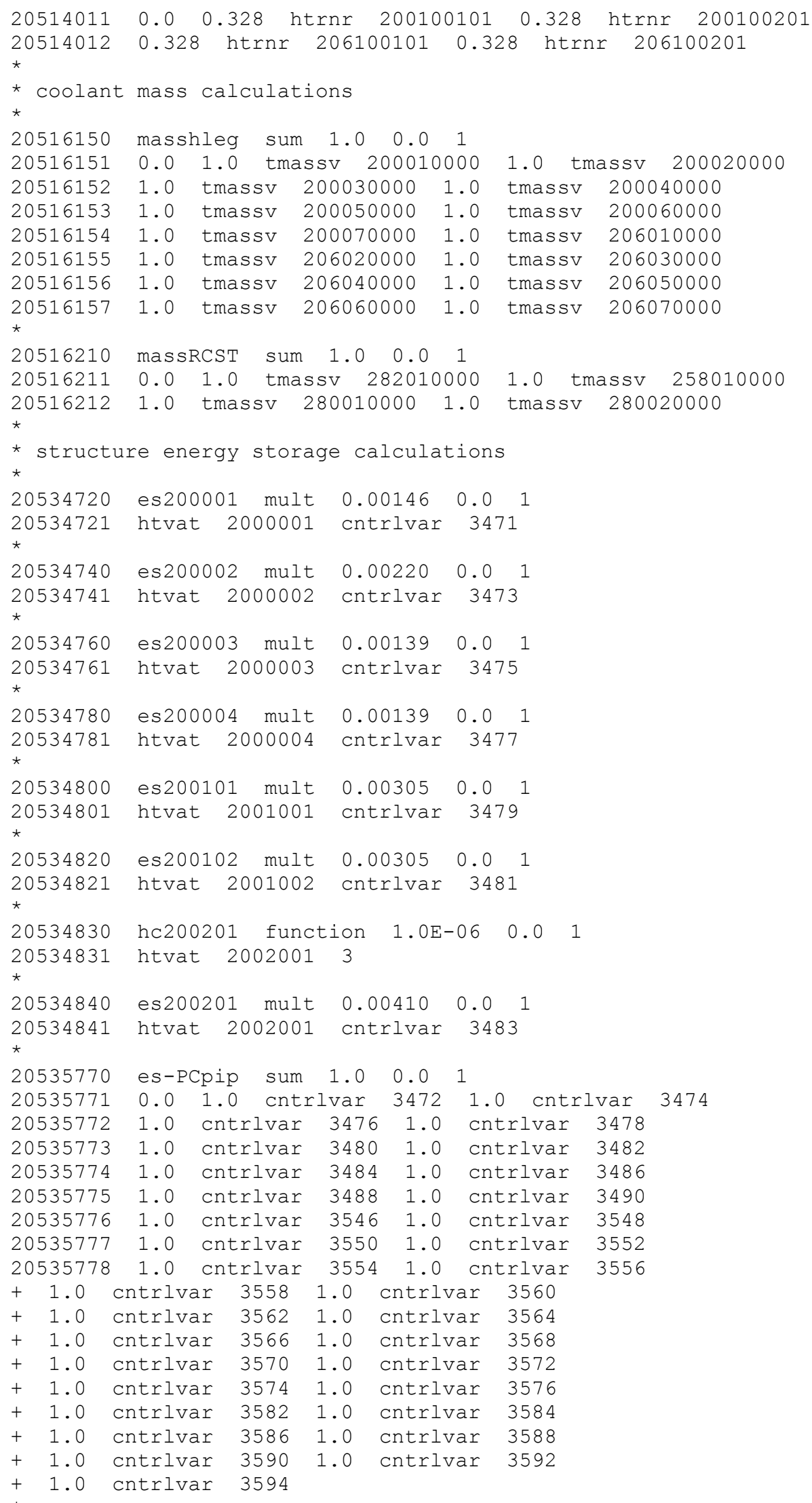




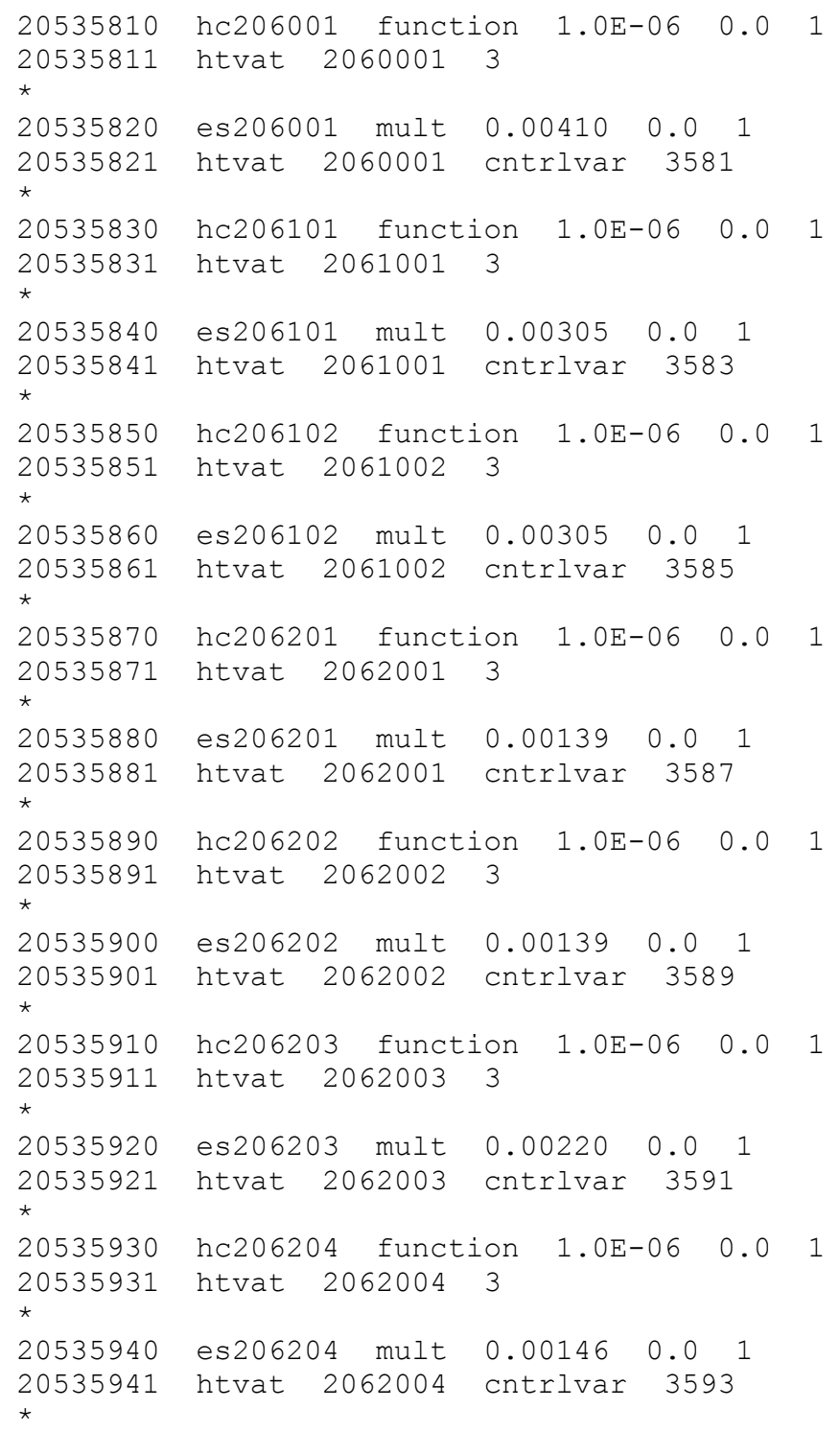

